NUREG/CR-6540

BMI-2196

\title{
State-of-the-Art Report on Piping Fracture Mechanics
}

Manuscript Completed: November 1997

Date Published: January 1998

\section{Prepared by}

G. M. Wilkowski, R. J. Olson, P. M. Scott

\section{Battelle}

505 King Avenue

Columbus, $\mathrm{OH} 43201$

M. Mayfield, NRC Project Manager

Prepared for

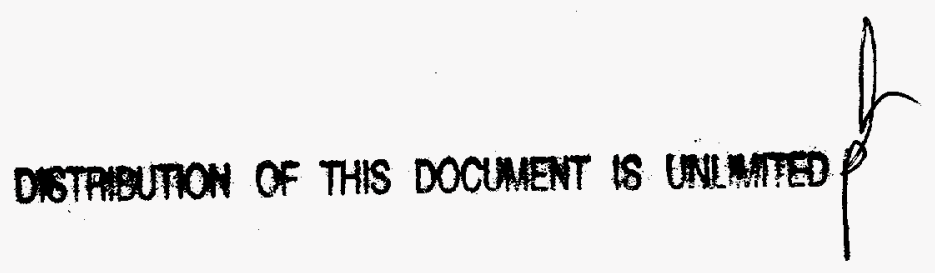

Division of Engineering Technology

Office of Nuclear Regulatory Research

U.S. Nuclear Regulatory Commission

Washington, DC 20555-0001

NRC Job Code D2060

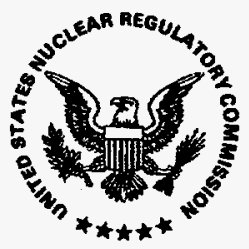




\section{NUREG/CR-6540 has been reproduced}

from the best ava hable copy. 


\section{DISCLAIMER}

This report was prepared as an account of work sponsored by an agency of the United States Government. Neither the United States Government nor any agency thereof, nor any of their employees, makes any warranty, express or implied, or assumes any legal liability or responsibility for the accuracy, completeness, or usefulness of any information, apparatus, product, or process disclosed, or represents that its use would not infringe privately owned rights. Reference herein to any specific commercial product, process, or service by trade name, trademark, manufac. turer, or otherwise does not necessarily constitute or imply its endorsement, recommendation, or favoring by the United States Government or any agency thereof. The views and opinions of authors expressed herein do not necessarily state or reflect those of the United States Government or any agency thereof. 


\section{DISCLAIMER}

Portions of this document may be illegible electronic image products. Images are produced from the best available original document. 


\begin{abstract}
This report is an in-depth summary of the state-of-the-art in nuclear piping fracture mechanics. It represents the culmination of 20 years of work done primarily in the U.S., but also attempts to include important aspects from other international efforts. Although the focus of this work was for the nuclear industry, the technology is also applicable in many cases to fossil plants, petrochemical/refinery plants, and the oil and gas industry. In compiling this detailed summary report, all of the equations and details of the analysis procedure or experimental results are not necessarily included. Rather, the report describes the important aspects and limitations, tells the reader where he can go for further information, and more importantly, describes the accuracy of the models. Nevertheless, the report still contains over 150 equations and over 400 references. The main sections of this report describe: (1) the evolution of piping fracture mechanics history relative to the developments of the nuclear industry, (2) technical developments in stress analyses, material property aspects, and fracture mechanics analyses, (3) unresolved issues and technically evolving areas, and (4) a summary of conclusions of major developments to date.
\end{abstract}




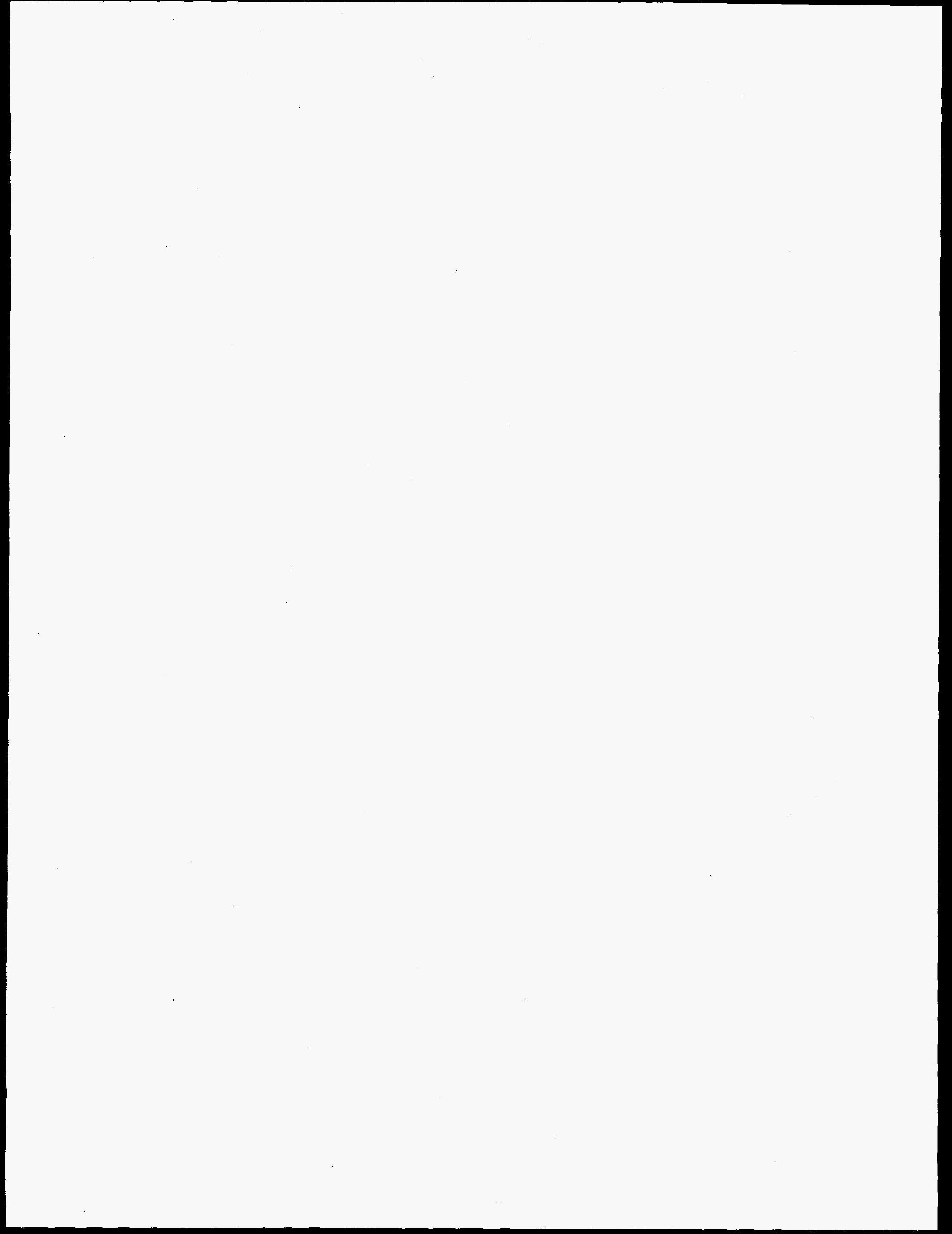




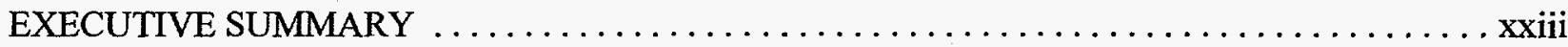

ACKNOWLEDGMENTS $\ldots \ldots \ldots \ldots \ldots \ldots \ldots \ldots \ldots \ldots \ldots \ldots \ldots \ldots \ldots \ldots \ldots \ldots \ldots \ldots$

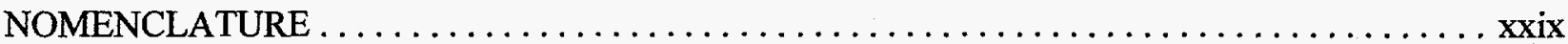

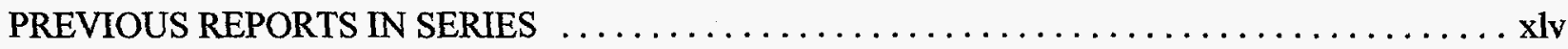

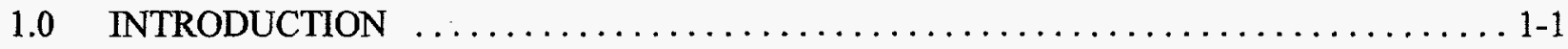

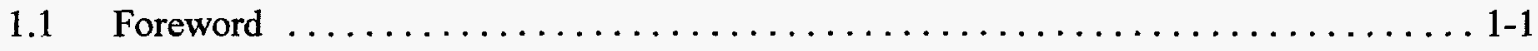

1.2 Milestone in Piping Fracture Mechanics $\ldots \ldots \ldots \ldots \ldots \ldots \ldots \ldots \ldots \ldots \ldots \ldots \ldots \ldots \ldots \ldots$

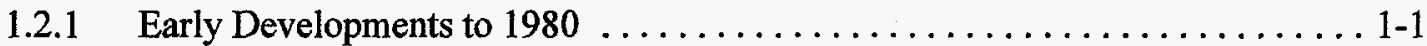

1.2.2 The Middle Ages of Piping Fracture Mechanics - the 1980's ......... 1-10

1.2.3 Recent Developments and Milestones -1990 to $1996 \ldots \ldots \ldots \ldots \ldots \ldots$. . . . . . . .

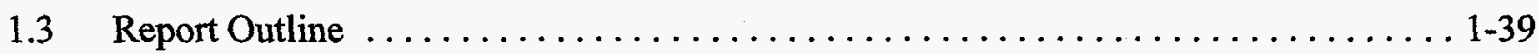

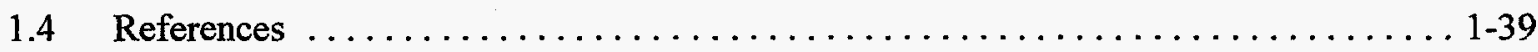

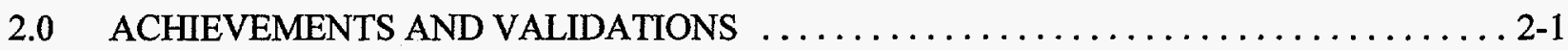

2.1 Achievements and Validations - Stress Analyses and Cracked

Pipe-System Behavior . . . . . . . . . . . . . . . . . .

2.1.1 Differences in Elastically Calculated Stresses and Actual Stresses . . . . . . . 2-1

2.1.2 Importance of Primary Versus Secondary Stresses $\ldots \ldots \ldots \ldots \ldots \ldots \ldots . . \ldots \ldots$

2.1.3 Residual Stress Consideration ........................ 2-5

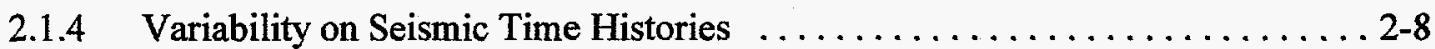

2.1.5 Other Interaction Effect Between Fracture Behavior and

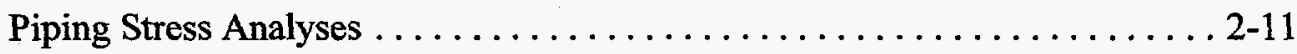

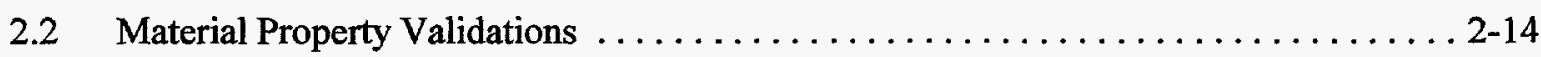

2.2.1 $\mathrm{J}_{\mathrm{Ic}}$ and J-R Curve Standards from Different Countries $\ldots \ldots \ldots \ldots \ldots \ldots .14$

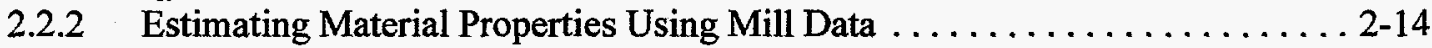

2.2.3 Extrapolated J-R Curves for Large Amounts of Crack Growth $\ldots \ldots \ldots \ldots$ 2-19

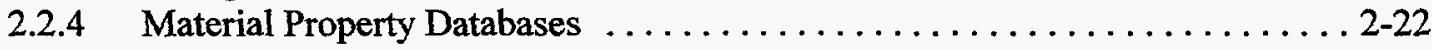

2.2.5 Particular Material Toughness Trends ..................... 2-22

2.2.6 Load History Effects on Fracture Toughness $\ldots \ldots \ldots \ldots \ldots \ldots \ldots \ldots . . \ldots \ldots$

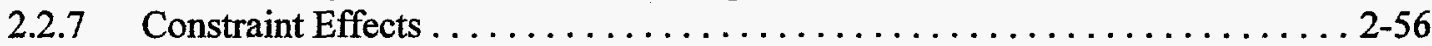




\section{CONTENTS}

2.3 Piping Fracture Mechanics Analyses - Straight Pipe $\ldots \ldots \ldots \ldots \ldots \ldots \ldots \ldots$

2.3.1 Predictions for Axially Cracked Pipes .................. 2-58

2.3.2 Accuracy of Fracture Predictions for Circumferentially Cracked Pipes . . . . . 2-70

2.4 Circumferential Through-Wall-Cracked Pipe Crack-Opening

Displacement Predictions and Leak-Rate Analyses $\ldots \ldots \ldots \ldots \ldots \ldots \ldots \ldots .2-162$

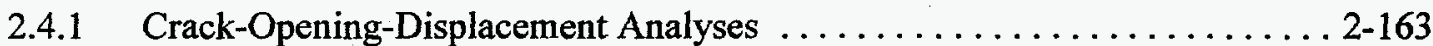

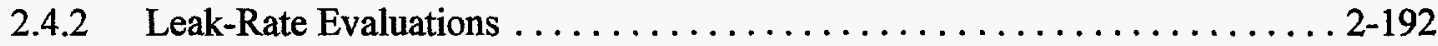

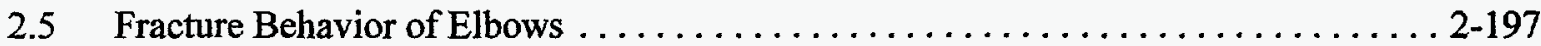

2.5.1 Fracture Prediction for Cracked Elbows . . . . . . . . . . . . . . . . . 2-198

2.5.2 Analysis of Surface-Cracked-Elbow Experiments . . . . . . . . . . . 2-205

2.5.3 Analysis of Through-Wall-Cracked-Elbow Experiments . . . . . . . . 2-207

2.5.4 A Simplified Method for Analysis of Cracked Elbows . . . . . . . . . . . . 2-208

2.5.5 Lessons Learned From the Elbow Studies .................. . 2-212

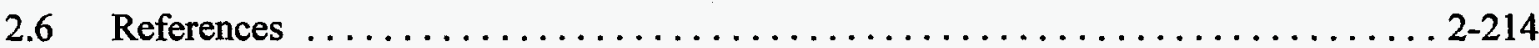

3.0 TECHNICALLY EVOLVING ISSUES AND ASPECTS NOT WELL UNDERSTOOD . . . . 3-1

3.1 Issues of Importance for Regulatory Organizations $\ldots \ldots \ldots \ldots \ldots \ldots \ldots \ldots \ldots \ldots \ldots$

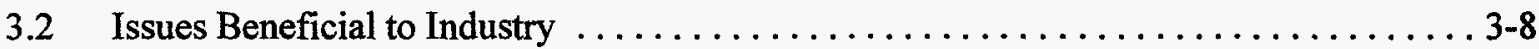

3.3 Observations of Aspects Not Well Understood $\ldots \ldots \ldots \ldots \ldots \ldots \ldots \ldots \ldots \ldots \ldots$

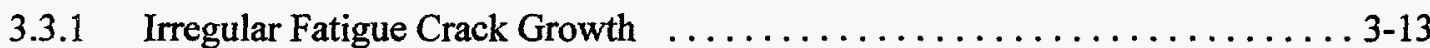

3.3.2 Fatigue Crack Growth in Cyclic Compressive Loading

with Mean Stresses from a Weld . . . . . . . . . . . . . . . . . . . . . 3-13

3.3.3 Splitting in Stainless Steel C(T) Specimens Causing Reduced Toughness . . . . 3-15

3.3.4 Through-Thickness Toughness Anisotropy $\ldots \ldots \ldots \ldots \ldots \ldots \ldots \ldots \ldots . \ldots \ldots$

3.3.5 Through-Thickness Splitting Causing Surface Crack Arrest $\ldots \ldots \ldots \ldots \ldots$ 3-15

3.3.6 Toughness Anisotropy for Circumferential Through-Wall-Cracked Pipe . . . 3-16

3.3.7 Crack Growth Around Hard Spots . . . . . . . . . . . . . . . . . . . 3-16

3.3.8 SEN(T) Fusion Line Toughness of Stainless Steel Weld Fusion Lines . . . . . 3-16

3.3.9 Unstable Crack Jumps in Ferritic Steels at LWR Temperatures . . . . . . . . . 3-18

3.3.10 Similitude Between Lab Specimens and Cracked Pipe Under Cyclic

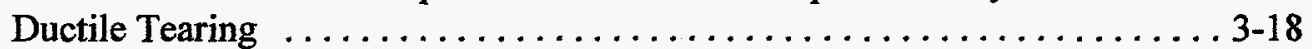

3.3.11 $\mathrm{J}_{\mathrm{M}}$ - Why Does it Work so Well for Pipe Test Predictions? ........ 3-18

3.3.12 Complex-Cracked Pipe Fracture Behavior ................. 3-19 
3.3.13 LBB Behavior of Circumferential Surface-Cracked Pipe

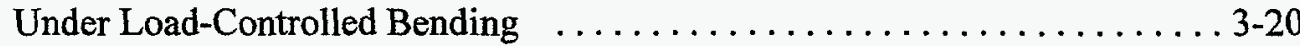

3.3.14 Brittle-to-Ductile Transition Temperature of Surface-Cracked Pipe . . . . . 3-20

3.3.15 FEM Analyses of Stainless Steel Cracked Pipe and Specimens . . . . . . . 3-20

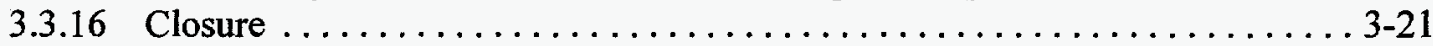

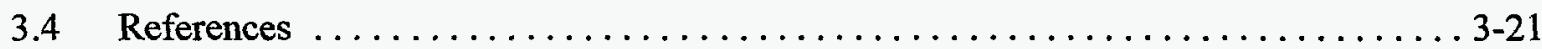

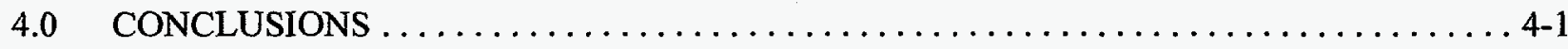

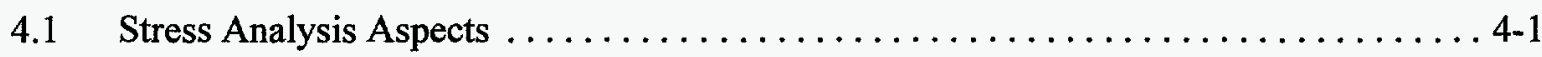

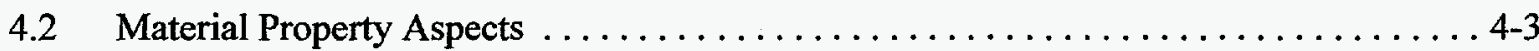

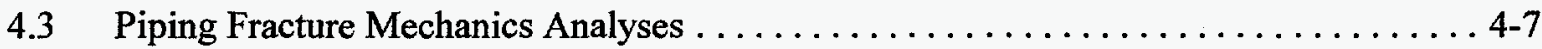

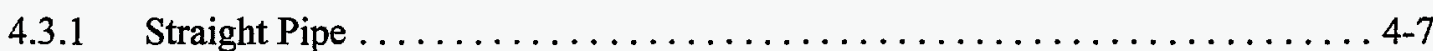

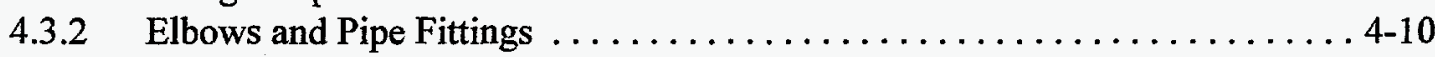

4.4 Aspects Not Well Understood and Evolving Technologies $\ldots \ldots \ldots \ldots \ldots \ldots \ldots$ 4-11

4.4.1 Aspects Potentially of Regulatory Concern $\ldots \ldots \ldots \ldots \ldots \ldots \ldots \ldots \ldots$ 4 11

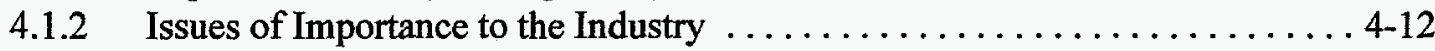

APPENDIX A - STRESS ANALYSIS METHODS $\ldots \ldots \ldots \ldots \ldots \ldots \ldots \ldots \ldots \ldots \ldots \ldots \ldots \ldots \ldots$

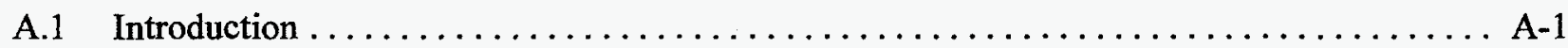

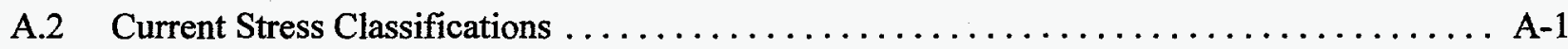

A.2.1 ASME Code Stress Limits $\ldots \ldots \ldots \ldots \ldots \ldots \ldots \ldots \ldots \ldots \ldots \ldots \ldots \ldots \ldots \ldots \ldots \ldots \ldots \ldots$

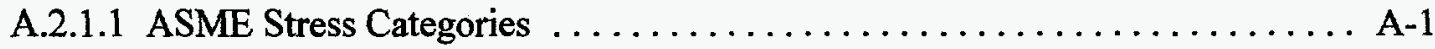

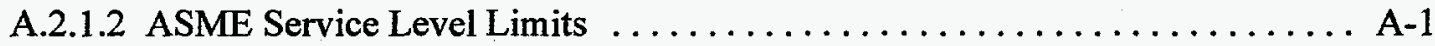

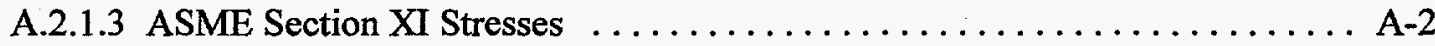

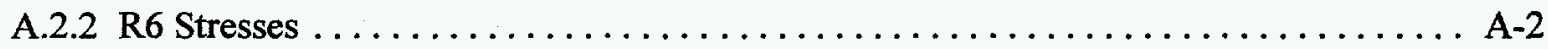

A.2.2.1 R6 Load Categories $\ldots \ldots \ldots \ldots \ldots \ldots \ldots \ldots \ldots \ldots \ldots \ldots \ldots \ldots \ldots \ldots \ldots \ldots \ldots \ldots \ldots$

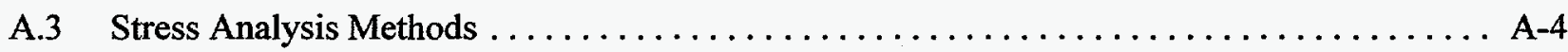

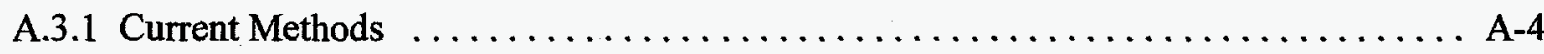




\section{CONTENTS}

A.3.2 Advanced Dynamic Methods . . . . . . . . . . . . . . . . .

A.3.2.1 Nonlinear Spring Model $\ldots \ldots \ldots \ldots \ldots \ldots \ldots \ldots \ldots \ldots \ldots \ldots \ldots \ldots \ldots$

A.3.3 Seismic Loading $\ldots \ldots \ldots \ldots \ldots \ldots \ldots \ldots \ldots \ldots \ldots \ldots \ldots \ldots \ldots \ldots \ldots \ldots \ldots$

A.4 Comments on Stress Analyses for Fracture Evaluations $\ldots \ldots \ldots \ldots \ldots \ldots \ldots \ldots \ldots \ldots$

A.4.1 Solution Accuracy $\ldots \ldots \ldots \ldots \ldots \ldots \ldots \ldots \ldots \ldots \ldots \ldots \ldots \ldots \ldots \ldots \ldots \ldots$

A.4.2 Elastic Analysis for an Inherently In-Elastic Behavior $\ldots \ldots \ldots \ldots \ldots \ldots \ldots \ldots$ A-10

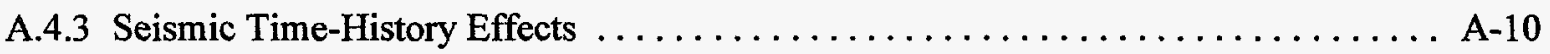

A.4.4 Combined Bending and Torsion $\ldots \ldots \ldots \ldots \ldots \ldots \ldots \ldots \ldots \ldots \ldots \ldots \ldots \ldots \ldots \ldots \ldots$

A.5 General Guidance $\ldots \ldots \ldots \ldots \ldots \ldots \ldots \ldots \ldots \ldots \ldots \ldots \ldots \ldots \ldots \ldots \ldots \ldots \ldots$

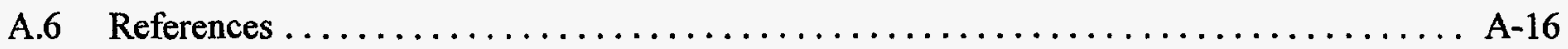




\section{LIST OF FIGURES}

1.1 A series of frames from a high speed movie taken during a brittle crack

propagation experiment

1.2 Comparison of $\mathrm{t}$ by $2 \mathrm{t} \mathrm{COD}$ transition temperature with axial through-wall cracked 48 -inch $(1,219 \mathrm{~mm})$ diameter pipe fracture data $\ldots \ldots \ldots \ldots \ldots \ldots \ldots \ldots$

1.3 Comparison of transition temperature from COD bend specimens with 24-inch $(610 \mathrm{~mm})$ diameter 0.375 -inch $(9.5 \mathrm{~mm})$ thick API 5LX nonstress-relieved pipe

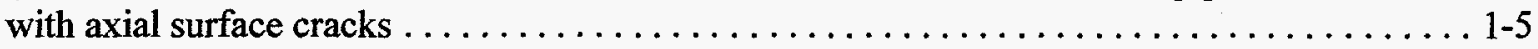

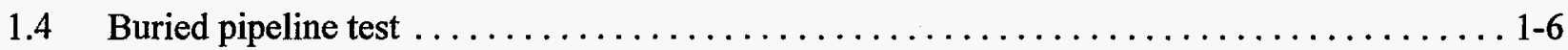

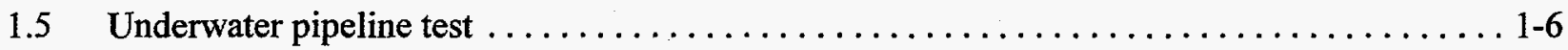

1.6 Modes of crack extension observed in 24-inch-diameter x 1.70-inch-thick A106B

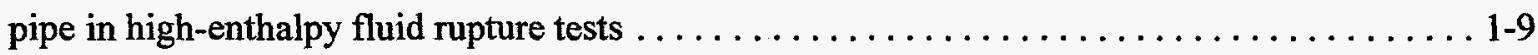

1.7 Elevation view of the EPRI Phase I leak rate measurement experimental facility $\ldots \ldots \ldots 1-13$

$1.8 \mathrm{~J} / \mathrm{T}$ stability assessment methodology (a) Material $\mathrm{J} / \mathrm{T}$ behavior,

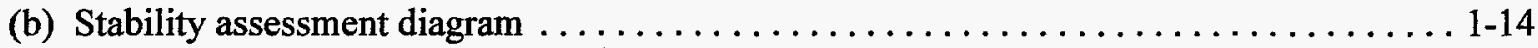

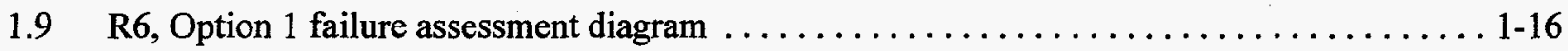

$1.10 \mathrm{~J}_{\mathrm{M}}$-resistance curves for Type 304 stainless steel at $288 \mathrm{C}(550 \mathrm{~F})$ showing the deleterious effect of submerged-arc welding

1.11 An experimental setup for induced transient bending stresses in the dynamic pipe fracture experiments in Reference 1.60

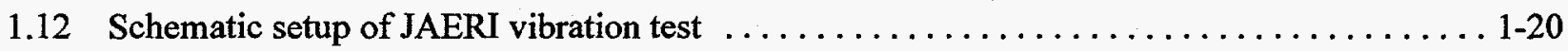

1.13 Schematic of DTRC compliant instability pipe experiments $\ldots \ldots \ldots \ldots \ldots \ldots \ldots \ldots \ldots 1-20$

1.14 Photograph of compact (tension) specimens used in large-crack growth studies (1T, 3T, and 10T planform-sized specimens, $25.4 \mathrm{~mm}$ [1 inch] thick)

1.15 Post-test photograph of test specimen for a 16-inch (406-mm) diameter weld-overlay pipe experiment (Experiment 4142-4) showing the extreme deformation remote from weld overlay . 


\section{CONTENTS}

1.16 Total applied load as a function of load-line displacement for Experiment 4111-2

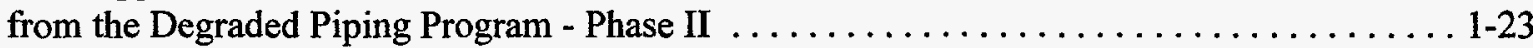

1.17 Photograph showing preferred crack growth in a seamless carbon steel pipe and a $C(T)$ specimen from the same pipe material

1.18 Schematic of test apparatus used for reversed four-bending in IPIRG-1 Subtask $1.2 \ldots \ldots \ldots$ 1-28

1.19 Measured load versus load-line displacement for quasi-static reversed $(\mathrm{R}=0)$ loading (Experiment 1.2-3 from the IPIRG-1 program)

1.20 Effect of dynamic loading on moment-rotation behavior of 6-inch-diameter through-wall-cracked pipe experiments from IPIRG-1 (a) TP304, (b) A106B

1.21 Sketch of test frame used in IPIRG-1 inertial experiments $\ldots \ldots \ldots \ldots \ldots \ldots \ldots \ldots \ldots \ldots$

1.22 Artist's conception of the IPIRG pipe loop test facility $\ldots \ldots \ldots \ldots \ldots \ldots \ldots \ldots \ldots \ldots$

1.23 Comparison of linear and nonlinear analyses of a complex crack under

3SSE seismic loading

1.24 HDR-E31 test system with flawed section

2.1 Comparison of the results from the IPIRG-1 pipe-system experiments with companion quasi-static, four-point bend experiments demonstrating how global secondary stresses, such as thermal expansion and seismic anchor motion stresses,

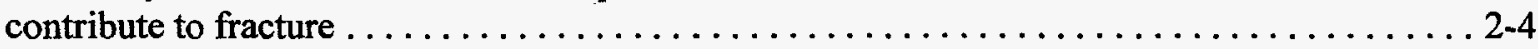

2.2 Potential local overstrain screening criteria (Flaws below the curves will have

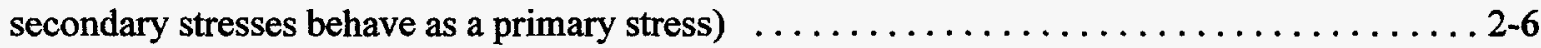

2.3 Comparison of total applied load as a function of load-line displacement for Type 304 stainless steel SAW pipe experiments with as-welded and solution-annealed stainless steel submerged arc welds (a) 152-mm (6-inch) through-wall-crack experiments, (b) 406-mm

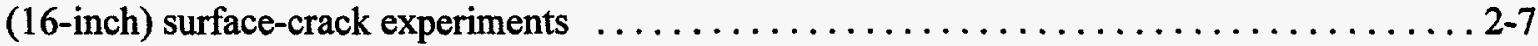

2.4 Percentage change in calculated COD due to residual stress as a function of applied moment (a) Thick-walled large-diameter pipe, (b) Thin-walled small-diameter pipe . . . . . . 2-9

2.5 Predicted moment response at 2-percent damping for various spectrum-compatible displacement time histories from a round-robin analysis (a), (b), (c), (d) $\ldots \ldots \ldots \ldots$ 2-10

2.6 Photograph of fracture from aged cast stainless experiment (Experiment 1.3-7) $\ldots \ldots \ldots 2-12$ 


\section{CONTENTS}

$\underline{\text { Page }}$

2.7 Net-Section-Collapse analyses predictions, with and without considering induced bending, as a function of the ratio of the through-wall-crack length to the pipe circumference $\ldots \ldots 2-12$

2.8 Effects of fully restrained bending conditions from crack location on COD normalized by the unrestrained COD $\ldots \ldots \ldots \ldots \ldots \ldots \ldots \ldots \ldots \ldots \ldots \ldots \ldots \ldots \ldots \ldots \ldots \ldots \ldots \ldots \ldots \ldots .13$

2.9 Correlation between Charpy V-notch energy and shear area percent to predict the plateau energy of carbon steels (a) Natural gas line-pipe steels, (b) Nuclear piping materials

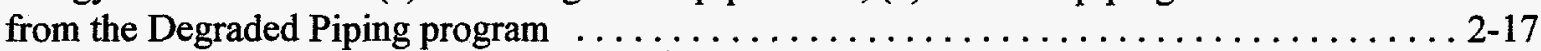

2.10 Schematic of NUREG $1061 \mathrm{~J}-\mathrm{R}$ curve extrapolation method $\ldots \ldots \ldots \ldots \ldots \ldots \ldots \ldots$

$2.11 \mathrm{~J}-\mathrm{R}$ curve for various planform-sized Type 304 stainless steel compact (tension)

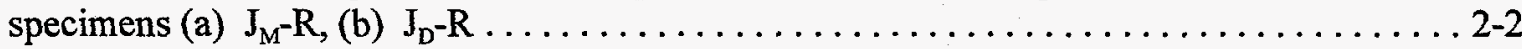

2.12 Comparison of the experimental moment-rotation curve with the predicted moment-rotation curves for the bimetal weld cold-leg Experiment 1.1.1.28 from the Short Cracks program for five analysis methods using the A516 Grade 70 carbon steel pipe stress-strain data

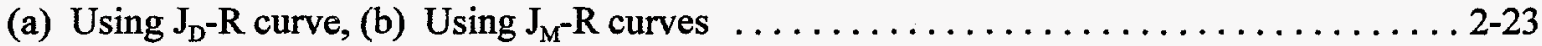

2.13 Load-displacement data for circumferential through-wall-cracked pipe bending experiment (Experiment 1.2-8) from Pipe DP2-F30 (A106 Grade B carbon steel), tested at 288 C (550 F) showing concave nature of curve after maximum load $\ldots \ldots \ldots \ldots \ldots \ldots \ldots \ldots \ldots 24$

2.14 IGSCC in 102-mm (4-inch) diameter BWR recirculation bypass line (Loop B of the

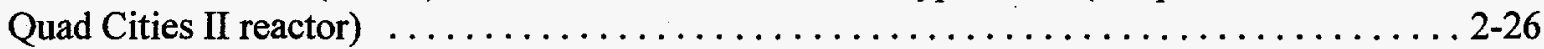

2.15 IGSCC in Nine Mile Point Plant; 711-mm (28-inch) diameter main recirculation line

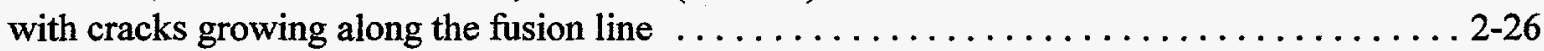

2.16 IGSCC in Nine Mile Point Plant; 711-mm (28-inch) diameter main recirculation line with a crack growing into the weld metal .

2.17 Crack propagation at $288 \mathrm{C}(550 \mathrm{~F})$ along fusion line of a TP316 SAW from a 711-mm (28-inch) diameter pipe test (weld crown ground off prior to test) (a) Initial crack tip location in center of weld, (b) Crack propagation paths $\ldots \ldots \ldots \ldots \ldots \ldots \ldots 29$

2.18 Crack propagation in base metal, HAZ remote from fusion line, and weld metal in

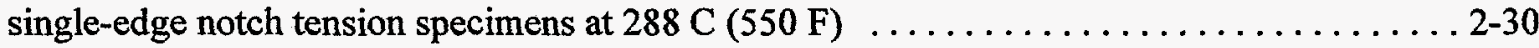

$2.19 \mathrm{~J}$-resistance curves of slant-notch, fusion-line specimens [limit on J-R curve data is $\Delta \mathrm{a} \leq \mathbf{0 . 3}\left(\mathrm{W}-\mathrm{a}_{\mathrm{o}}\right)$ ] (Note: The sudden load drop for Specimen A8W4-FL-5 corresponded to a significant crack jump) 


\section{CONTENTS}

2.20 Load-displacement record from a full-scale pipe test (Experiment No. 4111-2) to

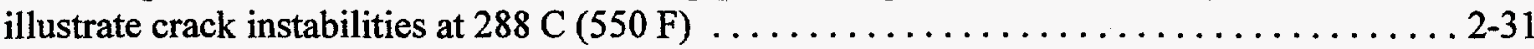

2.21 Comparison of $288 \mathrm{C}(550 \mathrm{~F})$ A516 Grade 70 base metal and Linde 44 SAW

SEN(T) specimen data

2.22 Toughness anisotropy of ASTM A106B pipe (Note: Reprinted with permission) . . . . . . 2-33

2.23 The variation of $J_{\text {applied }} / J_{i}$ (for Pipe DP2-F11) with crack-tip angle from the circumferential plane

2.24 Effect of angled crack growth on moment-rotation response

2.25 Metallographic section of unfailed V-notch in a pipe experiment where the surface crack arrested at a lamination

2.26 Effect of specimen thickness on the J-R curves of A302-B plate where laminations/banding acted as crack dividers

2.27 Effect of yield-to-ultimate strength ratio on the fracture toughness at dynamic loading rates relative to that of quasi-static rates

$2.28 \mathrm{~J}_{\mathrm{dyn}, \text { mono }} / \mathrm{J}_{\mathrm{QS} \text {,mono }}$ versus $\mathrm{BHN}_{288} / \mathrm{BHN}_{\mathrm{RT}}$ for a variety of carbon steel base and weld metals . .

2.29 Dowling analysis of area used in J calculations for crack growth in the presence

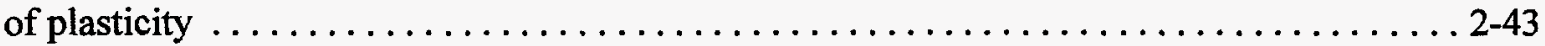

2.30 Mid-thickness cross sections showing crack-tip region in three interrupted carbon

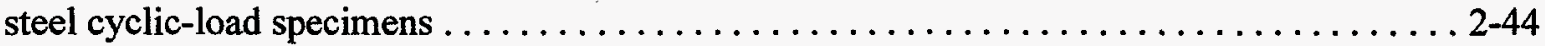

2.31 Measured load versus load-line displacement for quasi-static reversed $(R=0)$ loading

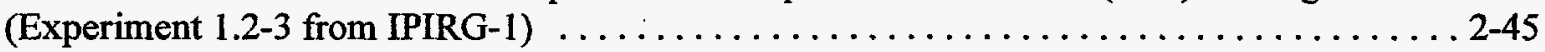

2.32 Load-displacement records for 152-mm (6-inch) nominal diameter carbon steel

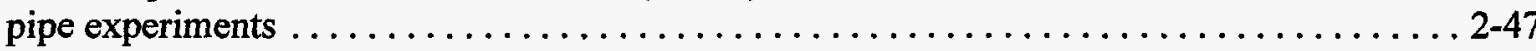

2.33 Comparison of cyclic-load J-R curves for carbon steel C(T) specimens tested with

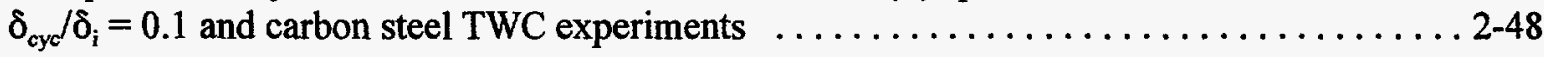

2.34 Comparison of J-R curves from FEM and ASTM using predicted load-displacement

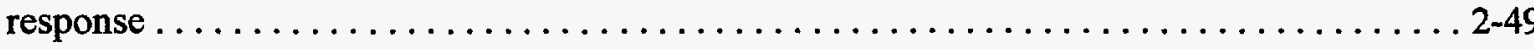

2.35 Schematic of relationship between cyclic toughness degradation and stress ratio $\ldots \ldots \ldots 2-50$ 
2.36 Carbon steel cyclic-load J-R curves tested at $\delta_{\text {cyc }} / \delta_{i}=0.1 \ldots \ldots \ldots \ldots \ldots \ldots \ldots \ldots \ldots$

2.37 Stainless steel cyclic-load J-R curves tested with $\delta_{\text {cyc }} / \delta_{\mathrm{i}}=0.1 \ldots \ldots \ldots \ldots \ldots \ldots \ldots \ldots \ldots$

2.38 Load-displacement-crack growth records from a GE/EPRI TWC pipe prediction and C(T) specimens illustrating the need to change $\delta_{\text {cyc }} / \delta_{i}$ after crack initiation to produce comparable cyclic crack growth between the two specimen types (a) GE/EPRI J-estimation scheme prediction of TWC pipe Experiment 4131-5 (Pipe DP2-A23) (J-R curve used in the

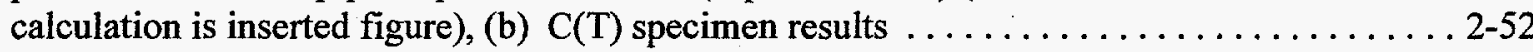

2.39 Calculated $\mathrm{J}$ for dynamic, cyclic loading for separate effect trends versus actually combined load $J$ values

2.40 Example of a worst case bounding seismic time history for a $4 \mathrm{~Hz}$ natural frequency pipe system

2.41 Comparison of $\mathrm{t} \times 2 \mathrm{t}$ COD transition to axial through-wall-cracked 1,219-mm (48-inch)

diameter pipe fracture data...

2.42 Comparison of the transition temperature from COD bend specimens to $610-\mathrm{mm}$ (24-inch) diameter by $9.5-\mathrm{mm}$ ( 0.375 -inch) thick API-5LX pipe with axial surface cracks

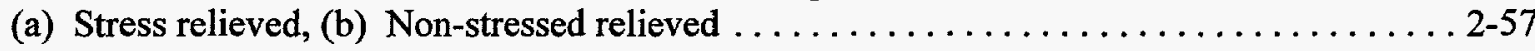

2.43 Comparison of original and updated Folias bulging factors $\left(\mathrm{M}_{\mathrm{T}}\right) \ldots \ldots \ldots \ldots \ldots \ldots$

2.44 Plot of $\log$-secant equation for axial through-wall cracks $\ldots \ldots \ldots \ldots \ldots \ldots \ldots \ldots \ldots \ldots$

2.45 Illustration of leak-before-break behavior of axial cracks under pressure loading $\ldots \ldots \ldots 2-63$

2.46 Modes of crack extension observed in 610-mm (24-inch) diameter x 43.2-mm $(1.70$-inch) thick A106B pipe in high-enthalpy fluid rupture tests $\ldots \ldots \ldots \ldots \ldots \ldots \ldots 2-65$

2.47 Schematic of types of decompression behavior $\ldots \ldots \ldots \ldots \ldots \ldots \ldots \ldots \ldots \ldots \ldots \ldots$

2.48 Flap formation in unstable axial crack propagation $\ldots \ldots \ldots \ldots \ldots \ldots \ldots \ldots \ldots \ldots \ldots$

2.49 Illustration of Maxey ductile fracture model $\ldots \ldots \ldots \ldots \ldots \ldots \ldots \ldots \ldots \ldots \ldots \ldots$

2.50 Data correlation describing ductile fracture arrest $\ldots \ldots \ldots \ldots \ldots \ldots \ldots \ldots \ldots \ldots \ldots$

2.51 Comparison of Sanders' $F$-function for $R / t=10$ and polynominal fit assuming $F=1$ as crack angle approaches zero 


\section{CONTENTS}

2.52 Comparison of recent FEM results from Reference 2.14 with Sanders' analytical F-function solutions from Reference 2.116 (a) $R / t=5$, (b) $R / t=10$

2.53 Representation of critical net-section-stress (flow stress) reached throughout the flawed ligament of a structure under fully plastic conditions

2.54 IPIRG member participant predictions of loads at crack initiation compared with experimental loads for IPIRG Round-Robin Problem 1

2.55 IPIRG participant predictions of loads at maximum load compared with experimental loads for IPIRG Round-Robin Problem 1

2.56 Normalized flow stress dependent relationship for failure of circumferential repairgrooves in pipes subjected to bending stresses

2.57 Load versus clip gage (groove opening) displacement record for a 102-mm (4-inch) diameter by $3.2 \mathrm{~mm}(0.125$-inch) thick pipe with a 70 percent repair-groove in tension

2.58 Predicted Net-Section-Collapse analysis bending stress versus normalized flaw length for various surface-crack depths (a) Plot of Equations 2-66 and 2-67 for pure bending,

(b) Case where normalized NSC stress held constant for longer crack lengths

2.59 Effects of flaw shapes on limit load for shallow and deep cracks (a) $a / t=10$ percent,

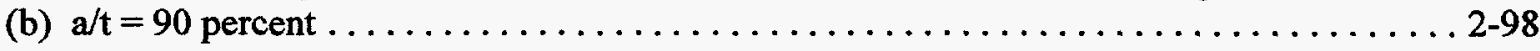

2.60 Plot of Kurihara-modified Net-Section-Collapse equations . . . . . . . . . . . . . 2-99

2.61 Comparison of original and Kurihara-modified Net-Section-Collapse equations

2.62 Plot of the ratio of experimental stress to predicted stress as a function of pipe radius-

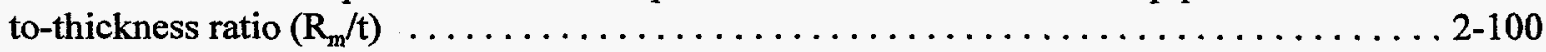

2.63 Plasticity function $h_{1}$ (ABAQUS - Solid Element Results) for pipe under bending with

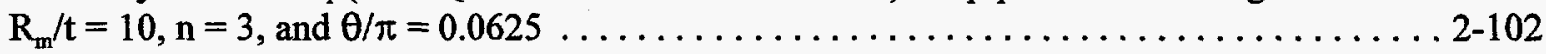

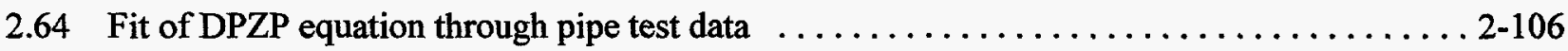

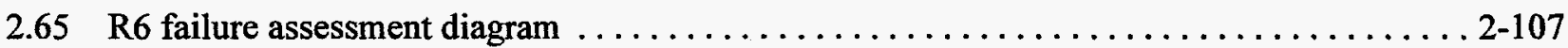

2.66 Comparison of Z-factors from DPZP analysis with ASME IWB-3640 analysis using $\sigma_{\mathrm{f}}=\left(\mathrm{S}_{\mathrm{y}}+\mathrm{S}_{\mathrm{u}}\right) / 2$ 
2.67 Comparison of Z-factors from the Code Case N-494-2 analysis with the ASME Section XI Appendix H values (a) 152-mm (4-inch) diameter pipe, (b) 406-mm (16-inch) diameter pipe, (c) 1,067-mm (42-inch) diameter pipe

2.68 Comparison of Z-factors from the SC.TNP1 analysis with the ASME Section XI Appendix $\mathrm{H}$ values (a) 102-mm (4-inch) diameter pipe, (b) 406-mm (16-inch)

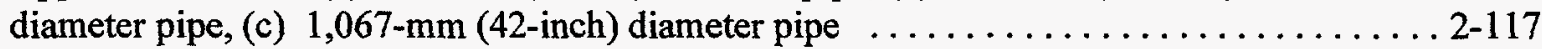

2.69 Comparison of the SC.TNP1 Z-factors with the ASME Appendix H equation Z-factor values versus pipe diameter using the $J / T$ extrapolated $J_{D}-R$ curve

2.70 Ratio of SC.TNP1 Z-factors using $\mathrm{J} / \mathrm{T}$ extrapolated $\mathrm{J}_{\mathrm{D}}-\mathrm{R}$ curve to $\mathrm{Z}$-factors using $J_{M}-R$ curve versus $\theta / \pi$

2.71 Plot of the maximum stress ratio (maximum experimental stress/maximum predicted stress) for the SC.ENG1 and SC.ENG2 analyses as a function of mean pipe radius-to-pipe wall thickness ratio $\left(R_{m} / t\right)$ for the combined pressure and bend experiments $\ldots \ldots \ldots \ldots 2-126$

2.72 Comparison of typical crack found in service with laboratory simulated "complex crack" . 2-129

2.73 Physical observations and calculated J-R curves for Type 304 stainless steel pipe with initial idealized through-wall cracks and complex cracks (a) Circumferential crack morphology during ductile tearing, (b) Calculated J-R curves from Type 304 stainless

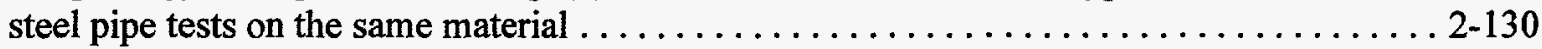

2.74 Comparison of SA-376 TP304 stainless steel complex-cracked pipe data to simple

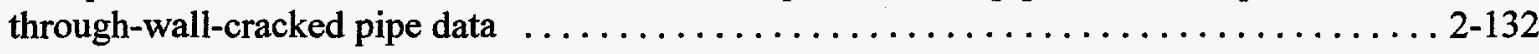

2.75 Posttest fracture surface from Experiment 4113-1 showing crack-growth profiles caused by unloadings

2.76 Computed J-R curves using $\eta$-factor analysis for Type 304 stainless steel 152-mm (6-inch) diameter complex-cracked pipes tested at $288 \mathrm{C}(550 \mathrm{~F})$

2.77 Ratio of J from complex-cracked pipe experiments to $\mathrm{J}$ of the simple through-wall-cracked pipe experiments as a function of $a / t$ for various experiments $\ldots \ldots \ldots \ldots \ldots \ldots \ldots \ldots \ldots \ldots \ldots$

2.78 Comparison of stable crack growth pipe test with low compliance with instability behavior in a moderate compliant test frame (a) Instability in a moderate compliant test frame, (b) Stable crack growth in low compliance test frame $2-134$

2.79 Total applied load versus actuator displacement for the Haddam Neck (Connecticut Yankee) Plant MIC experiment 


\section{CONTENTS}

Page

2.80 Reduced section analogy by the LBB.ENG and SC.ENG methods

2.81 Predicted load versus load-line displacements compared with results from Experiment 4141-3 on 406-mm (16-inch) diameter Type 304 stainless steel as-welded SAW pipe (a) Base metal stress-strain curve and $J_{D}-R$ curve,

(b) Base metal stress-strain curve and $J_{M}-R$ curve

2.82 Comparison of the experimental moment-rotation curve with the predicted moment-rotation curves for bimetallic weld cold leg experiment

(a) Using $J_{D}-R$ curve, (b) Using $J_{M}-R$ curve

2.83 Comparison of experimental data with analytical prediction of load versus pipe displacement at the load points for Experiment 1.2.1.20

2.84 Comparison of experimental data with analytical prediction of load versus pipe displacement at the load points for Experiment 1.2.3.15

2.85 Comparison of experimental data with analytical prediction of load versus pipe

displacement at the load points for Experiment 1.2.3.16

2.86 Comparison of experimental data with analytical prediction of load versus pipe

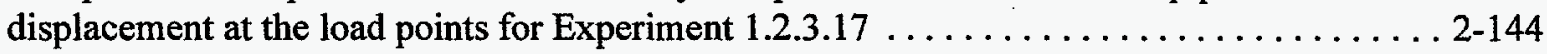

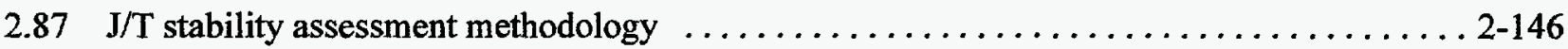

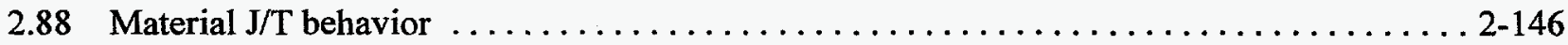

2.89 Energy available for driving an instability (a) Surface crack behavior,

(b) Pipe-system behavior, (c) Combined energy $\ldots \ldots \ldots \ldots \ldots \ldots \ldots \ldots \ldots \ldots \ldots \ldots \ldots$

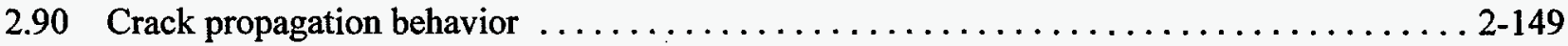

2.91 Energy Balance diagram showing balanced available and absorbed energies . . . . . . 2-149

2.92 Cracked pipe analysis beam and shell piping system model of Griesbach (Ref. 2.170) . . . 2-150

2.93 Combined surface-crack and through-wall-crack model for analyzing

dynamic surface to through-wall-crack transitions

2.94 Schematic of DTRC compliant instability pipe experiments $\ldots \ldots \ldots \ldots \ldots \ldots \ldots \ldots 2-155$

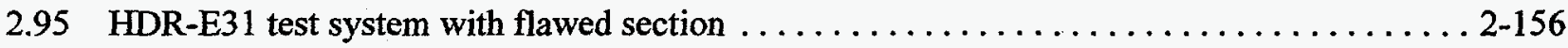


2.96 Energy balance for DTRC Experiment 13 with $6,480 \mathrm{~N} / \mathrm{mm}(37,000 \mathrm{lb} / \mathrm{in})$

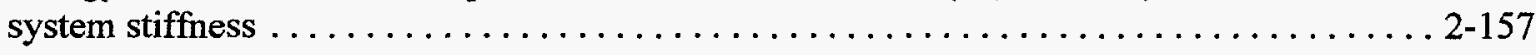

2.97 Energy balance for DTRC Experiment 13 with $12,959 \mathrm{~N} / \mathrm{mm}(74,000 \mathrm{lb} / \mathrm{in})$

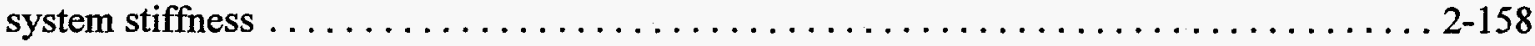

2.98 Energy balance for DTRC Experiment 13 with $15,761 \mathrm{~N} / \mathrm{mm}(90,000 \mathrm{lb} / \mathrm{in})$

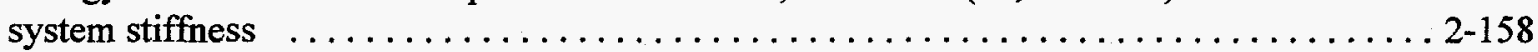

2.99 Load-controlled $\mathrm{J} / \mathrm{T}$ stability analysis of HDR-E31 experiments $\ldots \ldots \ldots \ldots \ldots \ldots \ldots$

2.100 Energy Balance stability analysis of HDR-E31.2 (Rotation is total rotation) $\ldots \ldots \ldots .2-160$

2.101 Energy Balance stability analysis of HDR-E31.3 (Rotation is total rotation) $\ldots \ldots \ldots \ldots 2-160$

2.102 Comparison of crack section moment as a function of time for IPIRG-1

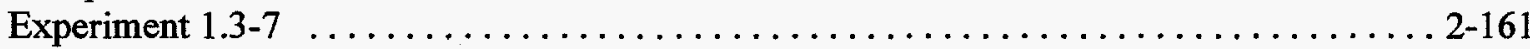

2.103 Schematic comparison of predicted and experimental load versus center-crack-opening displacement in a pipe (ideally COD and load are underpredicted for LBB analyses) . . . 2-162

2.104 Conditional failure probability of a BWR side-riser TP304 pipe system for various combinations of normal operating and N+SSE stresses (base metal), from

Reference 2.176

2.105 Crack-opening profiles at various applied bending moments for tension plus bending $\ldots \ldots$ 2-178

2.106 Crack-opening profiles at various effective moments (calculated using $C_{e}=\sqrt{3} / 2$ ) for combined tension, bending, and torsion (a) $\mathrm{M}_{\mathrm{b}} / \mathrm{T}=3.0$, (b) $\mathrm{M}_{\mathrm{b}} / \mathrm{T}=1.0 \ldots \ldots \ldots \ldots \ldots 2-179$

2.107 Variation of total crack-opening displacement with effective moment for the load cases of tension plus bending and combined tension, bending, and torsion (The effective moment for the latter cases is calculated for several values of $c_{e}$ )

2.108 Comparison of the variations of total crack-opening area with effective moment for the combined load cases of tension plus bending and tension plus bending plus

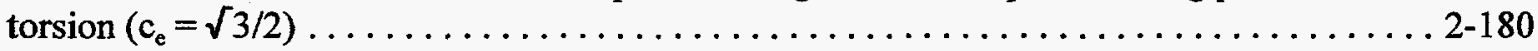

2.109 Photograph of fracture from aged cast stainless experiment (Experiment 1.3-7) $\ldots \ldots \ldots 2-182$

2.110 Net-Section-Collapse analyses predictions, with and without considering induced bending, as a function of the ratio of the through-wall crack length to the pipe circumference 


\section{CONTENTS}

2.111 Schematic of a through-wall-cracked pipe under pure tension (restrained locations

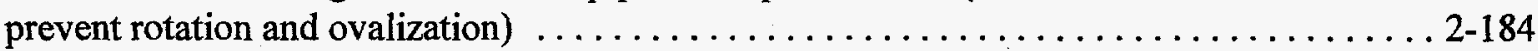

2.112 Calculated maximum loads for LBB with and without restraint of the pressure-induced bending from the pipe system

2.113 Geometric details of a carbon steel nozzle with a through-wall crack at thickness transition, dimensions in $\mathrm{mm}$

2.114 Crack-opening profiles under combined bending and tension (a) $\mathrm{M}=200 \mathrm{kN}-\mathrm{m}$,

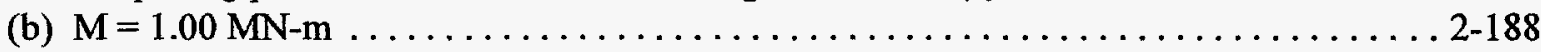

2.115 Total crack-opening displacement due to residual stresses $\ldots \ldots \ldots \ldots \ldots \ldots \ldots \ldots 2-189$

2.116 Prescribed residual stress field from ASME Section XI IWB-3640 analyses $\ldots \ldots \ldots \ldots$ 2-190

2.117 Percentage change in calculated COD due to residual stress as a function of applied moment for small diameter thin-wall and large diameter thick-wall pipe

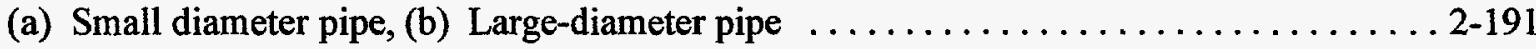

2.118 Ratio of leak rates, with and without residual stresses, as a function of applied loads . . . 2-192

2.119 Local and global surface roughness and number of turns $\ldots \ldots \ldots \ldots \ldots \ldots \ldots \ldots$

2.120 Histogram of leakage flaw size in a pipe for $3.785 \mathrm{liter} / \mathrm{min}(1 \mathrm{gpm})$ leak rate and 50 percent of ASME Service Level A stress limit

2.121 Probability distribution of leakage flaw size in a pipe for $3.785 \mathrm{liter} / \mathrm{min}$ (1 gpm) leak rate and 50 percent of ASME Service Level A stress limit $2-196$

2.122 Uncertainty bands for predictions from the SQUIRT thermal-hydraulic model $\ldots \ldots \ldots \ldots 2-197$

2.123 Comparison of limit-load definitions by design stress and fracture approaches $\ldots \ldots \ldots \ldots 2-198$

2.124 Schematic of circumferential crack geometry used for development of an elbow analysis

2.125 Schematic of axial crack geometry used for development of elbow analysis $2-203$

2.126 Maximum moment data for circumferential through-wall-cracked elbow experiments $2-208$

2.127 Comparison of ASME elbow stress indices to ratio of moment for circumferential, surface-cracked, straight pipe to moment for axial, flank, surface-cracked elbow at the same J values $\left(\mathrm{M}^{\mathrm{pipe}} / \mathrm{M}^{\mathrm{elbow}} \mathrm{J}_{\mathrm{J}}\right)$ 
2.128 Comparison of ASME elbow stress indices to ratio of moment for circumferential, surface-cracked, straight pipe to moment for circumferential, extrados, surface-cracked elbow at the same $J$ values $\left(\mathrm{M}^{\text {pipe }} / \mathrm{M}^{\text {elbow }} \mathrm{J}_{\mathrm{J}}\right.$ ) (a) Using SC.ELB1 analysis, (b) Using SC.ELB2 analysis

2.129 Comparison of IPIRG-2, circumferential, extrados, surface-cracked, experiments on A106-90 and WP304L elbows to criteria developed in Figure 2.128 (SC.ELB1 and SC.ELB2 analyses virtually identical)

2.130 Comparison of axial-flank and circumferential-extrados surface-cracked elbow failure avoidance criteria

3.1 Effects of fully restrained bending conditions from crack location on COD normalized by the unrestrained COD

3.2 Percentage change in calculated COD due to residual stress as a function of applied moment (a) Thin-walled small-diameter pipe, (b) Thick-walled large-diameter pipe . . . . . 3-3

3.3 Comparison of full-scale component fatigue data with ASME Section III fatigue design curves (a) Stainless steel data, (b) Carbon steel data

3.4 J-values at $1 \mathrm{~mm}(0.04$-inch $)$ and $2 \mathrm{~mm}(0.08$ inch $)$ of crack extension for bimetallic welds evaluated by NRC-Rez and Battelle

3.5 J-resistance curves of slant-notch, fusion-line specimens [limit on J-R curve data is $\Delta \mathrm{a} \leq 0.3\left(\mathrm{~W}-\mathrm{a}_{\mathrm{o}}\right)$ ] (Note: The sudden load drop for Specimen A8W4-FL-5 corresponded to a significant crack jump as shown in the load-displacement data)

3.6 Plot of the ratio of experimental stress to Net-Section-Collapse predicted stress

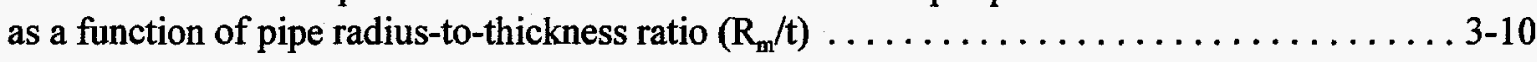

3.7 Example of transition temperature differences between bend specimens and

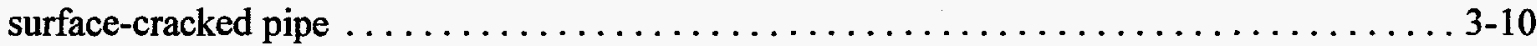

3.8 Comparison of axial-flank and circumferential-extrados surface-cracked elbow failure avoidance criteria

3.9 Photograph shows the internal scallops which comprised the initial flaw. The fatigue precrack can be clearly seen in this specimen (1.1-6) and it shows the two crack excursions which nearly made the flaw a TWC rather than SC. The deep fatigue cracks are very near the end of the flaw and did not appear to affect the maximum moment achieved during the test $3-14$

3.10 Arrest of axial surface crack in Battelle pipe test by through-thickness splitting 


\section{CONTENTS}

3.11 Fracture surface as a ductile tear in TP304 stainless steel grew through a "hard spot"

3.12 Observed relationship between $\mathrm{dJ}_{\mathrm{M}} / \mathrm{da}$ and crack-tip-opening angle (CTOA) from complex-cracked pipe tests

A.1 Nonlinear spring model for dynamic cracked pipe analysis $\ldots \ldots \ldots \ldots \ldots \ldots \ldots \ldots \ldots$

A.2 Nonlinear FEA pipe fracture crack model analysis of a through-wall crack demonstrating correct modeling of negative stiffness behavior past maximum load

A.3 Comparison showing surface to through-wall crack transition behavior of nonlinear FEA pipe fracture model for IPIRG-1 Experiment 1.3-7 (aged CF8M cast stainless steel, single frequency pipe-system test)

A.4 Nonlinear FEA pipe fracture model unloading behavior for selected cycles of IPIRG-1 Experiment 1.2-4 (A106 Grade B through-wall crack, $\mathrm{R}=-1$ cyclic loading)

A.5 Spectra for compatible time history $1 \ldots \ldots \ldots \ldots \ldots \ldots \ldots \ldots \ldots \ldots \ldots \ldots \ldots \ldots \ldots \ldots \ldots$

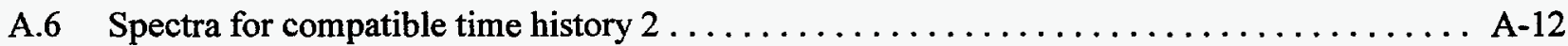

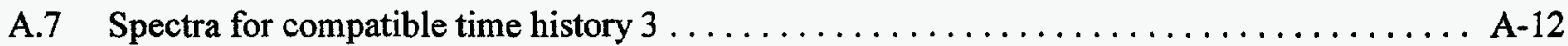

A.8 Spectra for compatible time history $4 \ldots \ldots \ldots \ldots \ldots \ldots \ldots \ldots \ldots \ldots \ldots \ldots \ldots \ldots \ldots$

A.9 Moment-time for spectrum-compatible time history $1 \ldots \ldots \ldots \ldots \ldots \ldots \ldots \ldots$ A-13

A.10 Moment-time for spectrum-compatible time history $2 \ldots \ldots \ldots \ldots \ldots \ldots \ldots \ldots$ A-14

A.11 Moment-time for spectrum-compatible time history $3 \ldots \ldots \ldots \ldots \ldots \ldots \ldots \ldots \ldots \ldots$

A.12 Moment-time for spectrum-compatible time history $4 \ldots \ldots \ldots \ldots \ldots \ldots \ldots \ldots \ldots \ldots$ 


\section{CONTENTS}

Page

\section{LIST OF TABLES}

1.1 Milestones in pipe fracture technology and the nuclear industry - the early years $\ldots \ldots \ldots \ldots 1-2$

1.2 Milestones in pipe fracture technology and the nuclear industry - the middle ages $\ldots \ldots \ldots 1-11$

1.3 Milestones in pipe fracture technology and the nuclear industry - 1990 to 1997

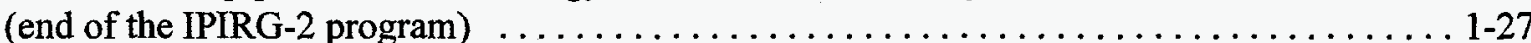

2.1 Advantages and disadvantages of several analysis methods for assessing cyclic load effects on the load-carrying capacity of cracked pipes $\ldots \ldots \ldots \ldots \ldots \ldots \ldots \ldots$

2.2 NRCPIPE predictions of initiation loads for through-wall-cracked pipe experiments $\ldots \ldots$ 2-84

2.3 NRCPIPE predictions of through-wall-cracked pipe using power

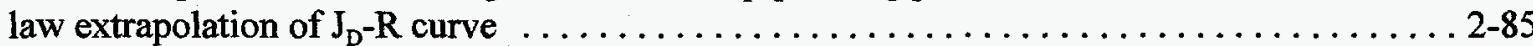

2.4 NRCPIPE predictions of through-wall-cracked pipe using power

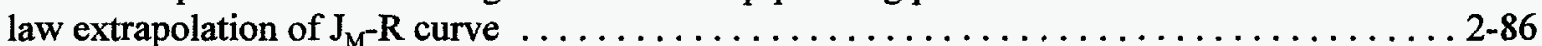

2.5 Mean and coefficient of variation of initiation load ratio predicted by various deterministic fracture-mechanics analyses from Reference 2.14

2.6 Mean and coefficient of variation of maximum load ratio predicted by various deterministic fracture-mechanics analyses from Reference 2.14

$2.7 \quad C_{a, b, c, d}$ mean $(\mu)$ and standard deviation $(\sigma)$ values (number of experiments)

2.8 Mean and coefficient of variation of initiation stress ratios predicted by various fracture analyses methods $\ldots \ldots \ldots \ldots \ldots \ldots \ldots \ldots \ldots \ldots \ldots \ldots \ldots \ldots \ldots \ldots \ldots \ldots \ldots \ldots \ldots \ldots \ldots .123$

2.9 Mean and coefficient of variation of maximum load ratio predicted by various

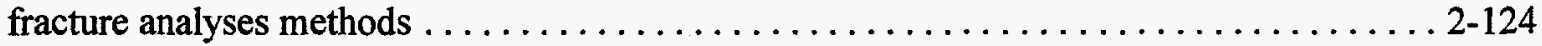

2.10 Experimental parameters for experiments shown in Figures 2.83 through $2.86 \ldots \ldots \ldots 2-142$

2.11 Test matrix for instability assessments of A106 steel pipes subjected to four-point

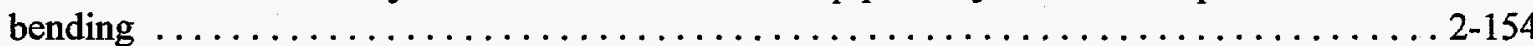

2.12 Stability comparison for DTRC compliant instability experiments $\ldots \ldots \ldots \ldots \ldots \ldots \ldots$ 2-157

2.13 Stability comparison for DTRC compliant instability Experiment 13 with various hypothetical stiffnesses . . 


\section{CONTENTS}

2.14 Flaw stability predictions for the E31 experiments

2.15 Mean and coefficient of variation of the ratio between experimental and predicted values of center-crack-opening displacement by various methods for simple through-wall-cracked pipes under various loading conditions

2.16 Mean and coefficient of variation of the ratio between experimental and predicted values of center-crack-opening displacement by various methods for simple through-wall-cracked pipes with short cracks and cracks in girth welds

2.17 Mean and coefficient of variation of the ratio between experimental and predicted values of center-crack-opening displacement by the LBB.ENG2 method for complex-cracked pipes with shallow and deep surface cracks

2.18 Differences in leakage flaw sizes due to restraint of pressure induced bending $2-183$

2.19 Fracture ratios for IPIRG-2 Task 2 elbow experiments $2-206$

2.20 Fracture ratios for through-wall-cracked elbows

A.1 ASME Section III Class 1 piping design limits

A.2 ASME Section III Class 2 and 3 piping design limits

A.3 Summary of elastic stress analysis predictions of the maximum load for a stainless steel base metal surface-cracked pipe-system experiment

A.4 IPIRG pipe-system moment response summary using spectrum-compatible displacement time histories and linear stress analysis 


\section{EXECUTIVE SUMMARY}

This report is an in-depth summary of the state-of-the-art in nuclear piping fracture mechanics. It represents the culmination of 20 years of work done primarily in the U.S., but also attempts to include important aspects from other international efforts. In doing so, this report does not necessarily include all the equations and details of an analysis procedure, but rather describes the important aspects and limitations, tells the reader where he can go for further data, and more importantly, describes the accuracy of the models. Although the report is aimed at nuclear piping, much of the technology is also applicable to oil and gas, fossil plants, and petrochemical/refinery plant piping. Discussions on subcritical crack growth mechanisms such as fatigue, corrosion fatigue, stress-corrosion, stress-corrosion cracking, and creep are not explicitly discussed here. Rather, the emphasis is on fracture analyses.

The first section of this report describes the history and developments of the nuclear industry relative to the evolution of piping fracture mechanics.

The second section of the report describes the technical developments in the areas of:

- $\quad$ stress analyses,

- material property aspects, and

- fracture mechanics analyses.

This section is rather long, and though intended as a summary document, still contains over 150 equations and about 200 references.

The third section of this report describes unresolved issues and technically evolving areas.

The fourth and final section of this report is a summary of the major conclusions from the complete body of piping fracture mechanics work done to date.

Appendix A is a summary of methods and issues related to stress analyses of plant piping. 



\section{ACKNOWLEDGMENTS}

This report was funded from efforts in the Second International Piping Integrity Research Group (IPIRG-2) program. The IPIRG-2 program was an international group program coordinated by the U.S. Nuclear Regulatory Commission's Electrical, Materials, and Mechanical Engineering Branch of the Office of Nuclear Regulatory Research under Contract Numbers NRC-04-91-063 with Battelle. Mr. Michael Mayfield was the U.S. NRC program manager.

The members of the IPIRG-2 program and their representatives to the IPIRG-2 Technical Advisory Group (TAG) were:

Bulgaria

- CUAEPP

Canada

- AECB

- Ontario Hydro

Czech Republic

- NRI

France

- EDF

- CEA

- Framatome

Hungary

- HAEC

Italy

- ANPA-DISP

Japan

- CRIEPI

- Hitachi

- Mitsubishi Heavy Industry

- Toshiba

- IHI

Lithuania

- VATESI

Republic of China

- INER

- ROC-AEC

- Taiwan Power Company

Republic of Korea

- KINS

- SKKU
Mr. Y. Yanev

Dr. A. Omar, Dr. B. Jarman, Mr. J. K. Pereira

Mr. M. Kozluk

Dr. J. Zdárek, Dr. M. Brumovsky, Dr. P. Kadečka, Mr. J. Palyza

Mr. C. Faidy, Mr. P. Le Delliou

Mr. Ph. Jamet, Ms. F. Gantenbein, Mr. E. Debec-Mathet

Dr. S. Bhandari, Dr. Ph. Gilles

Mr. A. Fehérvári

Dr. C. Maricchiolo

Dr. K. Kashima, Mr. N. Miura

Mr. J. Kawahata, Mr. K. Murayama

Mr. H. Yokota

Mr. K. Kitsukawa

Mr. H. Ogata, Mr. H. Sugino

Mr. P. Vaisnys

Dr. Li-Fu Lin, Dr. K. Ting

Mr. R. Y. Wu

Mr. Y. H. Cheng

Dr. J. B. Lee, Dr. Y. H. Choi, Dr. Y. W. Park

Dr. Y. J. Kim 
Acknowledgment

Slovak Republic

- VUJE

Dr. L. Kupca

- NRA

Dr. J. Misak

Sweden

- SKI

Dr. G. Hedner

- SAQ

Dr. B. Brickstad

Switzerland

- KKL

Mr. R. Wanner, Mr. D. Burns

- HSK

United Kingdom

- Nuclear Electric

Dr. D. H. Njo

- NII

Dr. T. C. Chivers, Dr. J. Darlaston

Mr. P. Harrop

United States

- U.S. NRC-RES

Mr. M. Mayfield

- U.S. NRC-NRR

Mr. K. Wichman

- EPRI

Mr. S. Gosselin, Dr. Y. K. Tang

This report provides a detailed summary of work done over the past 30 years on piping fracture mechanics. Much of the work involves past Battelle efforts, but we also tried to incorporate efforts from other U.S. and international sources. Although we started out with the concept of writing a short succinct report (with numerous suggestions on what it should be like), the work done in the area has been significant and the finished report has ended up being 400 pages in length, with over 150 equations, and over 400 references. Even with this length of report, we recognize that we did not cover every piece of work in the area. If you (the reader) feels that there is some work that was missed, we would like to hear from you. In that way, if we ever have the resources to update this report, we can make it a more complete document.

Needless to say, there are a tremendous number of Battelle researchers involved in efforts that are summarized in this report. Many of these may have retired or moved onto other organizations. Nevertheless, it is fitting to pay tribute to their past efforts. In alphatabetical order, these engineers, technicans, and secretaries are:

- I. Abou-Sayed, J. Ahmad, E. Alexander, G. Anthony, J. Anthony, A. Armitage,

- $\quad$ R. Barnes, C. Baxley, E. Blakesley, B. Blanton, D. Broek, F. Brust,

- R. Chaffin, R. Collier,

- P. Dong, A. Duffey,

- R. Eiber,

- L. Flanigan, M. Fleming, G. Foster, R. Francini, N. Frey, E. Fromme, B. Fuller,

- J. Garrabrant, R. Gertler, N. Ghadiali, E. R. Gilbert, R. Glover, T. Groeneveld, T. Goodrich,

D. Guerrieri,

- G. T. Hahn, D. Hayes, P. Held, D. Holbrook, A. Hopper,

- F. Jakobs, D. Jones,

- M. Kanninen, J. Kiefner, T. Kilinski, G. Kramer, J. Kramer, R. Kreachbaum,

V. Kreachbaum, P. Krishnaswamy, J. Kulhowvick,

- $\quad$ R. LaBounty, D. Lahrman, M. Landow, B. Leis,

- C. Marschall, P. Martin, W. Maxey, M. Mayfield, R. Mesloh, J. Meyer, P. Mincer,

R. Mohan, J. Morris, 
- M. Nakagaki,

- M. Oliver, R. Olson,

- J. Pan, V. Papaspyropoulos, D. Pape, J. Parks, V. Pasupathi, D. D. Paul, C. Pepper, R. Podlasek, C. Popelar, R. Pratt,

- $\quad$ S. Rahman, D. Rea, H. Rhee, D. Rider, D. Roberts, M. Rosenfeld, A. Rosenfield, D. Rudland, J. Rue, J. Ryan, E. Rybicki,

- $\quad$ B. Saffell, S. Sampath, K. Schueller, R. Schmidt, P. Scott, D. Shoemaker, F. Simonen, R. Stonesifer, F. Stulen, F. Syler

- L. Taggart, R. Tenaglia,

- D. Utz,

- P. Vieth,

- C. Wales, J. Ward, G. Wall, G. Walter, M. Whitehead, G. Wilkowski, M. Wilson, R. Wolterman, J. Wood,

- A. Zahoor, and Y. Zhao.

In addition, there were numerous visiting scientists that made contributions to the work contained in this report. The visiting scientists during the piping fracture mechanics work were:

during the Degraded Piping Program

- Dr. Karl-Heinz Herter (MPA-Stuttgart, Germany)

- $\quad$ Prof. Noriyuki Miyazaki (Kyushu University, Japan)

- Prof. Masanori Kikuchi (Science University of Tokyo, Japan)

during the Degraded Piping Program and IPIRG-1 Program

- $\quad$ Dr. Philippe Gilles (Framatome, France)

- Mr. Kuo-Sheng Chao (Taipower, Taiwan)

- Dr. Claudio Maricchiolo (ENEA, Italy)

during the Short Cracks in Piping and Piping Welds and IPIRG-2 Program

- Dr. Nicola Bonora (University of Roma, Italy)

- Mr. Naoki Miura (CRIEPI, Japan)

- Dr. Young Hwan Choi (KINS, S. Korea)

- Dr. Jesus Hidalgo Ibanez (CNSNS, Mexico)

A special note of appreciation is extended to Mrs. Brenda Blanton, the secretary for the Degraded Piping Program and IPIRG-1 Program, and Mrs. Verna Kreachbaum, the secretary for the Short Cracks in Piping and Piping Welds Program, and the IPIRG-2 Program. Their professional dedication and commitment to quality and hard work has been a key factor in the success of these programs. 



\section{NOMENCLATURE}

\section{SYMBOLS}

A

$A_{c}$

$\mathrm{A}_{\mathrm{ce}}$

$\mathrm{A}_{\mathrm{co}}$

$A_{f}$

a

$a_{e}$

$\mathrm{a}_{\max }$

$a_{o}$

$\mathbf{B}_{2}$

b

C

$\mathrm{C}_{\mathrm{a}}, \mathrm{C}_{\mathrm{b}}, \mathrm{C}_{\mathrm{c}}, \mathrm{C}_{\mathrm{d}}$

$\mathrm{C}_{\mathrm{e}}$

$\mathrm{C}_{\mathrm{v}}$

$\mathrm{C}_{1}$

$\mathrm{C}_{2}$

$\mathrm{C}_{3}$

$\mathrm{C}_{4}$

c

c
Function of $\mathrm{R} / \mathrm{t}$ ratio in ASME Section XI Appendix $\mathrm{H} Z$-factor criteria

Net section area of a Charpy specimen

Elastic crack-opening area

Area of crack opening

Cross sectional area of a surface crack

Crack depth

Effective (half) crack length

Crack depth at the deepest location along the crack front

Initial crack length

Stress indices from ASME code

Specimen ligament

Circumferential

Constants determined from pipe test database and Net-Section-Collapse equations

Empirical correction factor to NSC analysis which accounts for ovalization effects

Charpy V-notch impact energy

Statistically-based parameter from plastic zone size screening criteria

Stress indices from ASME code

Coefficient in power-law extrapolated J-R curve-fit expression

Backfill constraint

Distance from neutral bending axis

One-half crack length 
$c_{\mathrm{e}}$

$\mathbf{c}_{\text {eq }}$

D

D。

E

F

$F_{b}$

$F_{B}$

$F_{\text {cyc }}$

$F_{d y m}$

$\mathrm{F}_{\mathrm{m}}$

$f_{1}$

$\mathrm{F}_{1}{ }^{\mathrm{M}}$

$\mathrm{F}_{1}{ }^{\mathrm{PR}}$

G

$\mathrm{G}_{\mathbf{n}}$

$\mathrm{G}_{\mathrm{N}}$

$\mathbf{h}_{1}, \mathbf{h}_{2}, \mathbf{h}_{4}$

$\mathrm{H}(\mathrm{a} / \mathrm{t})$

$\mathrm{H}_{1}$

$\mathrm{H}_{\mathrm{B}}$

$\mathrm{H}_{\mathrm{n}}$

I

$\mathrm{I}_{\mathrm{B}}, \mathrm{I}_{\mathrm{T}}$,
Effective bending moment parameter for combined load case

Half of the equivalent crack length

Pipe diameter

Outside diameter

Elastic modulus

Elastic influence function

Bending stress component of elastic influence function

Geometry function

Function relating the monotonic fracture toughness to the cyclic fracture toughness

Function relating the quasi-static fracture toughness to the dynamic fracture toughness

Membrane stress component of elastic influence function

Function in GE/EPRI J-estimation scheme for calculating elastic component of $\mathrm{J}$

Function used in elastic stress intensity factor associated with bending moment

Function used in elastic stress intensity factor associated with internal pressure

Energy release rate

Function in surface-cracked J-estimation schemes

Function in surface-cracked J-estimation schemes

Functions in GE/EPRI method

Function in SC.ENG1 and SC.ENG2 J-estimation schemes

Function in EPRI/GE J-estimation scheme to calculate plastic contribution of $\mathbf{J}$

Function in LBB.ENG2 J-estimation schemes

Function in surface-cracked J-estimation schemes

Area moment of inertia

Influence functions 
$\mathbf{J}_{\text {applied }}$

$\mathrm{J}_{\mathrm{cc}}$

$\mathbf{J}_{\mathrm{D}}$

$\jmath_{e}$

$J_{e}^{p+M}$

$\hat{\mathbf{j}}$

$\mathrm{J}_{\mathrm{i}}$

$\mathrm{J}_{\mathrm{Ic}}$

$\mathrm{J}_{\mathrm{M}}$

$J_{\text {mat }}$

$\mathrm{J}_{\mathrm{p}}$

$\mathbf{J}_{\mathbf{p}} \mathbf{p}$

$\mathbf{J}_{\mathbf{p}}{ }^{\mathbf{M}}$

$\mathbf{J}_{\mathrm{QS}, \text { mono }}$

$\mathrm{J}_{\mathrm{QS}, \mathrm{cyc}}$

$\mathrm{J}_{\mathrm{dym}, \mathbf{c y c}}$

$\mathbf{J}_{\text {dygmono }}$

$J_{R}$

$\mathrm{J}_{\text {TwC }}$

$\mathrm{J}_{0.2}$

$\mathrm{J}_{0.2 \mathrm{BL}}$

k

K
J-integral fracture parameter

Applied value of the J-integral

J for a complex crack

Deformation theory $J$

Elastic component of $\mathbf{J}$

Elastic part of $\mathrm{J}$ associated with combined pressure and bending

Advanced fracture parameter

$\mathrm{J}$ at crack initiation

Plane strain J at crack initiation by ASTM813

Modified form of $\mathrm{J}$

Fracture toughness of the material in terms of $J$

Plastic component of J

Plastic part of $\mathrm{J}$ associated with pressure

Plastic part of $\mathrm{J}$ associated with bending

$\mathrm{J}$ for quasi-static, monotonic loading history

J for quasi-static, cyclic loading history

$\mathrm{J}$ for dynamic, cyclic loading history

J for dynamic, monotonic loading history

Crack growth resistance

J for a through-wall crack

Fracture parameter

Fracture parameter

Stiffness

LEFM stress intensity factor fracture parameter 


$$
\mathrm{K}_{\mathrm{c}}
$$

$\mathrm{K}_{\mathrm{e}}$

$\mathrm{K}_{\mathrm{I}}$

$\mathrm{K}_{1}^{\mathrm{M}}$

$\mathrm{K}_{1}^{\mathrm{pr}}$

$\mathrm{K}_{\mathrm{Ib}}$

$\mathrm{K}_{\mathrm{Ic}}$

$\mathrm{K}_{\mathrm{Im}}$

$K_{\mathrm{T}}$

$\mathrm{K}_{\text {shell }}$

$\mathrm{K}_{\text {plate }}$

$\hat{\mathbf{K}}$

L

L

$L_{B}$

$\mathbf{M}^{\text {elbow }}$

$L_{\mathrm{r}}$

$$
\ell
$$

m

$\mathrm{m}_{\mathrm{k}}$

M

$\mathrm{M}_{\mathrm{B}}$

$\mathrm{M}_{\mathrm{cs}}$

$\mathrm{M}_{\mathrm{ct}}$
Fracture toughness of the material

Elastic component of $\mathrm{K}$

Applied linear elastic stress intensity factor

Stress intensity factor associated with bending moment

Stress intensity factor associated with internal pressure

Bending stress component of applied stress intensity factor

Material toughness expressed in terms of $\mathrm{K}$

Membrane stress component of applied stress intensity factor

Ratio of $K_{I}$ to $K_{T}$ (a) from $R 6$ analysis

Stress intensity factor for a shell

Stress intensity factor for a flat plate

Stiffness parameter

Length parameter in SC.TNP analyses

Longitudinal

Function in LBB.ENG2 J-estimation scheme

Predicted moment for elbow

Load ratio in $\mathrm{R} 6$ analysis

Total length of axial surface crack

Exponent in power-law extrapolated J-R curve-fit expression

Empirical factor in Kurihara modified NSC analysis

Moment

Bending moment

Pipe and flaw geometry function for surface flaws

Through-wall flaw function 


\begin{tabular}{|c|c|}
\hline $\mathrm{M}_{\mathrm{eff}}$ & Effective moment for combined load case \\
\hline $\mathrm{M}^{\mathrm{elbow}}$ & Predicted moment for an elbow \\
\hline $\mathbf{M}_{\mathrm{eq}}$ & Resultant moment \\
\hline$M^{\text {pipe }}$ & Predicted moment for straight pipe \\
\hline $\mathrm{M}_{\mathrm{o}}$ & Limit moment for a cracked pipe under pure bending \\
\hline $\mathbf{M}_{\mathrm{nsc}}$ & Moment at Net-Section-Collapse \\
\hline $\mathbf{M}_{\mathrm{P}}$ & Surface crack bulging factor \\
\hline $\mathbf{M}_{\mathrm{RP}}$ & Rigid plastic moment from a limit-load solution \\
\hline $\mathrm{M}_{\mathrm{T}}$ & Folias bulging factor \\
\hline $\mathrm{M}_{\mathrm{xx}}$ & Moment about $\mathrm{x}$-axis \\
\hline $\mathrm{M}_{\mathrm{yy}}$ & Moment about $\mathrm{y}$-axis \\
\hline $\mathbf{M}_{z z}$ & Moment about z-axis \\
\hline n & Ramberg-Osgood strain-hardening exponent \\
\hline $\mathrm{p}$ & Internal pipe pressure \\
\hline $\mathrm{p}_{\mathrm{a}}$ & Allowable pressure \\
\hline $\mathrm{p}_{\mathrm{o}}$ & Limit pressure of corresponding straight pipe with equivalent axial crack \\
\hline $\mathbf{P}_{\mathrm{a}}$ & Arrest pressure \\
\hline$P_{a x}$ & Axial force \\
\hline $\mathrm{P}_{\mathrm{b}}$ & Bending stress \\
\hline$P_{d}$ & Decompression pressure \\
\hline$P_{e}$ & Thermal expansion stress \\
\hline $\mathbf{P}_{\text {sat }}$ & Saturation pressure \\
\hline $\mathrm{P}_{\mathrm{m}}$ & Membrane stress \\
\hline$P_{o}$ & Reference load \\
\hline
\end{tabular}


Q

$\mathbf{r}$

$\mathbf{R}$

R-ratio

$\mathbf{R}_{\mathbf{i}}$

$\mathrm{R}_{\mathrm{m}}$

$\mathrm{S}_{\mathrm{a}}$

$\mathrm{S}_{\mathrm{c}}$

$\mathrm{S}_{\mathrm{h}}$

$S_{r}$

$\mathrm{S}_{\mathrm{m}}$

$\mathrm{S}_{\mathrm{u}}$

$S_{y}$

t

$t_{\text {pipe }}$

$t_{e}$

$\mathbf{T}$

$\mathrm{T}$

$\mathbf{T}$

$T_{\text {applied }}$

$T_{\text {material }}$

$\mathrm{T}_{\mathrm{p}}{ }^{*}$

$\mathrm{V}_{\mathrm{ai}}$
Constraint parameter

Constant in power-law extrapolation J-R curve fit having a value of unity and same dimensions as $\Delta \mathrm{a}$

Radius

Stress or load ratio, i.e., minimum stress (load)/maximum stress (load)

Inside radius

Mean pipe radius

Alternating stress as per ASME Boiler and Pressure Vessel Code, Section III

Basic material allowable stress at room temperature for Class 2 and 3 piping systems

Basic material allowable stress at the design temperature for Class 2 and 3 piping systems

Primary stress normalized by limit-load stress

ASME code design stress intensity

ASME Section II Part D ultimate strength

ASME Section II Part D yield strength

Wall thickness

Pipe wall thickness

Equivalent thickness

Tearing modulus

Thickness of $C(T)$ specimen

Torque

Applied tearing modulus

Tearing modulus of the material

Advanced fracture parameter

Initial acoustic velocity 


\begin{tabular}{|c|c|}
\hline$V_{f}$ & Fracture speed \\
\hline$V_{R}$ & Ovalization correction factor to Net-Section-Collapse analysis \\
\hline $\mathrm{V}_{\mathrm{w}}$ & instantaneous pressure wave acoustic velocity \\
\hline $\mathrm{V}_{1}, \mathrm{~V}_{3}$ & Function in GE/EPRI method \\
\hline W & Width of $C(T)$ specimen \\
\hline $\mathrm{Z}$ & Stress multipliers in Section XI to account for low toughness \\
\hline$\alpha$ & Ramberg-Osgood parameter \\
\hline$\beta$ & Angle from bottom of pipe to neutral bending axis \\
\hline$\beta_{1}$ & $\begin{array}{l}\text { Parameter in Paris/Tada method which depends on whether plane strain or plane } \\
\text { stress conditions }\end{array}$ \\
\hline$\delta$ & Displacement \\
\hline$\delta_{\text {cyc }}$ & Incremental cyclic plastic displacement from a cyclic test \\
\hline$\delta_{\mathrm{e}}$ & Elastic component of crack-opening displacement \\
\hline$\delta_{i}$ & Displacement at crack initiation from a monotonic test \\
\hline$\delta_{\mathrm{p}}$ & Plastic component of crack-opening displacement \\
\hline$\Delta$ & Load-line displacement \\
\hline$\Delta \mathbf{a}$ & Change in crack length or depth, i.e., crack growth \\
\hline$\Delta \mathrm{a}_{\mathrm{ic}}$ & Actual crack growth that corresponds to $\mathrm{J}_{\mathrm{Ic}}$ \\
\hline$\Delta \mathbf{J}$ & Cyclic J-integral (Dowling approach) \\
\hline $\boldsymbol{\epsilon}$ & Strain \\
\hline$\epsilon_{\mathrm{o}}$ & Ramberg-Osgood reference strain \\
\hline$\epsilon_{\mathrm{p}}$ & Plastic strain \\
\hline$\epsilon_{\mathrm{y}}$ & Yield strain \\
\hline$\lambda$ & Normalized crack length parameter in axial crack analysis \\
\hline
\end{tabular}


$\mu$

$\eta$-factor

$\eta_{\mathrm{p}}$

$\phi$

$\phi^{\mathrm{c}}$

$\phi_{e}^{c}$

$\phi_{\mathrm{e}}^{\mathrm{nc}}$

$\phi_{\mathrm{p}}^{\mathrm{c}}$

$\phi_{\mathrm{p}}^{\mathrm{nc}}$

$\sigma$

$\sigma_{\mathrm{a}}$

$\sigma_{\mathrm{b}}$

$\sigma_{d}$

$\sigma_{\text {eff }}$

$\sigma_{\mathrm{EPFM}}$

$\sigma_{f}$

$\sigma_{h}$

$\sigma_{\text {nsc }}$

$\sigma_{\mathrm{o}}$

$\sigma_{p}$

$\sigma_{\mathrm{s}}$

$\sigma_{\text {sat }}$

$\sigma_{\mathrm{T}}$
Mean value

Method for estimating fracture toughness of a pipe experiment from the experimental moment-rotation or load-displacement relationship

Factor depending on flaw and pipe size

Pipe rotation

Rotation due to crack

Elastic component of rotation due to the crack

Elastic component of rotation due to the uncracked pipe

Plastic component of rotation due to the crack

Plastic component of rotation due to the uncracked pipe

Stress

Arrest stress

Bending stress

Decompressed hoop stress

Effective bending stress for combined load case

Applied stress for EPFM failure

Flow stress

Hoop stress of failure

Net-Section-Collapse stress

Ramberg-Osgood reference stress

Primary stress

Secondary stress

Hoop stress of the saturation pressure

Axial tensile stress 


\begin{tabular}{|c|c|}
\hline$\sigma_{u}$ & Ultimate strength \\
\hline$\sigma_{\mathrm{y}}$ & Yield strength \\
\hline$\tau_{\mathrm{T}}$ & Torsional stress \\
\hline$\theta$ & Half crack angle \\
\hline$\theta_{\mathrm{e}}$ & Effective half crack angle \\
\hline$\Omega$ & Angle from the crack plane \\
\hline$\psi$ & Elbow angle \\
\hline$\Upsilon_{\mathrm{a}}^{\mathrm{e}}$ & $\begin{array}{l}\text { Geometric stress multiplier related to the stress indices } B_{2} \text { which gives the predicted } \\
\text { moment for an axial crack in a pipe relative to the predicted moment for an axial crack } \\
\text { in an elbow }\end{array}$ \\
\hline$\Upsilon_{\mathrm{c}}^{\mathrm{e}}$ & $\begin{array}{l}\text { Geometric stress multiplier related to the stress indices } \mathrm{B}_{2} \text { which gives the predicted } \\
\text { stress for a circumferential crack in a pipe relative to the predicted stress for a } \\
\text { circumferential crack in an elbow }\end{array}$ \\
\hline$\Upsilon_{x}^{f}$ & $\begin{array}{l}\text { General geometric stress multiplier related to } \mathrm{B}_{2} \text { stress indices which gives the } \\
\text { predicted stress for a cracked pipe relative to the predicted stress for a cracked fitting } \\
\text { where } f \text { stands for the type of fitting and } x \text { is the crack orientation }\end{array}$ \\
\hline$v$ & Poisson ratio \\
\hline$\omega$ & Limit in extrapolated J-R curve analysis \\
\hline
\end{tabular}

\section{ACRONYMS AND INITIALISMS}

A.G.A.

AEC

AECB

AISI

ANPA-DISP

ANSI

ANL
American Gas Association

Atomic Energy Commission (U.S.)

Atomic Energy Control Board (Canada)

American Iron and Steel Institute

Agenzia Najionale per la Protezion dell'Ambiarte (Italy)

American National Standards Institute

Argonne National Laboratory (U.S.) 
API

ASME

ASTM

BHN

BOP

BWR

B\&W

$\mathrm{CC}$

CE

CEA

CEGB

C-L

COA

$\mathrm{COA}$

COD

COV

CRIEPI

CSNI

CTOA

$\mathrm{C}(\mathrm{T})$

CUAEPP

CVE

CVP
American Petroleum Institute

American Society of Mechanical Engineers

American Society for Testing and Materials

Brinnel hardness number

Balance of plant

Boiling Water Reactor

Babcock and Wilcox (U.S.)

Complex crack

Combustion Engineering

Commissariat A L'Energie Atomique (France)

Central Electric Generating Board, now Nuclear Electric (United Kingdom)

Orientation that indicates that crack plane is normal to the circumferential direction (C) and the crack growth direction is longitudinal (L)

Crack-opening angle

Crack-opening area

Crack-opening displacement

Coefficient of variation

Central Research Institute of Electric Power Industry (Japan)

Committee for the Safety of Nuclear Installations

Crack-tip-opening angle

Compact (Tension)

Commercial Use of Atomic Energy for Peaceful Purposes agency (Bulgaria)

Charpy energy at some specified temperature

Charpy upper plateau energy 
DEGB Double-ended guillotine break

DOE Department of Energy (U.S.)

DOS Disk operating system

DPFAD Deformation plasticity failure assessment diagram

DPZP Dimensionless plastic-zone parameter

DSA Dynamic strain aging

DTRC David Taylor Research Center (U.S.)

Dyn Dynamic

DWTT Drop weight tear test

EDF Electricité de France

ENEA Energia Nucleare e delle Energie Alternative (Italy)

EPFM Elastic-plastic fracture mechanics

EPR European pressurized water reactor

EPRI Electric Power Research Institute (U.S.)

ESIS European Structural Integrity Society

FAD Failure assessment diagram

FE Finite element

FEA Finite element analysis

FEM Finite element method

GE General Electric (U.S.)

GEAP General Electric Atomic Power (U.S.)

GRS Gesellschaft für Anlagenund Reaktorsicherheit (Germany)

HAEC Hungarian Atomic Energy Commission

HAZ Heat-affected zone 
HDR

HSK

HSLA

IGSCC

IHI

INER/AEC

IPIRG

IPIRG-1

IPIRG-2

JAERI

J-R

JSME

$\mathrm{J}_{\mathrm{D}}-\mathrm{R}$

$\mathrm{J}_{\mathrm{M}}-\mathrm{R}$

KINS

KKL

KWU

LBB

L-C

LEFM

L-R

L-T
Heissdampfreaktor (An experimental reactor facility in Germany)

Hauptabteilung für die Sicherheit der Kernanlagen (Switzerland)

High strength low alloy steel

Intergranular-stress-corrosion crack

Ishikawajima-Harima Heavy Industries (Japan)

Institute of Nuclear Energy Research/Atomic Energy Commission (Republic of China)

International Piping Integrity Research Group

First International Piping Integrity Research Group Program

Second International Piping Integrity Research Group Program

Japanese Atomic Energy Research Institute

J-resistance (curve)

Japanese Society of Mechanical Engineers

J-resistance curve based on deformation theory

J-resistance curve based on Modified J

Korean Institute of Nuclear Safety

Kernkraftwerk Leibstadt AG (Switzerland)

Kraftwerk Union (Germany)

Leak-Before-Break

Orientation that indicates crack plane is normal to longitudinal axis $(\mathrm{L})$ and crack growth direction is circumferential (C)

Linear-elastic-fracture mechanics

Orientation that indicates crack plane is normal to the longitudinal axis (L) and crack growth direction is radial $(\mathrm{R})$ through the pipe wall

Orientation that indicates crack plane is normal to the longitudinal axis $(\mathrm{L})$ and crack growth direction is transverse $(\mathrm{T})$ 


\begin{tabular}{|c|c|}
\hline LTA & Local thinned area \\
\hline LWR & Light water reactor \\
\hline MEA & Materials Engineering Associates (U.S.) \\
\hline MIC & Microbiologically-induced-corrosion \\
\hline MIG & Metal-inert-gas \\
\hline MITI & Ministry of International Trade and Industry \\
\hline Mono & Monotonic \\
\hline MPA & Staatliche Materialprüfungsanstalt (Germany) \\
\hline $\mathbf{N}$ & Normal \\
\hline NE & Nuclear Electric (U.K.) \\
\hline NPS & Nominal pipe size \\
\hline NRA & Nuclear Regulatory Authority (Slovak Republic) \\
\hline $\mathrm{NRC}$ & Nuclear Regulatory Commission (U.S.) \\
\hline NRC-NRR & Nuclear Regulatory Commission - Office of Nuclear Reactor Regulation (U.S.) \\
\hline NRC-RES & Nuclear Regulatory Commission - Office of Nuclear Reactor Research (U.S.) \\
\hline NRI & Nuclear Research Institute (Czech Republic) \\
\hline NSC & Net-Section-Collapse (analysis) \\
\hline NUPEC & Nuclear Power Engineering Test Center (Japan) \\
\hline OBE & Operational Basis Earthquake \\
\hline $\mathrm{PC}$ & Personal computer \\
\hline PICEP & PIpe Crack Evaluation Program \\
\hline PIFRAC & PIping FRACture mechanics material property database \\
\hline $\mathrm{PRCI}$ & Pipeline Research Committee International \\
\hline PVP & Pressure Vessel and Piping \\
\hline
\end{tabular}


Nomenclature

PWR

QS

ROC-AEC

RP

SA

SAM

SAW

SC

SEN(T)

SKI

SKKU

SMAW

SQUIRT

SRI

SRP

SSE

STA

TAG

TIG

TMI

TWC

U.K.

U.S. 
USAEC

U.S. NRC

UT

VATESI

VUJE

WRC
United States Atomic Energy Commission

United States Nuclear Regulatory Commission

Ultrasonic testing

State Nuclear Energy Safety Inspection of the Republic of Lithuania

Vyskumny Ustav Jadravyeh Elektrarni (Nuclear Power Plant Research Institute of Slovakia)

Welding Research Council 


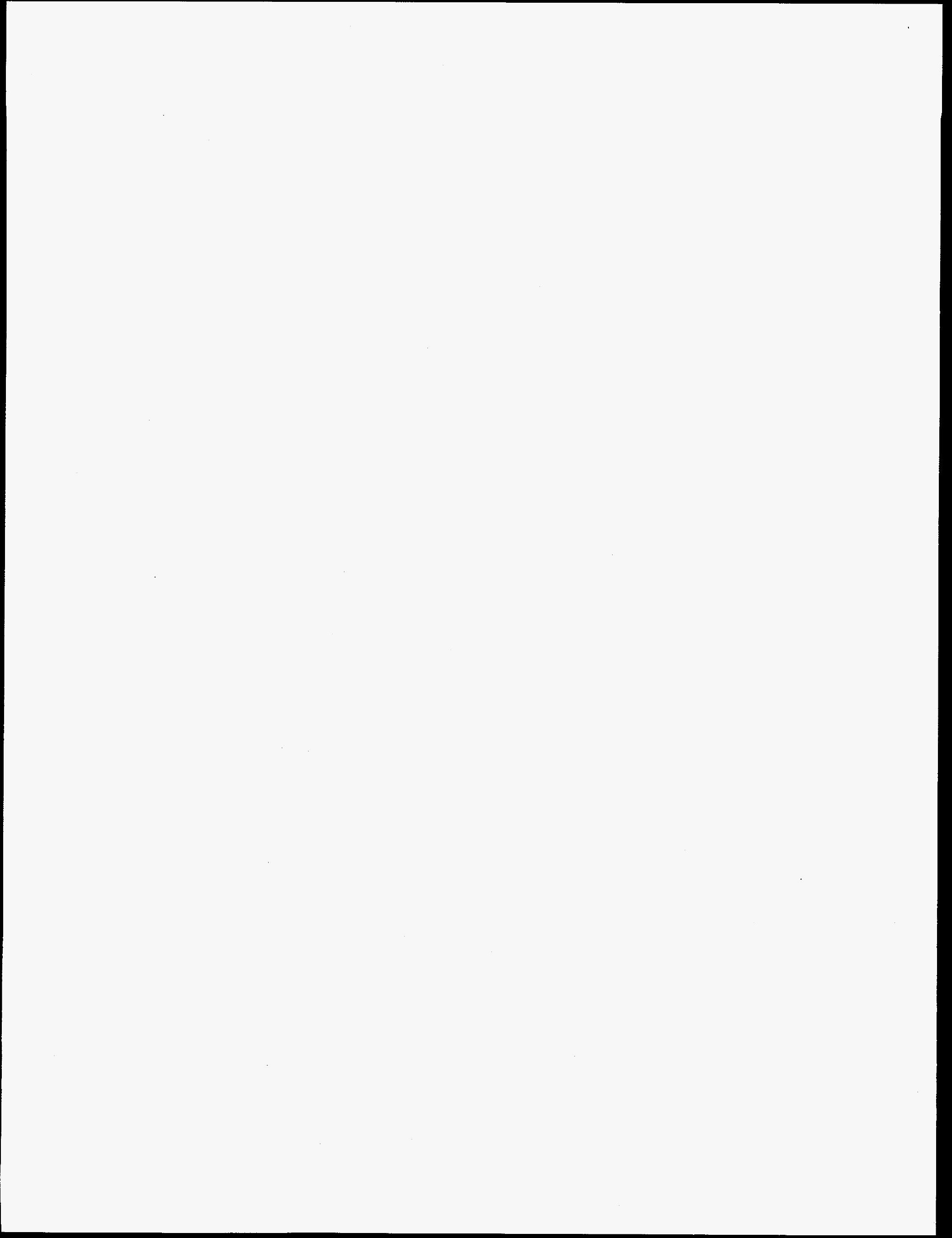




\section{PREVIOUS REPORTS IN SERIES}

\section{Reports from this Program}

"Summary of Results from the IPIRG-2 Round-Robin Analyses," NUREG/CR-6337, BMI-2186, January 1996.

"IPIRG-2 Task 1 - Pipe System Experiments With Circumferential Cracks in Straight-Pipe Locations," NUREG/CR-6389, BMI-2187, February 1997.

"The Effect of Cyclic and Dynamic Loads on Carbon Steel Pipe,"NUREG/CR-6438, BMI-2188, February 1996.

"Design of the IPIRG-2 Simulated Seismic Forcing Function," NUREG/CR-6439, BMI-2189, February 1996.

"The Effect of Cyclic and Dynamic Loading on the Fracture Resistance of Nuclear Piping Steels," NUREG/CR-6440, BMI-2190, December 1996.

"Deterministic and Probabilistic Evaluations for Uncertainty in Pipe Fracture Parameters in Leak-BeforeBreak and In-Service Flaw Evaluations," NUREG/CR-6443, BMI-2191, June 1996.

"Fracture Behavior of Circumferentially Surface-Cracked Elbows," NUREG/CR-6444, BMI-2192, December 1996.

"Development of a J-Estimation Scheme for Internal Circumferential and Axial Surface Cracks in Elbows," NUREG/CR-6445, BMI-2193, June 1996.

“Fracture Toughness Evaluations of TP304 Stainless Steel Pipes," NUREG/CR-6446, BMI-2194, February 1997.

“The Second International Piping Integrity Research Group (IPIRG-2) Program," Final Report, October 1991 - April 1996, NUREG/CR-6452, BMI-2195, March 1997.

\section{Reports from the IPIRG-1 Program}

"Evaluation and Refinement of Leak-Rate Estimation Models," NUREG/CR-5128, BMI-2164, Revision 1, June 1994.

"Loading Rate Effects on Strength and Fracture Toughness of Pipe Steels Used in Task 1 of the IPIRG Program," Topical Report, NUREG/CR-6098, BMI-2175, October 1993.

“Stability of Cracked Pipe Under Inertial Stresses," NUREG/CR-6233, BMI-2177, Vol. 1, August 1994. 
"Stability of Cracked Pipe Under Seismic/Dynamic Displacement-Controlled Stresses," NUREG/CR6233, BMI-2177, Vol. 2, June 1997.

"Cracked Stability in a Representative Piping System Under Combined Inertial and Seismic/Dynamic Displacement-Controlled Stresses," NUREG/CR-6233, BMI-2177, Vol. 3, June 1997.

"International Piping Integrity Research Group (IPIRG) Program," NUREG/CR-6233, BMI-2177, Vol. 4, June 1997.

\section{Previous Related Documents from NRC's Short Cracks in Piping and Piping Welds Program}

"Short Cracks in Piping and Piping Welds," First Semiannual Report, NUREG/CR-4599, BMI-2173, Vol. 1, No. 1, March 1991.

"Short Cracks in Piping and Piping Welds," Second Semiannual Report, NUREG/CR-4599, BMI-2173, Vol. 1, No. 2, April 1992.

"Short Cracks in Piping and Piping Welds," Third Semiannual Report, NUREG/CR-4599, BMI-2173, Vol. 2, No. 1, September 1992.

"Short Cracks in Piping and Piping Welds," Fourth Semiannual Report, NUREG/CR-4599, BMI-2173, Vol. 2, No. 2, February 1993.

"Short Cracks in Piping and Piping Welds," Fifth Semiannual Report, NUREG/CR-4599, BMI-2173, Vol. 3, No. 1, October 1993.

"Short Cracks in Piping and Piping Welds," Sixth Semiannual Report, NUREG/CR-4599, BMI-2173, Vol. 3, No. 2, March 1994.

"Short Cracks in Piping and Piping Welds," Progress Report, NUREG/CR-4599, BMI-2173, Vol. 4, No. 1, April 1995.

"Assessment of Short Through-Wall Circumferential Cracks in Pipes," NUREG/CR-6235, BMI-2178, April 1995.

"Fracture Behavior of Short Circumferential Short-Surface-Cracked Pipe," NUREG/CR-6298, BMI-2183, November 1995.

"Fracture Evaluations of Fusion Line Cracks in Nuclear Pipe Bimetallic Welds," NUREG/CR-6297, BMI-2182, April 1995.

"Effect of Dynamic Strain Aging on the Strength and Toughness of Nuclear Ferritic Piping at LWR Temperatures," NUREG/CR-6226, BMI-2176, October 1994. 
"Effects of Toughness Anisotropy and Combined Loading on Fracture Behavior of Ferritic Nuclear Pipe," NUREG/CR-6299, BMI-2184, April 1995.

"Refinement and Evaluation of Crack-Opening Analyses for Circumferential Through-Wall Cracks in Pipes," NUREG/CR-6300, April 1995.

"Probabilistic Pipe Fracture Evaluations for Leak-Rate Detection Applications," NUREG/CR-6004, BMI-2174, April 1995.

"Stainless Steel Submerged Arc Weld Fusion Line Toughness," NUREG/CR-6251, BMI-2180, April 1995.

"Validity Limits in J-Resistance Curve Determination: Volume 1: An Assessment of the $\mathrm{J}_{\mathrm{M}}$ Parameter," NUREG/CR-6264, BMI-2181, Vol. 1, February 1995.

"Validity Limits in J-Resistance Curve Determinations: Volume 2: A Computational Approach to Ductile Crack Growth Under Large-Scale Yielding Condition," NUREG/CR-6264, BMI-2181, Vol. 2, February 1995.

\section{Previous Related Documents from NRC's Degraded Piping Program - Phase I Reports}

"The Development of a Plan for the Assessment of Degraded Nuclear Piping by Experimentation and Tearing Instability Fracture Mechanics Analysis," NUREG/CR-3142, Vols. 1 and 2, June 1983.

\section{Previous Related Documents from NRC's Degraded Piping Program - Phase II Reports}

"Degraded Piping Program - Phase II," Semiannual Report, NUREG/CR-4082, BMI-2120, Vol. 1, Oct. 1984.

"Degraded Piping Program - Phase II," Semiannual Report, NUREG/CR-4082, BMI-2120, Vol. 2, June 1985.

"Degraded Piping Program - Phase II," Semiannual Report, NUREG/CR-4082, BMI-2120, Vol. 3, March 1986.

"Degraded Piping Program - Phase II," Semiannual Report, NUREG/CR-4082, BMI-2120, Vol. 4, July 1986.

"Degraded Piping Program - Phase II," Semiannual Report, NUREG/CR-4082, BMI-2120, Vol. 5, Dec. 1986. 
Previous Reports in Series

"Degraded Piping Program - Phase II," Semiannual Report, NUREG/CR-4082, BMI-2120, Vol. 6, April 1988.

"Degraded Piping Program - Phase II," Semiannual Report, NUREG/CR-4082, BMI-2120, Vol. 7, March 1989.

"Degraded Piping Program - Phase II," Semiannual Report, NUREG/CR-4082, BMI-2120, Vol. 8, March 1989.

"NRC Leak-Before-Break (LBB.NRC) Analysis Method for Circumferentially Through-Wall Cracked Pipes Under Axial Plus Bending Loads," Topical Report, NUREG/CR-4572, BMI-2134, March 1986.

"Elastic-Plastic Finite Element Analysis of Crack Growth in Large Compact Tension and Circumferentially Through-Wall-Cracked Pipe Specimen--Results of the First Battelle/NRC Analysis Round Robin," Topical Report, NUREG/CR-4573, BMI-2135, September 1986.

"An Experimental and Analytical Assessment of Circumferential Through-Wall Cracked Pipes Under Pure Bending," Topical Report, NUREG/CR-4574, BMI-2136, June 1986.

"Predictions of J-R Curves With Large Crack Growth From Small Specimen Data," Topical Report, NUREG/CR-4575, BMI-2137, September 1986.

"An Assessment of Circumferentially Complex-Cracked Pipe Subjected to Bending," Topical Report, NUREG/CR-4687, BMI-2142, September 1986.

"Analysis of Cracks in Stainless Steel TIG Welds," Topical Report, NUREG/CR-4806, BMI-2144, November 1986.

"Approximate Methods for Fracture Analyses of Through-Wall Cracked Pipes," Topical Report, NUREG/CR-4853, BMI-2145, January 1987.

“Assessment of Design Basis for Load-Carrying Capacity of Weld-Overlay Repair," Topical Report, NUREG/CR-4877, BMI-2150, February 1987.

"Analysis of Experiments on Stainless Steel Flux Welds," Topical Report, NUREG/CR-4878, BMI-2151, February 1987.

"Experimental and Analytical Assessment of Circumferentially Surface-Cracked Pipes Under Bending," Topical Report, NUREG/CR-4872, BMI-2149, April 1987.

\section{Other Related Program Reports}

"Validation of Analysis Methods for Assessing Flawed Piping Subjected to Dynamic Loading," NUREG/CR-6234, ANL-94/22, BMI-2178, August 1994. 


\subsection{INTRODUCTION}

\subsection{Foreword}

This report summarizes the state of knowledge as of 1997 on nuclear plant piping fracture mechanics. This broad subject requires expertise in several areas: material characterization, laboratory testing, fullscale piping and piping component testing, computational analysis (both stress analyses and fracture mechanics analyses), leak-rate analyses, and codes and standards requirements. Each of these will be touched on as well as emerging technology aspects in this field.

The report is intended to be a comprehensive survey of knowledge about nuclear piping fracture mechanics that is considered to be known, understood, and applied. Current capabilities that are generally accepted and their limitations are pointed out, thereby establishing a level of confidence about the knowledge. Where practical, the quality of experimental data is assessed and the accuracy of analytical procedures is established by comparison with good experimental data. Areas of uncertainty and gaps in knowledge where there are limiting factors to the applications have been identified, as well as, where the existing methodologies could be used to resolve piping issues of concern.

\subsection{Milestone in Piping Fracture Mechanics}

The development of piping fracture mechanics has been an evolutionary process that started from work done in the oil and gas industries, and eventually matured with the advent of specific problems and needs from the nuclear industry. This section of the report summarizes the historical development and milestones between piping fracture mechanics technology and major milestones in the nuclear industry.

\subsubsection{Early Developments to 1980}

During this time frame, piping fracture work was started for the oil and gas transmission pipeline industries, commercial nuclear power plants were just being built, some initial problems with pipe cracking and generic issues were identified, and some initial research efforts were directed specifically at understanding nuclear pipe fracture behavior. Additionally, work was started on developing the fundamental elastic-plastic fracture mechanics technology eventually used throughout the nuclear industry. The developments during this time are summarized in Table 1.1. Key points of these aspects are discussed in further detail below.

\subsubsection{Gas Pipeline Fracture Developments}

The early work in piping fracture mechanics initially dealt with solving problems in the oil and gas industry. This work started at Battelle in 1952, specifically to determine how to mitigate long-running brittle fractures in gas transmission pipelines. At low operating temperatures with carbon steel piping materials, brittle fractures of up to 8 miles have been documented. Figure 1.1 shows a high speed photograph of brittle fracture propagation in a $762-\mathrm{mm}$ (30-inch) diameter pipe test. There were four 
Table 1.1 Milestones in pipe fracture technology and the nuclear industry - the early years

\begin{tabular}{|c|c|c|}
\hline $\begin{array}{l}\text { PIPE FRACTURE TECHNOLOGY } \\
\text { MILESTONES }\end{array}$ & YEAR & NUCLEAR INDUSTRY MILESTONES \\
\hline \multirow{4}{*}{$\begin{array}{l}\text { Gas pipeline fracture research started at } \\
\text { Battelle }\end{array}$} & 1952 & \\
\hline & 1960 & $\begin{array}{l}\text { 1st commercial nuclear power plant starts in } \\
\text { U.S. }\end{array}$ \\
\hline & 1963 & $\begin{array}{l}\text { U.K 2nd generation AGR started } \\
\text { First Italian nuclear plants started }\end{array}$ \\
\hline & 1965 & IGSCC in small diameter U.S. BWR pipe \\
\hline Rice's 1st paper on J-integral & 1968 & $\begin{array}{l}\text { First commercial electricity produced } \\
\text { from CANDU plant }\end{array}$ \\
\hline $\begin{array}{l}\text { GEAP pipe fracture tests at room } \\
\text { temperature }\end{array}$ & 1969 & PWR feedwater line cracking \\
\hline AEC/Battelle axial crack program & 1970 & $\begin{array}{l}\text { ASME Section XI started } \\
\text { First Japanese BWR \& PWR started }\end{array}$ \\
\hline $\begin{array}{l}\text { A.G.A./Battelle gas pipeline corrosion } \\
\text { acceptance criteria (predecessor of ANSI } \\
\text { B31G) }\end{array}$ & 1974 & U.S. NRC splits from AEC \\
\hline $\begin{array}{l}\text { EPRI/Battelle Report NP-192, Net-Section- } \\
\text { Collapse analysis developed }\end{array}$ & 1976 & $\begin{array}{l}\text { NRC Unresolved Safety Issue A-2, } \\
\text { asymmetric blowdown loads. } \\
\text { (LBB incentive) } \\
\text { 1st CEGB plant in operation } \\
\end{array}$ \\
\hline \multirow[t]{3}{*}{ CEGB pipe fracture experiments } & 1977 & 1st French PWR plant started \\
\hline & 1978 & 1st Korean plant started \\
\hline & 1979 & $\begin{array}{l}\text { 1st NRC Pipe Crack Study Group Report } \\
\text { Three Mile Island accident }\end{array}$ \\
\hline
\end{tabular}




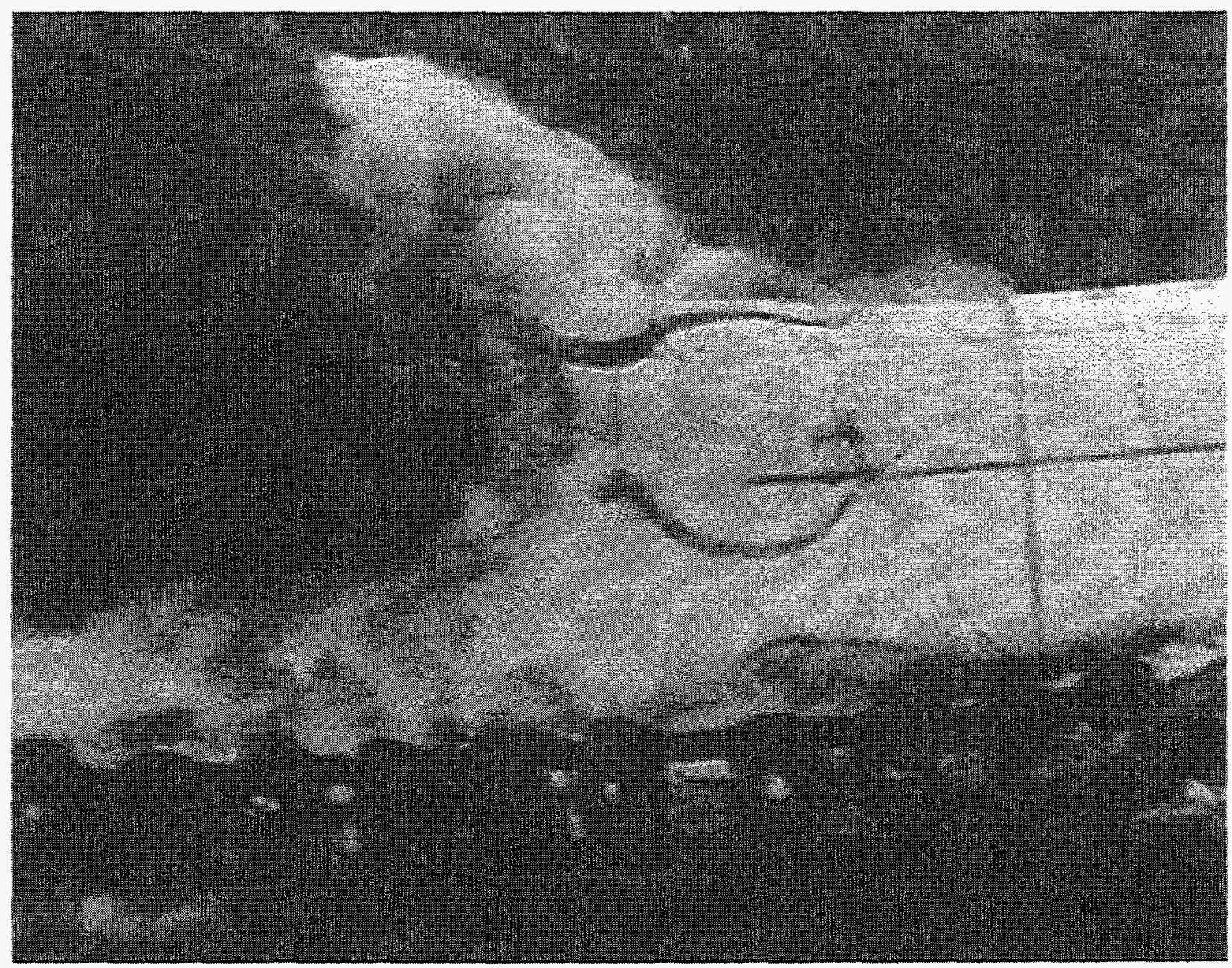

Figure 1.1 A frame from a high speed movie taken during a brittle crack propagation experiment 
simultaneous fractures in this case, which may propagate at speeds up to 1,000 meters per second $(3,000$ feet per second) (Ref. 1.1). The concern about brittle fracture propagation was probably the basis of the "instantaneous" DEGB design criteria for emergency core cooling and thermal hydraulic loads on reactor pressure vessel internals, steam generators, and piping supports. Today, the technology exists to demonstrate that the break-opening-area rate for circumferential cracks is much slower for actual nuclear plant conditions.

Other relevant aspects that have been studied in the oil and gas industries through the American Gas Association Project NG-18 at Battelle were: axial flaw failure criteria for cracks as well as corroded pipe, unstable axial ductile crack propagation, and fractures occurring from mechanical damage to pipelines.

Axial flaw criteria were developed and validated by numerous pipe fracture experiments. The criteria developed for the oil and gas industries were based on a relatively simple analysis procedure that related the fracture toughness to the Charpy upper shelf energy when the fracture was ductile (Ref. 1.2). This criteria eventually was implemented in the ASME Section XI ferritic pipe flaw evaluation criteria in Appendix H (Ref. 1.3). Interestingly, the work to determine when brittle crack initiation (i.e., linear elastic fracture mechanics) governs is still not fully explained. It was found that for axial through-wall-cracked pipe, the brittle-to-ductile transition temperature was explainable by standard bend-bar (or COD) specimens, see Figure 1.2. For an axially surface-cracked pipe, however, there is a large discrepancy between the bend-bar specimen transition temperature and the axially surface-cracked-pipe failure-pressure transition temperature. Figure 1.3 shows that the surface-cracked pipe brittle-to-ductile transition temperature was almost $100 \mathrm{C}$ lower than the bend-bar fracture mechanics specimen (Ref. 1.4). Current fracture mechanics technology using constraint theories in fracture can now be used to show why this occurs (Refs. 1.5 to 1.7 ).

Unstable axial propagation of ductile fractures also occurred in gas pipelines (Ref. 1.8). This is more prevalent with large diameter pipelines, and depends on the gas decompression characteristics, since the ductile fractures are slower than the acoustic velocity of the gas. Figures 1.4 and 1.5 show tests being conducted on buried pipelines, and an underwater pipeline. The medium surrounding the pipe also affects the ductile fracture behavior.

One of the leading causes of failures in the oil and gas transmission pipeline industry is from third-party mechanical damage. This might occur when a backhoe digging in the vicinity of a buried pipeline impacts the pipe and causes a failure. This is an extremely difficult problem to treat analytically, and hence, some empirical criteria have been developed to predict failure behavior. The purpose of these criteria was to determine if there is an optimum toughness for minimizing failures from such damage (Ref. 1.9).

\subsubsection{Start of Commercial Nuclear Power}

Starting in about 1960 , the first commercial nuclear plants were put into operation. Some dates for these plants are listed in Table 1. In the US, the first plants were started in 1960 (Yankee and Dresden plants). In 1963 plants were started in the United Kingdom (Advanced Gas Cooled Reactors) and in Italy. The first CANDU plant for commercial electricity was started in 1968. Japanese plants were first started in 
$x=$ Through-wall-cracked pipe data

$a=t \times 2 t$ COD bend specimens

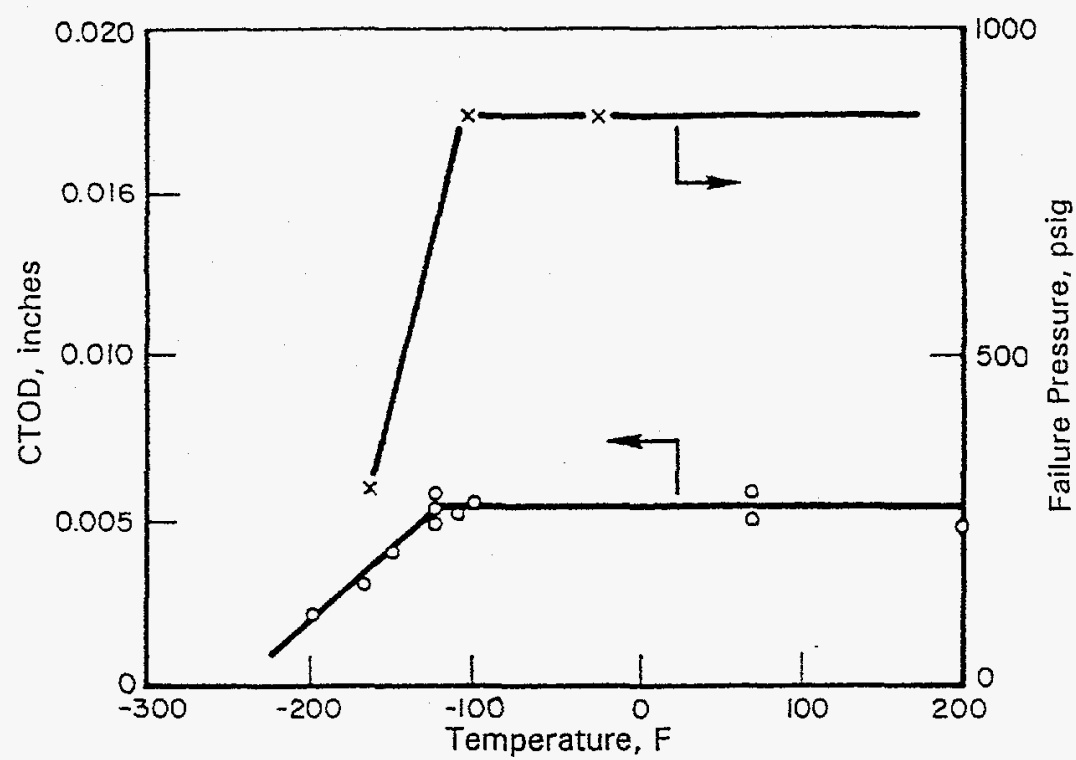

Figure 1.2 Comparison of $t$ by $2 t$ COD transition temperature with axial through-wall cracked 48-inch $(1,219 \mathrm{~mm})$ diameter pipe fracture data

$x$ = Surface-cracked pipe data

$0=t \times t$ COD bend specimens

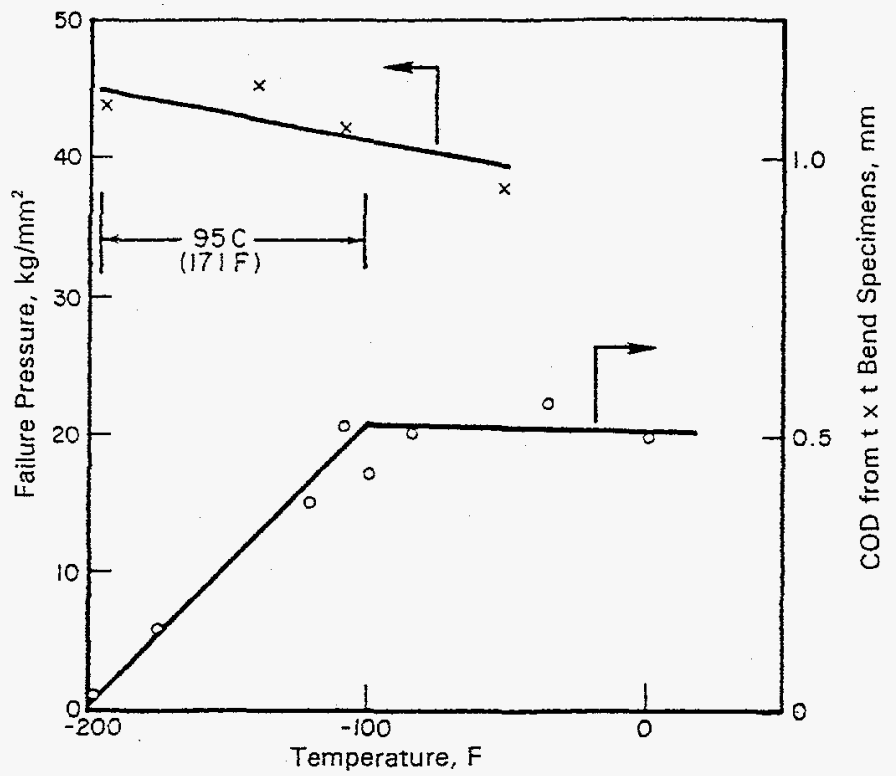

Figure 1.3 Comparison of transition temperature from COD bend specimens with 24-inch (610 $\mathrm{mm}$ ) diameter 0.375-inch $(9.5 \mathrm{~mm})$ thick API 5LX nonstress-relieved pipe with axial surface cracks 


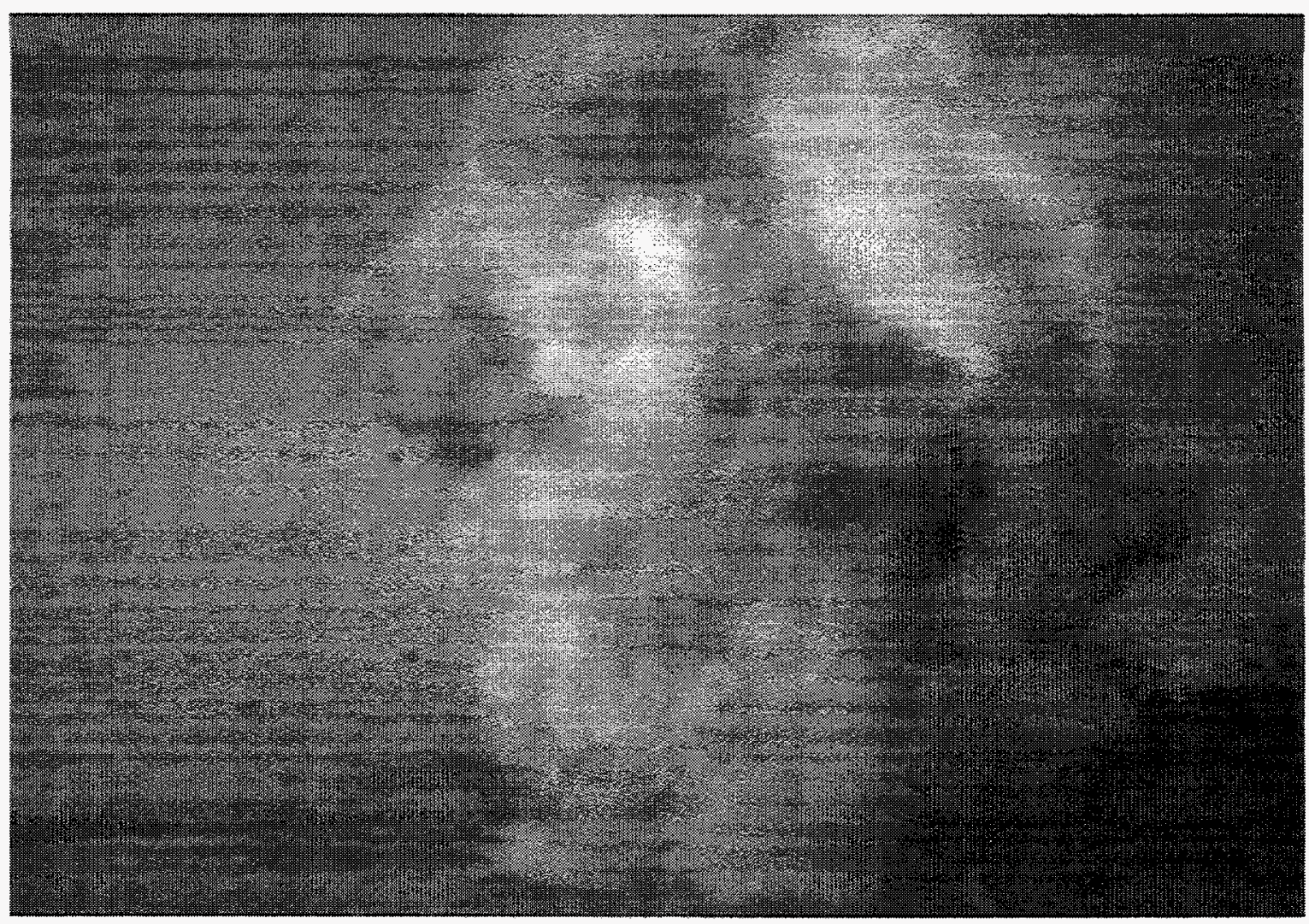

Figure 1.4 Buried pipeline test

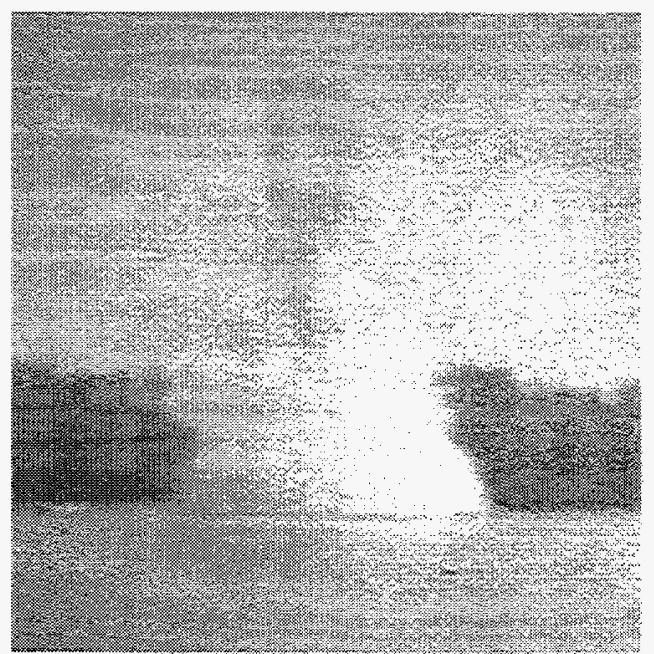

Figure 1.5 Underwater pipeline test 
1970, while the first French PWR plants were started in 1977, followed by the first Korean plant in 1978. Because these plants were started prior to most of the piping fracture mechanics developments, conservative design rules were implemented.

\subsubsection{First Nuclear Piping Problems}

As early as 1965 , cracks in 152-mm (6-inch) nominal diameter Type 304 stainless steel bypass lines associated with the recirculation loop of the Dresden I boiling water reactor (BWR) were discovered. From 1965 to 1974 cracks were found in six BWRs (Ref. 1.10). All affected piping was Type 304 stainless steel with nominal pipe diameters of 203-mm (8-inch) or less. All of the cracks were attributed to intergranular stress corrosion cracking (IGSCC) due to a combination of high local stresses at welds, material sensitization from the welding process, and high oxygen content in the water. By the mid-1970s, IGSCCs were starting to become a widespread problem. IGSCC in larger diameter piping systems was also being discovered. Examples include; cracks found in 660-mm (26-inch) diameter welds in a German BWR, 305-mm (12-inch) diameter riser pipe in Japan, and 711-mm (28-inch) diameter main recirculation pipe in the U.S. Nine Mile Point plant. In 1975, the first NRC Pipe Crack Study Group concluded that "Types 304 and 316 austenitic stainless steel piping...of boiling water reactors is susceptible to stress corrosion cracking." The group went on to summarized its findings and recommendations in 1979 (Ref. 1.10).

Shortly after discovering the IGSCC cracks at Dresden I, the first incidence of cracking in a feedwater piping system was discovered at the San Onofre pressurized water reactor (PWR) in the U.S. Cracks were subsequently found in the feedwater piping adjacent to the steam generators in 15 of the 32 PWRs inspected (Ref. 1.11). Analyses of the operating conditions for these plants suggested that thermal fatigue was the most probable cause for this feedwater line cracking. Temperature differences of over $200 \mathrm{C}$ (392 F) between the top (hot) and bottom (cold) of the piping were observed adjacent to the steam generator inlet during hot standby.

In 1970, the ASME Section XI committee was formed. This committee was charged with developing inspection and flaw evaluation standards for the ASME Code, and initially dealt with developing criteria to avoid brittle fracture and fatigue failures.

In 1976, the NRC issued Unresolved Safety Issue A-2. This dealt with the development of asymmetric loading on a reactor pressure vessel caused by thrust and pressure loads from a primary piping break at the reactor vessel nozzle. The postulated accident would cause large enough loads that older PWR vessels could tip and control of the reactor could be lost. The solution was to either retrofit the pipe with pipe whip restraints, or to show that a break could not occur. From this effort, the leak-before-break concept was developed in the nuclear industry as a means to show that retrofitting of pipe restraints was not needed. 


\subsubsection{Early Fracture Mechanics Work for the Nuclear Piping Industry}

Prior to 1968 , fracture mechanics typically encompassed only brittle or linear elastic fracture mechanics (LEFM). In 1968, Dr. James Rice first proposed the J-integral as an elastic-plastic fracture mechanics (EPFM) methodology (Ref. 1.12). Since then, this parameter has become the predominant method to characterize elastic-plastic fracture in the nuclear industry. The basic $\mathrm{J}$ parameter was extended to account for toughness changes with crack growth, resulting in what is known as the J-resistance curve.

In 1969, the U.S. Atomic Energy Commission (USAEC) funded efforts at General Electric plant for BWR plant development and operation investigations (Ref. 1.13). GE initially conducted pipe fracture tests under relatively simple loading conditions at room temperature, typically with machined notches. Some of these results were compared with the Battelle gas pipeline work.

In 1970, Battelle completed a program for the USAEC intended to study initiation, propagation, and arrest of cracks in nuclear piping at light water reactor (LWR) temperatures (Ref. 1.14). This work concentrated on axial cracks, Figure 1.6, where there were leaks, limited breaks (i.e., rapid decompression stopped the crack growth, but a large leak resulted), and ruptures. A small effort also evaluated circumferentiallycracked pipe under pressure loading. The axially-cracked pipe data provided the experimental verification of the Battelle gas and oil pipeline criterion that was used in the ASME Section XI pipe flaw evaluation criteria.

In 1974, Battelle developed the first corroded pipe acceptance criterion for the oil and gas pipeline industry. This was the predecessor of the ANSI B31G corroded pipe acceptance criterion (Ref. 1.15). This criterion was essentially the axially surface-cracked-pipe limit-load criterion. About 100 pipe burst test experiments were conducted with artificial (machined) defects and on many pipes removed from service to validate the criterion. The criterion was later improved to account for flaw depth variability in the modified B31G criterion. A Battelle-developed computer code called RSTRENG was written to make these calculations, and the quality control copy of this computer code is available from the American Gas Association (A.G.A.) (Ref. 1.16). The initial B31G criterion was also one of the criteria that was included in the proposed ASME Section XI Code Case N480 for evaluation of erosion-corrosion flaws in nuclear piping. This code case was never accepted, since neither the industry nor the U.S. NRC liked the inspection criteria. Efforts to develop erosion-corrosion flaw acceptance criteria and further efforts to refine methods to predict the residual strength of corroded pipe are in progress as of 1997.

Due to the significant amount of stress-corrosion cracking problems in BWRs, EPRI started a program at Battelle to develop flaw acceptance criteria for circumferential flaws (Ref. 1.17). This work involved the Net-Section-Collapse criterion. Net-Section-Collapse is a limit-load criterion that assumes that the material toughness is so high, that crack initiation is governed by the strength of the material, the flaw shape, and the pipe dimensions. Although the term collapse implies buckling to some people, the name was meant to imply that the pipe cross-section becomes fully plastic at the maximum load. The criterion also assumes that an insignificant amount of crack growth occurs from the start of ductile tearing to reaching maximum load. Hence, the initial crack length is used in the calculations. Initial experimental work to validate this approach was done on small diameter stainless steel pipe with circumferential through-wall cracks at room temperature, and also with numerous center-cracked flat-plate specimens. 
Section 1

INTRODUCTION
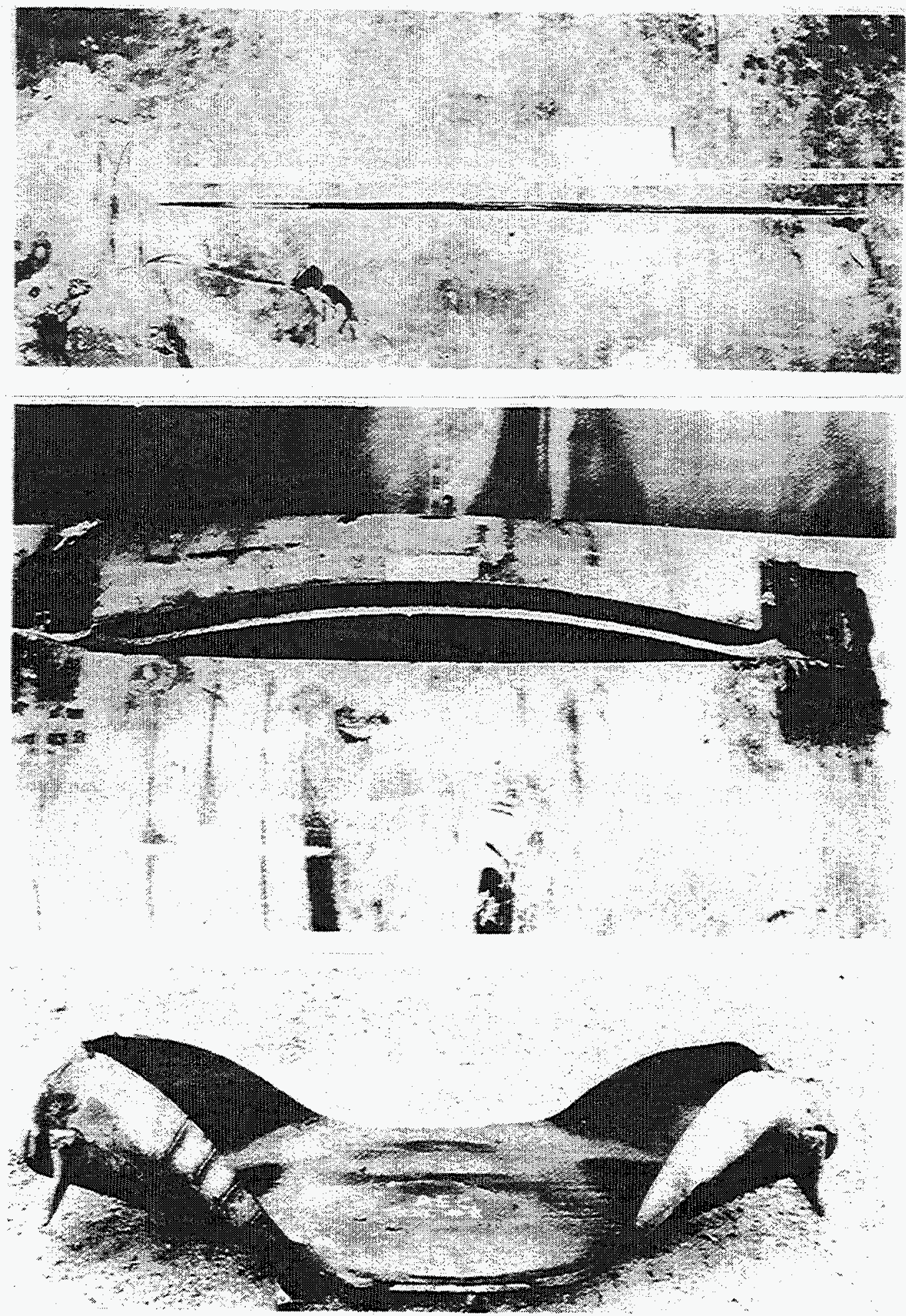

Figure 1.6 Modes of crack extension observed in 24-inch-diameter x 1.70-inch-thick A106B pipe in high-enthalpy fluid rupture tests 
In the mid-1970's, the CEGB in the U.K. also reported results from a number of pipe fracture experiments, typically at ambient temperature (Ref. 1.18).

\subsubsection{The Middle Ages of Piping Fracture Mechanics - the 1980's}

The milestones during this time frame are broken into the categories of, research development, developments in the nuclear industry, and standards and regulatory procedures.

The research developments were: development of J-integral based solutions for piping fracture analysis, standardization of the J-R curve testing method to develop elastic-plastic fracture toughness of piping materials, and validation of the $\mathrm{J}$ solutions for cracked pipe using pipe experiments typically done under simple quasi-static loading. Also of interest is that in 1981, the first commercial personal computers became publicly available. Hence, the ability to conduct more detailed analyses and to easily maintain databases was starting a period of rapid advancement.

In the nuclear industry, the development of nuclear power probably reached its peak, and in a few countries, nuclear plants were closed or closure was being considered due to political pressure. The severe accidents at the Three Mile Island plant in the U.S. and the Chornobyl plant in the Ukraine caused massive public concern over the safety of nuclear power, and showed the need for a common technical basis on nuclear safety-related issues.

In the standards and regulatory arena, the key milestones were: development of pipe flaw evaluation standards in the ASME Code, development of the U.S. NRC leak-before-break (LBB) criterion, as well as, several international meetings on LBB. Key points of these milestones are summarized in Table 1.2, and are further discussed in the following sections.

\subsubsection{Research Developments in Piping Fracture Mechanics and Related Technologies During the 1980's}

There were many efforts undertaken in this era and because there were so many, it is not possible to discuss or even mention all of them in this report. We have not attempted to summarize everything done in this time period, but have tried to give the reader a feeling of the major developments and what was happening world-wide in the nuclear pipe fracture arena.

\section{Analytical Developments}

One of the concerns in the design of nuclear power plants was the speed of a pipe fracture. Unstable axial crack propagation is one concern, and a double-ended guillotine break (DEGB) for a circumferential crack is a second concern. Fortunately, axial flaws are virtually nonexistent in the nuclear industry (except for erosion-corrosion flaws). Circumferential flaws, however, do occur. The DEGB term refers to the fact 
Table 1.2 Milestones in pipe fracture technology and the nuclear industry - the middle ages

\begin{tabular}{|c|c|c|}
\hline PIPE FRACTURE TECHNOLOGY MILESTONES & YEAR & NUCLEAR INDUSTRY MILESTONES \\
\hline $\begin{array}{l}\text { NRC/Battelle Cold-Leg Program - leak-rate analyses } \\
\text { CSNINRC Specialist Meeting on Plastic Tearing } \\
\text { Instability }\end{array}$ & 1980 & Swedish nuclear referendum (plants to close in 2010) \\
\hline $\begin{array}{l}\text { ASTM J } J_{\mathrm{I}_{0}} \text { E813 published } \\
\text { GE/EPRI Handbook } \\
\text { NUPEC/MITI TP304 pipe instability program } \\
\text { EPRI Dynamic Pipe Fracture Analysis Program } \\
\text { completed }\end{array}$ & 1981 & PC computers commercially available \\
\hline $\begin{array}{l}\text { EPRI plastic fracture methodology programs at GE and } \\
\text { Battelle completed } \\
\text { 2nd EPRI/Battelle pipe program for J/T \& NSC } \\
\text { validation, and first dynamic pipe test } \\
\text { NRC/DTRC stainless steel SAW toughness data } \\
\text { EPRI/GE program on inertial pipe tests and initial } \\
\text { concepts for IWB- } 3640 \text { stainless steel flaw evaluation } \\
\text { criterion }\end{array}$ & 1982 & $\begin{array}{l}\text { BWR IGSCC occurred in large diameter } \\
\text { pipe in U.S. }\end{array}$ \\
\hline NRC/Battelle Degraded Piping Program - Phase I & 1983 & \\
\hline $\begin{array}{l}\text { EPRL/Battelle leak-rate tests and development for PICEP } \\
\text { NRC/DTRC A106 B pipe instability tests } \\
\text { Start of Argonne work on thermal aged cast stainless } \\
\text { steel toughness } \\
\text { CEGB work on pipe rupture and fragmentation damage } \\
\text { from pipe or vessel ruptures }\end{array}$ & 1984 & 1st CSNI LBB - Monterey \\
\hline MPA/Phen. Burst Test Program - Phase I & 1985 & $\begin{array}{l}\text { 2nd NRC Pipe Crack Study Group - } \\
\text { NUREG/CR-1061 } \\
\text { ASME XI IWB-3640 }\end{array}$ \\
\hline $\begin{array}{l}\text { R6 Rev. } 3 \text { issued } \\
\text { Start of major French LBB and pipe fracture programs } \\
\text { Paris NUREG/CR-3464 J/T analysis for pipe (predecessor } \\
\text { of LBB.NRC analysis) } \\
\text { JAERI pipe tests on 6- and 16-inch diameter pipe } \\
\text { EPRI efforts in codification of flaw acceptance standards and } \\
\text { LBB applications }\end{array}$ & 1986 & $\begin{array}{l}\text { 2nd CSNI LBB - Columbus } \\
\text { Surry-2 plant carbon steel elbow erosion- } \\
\text { corrosion failure } \\
\text { Chornobyl accident }\end{array}$ \\
\hline $\begin{array}{l}\text { ASTM J-R curve E1152 standard published } \\
\text { MPA/Phen. Burst Test Program - Phase II } \\
\text { NRC/PIFRAC database first published } \\
\text { Additional Japanese leak-rate programs }\end{array}$ & 1987 & $\begin{array}{l}\text { NRC Draft SRP } 3.6 .3 \text { for LBB published } \\
\text { All Italian nuclear plants closed }\end{array}$ \\
\hline STA/Japan pipe-system tests & 1988 & $\begin{array}{l}\text { 3rd CSNI LBB meeting - Tokyo } \\
\text { ASME XI IWB-3650 }\end{array}$ \\
\hline $\begin{array}{l}\text { NRC Degraded Piping Program - Phase II } \\
\text { JAERI inertial pipe tests } \\
\text { ENEA/Italy pipe fracture program } \\
\text { EPRINRC Piping and Fitting Dynamic Reliability } \\
\text { Program }\end{array}$ & 1989 & 4th CSNI LBB meeting - Toronto \\
\hline
\end{tabular}


that the pipe completely severs due to a circumferential flaw, and the ends separate so there is full flow from the two ends at the same time. To address these technical concerns, EPRI commissioned University of Washington researchers (Emery, Kobayashi, Love and others) to conduct dynamic fracture analyses. This work was done between 1975 to 1981 under Project 231-1 (Ref. 1.19). Their efforts were more theoretical, and little experimental data existed for the circumferential crack case to confirm the high calculated fracture speeds.

In 1980, the NRC's "Cold Leg Integrity Evaluation" program at Battelle (Ref. 1.20) published the first leak-rate analysis for two-phase flow through cracks. This work was later followed-up in a separate EPRI program at Battelle in 1984, where numerous experiments were conducted with two-phase flow through artificial slits and through an IGSCC in a pipe, see Figure 1.7 (Ref. 1.21). A computer code was also developed in this project (Ref. 1.22). The Battelle two-phase-flow analysis was later implemented into the EPRI PICEP computer code along with the GE/EPRI estimation scheme for crack-opening displacements (Ref. 1.23). Additional leak-rate work was done later in Japan and other places in the 1980's.

At the end of the 1970's and the very beginning of the 1980's, the J-integral tearing modulus fracture instability methodology was coming into use. The tearing modulus $(T)$ is a dimensionless parameter that is

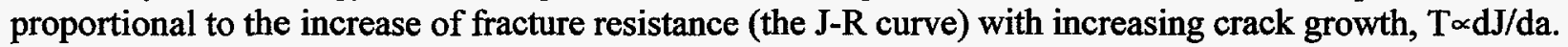
Initially, the change in the J-R curve was assumed to be linear, so that the tearing modulus was a constant. Later, it was recognized that there was a need to account for the nonlinear aspects in the J-R curve. Hence, material-specific $\mathrm{J}$ versus tearing modulus (or $\mathrm{J}_{\operatorname{mar}} / \mathrm{T}_{\text {mat }}$ ) curves were needed. Figure 1.8 shows a typical $\mathrm{J} / \mathrm{T}$ curve instability diagram. In 1980, the results of a CSNI/NRC workshop on the J/T theory and applications were published (Ref. 1.24).

EPRI funded several programs to develop a methodology for plastic fracture mechanics. Significant efforts were undertaken at GE (Ref. 1.25) and Battelle (Ref. 1.26), with some additional efforts at Westinghouse and Stanford Research Institute (SRI). The GE work looked at the J-R curve concept and the development of a J-estimation scheme methodology incorporating elastic and fully plastic contribution functions to the crack-driving force, crack-opening displacements, and global displacements or rotations of the structure/specimen due to the crack. The Battelle work examined the use of a combination of the Jintegral at crack initiation and small amounts of crack growth where $J$ was considered to be valid at the time, and the use of the crack-tip-opening angle (CTOA) fracture parameter for larger amounts of crack growth. The CTOA fracture parameter, although physically appealing, did not gain general acceptance since it required detailed FEM analyses and no simplified estimation schemes were available. The Westinghouse work looked at specimen geometry dependance of J-R curves. The SRI work was some of the earliest work in what is now referred to as the local approach. In the local approach, a very refined finite element mesh is required and the elements in the crack path account for void growth and coalescence (Refs. 1.27 and 1.28).

Other more sophisticated or general versions of Rice's J-integral parameter (e.g., $\hat{J}$ and $T_{p}{ }^{*}$ ) were proposed in the 1980 's. These methods were used to handle thermal-mechanical loading and incorporated incremental plasticity rather than deformation plasticity as required in Rice's development. Although these parameters were applied occasionally in the aerospace industry, they never saw widespread use in the nuclear industry other than in a few research investigations (Ref. 1.29). 
Section 1

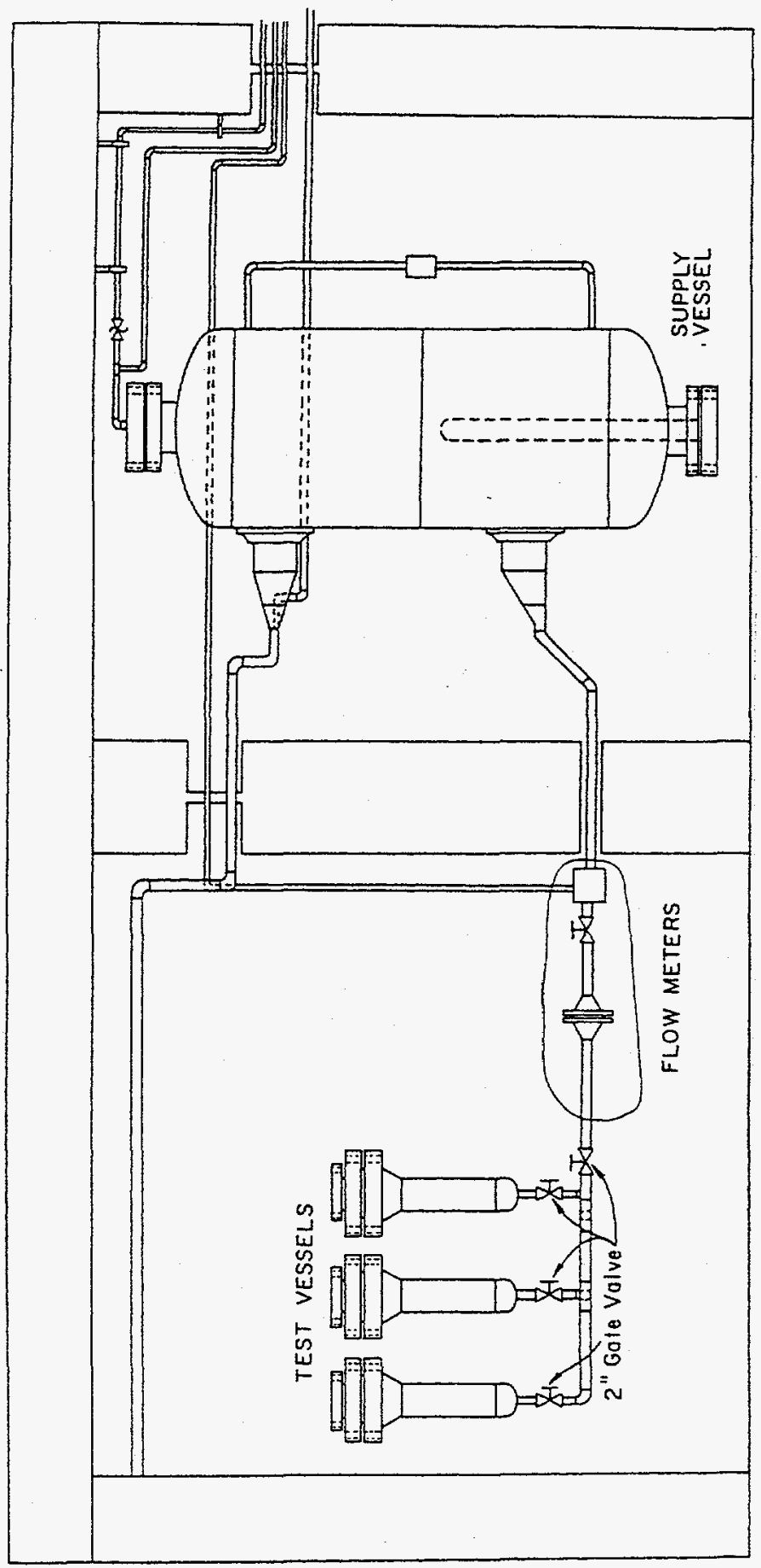

를 


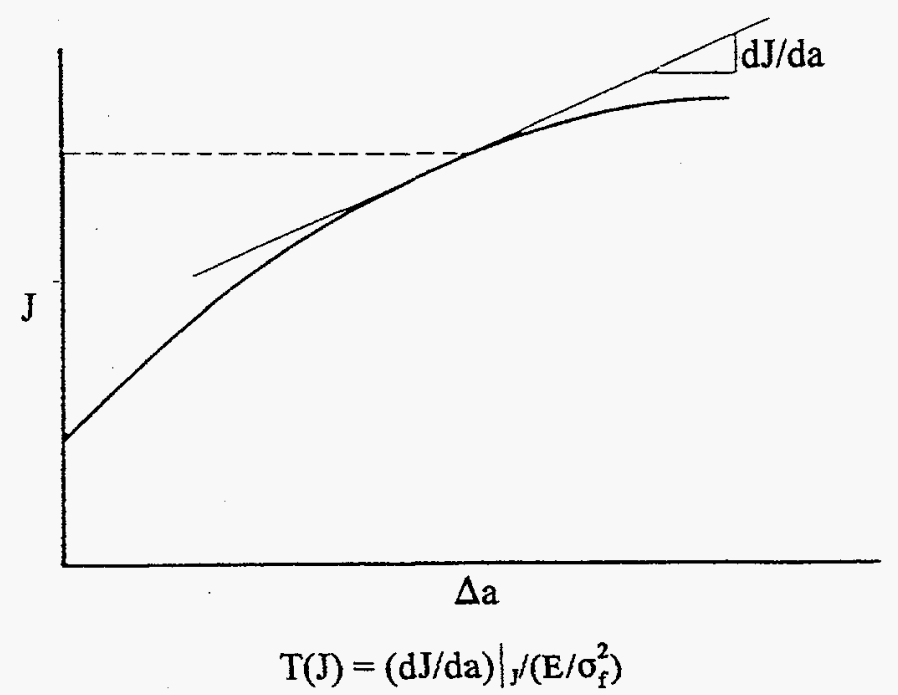

(a) Material J/T behavior

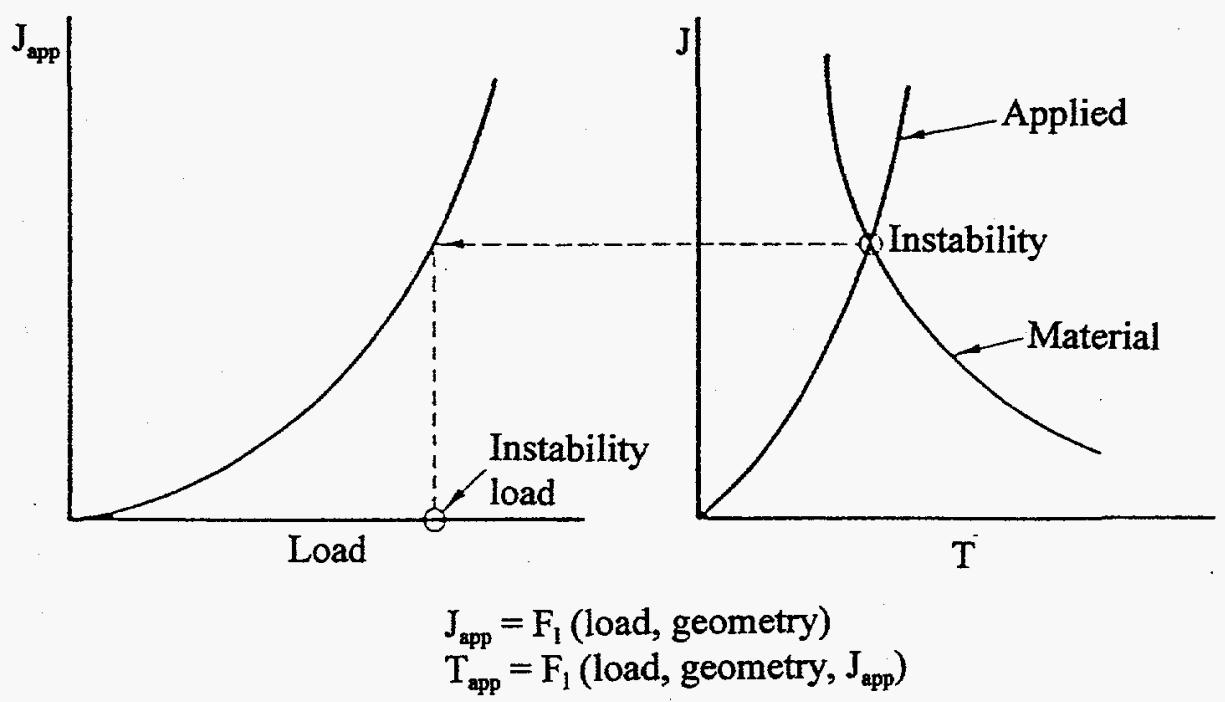

(b) Stability assessment diagram

Figure 1.8 J/T stability assessment methodology 
The GE/EPRI work eventually was compiled into the GE/EPRI Elastic-Plastic Fracture Mechanics Handbook. The initial handbook was published in 1981, with additional solutions added in 1984 (Refs. $1.30,1.31$, and 1.32). This was a powerful tool for engineering applications, and still is one of the most frequently used pipe fracture analysis methods.

In 1983, the J/T approach by Paris and coworkers was applied to pipe fracture analysis. The initial pipe $\mathrm{J} / \mathrm{T}$ solutions are given in Reference 1.33 , and were subsequently modified in 1986 by Klecker of the NRC to account for strain-hardening in the $\mathrm{J}_{\mathrm{p}}$ term. The Klecker method was called the LBB.NRC method (Ref. 1.34).

One of the other major fracture analysis approaches used in the world, the R6 methodology, was undergoing modifications at this time. The R6 analysis method was developed originally by the Central Electric Generating Board in the United Kingdom. The current R6 Revision 3 method was published in 1986 with several different optional analysis levels (Ref. 1.35). The general approach was to predict crack initiation and fracture loads through use of a dimensionless failure assessment diagram, or FAD curve, see Figure 1.9. Assessment points falling inside the FAD curve are deemed safe, points outside the curve are not necessarily unsafe, but at least require additional scrutiny. In all cases, the ratio of the applied load to limit load is plotted on the abscissa, and the ratio of linear elastic stress intensity to material toughness is plotted on the ordinate. In this methodology, there is an interpolation between linear elastic (brittle) failure and limit-load (or plastic collapse) failure. The simplest option uses a fixed FAD curve when the stressstrain curve of the material is unknown. The second option uses a fixed formula for incorporating the material's stress-strain curve in the shape of the FAD curve, but does not account for geometry effects. The last option, essentially allows the user to use any more sophisticated analysis method (e.g., FEM, GE/EPRI J-estimation scheme) to account for material and geometry effects, and puts these analyses in the format of a FAD curve.

In the middle to late 1980 's, EPRI funded numerous efforts to: (1) evaluate crack propagation in a high energy pipe loop (Ref. 1.36), (2) develop various J/T piping analyses (Ref. 1.37) that eventually led to the EPRI Ductile Fracture Handbook (Ref. 1.38), (3) analyze ongoing pipe fracture experiments (Ref. 1.39), (4) develop codification of procedures for pipe flaw acceptance standards for austenitic (Ref. 1.40) and ferritic pipe (Ref. 1.41), and (5) demonstrate applications of fracture evaluation to pipe systems for different plants (Refs. 1.42 to 1.45 ).

\section{Development of Pipe Material Property Data}

In the area of developing material property data for nuclear piping, the ASTM E813 $\mathrm{J}_{\mathrm{Ic}}$ standard was published in 1981, and the ASTM E1 $152 \mathrm{~J}-\mathrm{R}$ curve standard was published in 1987. The standards used both the deformation-theory based J-integral parameter $\left(\mathrm{J}_{\mathrm{D}}\right)$ from Rice, as well as a parameter called the Modified J that was proposed by Ernst while he was at Westinghouse (Ref. 1.46). The Modified J was proposed to reduce specimen geometry effects in the $J_{D}-R$ curve, but was later found to have problems (i.e., an upward hooking of the $J_{M}-R$ curve) with some materials (Ref. 1.47). 


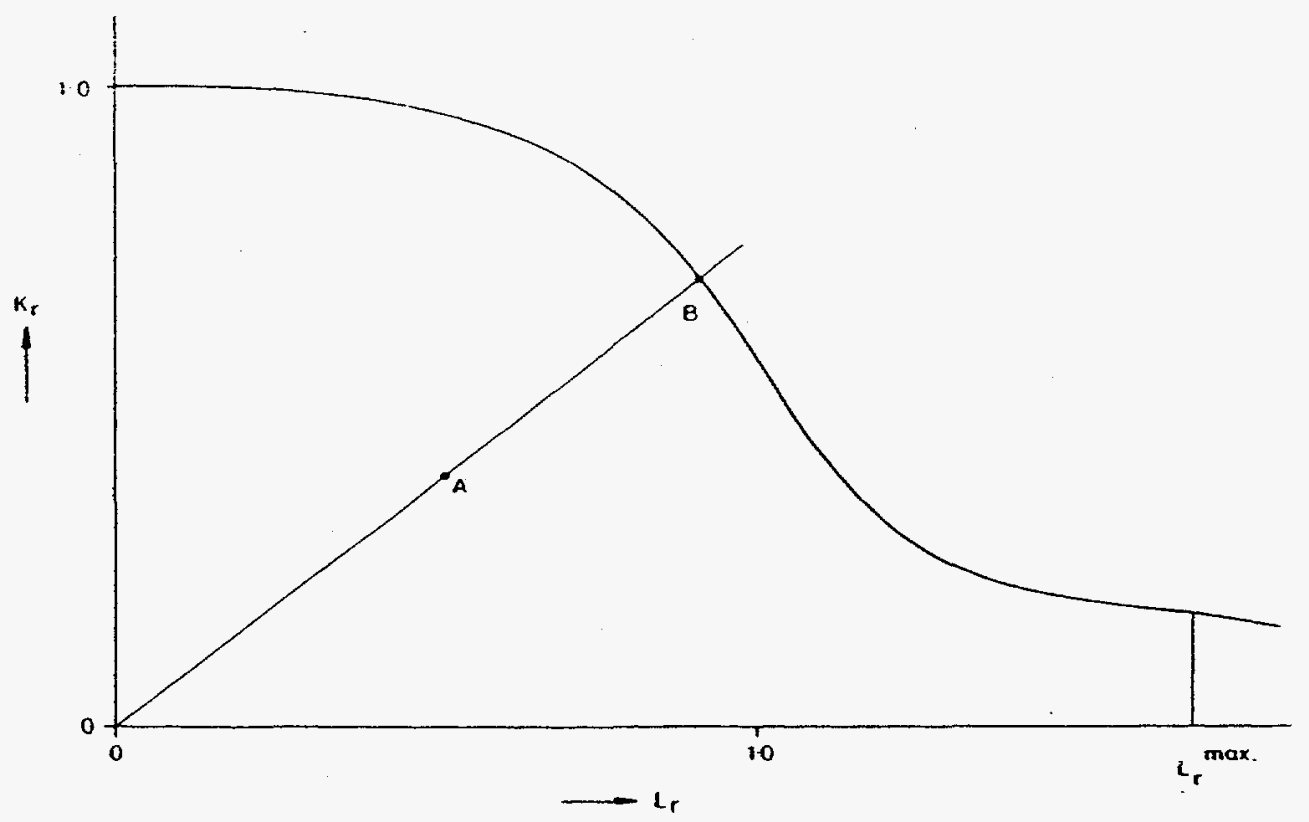

Figure 1.9 R6, Option 1 failure assessment diagram

Efforts were funded by the NRC to develop pipe material property data at the David Taylor Research Center (DTRC), Battelle, Argonne National Laboratory (ANL), and Materials Engineering Associates (MEA). The DTRC work involved specimen tests to determine the J-R curves of many materials. One of the key DTRC results found in 1981 was that the J-R curve of stainless steel flux (SMAW or SAW) welds was a factor of ten lower than that for stainless steel base metals (Ref. 1.48). Similar results were found in the Degraded Piping Program - Phase II, see Figure 1.10 (Ref. 1.49). This caused a major concern in the development of flaw evaluation standards in the ASME Section XI code. Hundreds of tensile and J-R curve tests were conducted as part of the Battelle program (Ref. 1.49).

The ANL work involved determining the effect of thermal aging on the toughness of cast stainless steels. The Argonne work started in 1984 and continued into the early 1990's (Ref. 1.50). Significant efforts on aged cast stainless steel were also undertaken at Framatome (Ref. 1.51) and Westinghouse (Ref. 1.52), although the Westinghouse database is proprietary.

EPRI also conducted several programs to develop pipe material property data. Programs were conducted at Westinghouse (Ref. 1.53), GE (Ref. 1.54), and Babcock and Wilcox (B\&W) (Ref. 1.55). The Westinghouse and GE efforts examined the toughness of austenitic steel base metals and welds, whereas B\&W developed data on ferritic steels and welds. 


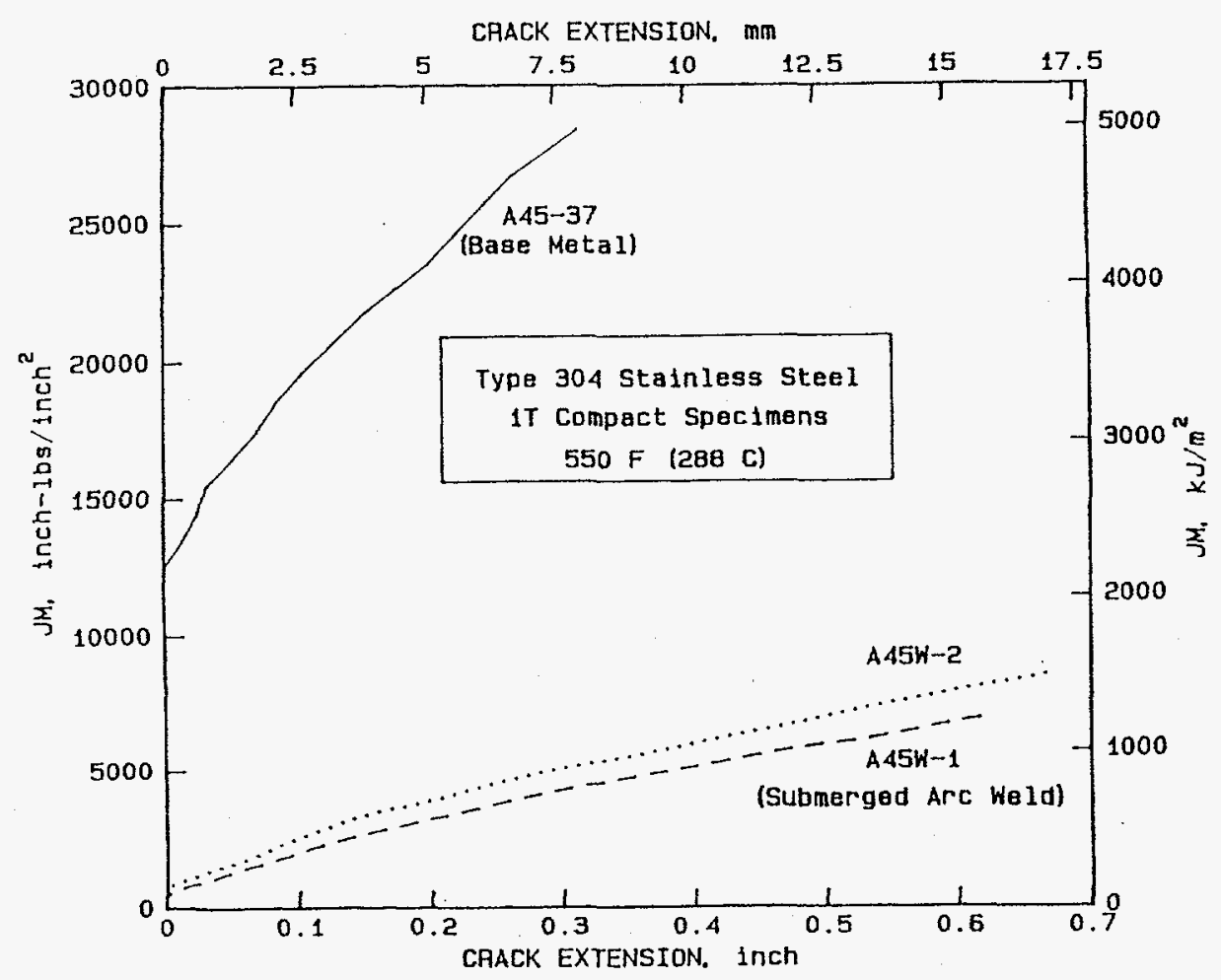

Figure $1.10 J_{\mathrm{M}}$-resistance curves for Type 304 stainless steel at $288 \mathrm{C}$ (550 F) showing the deleterious effect of submerged-arc welding

The NRC recognized the need to collect and generate additional data that were not already being developed elsewhere. To do this, a program was funded by the NRC at MEA to develop data on a variety of piping steels used in U.S. plants, and to establish a database. This database was called PIFRAC, and was initially available on a mainframe computer (Ref. 1.56). The database included information such as; chemical composition, Charpy data, stress-strain curves, and fracture specimen results. The fracture test data included J-R curves, as well as the load-displacement-crack growth data and the specimen dimensions. Because the test data are so extensively documented, if a new fracture parameter or standard is developed, the new fracture toughness resistance curves can be calculated using the existing test data. This database is now a PC database and has been updated several times by Battelle (Ref. 1.57). Version $3.1^{*}$ has over $800 \mathrm{~J}-\mathrm{R}$ curves and over 800 stress-strain curves, and includes the data from all the NRC and EPRI (except the B\&W data) programs, as well as data from Ontario Hydro developed for their LBB programs (Ref. 1.58), and data from some additional sources.

* PIFRAC Version 3.1 is currently available only through Battelle. The database uses dBase III+ or compatible software, and is on 313.5 -inch disks or a CD-ROM. 


\section{Full-Scale Tests and Validation of Analyses}

In the 1980's, there were a large number of pipe tests being conducted that built on the prior work. One of the early programs in the 1980's, was the NUPEC TP304 pipe fracture instability program (Ref. 1.59). This program, completed in 1981, examined pipe instability with circumferential through-wall and surface flaws under compliant axial tension loading. The compliant loading refers to the fact that there were springs in series with the pipe specimen to simulate the elastic energy of having a much longer pipe system than available in the length of the test pipe.

In 1982, the report on the second Battelle/EPRI stainless steel pipe fracture program was completed (Ref. 1.60). In this program, the first instability test on a stainless steel circumferential through-wall-cracked pipe was conducted in compliant bending. The compliant bending simulated the stored energy available to drive a fracture in a length of pipe typical in a nuclear plant piping system using a short pipe specimen. The limit-load and $\mathrm{J} / \mathrm{T}$ instability analyses were validated as engineering analysis methods. A method to calculate the J-R curve directly from a pipe test data was developed, although there was a factor of 2 error (on J) that was later caught in the formulation, and an errata sheet was issued. Additionally, the first dynamic circumferentially cracked-pipe experiment was conducted (Figure 1.11). The dynamic loading was more typical of a blow-down or water-hammer load, where there was a single large-amplitude cycle. The test design and analysis for this experiment showed that there were significant margins in the behavior of cracked pipe on the inertial moments being generated under dynamic loads due to the presence of the crack. Adequate dynamic analyses methods did not exist at that time to fully understand the significance to pipe-system fracture behavior.

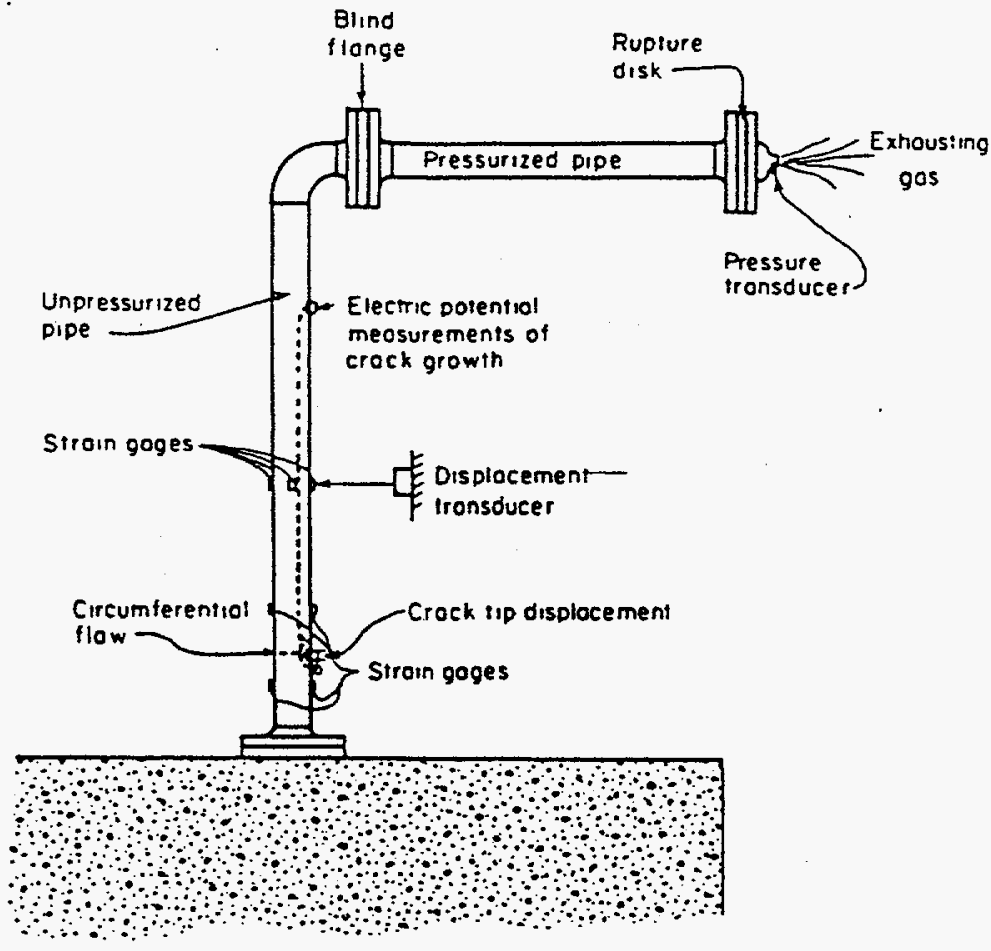

Figure 1.11 An experimental setup for induced transient bending stresses in the dynamic pipe fracture experiments in Reference 1.60 
In 1982, the EPRI/GE program on growth and stability of stress-corrosion cracks in large diameter BWR piping was completed (Ref. 1.61). In this program, the initial concepts for ASME Section XI Article IWB3640 stainless steel flaw evaluation criterion were developed. Additional efforts in this program involved IGSCC specimen and pipe tests, and some inertially loaded circumferential-cracked-pipe bending experiments. The inertially loaded pipe experiments were conducted at a single-frequency with constant amplitude and showed that low-cycle fatigue could lower the failure loads below the loads predicted by the Net-Section-Collapse analysis when the initial crack length was used. This result, and similar inertially loaded pipe tests at JAERI in Japan in 1989 (Figure 1.12), illustrated that the design of dynamic inertially loaded pipe tests needed to be done carefully to avoid low-cycle fatigue crack growth from too many cycles that would be atypical of seismic loading.

In 1984, DTRC conducted a program for the U.S. NRC (Ref. 1.62) on instability behavior of A106 Grade $B$ pipe with circumferential through-wall cracks in four-point bending, see Figure 1.13. This work involved comparisons of their experimental results with $\mathrm{J} / \mathrm{T}$ analyses of Paris (Ref. 1.33) and the Battelle/Zahoor methods (Ref. 1.60).

In Germany, MPA-Stuttgart undertook several programs for the German government on the burst strength of German pipe. The "Phänomenologische Behälterberstversuche - Phase I" report was completed in 1985 (Ref. 1.63). This report concentrated on axial cracks and a few circumferentially cracked pipes at operating temperatures under pressure loads. Such flaws cause very dynamic crack opening and are very energetic. Interesting data on dynamic depressurization, opening area, and velocities of severed pieces of pipes (end capped and pressurized to failure) were developed. The accompanying analyses examined the axial crack limit-load solution developed earlier by Battelle for the oil and gas industries (Ref. 1.2). This effort was very similar to an earlier Battelle/AEC effort in the 1970's (Ref. 1.14). The MPA Phase II effort was completed in 1987 (Ref. 1.64). This effort took a closer look at large-diameter low-alloy-steel pipe with circumferential flaws tested at LWR pressures and temperatures. The circumferential flaw results were compared with the analysis from the earlier work of Eiber in Reference 1.14 and the Battelle/EPRI Net-Section-Collapse analysis (Ref. 1.17). These German projects led to the development of their "Basis Safety Approach" (Ref. 1.65). As part of this approach, they postulated that the instantaneous DEGB design criteria could be replaced with a criterion that said that the crack opening would be at most 10 percent of the pipe cross-section.

In Japan, the JAERI efforts for the Science and Technology Agency (STA) were completed on 152-mm (6-inch) and 406-mm (16-inch) diameter pipes of both TP304 stainless steel and STS42 carbon steel (Ref. 1.66). These tests were four-point bend tests, generally without pressure, and typically at room temperature, sometimes with higher compliances for instability evaluations, and with either circumferential through-wall or surface cracks.

In Europe, there were also other programs going on in the 1980's. Baum at CEGB continued his work looking at dynamic pipe fracture and projectiles from vessel fracture (Refs. 1.67. and 1.68). The French started several major programs in 1986 (Ref. 1.69), and the Italians conducted several programs to examine axial and circumferential cracks in ferritic steel piping (Refs. 1.70 and 1.71).

In the U.S., the NRC undertook a major program called the Degraded Piping Program. The first phase was completed in 1983 (Ref. 1.72). This effort involved some analytical developments, as well as a planning effort for the larger Phase II effort. The Phase II program was completed in 1989 (Refs. 1.49 and 1.73 to 


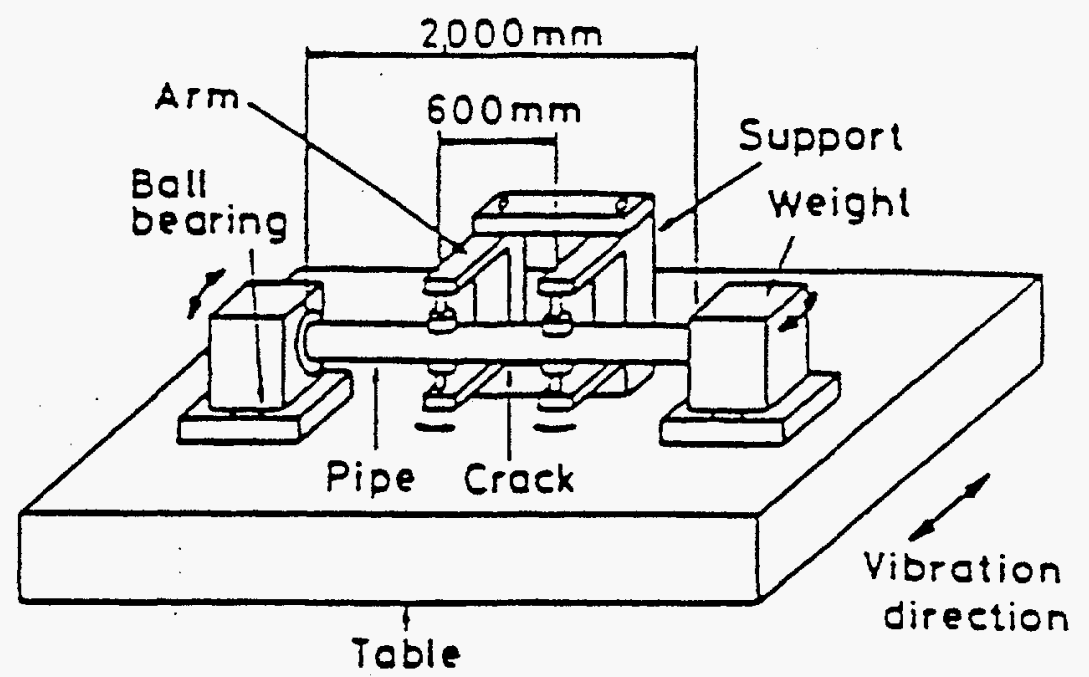

Figure 1.12 Schematic setup of JAERI vibration test

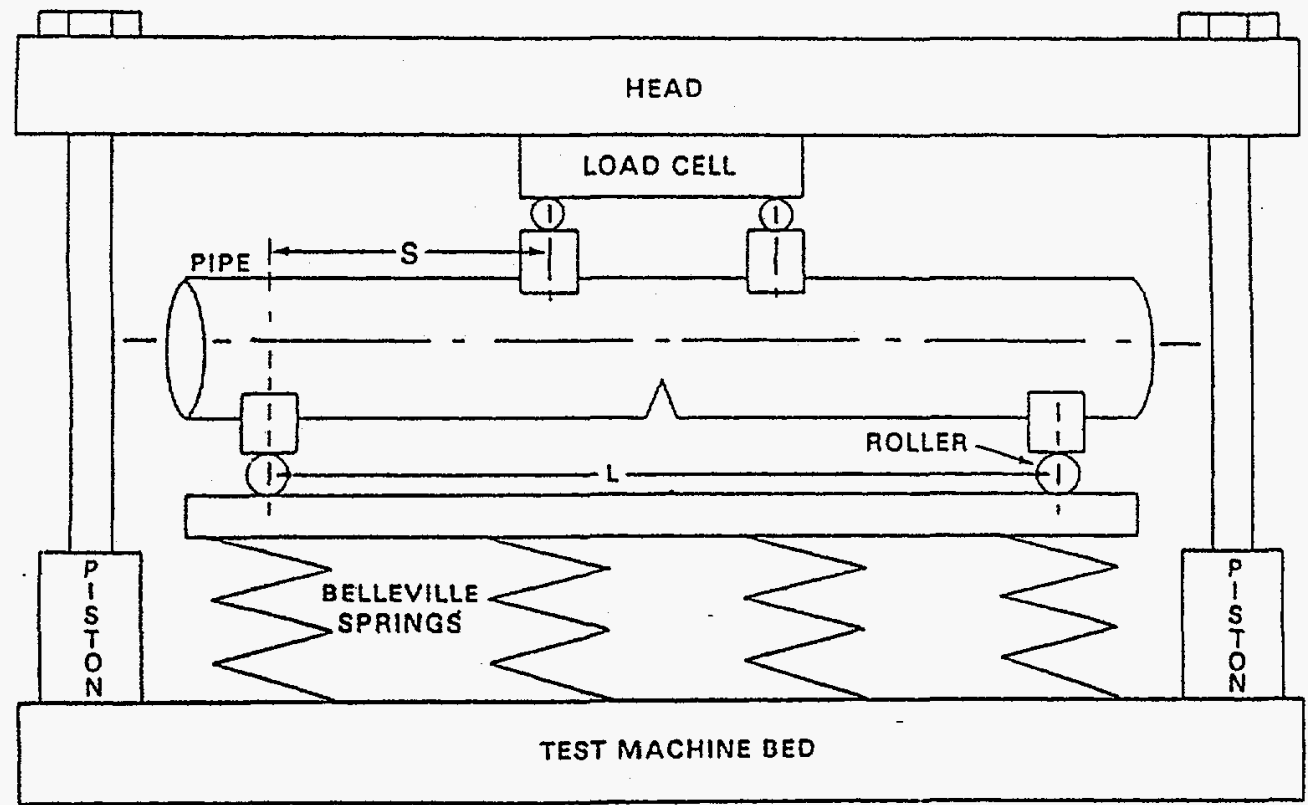

Figure 1.13 Schematic of DTRC compliant instability pipe experiments 
1.87), and unlike most past circumferentially cracked pipe programs, tests in this program were done at operating temperatures and pressures. There were numerous major efforts in this program, some of which entailed:

- Experimental and analytical assessment of ways to extrapolate J-R curves to large amounts of crack growth through use of various size $\mathrm{C}(\mathrm{T})$ specimens, see Figure 1.14 (Refs. 1.78, 1.80, and 1.82).

- Development, improvement, and validation of J-estimation schemes for circumferential through-wall-cracked pipes (Refs. 1.81 and 1.84).

- Development, improvement, and validation of J-estimation schemes for circumferential surfacecracked pipes (Ref. 1.87).

- Development, improvement, and validation of J-estimation schemes for cases of pipes with combined circumferential through-wall-cracks with circumferential surface cracks (known as compound or complex cracks) in the same plane. The results showed that there can be significant constraint of the toughness from the presence of the surface crack (Ref. 1.83).

- Validation of the stainless steel weld overlay repair method (Ref. 1.85). Figure 1.15 shows a picture of a 406-mm (16-inch) diameter pipe with a weld-overlay, where the base metal of the pipe deformed so much around the overlay that it practically made an elbow.

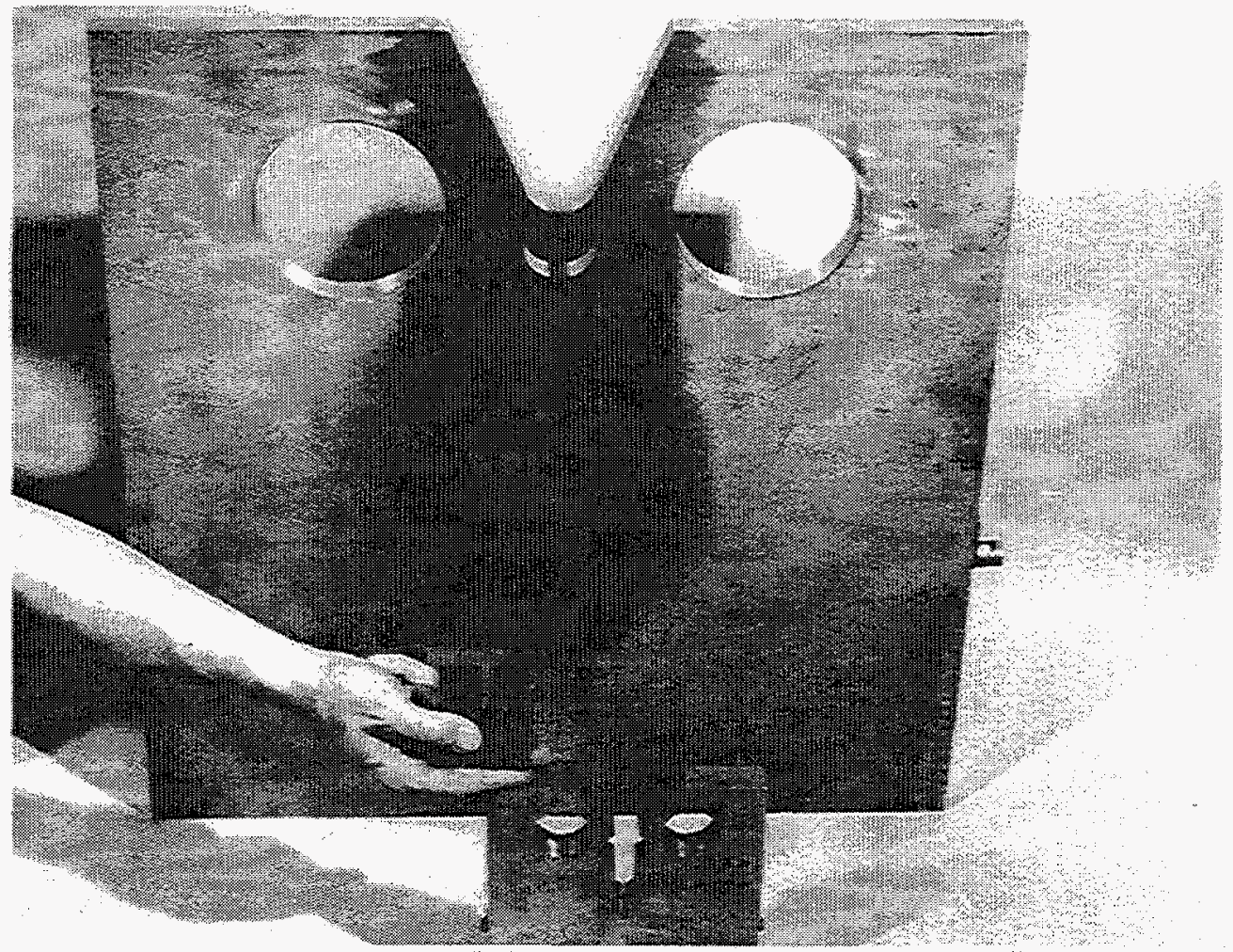

Figure 1.14 Photograph of compact (tension) specimens used in large-crack growth studies (1T, 3T, and 10T planform-sized specimens, $25.4 \mathrm{~mm}$ [1 inch] thick) 


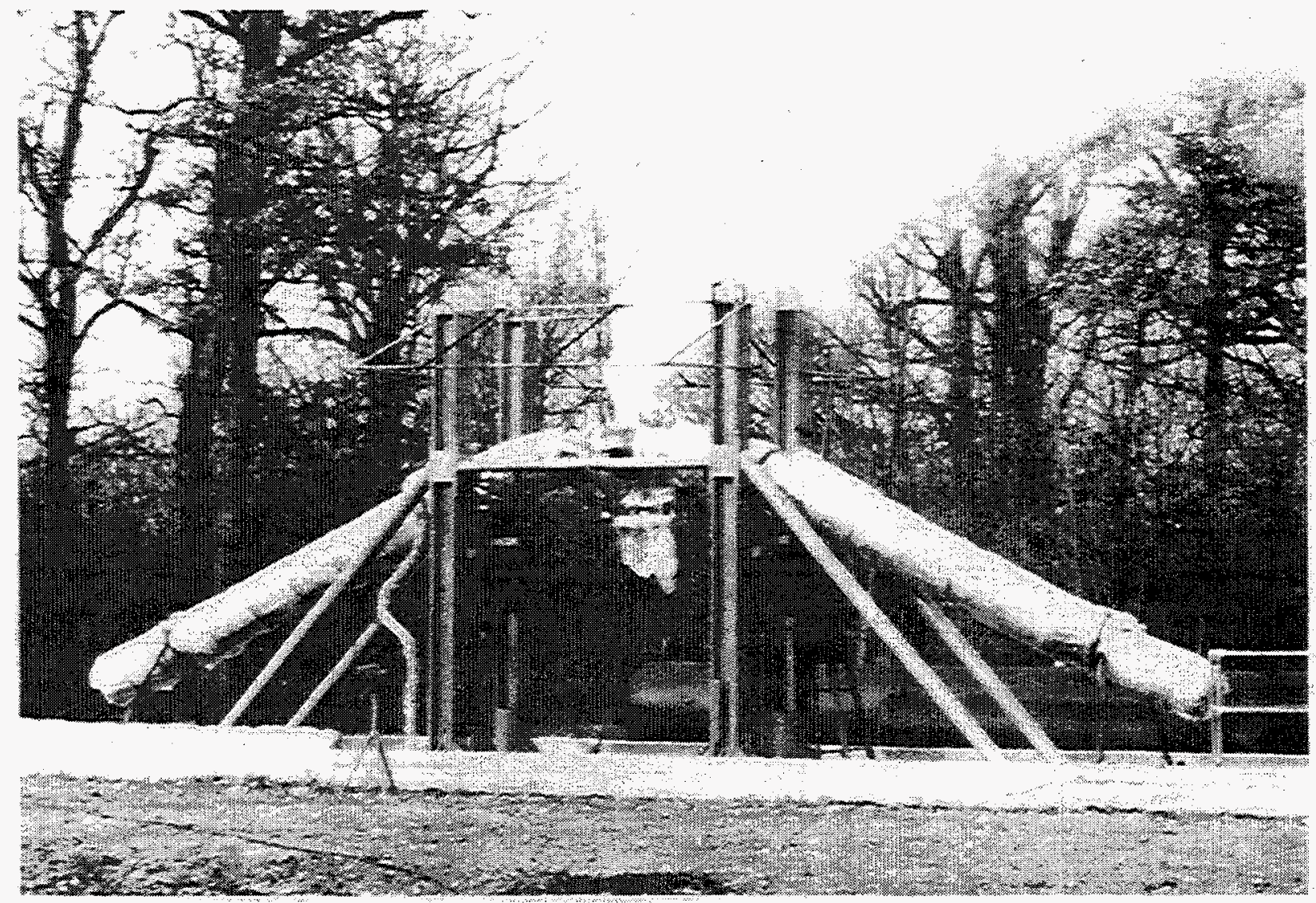

Figure 1.15 Post-test photograph of test specimen for a 16-inch (406-mm) diameter weld-overlay pipe experiment (Experiment 4142-4) showing the extreme deformation remote from weld overlay

- Development of a significant body of material property data (Ref. 1.49).

- Development of the energy balance instability criterion, and development of the initial concepts of a cracked-pipe element for time-history pipe-system fracture analyses (Ref. 1.76).

- Observations of several unusual fracture phenomenon such as: unstable crack jumps in ferritic steels at LWR temperatures (see Figure 1.16) that were believed to be due to dynamic strain aging; and helical crack growth from circumferential cracks in ferritic steel pipes (see Figure 1.17), probably due to toughness anisotropy (Refs. 1.49 and 1.81).

- Initial development of the computer code NRCPIPE that contained several different J-estimation schemes for circumferentially through-wall-cracked pipe (Ref. 1.84).

Somewhat related to the piping fracture work were various studies on jet forces, thrust loads, and pipe whip from DEGB failures. Significant efforts were conducted in Japan at JAERI (Refs. 1.88 and 1.89), as well as in Germany (Ref. 1.90). These efforts were conducted from 1983 to 1989. 
LOAD-LINE DISPLACEMENT, mm

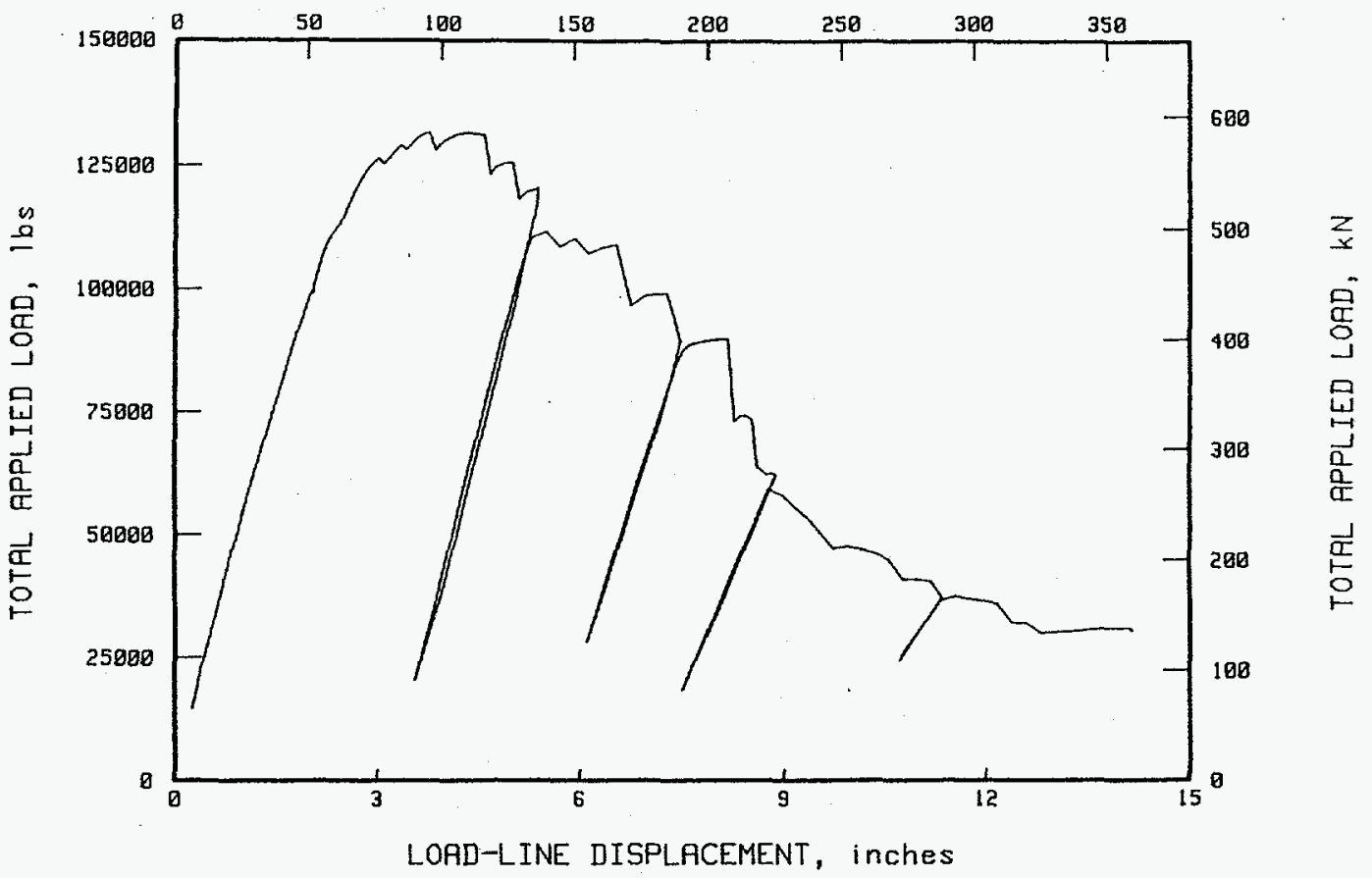

Figure 1.16 Total applied load as a function of load-line displacement for Experiment 4111-2 from the Degraded Piping Program - Phase II

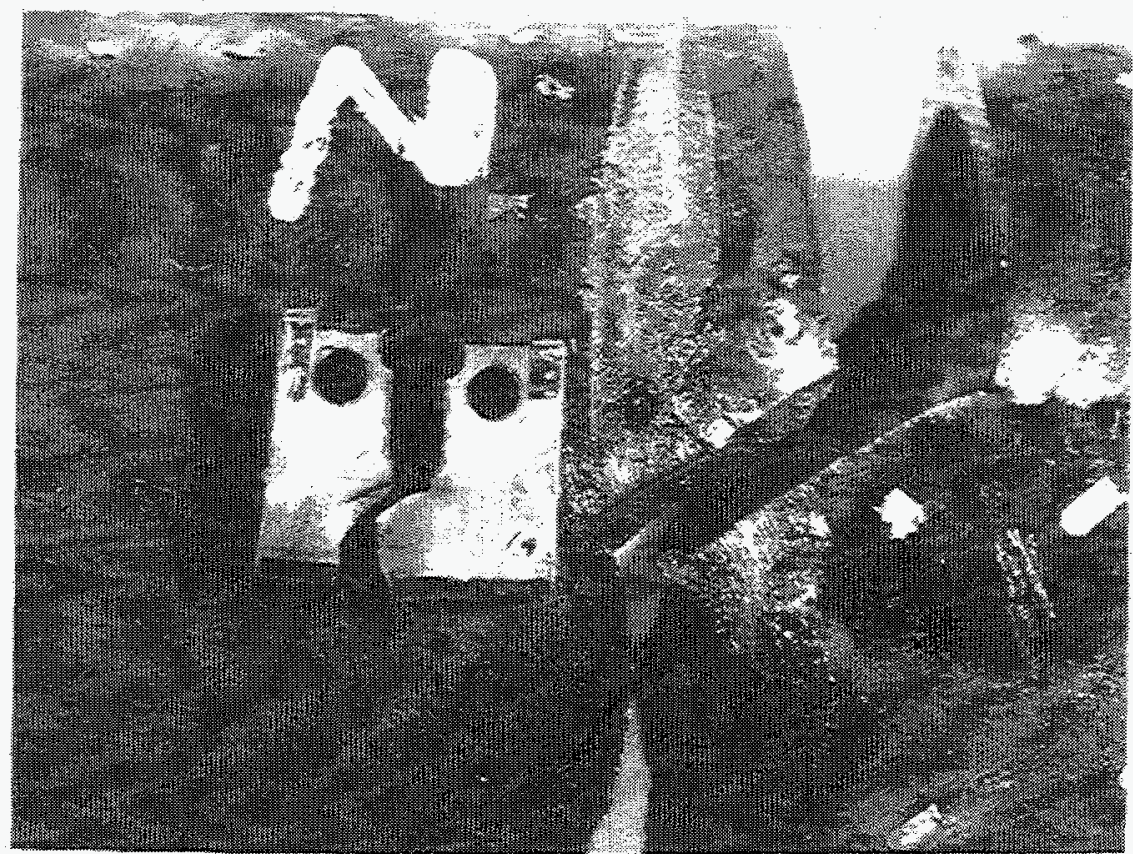

Figure 1.17 Photograph showing preferred crack growth in a seamless carbon steel pipe and a C(T) specimen from the same pipe material 
Another major piping integrity effort that was completed in 1989 was the EPRI/NRC Piping and Fitting Dynamic Reliability program. Results from this program were eventually published by EPRI in 1995 (Ref. 1.91), but there were numerous technical publications from this work in ASME PVP conference proceedings. The objective of this program was to determine whether the seismic design criteria in the ASME code could be relaxed. Inertially loaded component tests and pipe-system experiments were conducted without cracks at ambient temperature. These results were used to form the basis of the ASME Section III seismic design rules that were adopted into Article NB-3650 in the 1995 Version of the Code. However, as of this time, the U.S. NRC has objected to these rules, and so they are not allowed to be used by virtue of the fact that this version of the code has not be accepted in the U.S. Code of Federal Regulations. As of 1997, there was a special working group in the ASME Section III committee trying to resolve these differences. The NRC objections are based on numerous technical aspects, all related to the fact that they believe that the ASME design stress rules were relaxed too far without sufficient technical justification.

\subsubsection{Nuclear Industry Developments}

In the nuclear industry, the development of nuclear power probably reached its peak during the 1980's, and in a few countries, they looked at closing or did close their nuclear plants due to political pressure. As an example, in 1980, Sweden passed a referendum that called for using their 12 nuclear reactors and to not build any more, and also to shut them down when it is possible with respect to the need for electric power. After the referendum, there was a parliamentary resolution to shut down the Swedish nuclear plants in or before the year 2010. Technical safety aspects were to be considered to decide which of the reactors should be shut down first. It appears that Sweden may not shut all the plants down by this date, since there is no better alternative power supply available as yet. (About 50 percent of the Swedish electricity comes from nuclear power.)

In 1987, the Italians also passed a referendum to close all of their nuclear power plants, although there was a continuing effort to examine the use of advanced nuclear power plants for the future.

A major problem for the nuclear power industry came from the severe accidents that occurred at the Chornobyl plant in Ukraine, and at the U.S. Three Mile Island (TMI) Plant in the United States. The Chornobyl graphite moderated RBMK-type reactor caused considerable radioactive fallout in Europe and Asia. This failure occurred on April 26, 1986, at 1:23:04 a.m. The TMI accident occurred on March 28, 1979 , at 4 a.m., but the radioactivity release from the U.S. PWR plant failure was captured in the containment building. These accidents severely eroded public confidence in the safety of nuclear power, and showed the need for world-wide consensus on safety issues.

In 1986, a new type of failure mechanism in nuclear piping was discovered: erosion-corrosion (or flow accelerated corrosion) wall thinning. The failure at the U.S. Surry-2 plant in a carbon steel piping elbow killed several plant workers from the release of high-temperature steam. No radioactivity was released. Erosion-corrosion failures started to become more prevalent, and as a result, they have become the most significant challenge to the integrity of low- to moderate-energy carbon steel piping systems. 


\subsubsection{Regulatory, Codes, and Standards Developments}

In the standards and regulatory arena, there were several developments in the 1980's. In the U.S., IGSCC was starting to occur in large diameter BWR piping. This brought about formation of the 2nd NRC Pipe Crack Study Group. As a result of the work of this group, a series of NRC reports called NUREG 1061 was issued. Volume 1 dealt with the BWR IGSCC issue (Ref. 1.92). Volume 2 considered seismic design criteria (Ref. 1.93). Volume 3 (Ref. 1.94) formed the technical basis for the current (draft) NRC Standard Review Plan 3.6.3 leak-before-break (LBB) criteria (Ref. 1.95).

The LBB criteria is relative simple in concept. It effectively says if a review of plant piping operating conditions, and past histories of similar piping systems shows no history of cracking, and the stresses are low (e.g., water-hammer susceptible systems are excluded), LBB can be applied. However, the applicant still has to conduct a relatively simple LBB analysis to analytically show that LBB is viable.

In 1985, ASME passed the stainless steel Class 1 pipe flaw evaluation criteria. This covered axial and circumferential flaws. After initial objections by the U.S. NRC, EPFM analysis procedures were included to consider the low toughness of stainless steel flux (SAW and SMAW) welds. This standard is embodied in Section XI Article IWB-3640 and in Appendix C.

In 1988, ASME passed the ferritic pipe flaw evaluation criteria. These criteria also covered axial and circumferential flaws for Class 1 piping systems. This standard is embodied in Section XI Article IWB3650 and in Appendix $\mathrm{H}$.

In the 1980's there were four international LBB conferences. The first was in Monterey, California in 1984 (Ref. 1.96), and centered on the probabilistic work done for the NRC Generic Issue A-2 and the PRAISE Code (Ref. 1.97). The second conference was in Columbus, Ohio in 1985 (Ref. 1.98). This meeting marked the start of the NRC's International Piping Integrity Research Group (IPIRG) program. The third LBB conference was in 1987 in Tokyo, Japan, and was also held in conjunction with the IPIRG program (Ref. 1.99). The fourth LBB conference was in Toronto, Canada, and was related to CANDU reactors (Ref. 1.100).

\subsubsection{Recent Developments and Milestones - 1990 to 1996}

The 1990 's marked an age in piping fracture mechanics, where the basic fracture mechanics analyses were becoming mature. Efforts were started to examine the real fracture behavior of a pipe system subjected to simulated seismic loading conditions, rather than using analyses that had simplifying limitations. Although there were a few dynamic pipe fracture experiments in the 1980 's, either the results were not fully appreciated due to a lack of analytical tools, or the loading conditions were atypical of what a pipe system might see under seismic loading conditions. To design simulated-seismic pipe fracture experiments in a rational fashion, it was necessary to couple the piping fracture mechanics with the dynamic pipe stress analysis. The effect of secondary versus primary stresses was also an aspect where there was not much agreement in codes and standards, yet there were no pipe-system tests prior to that time to make a rational evaluation of the various approaches. The evolution of the dynamic pipe fracture analysis methodology represented a quantum leap over the typical pipe fracture analysis method at that time. The typical methodology in the early to middle 1990's used the elastic uncracked pipe peak dynamic stresses, where the peak stress (or moment) was used as a constant load-controlled stress in an elastic-plastic fracture 
mechanics or fully plastic limit-load solution. Hence, using the elastically calculated stresses added an unknown degree of conservatism to a fracture assessment. The typical analysis also used quasi-static material properties, whereas, seismic loading is dynamic and might involve interrupted ductile tearing.

Merging the piping fracture mechanics with the pipe-system stress analysis in the 1990's also showed other errors in predicting crack opening for leak rates, that were conceptually understood, but not demonstrated or quantified previously. The NRC International Piping Integrity Research Group program marked the start of this age of understanding of the significance of coupling the pipe fracture mechanics analysis to the pipe-system dynamic stress analysis.

During this time period, there were many changes in the nuclear industry. Additional erosion/corrosion failures were occurring. IGSCCs occurred in large diameter TP347 stainless steel piping in German BWRs, where this titanium stabilized stainless steel was previously thought to be immune to IGSCC. The ASME Section XI inspection criteria were refined, and plants required to reinspect every 10 years found that there were initial fabrication defects that now had to be addressed, particularly for Class 2 and 3 piping systems. Plant life extension evaluations were in progress, and aspects of fatigue life, and thermal aging of cast stainless steel became more important. Several U.S. plants were closed either due to reactor pressure vessel embrittlement problems or steam generator problems. Privatization and deregulation of the industry forced financial constraints on the industry resulting in a greater burden on the plant engineering staff to improve operating efficiencies required to meet financial goals. Yet, in an age where the U.S. nuclear industry seemed to be in a decline, many Pacific rim countries started new large-scale nuclear power plant construction projects or developed advanced reactors. In Europe, there was also work going on in the development of the next generation European pressurized water reactor (EPR). And in the U.S., advanced reactor designs were pursued by several companies. There was also concern over the Russian reactors since the end of the cold war and the Chornobyl accident. Ensuring LBB for Russian plants without adequate emergency core cooling continued to be a high-priority item, since the nuclear plants in the former Soviet Union countries are essential to their economies. Hence, there was a need to create appropriate computer codes and databases for older plants, as well as for design of advanced plants for the future.

Table 1.3 summarizes the key milestones from 1990 to 1997 when the IPIRG-2 program ended. Details of some of these aspects are discussed in the following sections.

\subsubsection{Research Developments in Piping Fracture Mechanies and Related Technologies from 1990 to 1997 - A Quantum Leap in Analysis Methodology}

\section{The IPIRG-1 Program}

One of the major piping fracture mechanics programs conducted from 1986 to 1991 was the NRC's International Piping Integrity Research Group (IPIRG) Program (Ref. 1.101). This was the first of two such programs, and was later referred to as the IPIRG-1 Program. This was a new concept in conducting piping fracture research, where there was an international consortium sharing the cost of large pipe fracture experiments, and development of a common technical consensus. There were nine countries involved in the IPIRG-1 program, including the NRC and EPRI from the U.S. 
Table 1.3 Milestones in pipe fracture technology and the nuclear industry - 1990 to 1997 (end of the IPIRG-2 program)

\begin{tabular}{|c|c|c|}
\hline Pipe Fracture Technology Milestones & Year & Nuclear Industry Milestones \\
\hline $\begin{array}{l}\text { DOE/Battelle NPR seismic analysis } \\
\text { to assess instantaneous DEGB } \\
\text { NUPEC/Japan carbon steel pipe } \\
\text { program }\end{array}$ & 1990 & $\begin{array}{l}\text { 5th CSNI LBB - Taipei } \\
\text { Erosion-corrosion DEGB in Finnish plant } \\
\text { Nuclear Electric (NE) splits from CEGB } \\
\text { ASME Code Case N494 - FAD approach } \\
\text { for ferritic pipe }\end{array}$ \\
\hline IPIRG-1 program ends & 1991 & \\
\hline NRC/HDR E31 test analyses & 1994 & IGSCC in German TP347 BWR pipes \\
\hline $\begin{array}{l}\text { NRC/Battelle Short Cracks in } \\
\text { Piping and Piping Welds program } \\
\text { ends }\end{array}$ & 1995 & $\begin{array}{l}\text { New ASME Section III seismic design } \\
\text { rules published } \\
\text { NE splits into Nuclear Electric Ltd (AGR } \\
\text { and PWR) and Magnox Electric plc } \\
\text { LBB'95 Conference - Lyon, France } \\
\end{array}$ \\
\hline IPIRG-2 program ends & 1997 & $\begin{array}{l}\text { Changes to ASME Section XI pipe } \\
\text { flaw evaluation criteria }\end{array}$ \\
\hline
\end{tabular}

The technical content of the IPIRG-1 Program was derived by reviewing results from the Degraded Piping Program and other pipe fracture programs conducted throughout the world. From these reviews, it was clear that a missing aspect of those programs was pipe fracture data at seismic rates and for representative piping systems. Since pipe size is a critical factor in determining whether a pipe will fail at limit-load stresses or at lower stresses due to elastic-plastic fracture, experiments needed to be conducted with relatively large diameter pipe. Conducting large diameter pipe fracture experiments is an expensive undertaking, especially when it involves a representative pipe system. The objective of conducting high temperature, dynamic pipe-system experiments was to look for unusual dynamic effects not accounted for in quasi-static studies. Effects such as increases or decreases in failure loads under dynamic loads, inadequacy of quasi-static pipe fracture and material characterization databases, and load-history effects that might cause changes in apparent fracture resistance were items to be considered. To address these concerns, the first IPIRG program was undertaken. This program was more experimental in nature, and built on the fracture mechanics analysis results from the Degraded Piping Program - Phase II.

There were three main experimental efforts undertaken in the IPIRG-1 program. The simplest involved through-wall-cracked pipe tests conducted under four-point bending, see Figure 1.18 (Ref. 1.102). Tests were done on 152-mm (6-inch) diameter TP304 stainless steel and A106 Grade B carbon steel pipes at $288 \mathrm{C}(550 \mathrm{~F})$. The following load histories were used:

- Quasi-static monotonic displacement-controlled loading (typically used in past programs),

- Dynamic monotonic loading, where the loading rate corresponded to the loading rate of a seismic event, 


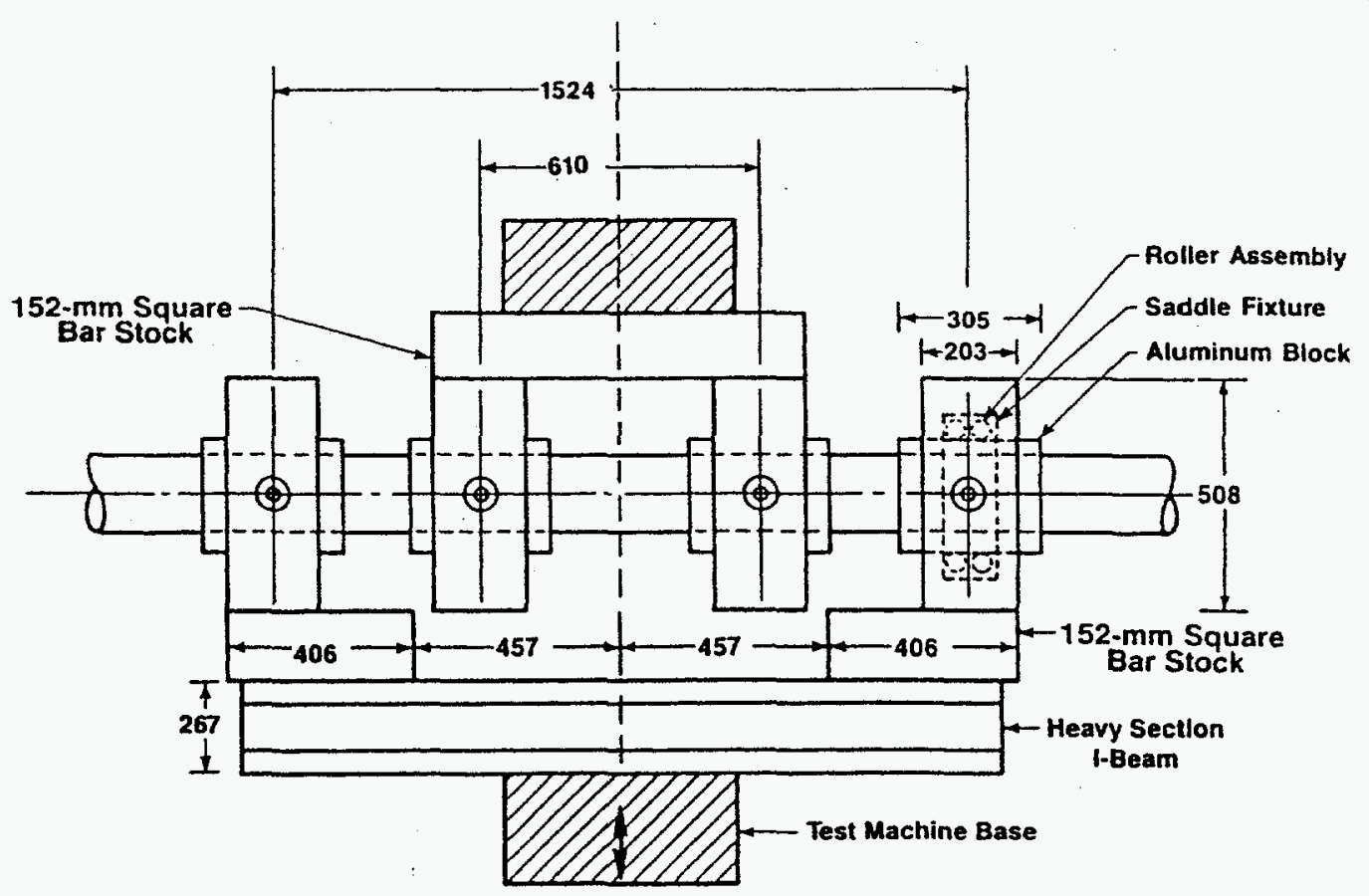

Note: All 4 saddle fixtures are identical to the detail. All dimensions in millimeters.

Figure 1.18 Schematic of test apparatus used for reversed four-bending in IPIRG-1 Subtask 1.2

- Quasi-static cyclic loading, where the cyclic loading either went to zero load $(R=0)$ or was fully reversed $(R=-1)$, and a cyclic displacement corresponding to having ten cycles to crack initiation, see Figure 1.19, and

- Dynamic cyclic loading using the same cyclic load history as in the quasi-static cyclic tests, and the dynamic rate of the dynamic monotonic tests to see if there were any load-history interaction effects.

These results showed that reversed cyclic loading during ductile tearing had a large effect on the apparent toughness of the material. The dynamic load effects were negligible for the TP304 steel, but tended to reduce the toughness and load-capacity of the A106 B pipe material. Since these were relatively small diameter pipe tests, the effect of toughness degradation on the maximum loads was relatively small, but there was a large effect on the displacement or rotation of the pipe, see Figure 1.20.

The next slightly more complicated effort involved inertially loaded pipe tests as shown in Figure 1.21 (Ref. 1.103). The same 152-mm (6-inch) diameter TP304 and A106 B pipes used in the four-point bending experiments were used with either through-wall or surface cracks. The tests were conducted with internal pressure, an initial dead-weight load, and inertial loads. Hence, there were load-controlled stresses and inertial stresses. In this case, once the pipe reached the maximum load, it only took two to four cycles 


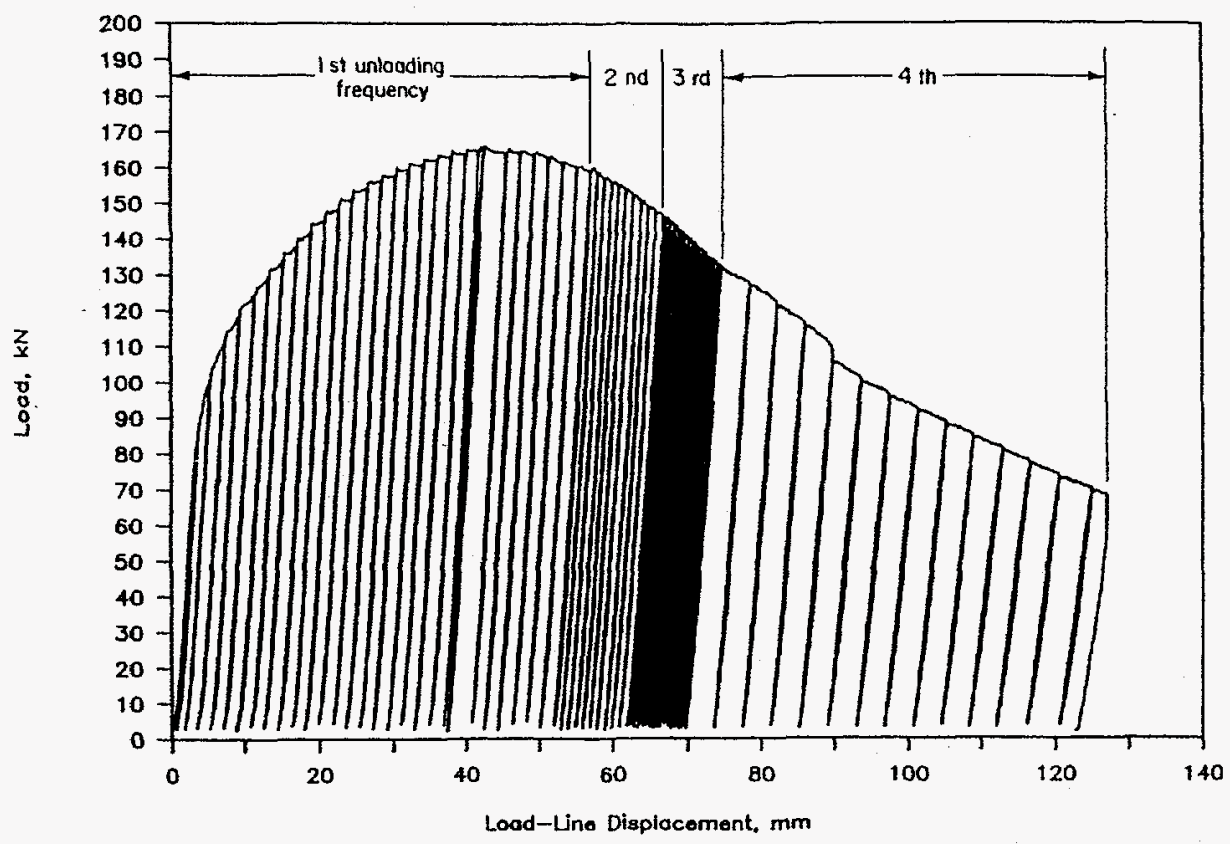

Figure 1.19 Measured load versus load-line displacement for quasi-static reversed $(R=0)$ loading (Experiment 1.2-3 from the IPIRG-1 program)

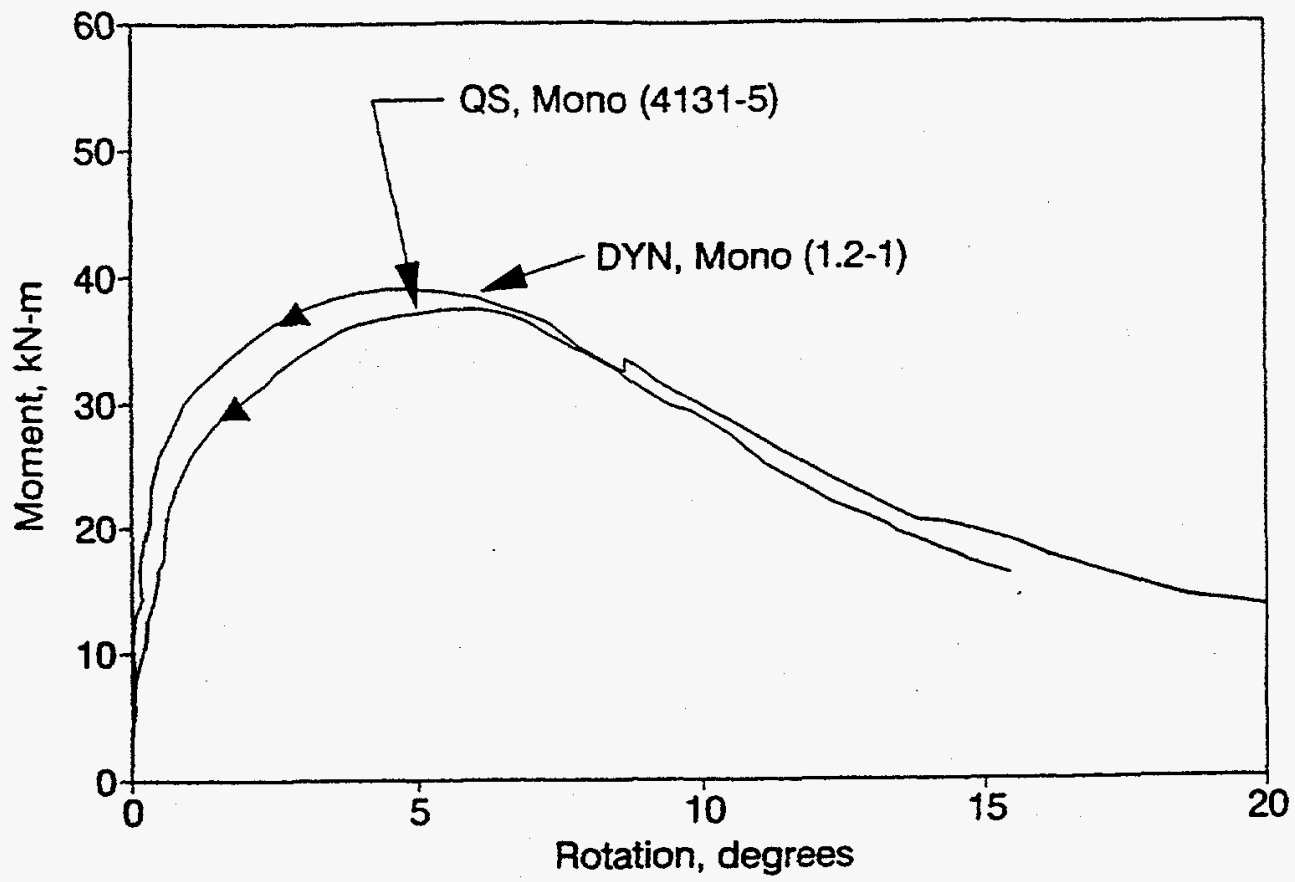

(a) TP304

Figure 1.20 Effect of dynamic loading on moment-rotation behavior of 6-inch-diameter throughwall-cracked pipe experiments from IPIRG-1 


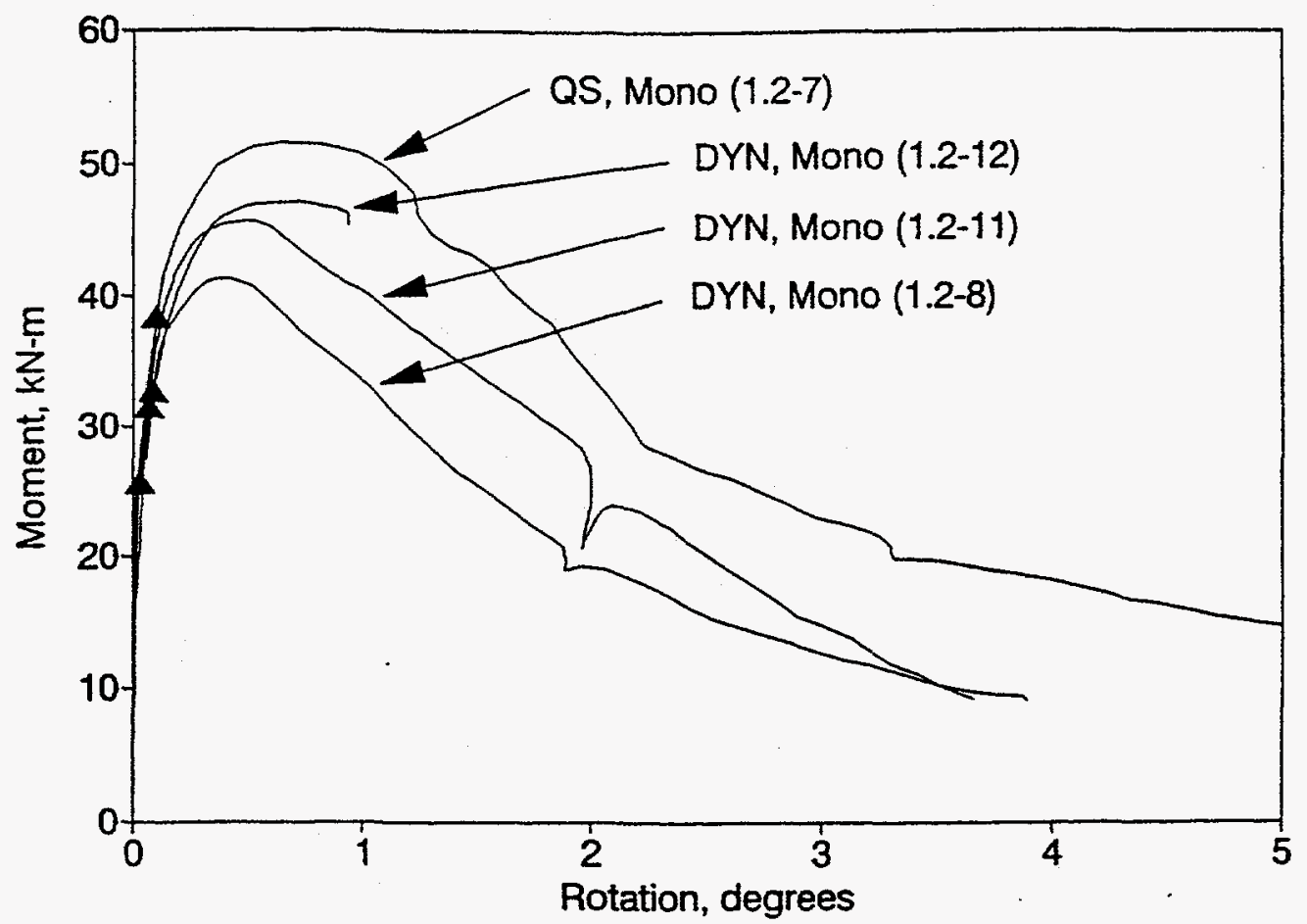

(b) A106B

Figure 1.20 (Continued)

WEST

EAST

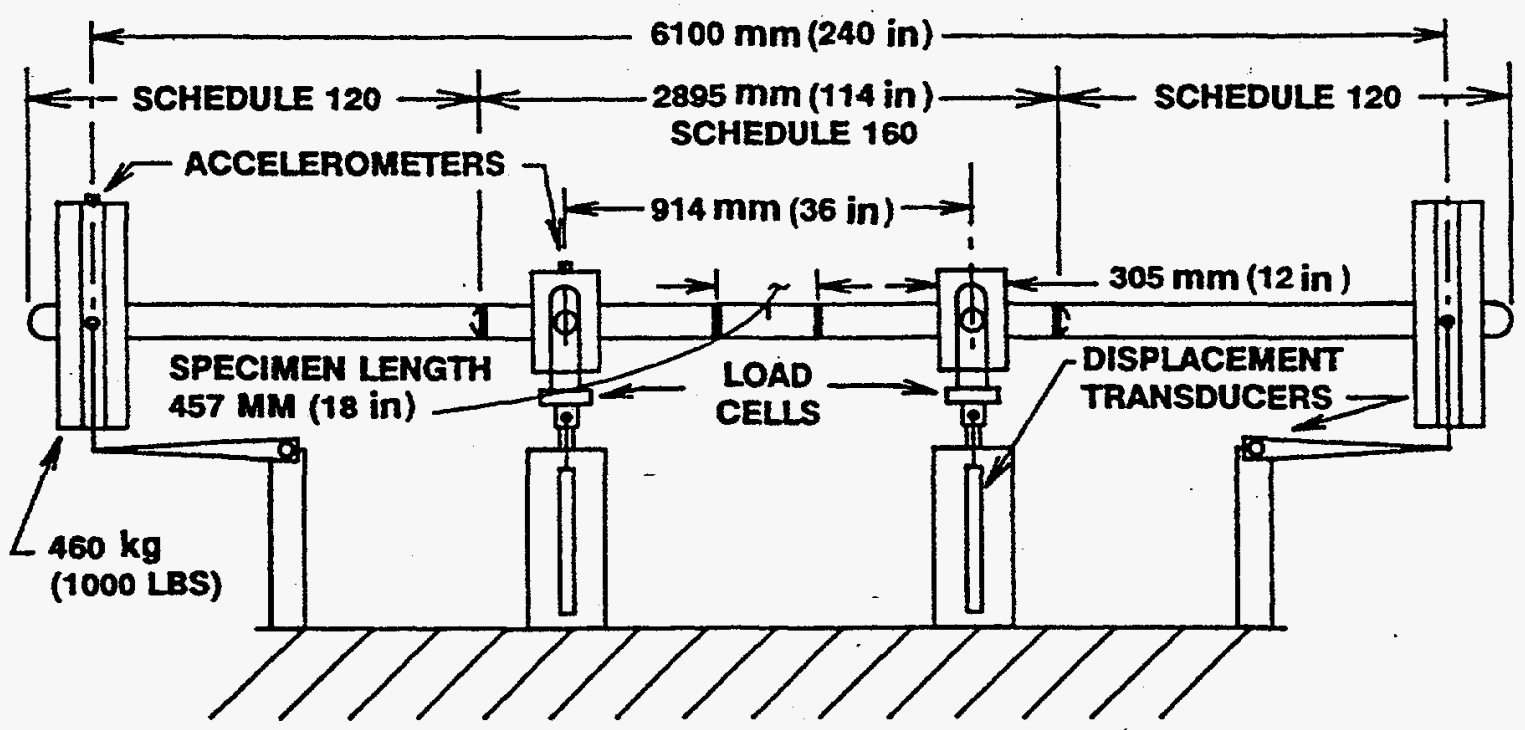

Figure 1.21 Sketch of test frame used in IPIRG-1 inertial experiments 
to get a DEGB. Dynamic analyses of these experiments was conducted using the ANSYS code with a new cracked-pipe element (Ref. 1.104), that was initially proposed in the Degraded Piping Program - Phase II (Ref. 1.73).

This element performed very well, and gave the confidence needed to design the more complicated pipesystem experiments.

The major feature of the IPIRG-1 program was pipe-system fracture experiments conducted at PWR conditions with a relatively large diameter pipe so that failure loads that may be sensitive to elastic-plastic fracture toughness would be possible, rather than simple limit-load failures (Ref. 1.105). Figure 1.22 shows a schematic of the IPIRG-1 pipe loop. This was a 406-mm (16-inch) diameter Schedule 100 pipe loop with a length of about 30 meters ( 100 feet) of pipe and five long-radius elbows. Specially designed spherical bearings and hydrostatic bearings were used to obtain precise boundary conditions for the stress analysis. The stresses generated in these experiments were: pressure, thermal expansion, inertial and seismic anchor motion. The dynamic loading was at a single frequency just below the first natural frequency of the pipe loop so that both inertial and seismic anchor motion stresses were developed. Hence, there was a mix of primary and secondary stresses that did not exist for validating piping fracture criteria in use at that time. (Note: in the IPIRG pipe-system experiments, there were no torsional stresses, the deadweight load stresses were negligible, and the bending was in one plane.)

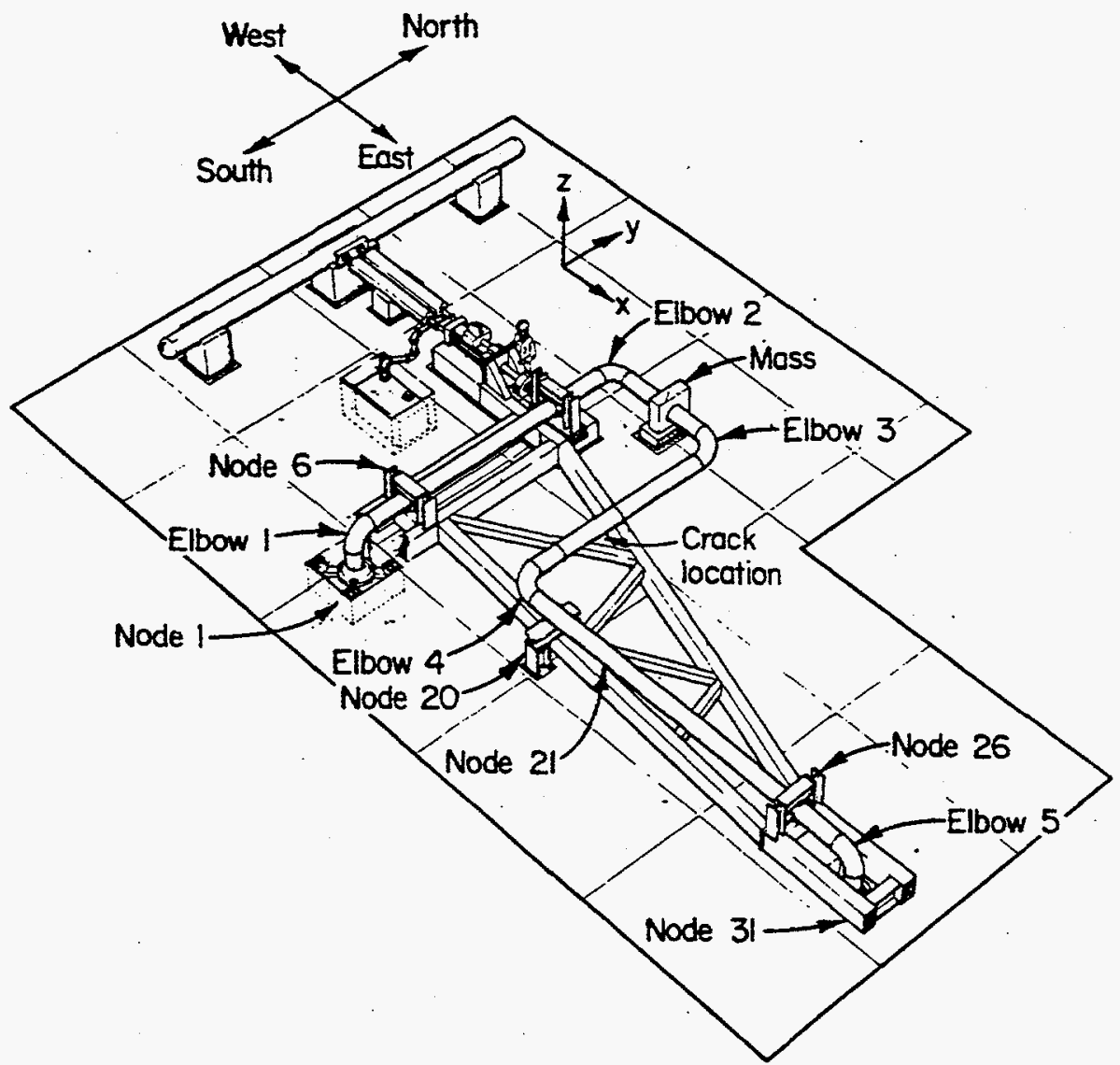

Figure 1.22 Artist's conception of the IPIRG pipe loop test facility 
Tests were done on pipes under quasi-static loading in the Degraded Piping Program, and these same pipes were used with similar flaw sizes in the IPIRG-1 program. Hence, there was a direct quasi-static versus dynamic pipe-system comparison for each material tested. The materials tested were:

- A106 B base metal,

- A106 B with the crack in a SAW,

- TP304 stainless steel base metal,

- TP304 stainless steel with the crack in the center of a SAW, and

- an artificially thermally-aged French cast stainless steel base metal.

Some of the key aspects from these tests were:

(1) The secondary stresses (thermal expansion and seismic anchor motion stresses) contributed just as much to fracture as the primary stresses (pressure and inertial).

(2) The stresses at maximum load were about the same or higher in the pipe-system experiments than in the quasi-static tests for the cases of cracks in the welds.

(3) The stresses at maximum load were significantly lower in the pipe-system experiment than in the quasi-static test for the A106B base metal (probably due to dynamic-strain-aging effects on the toughness), and slightly lower for the stainless steel base metal case.

\section{Japanese Carbon Steel Piping Program}

In 1990, the Japanese completed a program on carbon steel pipe fracture at NUPEC (Ref. 1.106). These tests were quasi-statically loaded pipe tests on $152-\mathrm{mm}$ (6-inch) and 406-mm (16-inch) diameter pipe. Related to this effort, two $762-\mathrm{mm}$ ( 30 -inch) diameter Schedule 80 pipe experiments were conducted on Japanese carbon steel pipe under pressure and bending at $300 \mathrm{C} \mathrm{(572} \mathrm{F)} \mathrm{at} \mathrm{Battelle} \mathrm{as} \mathrm{part} \mathrm{of} \mathrm{the} \mathrm{IPIRG-1}$ program. The pipes tested generally had sufficient toughness to fail at limit-load conditions.

Additional carbon steel pipe tests (Ref. 1.107) were conducted in Japan in the mid 1990's to evaluate whether Japanese carbon steel piping was susceptible to the cyclic degradation observed in the IPIRG-1 program (Ref. 1.102).

\section{U.S. DOE/Battelle Dynamic Pipe Fracture Analysis Efforts}

The cracked-pipe element for dynamic piping fracture analysis, that was initially developed during the IPIRG-1 program, was improved and implemented in several other studies. One of the studies involved an assessment of the fracture behavior of a proposed U.S. DOE nuclear plant (Ref. 1.108). In this case, the assumption of a DEGB caused concern of overheating the cladding of the fuel and possibly melting it. Analyses were performed to assess if the rate of opening of a crack in the primary coolant piping was slow enough to eliminate this transient cooling problem.

To accomplish this, the main coolant piping system of the plant was analyzed using the IPIRG "crackedpipe" element under seismic loading as well as using the typical uncracked pipe elastic analyses. The nonlinear cracked pipe results showed that even when the postulated through-wall crack was increased to 40-percent of the pipe circumference and there was a 360-degree, 75-percent deep surface crack in the 
same plane, the crack could survive a 3SSE loading. From this study there were two important general conclusions:

(1) When conducting the uncracked pipe elastic stress analysis with the same 3SSE loading, the calculated moments were 5 times higher than the moments from the nonlinear "cracked-pipe" element analysis, see Figure 1.23. Hence, for this case, there was a factor of 5 margin between coupling the fracture analysis in the pipe-system dynamic analysis, versus using the traditional elastic stress analysis and decoupled fracture analysis.

(2) Secondly, it was found that the negative loads were much greater when the cracked-pipe element was used. This element allowed the crack faces to close and the pipe to act as uncracked pipe when the crack went into compression. Apparently, when the crack faces came together dynamically, they generated a large compressive load spike, see Figure 1.23. This is important from the viewpoint of understanding cyclic effects on pipe fracture. The earlier IPIRG-1 results showed that fully reversed loading on the crack during ductile tearing reduces the apparent toughness. If the presence of the crack makes the compressive loads much larger, then at least for the through-wall crack case, it may be necessary to assume the fully reversed conditions, rather than calculating the stress ratio from uncracked pipe, i.e., $\mathrm{R}=(\mathrm{N}-\mathrm{SSE} /(\mathrm{N}+\mathrm{SSE})$ in the uncracked pipe case.

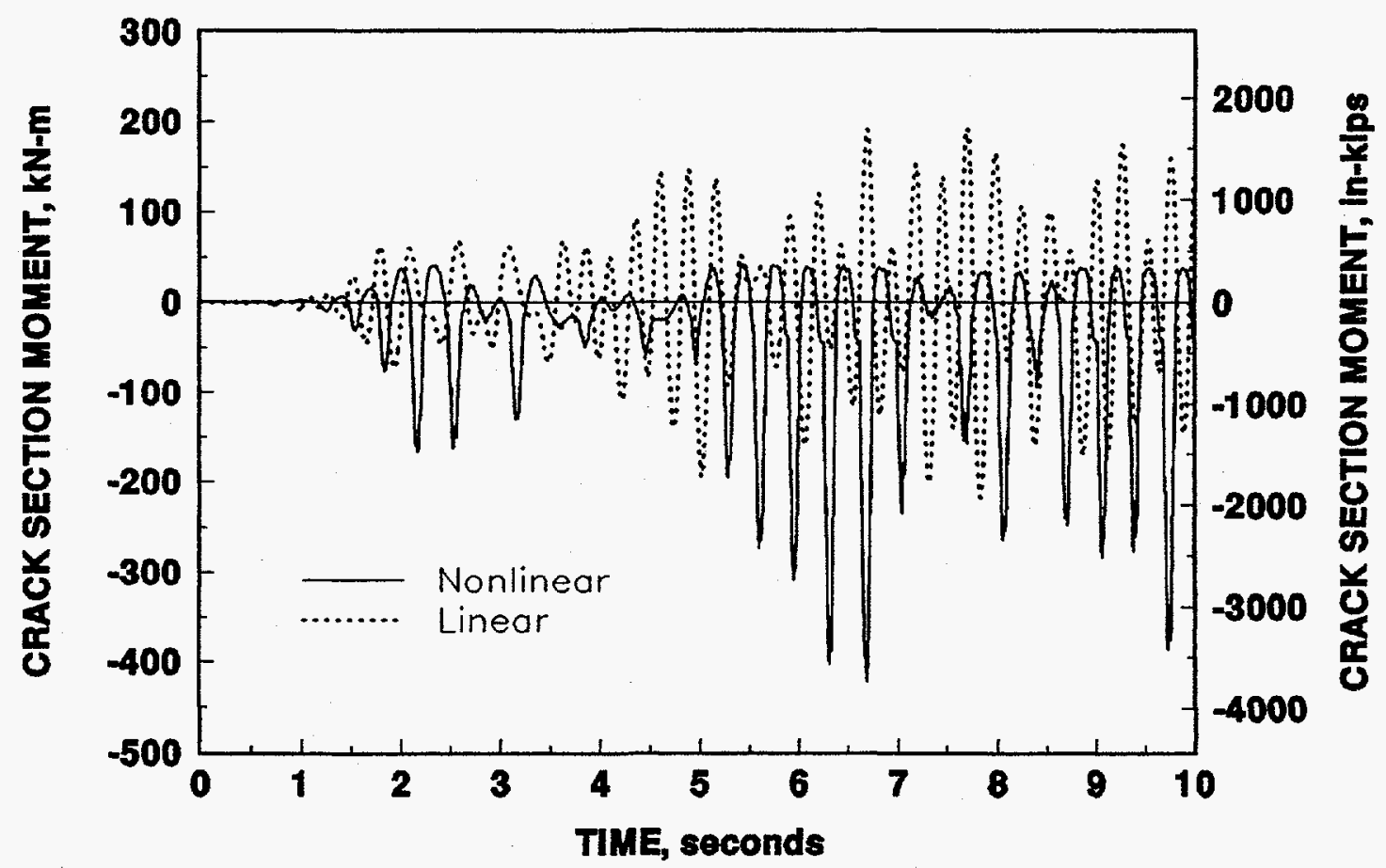

Figure 1.23 Comparison of linear and nonlinear analyses of a complex crack under 3SSE seismic loading 


\section{NRC/HDR/Battelle Dynamic Pipe Analyses}

A second program that implemented the IPIRG-1 cracked-pipe element methodology was conducted for the U.S. NRC at Battelle with Argonne National Laboratory to analyze two dynamic cracked pipe experiments conducted in Germany at the HDR facility (Ref. 1.109). In this program, the NRC wanted Battelle to conduct a blind analysis of these experiments to see how well this new methodology worked. Argonne acted as the intermediary between Battelle and HDR in comparing the blind analyses and the experimental results. Analyses of these experiments were also conducted by MPA-Stuttgart in Germany, Siemens in Germany, and Paul Scherrer Institut in Switzerland (Ref. 1.110 and 1.111).

Additionally, there were a number of improvements made to the Battelle cracked-pipe element, with documentation of how that element was created out of a combination of elements in the existing ANSYS library of elements. It should be noted that central to this methodology is the prediction of the crackedpipe moment-rotation relation. To incorporate this methodology, the nonlinear cracked-pipe element is calibrated using a J-estimation method that predicts the moment versus rotation due to the crack. Typically this is done using the NRCPIPES and NRCPIPE computer codes (Refs. 1.87 and 1.84).

In these efforts, the following was accomplished:

(1) The "cracked-pipe" element was extended to include the transition from a surface crack to a through-wall crack, and in the simplified conditions of load-controlled or displacementcontrolled loading, it gives the same results as a $\mathrm{J} / \mathrm{T}$ instability analysis.

(2) The "cracked-pipe" element method could be used to make stability analyses for combined loadcontrolled and displacement-controlled stresses.

(3) The surface-crack to through-wall crack transition could be predicted.

(4) The method predicts not only the start of an instability, but the amount of crack growth during an instability, i.e., there may not be a DEGB from an instability.

(5) Under quasi-static loading conditions, the "cracked-pipe" element results gave the same results as the Energy Balance Instability criterion from the Degraded Piping Program (Ref. 1.75). This agreement occurred even for the case of the circumferential surface crack to through-wall crack transition and when there were limited instabilities.

(6) Time-dependant calculations of crack velocities and crack openings could be made. Interrupted crack growth (periodic arrests and reinitiations) under seismic/inertial loading could also be predicted. These may be useful in developing alternate criteria to the "instantaneous" DEGB design criterion.

In the HDR program, there were two experiments conducted on approximately 475-mm (18.7-inch) diameter pipe, where a blowdown or water hammer-type load was introduced, see Figure 1.24. In this 


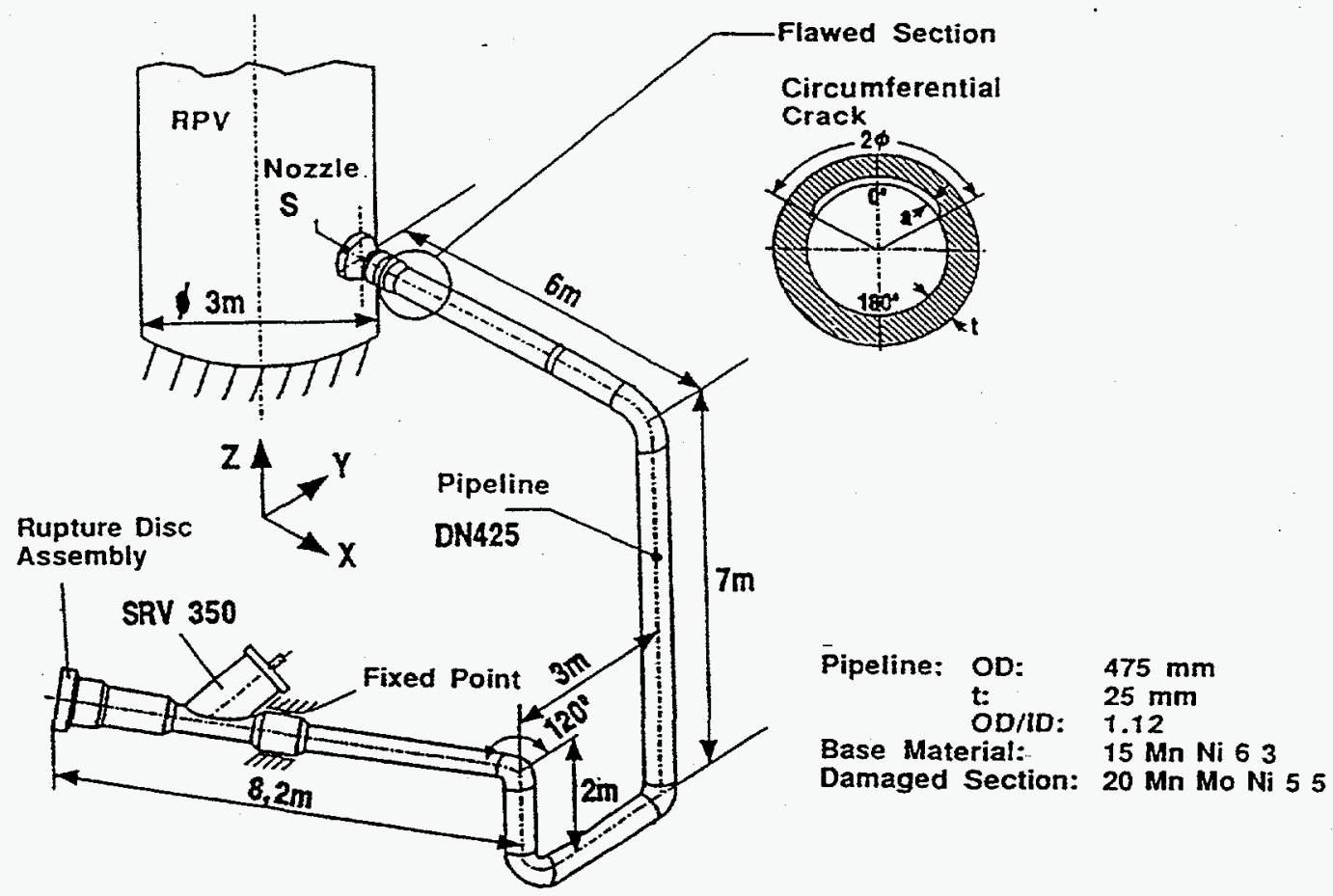

Figure 1.24 HDR-E31 test system with flawed section

case, a rupture disk was triggered, and then a fast-closing valve near the rupture disk closed shortly after the rupture disk failed. This dynamic depressurization event induced water hammer-type loads. The analysis by Battelle was very slightly conservative in predicting the failures, i.e., in one of the experiments, the crack just started to tear when there was dynamic unloading, whereas the Battelle cracked-pipe element dynamic analysis predicted the complete failure of the surface crack ligament but little growth around the circumference from the ends of the surface crack. Hence, this methodology was validated for the case of non-reversing dynamic loads.

\section{Short Cracks in Piping and Piping Welds Program}

The Short Cracks in Piping and Piping Welds Program was a follow-on program to the NRC's Degraded Piping Program. The Short Cracks Program was conducted at Battelle from 1990 to 1995 (Refs. 1.112 to 1.118). Like the Degraded Piping Program, it concentrated on making analytical improvements and experimental evaluations under quasi-static loading conditions. Some of the key results from that program were:

(1) Improvements were made to circumferential through-wall cracked (TWC) (Ref. 1.119) and surfacecracked pipe (SC) (Ref. 1.120) J-estimation schemes. Using new data from this program and prior programs, the statistical validation of which analyses were most accurate for short as well as long TWCs and SCs was made. Several computer codes were developed to allow use of these analysis procedures for circumferential through-wall cracked pipe (NRCPIPE code) and for surface-cracked pipe (NRCPIPES code). 
(2) A screening criterion was developed to determine when carbon piping steels are susceptible to dynamic strain aging (Ref. 1.121). Dynamic strain aging can cause a loss in toughness under dynamic loading, or unstable ductile crack jumps under quasi-static loading at LWR temperatures.

(3) Development of an analysis method to predict the angled crack growth behavior in carbon steels due to toughness anisotropy, as well as a simple method to account for combined bending and torsion stresses on the $\mathrm{J}$ and COD values for circumferential TWC (Ref. 1.122).

(4) Numerous refinements and improvements were made to COD analyses used in LBB analyses, i.e., effect of pipe-system boundary conditions on COD, weld residual stresses, cracks at nozzles, improved COD-dependant crack morphology relationships for leak-rate analyses, etc. (Refs. 1.123, 1.124).

(5) Determination that the J-R curve for stainless steel fusion lines was flat after a small amount of crack growth, which explains why cracks in the center of the austenitic welds typically turn to the fusion line (Ref. 1.125).

(6) Demonstration that the fusion line of bimetallic welds between Inconel 182 weld metal and carbon steel piping has a toughness comparable to or slightly higher than the carbon steel base metal. This was validated by a cold-leg pipe test (Ref. 1.126).

(7) A number of databases were developed or expanded. The PIFRAC database (Ref. 1.57) was expanded to contain material property on over 800 tensile specimens and over 800 fracture toughness specimens, as well as chemical analyses and Charpy data. Pipe fracture databases for circumferentially cracked straight pipe (CIRCUMCK) and axially cracked pipe (AXIALCK) were also created. CIRCUMCK has data on over 800 circumferentially-cracked pipe fracture experiments conducted throughout the world. AXIALCK contains results from over 300 axially-cracked pipe tests conducted at Battelle and MPA-Stuttgart.

\section{IPIRG-2 Program}

The Second International Piping Integrity Research Group Program started in April 1992 (Ref. 1.127), and was sponsored by the U.S. NRC and EPRI in the U. S., and members from 15 other countries. Emphasis was on developing experimental data on cracked nuclear piping under simulated-seismic time history loading (Ref. 1.128). This is in contrast to the prior IPIRG-1 program which used single-frequency excitation. Tests were conducted on 406-mm (16-inch) diameter carbon and stainless steel base metal pipe and circumferential welds, with cracks in straight pipe, pipe-to-elbow girth welds, and cracks in elbows (Refs. 1.129 and 1.130). Both quasi-static pipe tests and seismically loaded pipe-system experiments were conducted for relative comparisons. For the case of the cracks in elbows, there was some fundamental development of J-estimation schemes, whereas the rest of the program was generally experimental. At the end of the program, there was also an uncertainty study that was conducted to assess what technical aspects were more important to examine in the future (Ref. 1.131). Some of the key results from the IPIRG-2 program were:

(1) A relationship was developed between yield/ultimate strength ratio versus toughness under dynamic and cyclic loading relative to the toughness under quasi-static monotonic loading (Ref. 1.132). This 
type of relationship is important since most of the typical pipe material fracture toughness data in the world are developed under quasi-static loading.

(2) It was shown that cyclic plastic loading prior to crack initiation and during ductile crack growth causes a toughness degradation effect which is a function of a number of complicated parameters, but could be simplified for bounding cases (Refs. 1.129 and 1.132).

(3) The pipe-system experiments in both IPIRG programs showed that dynamic toughness should be accounted for in all seismic events, but the cyclic degradation effect would occur in some subset of seismic events (Ref. 1.127).

(4) Bounding seismic time-histories may vary from a dynamic monotonic loading (similar to what occurred in the Kobe or Northridge earthquakes), to a worst case history that would include cyclic effects on toughness degradation as well as a more gradual buildup of cyclic amplitudes (Ref. 1.127).

(5) A simplified methodology was developed to predict axial and circumferential surface-cracked elbow fracture loads that looks promising as a codifiable method (Ref. 1.130). This uses a simple geometric multiplier times the straight pipe solutions to predict the cracked elbow loads at the start of ductile tearing and at maximum load.

(6) It was demonstrated that the existing circumferential through-wall-cracked pipe analyses for short cracks, as used in LBB analyses for large diameter pipe, was valid in a pipe-system experiment (Ref. 1.129).

(7) It was shown that for a girth weld surface crack at a pipe-to-elbow weld, that the elbow ovalization did not effect the fracture loads (Ref. 1.129).

(8) When accounting for the actual strength of the materials, it was found that the ASME Section XI Appendix C (for austenitic pipe), Appendix $\mathrm{H}$ (for ferritic pipe), Code Case N-494-2 (for ferritic pipe), and R6 Option 1 approach (for both austenitic and ferritic pipe) all have about the same average inherent margin of about 1.4 (Ref. 1.127).

(9) For LBB analyses, factors that affect the COD for normal operating stresses were found to be more important for the conditional failure probabilities than the magnitude of the seismic loads, i.e., weld residual stresses, pipe-system boundary conditions that restrain the COD from pressure stresses, problems with the friction factor equations with tight cracks in the leak-rate codes, etc. (Ref. 1.131) are most important.

(10) UT flaw sizing uncertainty is not important to the failure loads for cracks that are less than 25 percent of the circumference, but are important for long deep cracks (Ref. 1.131). This was because such relatively small cracks fail close to the uncracked pipe moment. 


\subsubsection{Recent Milestones in the Nuclear Industry}

As noted earlier, during this time period, there were many changes in the nuclear industry. The types of failures that were occurring in piping were: more frequent erosion/corrosion failures, microbiologically induced corrosion in service water lines, and IGSCCs in large diameter titanium stabilized TP347 stainless steel piping in German BWRs previously thought to be immune to IGSCC.

The ASME Section XI inspection criteria were refined, and plants that were required to reinspect every 10 years, found that there were initial fabrication defects that they now had to address, particularly for Class 2 and 3 piping systems. Plant life extension evaluations were in progress, and aspects of fatigue life, and thermal aging of cast stainless steel became more important.

Several U.S. plants were closed either due to reactor pressure vessel embrittlement problems or steam generator problems. Privatization and deregulation of the industry forced financial constraints on the industry, resulting in a greater burden on the plant engineering staff to improve operating efficiencies required to meet financial goals. There was also concern over Russian reactors since the end of the cold war and the Chornobyl accident. Ensuring LBB for Russian plants without adequate emergency core cooling was a high priority item, since the nuclear plants in the former Soviet Union countries are essential to the economies of these countries.

In an age where the U.S. nuclear industry seemed to be in a decline, many Pacific rim countries started new large-scale nuclear power plant construction projects or developed advanced reactors. In Europe, there was also work going on in the development of the next generation European pressurized water reactor (EPR). And in the U.S., advanced reactor designs were pursued by several companies, but mainly for overseas sales.

Some changes in rulemaking involved:

- The inclusion of the Code Case N494-3 in the ASME Boiler and Pressure Vessel Code, which is a failure assessment diagram approach like the UK R6 approach, but with explicit safety factors.

- A proposed Code Case $\mathrm{N}-480$ for erosion/corrosion defects, that eventually was rejected by both the industry and the U.S. NRC. This code case included criteria on where to inspect, how frequently to inspect, estimates of corrosion rates, and flaw acceptance criteria. Both the NRC and industry objected to the inspection criterion. At the time of the preparation of this document, the flaw acceptance criteria were being considered as a new code case for erosion/corrosion flaw acceptance.

- In the end of 1994, ASME Section III adopted new rules for seismic design allowable stresses. These rules were not accepted by the U.S. NRC, and as this document was being prepared, there was a Special Working Group in Section III assigned to determining whether these differences could be resolved. Although it was felt that the older rules could be relaxed, there was concern that the committee relaxed them too much without an adequate technical basis.

- The ASME Code approved Code Case N-513 allowing low-energy systems to operate with a leaking flaw. 
- Flaw evaluation criteria, separate from the ASME Code, were being proposed in Sweden, France, and Japan.

Two more leak-before-break conferences were held in the 1990 to 1996 time frame. The fifth one in the series of CSNI conferences was held in Taipei, Taiwan in 1989 (Ref. 1.133). The latest conference was held in Lyon, France in 1995 (Ref. 1.134).

\subsection{Report Outline}

The main part of this report is in Section 2.0 on Achievements and Validation. Section 3.0, entitled Technically Evolving Issues and Aspects Not Well Understood, discusses areas that may need further attention. Section 4.0 presents a summary and the conclusions, and Appendix A presents some additional information on stress analysis methods.

\subsection{References}

1.1 Maxey, W. A., Keifner, J. F., and Eiber, R. J., "Brittle Fracture Arrest in Gas Pipelines", A.G.A. Report L51433, April 1983.

1.2 Kiefner, J. F., Maxey, W. A., Eiber, R. J. and Duffey, A. R., "Failure Stress Levels of Flaws in Pressurized Cylinders," Progress in Flaw Growth and Fracture Toughness Testing, ASTM STP 536, pp 461-481, 1973.

1.3 ASME Boiler and Pressure Vessel Code, Section XI, Appendix H, 1992 Edition, July 1992.

1.4 Wilkowski, G. M., Barnes, C. R., Scott, P. M., and Ahmad, J., "Development of Analyses to Predict the Interaction of Fracture Toughness and Constraint Effects for Surface Cracked Pipe," American Gas Association project report on Project PR-3-407, April 1985.

1.5 Hancock, J. W., Reuter, W. G., and Parks, D. M., "Constraint and Toughness Parameterized by T," Constraint Effects in Fracture, ASTM STP 1171, pp 21-40, 1993.

1.6 O'Dowd, N. P. and Shih, C. F., "Family of Crack-Tip Fields Characterized by A Triaxiality Parameter - I. Structure of Fields," J. of Mechanics and Physics of Solids, Vol. 39, No. 8, pp 9891015, 1991.

1.7 Brocks, W. And Künecke, G., "On the Influence of Triaxiality of the Stress State of Ductile Tearing Resistance," Defect Assessment in Components, Fundamentals and Applications, ESIS/EGF9, Mechanical Engineering Publications, London, pp 189-201, 1991.

1.8 Maxey, W., Keifner, J. F., and Eiber, R. J., "Ductile Fracture Arrest in Gas Pipelines," A.G.A. Catalogue No. L32176, May 1976. 
1.9 Maxey, W. A., "Outside Force Defect Behavior," American Gas Association, Report NG-18 No. 162, August 1986.

1.10 U.S. Nuclear Regulatory Commission, "Investigation and Evaluation of Stress Corrosion Cracking in Piping of Light Water Reactor Plants," NUREG-0531, Feb. 1979.

1.11 Goldberg, A., Streit, R. D., and Scott, R. G., "Evaluation of Cracking in Feedwater Piping Adjacent to the Steam Generators in Nine Pressurized Water Reactor Plants," NUREG/CR-1603, October 1980.

1.12 Rice, J. R., "A Path Independent Integral and the Approximate Analysis of Strain Concentrations by Notches and Cracks," Journal of Applied Mechanics', Vol. 35, pp 379-386, 1968.

1.13 Reynolds, R., "Reactor Primary Coolant System Study - Quarterly Progress Report No. 16," GEAP-100023, AEC Research and Development Report, January-March, 1969.

1.14 Eiber, R. J., Maxey, W. A., and Duffey, A. R., "Investigation of the Initiation and Extent of Ductile Pipe Rupture," Battelle Memorial Institute Report, BMI-1908, 1971.

1.15 "Manual for Determining the Remaining Strength of Corroded Pipelines," Supplement to ANSI/ASME B31 Code for Pressure Piping, The American Society of Mechanical Engineers, 1984.

1.16 Kiefner, J. F., and Vieth, P. H., "A Modified Criterion for Evaluating the Remaining Strength of Corroded Pipe," (with RSTRENG), American Gas Association, Catalog No. L51609, PR3-805, December 22, 1989.

1.17 Kanninen, M. F., and others, "Mechanical Fracture Predictions for Sensitized Stainless Steel Piping with Circumferential Cracks," EPRI Report NP-192, September 1976.

1.18 Darlaston, B. J. L. and Harrison, R. P. "Ductile Failure of Thin-Walled Pipes with Defects Under Combinations of Internal Pressure and Bending," 3rd International Conference on Pressure Vessel Technology, Part II, Materials and Fabrication, pp 669-676, April 1977.

1.19 Emery, A. F., and others, "Pipe Stress Intensity Factors and Coupled Depressurization and Dynamic Crack Propagation,” EPRI Report NP-763, Annual Report on Project 231-1, April 1978.

1.20 Mayfield, M. E., and others, "Cold-Leg Integrity Evaluation - Final Report," NUREG/CR-1319, February 1980.

1.21 Collier, R. P., and others, "Two Phase Flow Through Intergranular Stress Corrosion Cracks and Resulting Acoustic Emission,” EPRI Report NP-3540-LD, April 1984.

1.22 Collier, R. P., and others, "Two Phase Flow Through Intergranular Stress Corrosion Cracks and Resulting Acoustic Emission," EPRI Report NP-350-LD, Appendix E, April 1984. 
1.23 Norris, D., and others, "PICEP: Pipe Crack Evaluation Program," EPRI Report NP-3596-SR, August 1984.

1.24 "CSNI Specialist Meeting on Plastic Tearing Instability," NUREG/CP-0010, January 1980.

1.25 Shih, F. C., and others, "Methodology for Plastic Fracture," EPRI Report NP-1735, March 1981.

1.26 Kanninen, M. F., and others, "Development of a Plastic Fracture Methodology," EPRI Report NP1734, March 1981.

1.27 Gurson, A. L., "Continuum Theory of Ductile Rupture by Void Nucleation and Growth: Part I Yield Criteria and Flow Rules for Porous Ductile Media," J. Engineering Materials and Tech., 99, pp 2-15, 1977.

1.28 Bremin, F. M., "A Local Criterion for Cleavage Fracture of a Nuclear Pressure Vessel Steel," Metallurgical Transactions A, V14A, pp 2277-2287, 1983.

1.29 Nakagaki, M., Marschall, C., and Brust, F., "Analysis of Cracks in Stainless Steel TIG Welds," NUREG/CR-4806, December 1986.

1.30 Kumar, V., German, M., and Shih, C. F., "An Engineering Approach for Elastic-Plastic Fracture Analysis," EPRI Report NP-1931, July 1981.

1.31 Kumar, V., and others, "Advances in Elastic-Plastic Fracture Analysis," EPRI report NP-1237-1, August, 1984.

1.32 Kumar, V., and German M. D., "Elastic-Plastic Fracture Analysis of Through-Wall and Surface Flaws in Cylinders," EPRI Report NP-5596, January 1988.

1.33 Paris, P. C., and Tada, H., "The Application of Fracture Proof Design Methods Using Tearing Instability Theory to Nuclear Piping Postulating Circumferential Through-Wall Cracks," NUREG/CR-3464, September 1983.

1.34 Klecker, R., and others, "NRC Leak-Before-Break (LBB.NRC) Analysis Method for Circumferentially Through-Wall-Cracked Pipes Under Axial Plus Bending Loads," NUREG/CR4572, May 1986.

1.35 Milne, I., and others, “Assessment of the Integrity of Structures Containing Defects," R/H/R6-Rev. 3, Published by Central Electric Generating Board, England, May 1986.

1.36 Tang, H. T., and others, "Experimental Investigation of High Energy Pipe Leak and Rupture Phenomena," ASME Special Publication PVP Volume 98-8, Fracture, Fatigue and Advanced Mechanics, June 1985.

1.37 Zahoor, A., and Gamble, R., “Application of Tearing Modulus Stability Concepts to Nuclear Piping," EPRI NP-2261, Feb. 1982. 
1.38 Zahoor, A., "Ductile Fracture Handbook," EPRI Report NP-6301-D, June 1989.

1.39 Zahoor, A., and Gamble, R. M., "Evaluation of Flawed-Pipe Experiments," EPRI Report NP4883M, November, 1986.

1.40 "Evaluation of Flaws in Austenitic Steel Piping," (Technical basis document for ASME IWB3640 analysis procedure), prepared by Section XI Task Group for Piping Flaw Evaluation, EPRI Report NP-4690-SR, April 1986.

1.41 "Evaluation of Flaws in Ferritic Piping," EPRI Report NP-6045, prepared by Novetech Corporation, October 1988.

1.42 Swamy, S., and others, "Application of the Leak-Before-Break Approach to Westinghouse PWR Piping," EPRI Report NP-4971, December 1986.

1.43 Ayres, D. J., and others, "Application of the Leak-Before-Break Analysis to PWR Piping Designed by Combustion Engineering," EPRI Report NP-5010, February 1987.

1.44 Maxham, W. D., and Yoon, K. K., "Application of the Leak-Before-Break Analysis to PWR Piping Designed by Babcock and Wilcox," EPRI Report NP-4972, January 1987.

1.45 Mehta, H. S., and others, "Application of the Leak-Before-Break Analysis to BWR Piping," EPRI Report NP-4991; December 1986.

1.46 Ernst, H. A., "Material Resistance and Instability Beyond J-Controlled Crack Growth," ASTM STP 803, pp I-191 to I-213, 1983.

1.47 Landes, J. D., "Extrapolation of the J-R Curve for Predicting Reactor Vessel Integrity," NUREG/CR-5650, January 1992.

1.48 Gudas, J., "J-R Curve Characterization of Piping Materials and Welds," Ninth Water Reactor Safety Research Information Meeting, Gaithersburg, Maryland, October 1981.

1.49 Wilkowski, G. M., and others, "Degraded Piping Program - Phase II, Summary of Technical Results and Their Significance to Leak-Before-Break and In-Service Flaw Acceptance Criteria," March 1984-January 1989, NUREG/CR-4082, Vol. 8, March 1989.

1.50 Chopra, O., "Estimates of Fracture Toughness of Cast Stainless Steels in LWR Systems," in Transactions of the Eighteenth Water Reactor Safety Information Meeting, NUREG/CP-0113, October 1990.

1.51 Meyzaud, V., and others, "Tearing Resistance of Aged Cast Austenitic Stainless Steels," presented at NUCSAFE 88, Avignon, France, October, 1988.

1.52 Bamford, W. H., and Landerman, E. I., "Thermal Analysis of Cast Stainless Steel, and Its Impact on Piping Integrity," Circumferential Cracks in Pressure Vessels and Piping - Vol. II, ASME PVP - Vol 95, pp 137-172, 1984. 
1.53 Landes, J. D., McCabe, D. E., and Ernst, H. A., "Elastic-Plastic Methodology to Establish R Curves and Instability Criteria," Eighth Semiannual report on EPRI Contract No. RP1238-2, July 1, 1983 to December 31, 1983, by Westinghouse R\&D Center, July 24, 1984.

1.54 Horn, R. M., and others, "Evaluation of the Toughness of Austenitic Stainless Steel Pipe Weldments," GE San Jose, Ca. report to EPRI on Contract T303-3, April 1985.

1.55 Van der Sluys, W. A., "Toughness of Ferritic Piping Steels," EPRI NP- 6264, October 1988.

1.56 Hiser, A. L., and Callahan, G. M., "A User's Guide to the NRC's Piping Fracture Mechanics Database (PIFRAC)," NUREG/CR-4894, May 1987.

1.57 Ghadiali, N., and Wilkowski, G. M., "Fracture Mechanics Database for Nuclear Piping Materials (PIFRAC)," in Fatigue and Fracture - 1996 - Volume 2, PVP-Vol. 324, pp 77-84, July 1996.

1.58 Manning, B. W., "Fracture Mechanics Leak-Before-Break Material Test Program," Ontario Hydro Design and Development Division - Generation, Report No. 85120, September 1986 (Rev. 2).

1.59 Yagawa, G., and others, "Stable Growth and Instability of Circumferential Cracks in Type 304 Stainless Steel Pipes Under Tensile Load," Journal of Pressure Vessel Technology, Vol. 106, pp 405-411, November 1984.

1.60 Kanninen, M. F., and others, "Instability Predictions for Circumferentially Cracked Type 304 Stainless Steel Pipes Under Dynamic Loadings," EPRI Report NP-2347, April 1982.

1.61 Hale, D. A. and others, "The Growth and Stability of Stress Corrosion Cracks in Large-Diameter BWR Piping," EPRI Report NP-2472 Volume 2, July 1982.

1.62 Vassilaros, M. G., and others, "J-Integral Testing Instability Analysis for 8-Inch Diameter ASTM A106 Steel Pipe," NUREG/CR-2347, April 1984.

1.63 Kußmaul, K., and others, "Phänomenologische Behälterberstversuche - Phase I," BMFT Report BMFT-TB-150 279, by MPA-Stuttgart, July 1985.

1.64 Sturm, D., and others, "Phänomenologische Behälterberstversuche - Phase II," BMFT Report BMFT-TB-1500 279, by MPA-Stuttgart, December 1987.

1.65 RSK-Leitlinien DWR, second edition, sowie Rahmenspezifikation Basissisherheit von Drunkführenden Komponenten, 24 Jan. 1979 (in German).

1.66 Shibata, K., and others, "Evaluation of JAERI's Ductile Fracture Test Results on Stainless Steel and Carbon Steel Piping", in Nuclear Engineering and Design, Vol. 111, pp 135-146, 1989.

1.67 Baum, M. R., "The Development of the Breach Generated by Axial Rupture of a Gas-Pressurized Steel Pipe," Journal of Pressure Vessel Technology, Vol. 104, pp 253-261, November 1982. 
1.68 Baum, M. R., "The Velocity of Missels Generated by the Disintegration of Gas-Pressurized Vessels and Pipes," Journal of Pressure Vessel Technology, Vol. 106, pp 362-368, November 1984.

1.69 Faidy, C., Jamet, P., and Bhandari, S. "Developments in Leak Before Break Approach in France," NUREG/CP-0092, pp 69-82, March 1988.

1.70 Milella, P. P., Cella, A., and Squilloni, A., "Experimental and Numerical Evaluation of J Integral on Pipes," Proceedings of 7th Int. SMiRT Conference, 1983.

1.71 Maricchiolo C., and Milella, P. P., "Fracture Behavior of Carbon Steel Pipes Containing Circumferential Cracks at Room Temperature and 300 C," Nuclear Engineering and Design, 111, pp 35-46, 1989.

1.72 Kanninen, M. F., and others, "The Development of a Plan for the Assessment of Degraded Nuclear Piping by Experimentation and Tearing Instability Fracture Mechanics Analysis," NUREG/CR-3142, Vols. 1 and 2, June 1983.

1.73 Wilkowski, G. M., and others, "Degraded Piping Program - Phase II, Semiannual Report, March 1984-September 1984,” NUREG/CR-4082, Vol. 1, January 1985.

1.74 Wilkowski, G. M., and others, "Degraded Piping Program - Phase II, Semiannual Report, October 1984-March 1985,” NUREG/CR-4082, Vol. 2, July 1985.

1.75 Wilkowski, G. M. and others, "Degraded Piping Program - Phase II, Semiannual Report, April 1985-September 1985," NUREG/CR-4082, Vol. 3, March 1986.

1.76 Wilkowski, G. M., and others, "Degraded Piping Program - Phase II, Semiannual Report, October 1985-March 1986," NUREG/CR 4082, Vol. 4, September 1986.

1.77 Wilkowski, G. M., and others, "Degraded Piping Program - Phase II, Semiannual Report, April 1986-September 1986,"NUREG/CR-4082, Vol. 5, April 1987.

1.78 Wilkowski, G. M., and others, "Degraded Piping Program - Phase II, Sixth Program Report, October 1986-September 1987," NUREG/CR-4082, Vol. 6, April 1988.

1.79 Wilkowski, G. M., and others, "Degraded Piping Program - Phase II, Seventh Progress Report: October 1987 - January 1989," NUREG/CR-4082, Vol. 7, March 1989.

1.80 Ahmad, J., and others, "Elastic-Plastic Finite Element Analysis of Crack Growth in Large Compact Tension and Circumferentially Through-Wall-Cracked Pipe Specimen," NUREG/CR4573, October 1986.

1.81 Scott, P., and Brust, F., “An Experimental and Analytical Assessment of Circumferential ThroughWall Cracked Pipes Under Pure Bending," NUREG/CR-4574 September 1986. 
1.82 Papaspyropoulos, V., Marschall, C., and Landow, M., "Predictions of J-R Curves with Large Crack Growth from Small Specimen Data," NUREG/CR-4575, September 1986.

1.83 Kramer, G. and Papaspyropoulos, V., "An Assessment of Circumferentially Complex-Cracked Pipe Subjected to Bending," NUREG/CR-4687, October 1986.

1.84 Brust, F. W., "Approximate Methods for Fracture Analyses of Through-Wall Cracked Pipes," NUREG/CR-4853, February 1987.

1.85 Scott, P. M., "Assessment of Design Basis for Load-Carrying Capacity of Weld-Overlay Repairs," NUREG/CR-4877, April 1987.

1.86 Wilkowski, G. M., and others, "Analysis of Experiments on Stainless Steel Flux Welds," NUREG/CR-4878, April 1987.

1.87 Scott, P. M., and Ahmad, J. A., "Experimental and Analytical Assessment of Circumferentially Surface-Cracked Pipes Under Bending," NUREG/CR-4872, April 1972.

1.88 Kurihara, R., and others, "Experimental Studies of 4-inch Pipe Whip Test Under BWR LOCA Conditions," Nuclear Engineering and Design, Vol. 76, pp 23-33, 1983.

1.89 Isozaki, T., and Miyazono, S., "Experimental Study of Jet Discharge Test Results Under BWR and PWR Loss of Coolant Accident Conditions," Nuclear Engineering and Design, Vol. 96, pp 1-9, 1986.

1.90 Kastner, W., and Rippel R., "Jet Impingement Forces on Structures - Experiments and Empirical Calculation Methods," Nuclear Engineering and Design, Vol. 105, pp 269-284, 1988.

1.91 "Piping and Fitting Dynamic Reliability Program," EPRI report TR-102792 Volumes 1-5, 1995.

1.92 "Investigation and Evaluation of Stress Corrosion Cracking in Piping of Boiling Water Reactor Plants," prepared by U.S. NRC Pipe Break Task Group, NUREG 1061 Vol. 1, August 1984.

1.93 "Evaluation of Seismic Designs - A Review of Seismic Design Requirements for Nuclear Power Plant Piping," prepared by U.S. NRC Pipe Break Task Group, NUREG 1061, Vol. 2, April 1985.

1.94 "Evaluation of Potential for Pipe Breaks," prepared by U.S. NRC Pipe Break Task Group, NUREG-1061, Vol. 3, November 1984.

1.95 Standard Review Plan by Office of Nuclear Reactor Regulation, NUREG-0800, see "3.6.3 LEAKBEFORE-BREAK PROCEDURES," currently in draft form.

1.96 "Proceedings of the CSNI Specialist Meeting on Leak-Before-Break in Nuclear Reactor Piping," Proceedings of a seminar held in Monterey, California, NUREG/CP-0051, August 1984. 
1.97 Harris, D. O., Lim, E. Y., and Dedhia, D. D., "Probability of Pipe Fracture in the Primary Coolant Loop of a PWR Plant,"NUREG/CR-2189, Vol. 5, August 1981.

1.98 "Leak Before Break: International Policies and Supporting Research," Proceedings of a seminar held in Columbus, Ohio on October 28-30, 1985, NUREG/CP-0077, June 1986.

1.99 "Leak-Before-Break: Progress in Regulatory Policies and Supporting Research," Proceedings of a seminar held in Tokyo, Japan on May 14-15, 1987, NUREG/CP-0092, March 1988.

1.100 "Leak-Before-Break in Water Reactor Piping and Vessels", C.E. Coleman Editor, held on October 24-27, 1989, in Toronto, Canada, reprinted from The International Journal of Pressure Vessels and Piping, Vol. 43, Nos. 1-3, 1990.

1.101 Wilkowski, G., and others, "International Piping Integrity Research Group (IPIRG) Program, Final Report,"NUREG/CR-6233 Vol. 4, June 1997.

1.102 Kramer, G., and others, "Stability of Cracked Pipe Under Seismic/Dynamic DisplacementControlled Stresses," NUREG/CR-6233 Vol. 2, June 1997.

1.103 Scott, P., and others, "Stability of Cracked Pipe Under Inertial Stresses," NUREG/CR-6233 Vol. 1, August 1994.

1.104 Olson, R., Scott,P., and G. Wilkowski, "Application of a Nonlinear Spring Element to Analysis of Circumferentially Cracked Pipe under Dynamic Loading," in Pressure Vessel Fracture, Fatigue and Life Management, ASME PVP Vol. 233, pp 279-292, June 1992.

1.105 Scott, P., and others, "Crack Stability in a Representative Piping System Under Combined Inertial and Seismic/Dynamic Displacement-Controlled Stresses," NUREG/CR-6233 Vol. 3, June 1997.

1.106 Takumi, K., "Results of the Japanese Carbon Steel Pipe Fracture Program," NUREG/CP-0109, Leak-Before-Break: Further Development in Regulatory Policies and Supporting Research, Taipei, Taiwan, pp 13-31, February 1990.

1.107 Fujioka, T., Miura, N., Kashima, K., Kanno, S., Miyazaki, K., Ishiwata, M., and Gotoh, N., "A Fracture Strength Evaluation Method for Carbon Steel Pipes Subjected to Dynamic/Cyclic Loadings: Evaluation of Dynamic/Cyclic Pipe Fracture Tests at Elevated Temperature," ASME PVP Vol. 304, pp 191-197, 1995.

1.108 Poole, A., Battiste, R., and Clinard, J., "Final Report Pipe Break Testing of Primary Loop Piping Similar to Department of Energy's New Production Reactor-Heavy Water Reactor," ORNL/NPR92/64, January 1993.

1.109 Olson, R., and others, "Validation of Analysis Methods for Assessing Flawed Piping Subjected to Dynamic Loading," NUREG/CR-6234, August 1994.

1.110 Kussmaul, K, and others, "Leak-Before-Break Behavior of a Piping System DN 425 Subjected to Transient Loading by Water Hammer," SMiRT 12, Vol. G, pp 399-404, August 1993. 
1.111 Brosi, S., and others, "Precracked Pipe Under Waterhammer Action," SMiRT 12, Vol. G, pp 405-410, August 1993.

1.112 Wilkowski, G., and others, "Short Cracks in Piping and Piping Welds," First Semiannual Report, NUREG/CR-4599, Vol. 1, No. 1, March 1991.

1.113 Wilkowski, G., and others, "Short Cracks in Piping and Piping Welds," Second Semiannual Report, NUREG/CR-4599, Vol. 1, No. 2, April 1992.

1.114 Wilkowski, G., and others, "Short Cracks in Piping and Piping Welds," Third Semiannual Report, NUREG/CR-4599, Vol. 2, No. 1, September 1992.

1.115 Wilkowski, G., and others, "Short Cracks in Piping and Piping Welds," Fourth Semiannual Report, NUREG/CR-4599, Vol. 2, No. 2, February 1993.

1.116 Wilkowski, G., and others, "Short Cracks in Piping and Piping Welds," Fifth Semiannual Report, NUREG/CR-4599, Vol. 3, No. 1, October 1993.

1.117 Wilkowski, G., and others, "Short Cracks in Piping and Piping Welds," Sixth Semiannual Report, NUREG/CR-4599, Vol. 3, No. 2, March 1994.

1.118 Wilkowski, G., and others, "Short Cracks in Piping and Piping Welds," Seventh Program Report, NUREG/CR-4599, Vol. 4, No. 1, April 1995.

1.119 Brust, F., and others, "Assessment of Short Through-Wall Circumferential Cracks in Pipes," NUREG/CR-6235, April 1995.

1.120 Krishnaswamy, P., and others, "Fracture Behavior of Short Circumferential Surface-Cracked Pipe," NUREG/CR-6298, November 1995.

1.121 Marschall, C., and others, "Effect of Dynamic Strain Aging on the Strength and Toughness of Nuclear Ferritic Piping at LWR Temperatures," NUREG/CR-6226, October 1994.

1.122 Mohan, R., and others, "Effects of Toughness Anisotropy and Combined Loading on Fracture Behavior of Ferritic Nuclear Pipe," NUREG/CR-6299, April 1995.

1.123 Rahman, S., and others, "Refinement and Evaluation of Crack-Opening Analyses for Circumferential Through-Wall Cracks in Pipes," NUREG/CR-6300, April 1995.

1.124 Rahman, S., and others, "Probabilistic Pipe Fracture Evaluations for Leak-Rate Detection Applications," NUREG/CR-6004, April 1995.

1.125 Rosenfield, A., Held, P., and Wilkowski, G., "Stainless Steel Submerged Arc Weld Fusion Line Toughness," NUREG/CR-6251, April 1995. 
1.126 Scott, P., and others, "Fracture Evaluations of Fusion Line Cracks in Nuclear Pipe Bimetallic Welds," NUREG/CR-6297, April 1995.

1.127 Hopper, A., and others, "The Second International Piping Integrity Research Group (IPIRG-2) Program," NUREG/CR-6452, January 1997.

1.128 Olson, R., Scott, P., and Wilkowski, G., "Design of the IPIRG-2 Simulated Seismic Forcing Function," NUREG/CR-6439, February 1996.

1.129 Scott, P., and others, "IPIRG-2 Task 1 - Pipe System Experiments With Circumferential Cracks in Straight-Pipe Locations," NUREG/CR-6389, February 1997.

1.130 Kilinski, T., and others, "Fracture Behavior of Circumferentially Surface-Cracked Elbows," NUREG/CR-6444, December 1996.

1.131 Ghadiali, N., and others, "Deterministic and Probabilistic Evaluations for Uncertainty in Pipe Fracture Parameters in Leak-Before-Break and In-Service Flaw Evaluations," NUREG/CR-6443, June 1996.

1.132 Rudland, D., Brust, F., and Wilkowski, G., "The Effect of Cyclic and Dynamic Loading on the Fracture Resistance of Nuclear Piping Steels," NUREG/CR-6440, December 1996.

1.133 "Leak-Before-Break: Further Developments in Regulatory Policies and Supporting Research," Proceedings of a seminar in Taipei, Taiwan on May 11-12, 1989, NUREG/CP-0109, February 1990.

1.134 "Proceedings of the Seminar on Leak Before Break in Reactor Piping and Vessels", Proceedings of a seminar held in Lyon, France on October 9-11, 1995, NUREG/CP-0155. 


\subsection{ACHIEVEMENTS AND VALIDATIONS}

This section summarizes some of the achievements and validations of pipe fracture mechanics analyses relative to factors that affect the: (1) stress analyses, (2) material properties, (3) predictions of maximum load capabilities for either circumferential through-wall or surface cracks, (4) crack-opening-area prediction analyses, and (5) predictions of maximum load capabilities of cracked elbows.

\subsection{Achievements and Validations - Stress Analyses and Cracked Pipe-System Behavior}

Appendix A summarizes various aspects of piping stress analysis. Several other research programs have been conducted in the past to determine how accurately pipe finite element codes can reproduce experimental results on relatively complicated pipe systems (Refs. 2.1 to 2.3 ). To examine various aspects of pipe-system effects on fracture behavior, the pipe loop for the International Piping Integrity Research Group (IPIRG) program was built. The IPIRG pipe system was designed to have the following characteristics:

- a balance of displacement-controlled and load-controlled stresses,

- a natural frequency around $4 \mathrm{~Hz}$, typical of nuclear plant piping,

- a capability to conduct tests at high temperatures $(288 \mathrm{C}, 550 \mathrm{~F})$ where there would be thermal expansion stresses and different material behavior than at room temperature,

- test pressures at either BWR or PWR levels,

- $\quad$ capable of running simulated seismic tests, as well as single frequency tests,

- $\quad$ well-defined boundary conditions so the stress analysis unknowns from pipe supports and hangers do not cause uncertainties in the subsequent fracture analysis,

- $\quad$ bending in one plane, and no torsional loads, and

- negligible the dead-weight loads.

These conditions allowed for the evaluation of differences in elastically calculated stresses and actual stresses, as well as determination of the importance of primary versus secondary stresses. The following sections address these two key aspects, as well as residual stress considerations, variability of seismic time histories, and other interaction effects from a crack on the piping system stress analysis.

\subsubsection{Differences in Elastically Calculated Stresses and Actual Stresses}

In leak-before-break (LBB) or in-service flaw evaluation criteria (such as ASME Section XI, British R6 approach, Swedish SA/FoU 91-01 procedure, or the French RSE-M procedures), elastic uncracked pipe stresses are used. The peak dynamic seismic stresses are typically calculated from response spectrum analyses, and then are applied as a sustained load in the elastic-plastic pipe fracture mechanics analyses. Consequently, there is some inaccuracy in the elastic uncracked pipe stresses and the real pipe fracture analyses. 


\subsubsection{Margins from Elastic Stress Analyses for Circumferential Surface-Cracked Pipe Analyses}

During the IPIRG programs, there were pioneering attempts to couple the fracture mechanics analysis procedure with the seismic/dynamic piping stress analysis. Initially, this was done in the IPIRG-1 program to help design the inertially loaded cracked pipe tests. Subsequently, this approach was used to design the dynamic pipe-system experiments. Eventually, the methodology evolved to the point, where now it appears promising to use it to better quantify actual margins.

Since this approach involved modeling nonlinear behavior at the crack, and possible nonlinear behavior at uncracked locations in the piping system, time-history analyses are necessary. Not only is the loading variable in nature, but it is dynamic and there are repeated large amplitude cycles where the load-history may have some effect on the material properties. These material properties aspects are addressed elsewhere in the report.

From the pipe-system work conducted to date, it has been shown that even if there is a deep circumferential surface crack, that

(1) The natural frequency of the pipe system is virtually unaffected by the presence of the crack,

(2) The plasticity of the circumferential surface crack is small compared to the elastic displacement of the overall pipe system, and

(3) The calculated elastic uncracked pipe dynamic stresses are close to those experimentally measured.

In the IPIRG-1 pipe-system experiments, the elastic uncracked pipe dynamic stresses were calculated to be from -5 to +32 percent of the experimentally measured stresses.

On the other hand, it is well known that for uncracked pipe systems, the elastically calculated stresses can be very conservative estimates of the actual stresses in a cracked pipe system. In this case, wide-spread plasticity significantly increases the effective damping, and the elastically calculated stresses have been reported to be factors of 10 to 30 higher than maximum Code allowable stresses (Ref. 2.4).

It is, therefore, logical to assume that as the flaw size decreases, and the required moment for fracture increases, there will be more plasticity in the uncracked regions of the pipe loop. Hence, the elastically calculated stresses will become more conservative. What is lacking at this time is some simple way to quantify the actual margins.

\subsubsection{Margins from Elastic Stress Analyses for Circumferential Through-Wall-Cracked Pipe Analyses for LBB}

For circumferential through-wall cracks in pipe, the through-wall crack will allow much more displacement at the crack location than a surface crack. Significantly higher margins in the elastic stress analysis can occur, especially for a very large through-wall crack where the rest of the pipe system remains elastic. This was analytically demonstrated in work done for the U.S. Department of Energy at Battelle (Ref. 2.5). In this case, even with a circumferential through-wall crack of 40-percent of the circumference and a surface crack of 75-percent of the thickness in the remaining cross-section, the elastically uncracked pipe moments were five times larger than the non-linear cracked pipe moments. Hence, huge margins may 
exist for LBB fracture analyses. This could be very advantageous for demonstrating LBB for situations where LBB cannot currently be applied, such as main steam lines.

\subsubsection{Importance of Primary Versus Secondary Stresses}

The IPIRG pipe loop experiments also involved pipe fracture experiments where, for the first time, there were secondary stresses from thermal expansion and seismic anchor motions in conjunction with primary stresses from pressure and inertial loads. The determination of how to treat secondary stresses in pipe fracture is not universally agreed upon. For instance:

- $\quad$ NRC Draft SRP 3.6.3 for LBB treats the thermal expansion stresses and seismic anchor motion stresses equally with inertial, pressure and dead-weight load stresses. Weld residual stresses and through-thickness thermal stresses are not considered.

- The U.K. R6 method differentiates secondary stresses using the following test: if the pipe cross-section was cut at a location with only those stresses and the pipe did not separate, then those stresses would be considered as secondary stresses. Weld residual stresses and throughthickness thermal stresses would typically fall in this category. If the pipe would separate due to the stresses at the flaw location, then these stresses would be classified as a primary stress. Thermal expansion stresses and seismic anchor motion stresses would fall in this category.

- The ASME Section XI pipe flaw evaluation criteria use engineering judgement in determining whether the secondary stresses are important. Section XI assumes that stainless steel base metal is sufficiently tough that thermal expansion stresses do not contribute to fracture. For lower toughness stainless steel flux welds, carbon steel base metals and carbon steel welds, it is assumed that thermal expansion stresses need to be included, but with a safety factor of 1.0 , rather than the safety factor employed for primary stresses. Seismic anchor motion stresses are not explicitly cited in Section XI flaw evaluation procedures.

Hence, secondary stresses are treated anywhere from being negligible to being as important as the primary stresses.

\subsubsection{IPIRG Program Results on Thermal Expansion and Seismic Anchor Motion Stresses}

The IPIRG-1 program involved experiments with deep circumferential surface cracks where the rest of the pipe loop remained elastic. A comparison of the IPIRG-1 pipe-system results with the companion quasistatic pipe fracture experiments on sections of the same pipe with nearly identical flaws is shown in Figure 2.1. This figure shows that if the seismic anchor motion and thermal expansion stresses are ignored, even for the stainless steel base metal case, then the normalized pipe-system failure stress (normalized by the Net-Section-Collapse stress) would be only 40 to 50 percent of the quasi-static pipe test maximum stresses. Since the uncracked pipe elastically calculated stresses in the pipe-system experiments only provide a margin of -5 to +32 percent, not including these secondary stresses could erode all the applied safety 


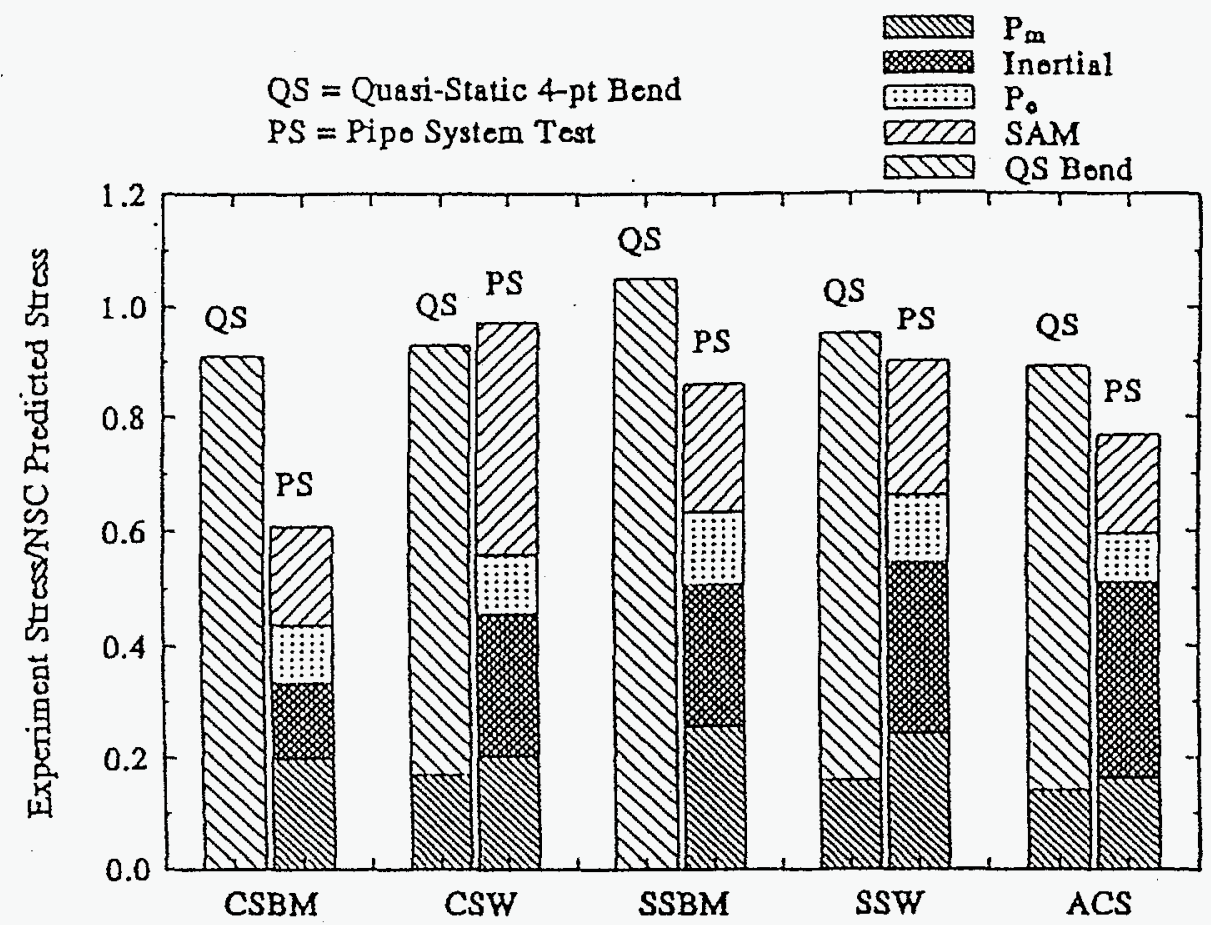

Figure 2.1 Comparison of the results from the IPIRG-1 pipe-system experiments with companion quasi-static, four-point bend experiments demonstrating how global secondary stresses, such as thermal expansion and seismic anchor motion stresses, contribute to fracture

factors. For the ASME Section XI analyses, there were cases where significant inherent margins in the fracture analyses compensated for some of this aspect of not considering these secondary stresses as primary stresses. The only case that totally eroded the ASME applied safety factor was the stainless steel base metal case. This could be resolved by including the thermal expansion and SAM stresses with a safety factor of 1.0. For the other analyses, it would be necessary to include the SAM stresses with a safety factor of 1.0 as well. If these ASME Section XI pipe fracture analyses are to be made accurate in the future, then the issue of applied safety factors for secondary stresses needs to be reevaluated.

Finally, it should not be a large surprise that the secondary stresses, in the case of a deep surface crack, behave as a primary stress. There are ample warnings about this in ANSI B31.1 Paragraph 119.3 on Local Overstrain, which is virtually identical to ASME Section III Article NC-3672.6(b). The B31.1 Paragraph 119.3 "Local Overstrain" is quoted below.

"All the commonly used methods of piping flexibility analysis assume elastic behavior of the entire piping system. This assumption is sufficiently accurate for systems where plastic straining occurs at many points or over relatively wide regions, but fails to reflect the actual strain distribution in unbalanced systems where only a small portion of the piping undergoes plastic strain, or where, in piping operating in the creep range, the strain distribution is very uneven. In these cases, the weaker or higher stressed portions will be subjected to strain concentrations due to elastic follow-up of the stiffer or lower stressed portions. Unbalance can be produced:

(A) [not relevant to this case] 
(B) by local reduction in size or cross section, or local use of a weaker material; or

(C) [not relevant to this case]

Conditions of this type should preferably be avoided, particularly where materials of relatively low ductility are used; if unavoidable, they may be mitigated by the judicious application of cold spring."

Hence, the piping design code writers decades ago recognized that elastic follow-up from secondary stresses can induce failure at locally weaker cross-sections. Yet in piping fracture mechanics, we have not come to grips with this yet.

As a further point of consideration, if there are thermal expansion stresses in an uncracked pipe system, the thermal stresses become less important as the rest of the pipe loop becomes plastic. Therefore, perhaps some bounds on the importance of secondary stresses can be created. The lower bound occurs when the failure load for the flaw of interest is below yield of the pipe loop material. In this case, the secondary stresses can act as a primary stress. As an upper bound, if the flaw gets smaller, then the rest of the uncracked pipe loop would have to go plastic to cause failure, and then the secondary stresses lose much of their importance. For these bounding cases, it might also be necessary to consider some statistical variation of the yield strength of the sections of pipe and elbows in the pipe loop. For instance, as a conservative estimate, one might consider the entire pipe loop to have a yield strength equal to the mean value plus one standard deviation for the material of interest. The flawed section then might have a strength equal to the code values or the mean minus one standard deviation. This would maximize the elastic energy in the pipe system, and minimize the loads generated by the flawed pipe, so that a statistically safe flaw size for secondary stress considerations could be estimated. At the time that this document was prepared, such a "local overstrain" screening procedure was under development for the evaluation of erosion-corrosion flaws in piping. Figure 2.2 illustrates some potential local overstrain screening criteria.

\subsubsection{Residual Stress Consideration}

The effect of weld residual stresses in piping fracture has also been treated with less than universal agreement. The aspects of weld residual stresses include consideration of subcritical crack growth, leakrate or crack-opening effects, and fracture. It has been well documented that weld residual stresses are important for subcritical crack growth such as in stress-corrosion cracking (Refs. 2.6 and 2.7). Hence, we will not discuss that aspect of residual stresses. We will discuss the significance to fracture and crackopening displacements.

\subsubsection{Effect of Weld Residual Stresses on Pipe Fracture}

For fracture considerations, the ASME Section XI pipe flaw evaluation criteria and the U.S. NRC's Draft Standard Review Plan 3.6.3 for LBB both say that residual stresses should be considered. However, there is little or no guidance on how to treat them. In the British R6 analysis procedure, the residual stresses are treated as contributors only to the elastic part of the crack-driving force. This is consistent with the multitude of observations that the weld residual stresses are important in subcritical crack growth where the crack-driving force is elastic. 

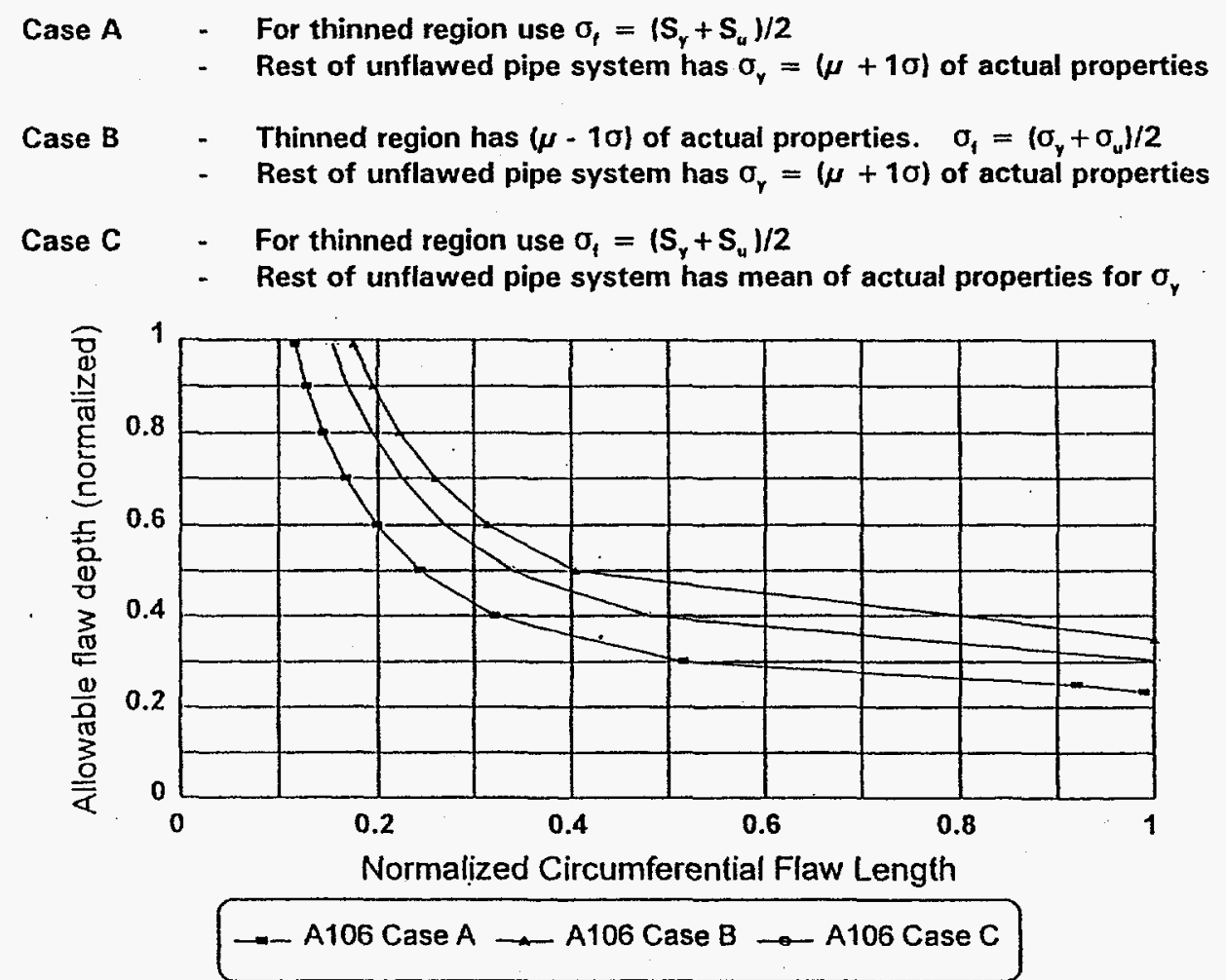

Figure 2.2 Potential local overstrain screening criteria (Flaws below the curves will have secondary stresses behave as a primary stress)

During the U.S. NRC's Degraded Piping Program, an effort was undertaken to assess the significance of weld residual stress on the fracture behavior of low toughness stainless steel flux welds (Ref. 2.8). Experiments were conducted on identical welds with similar circumferential flaws, but in one case the weld was in the as-welded condition and in the other case the weld was solution annealed. Tests on 406-mm (16-inch) diameter pipe were conducted with internal circumferential surface flaws in the center of the welds. Experiments on 152-mm (6-inch) diameter pipe were conducted with circumferential through-wall cracks in the center of the welds. The solution annealing raised the J-R curve of the weld metal when standard 1T C(T) specimens were used. The strength of the base metal was not affected by the solution annealing, but the weld metal yield strength was significantly decreased. Since it is typically recommended that the base metal stress-strain curve and the weld metal fracture properties be used in fracture analyses, it was anticipated that the solution-annealed weld would have a higher load-carrying capacity. The elimination of the weld residual stresses should have further increased the solution-annealed welded pipe load-carrying capacity.

Figure 2.3 shows the results of the 152-mm (6-inch) and 406-mm (16-inch) diameter pipe experiments. The surprising aspect was that the as-welded pipes had higher load-carrying capacities by 15 to 20 percent. Hence, the effect of the lower weld metal strength for the solution-annealed weld was much more important than the weld residual stresses or the effect of increasing the weld metal toughness by the solution annealing. Consequently, for pipe fracture applications where ductile tearing will occur, even in the EPFM range, the weld residual stresses can be ignored. This may not necessarily be true for Class 2 or 3 piping that operates at lower temperatures where LEFM fracture may be possible. 


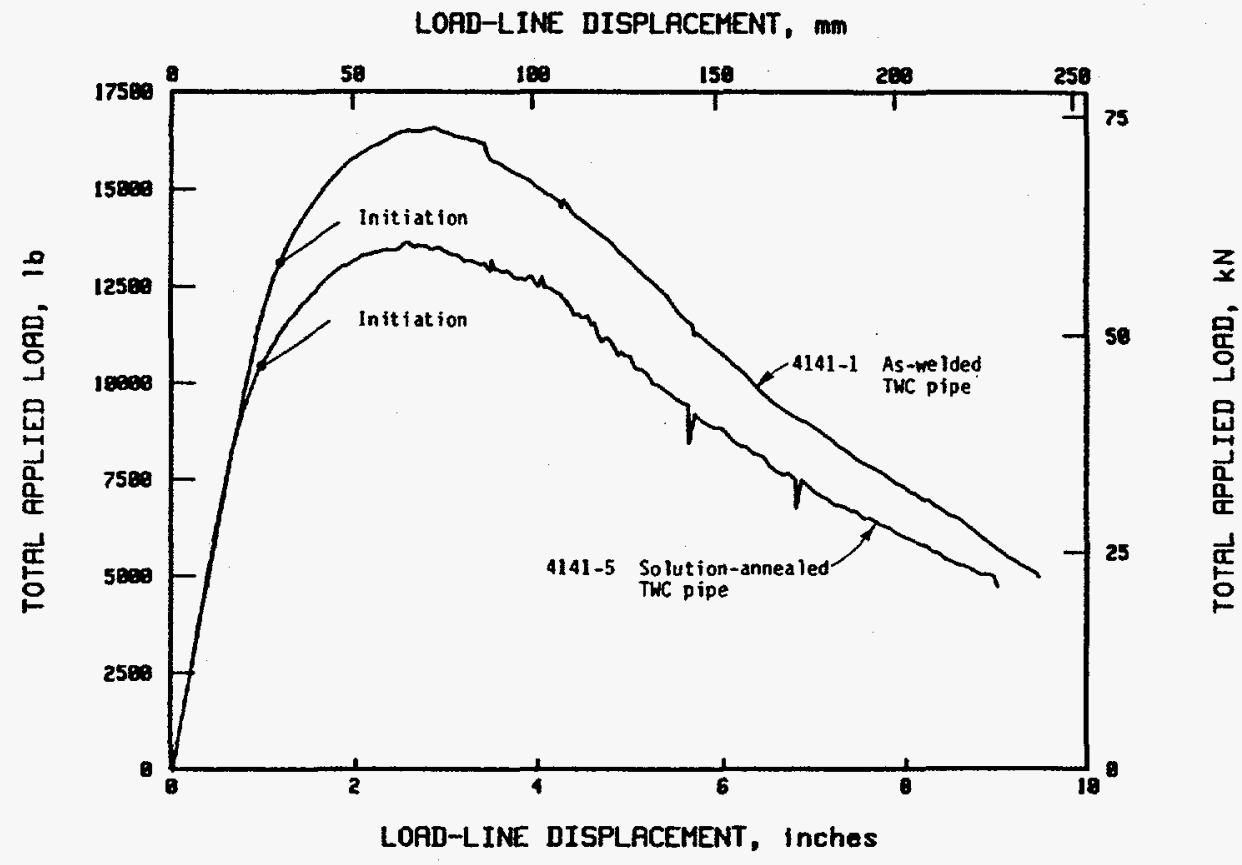

(a) 152-mm (6-inch) through-wall-crack experiments

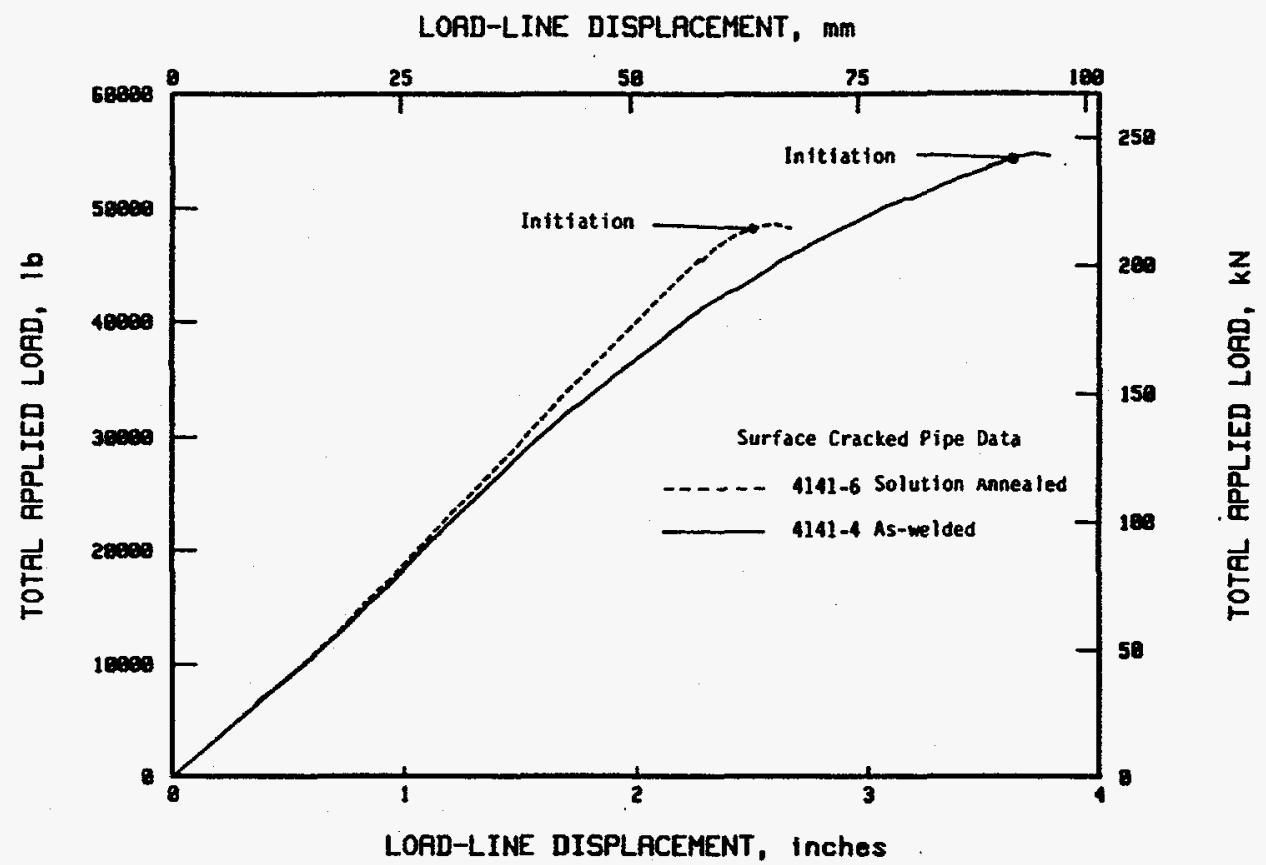

(b) 406-mm (16-inch) surface-crack experiments

Figure 2.3 Comparison of total applied load as a function of load-line displacement for Type 304 stainless steel SAW pipe experiments with as-welded and solution-annealed stainless steel submerged arc welds 


\subsubsection{Effect of Weld Residual Stresses on Crack Opening Displacement}

In recent years, the ability to analytically model weld residual stresses has taken a dramatic step forward (Ref. 2.9). Consequently, there have been more analyses to evaluate the effect of weld residual stresses on crack behavior. In References 2.10 and 2.11 , such efforts were undertaken as scoping efforts. The results showed that the weld residual stresses, if they involve through-thickness bending stresses (tension on one surface to compression on the other surface), could cause the crack faces to rotate. These types of residual stresses usually occur with thinner-walled piping, typically less than $25-\mathrm{mm}$ (1-inch) thick. Thicker pipe has a tension-compression-tension residual stress field through the thickness, which produces much less crack face rotation.

The rotation of the crack faces by itself is not important for leak-rate considerations (Ref. 2.10); rather the important aspect is whether or not the crack faces rotate enough to touch and effectively reduce the length of the leaking crack. This rotation to the touching condition depends on the magnitude of the applied stresses. Figure 2.4 from Reference 2.10 shows that the magnitude of the effect is important for systems operating at low to medium operating stresses with the thin-walled pipe residual stress distribution. For the thick-walled pipe type of residual stress distribution, the residual stress effects on leak rate were found to be negligible, except at unrealistically low applied stress levels.

The analytical evaluations conducted above were for a few specific cases. They point out the need to consider residual stresses for LBB applications for pipe less than 25-mm (1-inch) thick. The precise limit on this thickness is an aspect that needs further evaluation. Nevertheless, for smaller diameter pipe that has a lower thickness, the weld residual stresses may be important from a crack-opening area/leak rate perspective.

Finally, one also has to wonder whether concern about weld residual stresses is somewhat artificially driven by the LBB procedure used in the U.S. NRC SRP 3.6.3. In that procedure, one assumes a throughwall crack that is detectible by the leakage system. If there really were residual stresses, it is hard to imagine that they could cause a crack to grow through the thickness and then have the crack faces touch from the rotation effects. Clearly, the basic LBB philosophy needs to be examined further.

\subsubsection{Variability on Seismic Time Histories}

In the IPIRG-2 program, considerable time was spent on the design of a meaningful seismic time-history to use in the experiments conducted in that program (Ref. 2.12). The various U.S. NRC and ASME seismic design criteria were met, and the selected time history was reviewed with the international participants in the program. Also as part of that program, a round-robin effort was undertaken to explore the creation of time-histories from a common response spectrum (Ref. 2.11). In that round-robin effort, the participants generated displacement time histories. The various displacement-time histories were then used in the same piping stress analysis model of the IPIRG pipe loop with 0.5 percent and 2-percent damping. Figure 2.5 illustrates the differences in the moment-time histories at the crack location in the IPIRG pipe loop. Not only were there some differences in the peak magnitude, but there were also differences in the way the amplitudes built up and the number of large amplitude cycles. As discussed elsewhere in this report, the gradual build-up of the cyclic amplitudes is more damaging to the material toughness than a single large amplitude cycle. A more rapid build-up of large amplitudes will not cause cyclic degradation effects on 


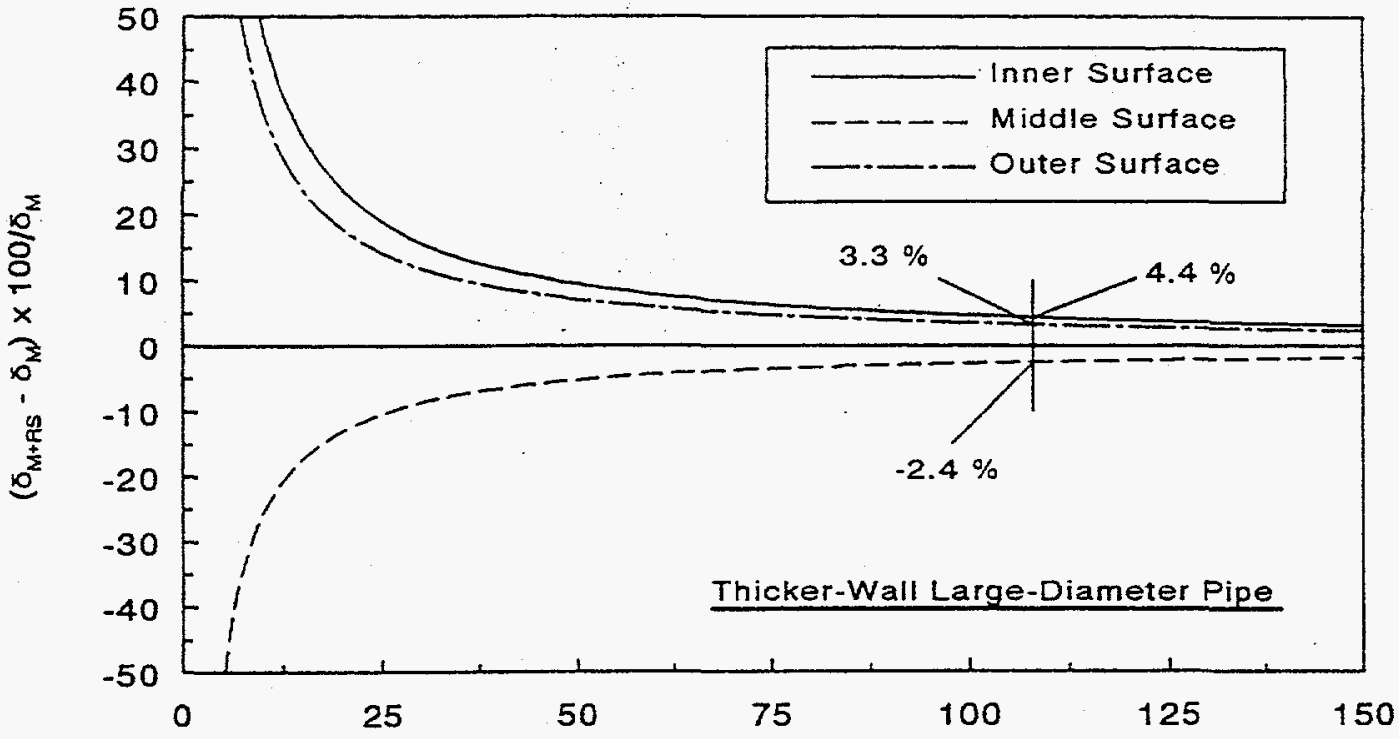

Applied Moment; \% of Service Level A

(a) Thick-walled large-diameter pipe

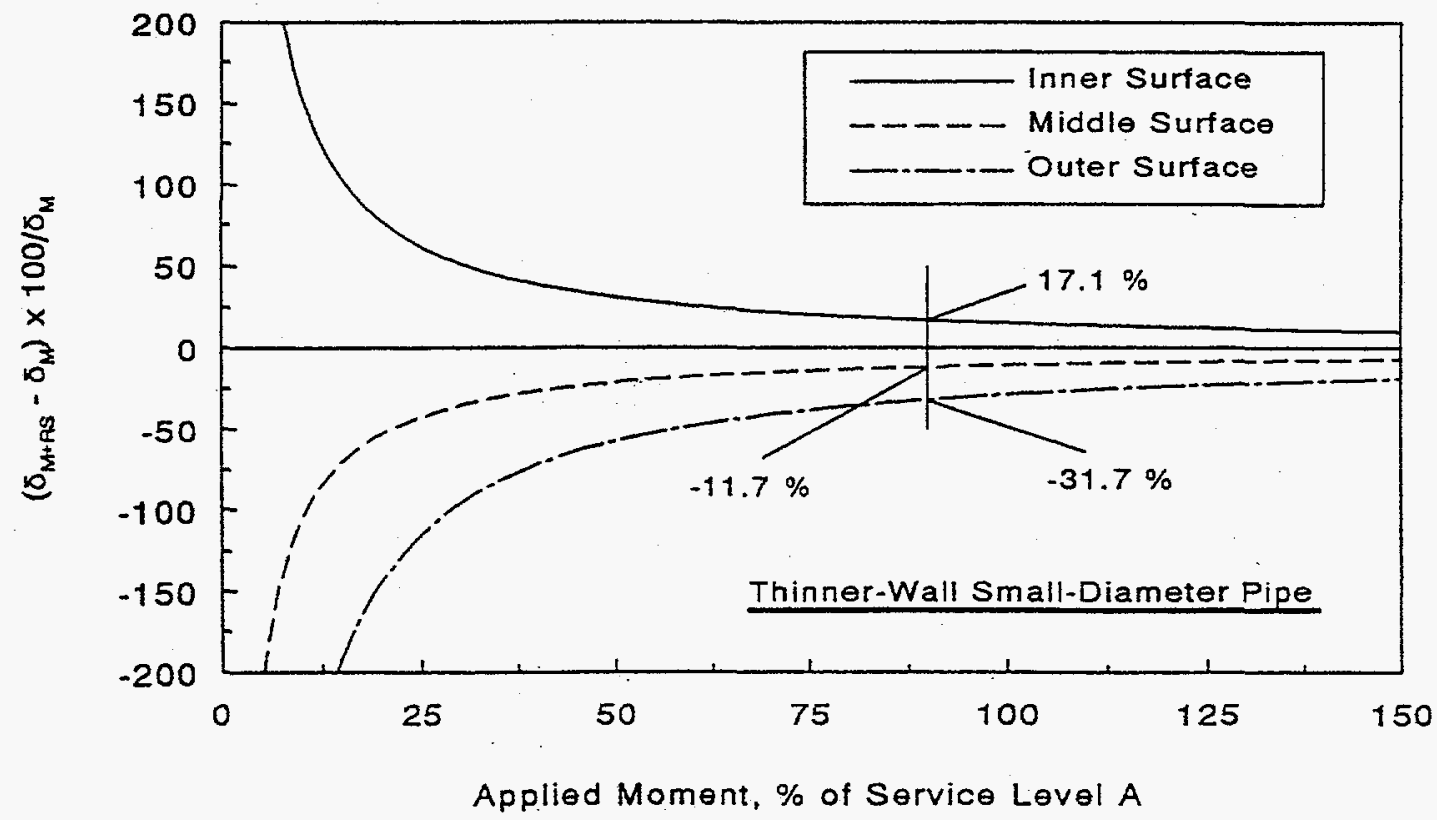

(b) Thin-walled small-diameter pipe

Figure 2.4 Percentage change in calculated COD due to residual stress as a function of applied moment 

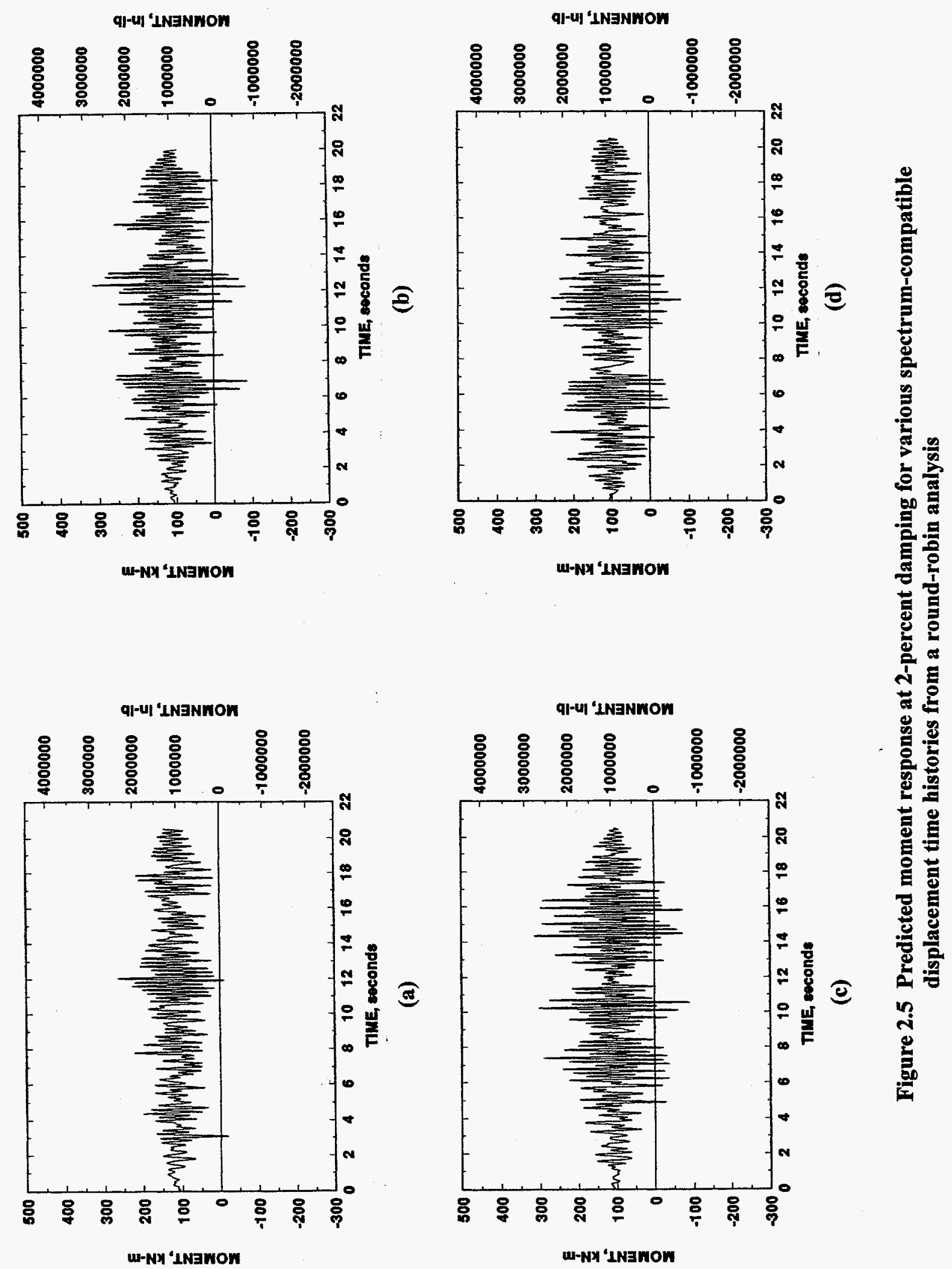
the material toughness, but there would still be dynamic effects on the toughness. Also, the number of large amplitude cycles will determine how far a crack may propagate for stability purposes.

Consequently, there is inherent scatter in the prediction of seismic time-histories. Some subset of these time-histories would cause cyclic degradation effects to occur, but all of them would show that dynamic loading effects on toughness should be considered.

\subsubsection{Other Interaction Effect Between Fracture Behavior and Piping Stress Analyses}

As noted earlier, typically, the piping stress analysis and the fracture analyses are conducted independently. From the work conducted in the IPIRG program, it has been found that there are some cases where the interaction or coupling of the two analyses is important.

One such case stemmed from the experimental observation of Experiment 1.3-7 from the IPIRG-1 program. In that pipe-system experiment, pressure restraining orifices (endcaps with holes) on either side of the cracked section that had been used in previous experiments were removed. Hence, the full depressurized loads at the saturation pressure were anticipated to contribute highly to the final instability. From the Net-Section-Collapse analysis for a circumferential through-wall cracked pipe under tension loading, it was anticipated that once the crack reached 63 percent of the circumference, the fracture would become unstable. Figure 2.6 shows the fracture surface and the fact that the crack remained stable until it reached 95 percent of the circumference. This was subsequently explained by examining the Net-SectionCollapse equations for axial tension, and eliminating the induced rotation effect, see Figure 2.7. If the rotational aspects were suppressed, then the predicted and experimental crack lengths at instability were properly predicted. This is an encouraging aspect for pipe fracture stability behavior. In effect, the pipesystem boundary conditions prevented free rotation of the pipe ends from the pressure-induced moments and increased the load-carrying capacity.

Further experimental data concerning the role of restraint of pressure-induced bending also exists in the comparison of the accuracy of analysis methods for pure bending to combined pressure and bending cases. The analyses are reasonably accurate for pure bending, but tend to become more conservative for the combined-load pipe tests. In these experiments (Refs. 2.13 and 2.14), the pipes are first pressurized and then loaded in four-point bending under displacement-controlled conditions. Hence, even in the simple four-point bend pipe tests, free rotation of the pipe is not allowed. This restraint of the pressure-induced bending is not included in any of the existing pipe fracture analyses. Some corrections to the existing surface-crack and through-wall-cracked pipe analyses appear to be warranted.

Another related aspect that was subsequently investigated in Reference 2.15 was the effect of this restraint of the induced bending on the crack-opening displacements. Since the restraint of the bending lowers the crack-driving force, and the crack-opening displacement is proportional the driving force, it is natural to assume that the crack-opening displacement would be reduced by this effect. In Reference 2.10 , a limited elastic finite element analysis study was conducted. Figure 2.8 shows these results. In this analysis, it was shown that if the initial crack length was small (as in LBB for large diameter pipe), then the effect of this restraint on the crack-opening displacement was negligible. As the crack length becomes longer, however, the effect on the center crack-opening displacement becomes very significant. 


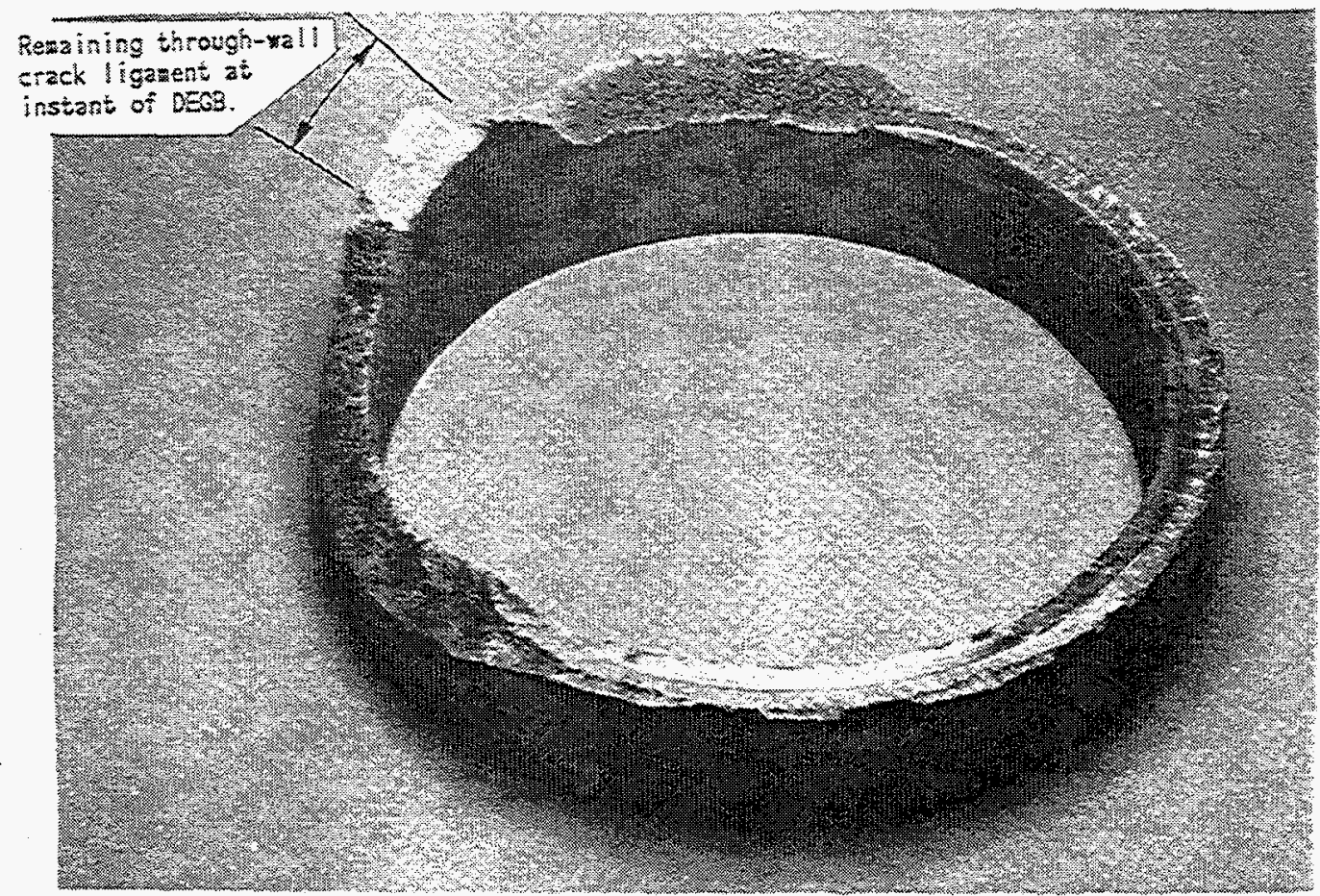

Figure 2.6 Photograph of fracture from aged cast stainless experiment (Experiment 1.3-7)

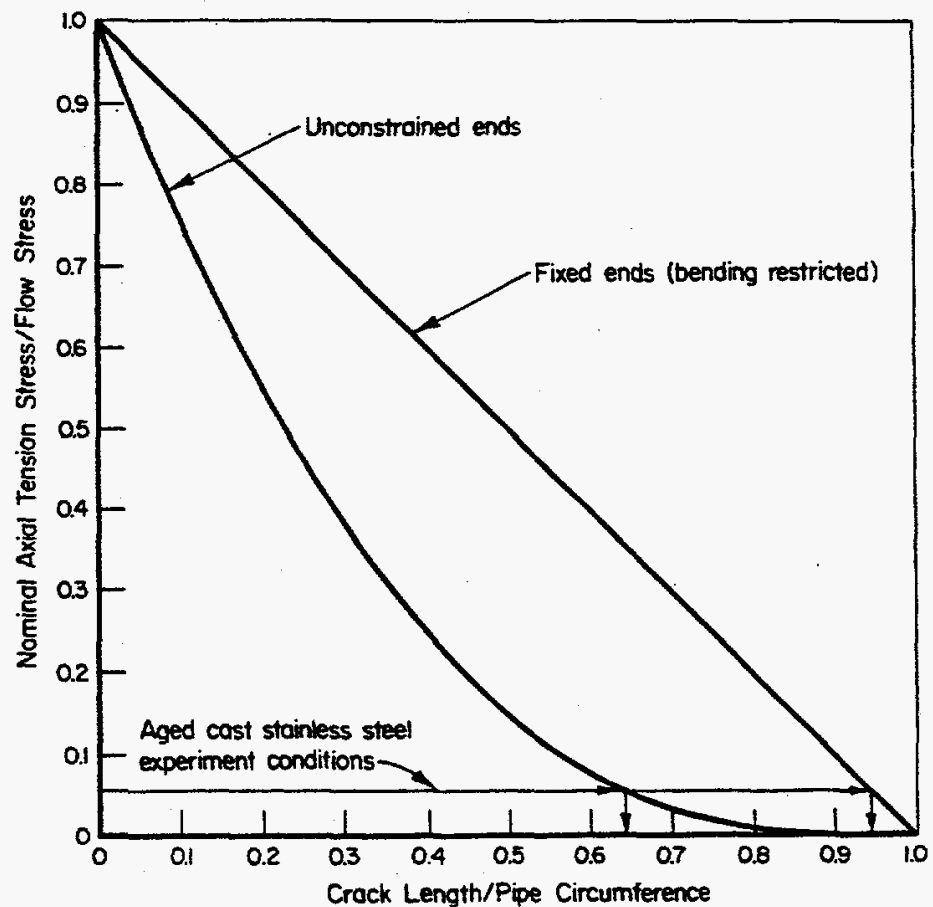

Figure 2.7 Net-Section-Collapse analyses predictions, with and without considering induced bending, as a function of the ratio of the through-wall-crack length to the pipe circumference 


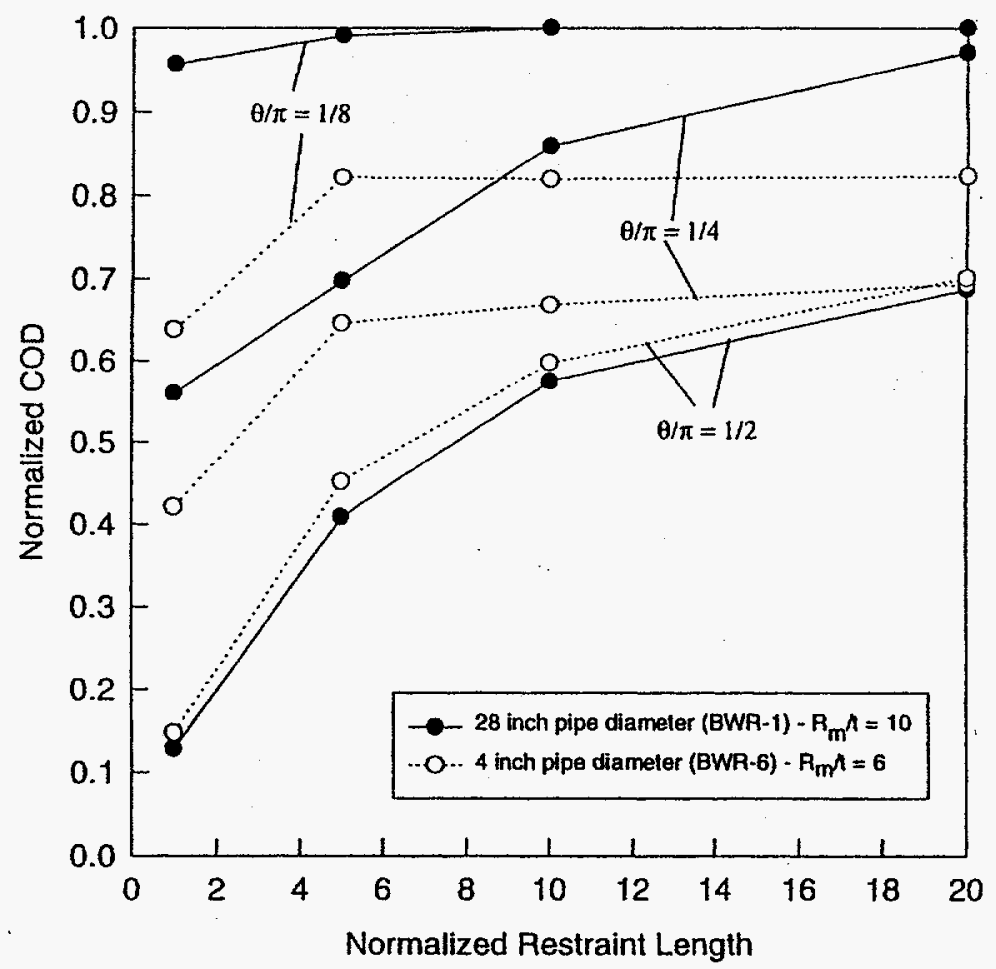

Figure 2.8 Effects of fully restrained bending conditions from crack location on COD normalized by the unrestrained $C O D$

Since the effects of the restraint of induced bending is beneficial to the fracture loads, but detrimental to the crack-opening displacements, a small sensitivity study was conducted in Reference 2.10 to see the combined effect in a LBB analysis. Two pipe sizes were considered in the analysis, 711 -mm (28-inch) diameter and $102-\mathrm{mm}$ (4-inch) diameter. With a leak rate of $1.89 \mathrm{lpm}(0.5 \mathrm{gpm})$, the resulting crack lengths, with and without the restraint of bending, were calculated. The normal operating stresses were 50 percent of Service Level A limits, and the pressure was $15.5 \mathrm{MPa}(2,250 \mathrm{psi})$. The $\mathrm{R} / \mathrm{t}$ ratios were 6 for the small diameter pipe and 10 for the large diameter pipe. The crack sizes were calculated using the SQUIRT leak-rate code (Ref. 2.16), with the crack morphology parameters for an IGSCC. It was further assumed that the crack was in a stainless steel submerged-arc weld. In the fracture analyses, the beneficial effect of the restraint of pressure-induced bending was considered.

The results showed no difference in the failure loads for the large diameter pipe case. In this case, the crack length was only 2-percent of the circumference; and there was no effect from the restraint of the pressure-induced bending on the calculated fracture loads. For the small diameter pipe, the restraint of pressure-induced bending increased the crack length from 24 to 73 percent of the circumference. The difference in the resulting fracture loads was a factor of nine.

The above study showed that pipe-system boundary conditions can have a major effect on pipe fracture behavior, especially for small diameter pipe. Considering that a safety factor of $\sqrt{ } 2$ is used, there may be intermediate diameter pipe where this effect is also significant. 


\subsection{Material Property Validations}

In elastic-plastic piping fracture mechanics, ideally the analyst would like to use the actual stress-strain curve of the material and the actual J-R curve. Historically, the quasi-static monotonically-loaded specimen data are used, whereas in a seismic event there are dynamic loading rates and cyclic effects during the ductile tearing. These dynamic and cyclic effects on the material properties constituted a significant part of the IPIRG program investigations. In fact, one may actually only have a database of similar material properties, or mill data at room temperature (yield, ultimate, and perhaps Charpy data at a few temperatures if you are lucky). The question of similarities and differences in $\mathrm{J}_{\mathrm{Ic}}$ and $\mathrm{J}-\mathrm{R}$ curve standards from different countries, and extrapolation of a J-R curve for large amounts of crack growth also are of concern. These aspects, along with some particular material observations, will be discussed in this section.

\subsection{1 $J_{I c}$ and J-R Curve Standards from Different Countries}

Different standards exist in many countries for J-integral fracture toughness testing. Some of them investigated as part of an IPIRG-2 program round-robin (Ref. 2.11) were:

- $\quad$ ASTM E813 (for $\mathrm{J}_{\mathrm{Ic}}$ )

- $\quad$ ASTM E1152 (for J-R curves)

- JSME S 001-1981 and JSME S 001-1992 (for $\mathrm{J}_{\mathrm{Ic}}$ )

- $\quad \operatorname{CEGB}\left(\mathrm{J}_{0.2}\right)$

- $\operatorname{ESIS}\left(\mathrm{J}_{0.2}\right.$ and $\left.\mathrm{J}_{0.2 / \mathrm{BL}}\right)$

In this round-robin, multiple specimen data, as well as single specimen crack growth data (from d-c potential drop), were supplied to the participants. The calculated J-R curves were essentially the same in all cases, since the methods used by the various participants were based on the same ASTM E1152 deformation plasticity analysis procedure. The standard deviation of the difference in the calculated values was less than 10-percent of the mean value at various $\mathrm{J}$ levels. This is somewhat higher than J-R curve round-robin efforts under taken with U.S. NRC contractors during the early part of the Degraded Piping Program, see Section 3.1.3 in Reference 2.17.

The $J_{\mathrm{Ic}}$ values calculated using the various $\mathrm{J}$-integral fracture toughness standards differed considerably. This is probably due to some of the methods calculating $J$ values at some small amount of crack growth, i.e., at $0.2 \mathrm{~mm}$ of crack extension. The $\mathrm{J}_{\mathrm{Ic}}$ values varied by about 20 -percent. $\mathrm{J}$ is proportional to moment to the $n+1$ power, where $n$ is the strain-hardening exponent of the material. Since $n$ may be from 4 to 10 , a difference of 20-percent on $\mathrm{J}_{\mathrm{Ic}}$ has very little impact on predictions of the bending moment.

It should be pointed out that this was a limited study, and that similar studies probably have also been undertaken by some of the various standards organizations.

\subsubsection{Estimating Material Properties Using Mill Data}

In some (probably very few) cases, one might have mill data on the pipe material of interest. Assuming that the data can be found, the question of how well one might be able to predict the properties at high 
temperature from such data might arise. In the IPIRG-2 program, such a round-robin effort was conducted (Ref. 2.11).

In the following discussions, the most successful of the methods are reviewed. These methods were subjected to only a limited evaluation, and hence should be scrutinized further prior to actual implementation.

\subsubsection{Predicting High-Temperature Yield and Ultimate Strengths of Ferritic Steels from Mill Data}

To conduct this round robin, three different ferritic steels (two base metals and one weld metal) were used. In the prediction of yield and ultimate strengths at $288 \mathrm{C}(550 \mathrm{~F})$ from the room temperature data, many people used the trend curves from Section II of the ASME Boiler and Pressure Vessel Code. The yield strength was predicted to within \pm 9 percent, but the ultimate strength was underpredicted by about 20 percent in all cases. The actual higher ultimate strength is probably due to some dynamic strain aging that occurs in most low carbon ferritic steels at temperatures between $150 \mathrm{C}$ and $350 \mathrm{C}$ ( $300 \mathrm{~F}$ to $660 \mathrm{~F}$ ), see Reference 2.18.

\subsubsection{Predicting High-Temperature Stress-Strain Curves of Ferritic Steels from Mill Data}

The next step in this round-robin activity was to predict the stress-strain curve of the materials at $288 \mathrm{C}$ $(550 \mathrm{~F})$. In this effort, a few participants were very close for some materials, but some were significantly in error. The best results came from using the following equations from EPRI NP-2431 (Ref. 2.19).

$$
\begin{gathered}
\left(\sigma_{\mathrm{u}} / \sigma_{\mathrm{y}}\right)\left[\mathrm{e}^{1 / \mathrm{n}} /\left(1.002+\sigma_{\mathrm{y}} / \mathrm{E}\right)\right]=\left[(1 / \mathrm{n}) / \ln \left(1.002+\sigma_{\mathrm{y}} / \mathrm{E}\right)\right]^{1 / \mathrm{n}} \\
\alpha=\left[\ln \left(1.002+\sigma_{\mathrm{y}} / \mathrm{E}\right)^{1 / \mathrm{n}} /\left(1.002+\sigma_{\mathrm{y}} / \mathrm{E}\right)\right]^{\mathrm{n}} /\left(\sigma_{\mathrm{y}} / \mathrm{E}\right) \\
\epsilon_{\mathrm{p}} / \epsilon_{\mathrm{y}}=\alpha\left(\sigma / \sigma_{\mathrm{y}}\right)^{\mathrm{n}}
\end{gathered}
$$

\subsubsection{Predicting Charpy Upper Shelf Energies of Ferritic Steels from Mill Data}

The next round-robin effort was to use the Charpy and shear area percent data to predict the Charpy upper shelf energy. Figure 2.9 shows one correlation used that is very helpful in such an analysis (Ref. 2.20). By predicting the upper shelf energy of the Charpy specimen, one is then better able to predict the $\mathrm{J}_{\mathrm{Ic}}$ and J-R curve of the material.

The equation for the mean value upper shelf energy is 


$$
\mathrm{CVP}=\mathrm{CVE} * 100 /(\mathrm{SA}+3)
$$

where

CVP $=$ Charpy upper plateau energy

CVE = Charpy energy at some specified temperature

$\mathrm{SA}=$ Shear area percent for the specimen with the CVE value.

The Charpy upper shelf energies were overpredicted by 20 to 25 percent, suggesting that some lower correlation than the average shown in Figure 2.9 should be used.

The equation for the mean minus two standard deviations is

$$
\mathrm{CVP}=\mathrm{CVE}^{*} 100 /(\mathrm{SA}+25)
$$

which is perhaps too conservative. The equation for the mean minus one standard deviation is

$$
\mathrm{CVP}=\mathrm{CVE}{ }^{*} 100 /(\mathrm{SA}+12.5)
$$

which does a reasonably accurate job for some of the nuclear ferritic pipe steels we have examined. This correlation works better for Charpy data where the shear area percent is greater than 40 percent.

\subsubsection{Predicting High-Temperature $\mathbf{J}_{\text {Ic }}$ Values of Ferritic Steels from Mill Data}

In the prediction of the $\mathrm{J}_{\mathrm{Ic}}$ values from the Charpy data, the predictions were not very good. The best results occurred for the base metals when using the Rolfe-Novak equation (Ref. 2.21):

$$
\mathrm{J}_{\mathrm{Ic}}=5 \sigma_{\mathrm{y}}\left[\mathrm{CVP}-\sigma_{\mathrm{y}} / 20\right] /\left[\mathrm{E}\left(1-v^{2}\right)\right]
$$

This equation overpredicted the J-R curve of the weld metal.

\subsubsection{Predicting High-Temperature J-R Curves of Ferritic Steels from Mill Data}

In the IPIRG round-robin efforts, there was a problem predicting the J-R curve from mill data. For the prediction of the J-R curve, several of the methods overpredicted the actual J-R curve for one material or another. The only method that was either close to or below the actual J-R curve used the following approach. 


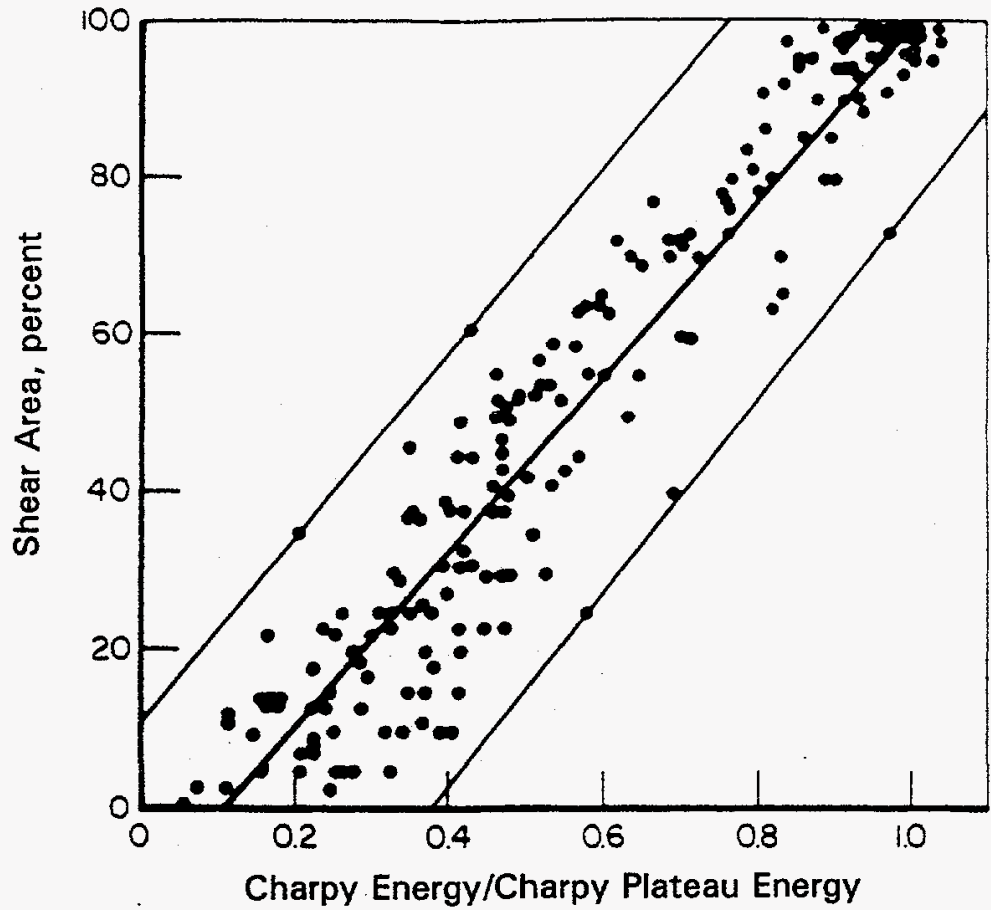

(a) Natural gas line-pipe steels

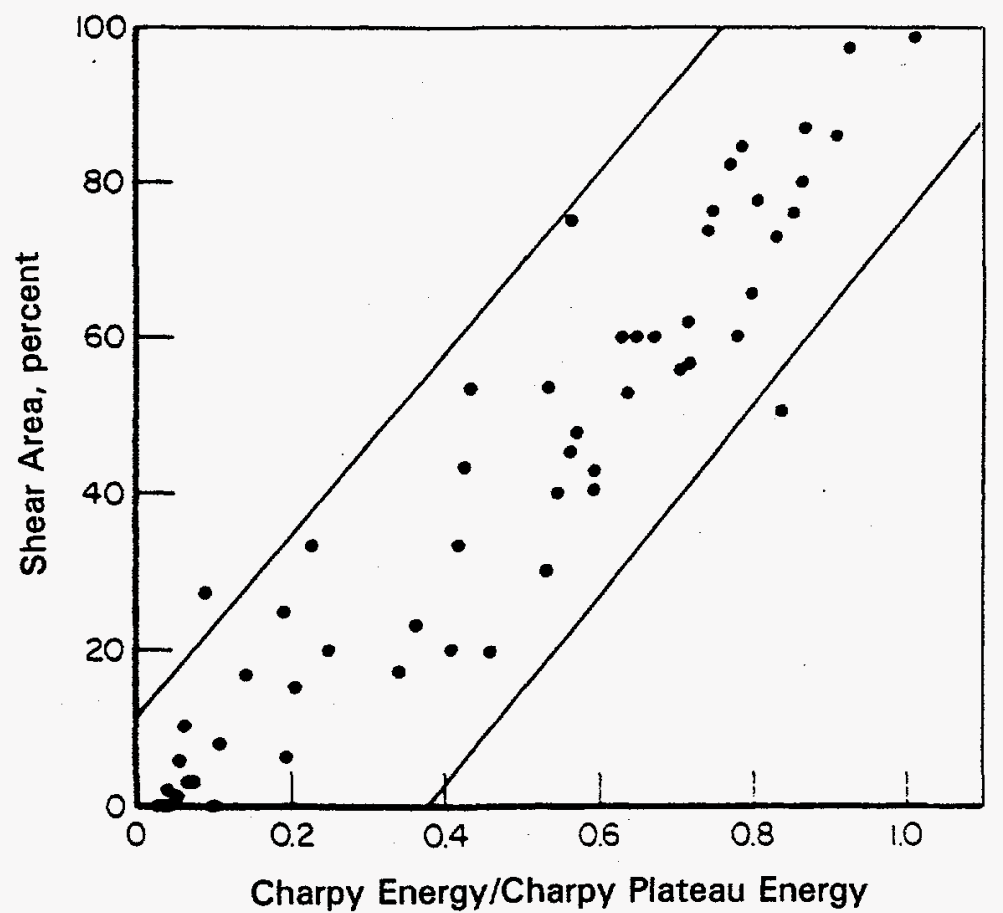

(b) Nuclear piping materials from the Degraded Piping program

Figure 2.9 Correlation between Charpy V-notch energy and shear area percent to predict the plateau energy of carbon steels 
For carbon steel base metals, it was assumed that the power law exponent, $m$, in the following equation was equal to 0.4 .

$$
\mathbf{J}=\mathrm{C}_{3} \Delta \mathbf{a}^{\mathbf{m}}
$$

The constant $\mathrm{C}_{3}$ was calculated from

$$
\mathrm{J}_{\mathrm{Ic}}=\mathrm{C}_{3} \Delta \mathbf{a}_{\mathrm{Ic}}^{\mathrm{m}}
$$

where

$$
\Delta \mathrm{a}_{\mathrm{lc}}=\mathrm{J}_{\mathrm{Ic}} / \sigma_{\mathrm{y}}+0.2 \mathrm{~mm}
$$

The results in the prediction of the J-R curve here were really based on experience for materials of this class, rather than any strong correlations. Correlations between Charpy energy and J-R curves have been developed by Hiser for the U.S. NRC (Ref. 2.22), Pavinich who based his correlation on earlier work by Richie and his colleagues (Ref. 2.23), Kussmaul and Roos of MPA-Stuttgart (Ref. 2.24), and Eason and coworkers for the U.S. NRC (Ref. 2.25). The Eason work includes piping base metals and piping welds, as well as reactor pressure vessel steels. The work of the others focused on reactor pressure vessel steels, explicitly to account for the effect of irradiation embrittlement.

In addition, work by Wilkowski and Scott (Ref. 2.20) showed that a correlation between Charpy upper shelf energy and $\mathrm{J}_{\mathrm{Ic}}$ exists that could be used in their empirical Dimensionless Plastic-Zone Parameter (DPZP) analysis. This criterion is

$$
\mathrm{J}_{\mathrm{Ic}}=7.5(\mathrm{CVP})
$$

where

$$
\begin{aligned}
& \mathrm{J}_{\mathrm{Ic}}=\mathrm{J} \text { value at initiation in units of in-lb/in } \\
& \mathrm{CVP}=\text { full-size specimen Charpy upper shelf energy in units of } \mathrm{ft}-\mathrm{lb} .
\end{aligned}
$$

The Battelle DPZP analysis predicts the maximum load for a cracked pipe based on the initiation toughness. Although using the initiation toughness to predict the maximum load seems technically questionable, it should be noted that this is an empirical relationship. However, since $\mathrm{J}_{\mathrm{Ic}}$ is proportional to Charpy energy, and $\mathrm{dJ} / \mathrm{da}$ has also been shown to be proportional to Charpy energy, this is not a completely unreasonable approach. 


\subsubsection{Significance of Scatter in Predicting High-Temperature Properties from Mill Data on Pipe Fracture Predictions}

One of the exercises in the IPIRG-2 round-robin efforts (Ref. 2.11) was to determine the magnitude of the error if the high-temperature properties predicted from the mill data were used in predicting the loadcarrying capacity for cracked pipe. A number of cases were examined. These included circumferential surface and through-wall cracks in small diameter and large diameter pipe, as well as small and large crack sizes for both surface and through-wall cracks. In some cases, there were actual pipe test data to check the absolute accuracy of the predictions, as well as the relative trends of the predictions.

Numerous graphs of these predictions are given in Reference 2.11 , but the results can be briefly summarized as follows. The effect of the variability of the J-R curves on the predicted loads, when using the actual stress-strain curve did not affect the predicted loads very much. The effect of the variability of the stress-strain curve on the predicted loads when using the actual J-R curve was much more significant on the predicted loads.

\subsubsection{Extrapolated J-R Curves for Large Amounts of Crack Growth}

In piping fracture mechanics, it is frequently desirable to extrapolate J-R curves to larger amounts of crack growth than allowed by current standards. This is not generally needed for surface-cracked pipe analyses, but becomes more important for LBB applications, and, if one wants to make an assessment of dynamic crack propagation and actual fracture times for pipe break, then this methodology is essential.

In the ASTM and other J-R curve standards, the crack growth from typical specimens is limited to 10 percent of the initial ligament of the specimen. Typically, 1T C(T) specimens are used, and the amount of allowed crack growth for this specimen is about $2.5 \mathrm{~mm}(0.1 \mathrm{inch})$. This limit initially came from what was known as an $\omega$-limit (Ref. 2.26) where

$$
\omega=(b / J)(d J / d a)
$$

where $b$ is the ligament of the specimen, and the requirement was that $\omega>>1$. The concern was that the original deformation plasticity J-integral did not allow for unloading that occurred in the wake of the crack during crack growth.

Methods to extrapolate the J-R curve were proposed in NUREG-1061 Volume 3 (Ref. 2.27), which was the basis of the U.S. NRC's SRP 3.6.3 on LBB. In that document, the J-R curve was replotted in J-T space, where

$$
T=(d J / d a)\left(E / \sigma_{y}^{2}\right)
$$

Once $T$ reached a value of 50 , then the J-T curve of the material was extrapolated linearly with the same slope as the $\mathrm{J}-\mathrm{T}$ curve at $\mathrm{T}=50$, see Figure 2.10. This approach, however, seemed very limiting. 


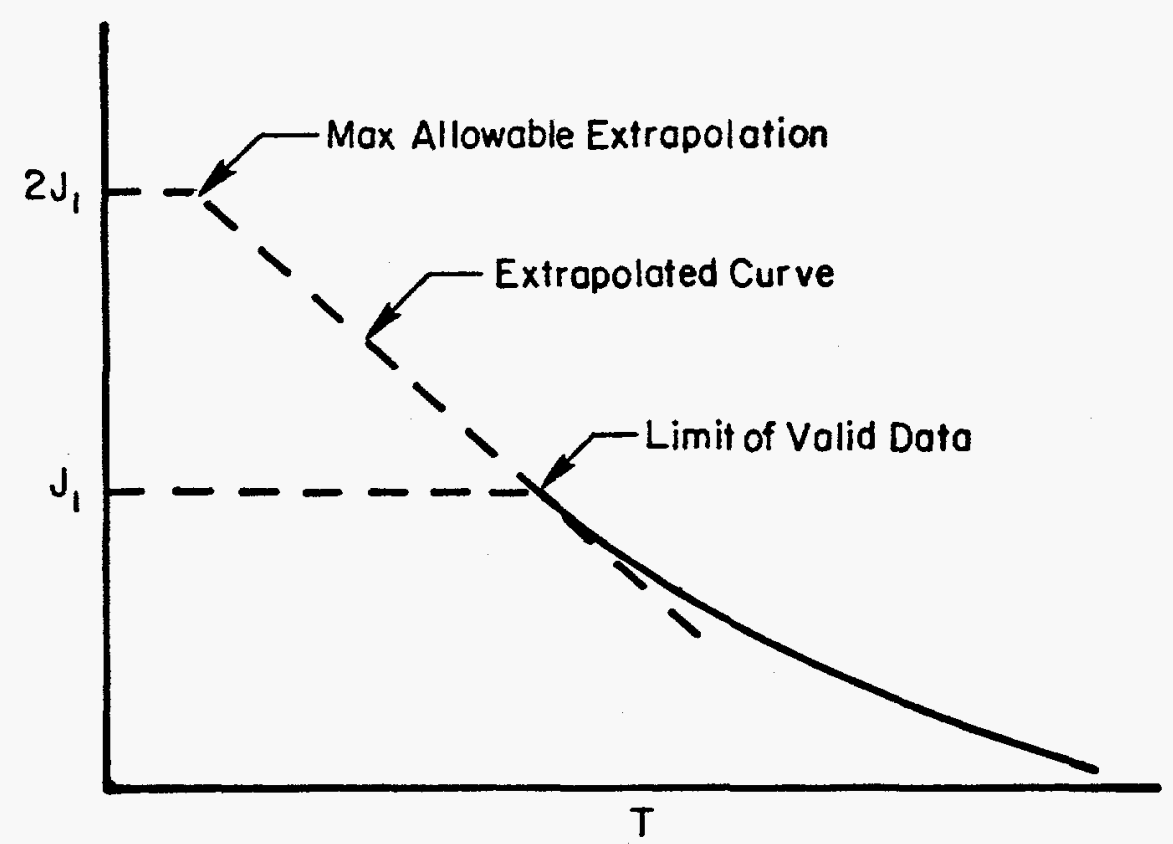

Figure 2.10 Schematic of NUREG $1061 \mathrm{~J}-\mathrm{R}$ curve extrapolation method

Another approach to extrapolating the deformation $J$-integral resistance curve $\left(\mathrm{J}_{\mathrm{D}}-\mathrm{R}\right.$ curve), was to fit a power-law curve to the data. This procedure was evaluated in the U.S. NRC's Degraded Piping Program (Ref. 2.28). In that case, six sets of $C(T)$ specimens were tested in which the thickness was held constant for each set, but the $\mathrm{C}(\mathrm{T})$ planform sizes were 1T, 3T, and 10T. It was found that a power-law fit of the $J_{D}-R$ curve of the data for crack growth to 30 -percent of the initial ligament could be used. Furthermore, the extrapolated $J_{D}-R$ curve from the $1 T$ specimens was always under those for the larger specimens. Hence, this method allowed for more generous extrapolation of the $J_{D}-R$ curve than the $J-T$ procedure, but still in a conservative manner.

Another approach to large crack growth involved the Modified J-integral developed at Westinghouse (Ref. 2.29). The Modified J-integral resistance curve (or $J_{M}-R$ curve) differed from the original deformation $\mathrm{J}$-integral resistance curve $\left(\mathrm{J}_{\mathrm{D}}-\mathrm{R}\right.$ curve $)$ in the crack growth correction term. At crack initiation, the two are identical. The $J_{M}-R$ curve tended to become linear after some small amount of crack growth, whereas the $J_{D}-R$ curve was more power-law in shape, see Figure 2.11. The $J_{M}-R$ curve method was initially included in the ASTM E1152 J-R curve standard. With the linear $\mathrm{J}_{\mathrm{M}}-\mathrm{R}$ curve, extrapolation was relatively easy. $\mathrm{J}_{\mathrm{M}}-\mathrm{R}$ curves from 1T, 3T, and 10T C(T) specimens from Reference 2.30 are shown in Figure 2.11(a).

Difficulties eventually were found with the $J_{M}-R$ curve. The problem was that for a few materials, the $J_{M}-R$ curve tended to hook upward, i.e., the power-law exponent in Equation 2-6 was greater than 1.0. When plotted in $\mathrm{J}-\mathrm{T}$ space, for stability analysis, this behavior predicted that fracture instability would never occur. Since some reactor pressure vessel steels behaved this way, this was a significant regulatory concern. Eventually, the $J_{M}-R$ curve approach fell out of favor, and is no longer in the ASTM standards.

The above discussion on the $J_{M}-R$ curve is important since during the course of the Degraded Piping Program and other U.S. NRC piping fracture programs, it was found that in order to make pipe fracture 


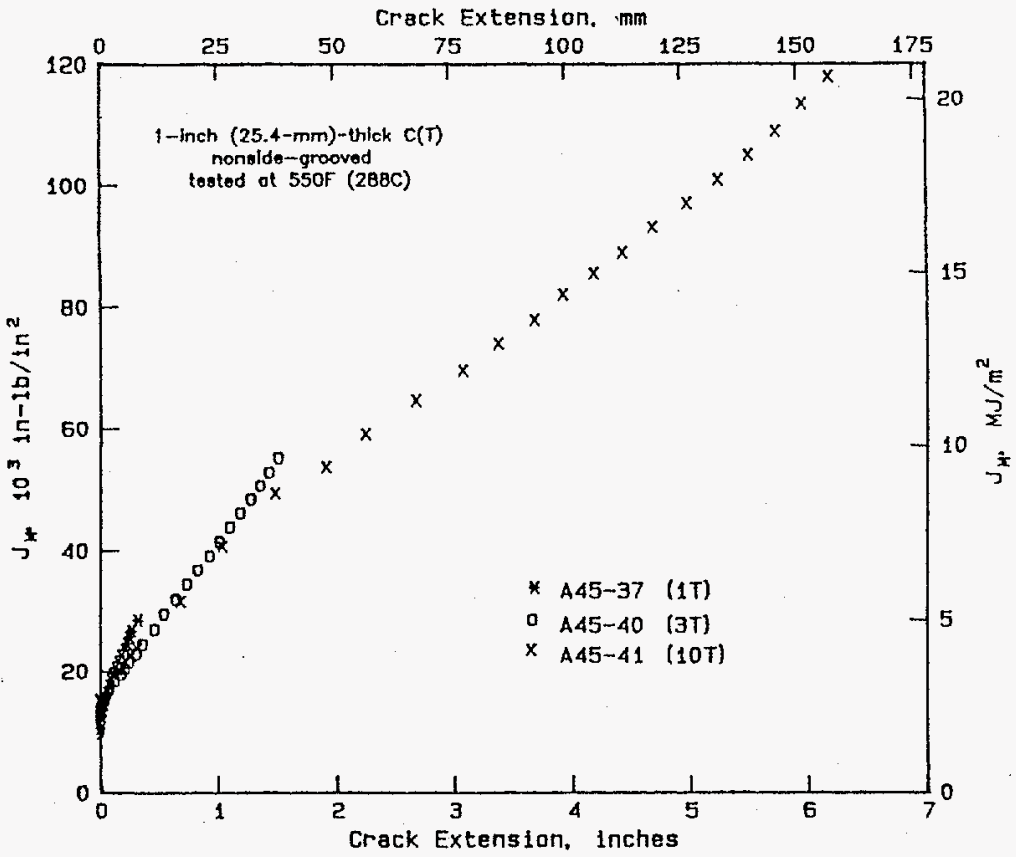

(a) $J_{M}-R$

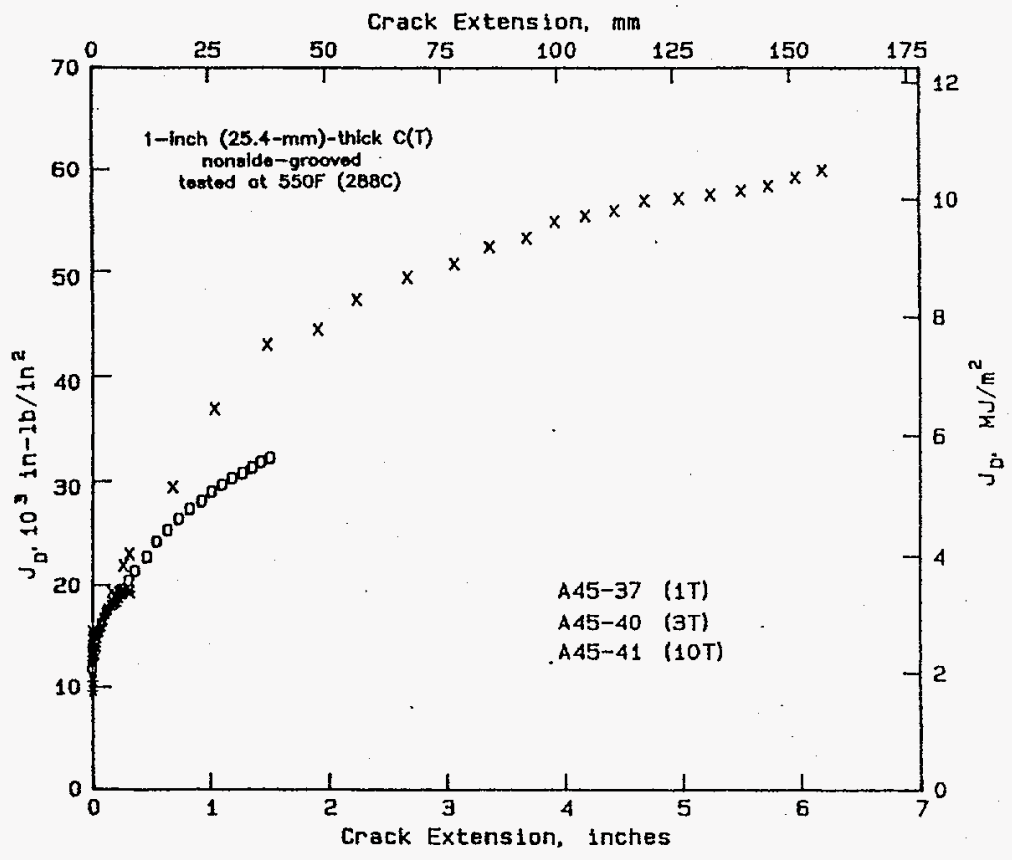

(b) $\mathbf{J}_{\mathbf{D}}-\mathbf{R}$

Figure 2.11 J-R curve for various planform-sized Type 304 stainless steel compact (tension) specimens 
predictions where very large crack extension extrapolations were needed, that the $J_{M}-R$ curve method was the most accurate approach. Figure 2.12 shows comparisons of predicted and actual load-displacement data for a large-diameter pipe test with power-law extrapolated $J_{D}-R$ and linearly extrapolated $J_{M}-R$ curves. The magnitude of the crack growth near the end of the test is about $400 \mathrm{~mm}$ (16 inches) from each of the through-wall-cracked pipe tips. Considering that the $J_{M}-R$ curve was extrapolated from a $1 T$ specimen with $7.5 \mathrm{~mm}(0.3 \mathrm{inch})$ of crack growth, the $\mathrm{J}_{M}-\mathrm{R}$ curve did a remarkable job. The load-displacement predictions using the power-law extrapolated $J_{D}-R$ curve significantly underpredicted the experimental load-displacements.

From the above discussions, it appears that there is still some merit to the $J_{M}-R$ curve, but limitations of some sort are needed. From observations of experimental data, the following was found. First, for the materials where the $J_{M}-R$ curve was well behaved (i.e., $m$ in Equation 2-6 was 1.0), there were cases where the load-displacement curve past maximum load was concave, see Figure 2.13. When there were problems with the $J_{M}-R$ curve, i.e., it hooked upward, it has been seen that for those materials the $J_{D}-R$ curve was linear. For these materials, the load-displacement curve was linear past maximum load. This suggests that one might use the $J_{M}-R$ curve unless it hooks upward. If the $J_{M}-R$ curve hooks upward, then in those cases the $J_{D}-R$ curve should be used. The exact reason for these behaviors should be explored further.

There are, of course, some more advanced methods proposed for extrapolation of crack growth resistance, but these methods are perhaps less pragmatic. The damage mechanics approaches of Roulessier et al. (Refs. 2.31 and 2.32) seem to have a good potential, but require large finite element computational efforts. The Gurson model employed by Shih in References 2.33 and 2.34 employs similar damage mechanics characteristics, and appears more computationally efficient, although it is still computationally intensive and requires good knowledge of this type of methodology.

\subsubsection{Material Property Databases}

Various types of databases exist for piping fracture mechanics analyses. There is a database on piping material properties called PIFRAC, and several databases on piping fracture experiments.

The PIFRAC database was first developed by Materials Engineering Associates for the U.S. NRC (Ref. 2.35). Initially, it ran on a mainframe computer, but later was put in $\mathrm{dBase} I I I+P C$ software-compatible files. PIFRAC was subsequently expanded and corrections were made to the original data. The latest version (Version 3.1) was created by Battelle in the Short Cracks in Piping and Piping Weld program (Ref. 2.36). This version has over $800 \mathrm{~J}-\mathrm{R}$ curves and over 800 stress-strain curves, as well as chemical analyses and Charpy data. The J-R curve data include load-displacement and crack growth data for recalculation of any fracture parameter that might be developed in the future. This database contains data from virtually all past NRC nuclear piping programs (Battelle, Argonne, MEA, and DTRC), EPRI-funded data by Westinghouse and GE, and data from Ontario Hydro.

\subsubsection{Particular Material Toughness Trends}

Some of the observed trends for nuclear piping materials are cited below. All of the data discussed are in the PIFRAC database Version 3.1. 
Section 2

ACHIEVEMENTS AND VALIDATIONS

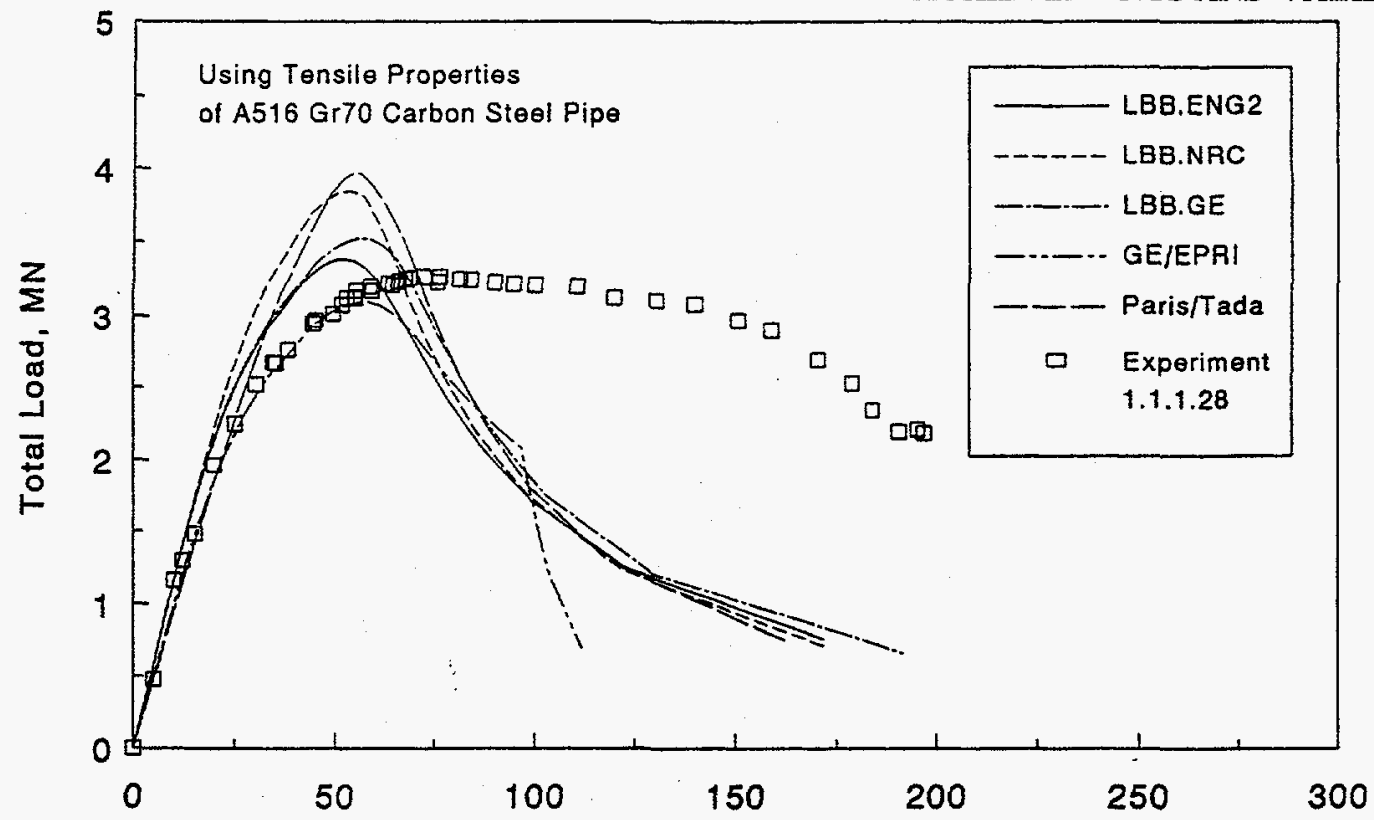

Pipe Displacement at Load Point, mm

(a) Using $\mathbf{J}_{\mathbf{D}}-\mathbf{R}$ curve

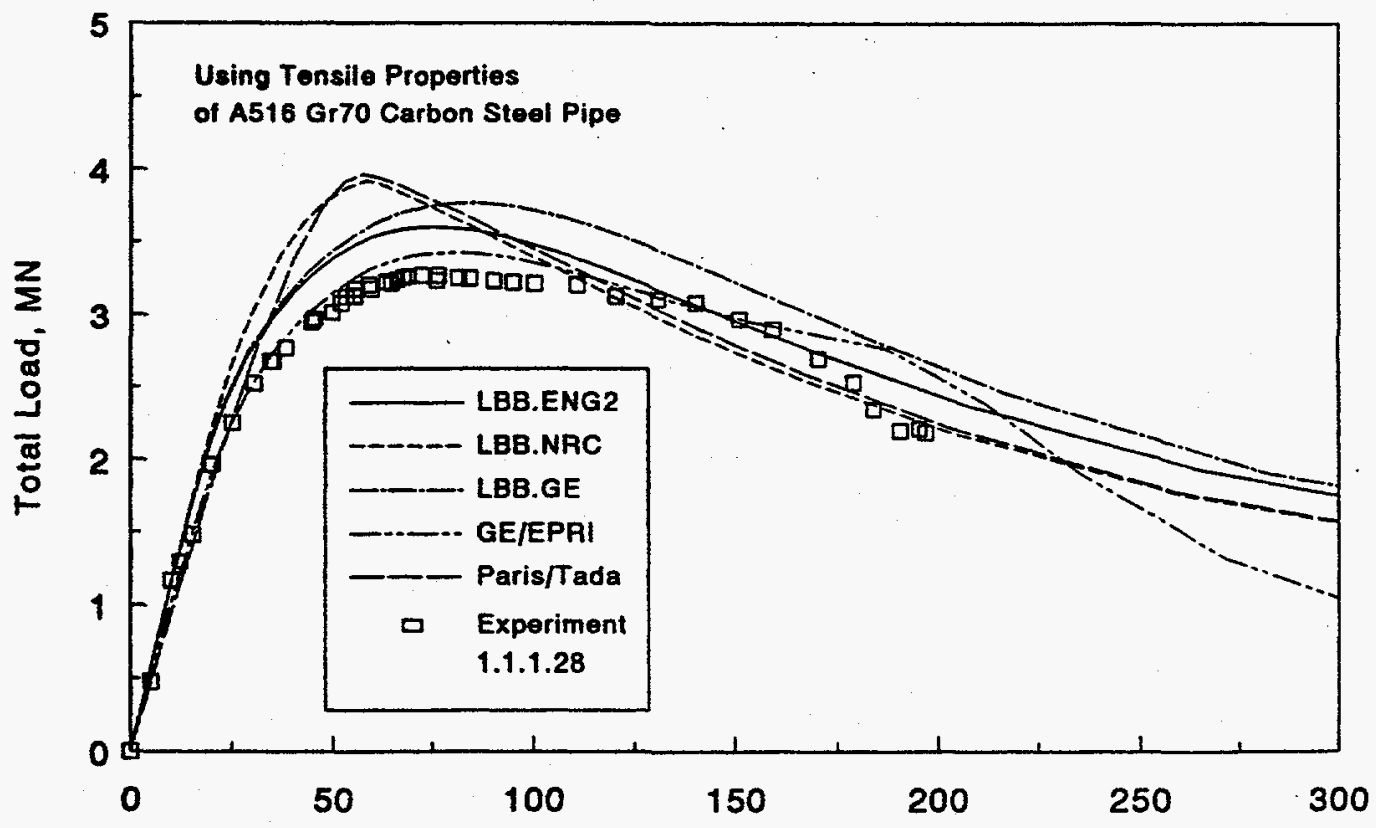

Pipe Displacement at Load Point, mm

(b) Using $J_{M}-R$ curves

Figure 2.12 Comparison of the experimental moment-rotation curve with the predicted momentrotation curves for the bimetal weld cold-leg Experiment 1.1.1.28 from the Short Cracks program for five analysis methods using the $\mathbf{A 5 1 6}$ Grade 70 carbon steel pipe stress-strain data 


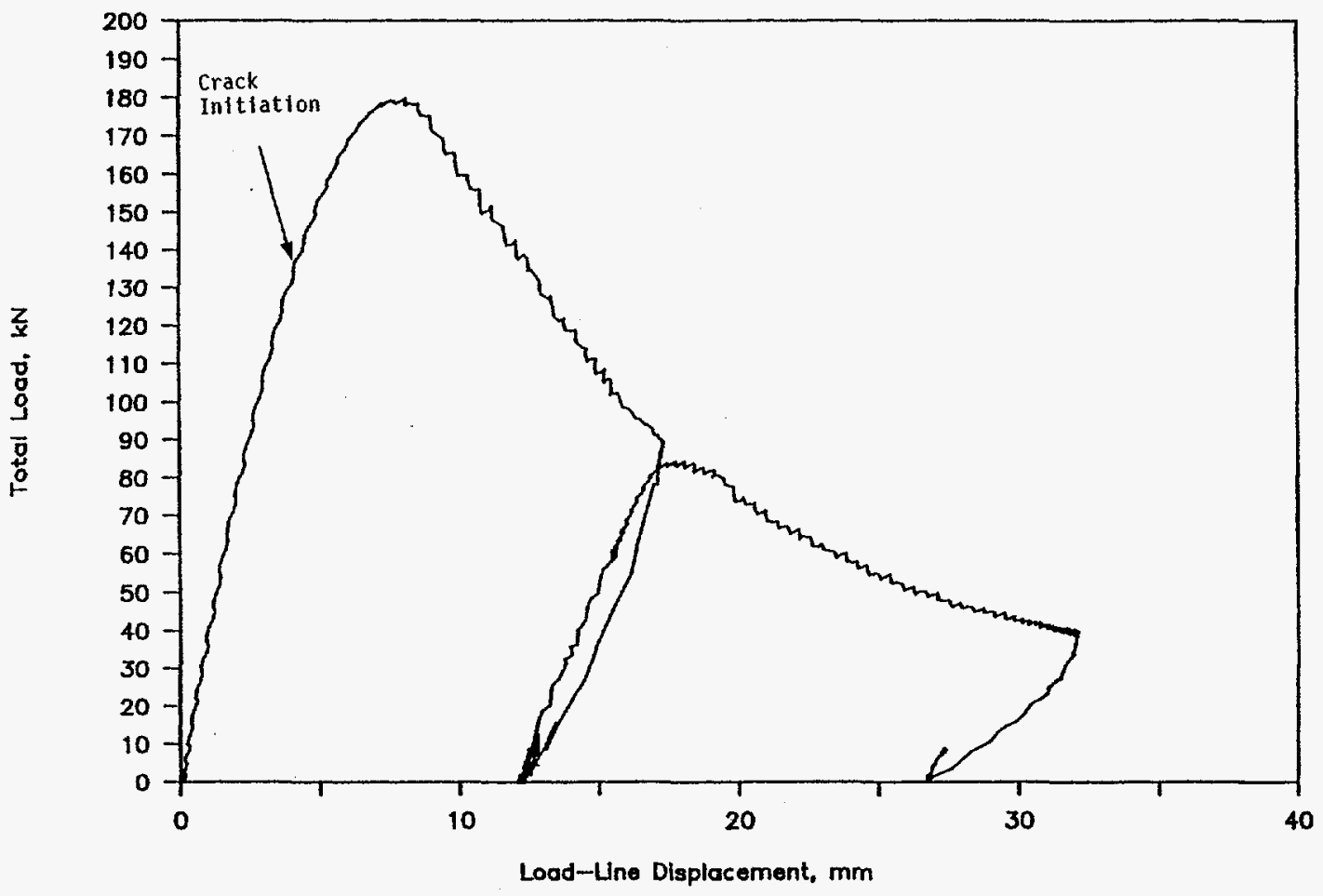

Figure 2.13 Load-displacement data for circumferential through-wall-cracked pipe bending experiment (Experiment 1.2-8) from Pipe DP2-F30 (A106 Grade B carbon steel), tested at $288 \mathrm{C}(550 \mathrm{~F})$ showing concave nature of curve after maximum load

\subsubsection{Testing of Welds}

The testing of welds could involve cases of the cracks in the center of the weld or in the HAZ or along the fusion line.

For the case of a crack in the center of a weld, there is a wealth of interesting data. For instance, for austenitic stainless steel flux welds (SAW and SMAW), it has been assumed by the ASME Section XI Pipe Flaw Evaluation standard, that there is a difference between SMAW, SAW and TIG welds. TIG (or MIG) welds are thought to have toughnesses as high as the base metal. SMAW and SAW welds have lower toughnesses. In the ASME Section XI criteria, it was thought that SAW metal has a lower toughness than SMAW metal. A statistical analysis from the PIFRAC database (Ref. 2.37) showed that there was no difference between the SMAW and SAW J-R curves.

In determining the toughness of weld metals, it is important to ensure that the specimen is close to the same thickness as the weld in the structure. For instance, austenitic SAW welds are typically made by first depositing two passes of TIG weld metal prior to the SAW. With the TIG weld metal having a higher toughness, the weld is really a composite structure. If the pipe is thin, it will have an effectively higher toughness, and if it is thicker, it will have a lower toughness (Ref. 2.8). If data from a thinner pipe is used to analyze a thicker pipe, it would overpredict the actual toughness. 
Another interesting aspect relative to analysis of cracks in weld metals deals with solution annealing of welds. Solution annealing was found in Reference 2.8 to increase the toughness (J-R curve) of the weld metal. To assess the effect of solution annealing on full-scale fracture behavior, identically flawed tests were conducted on as-welded and solution-annealed stainless steel pipe with girth weld cracks (Ref. 2.8). Typical analyses of cracks in girth welds assume that the base metal stress-strain curve should be used, and the weld metal J-R curve should be used. Hence, the solution-annealed pipe, with the higher J-R curve than the as-welded pipe, should have had a higher load-carrying capacity. The experimental results on 152-mm (6-inch) diameter pipes, Figure 2.3(a), and on 406-mm (16-inch) diameter pipe, Figure 2.3(b), showed that the as-welded pipe consistently had a higher load-carrying capacity than the solution-annealed pipe. The main reason for this was that the solution-annealed weld also had a lower yield strength than the as-welded weld metal. Hence, the weld metal strength should be included in the analysis since it is apparently a more important consideration than either the increased toughness from solution annealing or the weld residual stresses.

\subsubsection{Fusion Line Toughness}

In the nuclear industry, cracks are frequently characterized as being in either weld metal or base metal. However, weld cracks could also be in the HAZ or fusion line. For example, stress corrosion cracks typically occur in the sensitized material of a stainless steel weld. If the weld is thin, then the sensitized region may extend away from the fusion line, and the crack may be mainly in the base metal, see Figure 2.14. If the weld is thick, there is a greater heat sink, and the sensitized region is close to the fusion line, see Figure 2.15. From Reference 2.38, it was found that cracks occasionally also went into the weld metal, see Figure 2.16. Because of the lower toughness of the stainless steel weld metals compared with the base metals (about a factor of 10 in most cases), this was a major concern in the development of the ASME Section XI austenitic pipe flaw evaluation criterion. However, Reference 2.38 also showed that stress corrosion cracks tend to follow the fusion line more often than they go into the weld metal.

Fusion line planar flaws could also occur due to weld fabrication problems, i.e., lack of side-wall penetration. The discussion below summarizes some investigations on fusion line toughness.

Bimetallic Weld Fusion Line Toughness. Bimetallic welds occur at several locations in both PWR and BWR primary piping systems. For instance, cast stainless pipe in Westinghouse, Mitsibushi, and Framatome PWRs is welded to reactor pressure vessel and steam generator vessels. Wrought stainless steel pipe is welded to BWR vessels. In CE plants, the primary piping is clad ferritic pipe, that needs to be welded to the cast stainless steel pump housing. Sometimes, safety injection lines are austenitic pipe that are welded to Y-injection nozzles in the cold-leg. Numerous other examples could be cited.

One significant investigation on bimetallic weld fusion line toughness was conducted as part of the NRC's Short Cracks in Piping and Piping Welds Program (Ref. 2.39). In this program, several full-size cold-leg pipe bimetallic welds from a canceled plant were available for testing. The welds were between a 914-mm (36-inch) diameter by 71-mm (2.8-inch) thick A516 Grade 70 pipe and a TP316 stainless steel safe end. The weld metal was all Inconel 182. Prior to testing this material, no J-R curve data were available on such welds.

The material property tests conducted in Reference 2.39 involved tensile tests, Charpy tests along the fusion line, 2T C(T) fracture specimens with the notch along the fusion line, as well as tests in the A516 


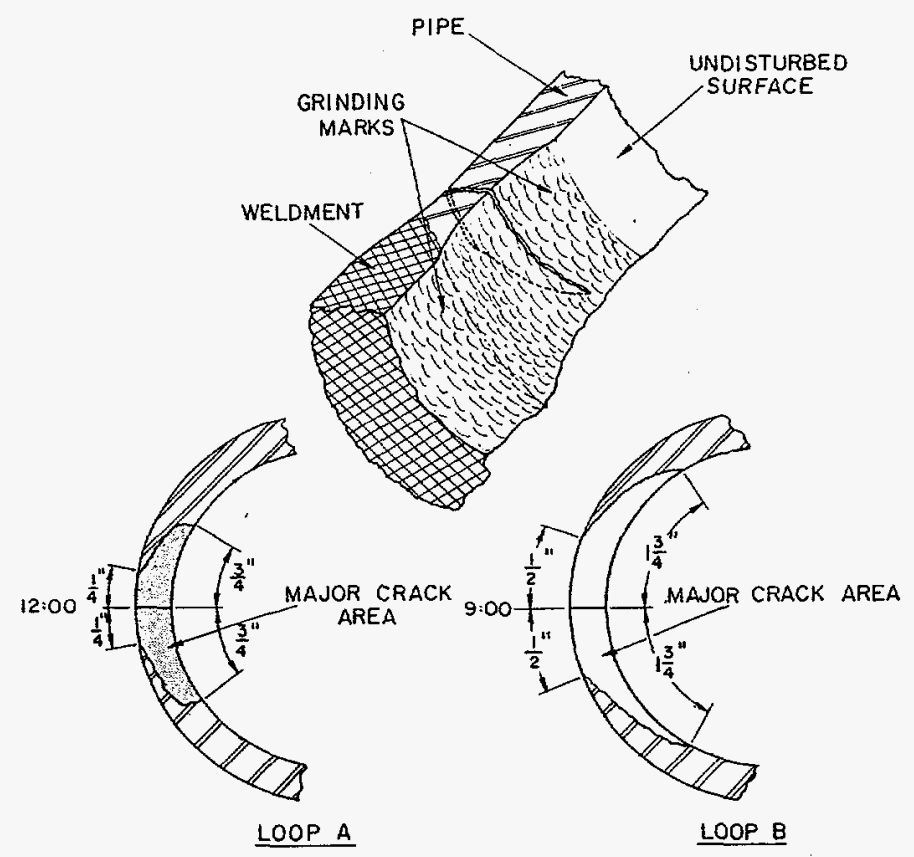

Figure 2.14 IGSCC in 102-mm (4-inch) diameter BWR recirculation bypass line (Loop B of the Quad Cities II reactor)

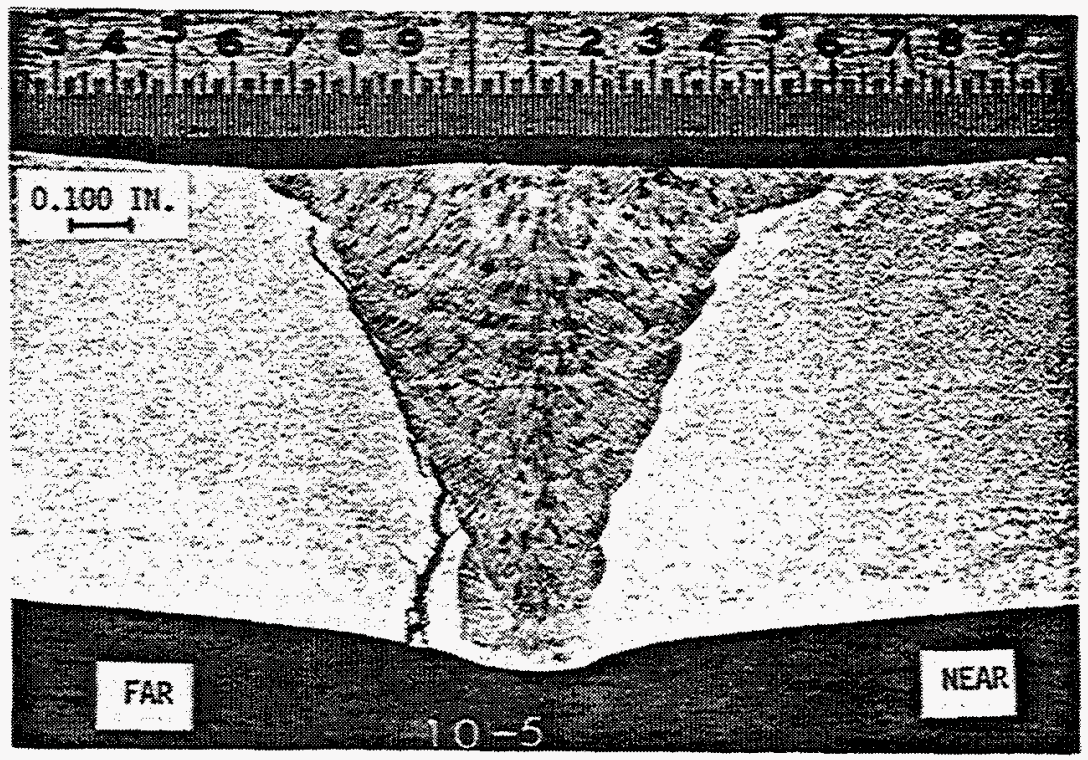

Figure 2.15 IGSCC in Nine Mile Point Plant; 711-mm (28-inch) diameter main recirculation line with cracks growing along the fusion line 

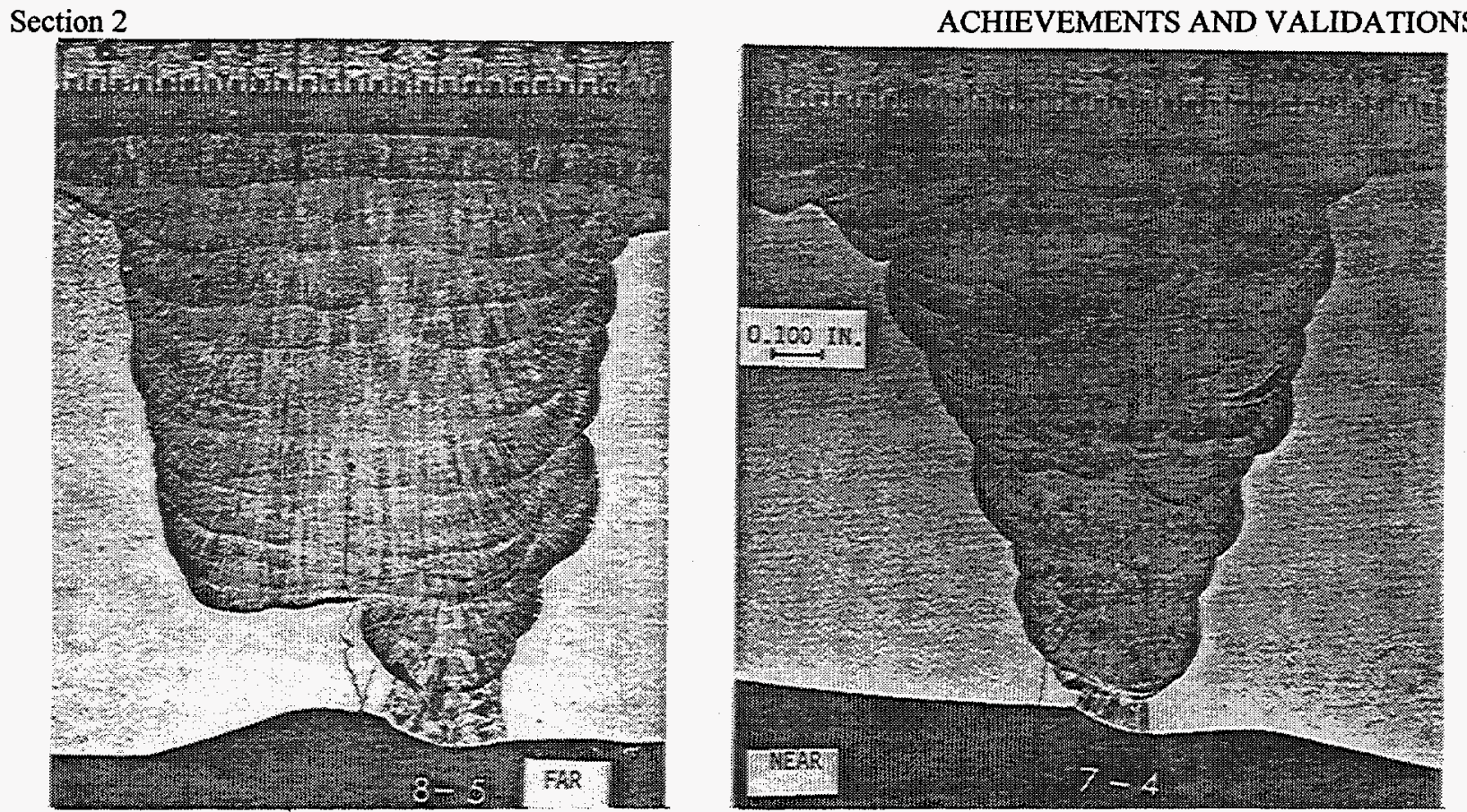

Figure 2.16 IGSCC in Nine Mile Point Plant; 711-mm (28-inch) diameter main recirculation line with a crack growing into the weld metal

Grade 70 base metal and the stainless steel safe end. A full-scale test with a circumferential through-wall crack along the fusion line of the pipe was also conducted. The pipe was loaded in four-point bending at $288 \mathrm{C}(550 \mathrm{~F})$.

The results of these tests showed that the crack stayed predominately in the HAZ of the A516 Grade 70 pipe material, and seldom propagated directly along the fusion line. The J-R curve from the $C(T)$ tests on the fusion line was comparable with that of the A516 Grade 70 base metal. The pipe test loaddisplacement was predicted remarkably well with the fusion line J-R curve and the A516 Grade 70 base metal stress-strain curve. (The $\mathrm{J}_{\mathrm{M}}-\mathrm{R}$ curve worked better in making the load-displacement predictions for the large amount of crack growth past maximum load, see Figure 2.12.) Since the fusion line J-R curve was close to that of the A516 Grade 70 base metal, the full-scale test result could also be adequately predicted with the base metal J-R curve in this case.

It was pointed out in Reference 2.39 that these results were for a certain combination of base and weld materials. For instance, using a stainless steel weld metal rather than an Inconel weld metal will cause some carbon depletion in the carbon steel base metal. The depletion of the carbon steel in the HAZ will cause the toughness to decrease further. In Reference $2.39, \mathrm{~J}-\mathrm{R}$ curve data on a stainless steel bimetallic weld from NRI-Rez in the Czech Republic was compared with the Inconel 182 weld J-R curve. The stainless steel bimetal fusion line toughness was about a factor of four lower in toughness. The NRI data were on a Russian reactor material, but similar behavior might be expected for Western reactor materials.

With the exception of the initial PWRs in the U.S., the rest of the bimetallic welds in the remaining U.S. plants are probably made with either, (1) buttered layers of Inconel weld metal and then completed with stainless steel weld rod, or (2) they were fabricated from all Inconel weld metal. This aspect was not considered in the initial LBB applications in the older plants for mitigation of the asymmetric blow-down dynamic loads. 
Stainless Steel Weld Fusion Line Toughness. As noted earlier, stress-corrosion cracks occur more frequently along the fusion line than in the weld metal. An additional observation from numerous pipe fracture experiments in Reference 2.38 , was that even though the cracks were initially put in the center of a low toughness weld, the cracks frequently turned and went into the fusion line. Figure 2.17 shows the results from one such test (Ref. 2.38). Also, in one of the TIG welded pipe tests in Reference 2.40, the crack grew into the fusion line driven by a lower apparent toughness. No full-scale pipe test data exists for the case of a circumferential through-wall flaw placed initially on the fusion line of a stainless steel weld.

Interestingly, in earlier work in Reference 2.41, a small study of different SEN(T) specimens was conducted with the cracks located in either a stainless steel base metal, the center of a SMAW and in the HAZ. Figure 2.18 shows that the crack-tip-opening angle (CTOA) was about 25 degrees in the base metal and about 12 degrees in the center of the weld. For the HAZ specimens, in one case the crack was farther away from the fusion line and the CTOA was the same as the base metal. For the other HAZ specimen, the crack grew along the fusion line and the CTOA was about 4 degrees. Since the CTOA is proportional to the slope of the J-R curve*, this implies that the fusion line had a tearing resistance one-third of that of the SMAW. The SAW and SMAW weld metals are considered the lower toughness region in most current flaw evaluation and LBB criteria.

An evaluation of the J-R curve of stainless steel SAW fusion line toughness values was made in Reference 2.38. This evaluation showed that the J-R curve in the HAZ was variable, as expected. However, once the crack started growing along the fusion line, then the J-R curve became flat after 2-mm of crack growth, see Figure 2.19. This consideration has not currently been accounted for in pipe flaw evaluation criteria or LBB analyses.

\subsubsection{Dynamic Strain Aging and Ferritic Steels}

During the initial investigations of the NRC's Degraded Piping Program - Phase II (Ref. 2.28), it was found that when some ferritic pipe tests were conducted at LWR temperatures, $288 \mathrm{C}(550 \mathrm{~F})$, an unusual behavior was frequently observed. This behavior involved the occurrence of limited unstable crack jumps, see Figure 2.20. The unstable crack jumps were very significant, such as in the SEN(T) specimen test shown in Figure 2.21, or in a DTRC A106 B MIG weld test where the crack started in the center of the weld, but when it grew out into the base metal, the crack jumped 1/4 of the way around the pipe circumference. These occurrences, together with additional tensile test data, led to the belief that the unstable crack jumps were due to dynamic strain aging.

Additional effects of lowering of quasi-static toughness as a function of temperature were also reported in References 2.42 and 2.43 as well as other sources.

This work led to a more in-depth study in the NRC's Short Crack in Piping and Piping Welds program (Ref. 2.18). The Short Cracks program work showed the following:

- Unstable crack jumps occurred in every one of the U.S. ferritic pipe grades investigated, but some pipe lengths in each grade were not susceptible to the detrimental effects from dynamic strain aging.

* Based on experimental observations from pipe experiments on various materials at Battelle. 


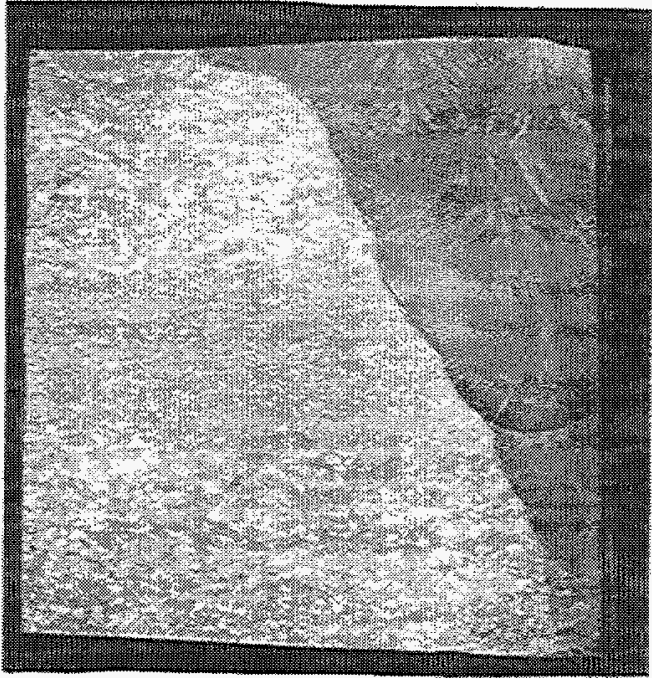

$2 \mathrm{X}$

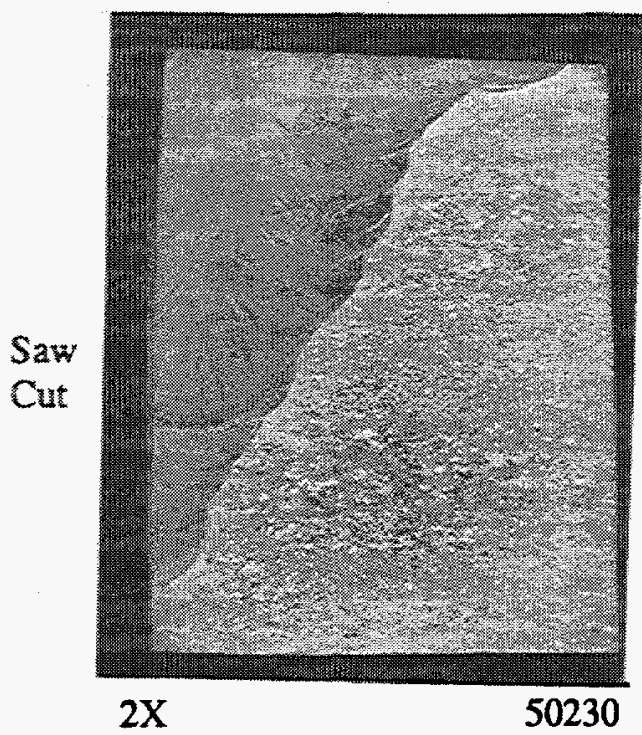

(a) Initial crack tip location in center of weld

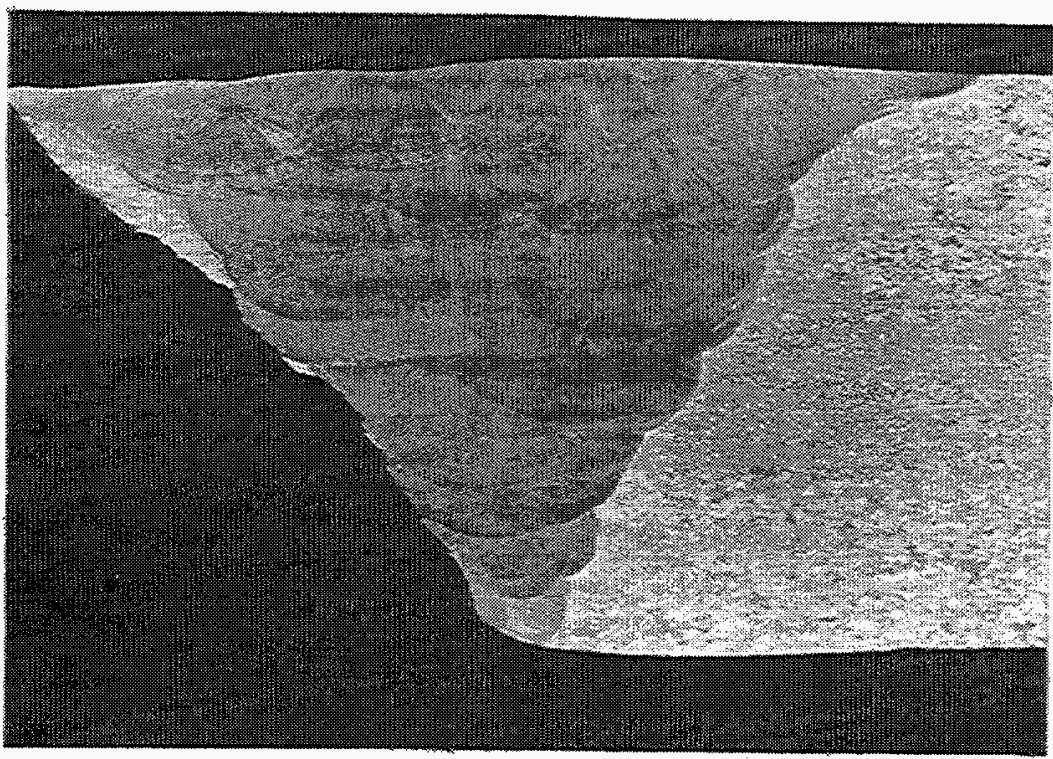

$2 \mathrm{X}$
50229

Section A2

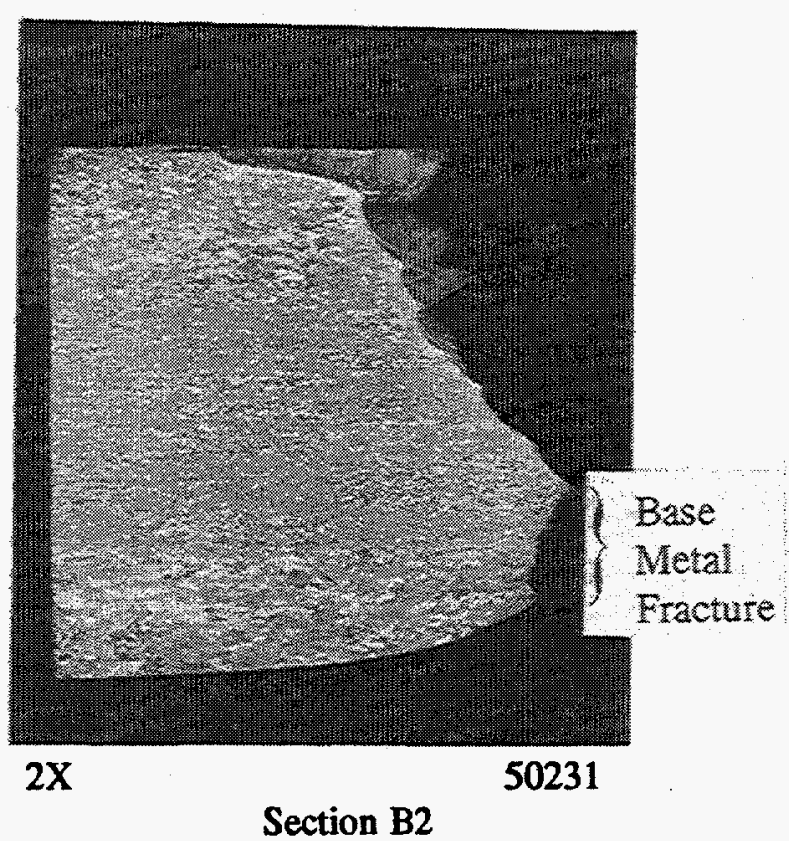

(b) Crack propagation paths

Figure 2.17 Crack propagation at $288 \mathrm{C}(550 \mathrm{~F})$ along fusion line of a TP316 SAW from a 711mm (28-inch) diameter pipe test (weld crown ground off prior to test) 
Type 304

CTOA $=25^{\circ}$

Stainless Steel

Base Metal

Heat Affected

Zone

CTOA $=25^{\circ}$

Fusion Line

$\mathrm{CTOA}=4^{\circ}$

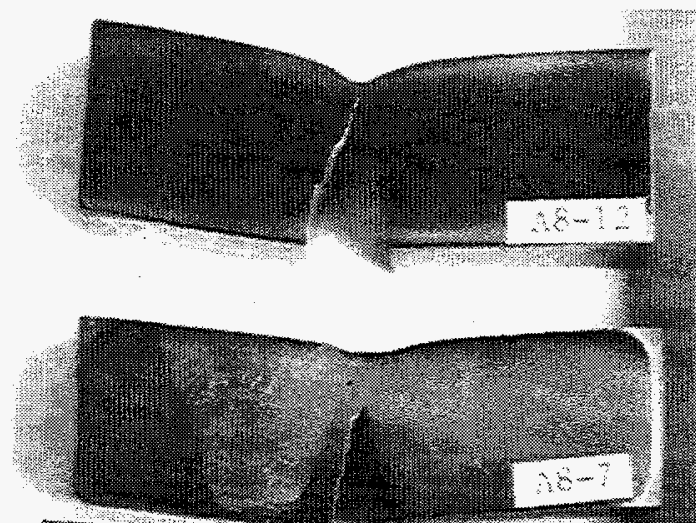

우

$\overline{5}$

$\infty$

$\bar{K}$

$\overline{6}$

$-$

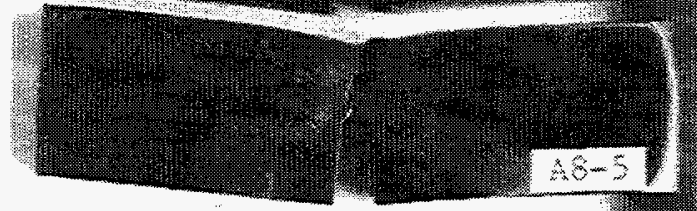

in

$\nabla$

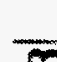

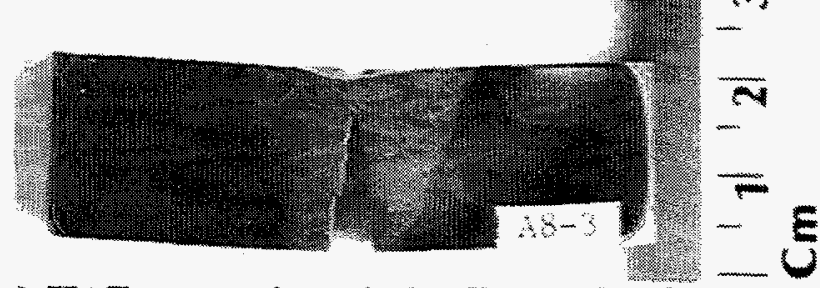

Figure 2.18 Crack propagation in base metal, $\overline{\mathrm{H}} \overline{\mathrm{Z}} \overline{\mathrm{Z}}$ remote from fusion line, and weld metal in single-edge notch tension specimens at $288 \mathrm{C}(550 \mathrm{~F})$

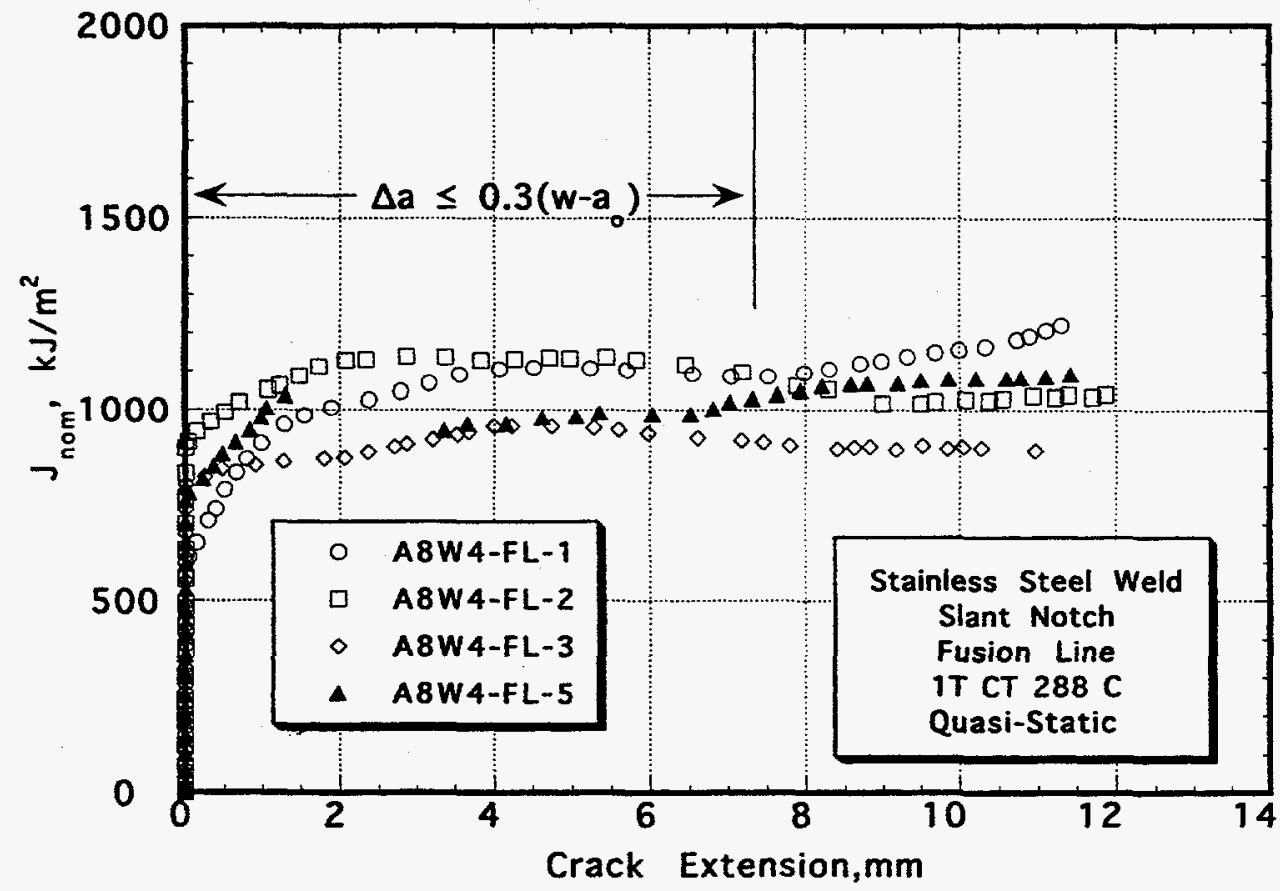

Figure 2.19 J-resistance curves of slant-notch, fusion-line specimens [limit on J-R curve data is $\left.\Delta \mathbf{a} \leq \mathbf{0 . 3}\left(\mathrm{W}-\mathbf{a}_{\mathrm{o}}\right)\right]$ (Note: The sudden load drop for Specimen A8W4-FL-5 corresponded to a significant crack jump) 
Section 2

Load-Line Displacement, $\mathrm{mm}$

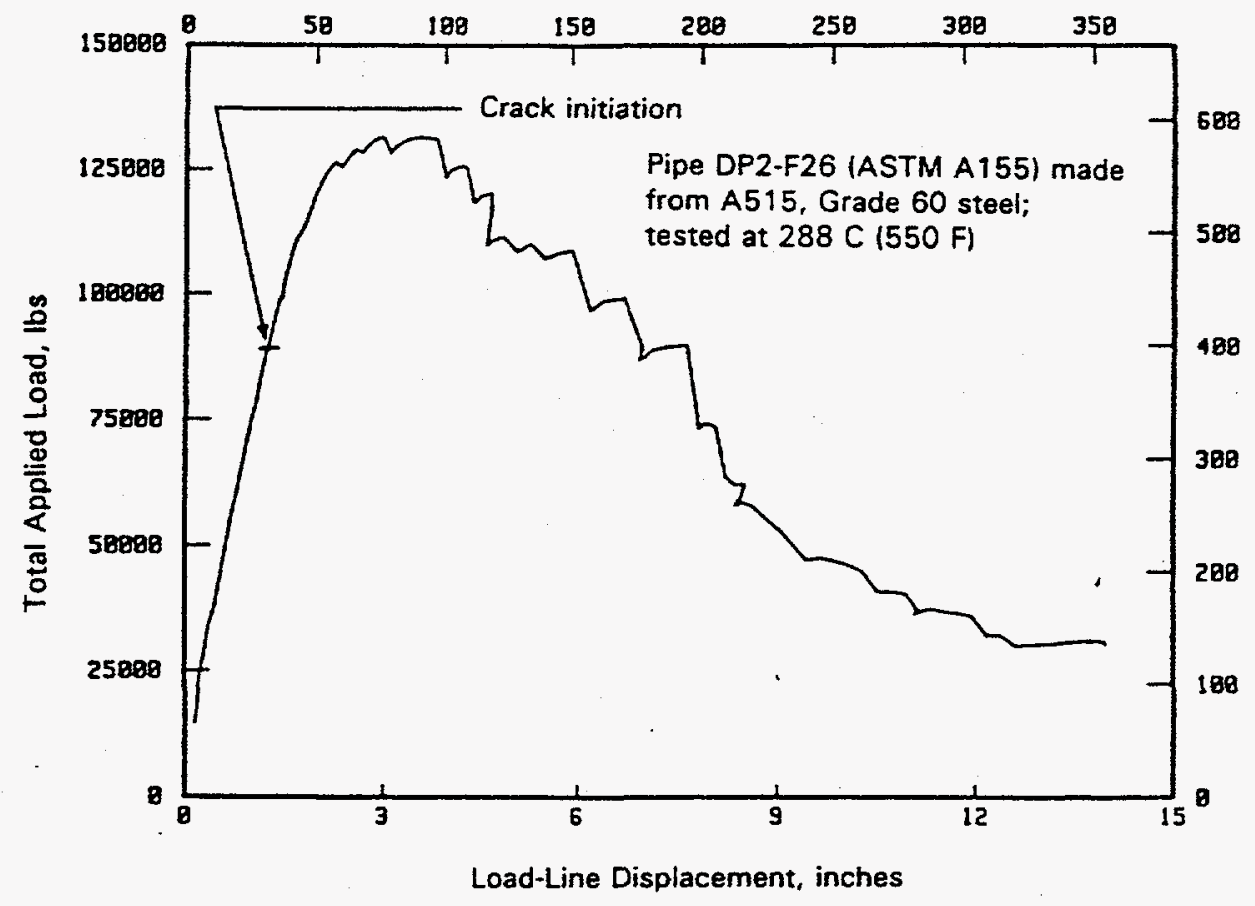

Figure 2.20 Load-displacement record from a full-scale pipe test (Experiment No. 4111-2) to illustrate crack instabilities at $288 \mathrm{C}(550 \mathrm{~F})$

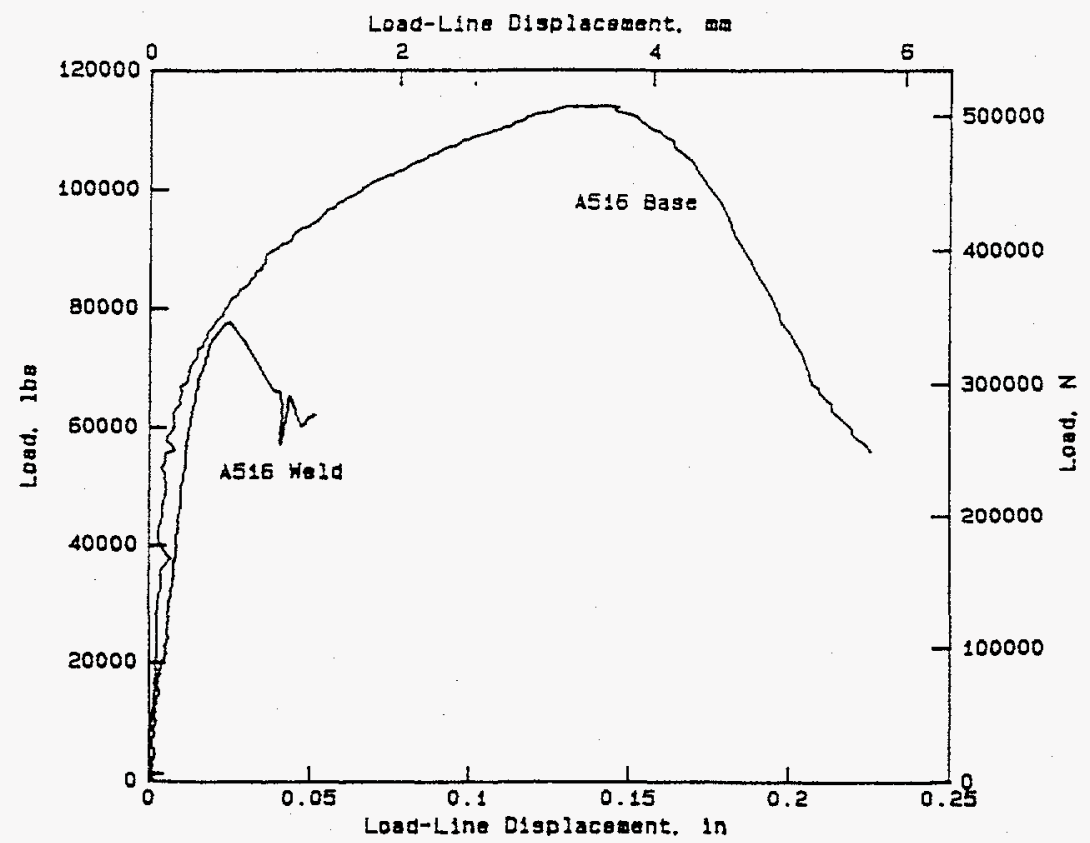

Figure 2.21 Comparison of 288 C (550 F) A516 Grade 70 base metal and Linde 44 SAW SEN(T) specimen data 
- Metallographic evaluations along the fracture surfaces and sections through the fracture surfaces did not show any clear reason why the crack jumps started or stopped.

- An evaluation of the test machine compliances showed that compliance was not the cause of the crack jumps, but once a crack jump started, then the machine compliance could affect the length of the crack jump.

- Compared to cleavage fractures, the unstable crack jumps were relatively slow, i.e., about 0.2 meters/second ( 8 inches/second).

- The crack jumps occurred in some random pattern, i.e., we could determine if a steel would have crack jumps, but not when along the crack path they would occur.

- A method to calculate the J-R curve after a crack jump was analytically explored (Ref. 2.18). Although not entirely successful, the results suggested that the ASTM method of integrating the area under the load-displacement curve was still reasonable.

- The propensity for a crack jump and dynamic strain aging could be determined from a relatively simple screening criterion. This screening criterion involved determining the ratio of the hardness at high temperature to the hardness at room temperature. Since the hardness reflects the ultimate strength, and dynamic strain aging increases the ultimate strength, this was a logical and simple screening criterion.

Since dynamic strain aging involves a pinning of the dislocations by free carbon or nitrogen atoms in the crystallographic matrix, it is a diffusion-based process that is not only affected by temperature, but also strain rate. The effects of strain rate on ferritic steels sensitivity to dynamic strain aging are discussed in Section 2.2.6.1.

Austenitic steels do not seem to be as sensitive to dynamic strain aging as ferritic steels, but there are some reports in the literature of dynamic strain aging affecting low alloy steels used in reactor pressure vessels (Ref. 2.44). The ferritic steel weld tested in Reference 2.18 in the piping work, used a weld procedure common in reactor pressure vessel construction in the U.S.

Finally, it should be noted that dynamic strain aging is not necessarily detrimental. If it occurs in moderate amounts, there can be an increase in strength with moderate to low loss in toughness. The increased strength will generally be more of a benefit to the load-carrying capacity of a cracked structure than the small loss in toughness. What remains to be shown is how to fabricate ferritic pipe in a consistent way so that dynamic strain aging will not be detrimental. This would be beneficial to new plant construction.

\subsubsection{Toughness Anisotropy}

Due to fabrication processes, most piping materials are not homogeneous in nature. Rather, most piping materials are anisotropic. Based on the nuclear piping materials investigated at Battelle over the years, it has been found that there are certain aspects of anisotropy that can be important. These may have been aspects that were documented decades ago, but nevertheless may be overlooked in current day analyses. In these cases, we will deal with only base metals, since welds and heat-affected zones were discussed earlier.

Of the different nuclear piping materials evaluated, those that tended to be more subject to anisotropy effects are the ferritic steels, including low alloy steel piping, and cast stainless steels. Of these, there is perhaps more documentation of ferritic steels anisotropic fracture properties. Wrought stainless steel, however, is frequently solution annealed, so there is effectively no anisotropy in such materials, unless there is cold-working after the solution annealing. 
Anisotropy in Ferritic Steels. It is fairly well known that ferritic steels are subject to anisotropic properties, and that the toughness is more sensitive to anisotropy than strength. Typically, the toughness in the rolling direction is the lowest, and that is the traditional direction for Charpy specimens in reactor pressure vessel surveillance capsule specimens.

For piping made from plate materials, the rolling direction of the plate corresponds to the axis of the pipe. For seamless pipe, the hot working direction (similar to the rolling direction for a plate) is typically in the axial direction of the pipe, but sometimes a helical working of the pipe material occurs (Ref. 2.45). Figure 2.22, from WRC Bulletin 175, shows that an A106 Grade B pipe had the lowest toughness in the direction corresponding to an axial through-wall crack (C-L direction), Specimen A in Figure 2.22. The circumferential through-wall crack growth direction (L-C orientation) had a much higher toughness, see Specimen $\mathrm{C}$ in Figure 2.22. The toughness values in the through-thickness directions that correspond to axial and circumferential surface crack growth, are higher than the toughness values in the corresponding through-wall crack growth directions. The highest toughness corresponds to a circumferential surface crack, Specimen D in Figure 2.22. There are numerous other reported similar results in the literature, see Reference 2.45 .

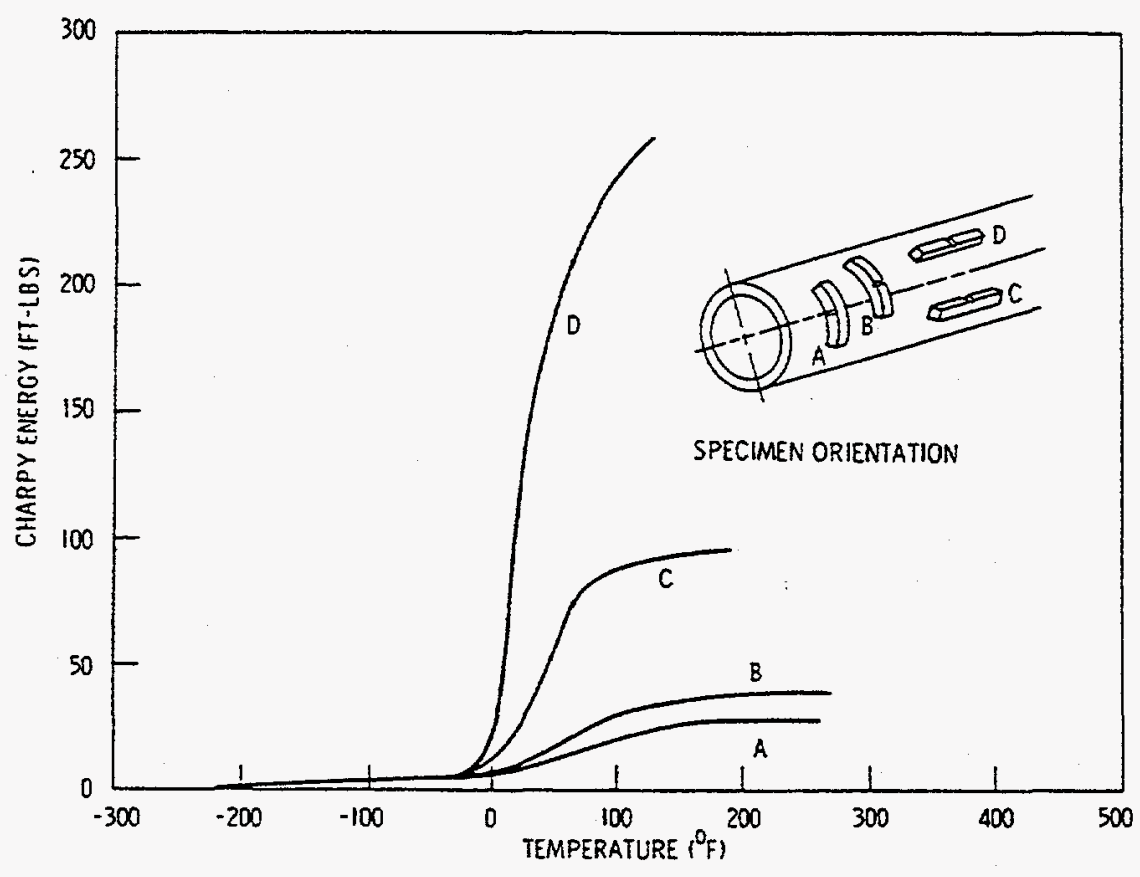

Figure 2.22 Toughness anisotropy of ASTM A106B pipe (Note: Reprinted with permission) 
Anisotropic Toughness Effects on Circumferential Through-Wall-Crack Behavior. The significance of such toughness anisotropy is that it can affect the fracture modes significantly (Ref. 2.46). For instance, for most experiments where a circumferential through-wall crack is put in the base metal of a ferritic pipe which is loaded in four-point bending, the initial circumferential crack turns and grows in a helical direction (Ref. 2.45). In one case, a circumferential through-wall crack in a 914-mm (36-inch) diameter cold-leg pipe grew in the axial direction, even though the pipe was loaded in four-point bending without any internal pressure (Ref. 2.47).

To address the role of anisotropy in out-of-plane crack growth, detailed finite element analyses were conducted in Reference 2.45 . This analysis compared the crack driving force as a function of the angle from the crack tip with the angular toughness variation. A criteria was proposed where the maximum of the ratio of the crack-driving force $\left(\mathrm{J}_{\text {applied }}\right)$ to the toughness $\left(\mathrm{J}_{\mathrm{i}}\right)$ as an angle from the crack plane $(\Omega)$ was found to predict the angle of crack growth, see Figure 2.23.

In regard to whether the helical crack growth phenomena is a problem or not, it was found from examining numerous pipe experiments that the greater the helical crack growth direction, the greater the loadcarrying capacity of the cracked pipe under either pure bending or combined pressure and bending. This is illustrated in Figure 2.24. The effect of helical crack growth for a pipe under torsional loading or combined torsion, bending and axial stress has not been evaluated either experimentally or analytically to date.

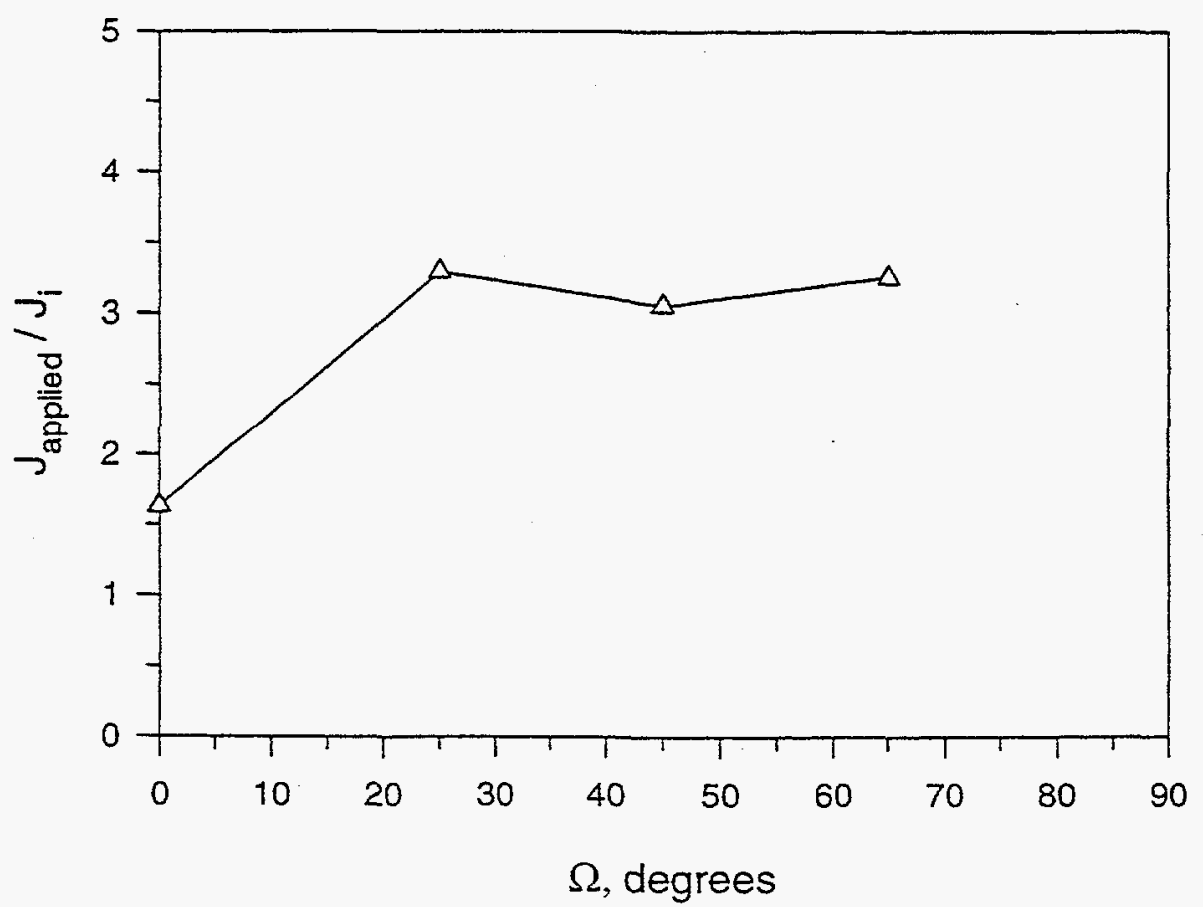

Figure 2.23 The variation of $J_{\text {applied }} / J_{i}$ (for Pipe DP2-F11) with crack-tip angle from the circumferential plane 


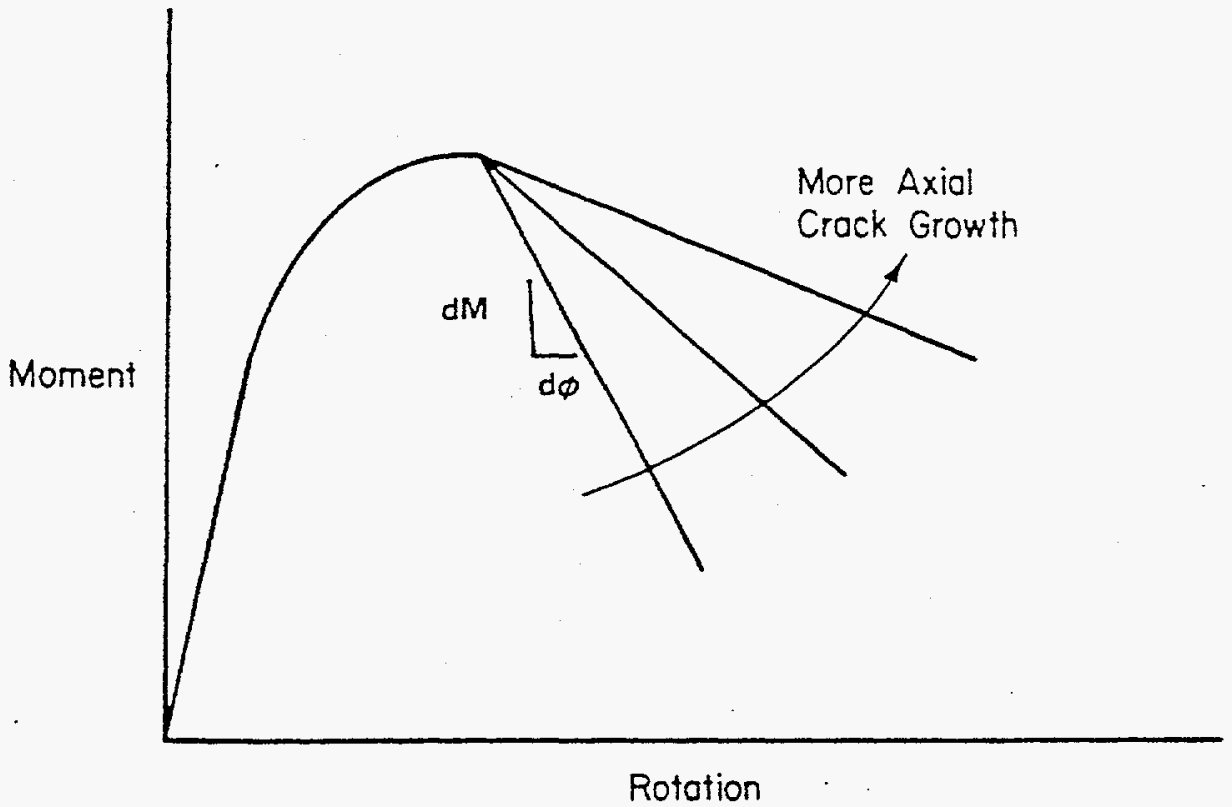

Figure 2.24 Effect of angled crack growth on moment-rotation response

Anisotropic Toughness Effects on Circumferential Surface Crack Behavior. As shown earlier, the toughness in the surface crack growth direction is typically much higher than the through-wall crack growth direction in the same fracture plane. Typically, for surface crack analyses, the toughness corresponding to the through-wall crack growth direction is used in the flaw evaluation procedures. Toughness values in the surface crack growth direction are typically not available. In Figure 2.22, the toughness in the radial direction was about three times higher than the circumferential through-wall crack growth direction. In Reference 2.13, Charpy and $\mathrm{J}_{\mathrm{i}}$ values were determined for an A516 Grade 70 plate material in the radial and through-wall crack growth directions. The ratio of the Charpy energy in the two directions was very close to the ratio of the $J_{i}$ values, i.e., a ratio of about 2.9. For cases where the toughness has been investigated in different directions, this toughness ratio was found to be quite common. Unfortunately, the toughness in the radial direction is not documented very frequently.

Anisotropy can also cause another unusual fracture mode behavior for surface cracks. In many ferritic steels, there may be laminations or metallographical layers through the thickness. The effect of these planar variations is that in some cases, the laminations will act as a natural crack arrestor. Figure 2.25 is an extreme example of such behavior. In this particular case, an axial pipe fracture test was conducted at Battelle. The particular pipe material was a thermomechanically controlled-rolled high-strength low-alloy steel (HSLA) that had layers of bainite through the thickness. In this case, the ductility ahead of the crack tip caused the bainitic layer to debond and the crack arrested. 


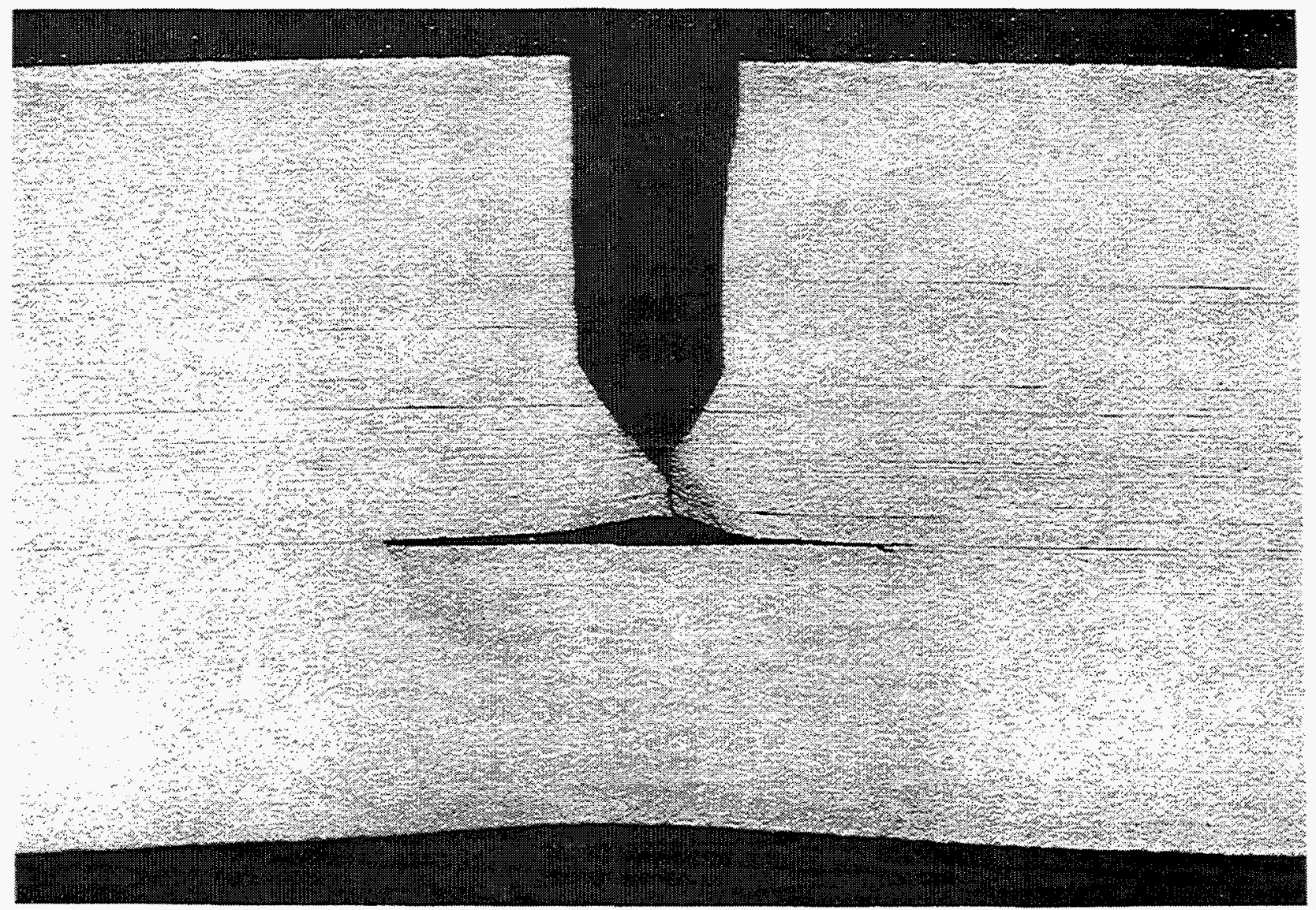

Figure 2.25 Metallographic section of unfailed V-notch in a pipe experiment where the surface crack arrested at a lamination

The effect of laminations on fracture behavior in different orientations was studied in Reference 2.48 . In this work, Charpy specimens were fabricated from bonded laminates in different orientations. The thickness of the orientations was also varied. The results showed that laminations parallel to the plate surface acted as crack arrestors for a surface crack oriented notch. Specimens that had the notch oriented as a through-wall crack had the laminations act as a crack divider. Furthermore, the greater the number of laminations, the lower the Charpy impact energy. Many papers have been written on the effect of laminations or separations on the fracture behavior of controlled-rolled steels for the oil and gas industries (Refs. 2.49 to 2.51 ).

In the nuclear industry, similar banding behavior was found to affect the fracture toughness results of an A302 reactor pressure vessel steel (Ref. 2.52). In that work, only specimens in the through-wall crack orientation were tested. The laminations/banding acted as crack dividers, and the resulting J-R curves decreased as the thickness increased, i.e., see Figure 2.26. Similar tests on materials without such banding showed the opposite trend, where the J-R curve increased with thickness. In such a material, the toughness in the radial direction would be tremendously higher. Since for a reactor pressure vessel, a leak is not tolerable, such a material, rather than being a problem from the through-wall-crack toughness evaluation, would actually be one of the best materials from the fact that it has natural surface crack arrestors. 


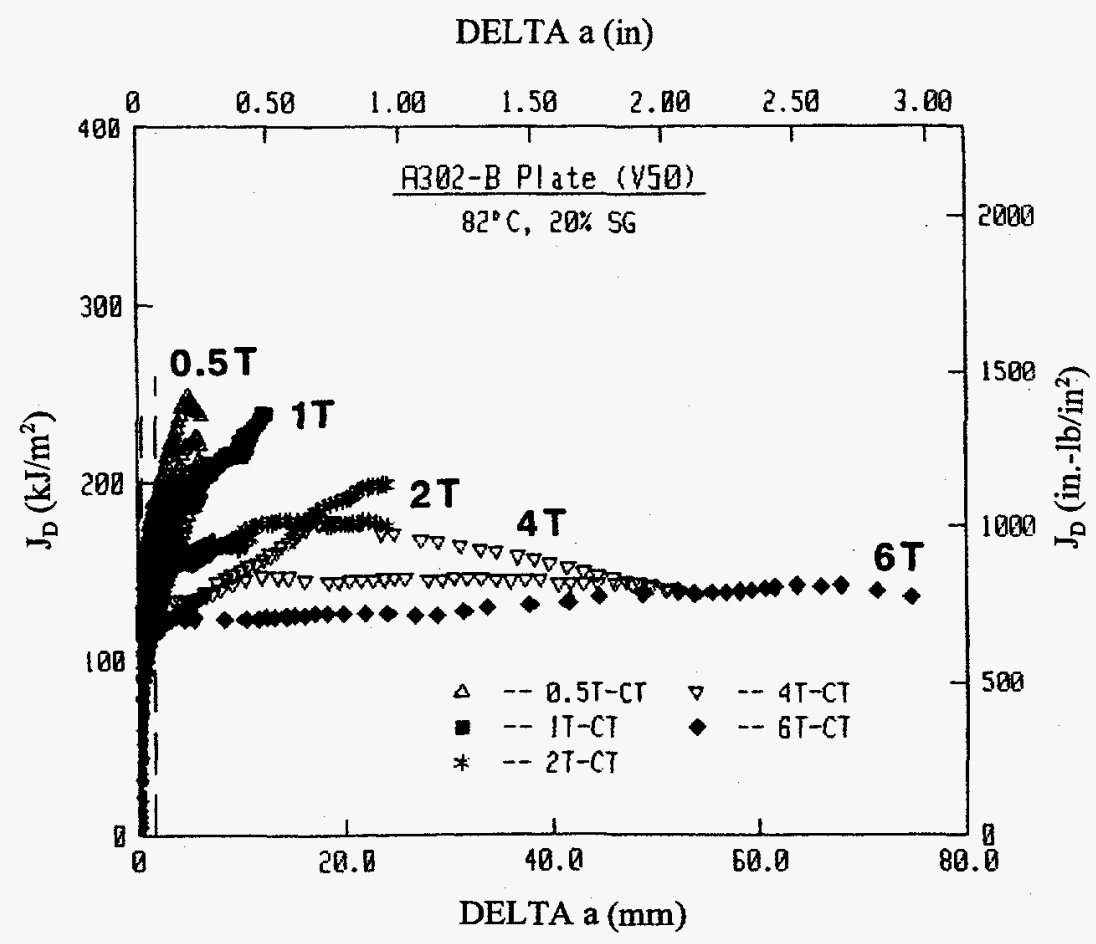

Figure 2.26 Effect of specimen thickness on the J-R curves of A302-B plate where laminations/banding acted as crack dividers

\subsubsection{Austenitic Base Metals}

Austenitic base metals, such as wrought stainless steels and Inconel 600 (used for safe ends), are very tough materials. These materials are typically used in the solution-annealed condition, so there is no coldworking. (This may not be true for steam generator tubes.) Typically, these wrought austenitic materials exhibit toughness values a factor of 10 higher than flux welds, such as submerged arc and shielded metal arc welds. (See earlier discussion on austenitic welds in Section 2.2.5.1.) TIG (or MIG) welds also are generally believed to have very high toughness values (Ref. 2.53), although there is at least one case of a lower toughness stainless steel TIG weld reported in the literature, see Reference 2.54.

Of the austenitic materials used in nuclear applications, cast stainless steels can have much lower toughness values depending on their chemistry and susceptibility to thermal aging. These two types of base metals are discussed below.

Wrought Stainless Steel Base Metals. Stainless steel base metals are typically thought to be so tough that their failure mode would always be a limit-load failure. In fact, the Net-Section-Collapse analysis (a type of limit-load solution for circumferential cracks) was originally developed for application to BWR stainless steel piping. Hence, in the ASME Section XI austenitic pipe flaw evaluation criteria, it is assumed that a limit-load analysis is needed for wrought stainless steel base metal cracks. Furthermore, in these criteria, engineering judgement suggested that with this high level of toughness, secondary stresses such as thermal expansion or seismic anchor motion stresses would not contribute to fracture and hence, can be ignored. (See discussion in Section 2.1.2 on this.) In the U.S. NRC's draft Standard Review Plan 
3.6.3 for Leak-Before-Break, it is also assumed that wrought stainless steel base metals and TIG welds are tough enough so that they will always result in limit-load type failures.

As will be noted in Section 2.3, there are limitations, even for tough materials like stainless steels, where they will not fail in a limit-load manner. For instance, in Reference 2.55, a 1,067 mm (42-inch) diameter pipe test on a thin-walled wrought stainless steel pipe with a circumferential through-wall crack had a maximum load of 80 percent of the Net-Section-Collapse analysis predicted load, even when using a conservative definition of flow stress, i.e., the average of the material's yield and ultimate strengths. Hence, there is a pipe diameter or $\mathrm{R} / \mathrm{t}$ ratio limitation to the assumption that wrought stainless steel will always fail at limit-load conditions.

Recent results from the Second International Piping Integrity Research Program (IPIRG-2) suggest that there is perhaps a relationship between chemical composition and toughness of stainless steel base metals (Ref. 2.56). In this report, it was documented that two different heats of a stainless steel pipe had virtually the same stress-strain curve, but the J-R curve of one of them was 40-percent lower than the other. The lower toughness pipe had a chemical composition that differed in sulphur content 0.019 percent compared with 0.002 percent sulfur content for the higher toughness material. The sulphur content of wrought stainless steels is frequently in the 0.002 range. However, the ASTM specification allows sulphur contents up to 0.030 percent. Hence, the lower toughness stainless steel pipe met the chemistry specification in the ASTM standard, but in the 406-mm (16-inch) diameter pipe test, it did not fail at limit-load conditions. Other unpublished data, at this time, showed that one particular heat of stainless steel had a J-R curve that was similar to that of a weld. It may be that that steel also had a higher sulphur content.

These results suggest that the importance of chemical composition (particularly sulphur content) on the toughness of stainless steels appears to be worthy of further evaluation. This would be of particular interest to new plant construction. Perhaps a supplemental requirement on the chemical composition would be sufficient to ensure that the limit-load condition failure criterion is satisfied. Since many of the stainless steels investigated to date do have very low sulphur contents, this should not be a significant financial burden on new plant construction or for the purchase of replacement pipe.

Cast Stainless Steel Base Metals. Cast stainless steel materials are frequently used in straight pipe, elbows, and pump housings. Straight pipe is typically centrifugally cast, while elbows and pump housings may be statically cast. Casting causes different grain sizes, which may be important in getting good ultrasonic signals for flaw detection.

A significant amount of work has been done to determine the effects of thermal aging on cast stainless steels, see References 2.57 and 2.58 as examples. There has also been a significant amount of proprietary work done, i.e., in the Westinghouse Owner's Group program. The U.S. NRC-funded work was done mainly at Argonne National Laboratory (ANL) (Ref. 2.59), although some pipe tests on aged and unaged cast stainless steel piping were conducted at Battelle (Refs. 2.60 and 2.61). Small diameter pipe tests were also conducted at Westinghouse (Ref. 2.62), and more recently, some aged cast stainless steel elbow experiments have been conducted at Electricité de France (Ref. 2.63).

From the Argonne work, it was concluded that the cast stainless steel of greatest concern was CF8M (molybdenum modified TP316 stainless steel). ANL developed trend curves of the yield strength, ultimate strength, and J-R curves as a function of time. The aging at LWR temperatures is a rather slow process, but it causes the material to harden, and as a result, the toughness decreases. The Argonne work 
(Ref. 2.59) suggests that the lowest the cast stainless steel toughness may go is about equal to that of the stainless steel submerged arc welds.

In the ASME Section XI pipe flaw evaluation criteria, it is assumed that the toughness of cast stainless steels will not be affected by thermal aging if the ferrite number is 20 or less. The Argonne work suggests a threshold ferrite number of about 12. On-going work in France suggests that the toughness of higher ferrite number cast stainless steels could be significantly lower than that for a stainless steel SAW (Ref. 2.63).

An interesting exercise to determine how aging affects the load-carrying capacity of cracked pipe was conducted in Reference 2.64. In this evaluation, the Argonne aging trend data curves for toughness, yield and ultimate strength were used. The aging raises the material's strength, which is beneficial, but with the increased strength there is a loss of toughness, which is detrimental. (This is somewhat akin to irradiation damage on reactor pressure vessel steels.) In Reference 2.64, three different elastic-plastic fracture mechanics analysis methods were used. The results of the load-carrying capacity with time analyses showed the following:

- Using the Tada-Paris NUREG/CR-3464 analysis method (Ref. 2.65) for circumferential through-wall cracks in pipes of various diameters, at time $=0$, the failure would be a limit-load failure. Furthermore, because the increased strength seemed to control, the load-carrying capacity increased with time.

- Using the R6 Option 1 approach (Ref. 2.66), for either circumferential through-wall cracks or surface cracks in various pipe diameters, it was found that at time $=0$, the failure would be below the limit-load failure loads. Furthermore, because the decreasing toughness seemed to control, the load-carrying capacity always decreased with time. This was the opposite of the Tada-Paris analysis conclusion.

- The third analysis was done using the Battelle Dimensionless Plastic-Zone Parameter semiempirical analysis (Ref. 2.20). This was used for both circumferential through-wall cracks and surface cracks in pipes of various diameters. The results showed that with small and intermediate diameter pipe with through-wall cracks, or surface-cracked pipe with even larger diameters, the maximum load started at limit-load, and then increased with time. For large diameter pipe, particularly with through-wall cracks, the load-carrying capacity decreased with time.

Hence, this initial investigation showed that the change in properties with aging is important, and the analysis method used should be validated, preferably with experiments and more detailed analyses. Since the initial investigation, Argonne has developed the Ramberg-Osgood coefficients for the stress-strain curve as a function of time. Using these time-dependent Ramberg-Osgood coefficients would allow more sophisticated analyses to be conducted than in the past.

\subsubsection{Load History Effects on Fracture Toughness}

In piping fracture mechanics applications, typically the quasi-static strength and fracture toughness values are used for transient events like seismic loads and water or steam hammer loading. One of the objectives 
of the IPIRG programs was to assess whether or not seismic load histories can affect fracture behavior. Seismic loading is not only dynamic in nature, but cyclic. The dynamic loading is slow compared to brittle fracture crack arrest, but is still on the order of 10,000 times faster than quasi-static loading. Cyclic loading from a seismic event may cause interrupted tearing, which could be considered as a low cycle fatigue process, rather than a ductile tearing process. These aspects and their significance are discussed in the following sections.

\subsubsection{Dynamic Loading Rates}

Seismic pipe fracture events are typically evaluated using quasi-static material properties. This is because the typical material test standards do not consider higher rate testing, or because it is not necessarily known how high the loading rate should be in material testing to account for seismic events.

During the IPIRG programs (Ref. 2.67 to 2.68), one of the aspects investigated was the effect of loading rates on J-R curves. The first concern was what loading rate should be used. From the IPIRG-2 program, it was concluded that a loading rate for a seismic event, or most other dynamic loading, would correspond to having the crack initiate in about one-quarter of the period of the first natural frequency of the piping system (Ref. 2.68). The assumption here is that the crack could initiate during the first large amplitude loading cycle. For a pipe system with a natural frequency of $4 \mathrm{~Hz}$, the approximate time to crack initiation would correspond to 0.0625 seconds.

From work in the IPIRG-2 program (Ref. 2.68), it was found that for austenitic steels (base metals, welds and cast stainless steels), that the J-R curve typically increased at the rates corresponding to seismic events. The magnitude of the toughness increase seemed to be related to the yield-to-ultimate strength, see Figure 2.27.

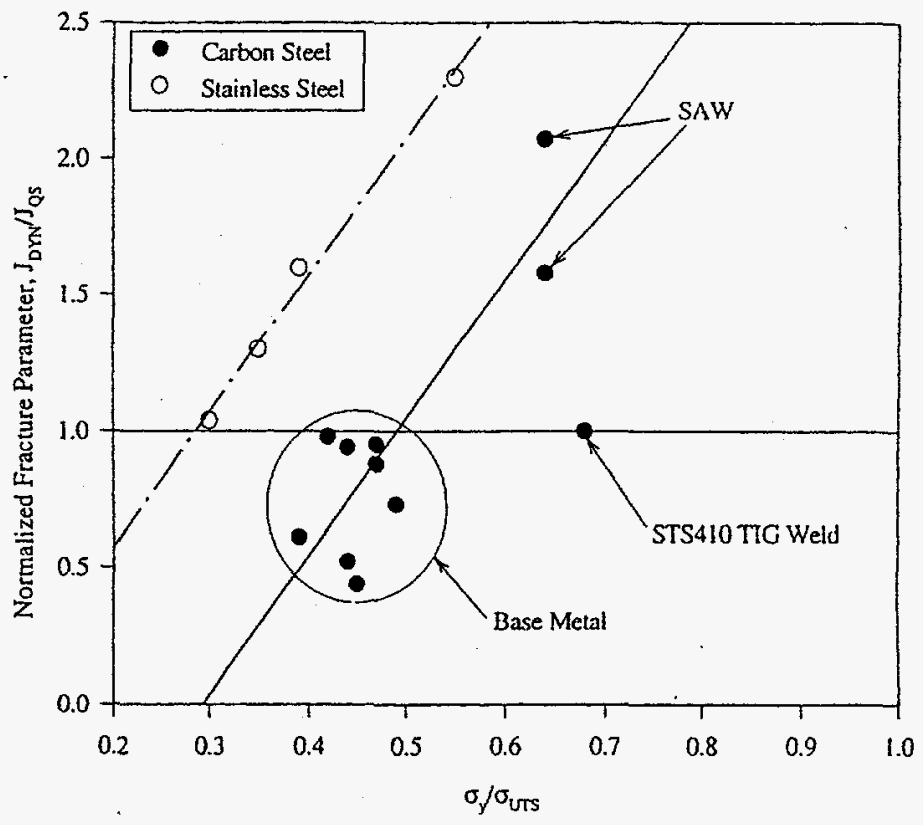

Figure 2.27 Effect of yield-to-ultimate strength ratio on the fracture toughness at dynamic loading rates relative to that of quasi-static rates 
For ferritic steels, the effect of dynamic loading was more complicated. For all of the plain carbon steel pipe grades used in the U.S., it was found that some of them showed a lower toughness at the seismic rates when compared with quasi-static rates. The correlation with the yield-to-ultimate strength was less reliable, see Figure 2.27.

The difference between the ferritic steels and the austenitic steels was that the ferritic steels are also susceptible to dynamic strain aging at LWR temperatures (Ref. 2.18). Dynamic strain aging is caused by free nitrogen or carbon atoms pinning dislocation movement, which increases the ultimate strength and lowers the elongation in tensile tests. This is a diffusion-based process, where temperature and strain rates affect the mobility of the free nitrogen and carbon atoms. It is believed that the lowering of the dynamic toughness depends on the dynamic strain aging sensitivity. To assess this, a screening criterion for dynamic strain aging was developed (Ref. 2.18). This screening criterion involved determining the ratio of the hardness at high temperature to the hardness at room temperature. Logically, this comes from the fact that a dynamic strain aging sensitive material will have a higher ultimate strength at high temperature than at room temperature. If the hardness ratio is greater than 1.0 , then a material is definitely going to be affected by dynamic strain aging.

Using this high temperature to room temperature hardness ratio, the $\mathrm{J}$ values at a crack extension of 30 percent of the initial ligament of the test specimens, i.e., at the limit of the valid J-R curve data, from the quasi-static and dynamic loading rates were compared. This is shown in Figure 2.28, where it can be seen that if the hardness ratio was greater than 1.0 , then the dynamic toughness was lower than the quasi-static toughness. The lowest dynamic toughness was 45-percent of the quasi-static toughness. Interestingly, however, the weld metal data showed an increased toughness with increasing strain rate. Hence, there was

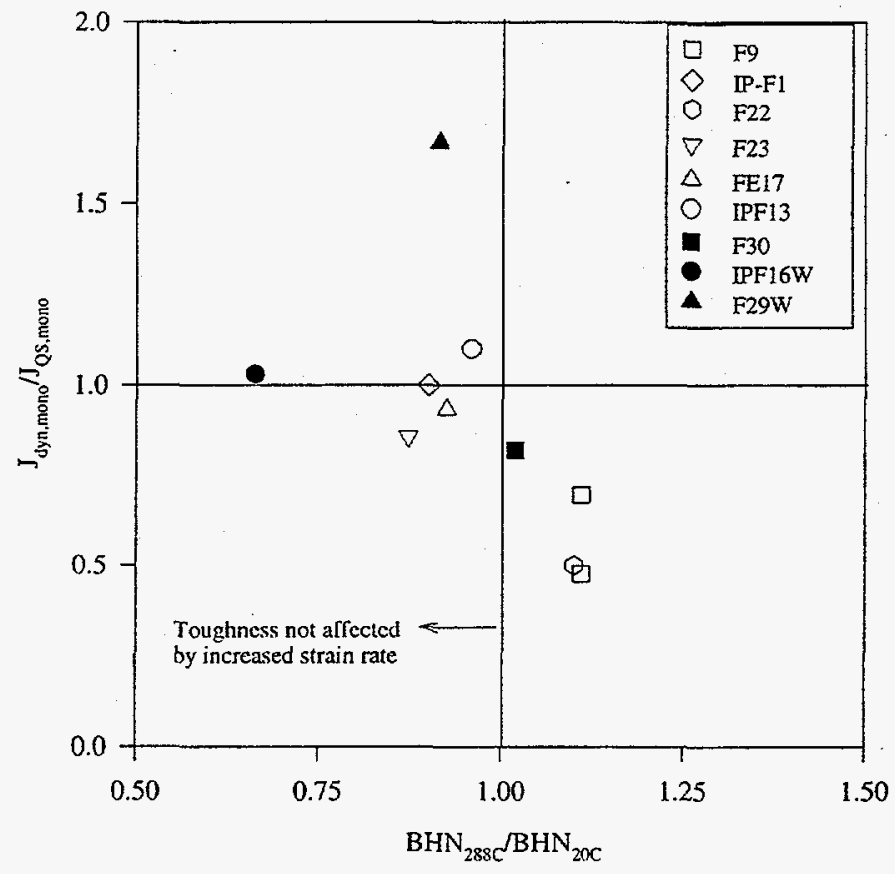

Figure 2.28 $\mathrm{J}_{\mathrm{dyn}, \text { mono }} / \mathrm{J}_{\mathrm{QS}, \text { mono }}$ versus $\mathrm{BHN}_{288} / \mathrm{BHN}_{\mathrm{RT}}$ for a variety of carbon steel base and weld metals 
some different behavior for ferritic steel welds when compared with base metals. It might even be that the initially higher base metal toughness decreases with increasing loading rates, while the lower weld metal toughness increases with loading rate. Thus, at the higher loading rates, there may not be much difference between base and weld metal toughnesses.

A final aspect of the effect of loading rate on the ferritic steels, is the concern for how low the toughness could be under dynamic loading compared with quasi-static loading. (Recall that these are data at $288 \mathrm{C}$ $(550 \mathrm{~F})$ so that we are not dealing with mode changes from ductile-to-brittle fracture at these temperatures.) That is a question that cannot be answered at this time. Interestingly, for all the grades of steel examined, it was found that some of them were not susceptible to the detrimental effects of dynamic strain aging. Consequently, there are some manufacturing variables that are within controllable ranges which will prevent dynamic strain aging from being detrimental to the dynamic toughness. Further investigation of these parameters could lead to development of specifications to produce better ferritic pipe steels for future plants.

\subsubsection{Cyclic Effects During Ductile Tearing}

As previously noted, during a seismic event the actual loading can be dynamic and it can involve interrupted or cyclic tearing. However, typically, quasi-static, monotonic fracture toughness and strength data are used in pipe fracture analyses.

\section{Background}

Earlier Work on Cyclic J-R Curves. Some of the first work on interrupted cyelic tearing was reported by Landes in Reference 2.69. In this work, he observed that under fully reversed loading, the apparent J-R curve was lowered significantly. To determine the J-R curve, he integrated the upper envelop of the loaddisplacement curve, as is typically done in quasi-static monotonic tests. At the time, Landes questioned whether this was an appropriate methodology. Further earlier work in this area can be found in Reference 2.70 .

Dowling Low-Cycle Fatigue Approach. Another tact that could be taken to account for cyclic effects on fracture, is to use the low-cycle fatigue approach of Dowling, see References 2.71 and 2.72 . In this methodology, it has been demonstrated that the load-displacement curve of a single cycle could be integrated to get a $\Delta \mathrm{J}$ value. The method is consistent with deformation plasticity $\mathrm{J}$ when the cyclic loads are positive. The $\Delta \mathrm{J}$ value versus the crack growth, $\Delta \mathrm{a}$, was found to agree with a linear extrapolation of typical high-cycle fatigue crack growth data.

If the cyclic loads become negative, then the Dowling approach to determine the $\Delta \mathrm{J}$ value that agrees with the high-cycle fatigue crack growth data requires that the load-displacement curve be integrated down to the load where the compressive load causes crack closure, see Figure 2.29. In this case, the Dowling $\Delta \mathbf{J}$ approach deviates from deformation theory $\mathbf{J}$, and in order to make predictions relative to different structures, the Dowling "operational definition of J" must be translated to the deformation theory of J. This transformation of the "Dowling Operational $\Delta \mathrm{J}$ " was conducted in Reference 2.73. 


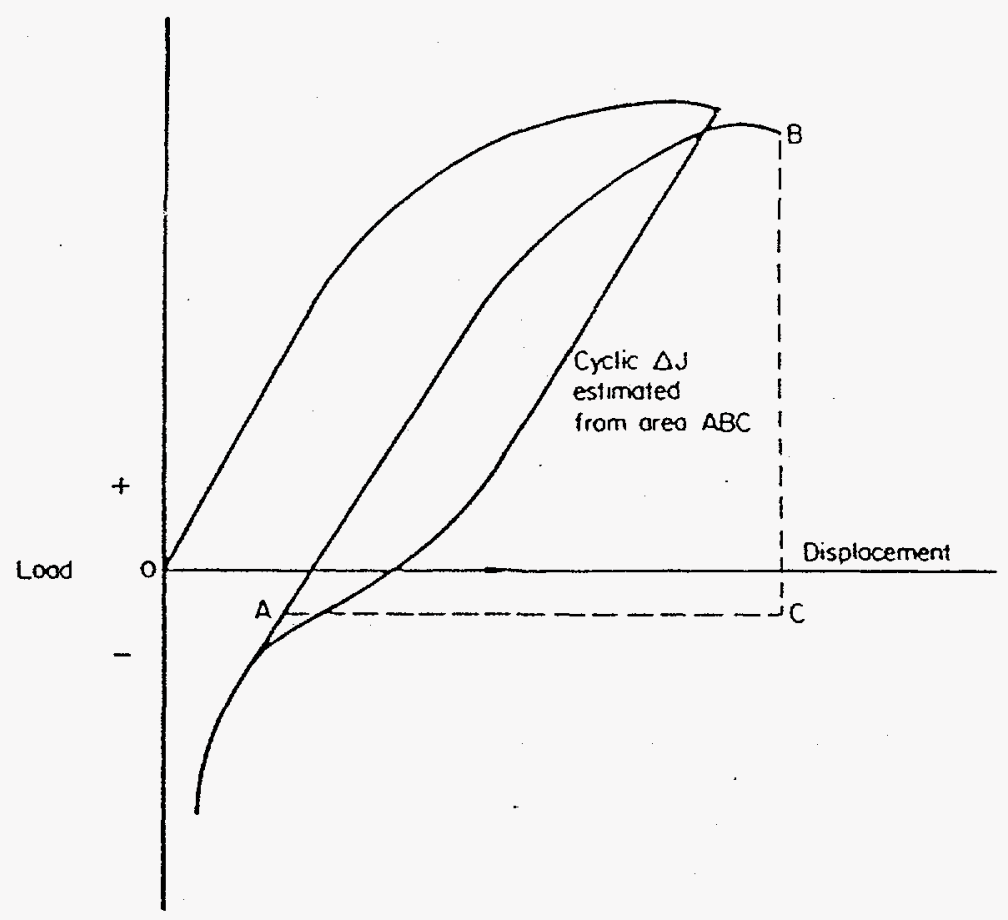

Figure 2.29 Dowling analysis of area used in $\mathbf{J}$ calculations for crack growth in the presence of plasticity

Detailed FEM Analyses. Analyses of cyclic unloading and reloading on ductile fracture has been the subject of a few detailed FEM analyses. Some of these are given in References 2.56 and 2.74 to 2.76. The results of these investigations show that the upper envelop method of calculating the J-R curve agrees well with J values from more detailed FEM analyses. They also show that the effect of the cyclic loading on $J$ can be appreciable, and that the J-R curve of the material under cyclic loading can be altered.

The Physical Phenomenon and Implications to Analysis Methodologies. A more detailed investigation of cyclically loaded $C(T)$ specimens was conducted in Reference 2.76 . In this case, identical specimens were loaded to different points along a cyclic load history and then metallographically sectioned. For the specimen sectioned after loading in tension, the void growth ahead of the crack tip can be seen in Figure 2.30(a). For the specimen loaded in tension and subsequently in compression, the metallographic section showed the voids ahead of the crack tip were flattened or sharpened, see Figure $2.30(\mathrm{~b})$. This flattening or sharpening of the voids, makes the voids easier to link together upon subsequent tensile loading.

Combining this effect with the potential for exhaustion of ductility from the local cyclic plasticity makes the loss in toughness for the cyclic loading physically understandable.

From the above discussion of void flattening, the modeling of this fracture phenomenon appears to be one that cannot easily be handled by damage mechanics approaches that approximate void nucleation and growth under monotonic loading as in References 2.31 to 2.34 . 


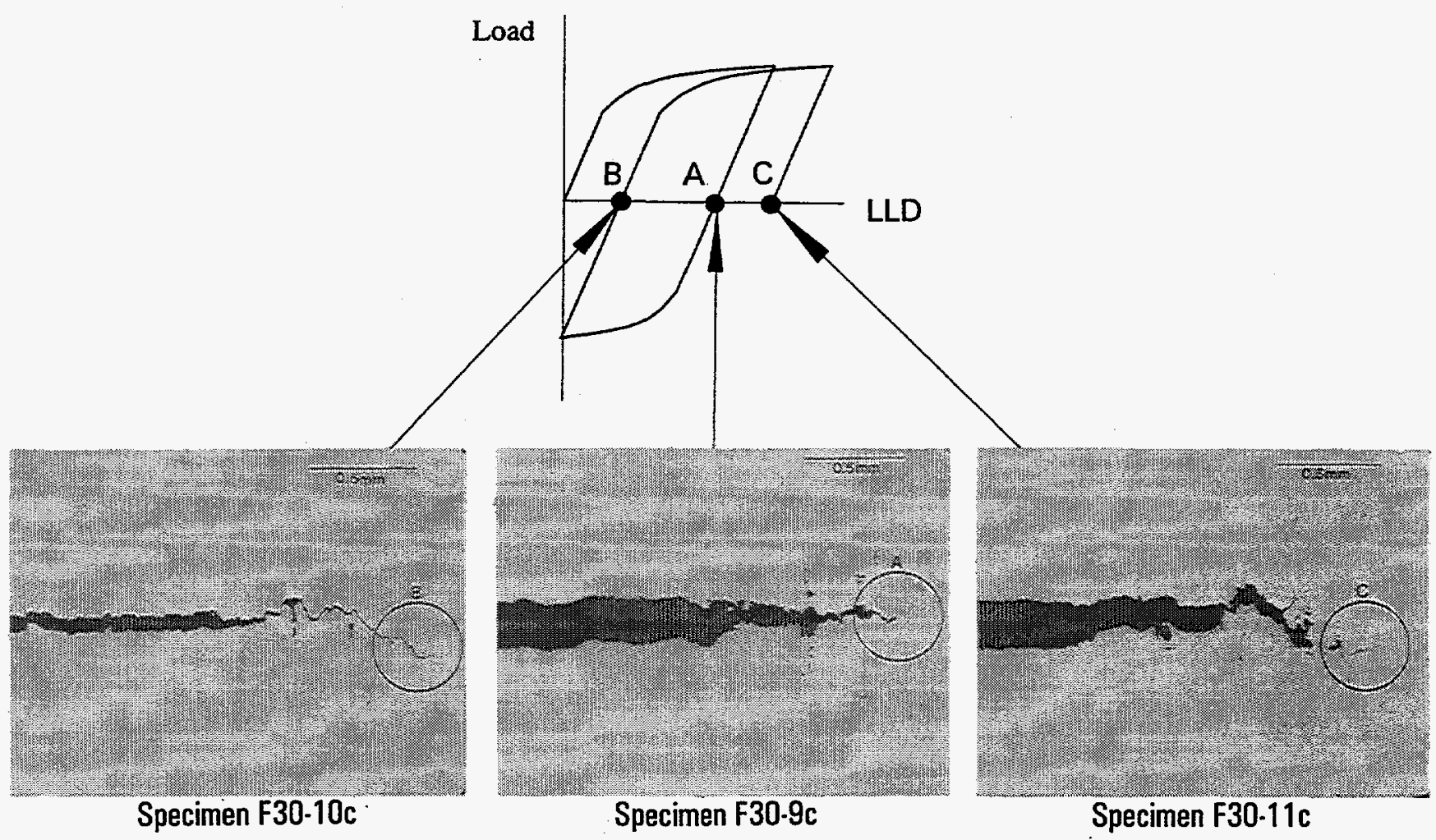

Figure 2.30 Mid-thickness cross sections showing crack-tip region in three interrupted carbon steel cyclic-load specimens

Furthermore, it appears that the void flattening effect is one where the damaging effect on the local material properties would decay as a function of distance from the crack tip. In fact, experimental results from pipe fracture experiments in the various U.S. NRC programs have shown that if there is only one fully-reversed cycle, once the crack tears a small amount, the crack behaves as if it was in virgin material. Consequently, it appears that the number of cycles, or cyclic crack growth, can become important.

Advantages and Disadvantages of the Various Cyclic Loading Analysis Approaches. Table 2.1 lists some of the main advantages and disadvantages of the competing methods for handling cyclic loading in a flaw evaluation. From this assessment, it was determined that it would be easier to implement the cyclic J-R curve approach for pipe fracture analyses, rather than to try to implement the other two methods. The cyclic J-R curve is computationally manageable and it can be integrated into the existing LBB framework with relative ease. Nevertheless, the experimental data in the IPIRG programs were obtained so that the Dowling Operational $\Delta \mathrm{J}$ approach could also be used. 


\subsubsection{Trends Observed in the IPIRG Cyclic J-R Curve Evaluations}

During the course of the IPIRG programs, the effect of cyclic loading on the fracture behavior of cracked pipe was identified. Initially, only cyclic pipe experiments were conducted in the IPIRG-1 program, and then when the results were found to be more significant than previously believed, cyclic $C(T)$ tests were conducted.

IPIRG-1 Cyclic Pipe Experiments. During the IPIRG-1 program, cyclic tearing tests were conducted on 152-mm (6-inch) diameter circumferential through-wall-cracked pipe under four-point bending (Refs. 2.77 to 2.79). This type of test was conducted so that there were about 10 cycles to reach the displacement where crack initiation occurred in the monotonic test. To maintain some constant parameters for these pioneering-type experiments, the cyclic plastic displacement was also held as a constant, so that the displacements kept ratcheting every cycle, see Figure 2.31. The ratio of the minimum to maximum load, or R-ratio, was also held constant, which is also shown in Figure 2.31 for $\mathrm{R}=0$ loading. To do this, combined load- and displacement-control was required in the test machine. On occasion, the plastic displacement increment was changed after a large number of cycles. This was done to investigate the cyclic displacement parameter on the crack growth resistance behavior. Special fixturing for the reverse loading was also required.

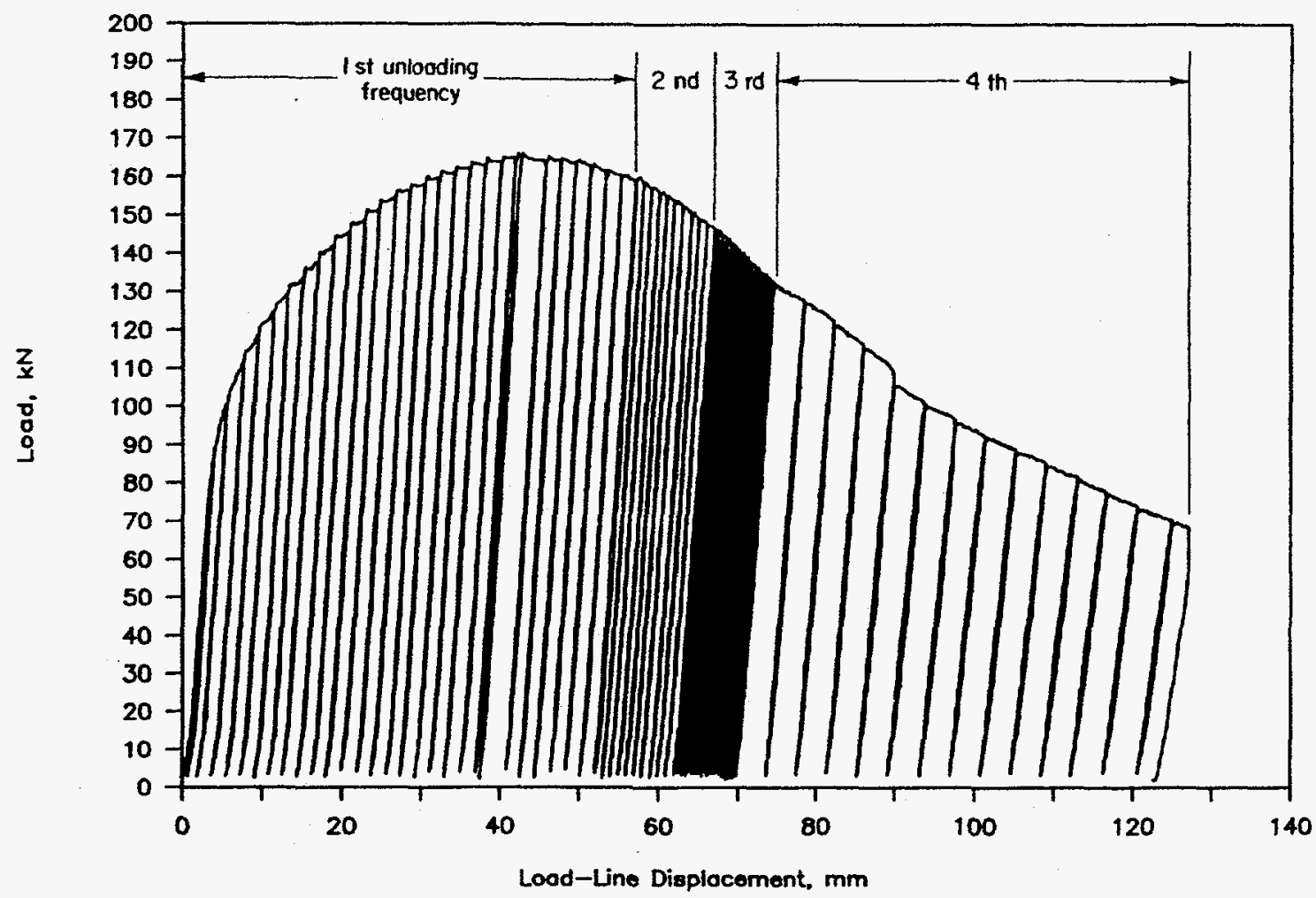

Figure 2.31 Measured load versus load-line displacement for quasi-static reversed $(\mathrm{R}=0)$ loading (Experiment 1.2-3 from IPIRG-1) 
Table 2.1 Advantages and disadvantages of several analysis methods for assessing cyclic load effects on the load-carrying capacity of cracked pipes

\begin{tabular}{|c|c|c|c|}
\hline Aspect & Detailed FEM Analyses & $\begin{array}{l}\text { Dowling Operational } \\
\Delta \mathbf{J} \text { Approach }\end{array}$ & $\begin{array}{l}\text { Cyclic J-R Curve } \\
\text { Approach }\end{array}$ \\
\hline Theoretical validity & $\begin{array}{l}\text { Can be assessed by various } \\
\text { integral fracture parameters }\end{array}$ & $\begin{array}{l}\text { Empirical } \\
\text { modification in } \\
\text { compressive load } \\
\text { region. } \\
\text { Transformation to } \mathrm{J}_{\mathrm{D}} \\
\text { needed. Application } \\
\text { to } \Delta \mathrm{J} \text { values above } \mathrm{J}_{\mathrm{Ic}} \\
\text { needs verification. }\end{array}$ & $\begin{array}{l}\text { Violates } \mathrm{J}_{\mathrm{D}} \text { theory. } \\
\text { Validation by FEM } \\
\text { needed. }\end{array}$ \\
\hline Ease of Application & Impractical at this time & $\begin{array}{l}\text { Much more } \\
\text { complicated than } \\
\text { current analysis } \\
\text { methods }\end{array}$ & $\begin{array}{l}\text { Consistent with current } \\
\text { LBB and in-service flaw } \\
\text { evaluation analysis } \\
\text { procedures }\end{array}$ \\
\hline $\begin{array}{l}\text { Material property } \\
\text { needs }\end{array}$ & $\begin{array}{l}\text { If a damage mechanism } \\
\text { unexplainable by other than } \\
\text { continuum mechanics occurs } \\
\text { (i.e., void flattening), then load- } \\
\text { history specific material } \\
\text { property data are needed. }\end{array}$ & $\begin{array}{l}\text { Extrapolation of high } \\
\text { cycle fatigue crack } \\
\text { growth curve. } \\
\text { (Fracture toughness } \\
\text { not a consideration.) }\end{array}$ & $\begin{array}{l}\text { Trend curve of the effects } \\
\text { of cyclic and dynamic } \\
\text { loading on J-R curve } \\
\text { needed. Similitude from } \\
\text { specimen to structural } \\
\text { cyclic J-R curves needs to } \\
\text { be shown. }\end{array}$ \\
\hline $\begin{array}{l}\text { Additional } \\
\text { requirements }\end{array}$ & $\begin{array}{l}\text { Knowledge of the load history, } \\
\text { i.e., global loads and } \\
\text { displacements }\end{array}$ & $\begin{array}{l}\text { Knowledge of the } \\
\text { load-history, i.e., } \\
\text { loads, displacements, } \\
\text { and when crack } \\
\text { closure occurs. }\end{array}$ & $\begin{array}{l}\text { Knowledge of the load } \\
\text { history, i.e., R-ratio, } \\
\text { incremental cyclic plastic } \\
\text { displacement. } \\
\text { These load-history } \\
\text { corrections on the } \\
\text { toughness may change } \\
\text { during the course of a } \\
\text { seismic event, so } \\
\text { simplification is required. }\end{array}$ \\
\hline Additional advantages & $\begin{array}{l}\text { Can consider each individual } \\
\text { cycle in detail }\end{array}$ & & $\begin{array}{l}\text { Readily lends itself to } \\
\text { dynamic cracked-pipe } \\
\text { analysis of the type in } \\
\text { Reference } 2.5 \text {. }\end{array}$ \\
\hline More disadvantages & High time and computer costs & & \\
\hline
\end{tabular}


Using the upper envelop of the load-displacement curves, comparisons could be easily made for the different load-histories, see Figure 2.32. The upper envelope of load-displacement was also used to calculate the cyclic J-R curve from the pipe tests, see Figure 2.33 . The displacements were significantly affected in the $\mathrm{R}=-1$ cyclic tests, resulting in greatly reduced J-R curves. The maximum loads in these pipe tests did not change significantly, since the pipes were small diameter, and hence the required toughness to reach limit-load conditions was easily met. These cyclic pipe tests were done on both TP304 stainless steel and A106 Grade B ferritic steel pipe at 288 C (550 F).

The results of this work showed that both ferritic and austenitic steel base metals could be susceptible to cyclic load-history effects that could lower the apparent toughness. Many questions were raised after these results were obtained, so a more comprehensive study was conducted in the IPIRG-2 program.

Cyclic C(T) Evaluations in IPIRG-2. In the IPIRG-2 program, various studies were conducted to get a better handle on the cyclic effects on material toughness. One effort involved the sectioning of specimens to determine physically what was happening. These results were summarized earlier.

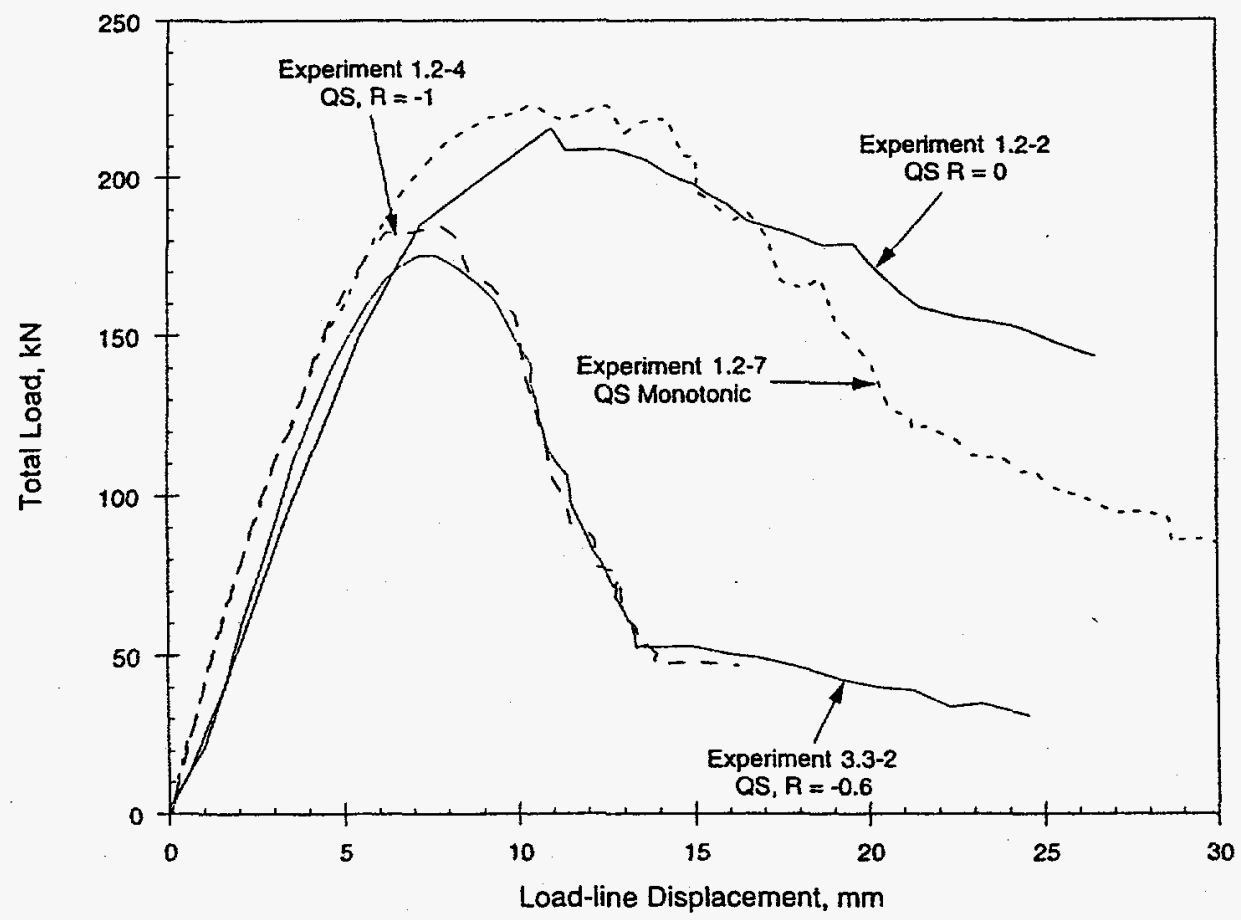

Figure 2.32 Load-displacement records for 152-mm (6-inch) nominal diameter carbon steel pipe experiments 


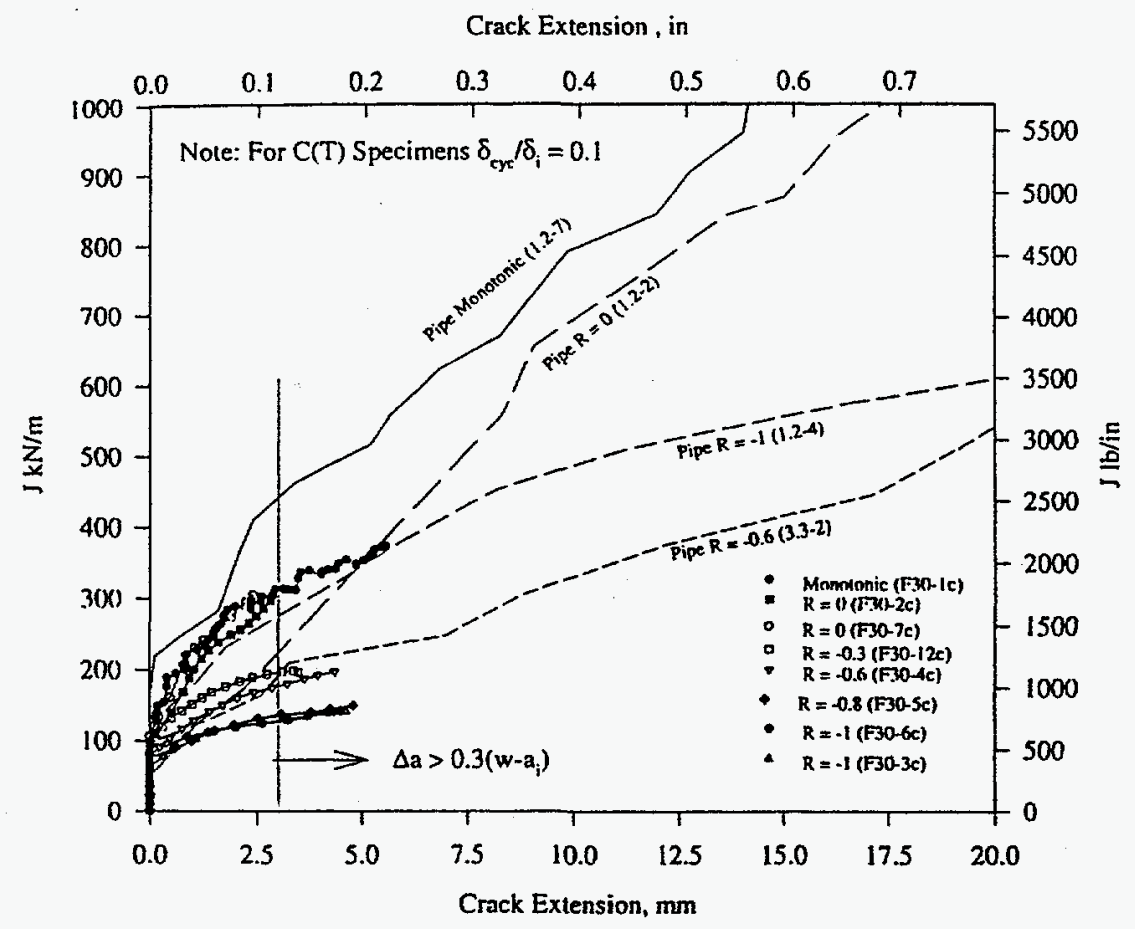

Figure 2.33 Comparison of cyclic-load J-R curves for carbon steel C(T) specimens tested with $\delta_{\text {cye }} / \delta_{i}=0.1$ and carbon steel TWC experiments

Another effort involved validating the J-R curve analysis procedure of using the upper envelop of the loaddisplacement curve. This procedure is the same as the current ASTM E1152 method for calculating a J-R curve for monotonic loading. Detailed finite element analyses were conducted of some cyclic $C(T)$ tests. Differences in the FEM loads occurred when isotropic or kinematic hardening was used, but they bounded the experimental load-displacement results. If either the isotropic or kinematic-hardening upper envelopes of the FEM load-displacement curves were used to calculate the J-R curve, then the ASTM and FEM J values were essentially the same, see Figure 2.34 . This validates this procedure for engineering purposes.

A large matrix of C(T) tests were conducted on TP304 base metal and A106 B base metal, both using the same pipe material as used in the IPIRG-1 TWC pipe experiments. The question of similitude between the $\mathrm{C}(\mathrm{T})$ and pipe results was the key aspect of this testing, with the secondary goal being able to assess the significance of variables such as the R-ratio. A limited amount of testing was also conducted on a stainless steel submerged-arc weld (SAW) and a ferritic SAW, as well as, a second 406-mm (16-inch) diameter TP304 stainless steel pipe. 


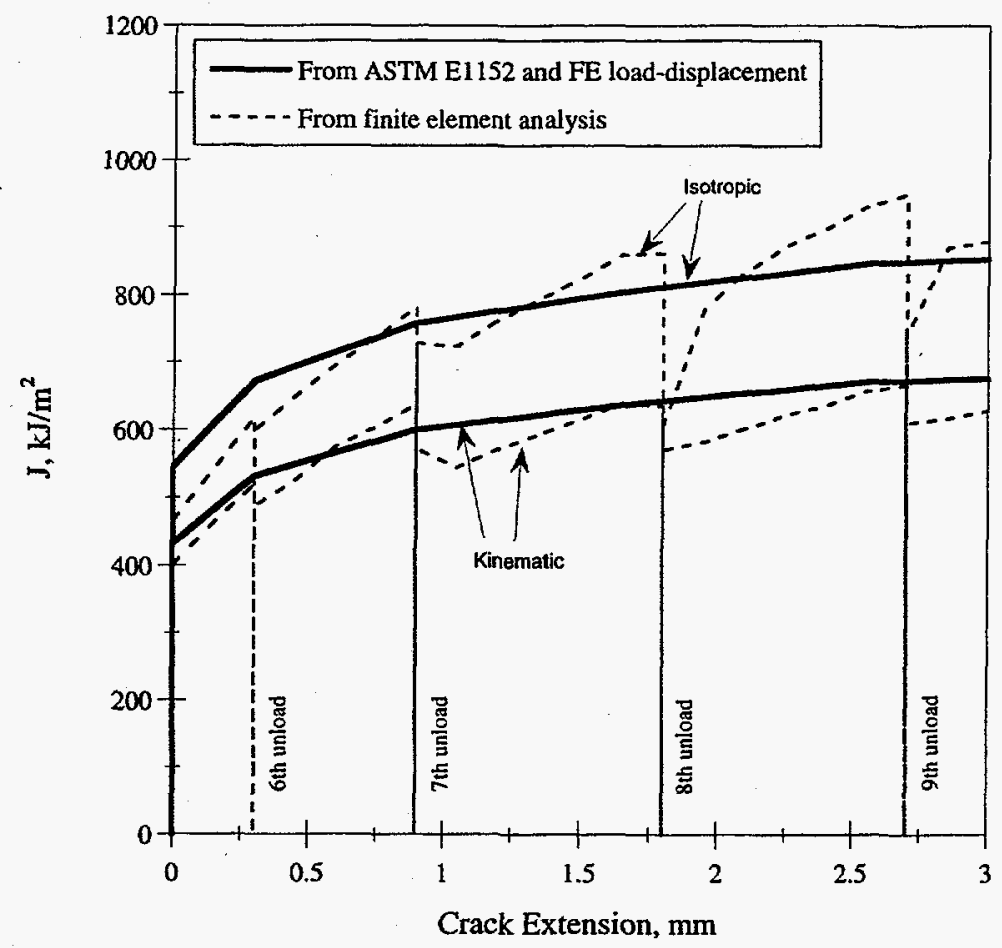

Figure 2.34 Comparison of J-R curves from FEM and ASTM using predicted load-displacement response

The results of all this work can be reduced to showing the general trends schematically in Figure 2.35. The trends are:

- Lowering of the R-ratio to -1 seemed to be a limiting case where the toughness may not decrease any further.

- If a material has a low monotonic toughness, then it may hit this lower bounding R-ratio at a more positive R-ratio.

- Decreasing the plastic cyclic increment lowers the apparent toughness of the material.

- The lower the yield-to-ultimate strength, the greater the loss in apparent toughness due to the cyclic loading.

Figures 2.36 and 2.37 show how the cyclic J-R curve compared with the monotonic J-R curve for both ferritic and stainless steels for various R-ratio loadings.

Similitude Between C(T) and Pipe Cyclic J-R Curves. In comparing the cyclic $\mathrm{C}(\mathrm{T})$ test results from the IPIRG-2 program with the cyclic circumferential through-wall-cracked pipe experiments conducted in IPIRG-1 on the same pipe material, it was found that the cyclic $J_{I c}$ values were essentially the same, i.e., 


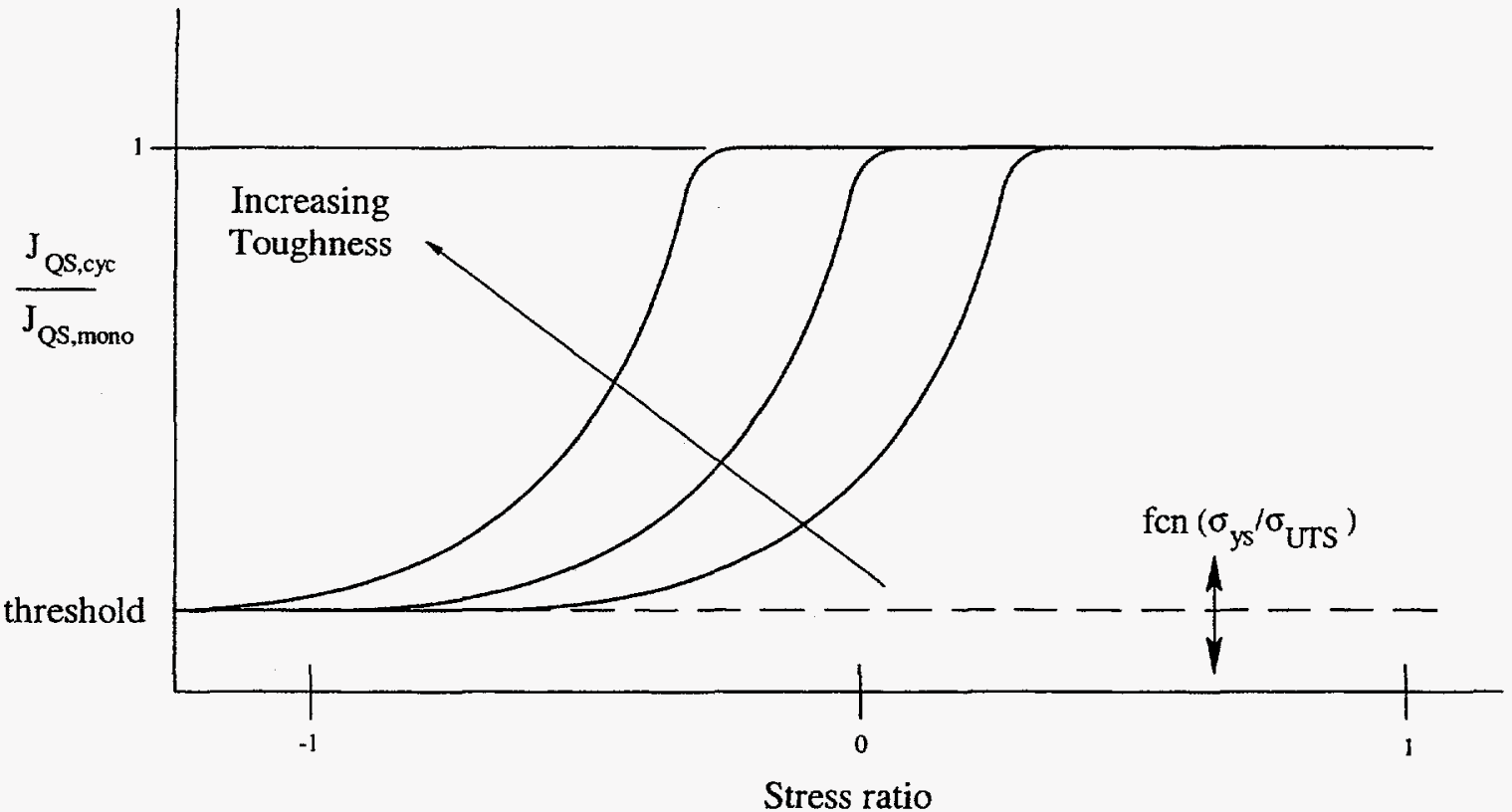

Figure 2.35 Schematic of relationship between cyclic toughness degradation and stress ratio

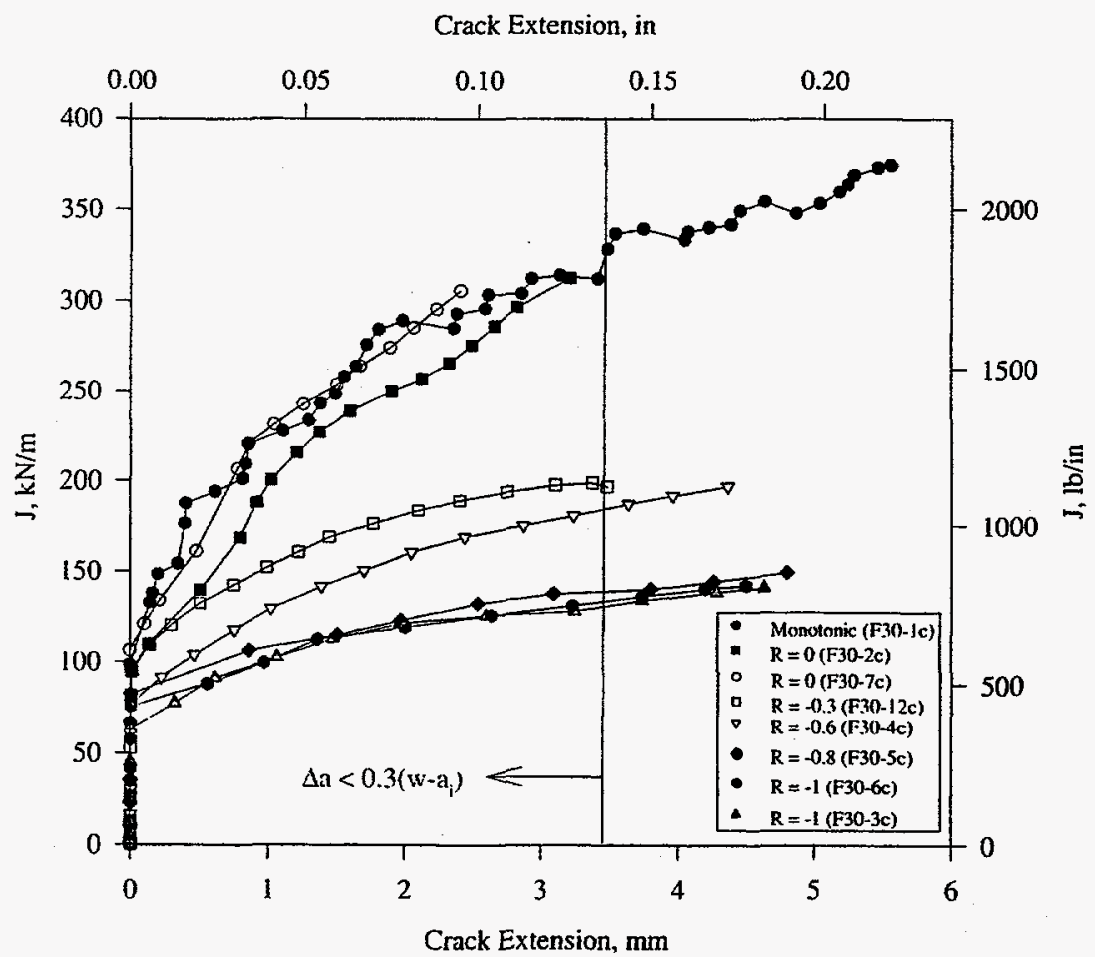

Figure 2.36 Carbon steel cyclic-load J-R curves tested at $\delta_{\text {cyc }} / \delta_{i}=0.1$ 


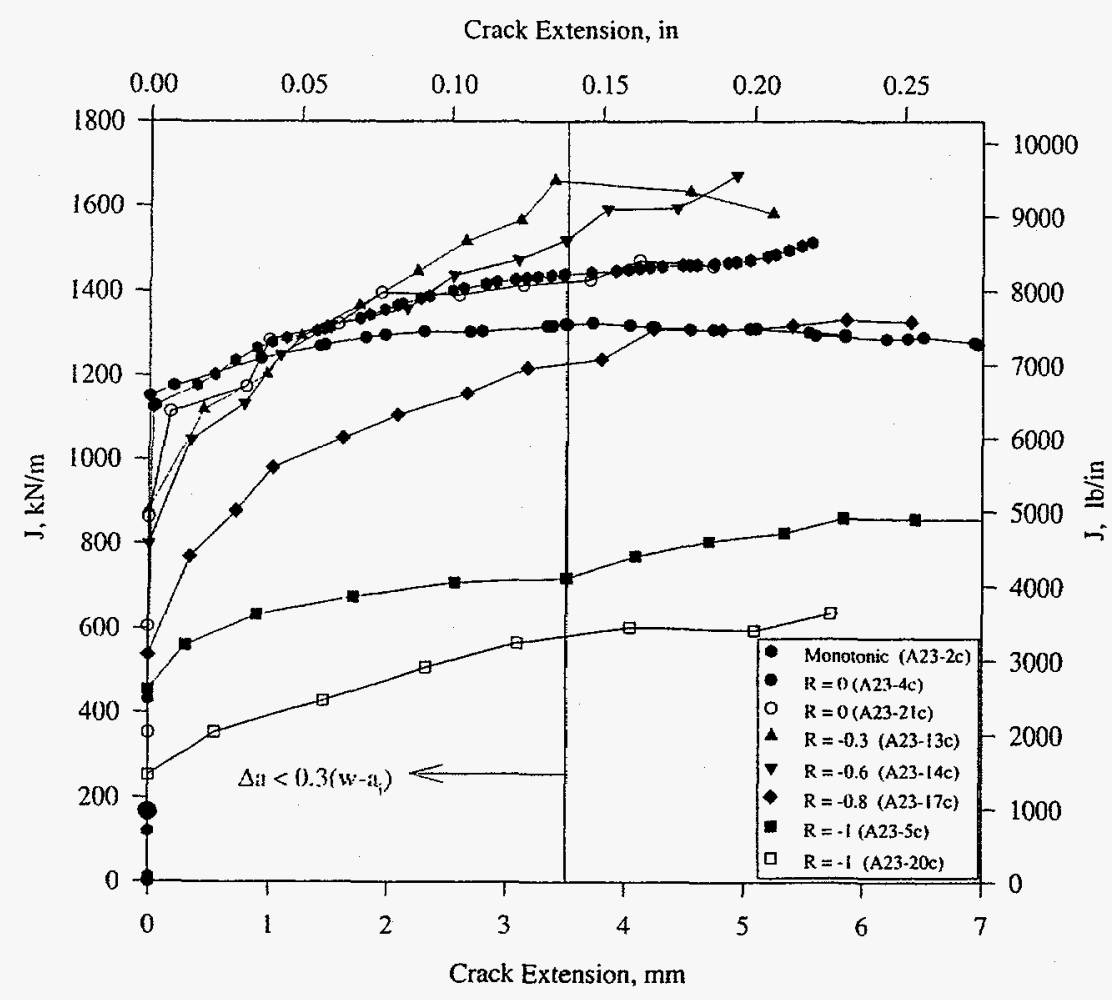

Figure 2.37 Stainless steel cyclic-load J-R curves tested with $\delta_{\text {cyd }} / \delta_{i}=0.1$

similitude existed when the same R-ratio and cyclic plastic displacement increment were used. The cyclic plastic displacement increment in each of these specimen geometries corresponded to having ten loading cycles occur before crack initiation.

The similitude between the $\mathrm{C}(\mathrm{T})$ and pipe specimens was more complicated for crack growth. Up to crack initiation, the cyclic plastic displacement seemed to be a good parameter (when normalized by the displacement to reach crack initiation in a monotonic test). However, after crack initiation, this parameter changes because of geometry effects. The cyclic crack growth is much smaller in the $C(T)$ specimens if this cyclic displacement increment is kept the same. Hence, the $C(T)$ results could be overly pessimistic for a through-wall-cracked pipe where a large amount of cyclic crack growth could occur. On the other hand, the ligament in a surface-cracked pipe is much smaller than that of a $C(T)$ specimen, so cyclic effects could be more significant for this flaw geometry. The size of the pipe will also affect this geometric similitude parameter for the cyclic crack growth between pipe and $C(T)$ specimens.

A methodology to account for the geometric effect was proposed in Reference 2.76. The determination of the displacement history needed in a C(T) specimen to get similitude with a cracked pipe involves the following:

- First, determine the cyclic displacement history that occurs prior to crack initiation. An assumption of having 10 cycles to crack initiation has been shown to be a reasonable bound.

- Second, using a J-estimation scheme for the cracked pipe, determine what this displacement history means in terms of crack growth per cycle once the crack initiates, see Figure 2.38. 


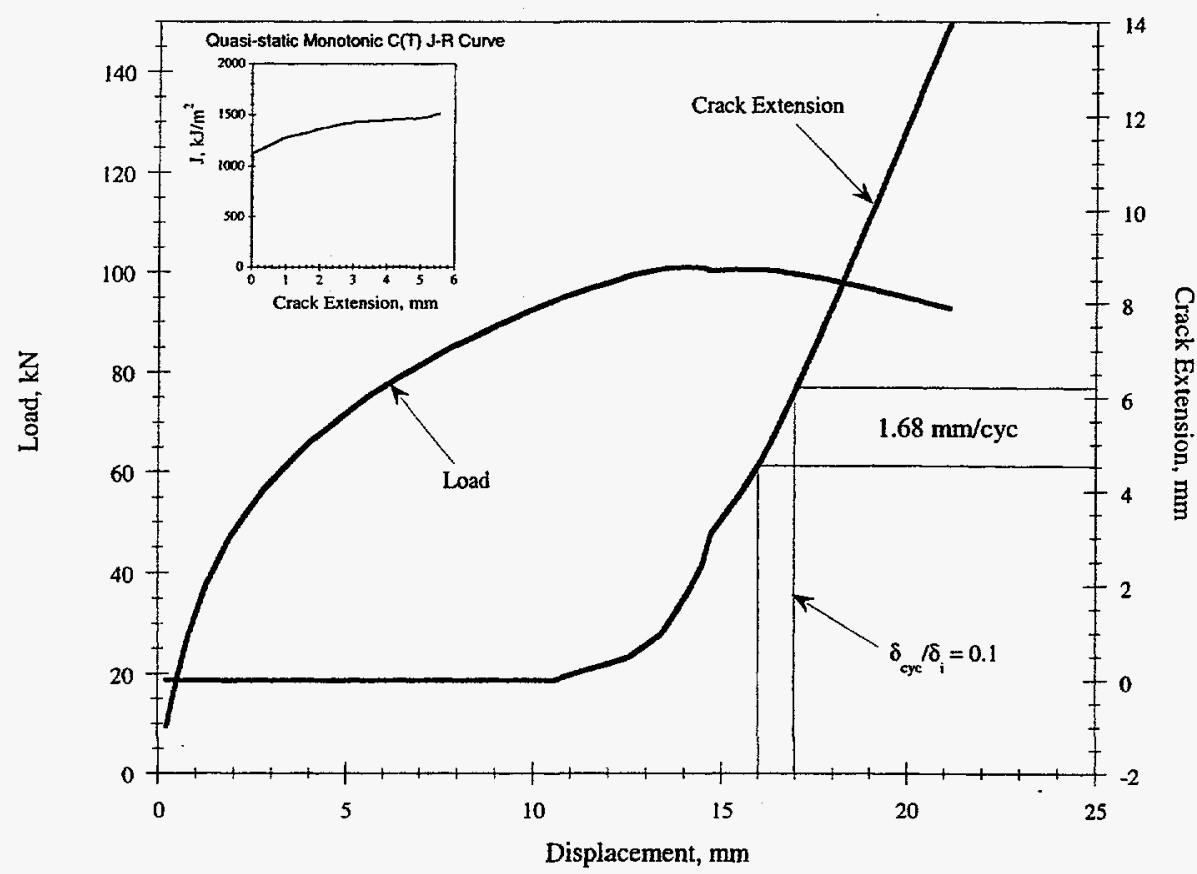

(a) GE/EPRI J-estimation scheme prediction of TWC pipe Experiment 4131-5 (Pipe DP2-A23) ( $J-R$ curve used in the calculation is inserted figure)

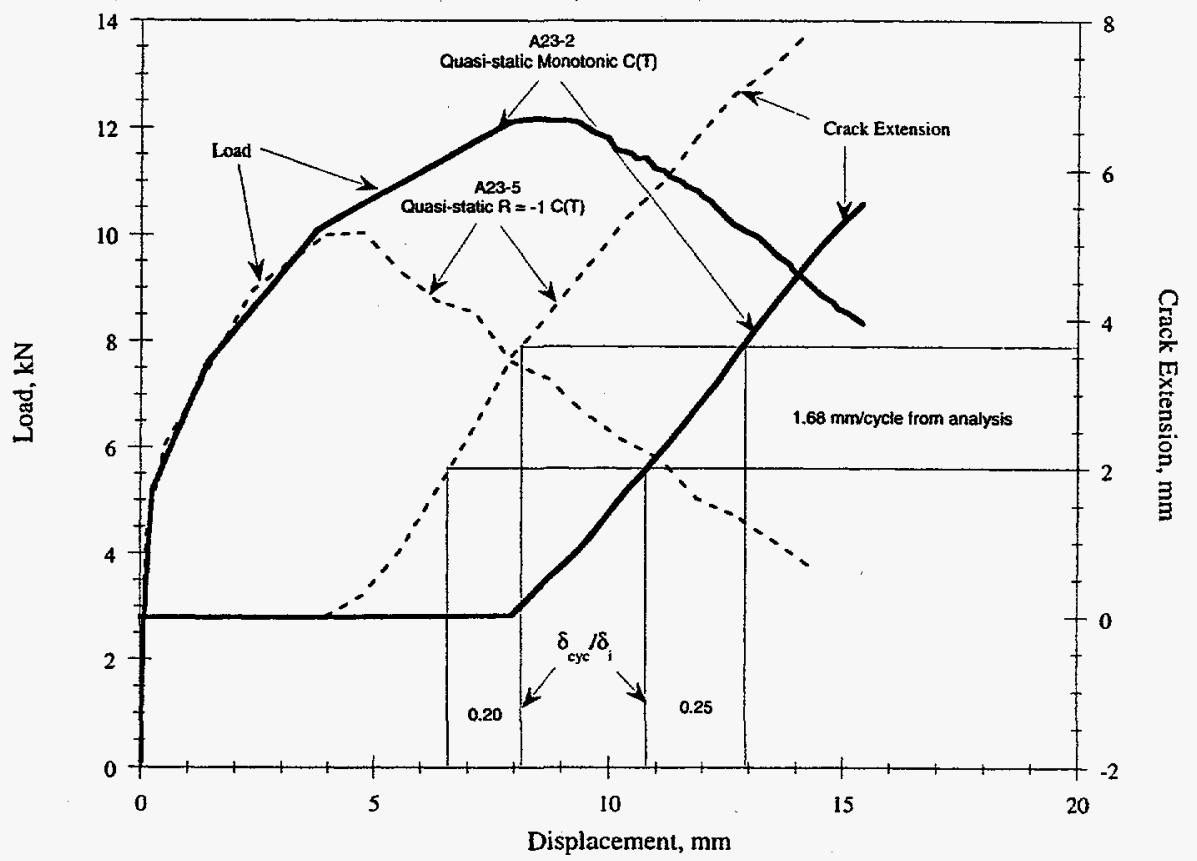

(b) $\mathrm{C}(\mathrm{T})$ specimen results

Figure 2.38 Load-displacement-crack growth records from a GE/EPRI TWC pipe prediction and C(T) specimens illustrating the need to change $\delta_{\mathrm{cyc}} / \delta_{i}$ after crack initiation to produce comparable cyclic crack growth between the two specimen types 
- $\quad$ Third, in a cyclic $C(T)$ test, conduct the cyclic experiment up to crack initiation so that the crack initiates in 10 cycles. After that number of cycles, change the $\mathrm{C}(\mathrm{T})$ specimen cyclic displacement history so that you get the same cyclic crack growth in the $C(T)$ specimen and pipe.

Using the above procedure, it should be possible to: (1) generate a time-history loading on a cracked pipe, (2) determine the effective load-history for $\mathrm{C}(\mathrm{T})$ or other laboratory specimens, (3) conduct the laboratory tests and then, (4) determine whether there are any significant load-history effects on the cracked-pipe material. With the cracked-pipe element developed in the IPIRG programs (Ref. 2.61), it therefore is possible to analyze any potential seismic load history in a cracked pipe system. With some iterative analyses and testing, the seismic effects could be precisely determined.

\subsubsection{Combined Dynamic and Cyclic Effects on Toughness}

The above discussion on cyclic loading was based on quasi-static loading rates. Likewise, the previous dynamic loading discussions on toughness were under monotonically increasing rates. Seismic events could have both dynamic and cyclic effects. The potential for interactions of dynamic and cyclic loading was evaluated in References 2.76 and 2.77 . In this work, experiments were conducted with:

- quasi-static monotonic loading,

- quasi-static cyclic loading,

- dynamic monotonic loading, and

- dynamic cyclic loading.

The work in Reference 2.77 was on TP304 and A106 Grade B pipes with circumferential through-wall cracks. The work in Reference 2.76 was on an austenitic SAW and a ferritic SAW using C(T) specimens. The results, which are summarized in Reference 2.76 , showed that there was no interaction between cyclic and dynamic loading effects. That was shown by separately determining the effect of just dynamic, monotonic loading relative to the quasi-static, monotonic loading on the J-R curve,

$$
\mathrm{F}_{\mathrm{dyn}}=\mathrm{J}_{\mathrm{dyn}, \text { mono }} / \mathrm{J}_{\mathrm{QS} \text {,mono }}
$$

and the effect of quasi-static, cyclic loading relative to the quasi-static, monotonic loading on the J-R curve,

$$
\mathrm{F}_{\text {cyc }}=\mathrm{J}_{\mathrm{QS}, \text { cyc }} / \mathrm{J}_{\mathrm{QS} \text {,mono }}
$$

The multiplicative effect of the two gave $J$ values that were equal to the tests conducted under combined dynamic and cyclic loading, $\mathbf{J}_{\mathrm{dyn}, \mathrm{cyc}}$, i.e.,

$$
\mathrm{J}_{\mathrm{dyn}, \mathrm{cyc}}=\mathrm{J}_{\mathrm{QS}, \mathrm{mono}} \mathrm{F}_{\mathrm{dyn}} \mathrm{F}_{\mathrm{cyc}}
$$

This is illustrated in Figure 2.39. 


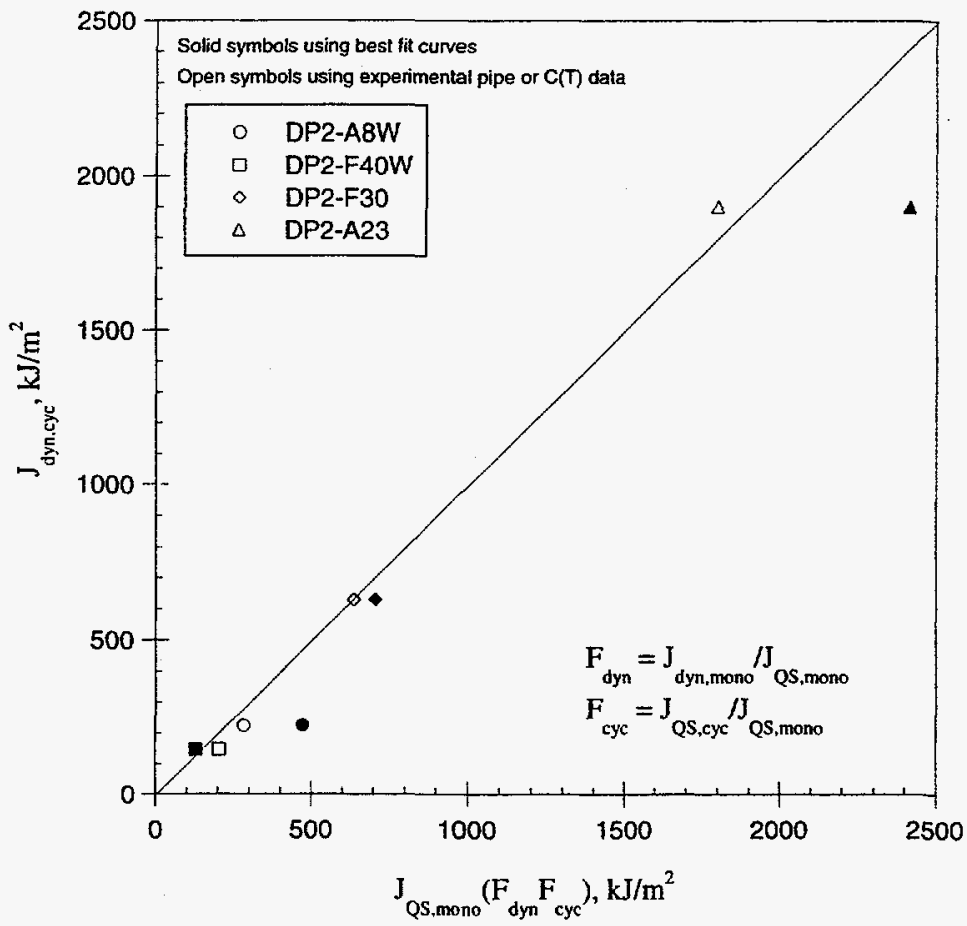

Figure 2.39 Calculated $\mathbf{J}$ for dynamic, cyclic loading for separate effect trends versus actually combined loading $J$ values

\subsubsection{What These Load History Effect Results Mean in Terms of Pipe Fracture Behavior}

The trends reported above are important in pointing out that there could be an effect of cyclic loading on the toughness, but whether this will occur in a seismic load history is still an open issue. The analysis procedure described in the immediately preceding Section 2.2 .6 .3 , although elegant, is perhaps too complicated for anything but a few rare cases. The question, therefore becomes, whether some practical bounds be created.

Since seismic events are probabalistic in nature, the answer is that the cyclic effects are also probabalistic. From the IPIRG-2 simulated-seismic pipe experiments (Ref. 2.80), it was found that the way the timehistory evolves could significantly affect the seismic results. If the seismic time-history involved elastic cycling, followed by a large amplitude cyclic load, then the seismic load history acts like a monotonic dynamic load. Seismic histories like the Northridge and Kobe earthquakes tended to have a sudden large amplitude loading of this type. On the other hand, if the amplitudes gradually built up, see prior discussion in Section 2.1.4 of this report, then there would be more cyclic damage at the crack tip. From the IPIRG-1 single-frequency and the IPIRG-2 seismic-load-histories, it was found that the single-frequency loading with a gradual build-up of the amplitudes was more damaging.

Consequently, one could make an argument that bounding cases of seismic loading effects on material behavior are between a monotonic dynamic loading (i.e., we need only to account for loading rate effect on toughness), and a cyclic load history (cyclic and dynamic loading effects together). 
A bounding cyclic load history was proposed in Reference 2.81 . This was based on work in Reference 2.5 that showed that when a crack was present, the R-ratios tended to become much more negative than the same load history for an uncracked pipe. Hence, a bounding negative R-ratio of -1 should be used. Secondly, it was assumed that the rise time of a typical seismic event was 2 to 5 seconds (typical seismic design criteria). Assuming increasing amplitudes occur at frequencies close to the natural frequency of the pipe system, then for a $4 \mathrm{~Hz}$ pipe system there would be 8 to 20 cycles, see Figure 2.40 . If there were 20 cycles, approximately half of them would involve plasticity, hence, having 10 plastic cycles up to crack initiation is not an unreasonable bound. Furthermore, since most seismic design criteria say that the strong motions or large amplitudes would occur during 4 to 15 seconds, and recognizing again that large amplitudes would have to occur at frequencies close to the natural frequency of the pipe system, then there would be from 16 to 60 cycles of loading for the $4 \mathrm{~Hz}$ pipe system. Since 10 to 30 large amplitude cycles are frequently quoted in seismic design code or regulatory work, the 30 cycles seems like a reasonable bound on the number of cycles. These 30 cycles would then determine how far the crack could propagate once it initiates. Further pipe-system dynamic analyses would be needed to assess the differences of these two bounding approaches using this more precise procedure.

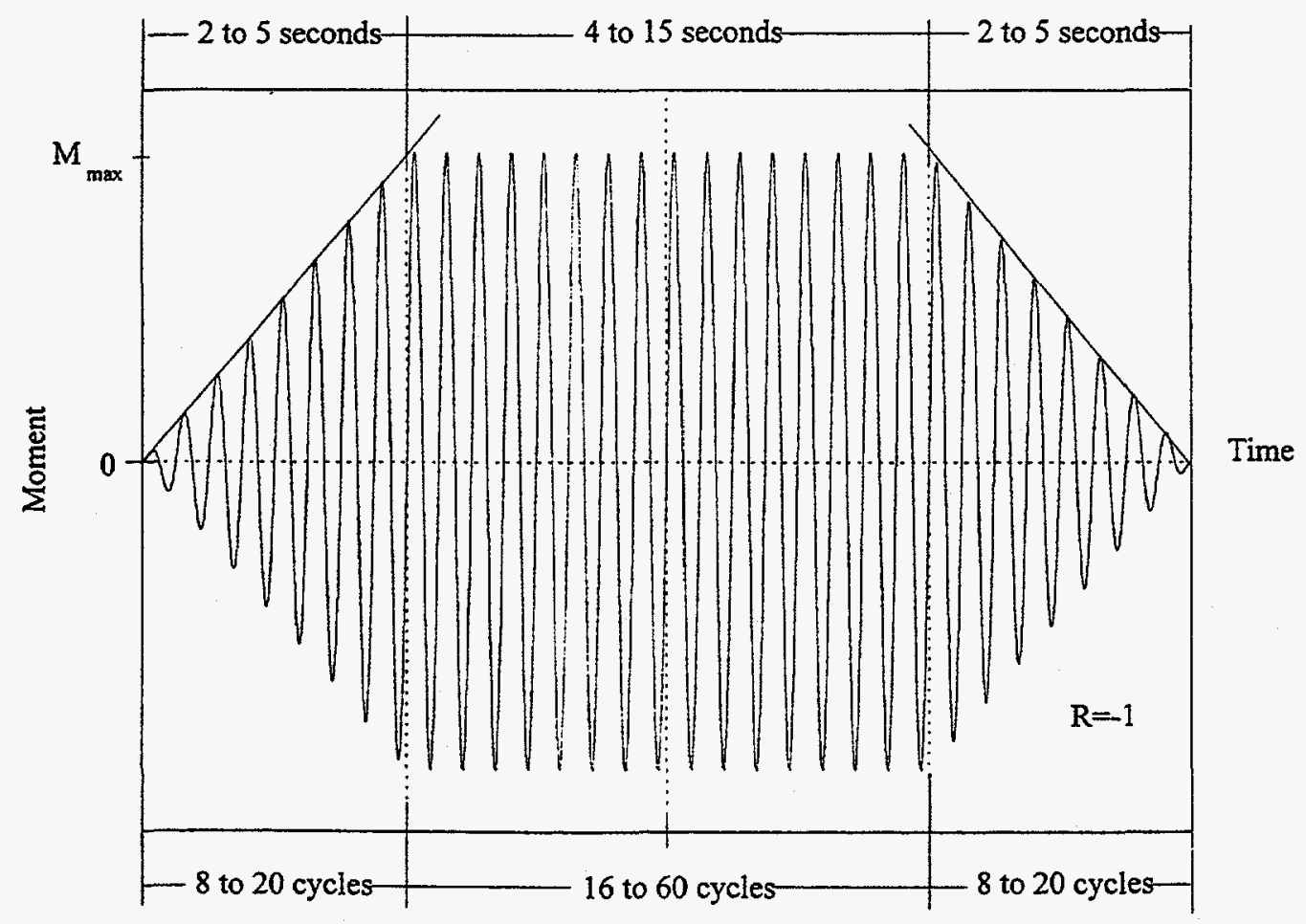

Figure 2.40 Example of a worst case bounding seismic time history for a $4 \mathrm{~Hz}$ natural frequency pipe system 


\subsubsection{Constraint Effects}

Fracture mechanics methodologies have always recognized that there are constraint effects (structural or specimen geometry, crack type or size, and thickness) effects on fracture toughness. Thickness limits on "valid" plane strain fracture toughness evaluations were part of the first fracture toughness standards. In more recent years, analytical methods have evolved to account for constraint effects on the fracture behavior so that going from one crack size and a relatively simple specimen geometry to another (Refs. 2.82 and 2.83 ) is now possible.

Past piping fracture mechanics data exist from the oil and gas industries that show that there are significant effects of constraint on the brittle-to-ductile transition temperatures for flawed pipes relative to standard bend bar or $\mathrm{C}(\mathrm{T})$ specimen results. For axial through-wall cracks in pipes pressurized to failure, it was found that the failure pressure versus temperature transition curve agreed well with COD bend-bar specimen transition temperatures, see Figure 2.41 from Reference 2.84. However, for axially surfacecracked pipe, it has been found that the surface-cracked pipe has a much lower brittle-to-ductile transition temperature than COD bend-bar specimens, see Figures 2.42(a) and 2.42(b) from References 2.85 and 2.86. Similar trends in the brittle-to-ductile transition temperatures between single-edge notched tension specimens (used to simulate surface crack constraint) and bend-bar specimens have been found in Reference 2.87. In that reference, the brittle-to-ductile transition temperature was also found to be highly sensitive to crack depth. Those results agree with the work on shallow versus deep notch bend-bar specimens.

$$
\begin{aligned}
& x=\text { Through }- \text { wall cracked pipe data } \\
& 0=t \times 2+\text { COD bend specimens }
\end{aligned}
$$

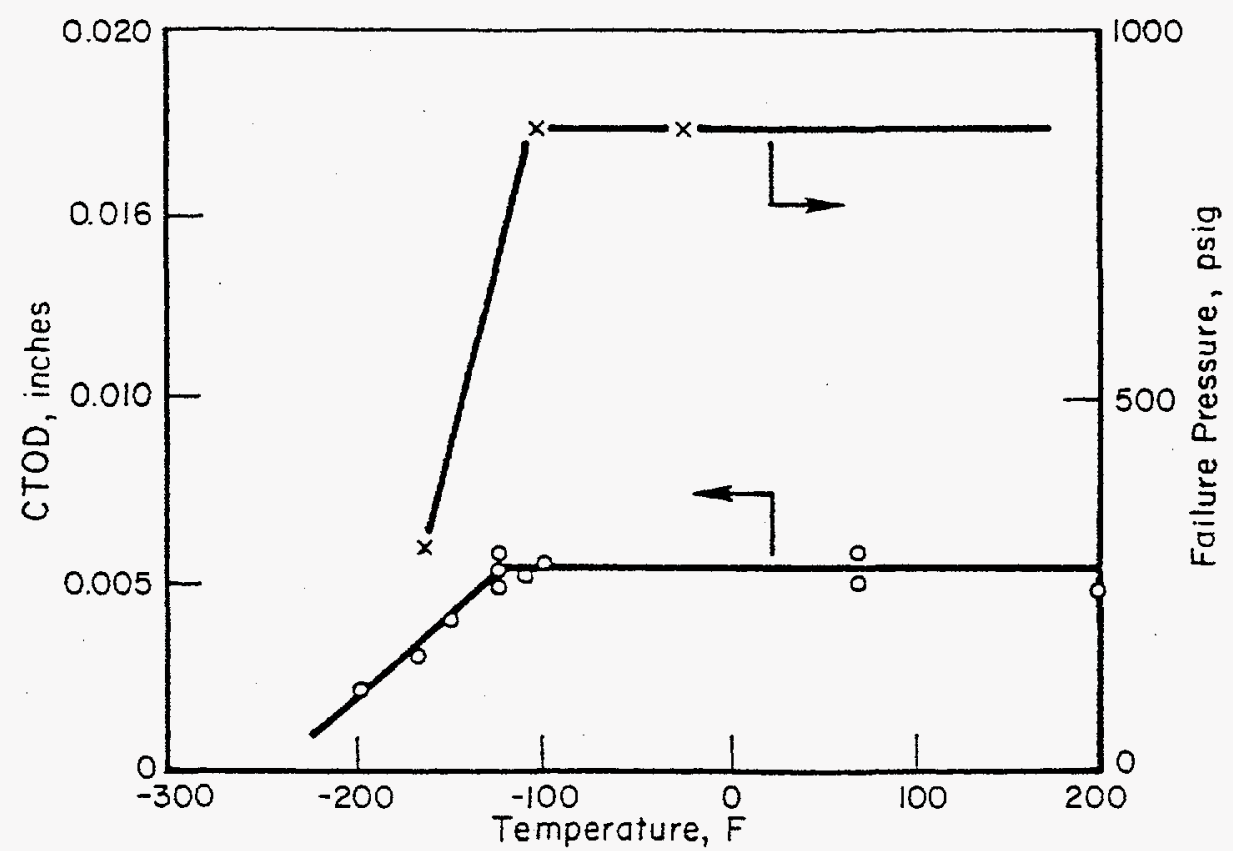

Figure 2.41 Comparison of $\mathrm{t} x \mathrm{2t}$ COD transition to axial through-wall-cracked 1,219-mm (48-inch) diameter pipe fracture data 
$x=$ Surface cracked pipe dato

$0=t x:$ COD benó specimens

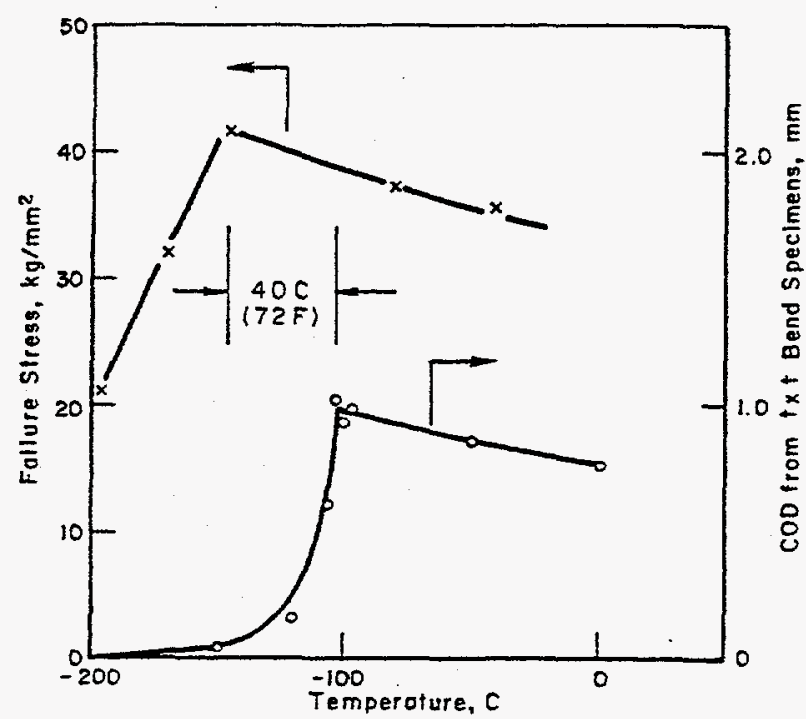

(a) Stress relieved

$x$ = Surfoce crocked pipe dato

$0=\uparrow x \uparrow C O D$ bend specimens

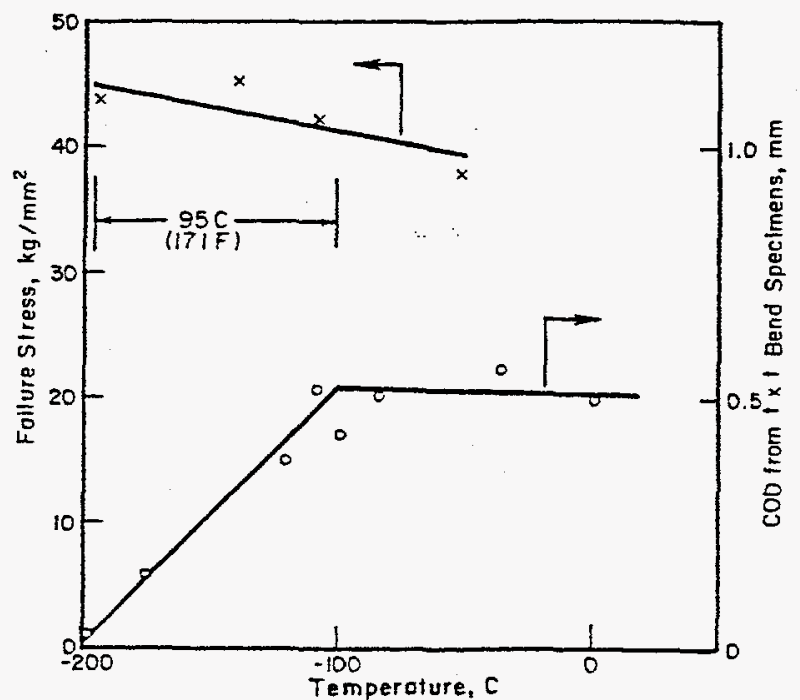

(b) Non-stressed relieved

Figure 2.42 Comparison of the transition temperature from COD bend specimens to 610-mm (24-inch) diameter by 9.5-mm (0.375-inch) thick API-5LX pipe with axial surface cracks 
These pipe tests results imply that Class 2,3 , and balance of plant (BOP) ferritic piping, that may be at lower operating temperatures than Class 1 piping, may behave in a more ductile manner than they are currently given credit for in standards like ASME Section XI. However, the effects of weld residual stresses on the constraint/fracture behavior needs to be addressed prior to taking advantage of these additional margins. This is because the weld residual stresses can cause a through-thickness bending stress that would increase the constraint.

\subsection{Piping Fracture Mechanics Analyses - Straight Pipe}

Piping fracture mechanics evaluations first started with work to resolve the problem with long running brittle fractures in natural gas transmission lines. These efforts started in the early 1950's at Battelle for the American Gas Association, which is now referred to as Pipeline Research Committee International (PRCI). Some of the history of this early work is reviewed in Section 1.0.

The initial concern with piping flaws was for axial cracks. Natural gas and oil transportation pipelines typically do not have high longitudinal stresses except in land subsidence areas, frost heave situations, or in offshore applications. Consequently, gas and oil industries have not been as concerned with circumferential cracks as has the nuclear industry. A limited amount of work has also been done for helical cracks in the oil and gas industry, mainly for the purpose of flaw evaluations in spiral welded pipe (Ref. 2.88).

In this section of the report, we will discuss piping fracture mechanics aspects that are relevant to plant piping applications (nuclear, fossil, petrochemical industries), but will not deal with subcritical crack growth issues such as stress corrosion cracking or creep. There is an abundance of information on these mechanisms in the open literature.

\subsubsection{Predictions for Axially Cracked Pipes}

The fracture behavior of axially cracked nuclear pipes was first investigated at LWR temperatures by Battelle for the U.S. Atomic Energy Commission in the mid 1960's to the early 1970's (Ref. 2.89). This work involved looking at maximum pressure predictions, as well as dynamic fracture and arrest in ferritic and austenitic pipes. A minor amount of work was also done on circumferential flaws in that program. Similar work was subsequently done at MPA-Stuttgart on German low alloy steel nuclear piping (Refs. 2.90 and 2.91).

Maximum Pressure Predictions - Axial Through-Wall Cracks. Some of the initial development work on the fracture mechanics analysis currently used in most axial flaw evaluations in piping came from developmental efforts for the gas pipeline industry (Ref. 2.92). The analysis uses a Dugdale plasticity correction in a flat plate, where originally the crack-driving force was given using a plane stress intensity factor, $\mathrm{K}_{\mathrm{c}}$ :

$$
\pi \mathrm{K}_{\mathrm{c}}{ }^{2} /\left(8 \operatorname{co} \sigma_{\mathrm{f}}^{2}\right)=\ln \left\{\sec \left[\pi \sigma /\left(2 \sigma_{\mathrm{f}}\right)\right]\right\}
$$

where 


$$
\begin{array}{ll}
2 c= & \text { total axial through-wall crack length } \\
\sigma_{\mathrm{f}}= & \text { flow stress } \\
\sigma= & \text { failure stress. }
\end{array}
$$

For the axial crack in the pipe, a Folias (Ref. 2.93) bulging factor $\left(\mathrm{M}_{\mathrm{T}}\right)$ modification was also included. The Folias bulging factor comes from a thin-wall shell analysis:

$$
\pi \mathrm{K}_{\mathrm{c}}{ }^{2} /\left(8 \operatorname{co}_{\mathrm{f}}^{2}\right)=\ln \left\{\sec \left[\pi \mathrm{M}_{\mathrm{T}} \sigma_{\mathrm{h}} /\left(2 \sigma_{\mathrm{f}}\right)\right]\right\}
$$

where

$$
\begin{aligned}
& \sigma_{\mathrm{h}}=\text { hoop stress at failure } \\
& \mathrm{M}_{\mathrm{T}}=\text { Folias bulging factor. }
\end{aligned}
$$

The original Folias bulging factor relationship was derived from thin shell theory, and is essentially the ratio of the stress intensity factors for the same size crack in an infinite flat plate and a crack in a cylinder. As the name implies, there is a higher crack driving force in the axially cracked pipe case than the flat plate case due to the pipe bulging outward from the pressure. The $\mathrm{M}_{\mathrm{T}}$ analysis comes from an elastic analysis where

$$
\mathrm{M}_{\mathrm{T}}=\mathrm{K}_{\text {shell }} / \mathrm{K}_{\text {plate }}
$$

Geometric relationships have been developed for this bulging factor, where the original Folias solution was

$$
\mathrm{M}_{\mathrm{T}}=\left[1+1.61\left(\mathrm{c}^{2} / \mathrm{Rt}\right)\right]^{0.5}
$$

where

$$
\begin{aligned}
& \mathrm{R}=\text { pipe radius } \\
& \mathrm{t}=\text { pipe wall thickness }
\end{aligned}
$$

which was good for shorter crack lengths, i.e., $\lambda<2$ where

$$
\lambda=\left[12\left(1-v^{2}\right)\right]^{1 / 4} \mathrm{c} /(\mathrm{Rt})^{0.5}
$$

where

$v=$ Poisson ratio.

An updated Folias equation, which is supposed to be good for $\lambda<8$, is

$$
\mathrm{M}_{\mathrm{T}}=\left[1+1.255\left(\mathrm{c}^{2} / \mathrm{Rt}\right)-0.0135\left(\mathrm{c}^{2} / \mathrm{Rt}\right)^{2}\right]^{0.5}
$$

This equation was validated by Krenk (Ref. 2.94) using 10th order shell analyses and for $\lambda<8$.

A comparison of these two $\mathrm{M}_{\mathrm{T}}$ equations is shown in Figure 2.43. This figure shows that the updated Folias equation is slightly lower than the original Folias equation. The limit on the updated Folias bulging 
factor equation of $\lambda<8$ corresponds to a $\mathrm{c} /(\mathrm{Rt})^{0.5}$ value of about 4.4 . Using this equation beyond this limit could result in very nonconservative failure pressure predictions.

In the initial Battelle work, a correlation was developed between $\mathrm{K}_{\mathrm{c}}{ }^{2}$ and Charpy $\mathrm{V}$-notch upper shelf impact energy for ductile fracture. This relationship is

$$
12 \mathrm{C}_{\sqrt{ }} / \mathrm{A}_{\mathrm{C}}=\mathrm{K}_{\mathrm{c}}{ }^{2} / \mathrm{E}
$$

where

$\mathrm{C}_{\mathrm{v}}=$ Charpy V-notch impact energy, ft-lb

$A_{C}=$ net-section area of the Charpy specimen, i.e., $0.124 \mathrm{in}^{2}$

$\mathrm{E}=$ elastic modulus.

This relationship was found from experimental data, and when combined with Equation 2-16 gives

$$
12 \pi \mathrm{C}_{\mathrm{v}} \mathrm{E} /\left(8 \mathrm{c} \sigma_{\mathrm{f}}^{2} \mathrm{~A}_{\mathrm{c}}\right)=\ln \left\{\sec \left[\pi \mathrm{M}_{\mathrm{T}} \sigma /\left(2 \sigma_{\mathrm{f}}\right)\right]\right\}
$$

The initial crack length was used in this relationship.

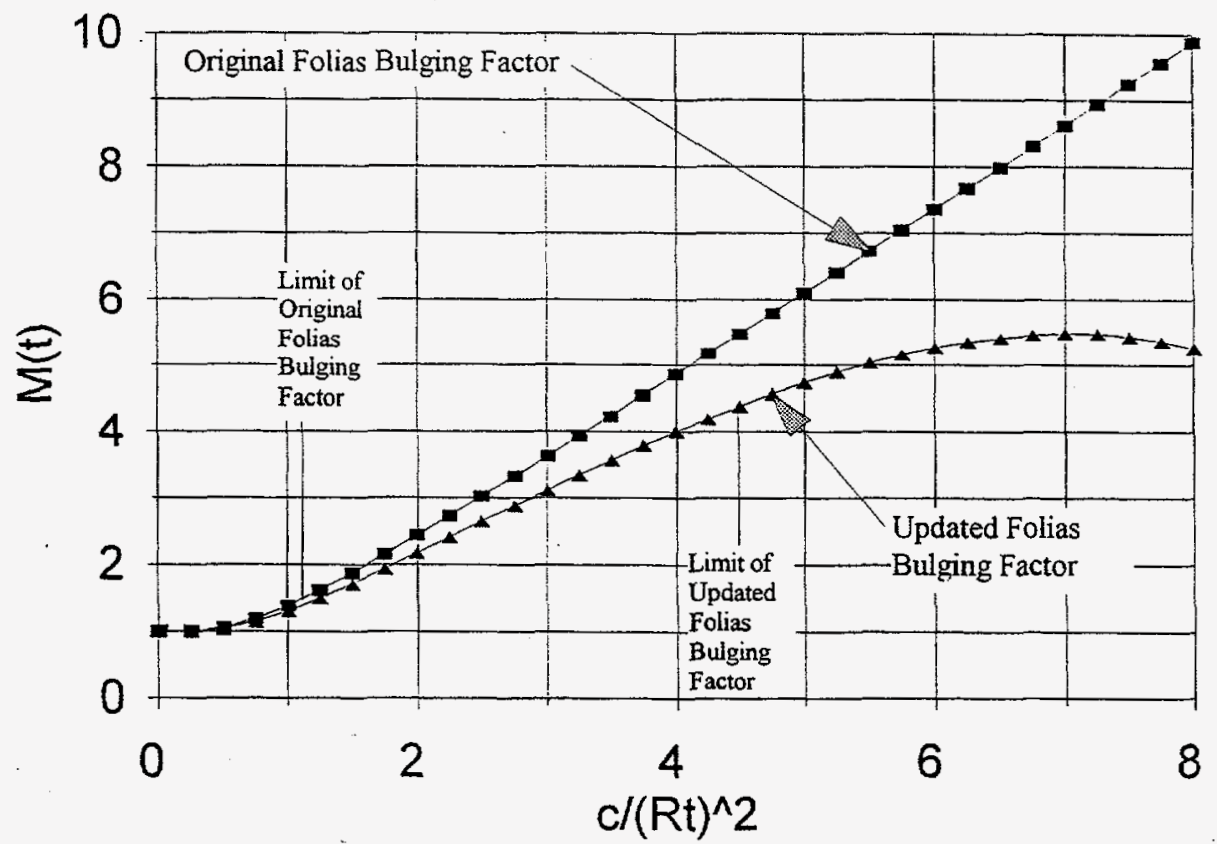

Figure 2.43 Comparison of original and updated Folias bulging factors $\left(\mathbf{M}_{\mathrm{T}}\right)$ 
Since that time, the J-R curve methodology has been developed. In Reference 2.95, it was shown that one could convert $K_{c}$ to $J$ values by

$$
\mathrm{J}=\mathrm{K}^{2} / \mathrm{E}
$$

and hence,

$$
\pi J E /\left(8 \operatorname{co} \sigma_{\mathrm{f}}^{2}\right)=\ln \left\{\sec \left[\pi \mathrm{M}_{\mathrm{T}} \sigma_{\mathrm{h}} /\left(2 \sigma_{\mathrm{f}}\right)\right]\right\}
$$

With a J-R curve for the material, one can then make crack growth and maximum load predictions that are more fundamentally correct.

An aspect to note is that as the toughness goes to infinity, then the solution above defaults to the limit-load solution of

$$
\mathrm{M}_{\mathrm{T}} \mathrm{\sigma}_{\mathrm{h}}=\sigma_{\mathrm{f}}
$$

This is illustrated in Figure 2.44. In this figure, it can be seen that the hoop stress at failure is approaching an asymptote. For design purposes, a practice that is used is to ensure that there is a minimum toughness so that the failure stress would be at least 85 percent of the limit-load hoop stress at failure. This is shown in Figure 2.44, which corresponds to the nondimensional toughness level of 1.455 . This could also be correlated back to a minimum Charpy energy rather than a $J_{I c}$ value.

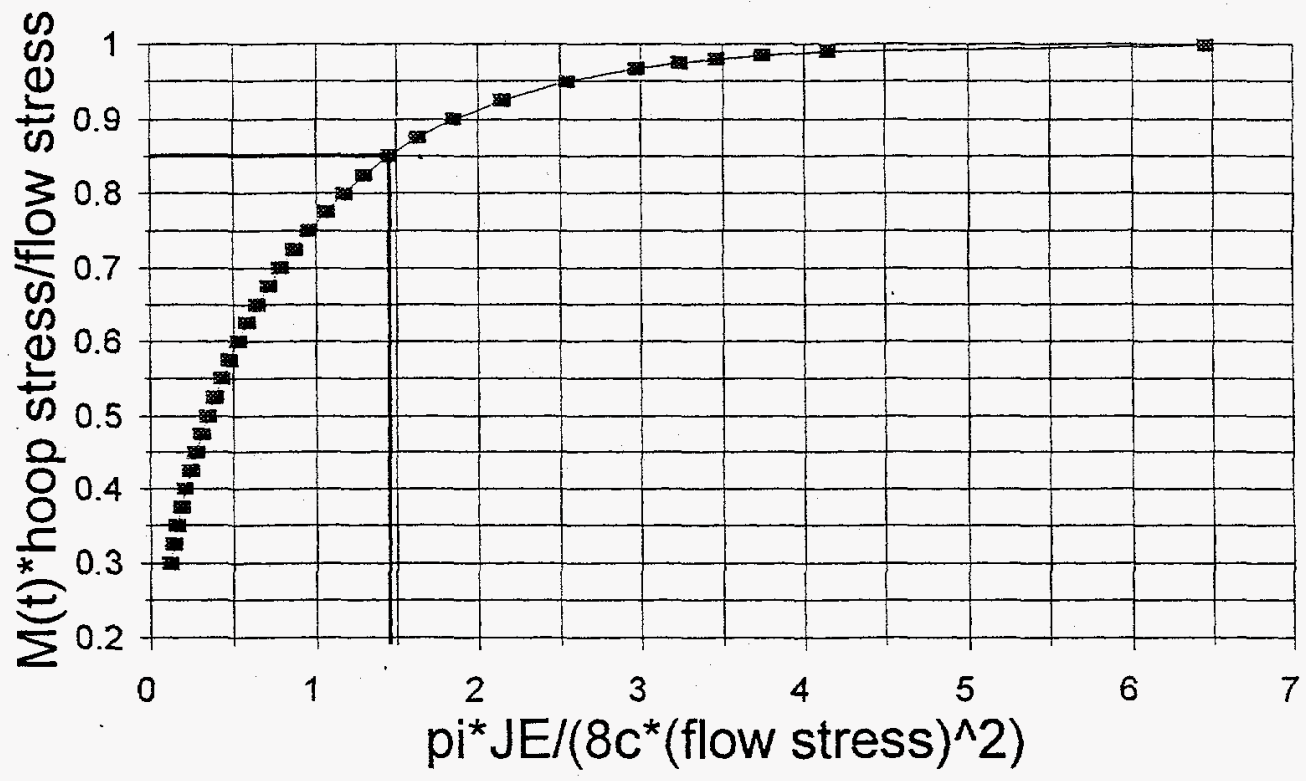

Figure 2.44 Plot of log-secant equation for axial through-wall cracks 
A final noteworthy point is that the definition of flow stress is somewhat arbitrary, and hence empirically defined. In the original gas pipeline work at Battelle, the flow stress was taken as yield strength plus $10 \mathrm{ksi}$ (68.9 MPa). Typically, people use flow stress as the average of the yield and ultimate strengths, and in the ASME Section XI pipe flaw evaluation standards, flow stress has been defined as either $2.4 \mathrm{~S}_{\mathrm{m}}$ for ferritic steels, or $3 \mathrm{~S}_{\mathrm{m}}$ for austenitic steels. Comparisons with databases such as the AXIALCK database in Reference 2.68 are useful in assessing the validity of such definitions.

Maximum Pressure Predictions - Axial Surface Cracks. One of the most frequently used axial surface-cracked pipe solutions came from the work of Kiefner and Maxey (Ref. 2.96). In this work, Maxey empirically determined a modification to the Folias through-wall crack bulging factor for a constant depth surface flaw. This modification is

$$
M_{p}=\left[1-a /\left(t M_{T}\right)\right] /(1-a / t)
$$

where

$$
\begin{aligned}
& M_{p}=\text { surface-crack bulging factor } \\
& a=\text { depth of the surface crack } \\
& t \quad=\text { pipe thickness. }
\end{aligned}
$$

In the $M_{T}$ term, the length of the surface crack is used. The $M_{p}$ term is then used instead of the $M_{T}$ term in Equations 2-16, 2-22, or 2-24. These equations will predict when an axial surface crack will break through the thickness. Whether such a flaw results in a leak or break, depends on the length of the surface crack relative to the critical through-wall crack length. Figure 2.45 illustrates this leak-before-break behavior under pressure loading. Note, that axial surface cracks with depths less than 50-percent of the pipe wall thickness will generally result in breaks, whereas the deeper, shorter flaws will result in leaks.

In a manner similar to the through-wall-cracked pipe solutions, the surface crack equation also defaults to a limit-load solution, where, as the toughness goes to infinity,

$$
M_{p} \sigma_{h}=\sigma_{f}
$$

The limit-load solution for axial flaws was found to be reasonably reliable for corrosion defects in pipes, Ref. 2.97. This work eventually led to the development of the ANSI B31G allowable corrosion criterion for gas and oil pipelines. In that work, the flaw shape was found to play an important role. For simplicity, the ANSI B31G approach used the maximum depth of the flaw, with the depth of the flaw assumed to have a parabolic shape. The surface crack equations cited above assume a constant depth flaw. An equivalent flaw length formulation was developed from experimental observations to be

where

$$
2 c_{e q}=A_{f} / a_{\max }
$$

$$
\begin{array}{ll}
2 c_{e q} & =\text { equivalent total flaw length to use in the } M_{p} \text { term } \\
A_{f} & =\text { cross sectional area of the surface flaw } \\
a_{\max } & =\text { maximum depth of the surface flaw. }
\end{array}
$$




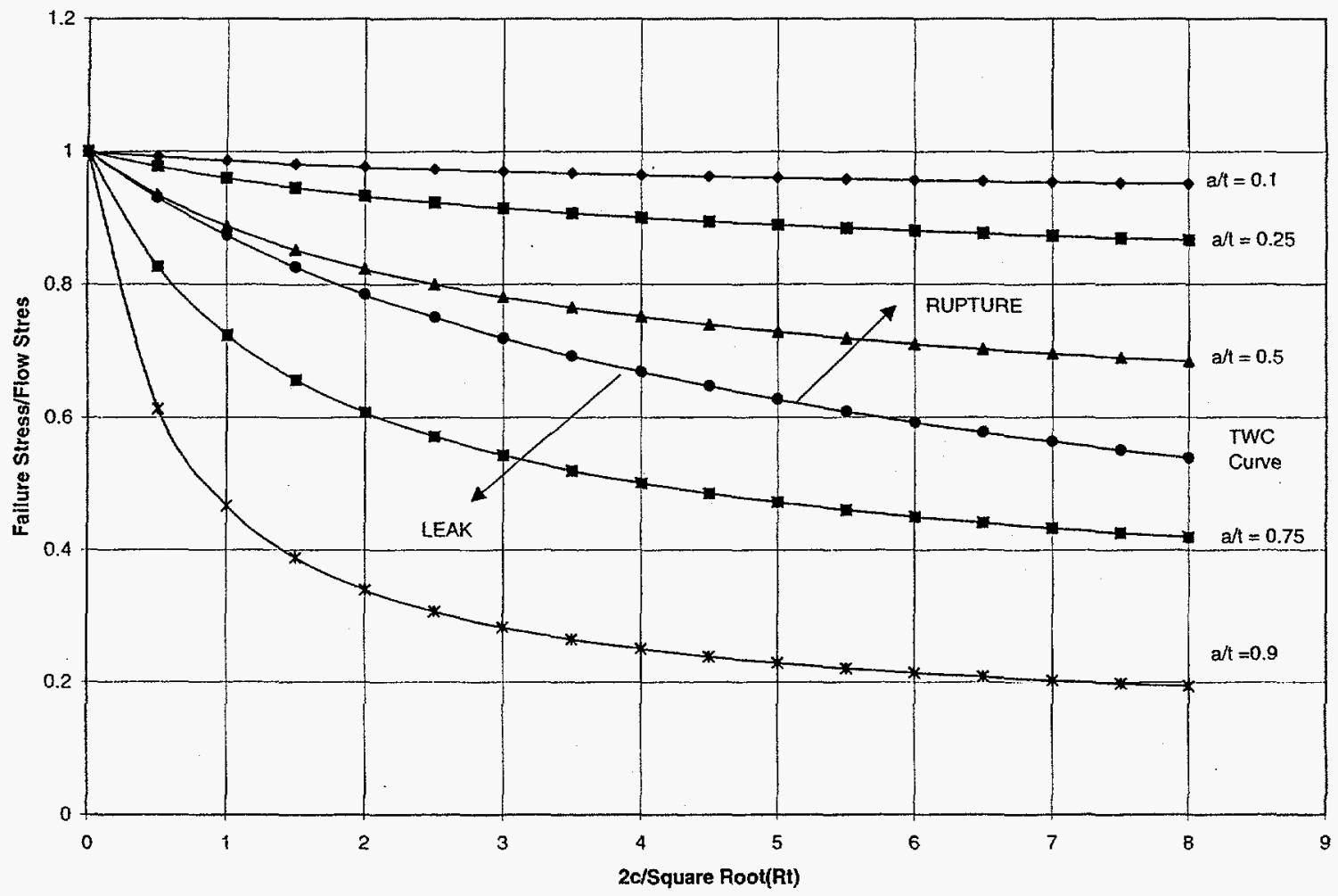

Figure 2.45 Illustration of leak-before-break behavior of axial cracks under pressure loading

The B31G solution used the original Folias bulging factor given in Equation 2-18. An improved, or modified, B31G criterion was subsequently developed to reduce some of the conservatisms (Ref. 2.98). In the modified B31G solution, the updated Folias bulging factor in Equation 2-20 was used, and rather than assuming a parabolic flaw shape, the actual flaw dimensions could be used to determine an equivalent flaw length, as per Equation 2-28. A simple computer code called RSTRENG was developed at Battelle that was subsequently released by the American Petroleum Institute (API) for making the $2 \mathrm{c}_{\mathrm{eq}}$ calculations from measurements down the length of the corrosion flaw, and for determining the allowable flaw size.

Several other corrosion acceptance criteria are also currently under development. For instance, the ASME Section XI Task Group on Erosion/Corrosion Acceptance is currently developing similar standards for the nuclear industry, and the ASME Post-Construction Committee is developing similar standards for nonnuclear plant applications, i.e., fossil and petrochemical plants. The ASME Section XI Code Case development essentially uses the ANSI B31G solution. The ASME Post-Construction Committee work is conducting a state-of-the-art review on corrosion defects that they refer to as local thinned area (LTA) flaws. A review of recent work on this topic is given in Reference 2.99 .

Several other types of axially cracked-pipe solutions exist in the literature. For instance, Chell has proposed different limit-load solutions with modifications to the bulging factor (Refs. 2.100 and 2.101). Infinite length axial surface crack solutions also have been developed as part of the GE/EPRI methodology (Ref. 2.102). Argonne has recently published a modification of the Battelle axial surface crack solution in Reference 2.103. Erdogan has also done a significant amount of work on axial surface flaws (Ref. 2.104) and MPA has used the AXIALCK database to explore the validity of several proposed axial flaw solutions as well (Ref. 2.105). 
Axial Crack Stability Analyses. Once an axial crack starts to propagate, the continued propagation depends on the decompression behavior of the internal fluid compared with the crack velocity. For instance, brittle fractures may propagate at 1,000 to 1,500 meters per second. In a natural gas pipeline, the initial acoustic velocity of the gas is about 350 meters per second. Since the brittle fracture speed is faster than the decompression wave, the crack would continue to propagate. Brittle fractures of up to $17.7 \mathrm{~km}$ (11 miles) in length in gas pipelines have been reported in the 1950's. Water, on the other hand, can rapidly decompress, and hence, except for very brittle materials, will decompress faster than the cracks can propagate. This is the reason why hydrostatic proof testing is recommended over pneumatic proof testing.

The occurrence of these types of fractures led to the development of the Battelle drop-weight tear test (DWTT), ASTM Standard E436 and API standard API RP 5L3. This was a full-thickness impact specimen, see Reference 2.106, and was used to determine the brittle-to-ductile transition temperature. Brittle fracture arrest criteria are provided in terms of Charpy energies and the DWTT specimen shear area percents (Ref. 2.107).

Soon after the gas pipeline industry solved the brittle fracture arrest problem, they encountered the propagating ductile fracture problem (Refs. 2.108 and 2.109). Ductile fractures propagate much slower than brittle fractures, so the decompression behavior of the internal fluid is very significant in propagating ductile fracture arrest.

In the nuclear industry, high energy lines could contain either subcooled water or steam. A steam line will decompress in a manner not terribly different from an air line. Subcooled water (and $\mathrm{CO}_{2}$ lines in oil and natural gas secondary recovery systems) will decompress rapidly to the saturation pressure, and then the pressure level will remain constant and have very low wave velocities. Hence, the subcooled lines could have a much higher crack driving force than a steam or natural gas line. Experiments on subcooled water lines in Reference 2.89 resulted in damage to buildings around the test site, requiring further work to be done at a remote test site (Ref. 2.95). Figure 2.46 shows the differences in the magnitude of the failures of either a leak-before-break (as discussed earlier), a limited instability due to rapid decompression and crack arrest, or unstable axial ductile fracture. The different types of decompression behaviors are schematically illustrated in Figure 2.47 as taken from Reference 2.110. (Note: This figure could also be shown in a temperature-entropy diagram since the decompression behavior is a constant entropy process.) Figure 2.47 shows the decompressed pressure, $P_{d}$, as a function of the ratio of the instantaneous pressure wave acoustic velocity to initial acoustic velocity $\left(\mathrm{V}_{\mathrm{w}} / \mathrm{V}_{\mathrm{ai}}\right)$. For the case of subcooled water (such as in a PWR main coolant line, CANDU reactor pressure tube water, or BWR recirculation line), the water will very rapidly decompress to the saturation pressure of the water at the initial temperature, then the pressure will essentially remain constant as the water undergoes decompression through the two-phase region, see upper left-hand sketch in Figure 2.47. The authors of Reference 2.110 believe that at the end of the decompression process that there is a drop in the pressure level from the saturation pressure level at very low wave velocities, i.e., about 70 to 100 meters per second ( 210 to $300 \mathrm{fps}$ ). This eventual drop in pressure from the saturation pressure is considered to be at such a low wave velocity relative to unstable axial ductile fracture speeds, that for practical concerns, the decompressed pressure is considered to remain constant at the saturation pressure.

In addition to accounting for the decompressed pressure, there is another different aspect between brittle and ductile fracture. This difference is the effect of the surrounding medium around the pipe. As will be shown later, the driving force for a ductile fracture has not only the hoop stress component, but also a component from the pressure on the pipe "flaps" behind the crack tip which tend to tear the pipe apart, 

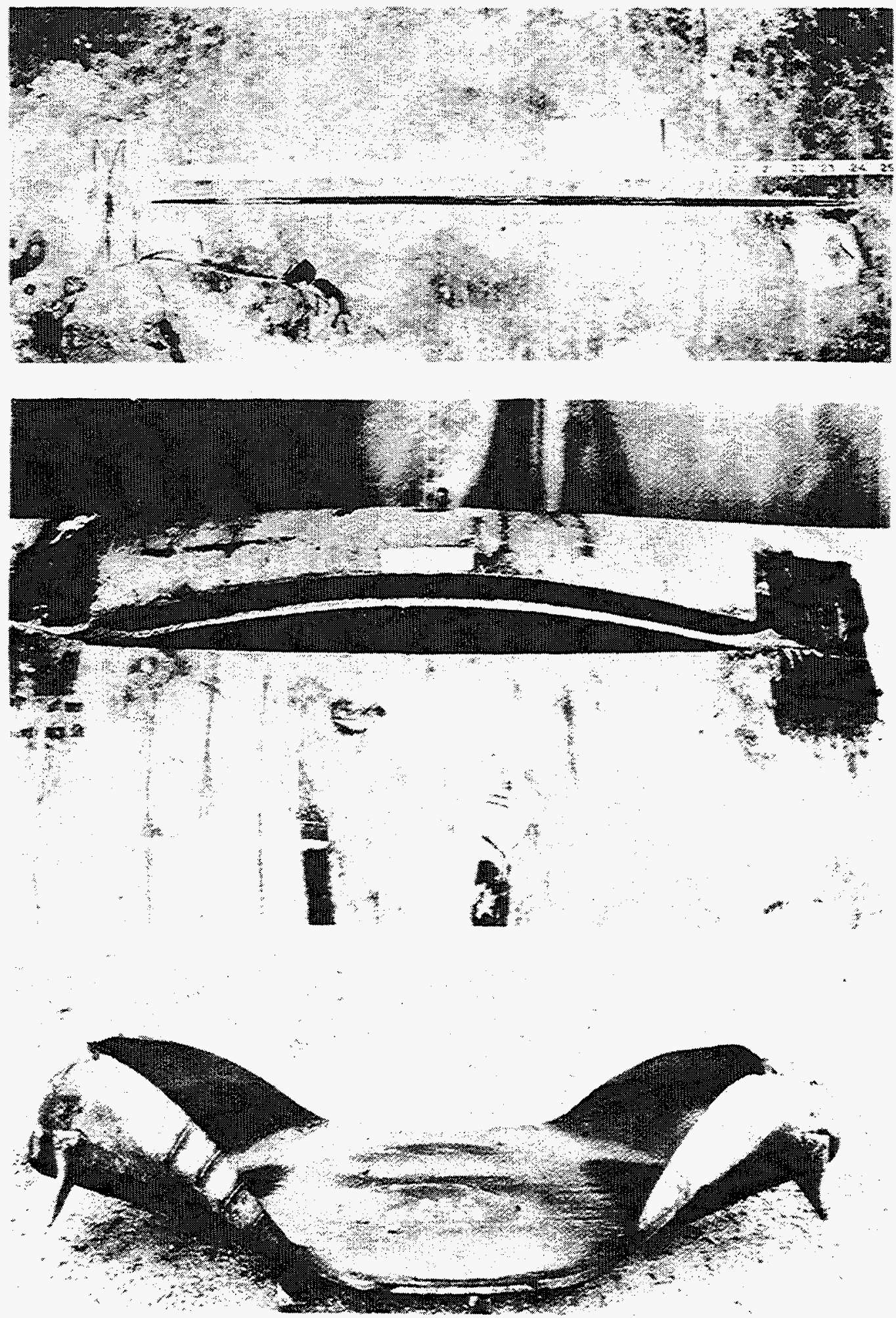

Figure 2.46 Modes of crack extension observed in 610-mm (24-inch) diameter x 43.2-mm (1.70-inch) thick A106B pipe in high-enthalpy fluid rupture tests 

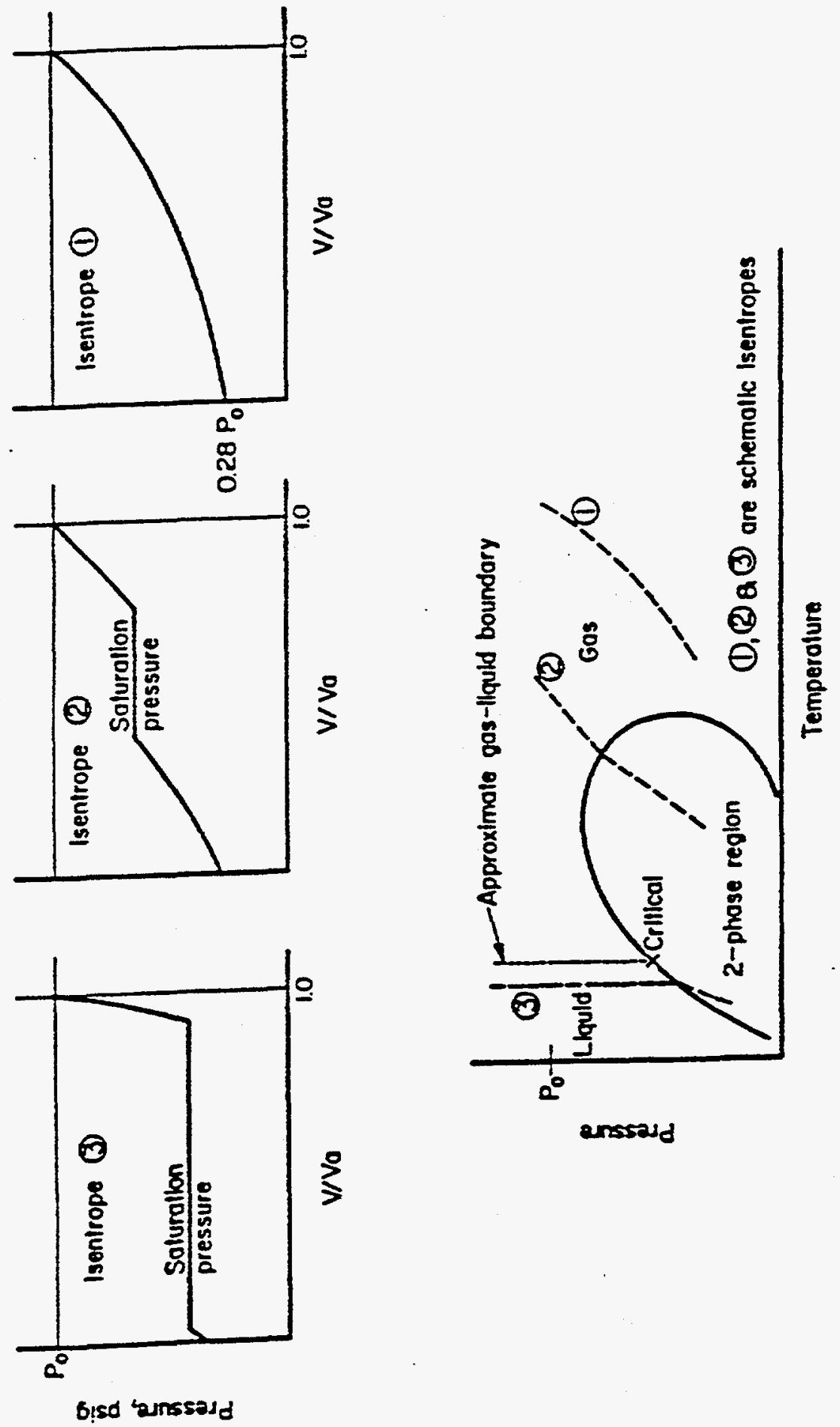
see Figure 2.48. Because pipe flap displacement is needed to drive the ductile crack, the surrounding medium or backfill will provide some resistance to the dynamic-crack-driving force. This backfill resistance has been determined empirically from numerous experiments. Two analytical models exist for such calculations. The Maxey model in Reference 2.110 is more empirical, whereas the analysis in Reference 2.111 is more theoretical, but in reality still has an empirically adjusted parameter. Both models were developed from work sponsored at Battelle by the American Gas Association. In this report, we will refer mainly to the Maxey ductile fracture model from Reference 2.110 , since it has been validated by more experiments than the model in Reference 2.111 , and lends itself more readily to two-phase flow decompression analyses.

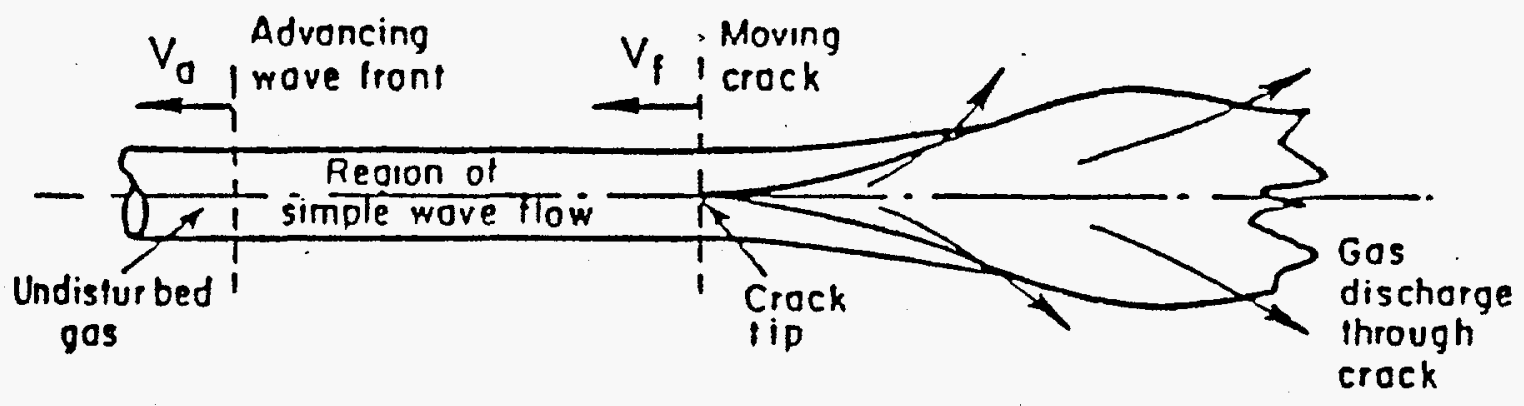

Figure 2.48 Flap formation in unstable axial crack propagation

The Maxey ductile fracture model determines a relationship between the fracture speed, $V_{f}$ and the decompressed pressure or hoop stress, where

$$
\mathrm{V}_{\mathrm{f}}=\left[\mathrm{C}_{4} \sigma_{\mathrm{f}} /(\sqrt{ } \mathrm{CVP})\right]\left[\left(\sigma_{\mathrm{d}} / \sigma_{\mathrm{a}}\right)-1\right]^{1 / 6}
$$

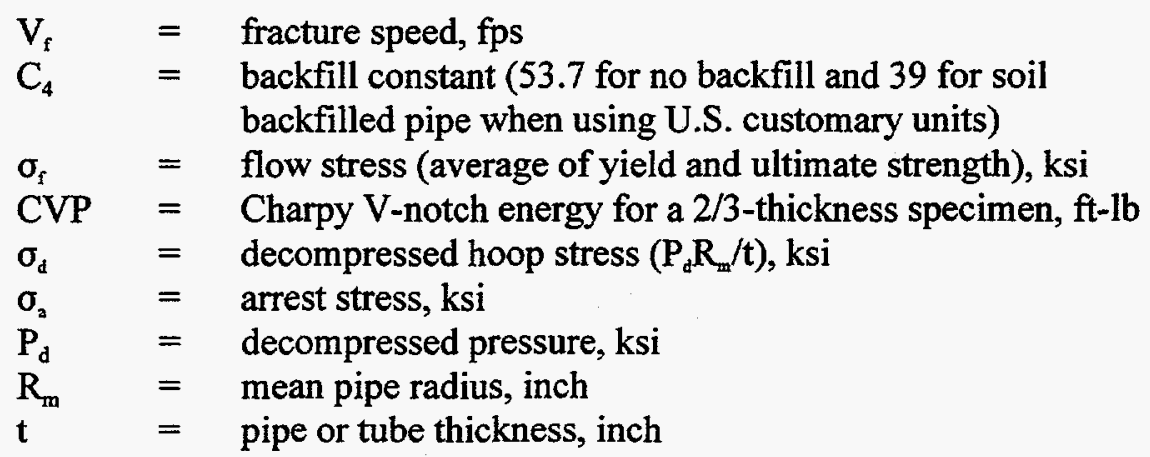


and

$$
\sigma_{\mathrm{s}}=\left[2 \sigma_{\mathrm{f}} /(3.333 \pi)\right] \arccos \left\{\exp -\left[\left(0.1455^{*} \mathrm{CVP} * \mathrm{E}^{*} \pi\right) /\left(24 \sigma_{\mathrm{f}}^{2} \sqrt{ }\left(\mathrm{R}_{\mathrm{m}} \mathrm{t}\right)\right]\right\}\right.
$$

with

$\mathrm{E}=$ elastic modulus, ksi.

Note: in Equation 2-29, $P_{d} / P_{a}$ could be used in place of $\sigma_{d} / \sigma_{a}$, where $P_{a}$ is the arrest pressure. The units used here are the units consistent with the empirically derived backfill constant from Reference 2.110 although calculations presented later are in SI units.

To determine whether a crack will propagate or not, the relationship between the decompressed pressure or hoop stress versus the fracture speed is then compared with the decompressed pressure versus the fluid wave velocity. If the curve from Equation 2-29 is higher than the fluid wave velocity curve (saturation pressure level in the subcooled water reactor piping case), then the crack will not propagate unstably. If the two curves intersect, then the intersection point determines the unstable fracture speed, see Figure 2.49. Figure 2.49 shows a sample calculation of decompressed pressure versus fracture speed or wave velocity for a high and low toughness material. The internal fluid is assumed to be water at a temperature where

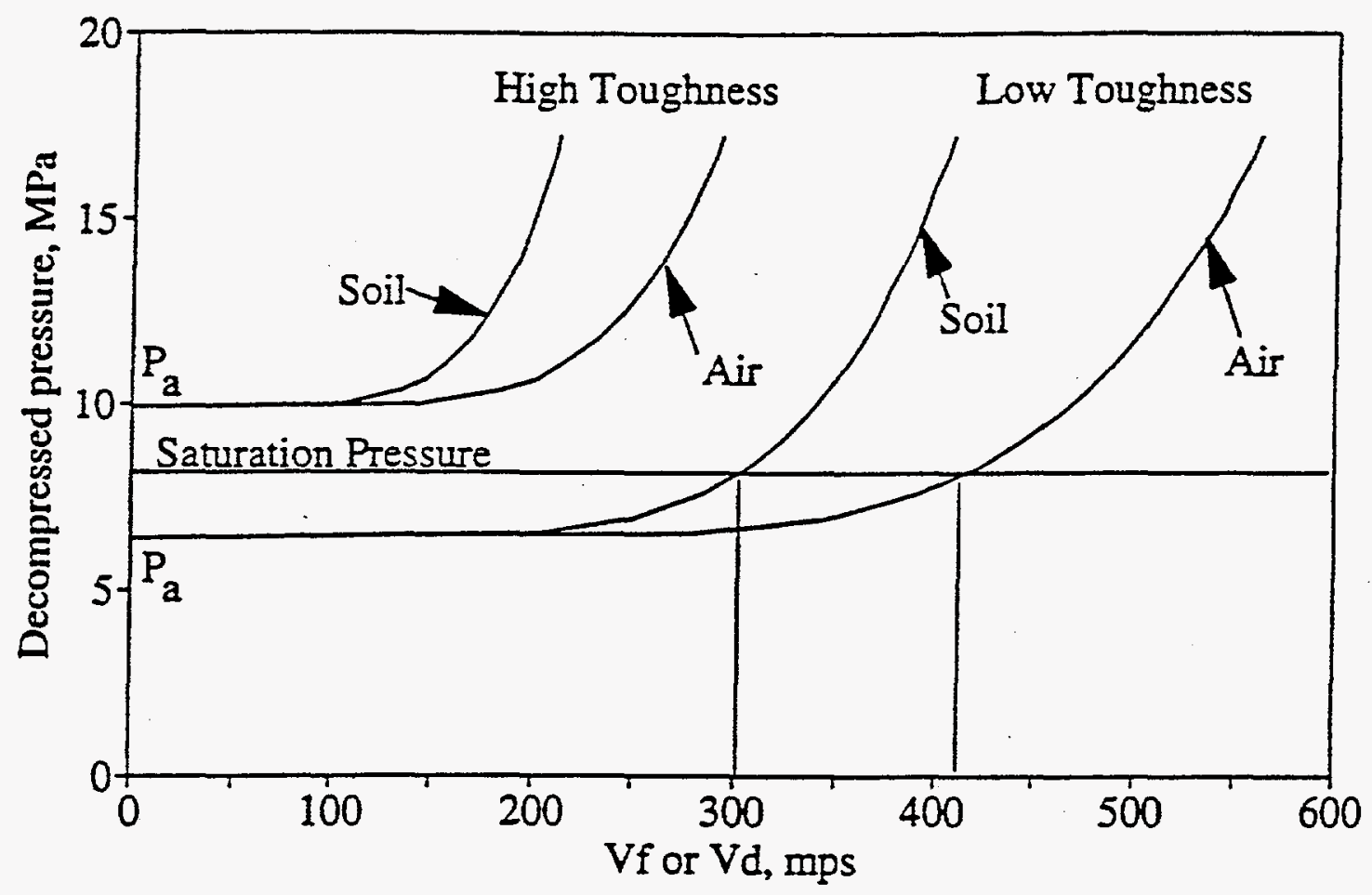

Figure 2.49 Illustration of Maxey ductile fracture model 
the saturation pressure is $8.0 \mathrm{MPa}$ (i.e., subcooled water at about $300 \mathrm{C}$ ). Since the low toughness pipe fracture velocity curves intersect the saturation pressure, that intersection point determines the unstable fracture speed. The high toughness curves are above the saturation pressure, hence it is predicted that the crack will arrest. The important points are therefore: (1) crack arrest for the subcooled water decompression case depends on whether the saturation pressure is above or below the arrest pressure, and (2) the backfill conditions only affect the fracture speed. This observation gives a much simpler design equation, where arrest of an axial crack in a pipe or tube with subcooled fluid is predicted by

$$
\mathrm{P}_{\mathrm{sat}}<\left[2 \mathrm{t \sigma}_{\mathrm{f}} /\left(3.333 \pi \mathrm{R}_{\mathrm{m}}\right)\right] \arccos \left\{\exp -\left[\left(0.1455^{*} \mathrm{CVP} * \mathrm{E}^{*} \pi\right) /\left(24 \sigma_{\mathrm{f}}^{2} \sqrt{ }\left(\mathrm{R}_{\mathrm{m}} \mathrm{t}\right)\right]\right\}\right.
$$

Furthermore, for very high toughness materials, such as a stainless steel base metal, this equation would further simplify to a limit-load ductile crack arrest condition where arrest would occur if

$$
\sigma_{\mathrm{SAT}}<\sigma_{\mathrm{f}} / 3.333
$$

where

$$
\sigma_{\mathrm{SAT}}=\text { the hoop stress at the saturation pressure. }
$$

Most of the full-scale pipe fracture tests in Reference 2.89 on nuclear pipe showed that A106B and TP304 stainless steel pipes exhibited ductile crack arrest according to Equation 2-32, see Figure 2.50. However, there were no tests on cracks in axial seam welds which might have lower toughness values.

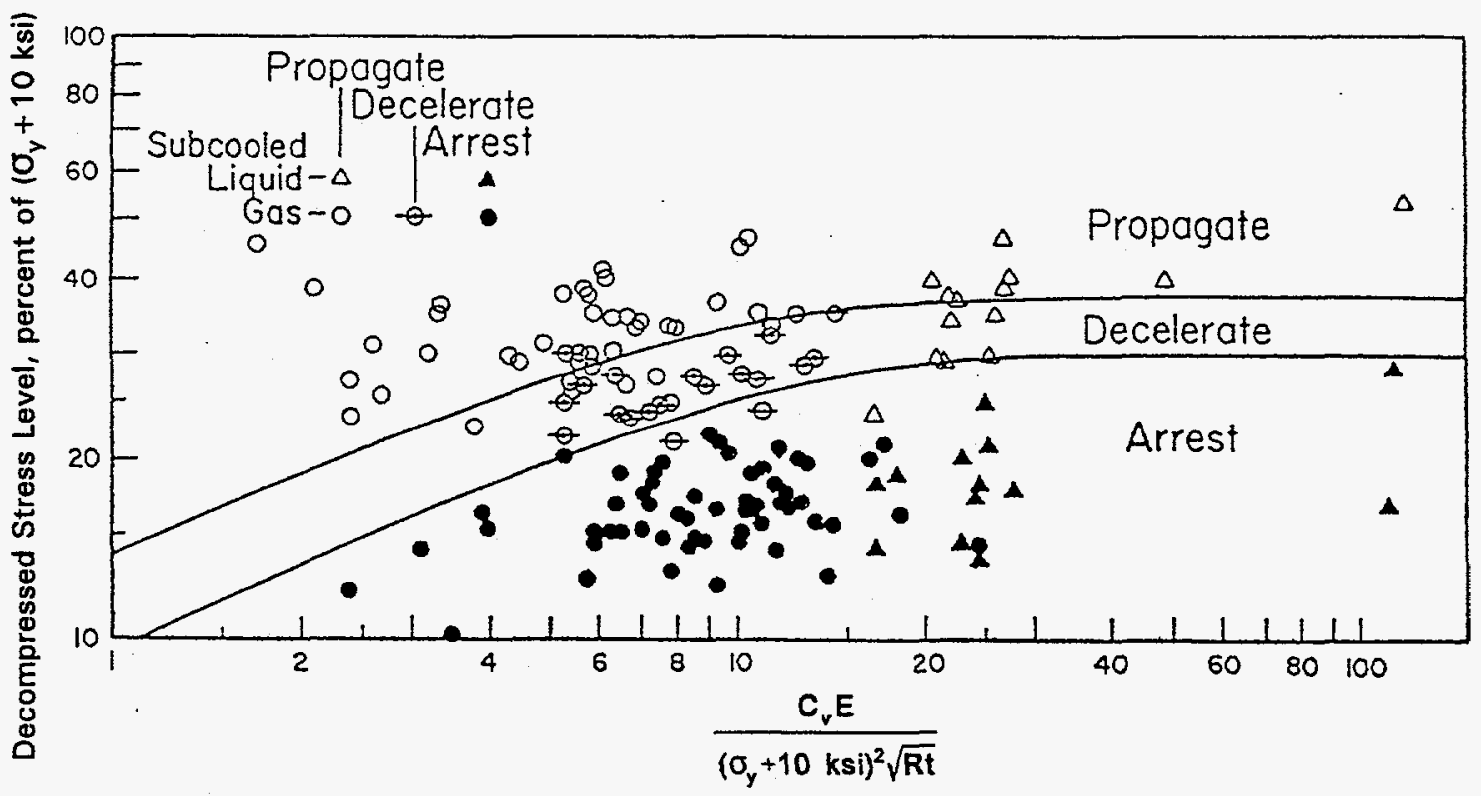

Figure 2.50 Data correlation describing ductile fracture arrest 
To see how Equation 2-32 works in some practical applications, the case of a line that has significantly subcooled water, and the case of a line that is operating just above the saturation temperature were considered. A significantly subcooled line might be a PWR hot leg, which may operate at $15.5 \mathrm{MPa}$ $(2,250 \mathrm{psi})$ and $320 \mathrm{C}(605 \mathrm{~F})$. Thus, the ratio of the saturation pressure at the operating temperature, 11.0 $\mathrm{MPa}(1,600 \mathrm{psi})$ to the operating pressure is 0.71 . Considering that the line might have a hoop stress of $\mathrm{S}_{\mathrm{m}}$ and the flow stress from the ASME Section XI Appendix $\mathrm{H}$ criteria is $2.4 \mathrm{~S}_{\mathrm{m}}$,

$$
0.71 \mathrm{~S}_{\mathrm{m}}<2.4 \mathrm{~S}_{m} / 3.333=0.72 \mathrm{~S}_{m}
$$

which just satisfies the criteria for ductile fracture arrest. Considering that the actual thickness of the pipe may be greater for longitudinal stress design conditions, and ferritic pipe typically has higher strength values than ASME Code values, there is probably some additional actual margins.

However, for the case of a line operating just above the saturation pressure, i.e., CANDU or BWR recirculation lines, then $\sigma_{\mathrm{SAT}}$ could be equal to $\mathrm{S}_{\mathrm{m}}$, and unstable axial ductile fracture is a possibility. This conclusion could be different if the actual strength and thickness of the pipe were greater than the assumption that the thickness is controlled by $\mathrm{S}_{\mathrm{m}}$ for pressure loading.

One can see from above that a line with more subcooling (operating pressure being greater than the saturation pressure) is inherently better from an axial ductile crack arrest viewpoint. Fortunately to date, very few cracks ever occur in the axial direction in nuclear piping. The few occurrences are typically stress-corrosion axial cracks that go across a girth weld and then stop as soon as they get out of the weld HAZ. Such cracks are very small in length compared with the critical axial flaw length.

\subsubsection{Predictions for Circumferentially Cracked Pipes}

The behavior of pipes containing circumferential cracks is considered in the following categories:

- Predictions of Maximum Load Capabilities for Circumferential Through-Wall-Cracked Pipes

- Predictions of Maximum Load Capabilities for Circumferential Surface-Cracked Pipes

- Complex or Compound Crack Assessments

- Moment-Rotation Predictions

- Circumferential Cracked-Pipe Stability Analyses.

\subsubsection{Predictions of Maximum Load Capabilities for Circumferential Through-Wall-Cracked Pipes}

Fracture mechanics predictions of circumferentially cracked pipes can involve linear elastic fracture mechanics (LEFM) behavior, elastic-plastic fracture mechanics (EPFM) behavior, or limit-load failure behavior. These failure behaviors are really categories of analysis methods. LEFM failure would only apply to very brittle materials, which is not typically relevant for nuclear piping materials, except perhaps piping systems operating at low temperatures or highly thermally aged cast stainless steels at less than LWR primary piping normal operating temperatures. EPFM analyses are needed frequently for nuclear piping materials, as are limit-load analyses. 
Linear-Elastic Fracture Mechanics (LEFM) Analyses. Perhaps the most frequently used LEFM analysis method for circumferentially through-wall-cracked pipe is that of Sanders for either pipes in tension or bending (Refs 2.112 and 2.113). This analysis accounts for thick-shell behavior, hence, $R / t$ effects are included. In the limit it should agree with the thin-shell solutions by Folias, Erdogan, and others (Refs. 2.114 and 2.115).

Sanders' analysis is not very good for short cracks, so a procedure has been developed that uses the Sanders energy release rate solution to calculate the elastic F-function (or influence function) for longer cracks, and then forces the F-function to go to 1.0 as the crack length goes to zero (Refs. 2.65 and 2.116). This extrapolation procedure is illustrated in Figure 2.51 for an $R / t$ of 10 pipe.

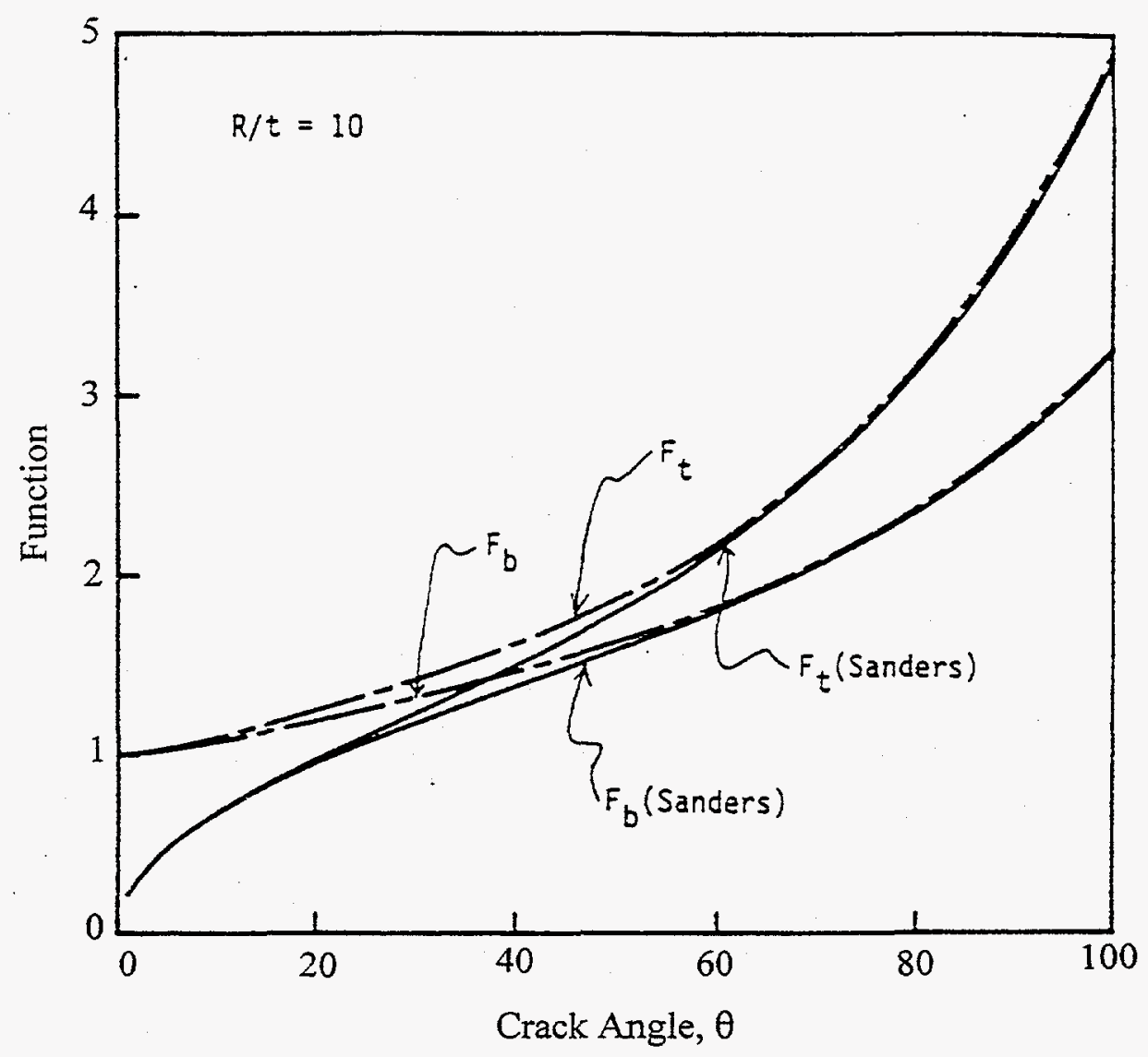

Figure 2.51 Comparison of Sanders' F-function for $R / t=10$ and polynominal fit assuming $F=1$ as crack angle approaches zero

No nuclear pipe experiments have been conducted that were pure LEFM failures, so the validation of this F-function approach can best be made by comparison with FEM results. Recent detailed FEM results are available in Reference 2.14, and are compared with the Sanders analytical solutions given in Reference 
2.116. This comparison is illustrated in Figure $2.52 \mathrm{a}$ and $2.52 \mathrm{~b}$ for $\mathrm{R} / \mathrm{t}$ values of 5 and 10 , respectively. The comparison shows that the assumption of the F-functions going to 1 as the crack length goes to zero was correct. The FEM F-function values, however, were slightly higher for the longer crack lengths. The maximum difference was about 10 percent. Considering that the elastic contribution to the typical elasticplastic practical solutions are generally very small, this difference is not of practical concern.

Limit-Load Analyses. One of the first circumferential flaw limit-load analyses developed was by Maxey in Reference 2.89. In this analysis, he used elastic stress analysis, considered the change in the section modulus due to the presence of the crack, considered a term for the induced bending due to the eccentricity of the crack and the centroid of the pipe, and assumed failure occurred when the maximum elasticallycalculated stress was equal to the ultimate strength of the material. This analysis method was adopted by MPA-Stuttgart (Ref. 2.117).

Another circumferential flaw limit-load development was one called the Net-Section-Collapse analysis. This was developed by Broek (Ref. 2.118). In this analysis procedure, the entire net-section of the pipe is considered to become fully plastic and reach an idealized stress value called the flow stress. This is schematically shown in Figure 2.53. This analysis procedure is the basis of the ASME Section XI pipe flaw evaluation criteria. The Section XI criteria simplified the original Net-Section-Collapse equations and defined the flow stress $\left(\sigma_{f}\right)$ as $2.4 \mathrm{~S}_{\mathrm{m}}$ for ferritic steels and $3 \mathrm{~S}_{\mathrm{m}}$ for austenitic steels. The accuracy of this analysis for surface-cracked pipe, which is relevant to the ASME Section XI criteria, will be discussed later.

The Net-Section-Collapse analysis predicted bending moment at failure $\left(M_{\text {nsc }}\right)$ for a pipe in pure bending is given by

$$
M_{n s c}=4 \sigma_{f} R_{m}^{2} t\left(\cos \frac{\theta}{2}-\frac{1}{2} \sin \theta\right)
$$

where

$$
\begin{aligned}
& t=\text { pipe wall thickness } \\
& R_{m}=\text { mean pipe radius } \\
& \sigma_{\mathrm{f}}=\text { flow stress } \\
& \theta=\text { the half crack angle. }
\end{aligned}
$$

The Net-Section-Collapse equations are used in most of the EPFM analyses discussed in the next section.

Elastic-Plastic Fracture Mechanics (EPFM) Analyses. There are numerous EPFM analyses for circumferential through-wall-cracked pipe under bending, tension, or combined bending and tension. Some of these are listed below, and more details on them can be found in the cited references. In this report, only the basic philosophy of the analysis aspects will be discussed, with details left for the reader to discover in the cited references. 


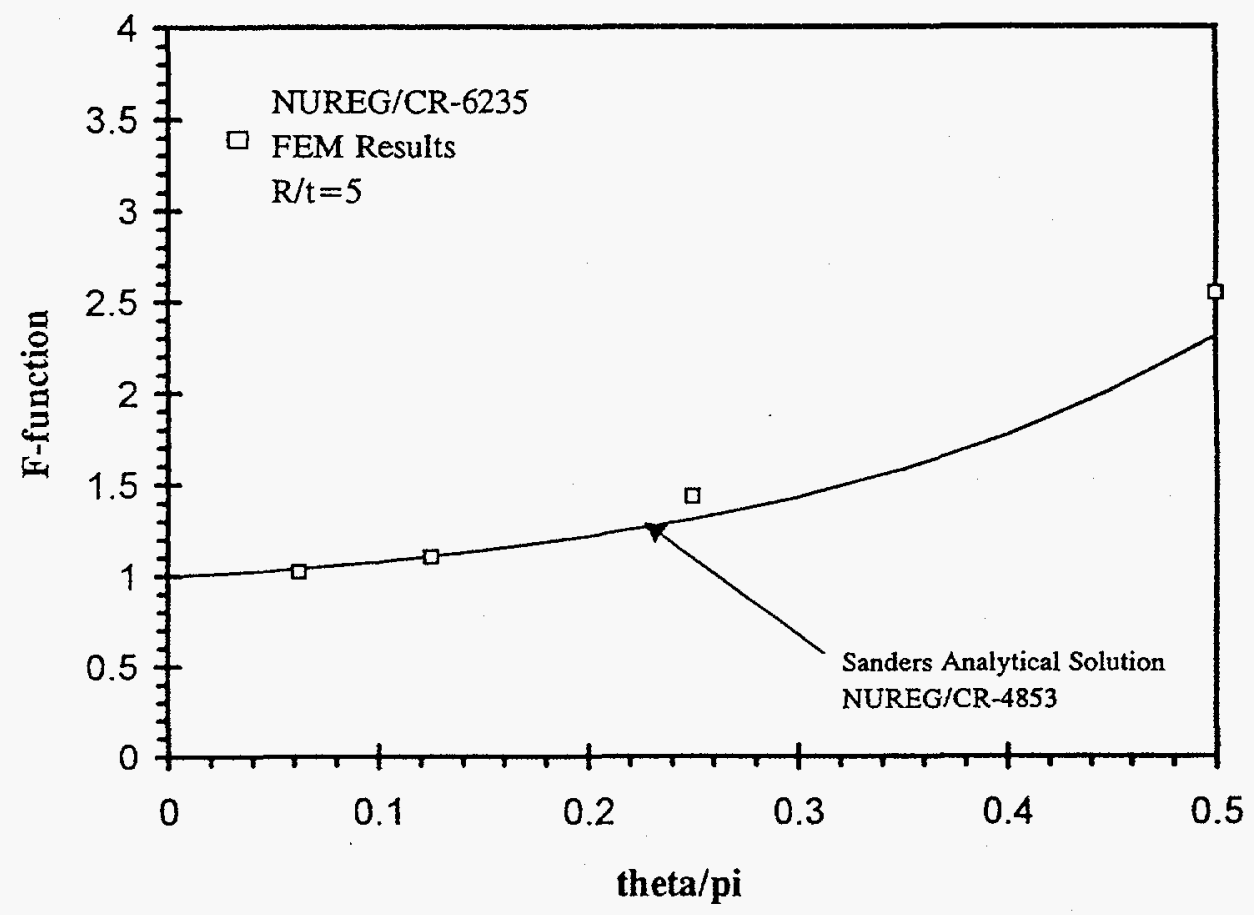

(a) $\mathbf{R} / \mathbf{t}=\mathbf{5}$

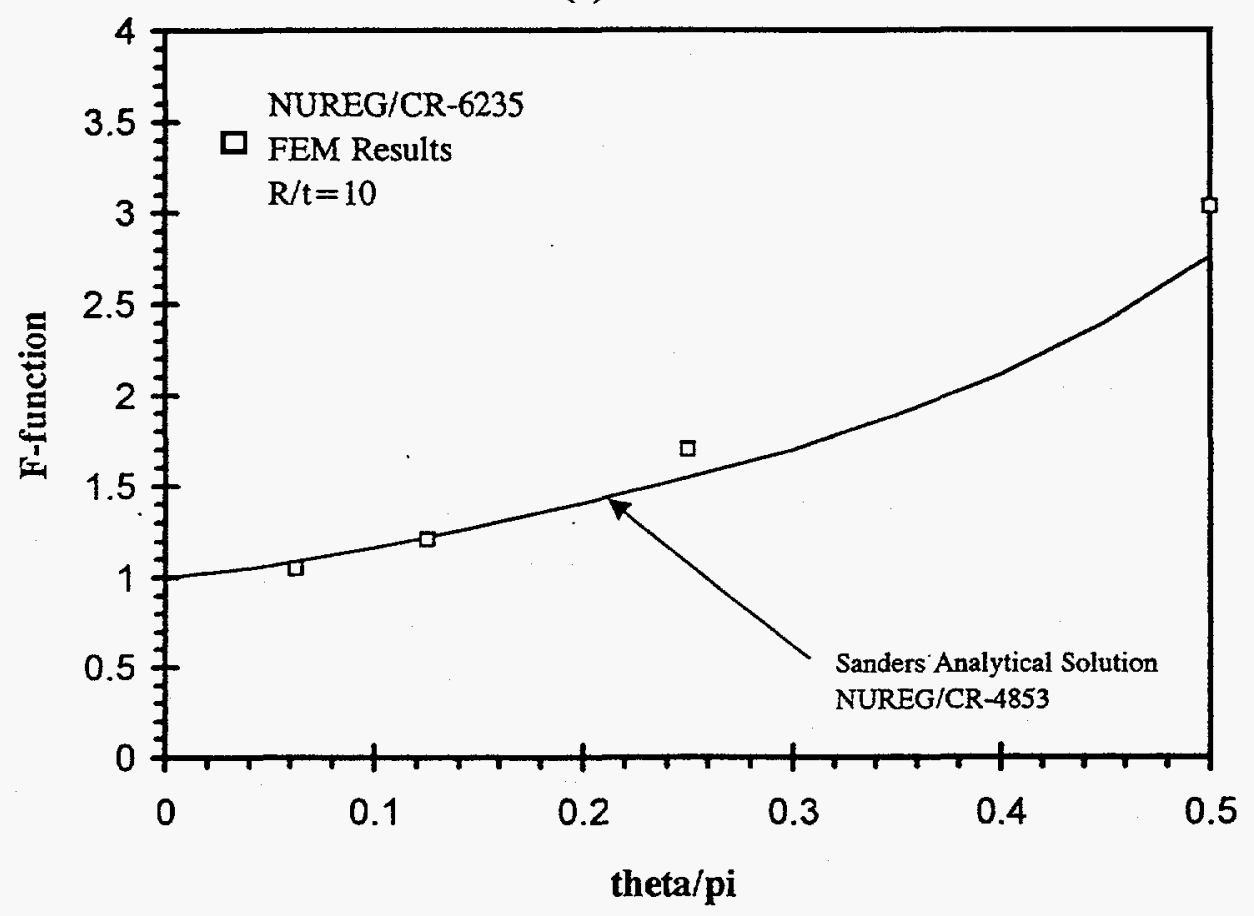

(b) $\mathbf{R} / \mathbf{t}=\mathbf{1 0}$

Figure 2.52 Comparison of recent FEM results from Reference 2.14 with Sanders' analytical F-function solutions from Reference $\mathbf{2 . 1 1 6}$ 

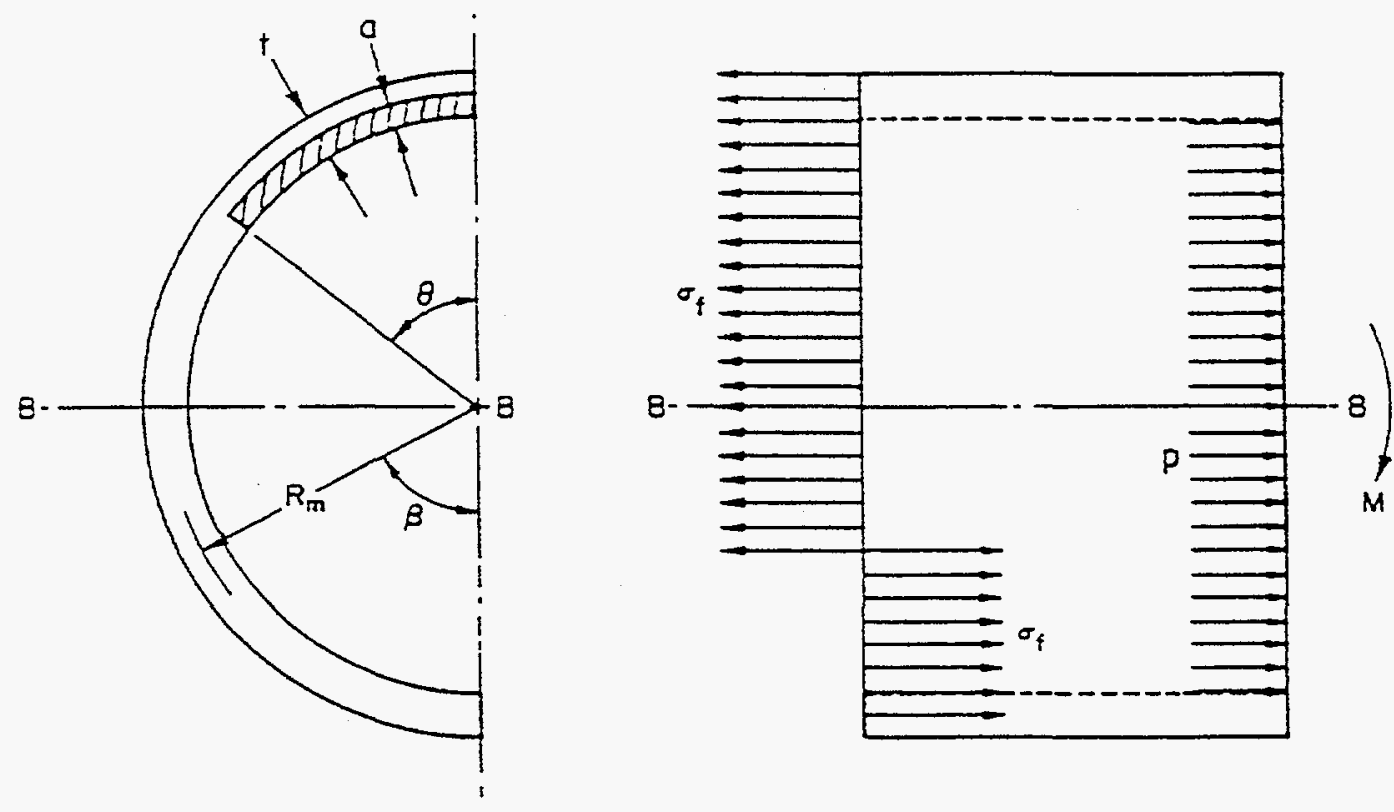

Figure 2.53 Representation of critical net-section-stress (flow stress) reached throughout the flawed ligament of a structure under fully plastic conditions

The analyses that are able to predict crack initiation loads, maximum loads and load-displacement behavior by the use of a J-R curve are:

- The original GE/EPRI method (Ref. 2.102), and modifications of it (Ref. 2.119),

- The Tada-Paris NUREG/CR-3464 method (Ref. 2.65),

- The LBB.NRC method (Ref. 2.116),

- The LBB.ENG2 method (Ref. 2.120), and

- The LBB.GE method (Ref. 2.121).

The ability to predict load-displacement curves, or moment-rotation curves is highly advantageous from a crack stability viewpoint when the stresses are not totally load-controlled.

The methods that can be used to predict loads at crack initiation as well as the maximum loads are:

- The R6 method (and various options) (Ref. 2.66), and

- The ASME Code Case N-494 (Ref. 2.122).

Methods that are used to predict maximum loads are:

- The ASME Section XI Appendices C and H for austenitic and ferritic pipe, respectively (Ref. 2.123), and

- The Battelle Dimensionless Plastic-Zone Parameter analysis (Ref. 2.20). 
In most of these analysis methods, a certain amount of idealization of the material properties is needed. For example, it is assumed that the constitutive law characterizing the material's stress-strain response can be represented by the Ramberg-Osgood model

$$
\frac{\epsilon}{\epsilon_{0}}=\frac{\sigma}{\sigma_{0}}+\alpha\left(\frac{\sigma}{\sigma_{0}}\right)^{n}
$$

in which $\sigma_{\mathrm{o}}$ is a reference stress usually assumed to be the yield stress, $\epsilon_{\mathrm{o}}=\sigma_{\mathrm{o}} / \mathrm{E}$ is the associated reference strain, $E$ is the modulus of elasticity, and $\alpha$ and $n$ are strain-hardening parameters usually chosen from the best fit of laboratory specimen tensile data. This representation of the stress-strain curve is necessary, since the J-integral in most estimation schemes is formulated based on power-law idealizations.

In characterizing the fracture toughness of materials, the ASTM Deformation J-resistance curve $\left(\mathrm{J}_{\mathrm{D}}-\mathrm{R}\right.$ curve) is frequently used, and the curve is extrapolated using a power-law form for crack-growth beyond 30 percent of the uncracked ligament in the $C(T)$ specimens. Thus, the $J_{D}-R$ curve is deemed to be adequately characterized by a power-law equation of the form

$$
\mathrm{J}_{\mathrm{R}}(\Delta \mathrm{a})=\mathrm{J}_{\mathrm{Ic}}+\mathrm{C}_{3}\left(\frac{\Delta \mathrm{a}}{\mathrm{r}}\right)^{\mathrm{m}}
$$

in which $\Delta \mathrm{a}$ is the crack length extension during crack growth, $\mathrm{J}_{\mathrm{Ic}}$ is the toughness at crack initiation, and $\mathrm{C}_{3}$ and $\mathrm{m}$ are power-law parameters from a best fit of experimental data. In Equation 2-36, $\mathrm{r}$ is a convenient normalizing parameter with a value of unity and the same units as $\Delta \mathrm{a}$. For example, if $\mathrm{J}$ and $\Delta \mathrm{a}$ are expressed in $\mathrm{kJ} / \mathrm{m}^{2}$ and $\mathrm{mm}$, respectively, the dimension of $\mathrm{C}_{3}$ also becomes $\mathrm{kJ} / \mathrm{m}^{2}$ if $\mathrm{r}=1 \mathrm{~mm}$.

Because C(T) specimens that are cut from pipe are small, large extrapolation of the J-R curve is required in order to predict maximum load in a pipe. Note that " $\Delta \mathrm{a}$ " here is the physical crack extension, i.e., without blunting. This is because blunting is automatically accounted for in the pipe estimation schemes.

In a typical J-estimation scheme analysis, it is generally assumed that the load-point rotation due to the presence of crack, $\phi^{c}$, and the relevant crack-driving force, such as J-integral, admit additive decomposition of elastic and plastic components given by (Ref. 2.119)

$$
\begin{gathered}
J=J_{c}+J_{p} \\
\phi^{c}=\phi_{c}^{c}+\phi_{p}^{c}
\end{gathered}
$$

where the subscripts " $e$ " and " $p$ " refer to elastic and plastic contributions. In the elastic range, $\phi_{e}^{c}$ and $\mathrm{M}$ are uniquely related. In addition, if the deformation theory of plasticity holds, a unique relationship also exists between $\phi_{\mathrm{p}}^{\mathrm{c}}$ and $\mathrm{M}$. Once these relationships are determined, the elastic component, $\mathrm{J}_{\mathrm{e}}$, and the plastic component, $\mathrm{J}_{\mathrm{p}}$, of the total energy release rate $\mathrm{J}$ can be readily obtained. The philosophies of these analysis methods are briefly discussed below. 
Original GE/EPRI Method and its Modifications. The GE/EPRI method is based on a compilation of finite-element solutions for TWC pipes using deformation theory of plasticity. These solutions are catalogued in References 2.102 and 2.119 for various geometric and material parameters. For pure bending in pipes containing through-wall cracks, the J-integral is calculated by Equation 2-37 in which $\mathrm{J}_{\mathrm{e}}$ and $\mathrm{J}_{\mathrm{p}}$ are given by (Refs. 2.102 and 2.119):

$$
\begin{gathered}
J_{e}=f_{1}\left(\theta / \pi, R_{m} / t\right) M^{2} / E \\
J_{p}=\alpha \sigma_{0} \epsilon_{0} R_{m} \theta(1-\theta / \pi) h_{1}\left(\theta / \pi, R_{m} / t, n\right)\left(M / M_{0}\right)^{n+1}
\end{gathered}
$$

where $f_{1}\left(\theta / \pi, R_{m} / t\right)$ and $h_{1}\left(\theta / \pi, R_{m} / t, n\right)$ are influence functions calculated from finite element results and tabulated in References 2.102 and 2.119. $\mathrm{M}_{0}$ is the limit-moment of a through-wall-cracked pipe under pure bending from the Net-Section-Collapse analysis. The original GE/EPRI solution used a plastic-zone correction in the elastic term. In recent work (Ref. 2.14), no plastic-zone correction was made in the elastic solution since plasticity is explicitly accounted for in the plastic part of the J-integral.

Tada-Paris NUREG/CR-3464 Method. In the Paris/Tada method (Ref. 2.65), J is obtained by an $\eta$-factor method using the moment versus pipe rotation solution from an interpolation between the linear-elastic and fully-plastic limit-load solutions. In effect, the procedure uses the techniques developed in References 2.124 and 2.125 for a planar fracture specimen, appropriately adapted for a through-wall-cracked pipe. Thus, $\mathbf{J}$ calculated by this method depends only on the cracked-pipe geometry and flow stress, and does not explicitly account for the strain-hardening behavior of the material.

For linear-elastic and rigid-plastic conditions in through-wall-cracked pipes, the moment-rotation and Jrotation relationships are well-established (Ref. 2.65). The Paris/Tada method interpolates between these two solutions by artificially increasing the crack size using a plastic-zone size correction and substituting this artificially increased crack size into the elastic solution to obtain the moment-rotation relationship in the elastic-plastic regime. The procedure is based on the Irwin estimate of the size of the plastic zone. Hence, it is not theoretically rigorous and should be treated as an engineering tool.

From linear-elastic fracture mechanics, it can be shown that the moment and elastic rotation, due to the crack, $\phi_{e}^{c}$, are related via (Refs. $2.65,2.121$, and 2.126 to 2.128 )

$$
M=\frac{E \pi R_{m}^{2} t}{I_{B}} \phi_{e}^{c}
$$

where $I_{B}$ is a compliance function defined in Reference 2.121. Using the effective crack size, $\theta_{e}$, (i.e., applying plastic-zone correction) and total rotation, $\phi^{c}$, in place of $\theta$ and $\phi_{c}^{c}$ in Equation 2-41 and the expression for rigid-plastic moment, the final equations for $J_{e}$ and $J_{p}$ by Paris/Tada method are (Refs. 2.65 and 2.121)

$$
\mathbf{J}_{\mathrm{e}}=\frac{\mathbf{K}_{\mathrm{I}}^{2}}{\mathbf{E}}
$$


where

$$
K_{I}=\frac{M}{\pi R_{m}^{2} t} F_{B} \sqrt{\pi R_{m} \theta}
$$

and

$$
J_{p}=\frac{\sigma_{f} R_{m}[\sin (\theta / 2)+\cos \theta]}{M_{R P}} \int_{0}^{\phi_{p}^{c}} M d \phi_{p}^{c}
$$

where $\sigma_{\mathrm{f}}$ is the flow stress and $\mathrm{M}_{\mathrm{RP}}$ is the rigid-plastic moment from a limit-load analysis (Ref. 2.65). $F_{B}$ in Equation 2-43 represents an appropriate geometry function with the explicit functional forms of $F_{B}$ and $I_{B}$. Equation 2-44 is the $\eta$-factor solution where the constants outside the integral are the $\eta$-factor. (Note: during crack growth calculations, this term should be inside the integral since $\theta$ changes with increasing ф.)

NRC.LBB Method. The LBB.NRC method (Ref. 2.116) for through-wall-cracked pipes subjected to bending is similar to the Paris/Tada method described above. However, the plastic component of rotation due to a crack is written as

$$
\phi_{p}^{c}=\alpha\left(\frac{\sigma}{\sigma_{f}}\right)^{n-1} \phi_{e}^{c}
$$

with $\phi_{e}^{c}=\phi_{e}^{c}\left(\theta_{e}\right)$ from the Paris/Tada solution. Hence, the elastic component of rotation is increased by the Irwin plastic-zone correction and the plastic component of rotation is increased or decreased depending on the current applied stress level. In this method, the effects of strain-hardening are incorporated in the evaluation of the J-integral.

LBB.ENG2 Method. The LBB.ENG2 method was originally developed by Brust and Gilles during the Degraded Piping Program (Refs. 2.120, 1.129, and 2.130) to compute energy release rates for throughwall-cracked pipes under pure bending. It involves an equivalence criterion incorporating a reduced thickness analogy for simulating system compliance due to the presence of a crack in pipe. Detailed derivations of both the elastic and plastic components of the J-integral in this method are available in the references cited above. Only the final expressions are presented here.

The elastic component, $\mathrm{J}_{\mathrm{e}}$, by LBB.ENG2 method, is the Sanders solution. The plastic component, $\mathrm{J}_{\mathrm{p}}$, is given by

$$
J_{p}=\frac{\alpha}{E \sigma_{0}^{n-1}} \frac{\pi R_{m}}{2(n+1)} H_{B}(n, \theta) L_{B}(n, \theta) I_{B}\left(\frac{M}{\pi R_{m}^{2} t}\right)^{n+1}
$$


where $H_{B}(n, \theta)$ and $L_{B}(n, \theta)$ are conveniently defined elementary functions with explicit forms available in References $2.120,2.129$, and 2.130 .

The LBB.ENG2 method was also extended by Rahman and Brust (Ref. 2.14) to account for a crack in a weld where the weld metal stress-strain curve could be used. This was called the LBB.ENG3 method. The plastic solution is given by

$$
J_{p}=\frac{\alpha_{1}}{E_{1} \sigma_{01}^{n_{1}-1}} \frac{\pi R_{m}}{2\left(n_{1}+1\right)} H_{B}\left(n_{1}, n_{2}, \theta\right) L_{B}\left(n_{1}, n_{2}, \theta\right) I_{B}\left(\frac{M}{\pi R_{m}^{2} t}\right)^{n_{1}+1}
$$

in which the additional subscripts " 1 " and " 2 " on the variables $E, \sigma_{0}, \alpha$, and $n$ are needed to represent base and weld metal properties, respectively. In Equation 2-47, $\mathrm{H}_{B}\left(\mathrm{n}_{1}, \mathrm{n}_{2}, \theta\right)$ and $\mathrm{L}_{B}\left(\mathrm{n}_{1}, \mathrm{n}_{2}, \theta\right)$ are algebraic functions and are more complex than their counterparts in Equation 2-46 due to the inclusion of both base and weld metal properties. These relationships were determined from numerous finite element analyses. When differences in the base metal and weld metal properties vanish, it can be shown that Equation 2-47 degenerates to Equation 2-46, as one would expect.

LBB.GE Method. The LBB.GE method was developed by Brust (Ref. 2.121). This method uses the GE/EPRI (Ref. 2.102) solutions to relate moment to rotation of the pipe due to the crack. $J$ is then calculated by an eta-factor analysis that integrates the moment-rotation curve. In this way, the solution is independent of the GE/EPRI $h_{1}$ functions when calculating $J$ from the moment.

R6 Method (and Various Options). The latest version of the R6 methodology is the Revision 3 document (Ref. 2.66). This methodology involves putting the flaw analysis in the format of a failure analysis diagram or FAD curve. The FAD curve approach involves an interpolation between linear elastic and limit-load solutions. In this methodology, there are three options for doing the interpolation:

- Option 1 involves a fixed shape FAD curve that is independent of the structural geometry or material strain-hardening,

- Option 2 involves using the material stress-strain curve, but geometrical effects are not included,

- Option 3 allows the user to put any more detailed analysis procedure in the format of a FAD curve to account for material and geometry effects, if so desired. Hence, any of the previously mentioned methods could be considered an R6 Option 3 analysis.

In this report, analysis validations were done only with the R6 Option 1 method. It should be noted, that since there are numerous LEFM F-function solutions and modifications to the limit-load solutions, it is quite possible to have different organizations give "R6" analysis that don't exactly agree. This was found to occur in IPIRG-1 program round robin efforts in Reference 2.67.

ASME Section XI Article IWB-3640 and Appendix C for Austenitic Pipe. The Net-Section-Collapse analysis was slightly modified and used as the technical basis for the ASME Section XI Article IWB-3640 and Appendix $C$ analyses of flaws in austenitic piping (Ref. 2.131) and was subsequently used in the NRC's SRP 3.6.3 for leak-before-break. The ASME Section XI criteria deal with surface cracks rather than through-wall cracks, however the EPFM Z-factor approach that was developed in Reference 2.131 
was based on circumferential through-wall flaws. Hence, it was appropriate to use it in the NRC's LBB criteria. This procedure is reviewed here for that reason.

For pure bending, there are three differences between Net-Section-Collapse analysis and the IWB-3640 analysis.

The first difference in the limit-load solutions is the definition of flow stress. The IWB-3640 analysis uses a definition of $3 \mathrm{~S}_{\mathrm{m}}$ for austenitic steels, where $S_{\mathrm{m}}$ is defined as the material design stress intensity and is tabulated as a function of temperature for a wide variety of material grades and types in Section II of the ASME Code.

The second difference is that Article IWB-3640 is applicable only for Class 1 piping for which Section III requires that the bending stress be calculated at the outer fiber with the exact expression for the moment of inertia of an uncracked pipe. In the original Net-Section-Collapse analysis, the bending stress is defined using thin-wall shell equations and is similar to the ASME Code for Class 2 piping stress analysis. The limit-load solution is allowed to be used on austenitic base metals (wrought stainless steels, Inconels, and cast stainless steels with ferrite numbers less than 20) and inert gas welds (TIG or MIG).

The third and most important difference is that the IWB-3640 analysis requires that a correction factor, known as the Z-factor, be used in reducing the predicted maximum allowable stress by $1 / Z$. The Z-factor is introduced to account for lower toughness of the flux welds, i.e., SAW and SMAW. From circumferential through-wall-cracked pipe analyses conducted using the original GE/EPRI estimation scheme, it was proposed that (Ref. 2.131).

$$
\begin{aligned}
& Z=1.15[1+0.013(D-4)] \text { for austenitic SMAW cracks } \\
& Z=1.30[1+0.010(D-4)] \text { for austenitic SAW cracks }
\end{aligned}
$$

where $\mathrm{D}$ is the nominal diameter, in inches. To develop the $\mathrm{Z}$-factors, a crack length to maximize the $\mathrm{Z}$ value was used. This crack length is about 20 to 30 percent of the circumference. That was done as a conservatism since sufficient surface-cracked pipe solutions did not exist at that time. This procedure should also be conservative for the NRC LBB procedure, since most large diameter pipe will have LBB crack sizes that are much smaller than this crack length, i.e., around 6-percent of the circumference, and hence, the actual $Z$-factor should be smaller.

When the method was originally developed, if the diameter of the pipe was less than $610 \mathrm{~mm}$ ( $24 \mathrm{inch}$ ), then the Code required the user to use $D=24$ inches to account for uncertainties in the thermal expansion stresses in small-diameter pipes. This restriction was eliminated in the 1996 edition of the ASME Code. This methodology was also included in NRC Draft Standard Review Plan 3.6.3 for LBB. Further details on this method can be found in Reference 2.131. Improvements on this methodology will be discussed in the surface-cracked pipe analysis section.

ASME Section XI Article IWB-3650 and Appendix $H$ for Ferritic Pipe. The procedures embodied in Article IWB-3650, and Appendix $\mathrm{H}$ of Section XI, for evaluating flaws in ferritic piping are fundamentally similar to those embodied in Article IWB-3640 and Appendix C for austenitic piping. As with the ASME 
austenitic criteria, in principle this criteria could be used in LBB applications for circumferential throughwall flaws, and hence, is included in this section of this report. Both sets of procedures incorporate a limitload analysis based on the Net-Section-Collapse analysis for evaluating flaws in high toughness materials. Both also incorporate an approximate elastic-plastic analysis, using a stress multiplier (i.e., a Z-factor), for evaluating flaws in lower toughness materials, such as welds. However, only the ferritic pipe criteria include a linear-elastic analysis for evaluating flaws in very low toughness materials. This linear-elastic analysis and the transition to EPFM has not been heavily scrutinized, since the application is for Class 1 pipe that operates at high temperatures.

The procedures in Appendix $\mathrm{H}$ for the ferritic pipe criteria include a screening criterion for assessing which type of analysis procedure, i.e., limit-load, elastic-plastic, or linear-elastic, is most appropriate. This is a FAD curve based approach. If the screening criterion parameter, which is the ratio of the stress intensity factor normalized by the material toughness $\left(\mathrm{K}_{\mathrm{r}}\right)$ to the sum of the primary bending and expansion stresses normalized by the bending stress at limit-load $\left(\mathrm{S}_{\mathrm{r}}\right)$, is less than 0.2 , then the limit-load analysis is to be used. For all intents and purposes, the limit-load analysis in Appendix $\mathrm{H}$ for ferritic piping is the same as the limit-load analysis in Appendix $C$ with the exception that the flow stress in Appendix $C$ is defined as $3 \mathrm{~S}_{\mathrm{m}}$, while the flow stress in Appendix $\mathrm{H}$ is defined as the average of the material's yield and ultimate strengths, if those values are known. If the yield and ultimate strengths are unknown, then the flow stress is defined as $2.4 \mathrm{~S}_{\mathrm{m}}$.

If the screening criterion parameter is greater than or equal to 0.2 but less than 1.8 , then an elastic-plastic analysis should be used. The elastic-plastic analysis in Appendix $\mathrm{H}$ for ferritic piping is the same as the elastic-plastic analysis in Appendix C (for austenitic piping) except for the differences in the flow stress definition as discussed above. Different formulations for the elastic-plastic stress and load multiplier, $Z$, are also used in the two appendices. The $Z$-factor formulations for the ferritic piping cases are as follows:

$$
Z=1.2[1+0.021 \mathrm{~A}(\mathrm{NPS}-4)]
$$

for Material Category 1 (seamless or welded wrought carbon steel pipe and pipe fittings that have a specified minimum yield strength not greater than $275 \mathrm{MPa}(40 \mathrm{ksi})$ and welds made with E7015, E7016, or E7018 electrodes in the as-welded or post-weld heat treated condition), and

$$
\mathrm{Z}=1.35[1+0.184 \mathrm{~A}(\mathrm{NPS}-4)]
$$

for Material Category 2 (all other ferritic shielded-metal-arc and submerged-arc welds with specified minimum tensile strengths not greater than $550 \mathrm{MPa}(80 \mathrm{ksi})$ in the as-welded or post-weld heat treat condition).

The " $A$ " in these $\mathrm{Z}$-factor expressions is a function of the pipe $\mathrm{R}_{\mathrm{m}} / \mathrm{t}$ ratio and is given by

$$
A=\left[0.125\left(R_{m} / t\right)-0.25\right]^{0.25} \text { for } 5 \leq R_{m} / t \leq 10
$$

or 


$$
A=\left[0.4\left(R_{m} / t\right)-3.0\right]^{0.25} \text { for } 10<R_{m} / t \leq 20
$$

The term NPS in the above expressions is the nominal pipe size, in inches, and the terms " $R_{m}$ " and " $t$ " denote the mean pipe radius and pipe wall thickness, respectively.

Finally, if the screening criterion parameter is greater than or equal to 1.8 then the linear-elastic fracture mechanics analysis must be used. This analysis stipulates that the applied stress intensity factor, $\mathrm{K}_{\mathrm{I}}$, must be less than the plane stress fracture toughness of the material. The plane stress fracture toughness is expressed in terms of the parameter $\mathrm{J}_{\mathrm{Ic}}$ and the elastic modulus, $\mathrm{E}$, using the expression

$$
\mathrm{K}_{\mathrm{Ic}}=\left\{\mathrm{J}_{\mathrm{Ic}} \mathrm{E} /\left(1-v^{2}\right)\right\}^{0.5}
$$

For this analysis, it is assumed that ductile crack extension does not occur prior to fracture. Further details of these analyses can be found in Reference 2.132 .

Battelle Dimensionless Plastic-Zone Parameter Analysis. This analysis procedure originally was developed as a screening criterion to determine when limit-load or EPFM failure would occur at either crack initiation or maximum load. The procedure essentially says that when the plastic zone from the crack tip extends to the fully-plastic neutral axis of the pipe, then limit-load conditions occur. This is applicable to either a circumferential through-wall crack or a circumferential surface crack. For a circumferential through-wall cracked pipe in pure bending this occurs when

$$
\left(\mathrm{EJ}_{\mathrm{i}}\right) /\left(2 \pi \sigma_{\mathrm{f}}^{2}\right)>\mathrm{D}(\pi-\theta) / 4
$$

where

$$
\begin{aligned}
& E=\text { Elastic modulus } \\
& J_{i}=J \text { at crack initiation, typically from an L-C oriented specimen } \\
& \sigma_{\mathrm{f}}=\text { flow stress, typically }\left(\sigma_{\mathrm{y}}+\sigma_{\mathrm{u}}\right) / 2 \\
& \sigma_{\mathrm{y}}=\text { material yield stress } \\
& \sigma_{\mathrm{u}}=\text { material ultimate stress } \\
& D=\text { pipe diameter } \\
& \theta=\text { half of the circumferential crack angle. }
\end{aligned}
$$

Similar equations would exist for a pipe under pressure (tension) and bending.

From the investigations done in Reference 2.20, it was found that these plastic-zone parameter conditions for different surface-cracked and through-wall cracked pipes under various loading conditions could be approximated by

$$
2 \mathrm{EJ}_{\mathrm{i}}>\pi^{2} \sigma_{\mathrm{f}}^{2} \mathrm{D}
$$


Once a sufficient database existed, then it was found that a relatively simple EPFM equation could be developed for either the load at crack initiation or the maximum load. The equation for maximum load predictions is

$$
\sigma / \sigma_{\text {nsc }}=(2 / \pi) \arccos \left[e^{\mathrm{C}_{1}(\mathrm{DPZP})}\right]
$$

where

$$
\begin{array}{ll}
\sigma & =\text { stress in the pipe at maximum load } \\
\sigma_{\text {nsc }} & =\text { Net-Section-Collapse analysis predicted pipe stress } \\
C_{1} & =\text { empirical constant } \\
\text { DPZP } & =\text { the simplified Dimensionless Plastic-Zone Parameter }=\left(2 E J_{i}\right) /\left(\pi^{2} \sigma_{\mathrm{f}}^{2} \mathrm{D}\right) .
\end{array}
$$

The parameter " $\mathrm{C}_{1}$ " could be defined as a mean fit to the data or a 95-percent confidence number. The mean fit value of " $\mathrm{C}_{\mathrm{I}}$ " is 18.3 (Ref. 2.133) for through-wall-cracked pipes.

Eta-Factor Analyses. Eta-factor analyses are a generic analysis to calculate a material's resistance from a fracture test. Typically, this involves a constant $(\eta)$ times the integral of the experimental loaddisplacement curve. The ASTM standard for calculation of a J-R curve is such an analysis. Similarly, there are eta-factor analyses for cracks in pipe. These eta-factor analyses are not only used in determining the J-R curve for a cracked pipe for comparisons with $C(T)$ tests, but are also used in predictive analyses such as in the Tada-Paris NUREG/CR-6434 procedure, LBB.NRC, LBB.ENG, LBB.GE, etc.,.

For a circumferential through-wall crack in a pipe under bending, the plastic $J$ eta-factor solution $\left(J_{p}\right)$ was first published in Reference 2.124. A factor of 2 error was found in Reference 2.95 so that the correct equation is

$$
J_{p}=\frac{\sigma_{f} R_{m}[\sin (\theta / 2)+\cos \theta]}{M_{R P}} \int_{0}^{\phi_{p}^{c}} M d \phi_{p}^{c}
$$

where

$$
\begin{aligned}
& M_{R P}=\text { the rigid plastic moment from the Net-Section-Collapse equation, } \\
& R_{m}=\text { pipe mean radius, and } \\
& \phi_{p}^{c}=\text { the plastic contribution of half of the pipe rotation due to the crack. }
\end{aligned}
$$

During the IPIRG-2 program, an automated computer code called ETAFACTR was developed by Muira (Ref. 2.14) which accounts for the test machine compliance and elastic contributions to $J$, and it checks that there is no plasticity from the uncracked pipe that would affect the $\mathrm{J}_{\mathrm{p}}$ value. This computer code, along with several others, is included in the "Pipe Fracture Encyclopedia CD-ROM" developed in the IPIRG-2 program. 
Finite-Element Analysis. Finite-element analysis is perhaps the most rigorously pure analysis method that could be used to analyze through-wall cracks. It eliminates many of the assumptions that are used in the EPFM J-estimation schemes. One of the big drawbacks of the finite element analysis method is that it is computationally more involved, and an expert in computer codes, such as ABAQUS $\otimes$, is needed. Consequently, such analyses are typically only done to check simple analytical methods. Perhaps in the future, an automatic mesh generator program could be coupled with a special purpose finite element program so that such analyses could be done routinely on a desktop computer.

Numerous finite element analyses have been conducted to date. Many of these are cited in Reference 2.134. Of these different analyses, it was found in round robin efforts (Ref. 2.11), that for circumferentially cracked pipe in bending, everyone typically does a good job of getting the same loaddisplacement and J-R curves.

One of the observations from examining FEM results was that in several cases involving stainless steel pipes with circumferential through-wall cracks, that the FEM analysis significantly (about 30 percent) underpredicted the experimental load-displacement curve, even at crack initiation. This occurred even in a round-robin effort, where all the analysts made the same prediction. A detailed investigation of that particular experiment showed that there was no experimental error. In fact, there were multiple pipe experiments with cracks of the same size from pipe segments from the same pipe length that gave the same results on two different test machines at Battelle. Furthermore, duplicate pipe experiments were conducted at Battelle and two other organizations (on different pipes in those cases), and the differences were found to be insignificant. Hence, after exhausting all other possible and logical explanations, the only other explanation was that some wrought stainless steels have unique constitutive law behaviors that are not adequately accounted for in the FEM analyses. This same conclusion was found in a study in Sweden in looking at test records of uncracked bend bar specimens, see Section 3.3.4.3 in Reference 2.199.

The various solutions discussed above have been programmed into the NRCPIPES computer code. The latest version of this code is Windows Version 3.0. This version was created in the IPIRG program, and is available to IPIRG program members (see Acknowledgment Section of this report for the IPIRG organizations and members). The earlier DOS version was available from the U.S. NRC (Version 2.0), but a few technical changes were made in Version 3.0.

Comparisons of Analytical Predictions with Experimental Results. Numerous comparisons between circumferential through-wall-cracked pipe experiments and various analyses have been made over the years. Some of the more significant ones from NRC-related programs are:

- Degraded Piping Program - Phase II (Ref. 2.28)

- IPIRG-1 program round-robin efforts (Ref. 2.67)

- Short Cracks in Piping and Piping Welds program (Ref. 2.14), and

- IPIRG-1 and IPIRG-2 results (Refs. 2.67 and 2.68).

Results of the Battelle evaluations for quasi-static pipe tests are shown in; Tables 2.2, 2.3, and 2.4 from Reference 2.28; and Tables 2.5 and 2.6 from Reference 2.14. The general trends are: 
Table 2.2 NRCPIPE ${ }^{(2)}$ predictions of initiation loads for through-wall-cracked pipe experiments

\begin{tabular}{|c|c|c|c|c|c|c|c|c|}
\hline \multirow[b]{2}{*}{$\begin{array}{c}\text { Experiment } \\
\text { No. } \\
\end{array}$} & \multirow[b]{2}{*}{$\begin{array}{l}\text { O.D., } \\
\text { inch }\end{array}$} & \multirow[b]{2}{*}{ Pipe No. } & \multicolumn{5}{|c|}{ Predicted/Experiment Initiation Load } & \\
\hline & & & GE/EPRI & Paris & LBB.NRC & LBB.GE & LBB.ENG & \\
\hline \multicolumn{8}{|c|}{ Stainless Steel Base Metal } & \\
\hline $\mathrm{NP}-2347-6 \mathrm{~T}$ & 2.375 & $\mathrm{~A} 34$ & 0.85 & 1.00 & 0.97 & 0.99 & 0.92 & \\
\hline $4131-5$ & 6.254 & $\mathrm{~A} 23$ & 0.87 & 1.04 & 1.04 & 1.01 & 0.98 & \\
\hline NP-2347-8T & 16.28 & $\mathrm{~A} 8$ & 0.73 & 1.13 & 0.96 & 0.86 & 0.84 & \\
\hline \multirow[t]{3}{*}{ 4111-3 } & 42.00 & $\mathrm{~A} 12$ & 0.80 & 0.78 & 0.91 & 0.87 & 0.87 & \\
\hline & \multicolumn{2}{|c|}{ Average } & 0.81 & 0.99 & 0.97 & 0.93 & 0.90 & \\
\hline & \multicolumn{2}{|c|}{ Standard Deviation } & 0.05 & 0.13 & 0.05 & 0.07 & 0.05 & \\
\hline \multicolumn{8}{|c|}{ Carbon Steel Base Metal } & \\
\hline 4111-1 & 4.50 & F11 & 0.82 & 1.00 & 0.99 & 0.95 & 0.93 & \\
\hline DTRC-7 & 8.63 & DT7 & 0.84 & 1.13 & 1.02 & 0.95 & 0.95 & \\
\hline 4111-2 & 28.00 & F26 & 0.76 & 0.70 & 0.83 & 0.83 & 0.83 & \\
\hline $4111-6$ & 35.83 & F38 & 0.73 & 0.64 & 0.75 & 0.73 & 0.73 & \\
\hline \multirow[t]{3}{*}{$4111-4$} & 42.00 & F32 & 0.71 & 0.62 & 0.74 & 0.76 & 0.76 & \\
\hline & \multicolumn{2}{|l|}{ Average } & 0.75 & 0.82 & 0.87 & 0.84 & 0.84 & \\
\hline & \multicolumn{2}{|c|}{ Standard Deviation } & 0.08 & 0.21 & 0.12 & 0.09 & 0.09 & \\
\hline \multicolumn{8}{|c|}{ Stainless Steel Weld Metal ${ }^{(b)}$} & \\
\hline 4141-1 & 6.625 & $\mathrm{~A} 45$ & 0.63 & 1.08 & 0.87 & 0.73 & 0.72 & \\
\hline 4141-3 & 16.28 & $\mathrm{~A} 45$ & 1.14 & 1.29 & 1.43 & 1.29 & 1.29 & \\
\hline $4111-5$ & 28.33 & $\mathrm{~A} 50$ & 0.65 & 0.59 & 0.70 & 0.72 & 0.72 & \\
\hline \multirow[t]{5}{*}{$4141-5$} & 6.605 & A45a & 0.77 & 1.35 & 1.08 & 0.90 & 0.87 & \\
\hline & \multicolumn{2}{|l|}{ Average } & 0.80 & 1.08 & 1.02 & 0.91 & 0.90 & \\
\hline & \multicolumn{2}{|c|}{ Standard Deviation } & 0.21 & 0.30 & 0.27 & 0.23 & 0.24 & \\
\hline & \multicolumn{2}{|c|}{ Total Average } & 0.78 & 0.95 & 0.95 & 0.89 & 0.88 & $0.89^{(c)}$ \\
\hline & \multicolumn{2}{|c|}{ Standard Deviation } & 0.13 & 0.25 & 0.18 & 0.15 & 0.15 & $0.19^{(c)}$ \\
\hline
\end{tabular}

(a) Using Version 1.4

(b) Using base metal stress-strain curve.

(c) Average and standard deviation of all methods. 
Table 2.3 NRCPIPE ${ }^{(a)}$ predictions of through-wall-cracked pipe using power law extrapolation of $J_{D}-R$ curve

\begin{tabular}{|c|c|c|c|c|c|c|c|c|}
\hline \multirow[b]{2}{*}{$\begin{array}{c}\text { Experiment } \\
\text { No. }\end{array}$} & \multirow[b]{2}{*}{$\begin{array}{l}\text { O.D., } \\
\text { inch }\end{array}$} & \multirow[b]{2}{*}{ Pipe No. } & \multicolumn{4}{|c|}{ Predicted/Experiment Maximum Load } & \multirow[b]{2}{*}{ LBB.ENG } & \\
\hline & & & GE/EPRI & Paris & LBB.NRC & LBB.GE & & \\
\hline \multicolumn{8}{|c|}{ Stainless Steel Base Metal } & \\
\hline NP-2347-6T & 2.375 & A34 & 0.98 & 0.98 & 0.97 & 1.12 & 1.05 & \\
\hline $4131-5$ & 6.254 & $\mathrm{~A} 23$ & 0.69 & 0.80 & 0.89 & 0.80 & 0.77 & \\
\hline $\mathrm{NP}-2347-8 \mathrm{~T}$ & 16.28 & A8 & 0.99 & 1.07 & 1.03 & 0.13 & 1.08 & \\
\hline \multirow[t]{3}{*}{ 4111-3 } & 42.00 & $\mathrm{~A} 12$ & 0.83 & 1.15 & 1.12 & 0.90 & 0.90 & \\
\hline & \multicolumn{2}{|l|}{ Average } & 0.87 & 1.00 & 0.98 & 0.99 & 0.95 & \\
\hline & \multicolumn{2}{|c|}{ Standard Deviation } & 0.12 & 0.13 & 0.12 & 0.14 & 0.12 & \\
\hline \multicolumn{8}{|c|}{ Carbon Steel Base Metal } & \\
\hline $4111-1$ & 4.50 & F11 & 0.67 & 0.82 & 0.81 & 0.78 & 0.77 & \\
\hline DTRC-7 & 8.63 & DT7 & 0.91 & 1.10 & 1.06 & 1.03 & 1.05 & \\
\hline $4111-2$ & 28.00 & F26 & 0.80 & 0.89 & 0.97 & 0.88 & 0.88 & \\
\hline $4111-6$ & 35.83 & F38 & 0.72 & 0.89 & 0.88 & 0.80 & 0.80 & \\
\hline \multirow[t]{3}{*}{ 4111-4 } & 42.00 & F32 & 0.99 & 0.99 & 1.05 & 1.03 & 1.12 & \\
\hline & \multicolumn{2}{|l|}{ Average } & 0.82 & 0.94 & 0.95 & 0.90 & 0.92 & \\
\hline & \multicolumn{2}{|c|}{ Standard Deviation } & 0.12 & 0.10 & 0.09 & 0.11 & 0.14 & \\
\hline \multicolumn{8}{|c|}{ Stainless Steel Weld Metal ${ }^{(\mathbf{b})}$} & \\
\hline $4141-1$ & 6.625 & A45 & 0.66 & 0.98 & 0.88 & 0.76 & 0.74 & \\
\hline $4141-3$ & 16.28 & $\mathrm{A45}$ & 1.89 & 1.21 & 1.15 & 0.99 & 0.98 & \\
\hline $4111-5$ & 28.33 & A50 & \multicolumn{5}{|c|}{ No $J_{D}$ data available } & \\
\hline \multirow[t]{5}{*}{$4141-5$} & 6.605 & A45a & 0.82 & 1.13 & 1.05 & 0.94 & 0.90 & \\
\hline & \multicolumn{2}{|l|}{ Average } & 0.79 & 1.11 & 1.03 & 0.90 & 0.87 & \\
\hline & \multicolumn{2}{|c|}{ Standard Deviation } & 0.10 & 0.10 & 0.11 & 0.10 & 0.10 & \\
\hline & \multicolumn{2}{|c|}{ Total Average } & 0.83 & 1.02 & 0.99 & 0.93 & 0.92 & $0.93^{(c)}$ \\
\hline & \multicolumn{2}{|c|}{ Standard Deviation } & 0.12 & 0.13 & 0.11 & 0.12 & 0.13 & $0.14^{(\mathrm{c})}$ \\
\hline
\end{tabular}

(a) Using Version 1.4

(b) Using base metal stress-strain curve.

(c) Average and standard deviation of all methods. 
Table 2.4 NRCPIPE ${ }^{(a)}$ predictions of through-wall-cracked pipe using power law extrapolation of $\mathbf{J}_{\mathbf{M}}-\mathbf{R}$ curve

\begin{tabular}{|c|c|c|c|c|c|c|c|c|}
\hline & & & & edicted & eriment $\mathrm{Mz}$ & num Load & & \\
\hline $\begin{array}{c}\text { Experiment } \\
\text { No. }\end{array}$ & $\begin{array}{l}\text { O.D., } \\
\text { inch }\end{array}$ & Pipe No. & GE/EPRI & Paris & LBB.NRC & LBB.GE & LBB.ENG & \\
\hline Stainless Stee & se Metal & & & & & & & \\
\hline NP-2347-6T & 2.375 & A34 & 0.98 & 0.98 & 0.97 & 1.14 & 1.05 & \\
\hline $4131-5$ & 6.254 & A23 & 0.72 & 0.80 & 0.80 & 0.83 & 0.80 & \\
\hline NP-2347-8T & 16.28 & A8 & 1.00 & 1.07 & 1.03 & 1.13 & 1.09 & \\
\hline $4111-3$ & 42.00 & $\mathrm{~A} 12$ & 0.99 & 1.35 & 1.28 & 1.07 & 1.06 & \\
\hline & Average & & 0.92 & 1.05 & 1.02 & 1.04 & 1.00 & \\
\hline & Standar & iation & 0.12 & 0.20 & 0.17 & 0.13 & 0.12 & \\
\hline Carbon Steel & se Metal & & & & & & & \\
\hline 4111-1 & 4.50 & F11 & & & $M$ data availe & & & \\
\hline DTRC-7 & 8.63 & DT7 & & & $M$ data avail & & & \\
\hline 4111-2 & 28.00 & F26 & 0.95 & 1.14 & 1.15 & 1.03 & 1.03 & \\
\hline $4111-6$ & 35.83 & F38 & 0.79 & 0.91 & 0.91 & 0.88 & 0.87 & \\
\hline 4111-4 & 42.00 & F32 & 1.05 & 1.08 & 1.11 & 1.10 & 1.20 & \\
\hline & Average & & 0.93 & 1.05 & 1.06 & 1.00 & 1.03 & \\
\hline & Standar & iation & 0.11 & 0.10 & 0.11 & 0.09 & 0.14 & \\
\hline Stainless Stee & eld Meta & & & & & & & \\
\hline 4141-1 & 6.625 & $\mathrm{~A} 45$ & 0.69 & 0.98 & 0.90 & 0.80 & 0.77 & \\
\hline 4141-3 & 16.28 & A45 & 0.93 & 1.22 & 1.18 & 1.03 & 1.02 & \\
\hline $4111-5$ & 28.33 & A50 & 1.19 & 1.38 & 1.41 & 1.26 & 1.32 & \\
\hline $4141-5$ & 6.605 & A45a & 0.84 & 1.13 & 1.06 & 0.97 & 0.93 & \\
\hline & Average & & 0.91 & 1.18 & 1.14 & 1.02 & 1.01 & \\
\hline & Standar & iation & 0.18 & 0.15 & 0.19 & 0.17 & 0.20 & \\
\hline & Total AI & & 0.92 & 1.09 & 1.07 & 1.02 & 1.02 & $1.03^{(\mathrm{c})}$ \\
\hline & Standar & iation & 0.14 & 0.17 & 0.17 & 0.14 & 0.16 & $0.17^{(c)}$ \\
\hline
\end{tabular}

(a) Using Version 1.4.

(b) Using base metal stress-strain curve.

(c) Average and standard deviation of all methods. 
Table 2.5 Mean and coefficient of variation of initiation load ratio predicted by various deterministic fracture-mechanics analyses from Reference $\mathbf{2 . 1 4}$

\begin{tabular}{|c|c|c|c|c|}
\hline \multirow[b]{3}{*}{$\begin{array}{l}\text { Fracture } \\
\text { Analysis Methods } \\
\end{array}$} & \multicolumn{4}{|c|}{ Initiation Load Ratio $^{(\mathrm{a})}$} \\
\hline & \multicolumn{2}{|c|}{$\begin{array}{c}\text { TWC Pipes Under Bending } \\
(8 \text { tests })\end{array}$} & \multicolumn{2}{|c|}{$\begin{array}{c}\text { TWC Pipes Under Bending } \\
\text { Plus Tension } \\
\text { (5 tests) } \\
\end{array}$} \\
\hline & Mean & $\begin{array}{c}\text { Coefficient of } \\
\text { Variation, }^{(\boldsymbol{b})} \\
\text { percent } \\
\end{array}$ & Mean & $\begin{array}{c}\text { Coefficient of } \\
\text { Variation, } \\
\text { percent } \\
\end{array}$ \\
\hline LBB.ENG2 & 1.12 & 17.64 & 1.13 & 20.45 \\
\hline LBB.NRC & 1.04 & 17.71 & 1.09 & 21.46 \\
\hline LBB.GE & 1.05 & 19.28 & $--^{(c)}$ & $--^{(c)}$ \\
\hline GE/EPRI & 1.20 & 16.91 & 1.18 & 17.71 \\
\hline Paris/Tada & 0.98 & 19.99 & 0.91 & 20.76 \\
\hline LBB.ENG3 & 1.03 & 10.65 & 1.13 & 20.45 \\
\hline
\end{tabular}

(a) Initiation load ratio = experimental initiation load/predicted initiation load.

(b) Coefficient of variation $=($ standard deviation $/$ mean $) \times 100$.

(c) Not analyzed. 
Table 2.6 Mean and coefficient of variation of maximum load ratio predicted by various deterministic fracture-mechanics analyses from Reference 2.14

\begin{tabular}{|c|c|c|c|c|c|c|c|c|}
\hline \multirow[b]{3}{*}{$\begin{array}{l}\text { Fracture } \\
\text { Analysis } \\
\text { Methods }\end{array}$} & \multicolumn{8}{|c|}{ Maximum Load Ratio $^{(\mathrm{a})}$} \\
\hline & \multicolumn{2}{|c|}{$\begin{array}{c}\text { All TWC Pipes } \\
\text { Under Bending } \\
\text { (12 Tests) } \\
\end{array}$} & \multicolumn{2}{|c|}{$\begin{array}{c}\text { Short TWC Pipes } \\
\text { Under Bending } \\
\text { (5 Tests) }\end{array}$} & \multicolumn{2}{|c|}{$\begin{array}{c}\text { TWC Welded Pipes } \\
\text { Under Bending } \\
\text { (4 Tests) } \\
\end{array}$} & \multicolumn{2}{|c|}{$\begin{array}{c}\text { All TWC Pipes } \\
\text { Under Bending and } \\
\text { Tension } \\
\text { (6 Tests) } \\
\end{array}$} \\
\hline & Mean & $\begin{array}{c}\text { Coefficient } \\
\text { of } \\
\text { Variation }^{(\mathbf{b})}, \\
\text { percent }\end{array}$ & Mean & $\begin{array}{c}\text { Coefficient } \\
\text { of } \\
\text { Variation }^{(\mathbf{b})} \text {, } \\
\text { percent }\end{array}$ & Mean & $\begin{array}{c}\text { Coefficient } \\
\text { of } \\
\text { Variation }^{(\mathbf{b})}, \\
\text { percent }\end{array}$ & Mean & $\begin{array}{c}\text { Coefficient } \\
\text { of } \\
\text { Variation }^{(\mathbf{b})}, \\
\text { percent }^{-}\end{array}$ \\
\hline LBB.ENG2 & 1.04 & 12.93 & 0.96 & 16.27 & 1.08 & 7.61 & 1.18 & 11.06 \\
\hline LBB.NRC & 1.01 & 10.50 & 1.02 & 9.02 & 0.94 & 12.74 & 1.17 & 15.45 \\
\hline LBB.GE & 1.01 & 11.62 & 0.98 & 13.91 & 0.98 & 6.38 & $--^{(c)}$ & $\ldots(c)$ \\
\hline GE/EPRI & 1.15 & 11.14 & 1.12 & 14.97 & 1.18 & 9.50 & 1.31 & 13.75 \\
\hline Paris/Tada & 0.96 & 12.72 & 0.91 & 6.95 & 0.87 & 11.87 & 1.03 & 13.62 \\
\hline LBB.ENG3 & 1.00 & 12.48 & 0.90 & 11.58 & 1.02 & 5.83 & 1.18 & 11.06 \\
\hline $\begin{array}{c}\text { ASME } \\
\text { Section XI }\end{array}$ & $1.34^{(\mathrm{d})}$ & $26.87^{(d)}$ & $1.47^{(\mathrm{d})}$ & $34.71^{(\mathrm{d})}$ & $1.28^{(\mathrm{d})}$ & $13.16^{(\mathrm{d})}$ & $1.58^{(\mathrm{d})}$ & $27.82^{(d)}$ \\
\hline $\begin{array}{l}\text { - Austenitic } \\
\text { - Ferritic }\end{array}$ & $\begin{array}{c}1.2^{(e)} \\
1.78^{(i)}\end{array}$ & $\begin{array}{l}12.96^{(\mathrm{e})} \\
24.69^{(\mathrm{f})}\end{array}$ & $\begin{array}{l}-- \\
--\end{array}$ & $\begin{array}{l}-- \\
--\end{array}$ & -- & $\begin{array}{l}-- \\
--\end{array}$ & $\begin{array}{l}1.20^{(f)} \\
1.95^{(t)}\end{array}$ & $\begin{array}{l}21.64^{(n)} \\
10.17^{(n)}\end{array}$ \\
\hline NSC & 0.91 & 15.36 & 0.89 & 9.11 & 0.84 & 15.92 & 1.06 & 13.64 \\
\hline
\end{tabular}

(a) Maximum load ratio = experimental maximum load/predicted maximum load.

(b) Coefficient of variation $=($ standard deviation $/$ mean $) \times 100$.

(c) Not analyzed.

(d) Considering both the ferritic and austenitic experiments together.

(e) From nine tests.

(f) From three tests.

The methods that tend to underpredict the experimental loads the most are:

- The R6 method Option 1 method, and

- The original GE/EPRI method.

The methods that tended to overpredict the experimental loads were:

- $\quad$ NRC.LBB method,

- Tada-Paris NUREG/CR-6434 method, and

- Net-Section-Collapse analysis. 
The Net-Section-Collapse analysis overpredicted the experimental loads since some of the experiments were EPFM failures. However, if a sufficiently conservative definition of flow stress was used, then the Net-Section-Collapse solution could be used, but such an approach may be overly pessimistic in many cases.

The methods that were the most accurate, yet slightly conservative were:

- The Battelle Dimensionless Plastic-Zone Parameter analysis,

- The LBB.ENG2 method, and

- The LBB.GE method.

In the IPIRG-1 program, round-robin analyses were also conducted on many of the same pipe experiments by different organizations (Ref. 2.67). These results are shown in Figures 2.54 and 2.55. These results, along with some of the round-robin results on FEM analyses showed some interesting points, for instance:

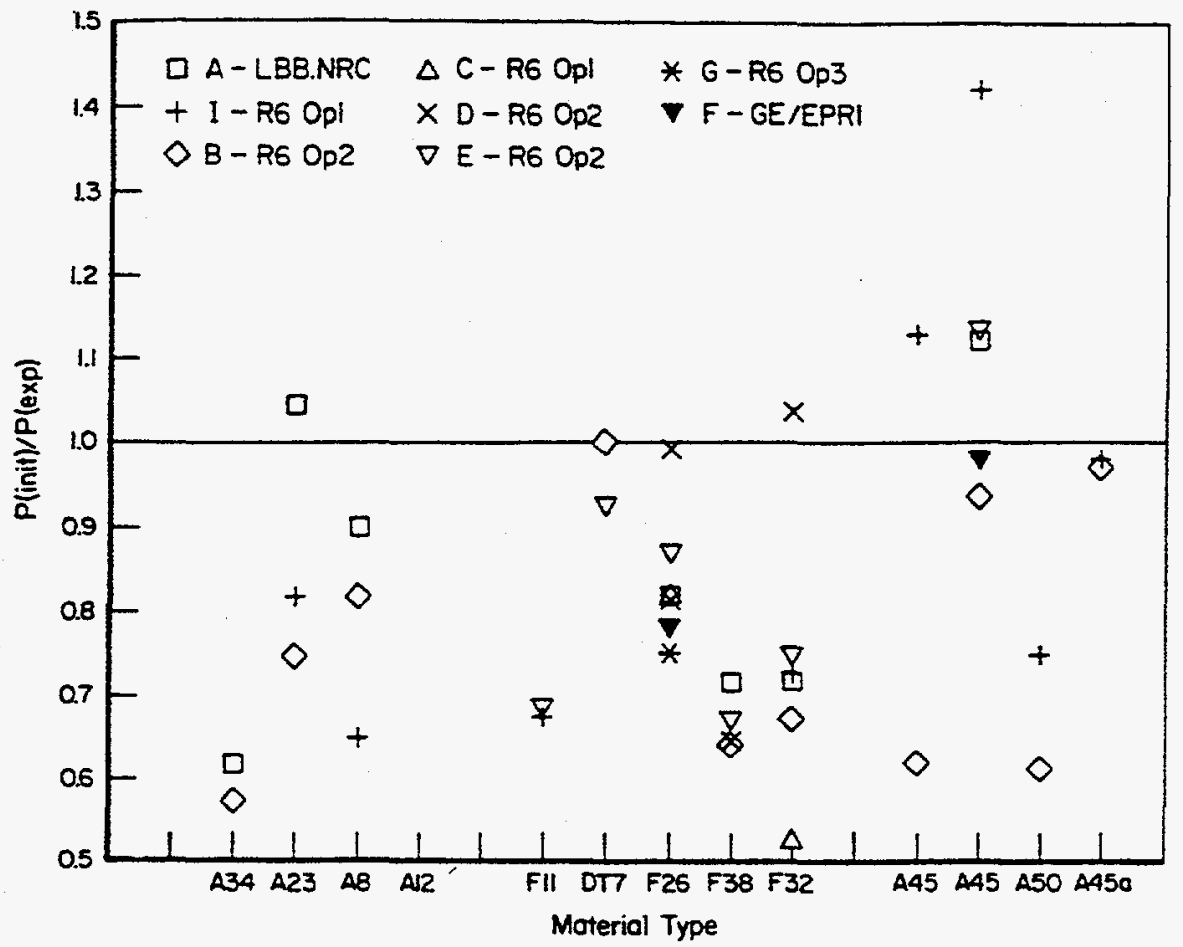

Figure 2.54 IPIRG member participant predictions of loads at crack initiation compared with experimental loads for IPIRG Round-Robin Problem 1 


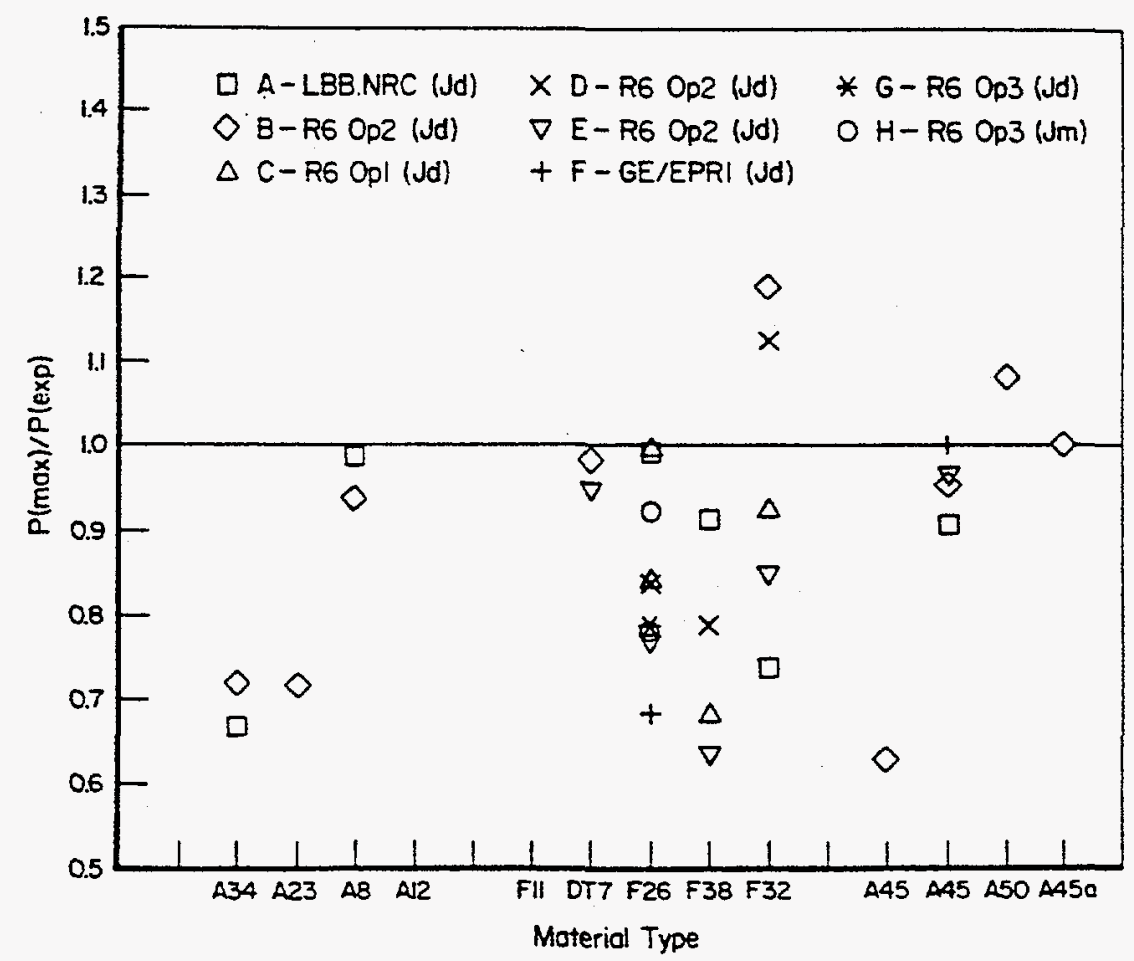

Figure 2.55 IPIRG participant predictions of loads at maximum load compared with experimental loads for IPIRG Round-Robin Problem 1

(1) There was better agreement conducting finite element analysis than in doing simple limit-load analyses. This may stem from people paying less attention to details using a simple procedure;

(2) There was as much scatter in R6 EPFM predictions as in predictions by all other methods combined. This comes from people using a variety of limit-load and EPFM solutions in the R6 framework and all of them calling it an R6 solution.

\subsubsection{Predictions of Maximum Load Capabilities for Circumferential Surface-Cracked Pipes}

The maximum load-carrying capacity of circumferentially surface-cracked pipe is important for in-service flaw evaluation standards. Traditional leak-before-break analyses, such as in the U.S. nuclear industry (Ref. 2.135), assume that there is a circumferential through-wall flaw. However, some international organizations are also interested in whether leak-before-break should also be approached from a surface flaw viewpoint.

As with through-wall cracked pipes, fracture mechanics predictions of circumferentially surface-cracked pipes can involve linear elastic fracture mechanics (LEFM) behavior, elastic-plastic fracture mechanics (EPFM) behavior, or limit-load failure behavior. These failure behaviors are really categories of analysis methods. LEFM failure would only apply to very brittle materials, which is not typically relevant for nuclear piping materials, except perhaps piping systems operating at low temperatures or highly thermally 
aged cast stainless steels at less than LWR primary piping normal operating temperatures. EPFM analyses are needed frequently for nuclear piping materials, as are limit-load analyses.

Linear-Elastic Fracture Mechanics (LEFM) Analyses. The circumferential surface-crack geometry adds additional parameters to the solutions that make them more complicated than a simple idealized through-wall crack. Not only is the length and depth of the crack important, but the shape of the crack can also change the driving force. In the ASME Section XI criteria for surface cracks, the maximum depth of the crack is assumed to exist for the entire length of the flaw (Ref. 2.123). Analytical solutions have been developed for elliptical crack shapes, and less frequently for parabolic flaw shapes.

Solutions developed using the line-spring finite element method, are typically used to develop constant depth flaw solutions (Refs. 2.136 and 2.137). Elliptical crack shape FEM solutions require 3-dimensional modeling.

In the 1995 ASME Section XI pipe flaw evaluation criteria in Appendix $\mathrm{H}$ and Code Case N-494, an LEFM solution by Zahoor (Ref. 2.138) was used. The solutions for tension and bending are given below.

$$
\begin{gathered}
J_{e}=\left(\mathrm{K}_{\mathrm{Im}}+\mathrm{K}_{\mathrm{Ib}}\right)^{2} / \mathrm{E}^{\prime} \\
\mathrm{K}_{\mathrm{Im}}=\left[\mathrm{P}_{\mathrm{ax}} /\left(2 \pi \mathrm{R}_{\mathrm{m}} \mathrm{t}\right)\right] \mathrm{F}_{\mathrm{m}}(\pi \mathrm{a})^{0.5} \\
\mathrm{~K}_{\mathrm{lb}}=\left[\mathrm{M} /\left(\pi \mathrm{R}_{\mathrm{m}}{ }^{2} \mathrm{t}\right)\right] \mathrm{F}_{\mathrm{b}}(\pi \mathrm{a})^{0.5} \\
\mathrm{~F}_{\mathrm{m}}=1.1+(\mathrm{a} / \mathrm{t})\left[0.15241+16.772[\theta \mathrm{a} /(\mathrm{t} \pi)]^{0.855}-14.944[\theta \mathrm{a} /(\mathrm{t} \pi)]\right. \\
\mathrm{F}_{\mathrm{b}}=1.1+(\mathrm{a} / \mathrm{t})\left[-0.09967+5.0057[\theta \mathrm{a} /(\mathrm{t} \pi)]^{0.565}-2.8329[\theta \mathrm{a} /(\mathrm{t} \pi)]\right.
\end{gathered}
$$

where

$$
\begin{aligned}
& \mathrm{P}_{\mathrm{ax}}=\pi \mathrm{R}_{\mathrm{i}}^{2} \mathrm{p}=\text { axial force } \\
& \mathrm{R}_{\mathrm{m}}=\text { mean radius } \\
& \mathrm{R}_{\mathrm{i}}=\text { inside radius } \\
& \mathrm{p}=\text { pressure } \\
& \mathrm{t}=\text { thickness } \\
& \mathrm{E}^{\prime}=\mathrm{E} /\left(1-v^{2}\right) \\
& \mathrm{E}=\text { elastic modulus } \\
& v=\text { Poisson's ratio } \\
& \mathrm{M}=\text { moment } \\
& \mathrm{a}=\text { surface crack depth } \\
& \theta=\text { half crack angle, radians. }
\end{aligned}
$$


Note that there is a lack of $R / t$ dependancy in these equations. ASME Section XI Appendix $H$ procedure says that these equations could be used for $R / t$ values of 5 to 20 . Reference 2.138 says that they are valid for $R / t$ of 5 to 10 , but did not provide a basis for this limitation. It is believed that they probably came from the few line-spring results from the GE results in Reference 2.136, where there were solutions only for a few flaw geometry cases with $R / t$ values of 5 and 10 .

Work in Reference 2.13 and 2.139 for the ASME Section XI Working Group on Pipe Flaw Evaluation showed that for a pipe with an $R / t$ of 20, Equation 2-62 underpredicted the actual $F_{b}$ when compared with detailed FEM analyses. The error was about 26 percent on $\mathrm{K}_{e}$ (or 58 percent on $\mathrm{J}_{e}$ ).

Clearly, a better set of $\mathrm{K}$-solutions as a function of $\mathrm{R} / \mathrm{t}$ ratios is needed for constant-depth circumferential surface cracks.

Limit-Load Analyses. A very simple method for handling plastic fracture problems is to assume that fracture occurs when some limiting stress state is reached in the cracked component. Such analyses, known as collapse or net section yield analyses, often provide very satisfactory engineering answers.

Maxey Method. One of the first circumferential flaw limit-load analyses developed was by Maxey in Reference 2.89. In this analysis, he used elastic stress analysis, considered the change in the section modulus due to the presence of the crack, considered a term for the induced bending due to the eccentricity of the crack and the offset centroid of the cross section of the pipe, and assumed failure when the maximum elastically-calculated stress was equal to the ultimate strength of the material. This analysis method was adopted by MPA-Stuttgart (Ref. 2.117).

Wilkowski/Offshore Pipe Laying Empirical Criteria. In work done at Battelle for the American Gas Association, a series of experiments were conducted and an empirical limit-load solution was developed for blunt external circumferentially surface flawed pipes in pure bending. The application was for assessing the maximum allowable size of a girth weld repair groove on an offshore lay barge. In such applications, the pipe is first welded, then x-rayed, and if a weld defect exists, then it has to be repaired at a location on the lay barge where there are high bending stresses. The weld defect is removed by arc gouging which results in a blunt circumferential groove (Ref. 2.140).

The procedure that was found successful for predicting the maximum load-carrying capacity for the blunt circumferential flaw was to relate the surface flaw to an equivalent through-wall flaw using a parallel approach used for axial flaws, i.e.,

$$
\sigma_{b}=\sigma_{\mathrm{f}} \mathrm{M}_{\mathrm{cs}}
$$

where

\footnotetext{
$\sigma_{\mathrm{b}}=$ Nominal bending stress in uncracked pipe

$\sigma_{\mathrm{f}}=$ Flow stress [taken as $\sigma_{\mathrm{y}}+10 \mathrm{ksi}(68.9 \mathrm{MPa})$ in Reference 2.140 , but frequently $\left(\sigma_{\mathrm{y}}+\sigma_{\mathrm{u}}\right) / 2$ is used.]
} 


$$
M_{c s}=(a / t) /\left[1-M_{c t}(1-a / t)\right]
$$

From 102-, 152-, and 762-mm (4-, 6-, and 30-inch) diameter pipe experiments conducted in Reference 2.140 ,

$$
M_{\mathrm{ct}}=\left[1+0.26(\theta / \pi)+47(\theta / \pi)^{2}-59(\theta / \pi)^{3}\right]^{0.5}
$$

where,

$$
\begin{aligned}
& M_{c s}=\text { pipe and flaw geometry function for surface flaws } \\
& a=\text { depth of surface flaw } \\
& t=\text { pipe thickness } \\
& M_{c t}=\text { through-wall flaw function from Reference } 2.140 \\
& \theta=\text { half angle of circumferential surface flaw. }
\end{aligned}
$$

This solution was found to be valid for crack lengths of 10 to 30 percent of the circumference, and $a / t$ values of 0.5 to 0.7 , see Figure 2.56. For longer crack lengths, $\theta / \pi>0.3$, this solution is probably not valid.

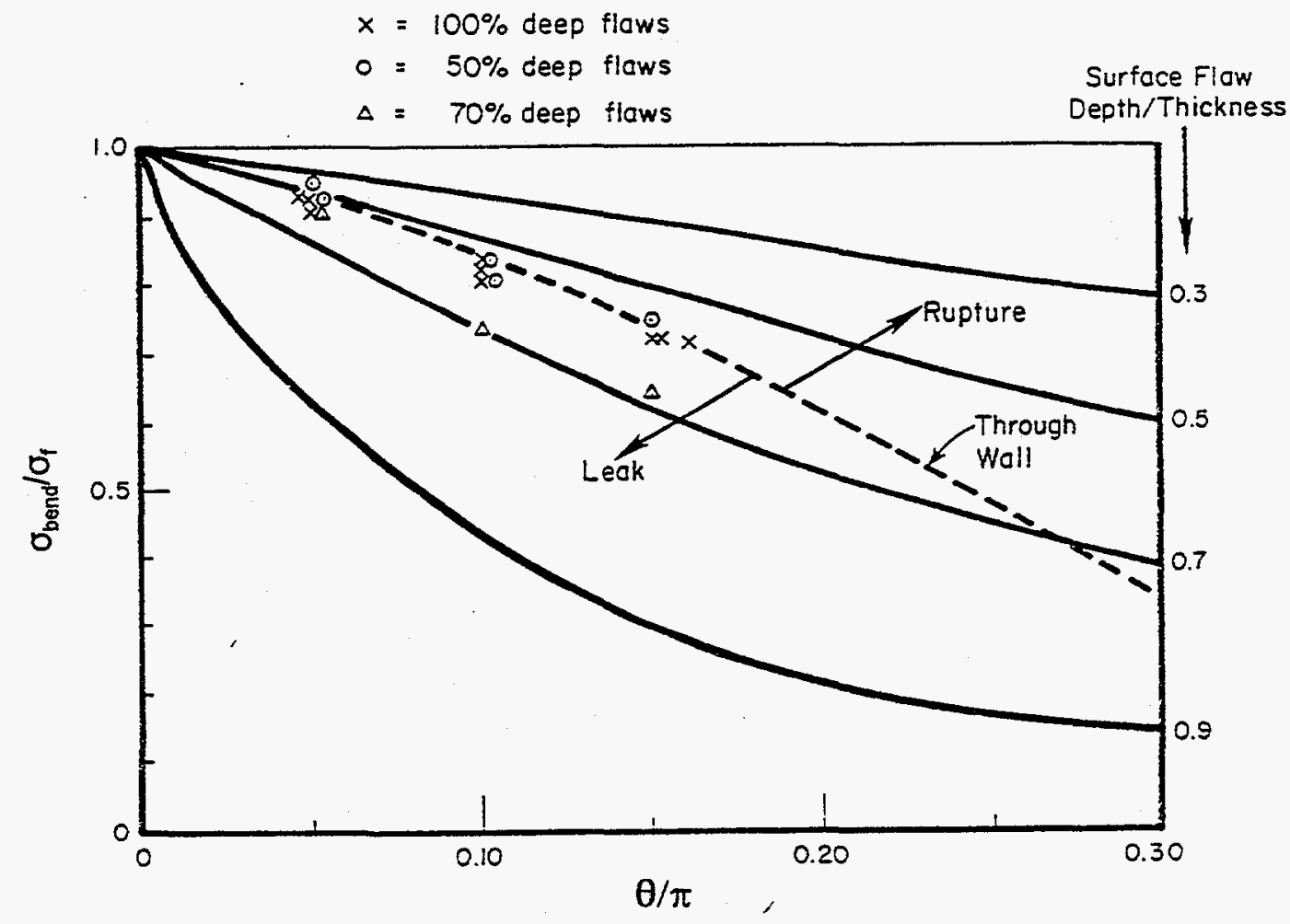

Figure 2.56 Normalized flow stress dependent relationship for failure of circumferential repairgrooves in pipes subjected to bending stresses 
An interesting aspect of this analysis is that for short deep flaws, the surface-flawed pipe had a maximum load at crack penetration that was less than that exhibited by the through-wall flaw of the same circumferential length, see Figure 2.57. In these cases, after the surface flaw penetrated the thickness, then the load had to increase for the flaw to grow circumferentially. This is essentially a load-controlled leakbefore-break behavior.

It was also found that one of the small diameter pipes used (AISI 1020 carbon steel tubing) was heavily cold worked during fabrication. Because of this, there was a much lower crack-tip-opening angle during crack propagation, indicating a lower ductile fracture toughness. In this material, even with a blunt starter notch, the maximum loads were below the limit load of the other pipes. Hence, limit-load is not necessarily guaranteed for blunt flaw defects.

The Original Net-Section-Collapse. The next circumferential flaw limit-load development was one called the Net-Section-Collapse analysis. This was developed by Broek (Ref. 2.118). In this analysis procedure, the entire net-section of the pipe is considered to become fully plastic and reach an idealized stress value called the flow stress. This is schematically shown in Figure 2.53 . This analysis procedure is the basis of the ASME Section XI pipe flaw evaluation criteria. The Section XI criteria simplified the original NetSection-Collapse equations and defined the flow stress $\left(\sigma_{\mathrm{f}}\right)$ as $2.4 \mathrm{~S}_{\mathrm{m}}$ for ferritic steels and $3 \mathrm{~S}_{\mathrm{m}}$ for austenitic steels.

The predicted Net-Section-Collapse analysis bending moment at failure $\left(\mathrm{M}_{\mathrm{nsc}}\right)$ for a pipe in pure bending is given by a simple beam theory analysis wherein static equilibrium conditions are enforced and show that the maximum moment-carrying capacity is

$$
M_{\text {vsc }}=2 \sigma_{f} R_{m}^{2} t\left(2 \sin \beta-\frac{a}{t} \sin \theta\right)
$$

where the stress inversion angle $(\beta)$ is given by

$$
\beta=\frac{\pi-\theta(a / t)}{2}-\frac{\pi R_{i}^{2} p}{4 R_{m} \sigma_{f}^{t}}
$$

where

$$
\begin{aligned}
& \theta=\text { half crack angle } \\
& M_{n s c}=\text { NSC limit moment } \\
& R_{i}=\text { inner radius of pipe } \\
& R_{m}=\text { mean radius of the pipe } \\
& p=\text { internal pressure } \\
& t=\text { pipe wall thickness } \\
& a \quad=\text { surface crack depth, and } \\
& \sigma_{f}=\text { flow stress. }
\end{aligned}
$$



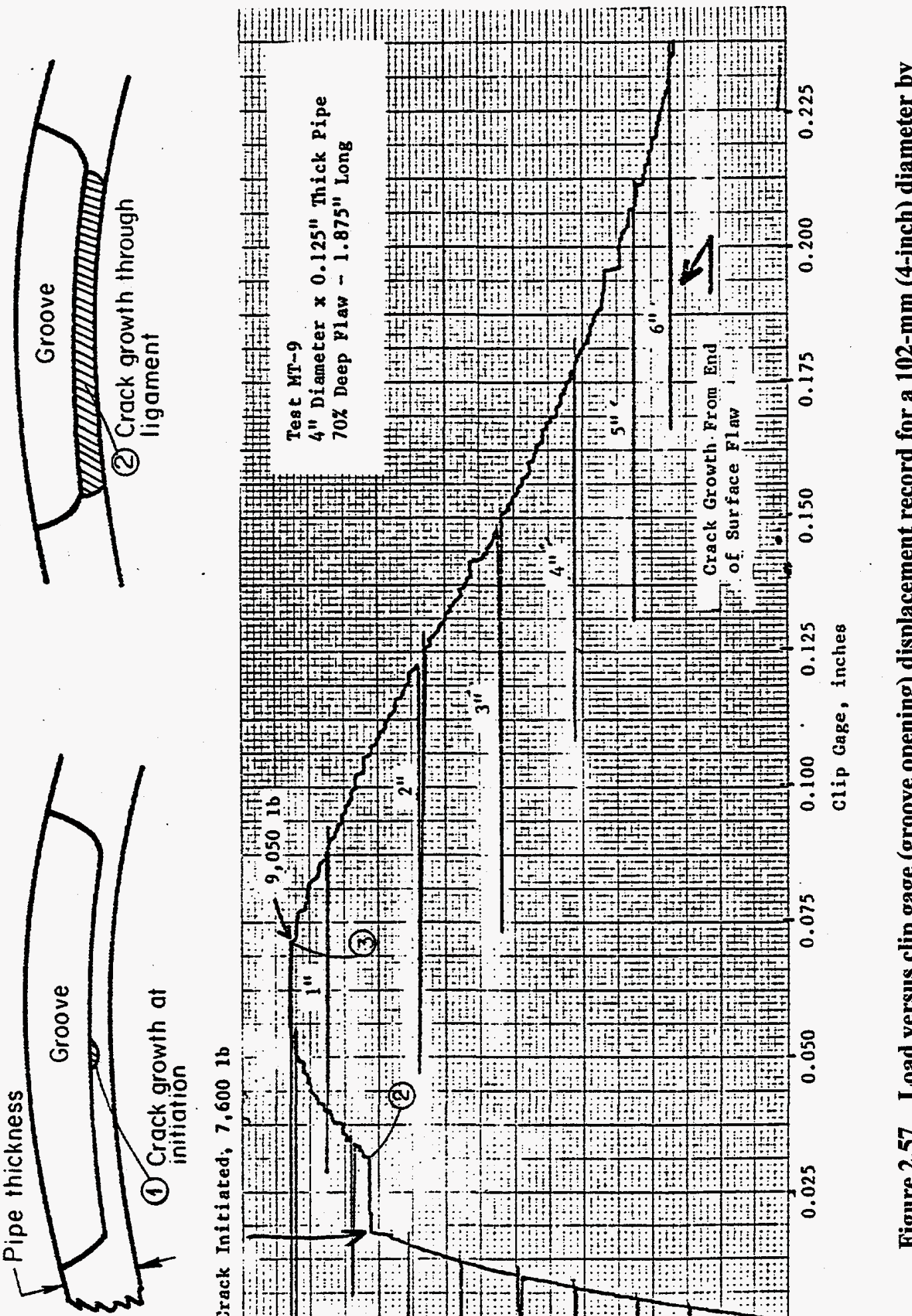

$\times$

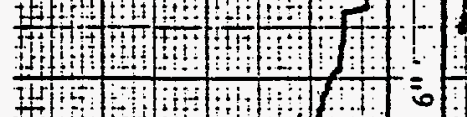

1 a
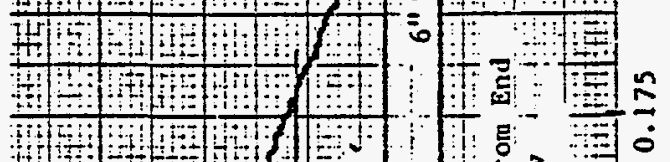

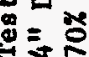

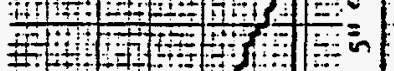

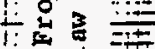

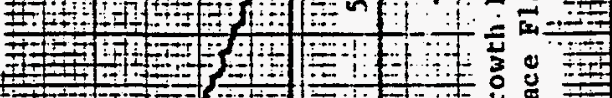

$+$

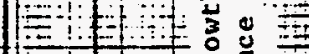

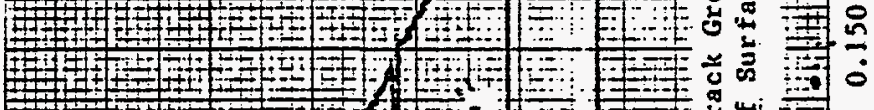

$+$

$+$

$7+1$

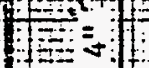

10

$+$

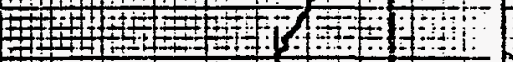

$+$

$+1+2$

$+7+7+1$

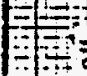

$+1+1+1+1+10$
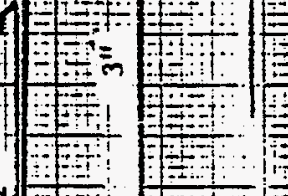

$+$

$=0$

to:

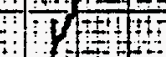

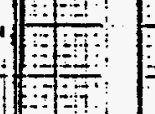

0 -

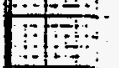

$\frac{1+1}{y-1}=$

$-1= \pm+1$

$1+1000100$

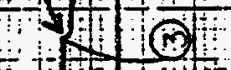

:

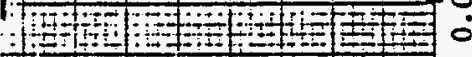

7 7O

$+1=-$

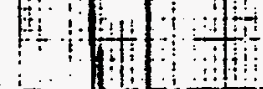

8

$\mathrm{H}^{-} \frac{\mathrm{a}}{\vdots}$

(i)

(1)

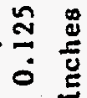

CFi E

$-1+1+1$

$+5+18$

-

(1)

ias

(4)
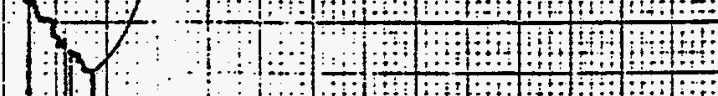

:ै

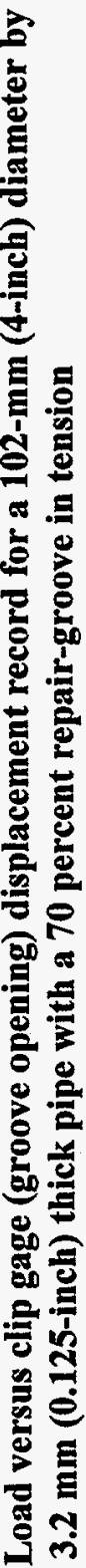

敌

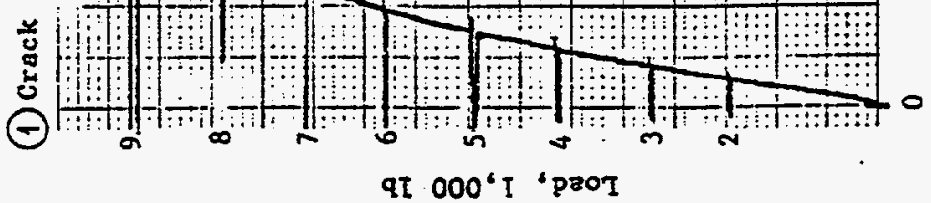


The above analysis assumes that the ratio $R_{m} / t$ is large $(>10)$ and, therefore, thin-wall pipe approximations are valid. Thick-walled solutions have also been derived (Refs. 2.141 and 2.142), but are seldom used. In fact, comparisons at Battelle showed that the thick-shell solutions were less accurate than the thin-shell assumption. (The flow stress had to be significantly reduced to make the thick-shell solution accurately predict pipe experiments.)

Figures $2.58 \mathrm{a}$ and $2.58 \mathrm{~b}$ show the predicted Net-Section-Collapse analysis bending stresses versus normalized flaw length for various surface-crack depths. Figure 2.58a is a plot of Equations 2-66 and 2-67 for the case of pure bending which shows an inflection point where, for longer crack lengths, the normalized NSC stress values start to increase slightly. In Figure $2.58 \mathrm{~b}$, the curves have been flattened off where, for the longer crack lengths, the normalizing NSC stresses were set at the minimum values from Figure 2.58a. A significant observation from these figures is that all the surface-crack curves are above the through-wall crack curve. Experimental evidence contradicts these results (Refs. 2.140 and 2.143).

The above solutions were for constant-depth surface flaws. The same general Net-Section-Collapse integral equations could also be used for surface-flaw geometries of various shapes. Reference 2.144 for instance, shows the solutions for elliptical and parabolic flaw shapes relative to constant depth solutions. For deep flaws the difference is larger than for shallow flaws, see Figures $2.59 \mathrm{a}$ and $2.59 \mathrm{~b}$.

Kurihara Modification of Net-Section-Collapse Analysis. Based on experimental results, Kurihara (Ref. 2.143) modified the NSC equation for pipes with short, but deep, surface flaws. An empirical factor " $m_{k}$ " with the proposed form

$$
m_{k}=1-(a / t)^{a_{k}}(\theta / \pi)^{b_{k}}
$$

was used as a scaling factor to multiply the right-hand side of the NSC criterion, Equation 2-66. Using data from JAERI pipe tests with deep notches, Kurihara determined that the appropriate values of $a_{k}$ and $b_{k}$ were 2 and 0.2 , respectively. Figure 2.60 shows a plot of the Kurihara-modified Net-Section-Collapse equation compared with some JAERI pipe test data. The differences with the Kurihara modification and the original Net-Section-Collapse analysis are illustrated in Figure 2.61. Note the large differences with short shallow cracks.

There are two major limitations to the NSC analysis. First, fully plastic conditions in the remaining ligament do not necessarily exist in surface-cracked pipes in all cases, and therefore, contained plasticity sometimes needs to be considered in the analysis. Secondly, the moments at crack initiation and the moment-rotation behavior of the cracked pipe are not predicted by this method. EPFM analyses are needed to overcome both of these limitations.

Battelle R/t Modification of Net-Section-Collapse Analysis. Based on comparisons with experimental results, Scott and Wilkowski suggested that there is an inaccuracy in the Net-Section-Collapse solution. Their comparisons show there is an $\mathrm{R} / \mathrm{t}$ effect, possibly due to pipe ovalization. This effect is shown in Figure 2.62 (Ref. 2.13). From the figure, it can be seen that thicker pipe reaches loads higher than the original Net-Section-Collapse equation predicts, and thin-walled pipe will fail at lower loads. 


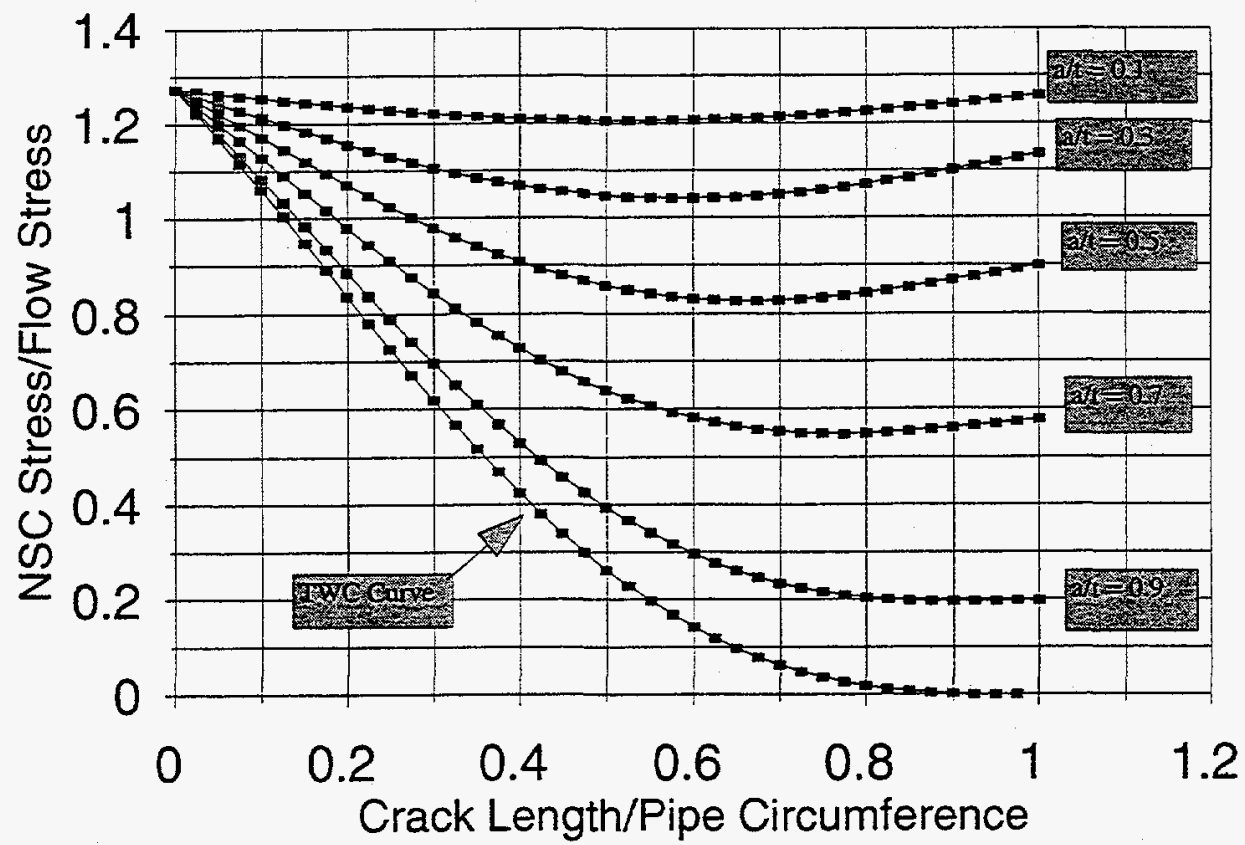

(a) Plot of Equations 2-66 and 2-67 for pure bending

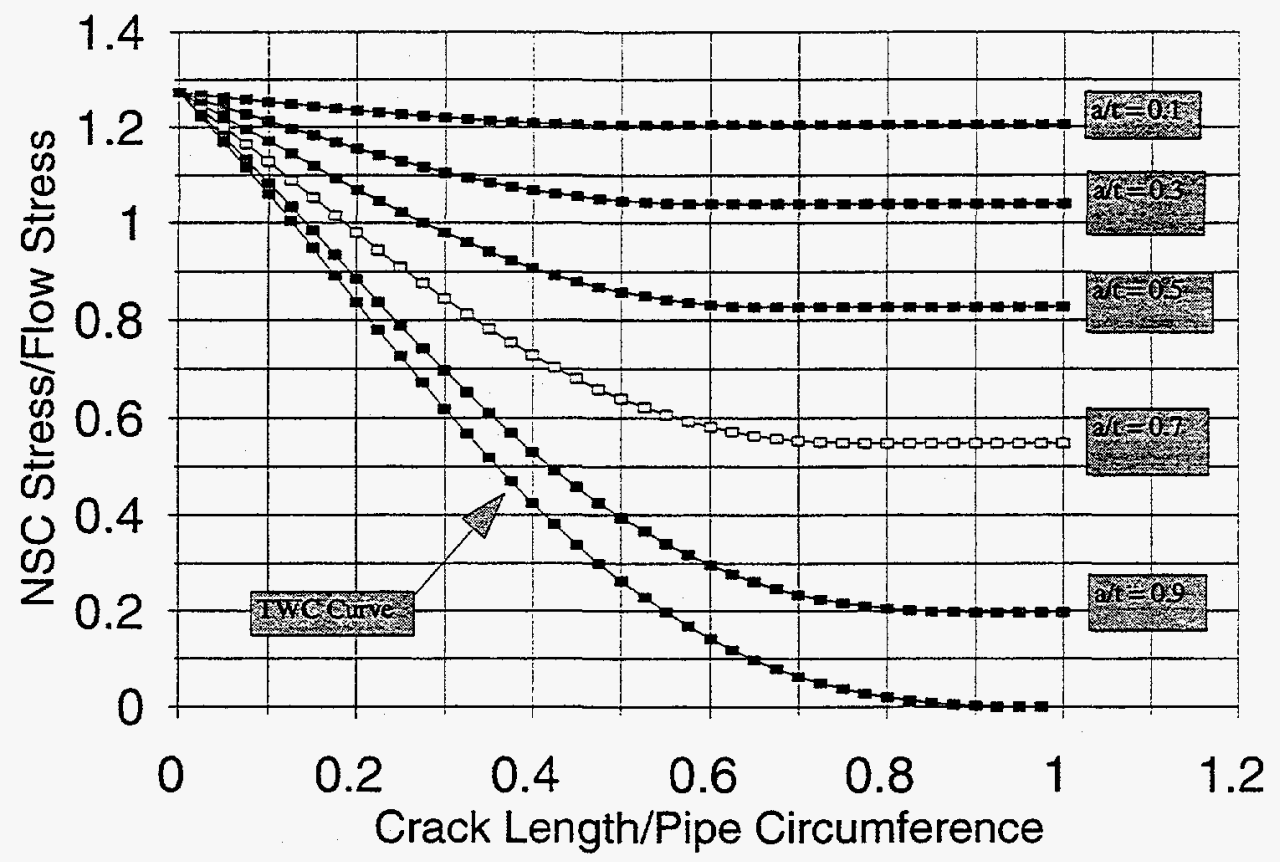

(b) Case where normalized NSC stress held constant for longer crack lengths

Figure 2.58 Predicted Net-Section-Collapse analysis bending stress versus normalized flaw length for various surface-crack depths 


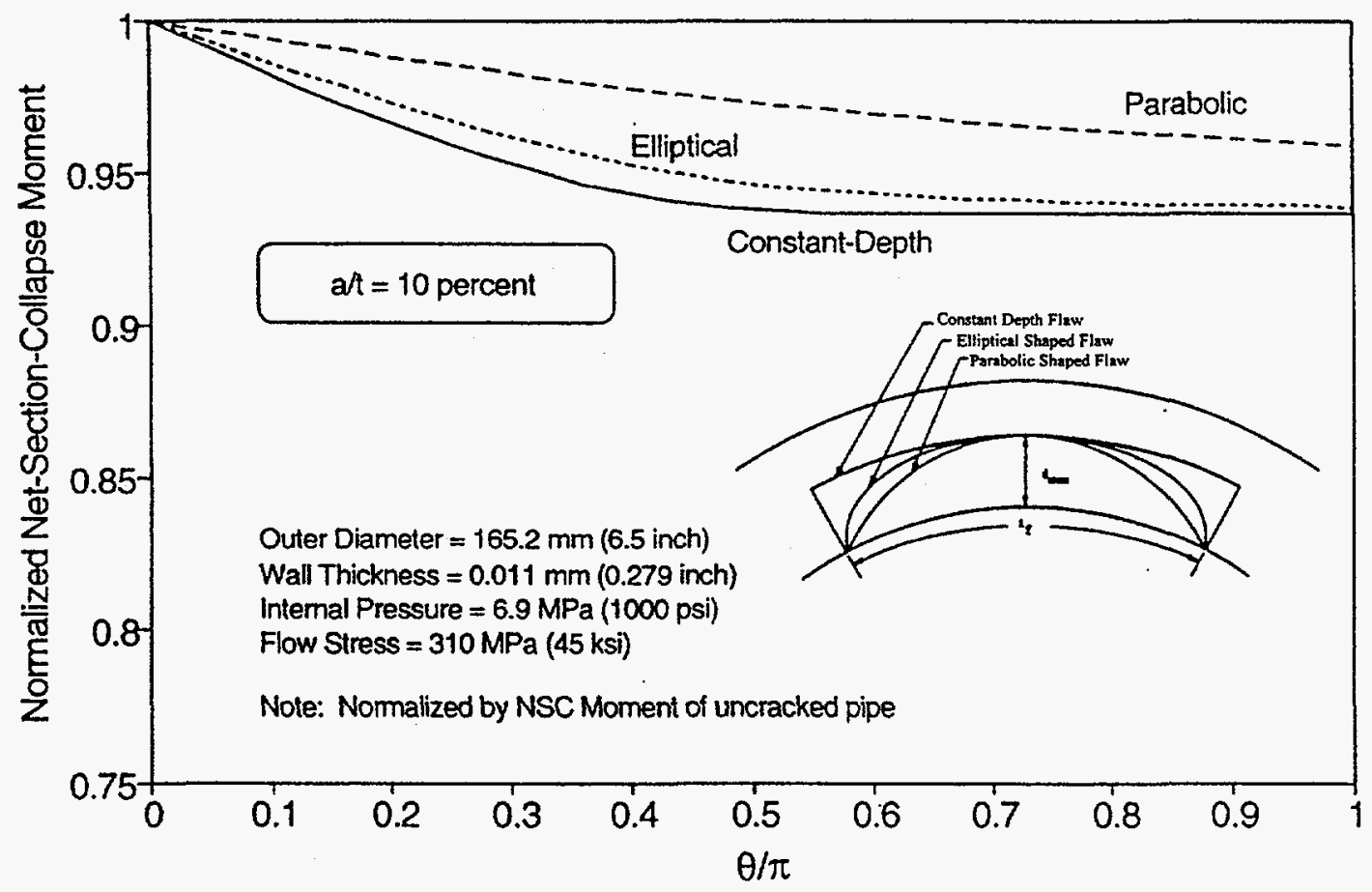

(a) $a / t=10$ percent

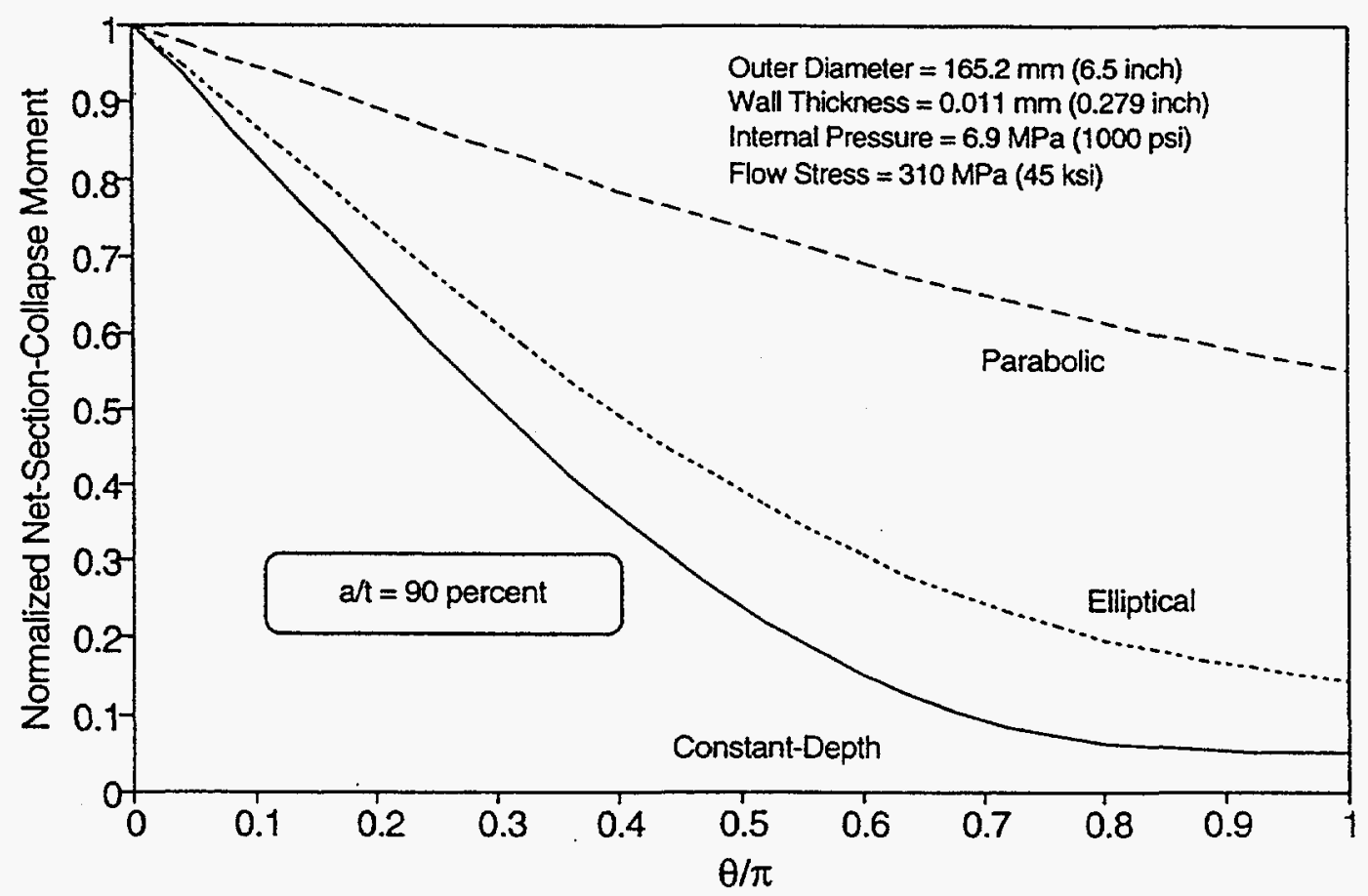

(b) $a / t=90$ percent

Figure 2.59 Effects of flaw shapes on limit load for shallow and deep cracks 


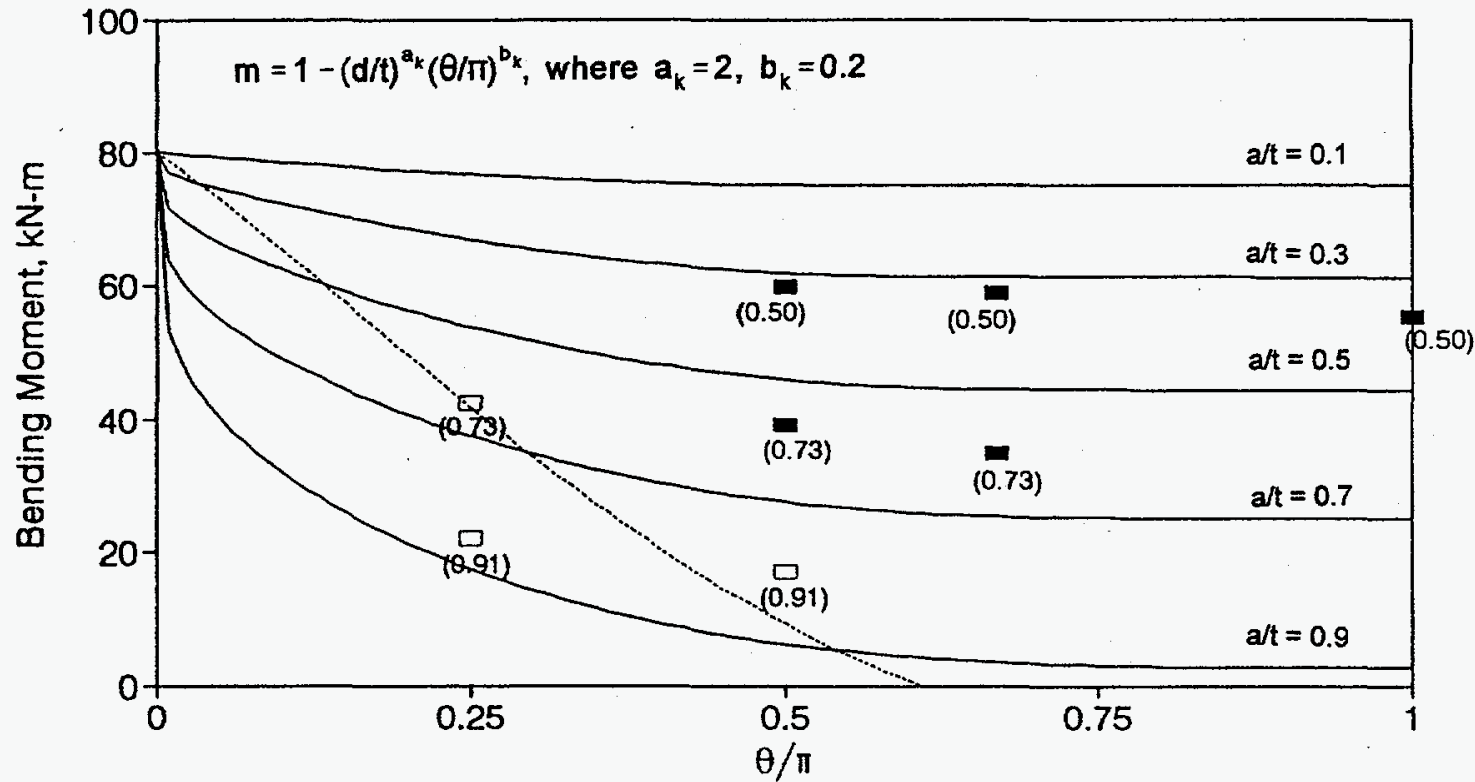

Kurihara (SC) - Kurihara (TWC) $\square$ Leak Data Break Data

Figure 2.60 Plot of Kurihara-modified Net-Section-Collapse equations

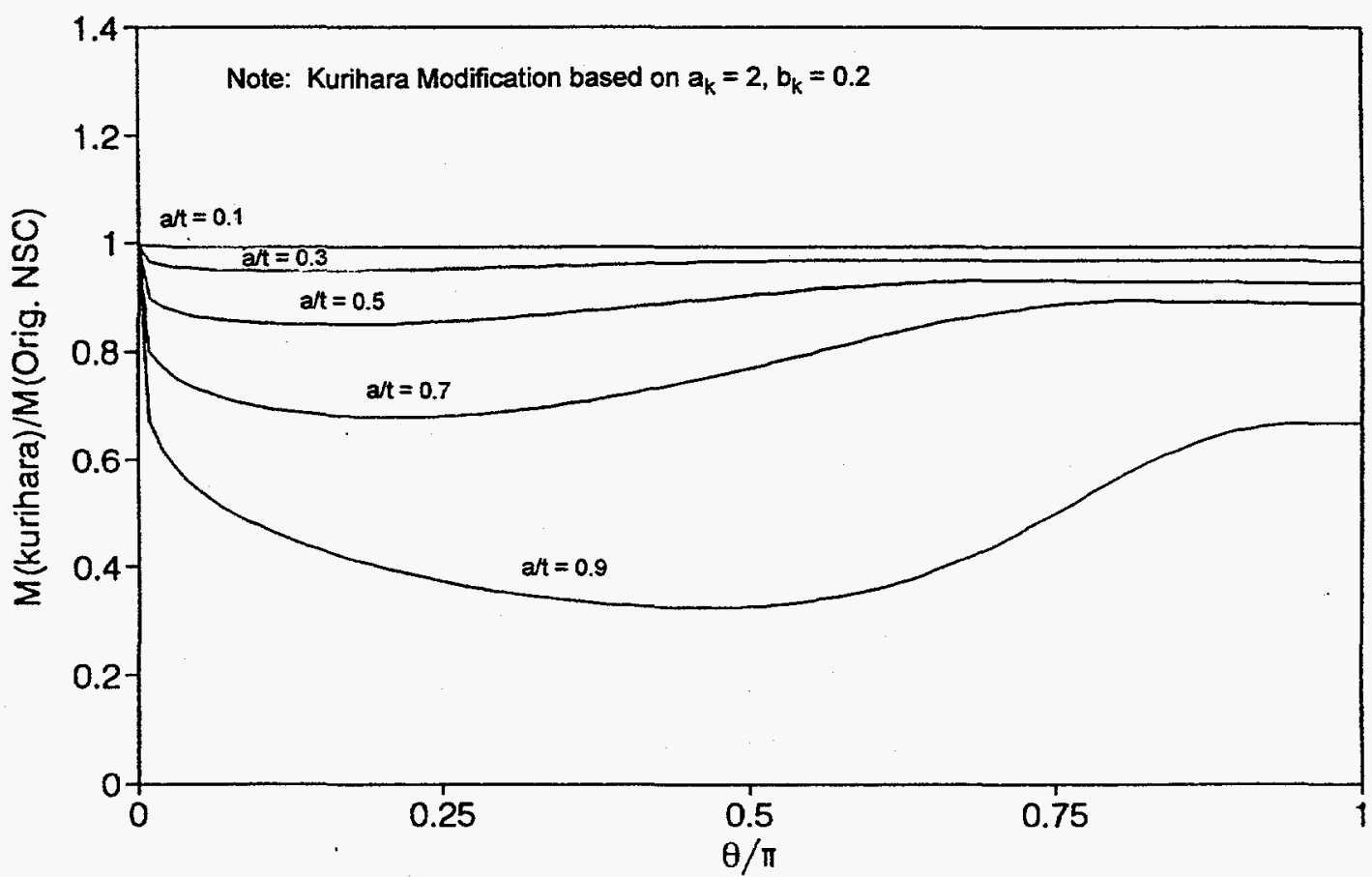

Figure 2.61 Comparison of original and Kurihara-modified Net-Section-Collapse equations 


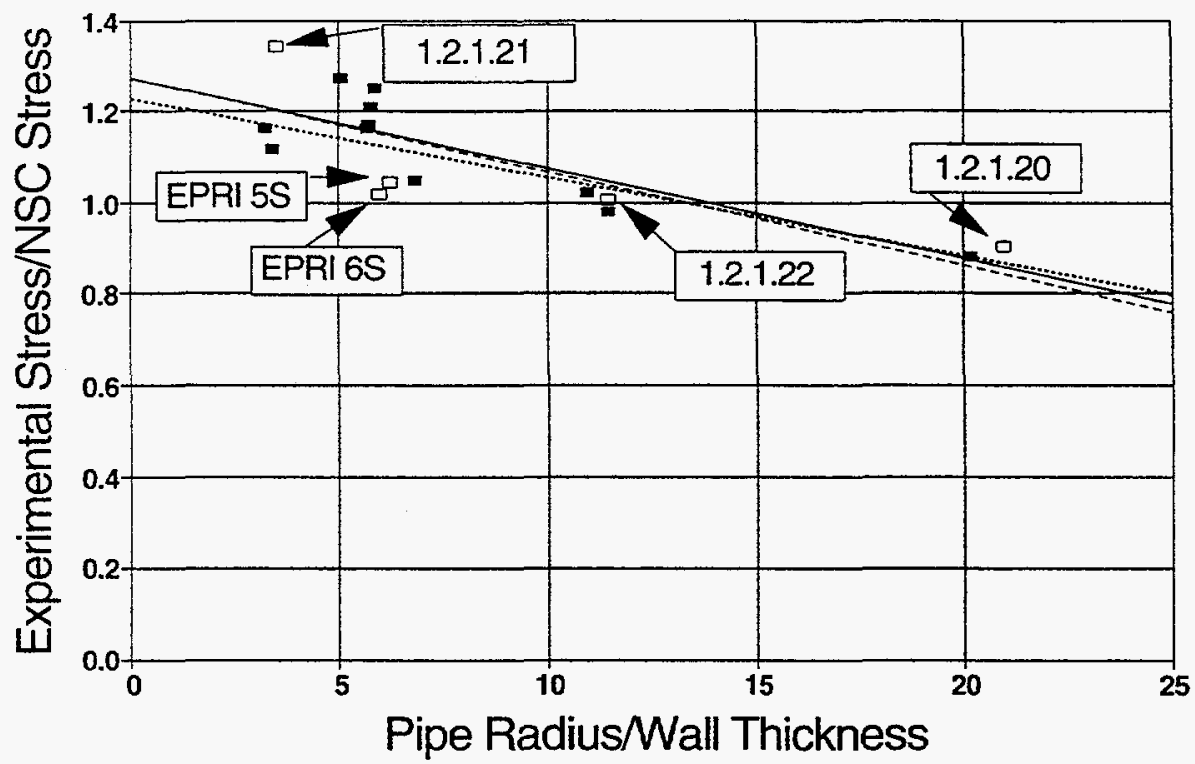

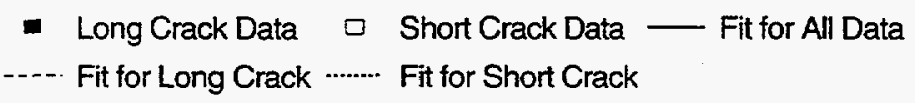

Figure 2.62 Plot of the ratio of experimental stress to predicted stress as a function of pipe radiusto-thickness ratio $\left(R_{m} / t\right)$

The correction on the Net-Section-Collapse equation they suggest is a function of the pipe $R / t$, where

$$
M_{n s c}=2 \sigma_{f} R_{m}^{2} t\left(2 \sin \beta-\frac{a}{t} \sin \theta\right) V_{R}
$$

and,

$$
V_{R}=1.257-0.01919\left(R_{m} / t\right)
$$

This equation was experimentally validated for pipe from $3.5<R_{m} / t<21$, and probably should not be used for very high $R / t$ pipe.

Elastic-Plastic Fracture Mechanics (EPFM) Analyses. There are fewer EPFM analyses for circumferential surface-cracked pipe than for through-wall-cracked pipe. Some of these are listed below, and more details on them can be found in the cited references.

The analyses that are able to predict crack initiation loads, maximum loads and load-displacement behavior by the use of a J-R curve are:

- Limited solutions from the original GE/EPRI method (Refs. 2.102, 2.119, and 2.136), 
- The SC.TNP thin-shell analysis, where the original analysis (SC.TNP1) from Reference 2.142 was further improved by FEM calibrations in Reference 2.13 (SC.TNP2),

- $\quad$ The SC.TKP thick-shell analysis, where the original analysis (SC.TKP1) from Reference 2.142 was further improved by FEM calibrations in Reference 2.13 (SC.TKP2),

- The SC.ENG1 and SC.ENG2 methods which were developed in Reference 2.13 as independent checks against the solutions that use the GE/EPRI h-functions. The SC.ENG1 uses the original Net-Section-Collapse equations within it, whereas the SC.ENG2 solution uses the Kuriharamodified Net-Section-Collapse solution.

The methods that can be used to predict loads at crack initiation as well as the maximum loads are:

- The R6 method (and various options) (Ref. 2.66), and

- The ASME Code Case N-494 (Ref. 2.122).

Methods that can predict only maximum loads are:

- $\quad$ ASME Section XI Appendix C and $\mathrm{H}$ for ferritic and austenitic pipe, respectively (Ref. 2.123), and

- The Battelle Dimensionless Plastic-Zone Parameter (DPZP) analysis (Ref. 2.20).

In addition, another type of EPFM analysis that is also used is one where the moment-rotation or loaddisplacement curves are integrated to calculate the fracture resistance of the material. This is referred to as an $\eta$-factor analysis. An $\eta$-factor analysis is used as part of the SC.TNP, SC.TKP, and.SC.ENG analysis methods.

GE/EPRI Method. The GE-EPRI method was one of the first J-estimation schemes developed. As noted earlier for circumferential through-wall cracks, the driving force is characterized in terms of the J-integral parameter where

$$
\mathrm{J}=\mathrm{J}_{\mathrm{e}}+\mathrm{J}_{\mathrm{p}}
$$

The $\mathrm{J}_{\mathrm{e}}$ term comes from the elastic solutions previously described in the LEFM section, and the $\mathrm{J}_{\mathrm{p}}$ term is a fully plastic term where

$$
J_{p}=\alpha_{o} \epsilon_{o} \sigma_{o}(t-a) h_{1}\left[M / M_{o}\right]^{(n+1)}
$$

where $\alpha_{0}, \epsilon_{0}, \sigma_{0}$, come from the Ramberg-Osgood fit to the material's stress-strain curve,

$$
\epsilon / \epsilon_{\mathrm{o}}=\sigma / \sigma_{\mathrm{o}}+\alpha\left(\sigma / \sigma_{\mathrm{o}}\right)^{\mathrm{n}}
$$


and

$$
\begin{aligned}
& \alpha_{\mathrm{o}}=\text { Ramberg-Osgood parameter } \\
& \sigma_{\mathrm{o}}=\text { Reference stress, typically the yield strength }\left(\sigma_{\mathrm{y}}\right) \\
& \epsilon_{\mathrm{o}}=\text { Reference strain, } \sigma_{\mathrm{o}} / \mathrm{E} \\
& \mathrm{E}=\text { Elastic modulus } \\
& \mathbf{n}=\text { strain-hardening exponent } \\
& \mathrm{t}=\text { pipe thickness } \\
& \mathrm{a}=\text { surface crack depth } \\
& \mathrm{M}=\text { applied moment } \\
& \mathrm{M}_{\mathrm{o}}=\text { moment corresponding to } \sigma_{\mathrm{o}} \text { in uncracked pipe. }
\end{aligned}
$$

The $h_{1}$ function is calculated from finite element analyses where it typically is a high value under elastic loading, and as plasticity occurs, then the $h_{1}$ value reaches a constant value, see Figure 2.63 , from Reference 2.14 for a circumferential through-wall crack. The value of $h_{1}$ for a circumferentially surfacecracked pipe is a function of the pipe $R_{m} / t, \theta / \pi, n$, and type of loading.

Just as $\mathrm{J}$ can be defined using the above process, the crack-mouth opening displacement, crack-tip opening displacement, pipe rotation, and axial extension of the pipe can also be determined. For instance, the pipe rotation, $\phi$, can be described as

$$
\phi=\phi_{\mathrm{e}}+\phi_{\mathrm{p}}
$$

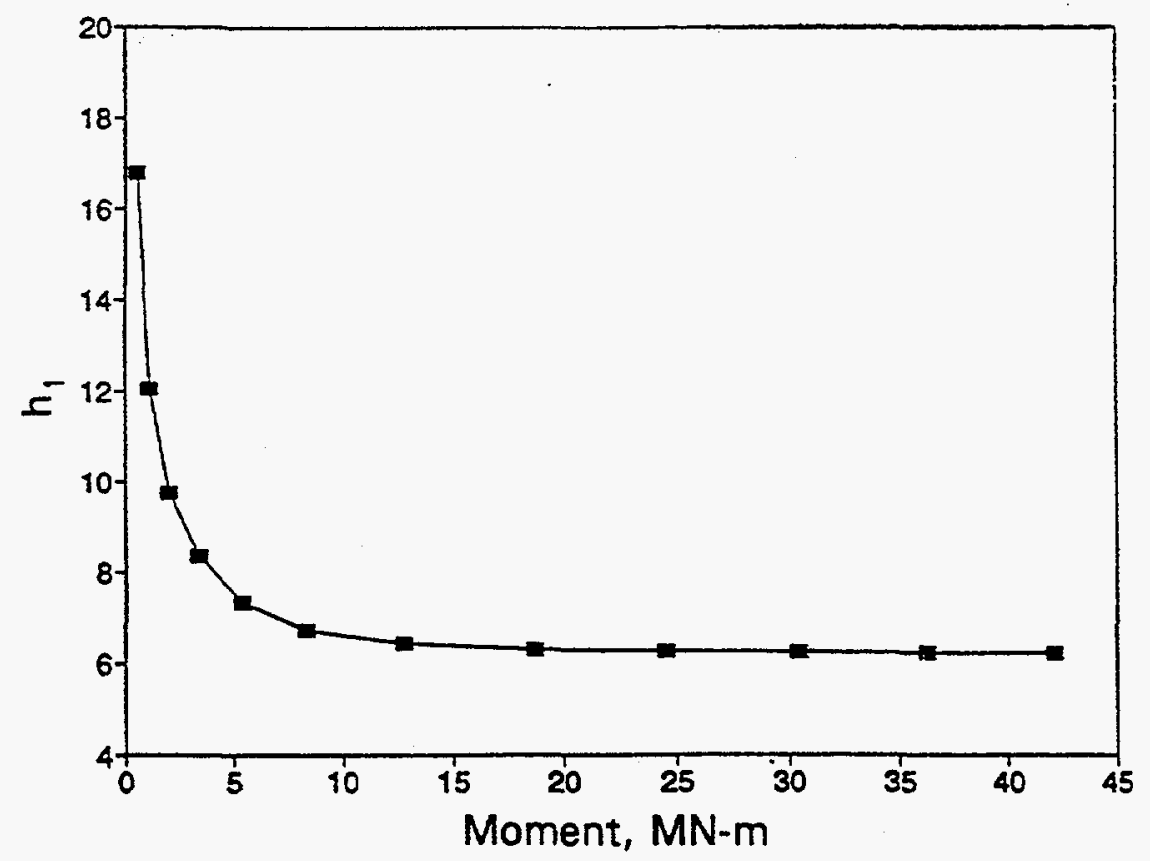

Figure 2.63 Plasticity function $h_{1}$ (ABAQUS - Solid Element Results) for pipe under bending with $R_{m} / t=10, n=3$, and $\theta / \pi=0.0625$ 
Furthermore, these rotations can be due either to the crack (c) or the uncracked pipe (nc), i.e.,

$$
\begin{aligned}
& \phi_{\mathrm{e}}=\phi_{\mathrm{e}}^{\mathrm{c}}+\phi_{\mathrm{e}}^{\mathrm{nc}} \\
& \phi_{\mathrm{p}}=\phi_{\mathrm{p}}{ }^{\mathrm{c}}+\phi_{\mathrm{p}}^{\mathrm{nc}}
\end{aligned}
$$

where for the cracked pipe rotations,

$$
\begin{aligned}
& \phi_{\mathrm{e}}^{\mathrm{c}}=4\left(\mathrm{R}_{\mathrm{m}} / \mathrm{I}\right) \mathrm{V}_{3} \mathrm{M} / \mathrm{E} \\
& \phi_{\mathrm{p}}^{\mathrm{c}}=\alpha \epsilon_{\mathrm{o}} \mathrm{h}_{4}\left[\mathrm{M} / \mathrm{M}_{\mathrm{o}}\right]^{\mathrm{n}}
\end{aligned}
$$

The $V_{3}$ and $h_{4}$ values are influence functions calculated from finite element analyses and are a function of the pipe $R_{m} / t, \theta / \pi$, and type of loading. The $h_{4}$ value is also a function of the material strain-hardening exponent, $\mathrm{n}$.

For surface-cracked pipe, the only functions developed initially were those for 360-degree circumferential cracks under pure tensile loading (Ref. 2.102). Functions for finite-length cracks were subsequently determined for certain limited cases (Refs. 2.119 and 2.136). For a circumferential surface-cracked pipe, these functions depend on the following parameters; $R / t$, type of loading (i.e., tension, bending, or combined loading), circumferential crack length $(\theta / \pi)$, surface crack depth $(\mathrm{a} / \mathrm{t})$, and strain-hardening exponent. To fully cover this range of parameters, about 1,500 finite element analyses would be needed to develop all of the influence functions. Even with the powerful line-spring element tool for performing such analyses more efficiently (Ref. 2.137), there are not enough existing solutions for this work to be generally applicable.

Errors introduced in extrapolating the existing influence functions, which were developed originally for tension loads, to bending loads, as well as the errors introduced in using the functions for finite-length surface cracks limit the usefulness of these solutions. Additional solutions for deep 360-degree surfacecracked pipe functions were developed in Reference 2.13, and there are some additional finite-length circumferential surface-cracked pipe solutions in Reference 2.139 , but these do not even begin to address the full range of practical interest.

SC.TNP and SC.TKP Analyses. Realizing the limitations of the GE/EPRI method, efforts were undertaken in the Degraded Piping Program - Phase II (Ref. 2.28) to develop a J-estimation scheme for surface-cracked pipe similar to those that existed for through-wall-cracked pipes. Using existing GE/EPRI functions (Ref. 2.119) for a 360-degree surface-cracked pipe under tension loading, a complete scheme was developed to predict the applied $J$, and the moment-rotation behavior of a pipe under pure bending with a finite-length circumferential surface crack. Tables of the dimensionless functions required for the numerical computations were presented in Reference 2.142 and incorporated into two computer programs called SC.TNP and SC.TKP. SC.TNP involved thin-walled approximations in the analysis. The SC.TKP methods used the thick-shell net-section-collapse equations within it, which was found to need a much 
different flow stress than the thin-shell solution in order to accurately predict pipe experiments. Predictions using SC.TNP analysis agreed better with experimental data than those using the SC.TKP method (Ref. 2.142).

There were three limitations in the SC.TNP and SC.TKP analysis methodology. First, this method (Ref. 2.142 ) involves a "disposable" length parameter " $L$ ", the distance from the plane of the crack to that cross section where the stresses are assumed to become uniform. This parameter was not well defined and the results varied with the choice of "L". Also, the GE/EPRI functions for deeply cracked specimens were not available. Another limitation was that the method was applicable only for pure bending loads. Combined loads could not be handled by this method. However, it must be noted that this was the only $\mathrm{J}$-estimation scheme available for finite-length surface-cracked pipes under bending loads.

Two improvements to the original SC.TNP and SC.TKP analyses were undertaken as discussed in Reference 2.13. First, 360-degree-surface cracked pipe solutions for deeper cracks were incorporated. Secondly, the disposable " $L$ " parameter was calibrated by numerous finite element solutions. The original SC.TNP and SC.TKP solutions were thereafter called SC.TNP1 and SC.TKP1. For these methods, "L" was assumed equal to the well thickness of the pipe, " $t$ ".

The finite-element solutions showed that the "L" parameter was related to the material's strain-hardening exponent. Slight modifications to the computational procedures were made, wherein the SC.TNP analysis was modified so that

$$
L=(n-1) t
$$

and in the SC.TKP analysis

$$
L=[(n+1) /(2 n+1)] t
$$

Again, only limited FEM analyses were conducted to validate this " $L$ " parameter relationship, so some care should be taken in using this method. The modified analyses were called SC.TNP2 and SC.TKP2.

The result of comparing these analyses to FEM analyses showed the following:

- The SC.TNP2 and SC.TKP2 analyses are now very close to the moment versus applied J curves from the FEM analyses, at least for the cases that were examined (R/t of $10, n$ from 3 to 10 , and a limited number of crack geometries).

- The SC.TNP1 analysis gave much lower applied J values than the FEM analysis, and hence for a given J-R curve would predict higher loads.

- The SC.TKP1 analysis gave much larger applied J values than the FEM analyses, and hence for a given J-R curve would predict much lower loads.

The above analyses were for internal surface cracks. Parallel analyses for external surface cracks were developed and were included in a Fortran-based computer program called EXTCRK7 at Battelle (Appendix B of Reference 2.13). 
Comparison to experiment data for the internal circumferential surface-cracked pipe experiments are reviewed later.

SC.ENG Method. Since very few EPFM solutions existed for finite-length circumferential surfacecracked pipe, the SC.ENG method was developed in Reference 2.13 as an independent method. This method is similar in nature to the LBB.ENG circumferential through-wall-cracked pipe solution described earlier in Section 2.3.2.1, also see Reference 2.121.

This method of analysis involves determining the moment-rotation behavior based on:

- classical deformation theory of plasticity,

- a constitutive law characterized by the Ramberg-Osgood model, and

- an equivalence criterion incorporating a reduced thickness analogy for simulating system compliance due to the presence of a crack in a pipe.

The method is general in the sense that it may be applied in the complete range between elastic and fully plastic conditions.

The elastic solution uses the F-functions that are in ASME Section XI Appendix H, and hence, are subject to any inaccuracies in those solutions that were discussed earlier, i.e., the limited applicability to $R / t$ values larger than 10.

The plastic solution uses the reduced thickness analogy used in Reference 2.121. From this, a momentrotation curve is predicted as a function of the material strain-hardening exponent. This relationship depends on the limit-load equations used. One version of SC.ENG uses the original Net-Section-Collapse solutions (Ref. 2.118) for a thin-shell pipe. This solution was referred to as SC.ENG1. The other solution, called SC.ENG2, used the Kurihara (Ref. 2.143) modification of the Net-Section-Collapse analysis.

For both of these solutions, the moment versus rotation due to the crack curves are integrated to determine the $J$ values at any given moment or displacement. The integration procedure is the $\eta$-factor solution for a circumferentially surface-cracked pipe in bending. The Pan $\eta$-factor solution (Ref. 2.145), is used in this step of the analysis. The $\eta$-factor analysis procedures are described in a later section of this report.

Battelle Dimensionless Plastic-Zone Parameter (DPZP) Analysis. The DPZP analysis is a semiempirical procedure developed at Battelle (Refs. 2.20 and 2.28) and is used to analyze surface-cracked pipe under bending and tension loads. In this analysis, a fully plastic condition is assumed to occur when the Irwin plastic-zone size equals the remaining tensile ligament length. The ratio of the maximum predicted stress to the calculated NSC stress is expressed as a function of the DPZP as

$$
\frac{\sigma}{\sigma_{\text {nsc }}}=\left(\frac{2}{\pi}\right) \operatorname{arc~cos} \exp ^{\left[-c_{1}(D P Z P)\right]}
$$

where

$$
D P Z P=2 E J_{i} /\left(\pi^{2} \sigma_{f}^{2} D\right)
$$




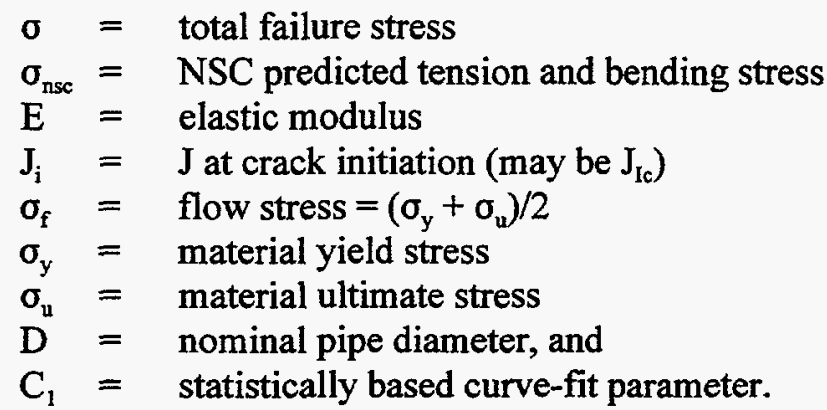

For surface-cracked pipe fracture data, the parameter $C_{1}$ for a best fit through the data is 34 . For a 95percent-confidence-level fit of the data, the parameter $C_{1}$ is 8.9. A plot of $\sigma / \sigma_{\text {nsc }}$ versus DPZP, Figure 2.64, shows the most recent surface-cracked pipe data.

The primary limitation of this method includes the empiricism involved in determining $C_{1}$, the statistically based parameter. This parameter is based on pipe tests with large surface cracks, and hence may not accurately predict short surface-crack behavior. Also, moment-rotation behavior of the pipe is not predicted. Major advantages are that it is relatively simple to use and inherently accounts for throughthickness toughness anisotropy, constraint effects on toughness, and pipe ovalization effects.

R6 Method (and Various Options). The latest version of the R6 methodology is the Revision 3 document (Ref. 2.66). This methodology involves putting the analysis in the format of a failure analysis diagram or FAD curve, see Figure 2:65. The FAD curve approach involves an interpolation between linear elastic and limit-load solutions. In this methodology, there are three options for doing the interpolation:

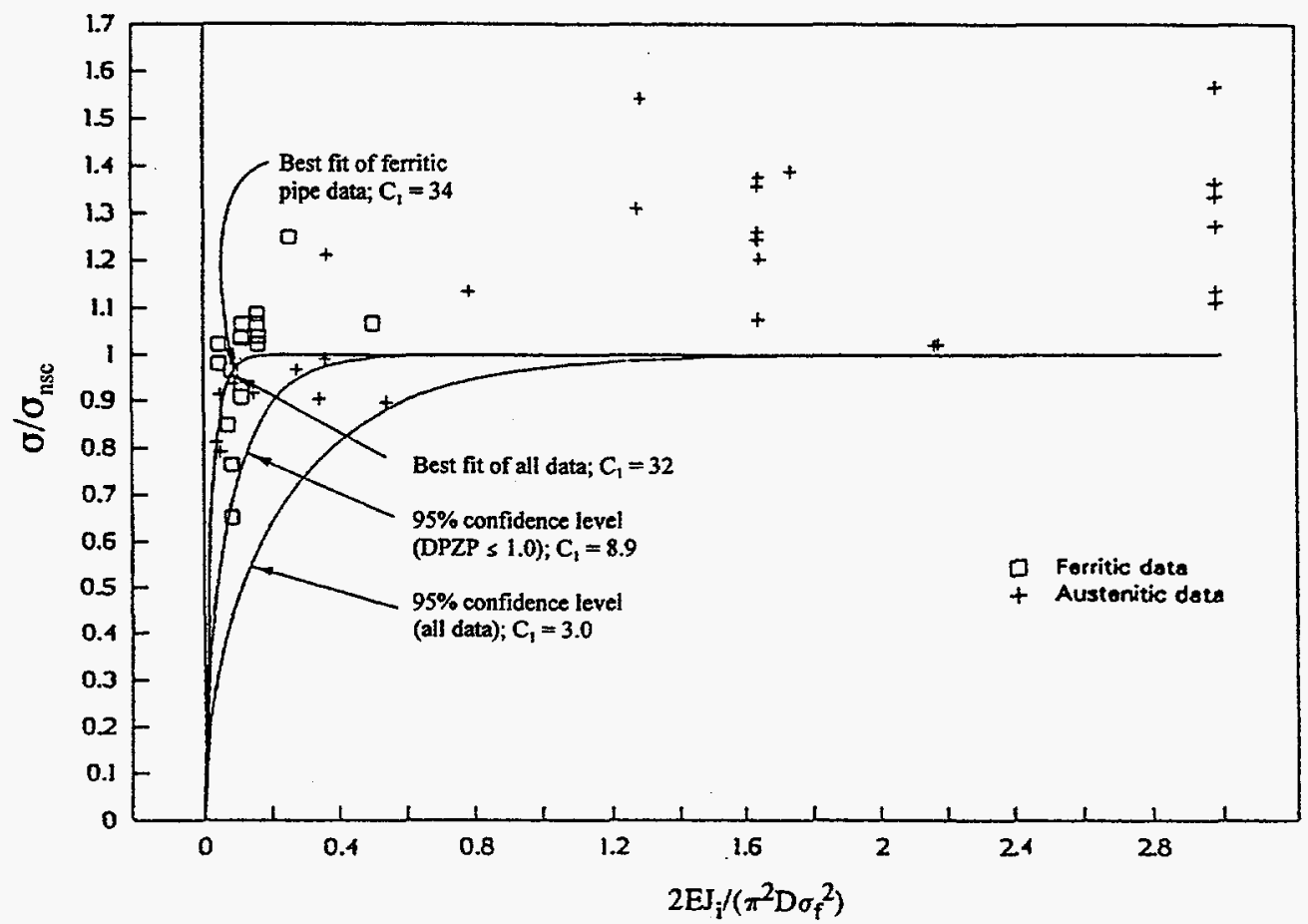

Figure 2.64 Fit of DPZP equation through pipe test data 


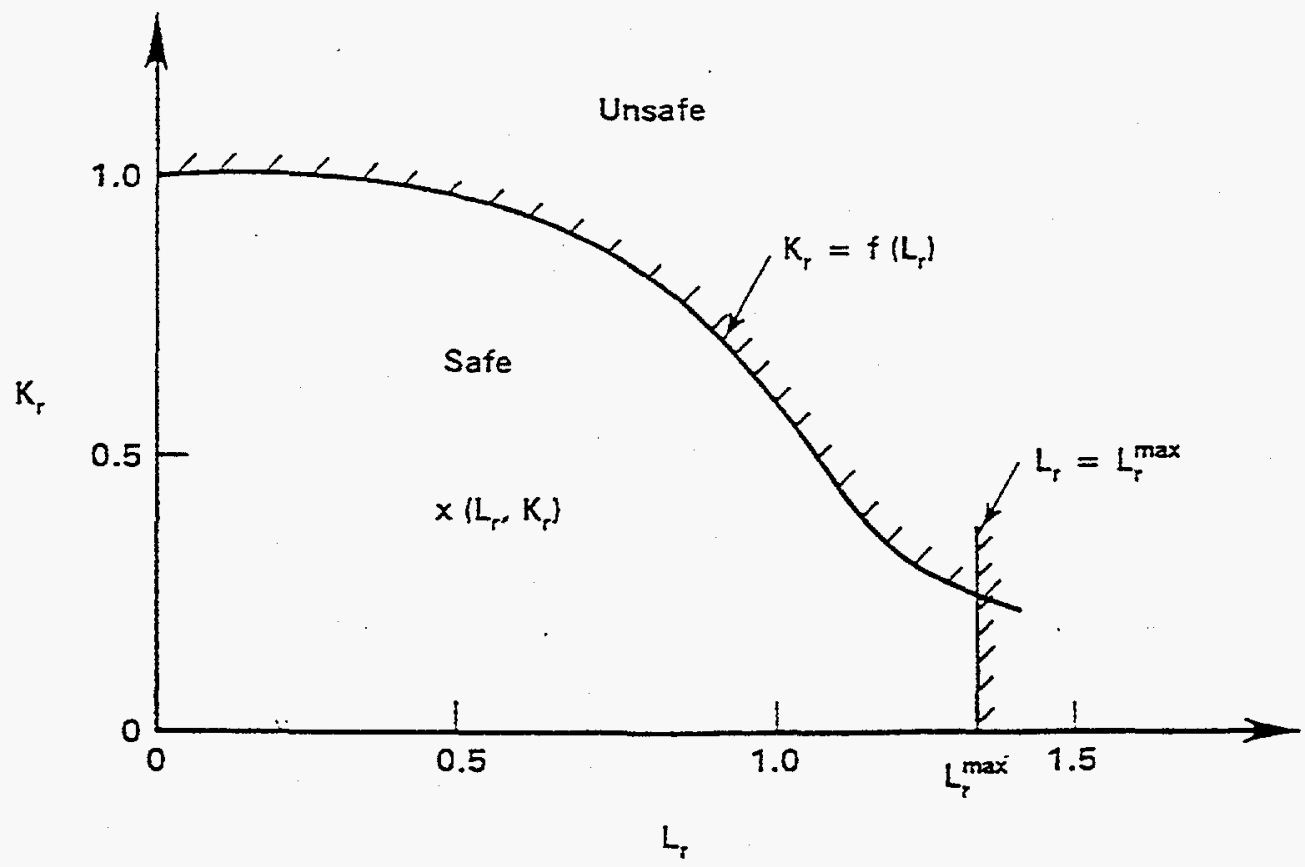

Figure 2.65 R6 failure assessment diagram

- Option 1 involves a fixed-shape FAD curve that is independent of the structural geometry or material strain-hardening.

- Option 2 involves using the material stress-strain curve, but geometrical effects are not included.

- Option 3 allows the user to put any more detailed analysis procedure in the format of a FAD curve to account for material and geometry effects, if so desired. Hence, any other analysis method could be considered an R6 Option 3 analysis.

In this report, analysis validations were done only with the R6 Option 1 method. It should be noted, that since there are numerous LEFM F-function solutions and modifications to the limit-load solutions, it is quite possible to have different organizations give "R6" analysis that don't exactly agree. This was found to occur in IPIRG-1 program round robin efforts (Ref. 2.67).

There are several subtle aspects that one has to be aware of in conducting an R6 analysis. For instance, under combined pressure and bending loads, the $S_{r}$ axis should use the combined stresses. The cut-off stress for combined loading is not simply the ratio of the flow stress to the yield strength, as might be assumed for pure bending or pure tension loading. In order to have consistency with the Net-SectionCollapse stress analysis, the cutoff stress $\left(\mathrm{L}_{\mathrm{r}}^{\max }\right)$ needs to be defined as

$$
L_{x}^{\max }=\frac{\text { Net-Section-Collapse total stress using } \sigma_{f}}{\text { Net-Section-Collapse total stress using } \sigma_{y}}
$$


This is necessary since in the Net-Section-Collapse equation, there is a $\beta$ term (see Equation 2-67) where the axial stress from pressure loading is related to the flow stress.

A limitation of the R6 methodology is that it only predicts the failure load and not pipe rotations, COD, etc.

Code Case N-494 Approach. This code case analysis procedure is a failure assessment diagram (FAD) curve methodology developed by Bloom (Refs. 2.146 to 2.147). This is basically an R6 Option 3 method that invokes the GE/EPRI solutions cast into a FAD curve format. The shape of the FAD curve is material- and geometry-dependent, and comes from a few circumferential surface-cracked pipe solutions available in Reference 2.136.

While safety factors may be specified externally in this method, it suffers from the same limitations as those for the R6 approach, namely that rotations and/or displacements are not predicted. This method is currently being incorporated into the ASME Section XI flaw evaluation procedures by using a lower bounding FAD curve shape (Ref. 2.122 ).

Recent work using experimental and finite element analyses compared with the analytical FAD curve showed that the effect of the pipe $R / t$ ratio can be important in developing the FAD curve shape for pipes in bending (Ref. 2.139). From that work, the most recent version of this Code Case (N-494-3) was limited to pipe with $R / t$ values less than 15 .

ASME Section XI Article IWB-3640 and Appendix C for Austenitic Pipe. In this analysis, the NetSection-Collapse analysis was slightly modified and used as the technical basis for the ASME Section XI Article IWB-3640 and Appendix C analyses for flaws in austenitic piping (Ref. 2.131). This method, however, accounts for low-toughness flux welds only in an approximate manner. For pure bending, there are three differences between Net-Section-Collapse analysis and the IWB-3640 analysis.

The first difference in the limit-load solutions is the definition of flow stress. The IWB-3640 analysis uses a definition of $3 \mathrm{~S}_{\mathrm{m}}$ for austenitic steels, where $\mathrm{S}_{\mathrm{m}}$ is defined as the material design stress intensity and is tabulated as a function of temperature for a wide variety of material grades and types in Section II of the ASME Code.

The second difference is that Article IWB-3640 is applicable only for Class 1 piping for which Section III requires that the bending stress be calculated at the outer fiber with the exact expression for the moment of inertia of an uncracked pipe. In the original Net-Section-Collapse analysis, the bending stress is defined using thin-wall shell equations and is similar to the ASME Code for a Class 2 piping stress analysis. The limit-load solution is allowed to be used on austenitic base metals (wrought stainless steels, Inconels, and cast stainless steels with ferrite numbers less than 20) and inert gas welds (TIG or MIG).

The third and most important difference is that the IWB-3640 analysis requires that a correction factor, known as the $Z$-factor, be used in reducing the predicted maximum allowable stress by $1 / Z$. The $Z$-factor is introduced to account for the lower toughness of flux welds, i.e., SAW and SMAW. From circumferential through-wall-cracked pipe analyses conducted using the original GE/EPRI estimation scheme, it was proposed that the Z-factors be expressed as (Ref. 2.131): 


$$
\begin{aligned}
& Z=1.15[1+0.013(D-4)] \text { for austenitic SMAW cracks } \\
& Z=1.15[1+0.013(D-4)] \text { for austenitic SAW cracks }
\end{aligned}
$$

where $\mathrm{D}$ is the nominal diameter, in inches. To develop the $\mathrm{Z}$-factors, a crack length to maximize the $\mathrm{Z}$ value was used. That was done as a conservative measure since a sufficient number of surface-cracked pipe solutions did not exist at that time.

When the method was originally developed, if the diameter of the pipe was less than $610 \mathrm{~mm}$ ( $24 \mathrm{inch}$ ), then the Code required the user to use $D=24$ inches in Equation 2-84 to account for uncertainties in the thermal expansion stresses for small-diameter pipes. This restriction was eliminated in the 1996 edition of the ASME Code. This methodology was also included in NRC Draft Standard Review Plan 3.6.3 for LBB. Further details on this method can be found in Reference 2.131 .

ASME Section XI Article IWB-3650 and Appendix $H$ for Ferritic Pipe. The procedures embodied in Article IWB-3650, and Appendix $\mathrm{H}$ of Section XI, for evaluating flaws in ferritic piping are fundamentally similar to those embodied in Article IWB-3640 and Appendix C for austenitic piping. Both sets of procedures incorporate a limit-load analysis based on the Net-Section-Collapse analysis for evaluating flaws in high toughness materials. Both also incorporate an approximate elastic-plastic analysis, using a stress multiplier (i.e., a Z-factor), for evaluating flaws in lower toughness materials, such as welds. However, only the ferritic pipe criteria include a linear-elastic analysis for evaluating flaws in very low toughness materials. This linear-elastic analysis, and the transition to EPFM, has not been heavily scrutinized, since the application is for Class 1 pipe that operates at high temperatures.

The procedures in Appendix $\mathrm{H}$ for the ferritic pipe criteria include a screening criterion for assessing which type of analysis procedure, i.e., limit-load, elastic-plastic, or linear-elastic, is most appropriate. This is a FAD curve based approach. If the screening criterion parameter, which is the ratio of the stress intensity factor normalized by the material toughness $\left(\mathrm{K}_{\mathrm{r}}\right)$ to the sum of the primary bending and expansion stresses normalized by the bending stress at limit-load $\left(\mathrm{S}_{\mathrm{r}}\right)$, is less than 0.2 , then the limit-load analysis should be used. For all intents and purposes the limit-load analysis in Appendix $\mathrm{H}$ for ferritic piping is the same as the limit-load analysis in Appendix $C$ with the exception that the flow stress in Appendix $C$ is defined as $3 \mathrm{~S}_{\mathrm{m}}$, while the flow stress in Appendix $\mathrm{H}$ is defined as the average of the material's yield and ultimate strengths, if those values are known. If the yield and ultimate strengths are unknown, then the flow stress is defined as $2.4 \mathrm{~S}_{\mathrm{m}}$.

If the screening criterion parameter is greater than or equal to 0.2 but less than 1.8 , then the elastic-plastic analysis should be used. The elastic-plastic analysis in Appendix $\mathrm{H}$ for ferritic piping is the same as the elastic-plastic analysis in Appendix $\mathrm{C}$ (for austenitic piping) except for the differences in the flow stress definition noted above. Different formulations for the elastic-plastic stress and load multiplier, $Z$, are also used in the two appendices. The Z-factor formulation for the ferritic piping cases are as follows:

$$
Z=1.2[1+0.021 \text { A(NPS }-4)]
$$




$$
\mathrm{Z}=1.2[1+0.021 \mathrm{~A}(\mathrm{NPS}-4)]
$$

for Material Category 1 (seamless or welded wrought carbon steel pipe and pipe fittings that have a specified minimum yield strength not greater than $275 \mathrm{MPa}(40 \mathrm{ksi})$ and welds made with E7015, E7016, or E7018 electrodes in the as-welded or post-weld heat treated condition), and

$$
\mathrm{Z}=1.35[1+0.184 \mathrm{~A}(\mathrm{NPS}-4)]
$$

for Material Category 2 (all other ferritic shielded-metal-arc and submerged-arc welds with specified minimum tensile strengths not greater than $550 \mathrm{MPa}(80 \mathrm{ksi})$ in the as-welded or post-weld heat treat condition).

The "A" in these $Z$-factor expressions is a function of the pipe $R_{m} / t$ ratio and is given by

$$
A=\left[0.125\left(R_{m} / t\right)-0.25\right]^{0.25} \text { for } 5 \leq R_{m} / t \leq 10
$$

or

$$
A=\left[0.4\left(R_{m} / t\right)-3.0\right]^{0.25} \text { for } 10<R_{m} / t \leq 20
$$

The term NPS in the above expressions is the nominal pipe size, in inches, and the terms " $R_{m}$ " and " $t$ " denote the mean pipe radius and pipe wall thickness, respectively.

Finally, if the screening criterion parameter is greater than or equal to 1.8 then the linear-elastic fracture mechanics analysis must be used. This analysis stipulates that the applied stress intensity factor, $\mathrm{K}_{\mathrm{l}}$, must be less than the plane stress fracture toughness of the material. The plane stress fracture toughness is expressed in terms of the parameter $\mathrm{J}_{\mathrm{lc}}$ and the elastic modulus, $\mathrm{E}$, using the expression

$$
\mathrm{K}_{\mathrm{Ic}}=\left\{\mathrm{J}_{\mathrm{Ic}} \mathrm{E} /\left(1-v^{2}\right)\right\}^{0.5}
$$

For this analysis, it is assumed that ductile crack extension does not occur prior to fracture. Further details of these analyses can be found in Reference 2.132. Although both ASME criteria are used for surfacecracked pipe flaw evaluations, they were originally developed from through-wall-cracked pipe J-estimation schemes. These methods are reviewed in detail in the short surface-cracked pipe report from the Short Cracks in Piping and Piping Welds Program (Ref. 2.13).

Improvements to ASME Code Criteria. Since the implementation of the current flaw evaluation criteria into the ASME Code, user experience and additional technical developments suggest that several 
modifications are desired or needed. Possible improvements that could be made in future revisions to the Code are documented in Reference 2.13 and elsewhere. These aspects are summarized below:

- There is a desire to combine the austenitic and ferritic pipe criteria and expand them to Class 2 and 3 piping. The current piping rules are only for Class 1 piping. This desire comes from changes in the ASME Section XI inspection criteria where pipes, that have not been inspected before, are now being examined. In many cases, initial fabrication flaws are now being found. These flaws may not represent any challenge to the structural integrity of the piping, and in the reported cases there was no service flaw growth, but they now must be reconciled against the Code allowable flaw sizes.

By redefining the flow stress in terms of the average of yield and ultimate strengths (rather than as a function of $\mathrm{S}_{\mathrm{m}}$ ), combining the austenitic and ferritic pipe criteria can be accomplished easily and extended to other classes of pipe.

To develop an acceptable definition of flow stress, a statistical analysis of various possible flow stress definitions for ferritic and austenitic steels was performed using the CIRCUMCK database (Ref. 2.133). The CIRCUMCK database has over 800 circumferentially cracked pipe experiments in it from international sources in the oil, gas, and nuclear industries. To make the determination of flow stress values for ferritic and austenitic pipe, the flow stress was calculated from the pipe experiments and then compared with tensile tests values. Flow stress $\left(\sigma_{f}\right)$ was defined as either:

- $\sigma_{f}=\mathrm{C}_{\mathrm{a}}\left(\sigma_{\mathrm{y}}+\sigma_{\mathrm{u}}\right) / 2$

- $\sigma_{\mathrm{f}}=\mathrm{C}_{\mathrm{b}} \mathrm{S}_{\mathrm{m}}($ Code $)$

- $\quad \sigma_{\mathrm{f}}=\mathrm{C}_{\mathrm{c}} \mathrm{S}_{\mathrm{m}}$ (actual)

- $\quad \sigma_{\mathrm{f}}=\mathrm{C}_{\mathrm{d}}\left(\mathrm{S}_{\mathrm{y}}+\mathrm{S}_{\mathrm{u}}\right) / 2$

where,

$\begin{array}{ll}\mathrm{C}_{\mathrm{a}}, \mathrm{C}_{\mathrm{b}}, \mathrm{C}_{\mathrm{c}}, \mathrm{C}_{\mathrm{d}}= & \begin{array}{l}\text { Constants determined from pipe test database and Net-Section- } \\ \text { Collapse equations, }\end{array} \\ \mathrm{S}_{\mathrm{m}}(\text { Code }) & =\begin{array}{l}\text { Design stress from Section II of ASME Code at the pipe test } \\ \text { temperature, }\end{array} \\ \mathrm{S}_{\mathrm{m}} \text { (actual) } & =\begin{array}{l}\text { Design stress calculated from actual properties at the pipe test } \\ \text { temperature, }\end{array} \\ \sigma_{\mathrm{y}} & =\text { Actual yield strength at the pipe test temperature, } \\ \sigma_{\mathrm{u}} & =\text { Actual ultimate strength at the pipe test temperature, } \\ \mathrm{S}_{\mathrm{y}} & \text { ASME Section II Code yield strength at the pipe test temperature, } \\ \mathrm{S}_{\mathrm{u}} & =\text { and }\end{array}$

The experimental database was exercised and only data from circumferential surface-cracked pipe experiments were used. Furthermore, the analysis eliminated data where limit-load should not occur. Only nuclear piping steels were also used in this evaluation, i.e., higher strength oil and gas or low alloy steel piping was not used. The database was also divided into austenitic and ferritic pipe steels. 
Prior to conducting the statistical analysis, the following general observations were made:

- Since the original Net-Section-Collapse equations do not work well for deep flaws (see earlier discussion), these data were not used. This result showed why the ASME cut off of $a / t>0.75$ is needed.

- The $S_{m}$ (Code) definition of flow stress was more conservative at room temperature than at high temperature.

High $R_{m} / t$ pipe have lower "flow stresses," and low $R_{m} / t$ pipe have higher "flow stresses". The Net-Section-Collapse equation should have an $R_{m} / t$ dependance or limit as recently implemented into Code Case N-494-3. (See earlier discussion in the limit-load section in this report.)

The statistical results for determining the flow stress from the pipe experiments and comparison with tensile test properties are given in Table 2.7 .

Table 2.7 $C_{a, b, c, d}$ mean $(\mu)$ and standard deviation $(\sigma)$ values (number of experiments)

\begin{tabular}{|c|c|c|c|c|c|c|}
\hline $\begin{array}{c}\text { Flow Stress } \\
\text { Definition }\end{array}$ & $\boldsymbol{\mu}$ - Aust. & $\mu$ - Ferr. & o-Aust. & o-Ferr. & $\underset{\text { Aust. }}{\operatorname{COV} \text { or } \sigma / \mu}$ & $\begin{array}{c}\text { COV or } \sigma / \mu \\
\text { Ferr. }\end{array}$ \\
\hline $\mathrm{C}_{\mathrm{a}} *\left(\sigma_{\mathrm{y}}+\sigma_{\mathrm{u}}\right) / 2$ & $1.052(46)$ & $1.041(45)$ & 0.188 & 0.112 & 0.179 & 0.108 \\
\hline $\mathrm{C}_{\mathrm{b}} * \mathrm{~S}_{\mathrm{m}}($ Code $)$ & $3.213(46)$ & $3.04 \quad(45)$ & 0.655 & 0.326 & 0.204 & 0.107 \\
\hline $\mathrm{C}_{\mathrm{c}}{ }^{*} \mathrm{~S}_{\mathrm{m}}$ (Actual) & $2.907(46)$ & $2.483(45)$ & 0.653 & 0.420 & 0.225 & 0.169 \\
\hline $\mathrm{C}_{\mathrm{d}}{ }^{*}\left(\mathrm{~S}_{\mathrm{y}}+\mathrm{S}_{\mathrm{u}}\right) / 2$ & $1.321(46)$ & $1.248(45)$ & 0.269 & 0.151 & 0.204 & 0.121 \\
\hline
\end{tabular}

Conclusions from this study showed that:

(i) Mean flow stress definition for austenitics and ferritics is about the same when using either the $C_{a} *\left(\sigma_{y}+\sigma_{u}\right) / 2, C_{b} * S_{m}($ Code $)$, or $C_{d} *\left(S_{y}+S_{u}\right) / 2$ definitions, where $\mathrm{C}_{\mathrm{a}}=1, \mathrm{C}_{\mathrm{b}}=3.0$, and $\mathrm{C}_{\mathrm{d}}=1.25$.

(ii) There was a significant difference between austenitics and ferritics using the $\mathrm{S}_{\mathrm{m}}$ (Actual) definition.

(iii) The coefficient of variance - COV (mean divided by the standard deviation) was: - $\quad$ about 0.2 for austenitics for all definitions (20-percent of the mean)

- $\quad$ about 0.1 for ferritics for all definitions (10-percent of the mean), except the $\mathrm{S}_{\mathrm{m}}$ (Actual) COV, which was 17-percent of the mean.

The result of this investigation was recently reported to the ASME Working Group on Pipe Flaw Evaluation, and in the future, the flow stress definition in the ASME Section XI criteria will probably be changed to $1.25\left(\mathrm{~S}_{\mathrm{y}}+\mathrm{S}_{\mathrm{u}}\right) / 2$ or $\left(\sigma_{\mathrm{y}}+\sigma_{\mathrm{u}}\right) / 2$ for both austenitic and ferritic pipe.

- The Appendix $\mathrm{H}$ procedure has a step change in allowable stresses from limit-load to EPFM analysis procedures and also from EPFM to LEFM procedures. A smooth transition between the 
given in Reference 2.13, but an important aspect worth mentioning here is that this same correlation can be put in terms of Charpy plateau energy (CVP) where,

$$
Z=\pi /\left\{2 \arccos \left[\mathrm{e}^{-1.52 \mathrm{C}_{1} \mathrm{E} \mathrm{CvP}_{/}\left(\mathrm{D \sigma}_{\mathrm{f}}^{2}\right)}\right]\right\}
$$

where in this equation,

$$
\begin{array}{ll}
\mathrm{E} & =\text { Elastic modulus, } \mathrm{ksi} \\
\mathrm{D} & =\text { Pipe diameter, inch } \\
\mathrm{\sigma}_{\mathrm{f}} & =\text { Flow stress, } \mathrm{ksi} \\
\mathrm{CVP} & =\text { Full-size Charpy plateau energy, } \mathrm{ft}-\mathrm{lb} \\
\mathrm{C}_{1} & =34 \text { for a mean curve, and } \\
\mathrm{C}_{1} & =10 \text { for the } 95 \text {-percent-confidence curve. }
\end{array}
$$

Figure 2.66 shows an example of the Z-factors calculated using this approach. Note how the Z-factor approaches 1.0 (limit-load) as the Charpy Plateau energy increases, and that these Z-factors are significantly lower than the existing ferritic Z-factors.

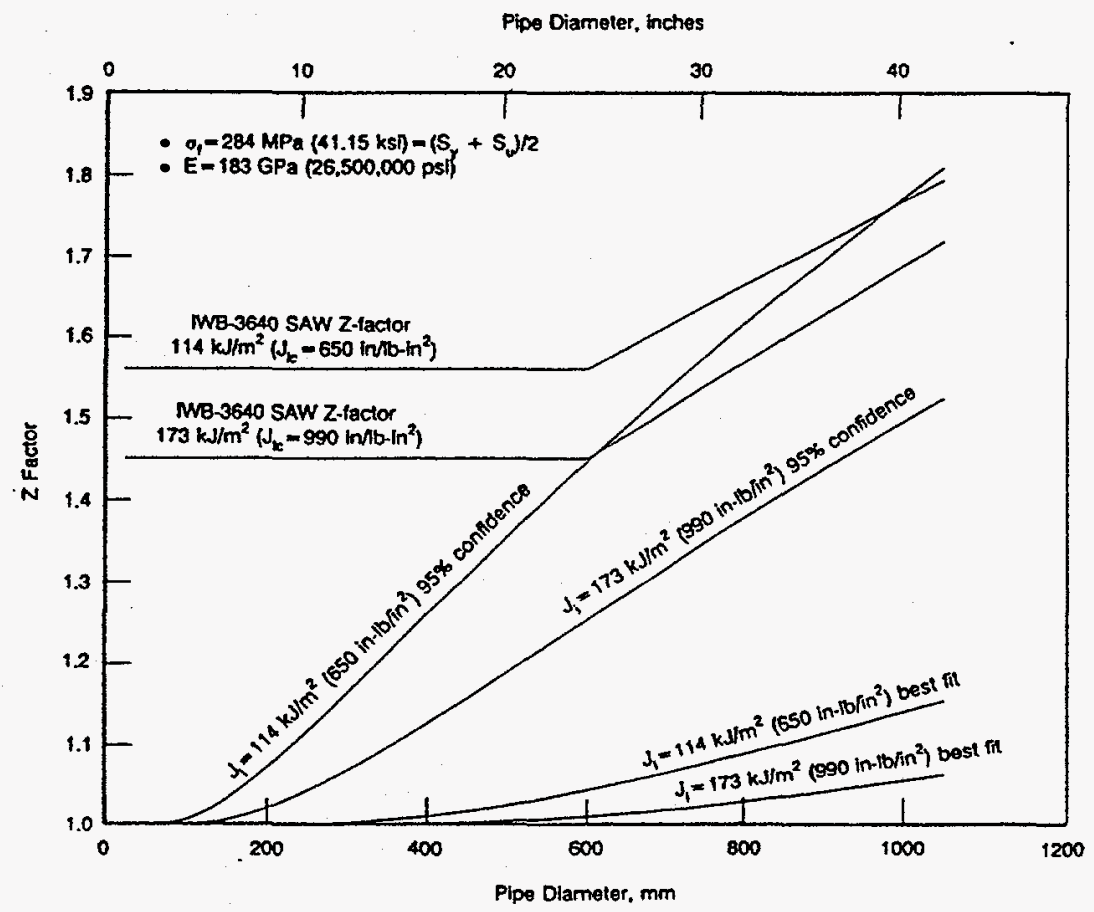

Figure 2.66 Comparison of Z-factors from DPZP analysis with ASME IWB-3640 analysis using $\sigma_{f}=\left(S_{y}+S_{u}\right) / 2$

There have been some reported cases in Section XI meetings where for the Appendix $\mathrm{H}$ ferritic piping criteria, the allowable stresses for EPFM were said to be lower than those using LEFM analysis. A small sensitivity study of this possibility was made at Battelle, but no such cases could 
- There have been some reported cases in Section XI meetings where for the Appendix $\mathrm{H}$ ferritic piping criteria, the allowable stresses for EPFM were said to be lower than those using LEFM analysis. A small sensitivity study of this possibility was made at Battelle, but no such cases could be found. What was found was that sometimes when using the default LEFM toughness value, the screening criterion incorrectly put the user in the EPFM fracture analysis. Hence, the screening criterion in the LEFM-EPFM transition should be examined closer.

- The IPIRG-1 surface-cracked-pipe system experiments showed that if the stresses are below yield, such as may occur when evaluating large surface-flaw sizes, the thermal expansion $\left(\mathrm{P}_{\mathrm{e}}\right)$ stresses and seismic anchor motion (SAM) stresses contributed equally to fracture, even for flaws in TP304 stainless steel base metal (Ref. 2.148). Hence, the secondary stresses should be incorporated with a full safety factor for surface flaws that would fail below yield. This occurs since the crackopening displacement and pipe rotations due to the surface crack are small compared with the displacements of a typical pipe system. (See later discussion in pipe instability behavior.) This conclusion on treating the secondary stresses as a primary stress for large flaws is consistent with the "Local Overstrain" warning in ASME design stress rules in Section III Article NC-3672.6(b) and ANSI B31.1 Article 119.3.

There is probably some nonlinear transition for stresses above yield in the uncracked pipe where the secondary stresses become less important. This transition is thought to be due more to plasticity in the rest of the pipe loop limiting the elastic displacements from the secondary stresses than from the surface-crack plasticity. (This same concern exists for circumferential erosioncorrosion flaws.) This topic is discussed further in References 2.79 and 2.149.

- The treatment of aged cast stainless steels is not fully addressed, and there are no bimetal weld criteria. Criteria for these cases need to be developed. (See discussions in Sections 2.2.5.2 and 2.2.5.5.)

- Seismic loading can:

(1) cause low-cycle fatigue crack growth,

(2) reduce the J-R curve due to the cyclic loadings (Ref. 2.79), and

(3) increase the toughness of austenitic steels, but lower the toughness and strength of ferritic steels due to high loading rates.

The effect of seismic load-history effects on material properties was reviewed in Section 2.2.6 of this report. The Code currently does not consider any of these effects, and any changes should account for these effects in determining acceptable margins.

- There may be constraint and anisotropy effects for surface-cracked pipe that give a higher effective toughness than considered in the current flaw evaluation criteria (Ref. 2.150). Currently, the L-C oriented $C(T)$ specimen data are used. This orientation is for the circumferential through-wallcrack growth direction. Such toughness anisotropy should be accounted for in the criteria. (See discussion earlier in Section 2.2.5.4.)

- The flaw evaluation criteria consider constant depth surface flaws with the depth equal to the maximum depth over the entire length of the flaw. Real cracks seldom have a constant depth. The 
development of an equivalent flaw length criterion would be helpful. As an example, this was done in the Modified ANSI Standard B31G for axially oriented corrosion flaws in oil and gas pipelines (Ref. 2.98). Also see Reference 2.144 for a similar application to circumferential flaws.

- The Code Case N-494 method is limited to flaw lengths less than $\theta / \pi=0.5$, so the Appendix $C$ or $\mathrm{H}$ methods must be used for long cracks. Using the Appendix $\mathrm{C}$ and $\mathrm{H}$ default material properties in Code Case N-494-3 will give greater allowable stresses then using the Appendix C or $\mathrm{H}$ criteria, except for surface flaws approaching $a / t$ of 0.75 .

- Appendix $\mathrm{H}$ uses elastic $\mathrm{F}$-functions for determining stress intensity factors. As stated in Reference 2.138, these functions are valid for $R_{m} / t$ of 5 to 10 , but are used in the Code for $R_{m} / t$ of 5 to 20. There is considerable difference in the Code F-functions and finite element results for a surface-cracked pipe with an $R_{m} / t$ of 20.3 (Ref. 2.13). Hence, the F-function in Appendix $H$ should be corrected. A limit on the Code F-functions of $R_{m} / t<15$ was recently established in Code Case N-494-3 (Ref. 2.139).

- There are numerous Z-factor issues or improvements that need to be addressed:

(1) The ASME Section XI pipe flaw evaluation criteria cannot be reproduced using the same input as the technical basis documents. For the austenitic pipe Z-factor case, even the material property input were not traceable or appropriate. For example:

- The SAW J-R curve used was traced to being a SMAW J-R curve, although subsequent statistical analysis of austenitic SAW and SMAW J-R curves showed no differences for SAW and SMAW's (Ref. 2.37).

- The stress-strain curve used to develop the austenitic weld Z-factors appeared to be either the weld metal at $288 \mathrm{C}(550 \mathrm{~F})$ or the base metal at room temperature (Ref. 2.151).

Both of these stress-strain curves are much higher than the base metal stress-strain curve at $288 \mathrm{C}(550 \mathrm{~F})$ that should have been used.

- The trade-offs of using the nonconservative material properties and the conservative GE/EPRI estimation scheme resulted in austenitic SAW Z-factors that were reasonably accurate when compared with pipe test results (Ref. 2.8). In fact, the austenitic Z-factors are more accurate than the ferritic Z-factors (Ref. 2.13).

(2) It was found that when using Code Case N-494-2 analysis procedures to develop Z-factors for ferritic pipe SAW flaws, the Appendix-H Z-factors are higher than the Code Case $Z$-factors except at an $a / t=0.75$, see Figures $2.67 a, b$ and $c$. The Code Case $Z$-factors tend to increase with decreasing $\theta / \pi$, which is contrary to what is expected since elastic F-functions and fully plastic $h_{1}$ functions do not increase as $\theta / \pi$ goes to zero.

(3) In developing Z-factors for ferritic pipe SAW flaws using the SC.TNP1 J-estimation scheme, the $Z$-factors were found to be constant over a large range of flaw sizes, i.e., for $\theta / \pi$ values from 0.1 to 1.0 and a/t values from 0.3 to 0.75 , see Figure 2.68 (Ref. 2.13). For a/t values from 0.0 to 0.3 , it appears that the $Z$-factor could be linearly interpolated from the $a / t=0.3$ value to $\mathrm{a} Z$ of 1.0 for $a / t=0.0$. Likewise for $\theta / \pi$ from 0.0 to 0.1 , it appears that the $Z$-factor 


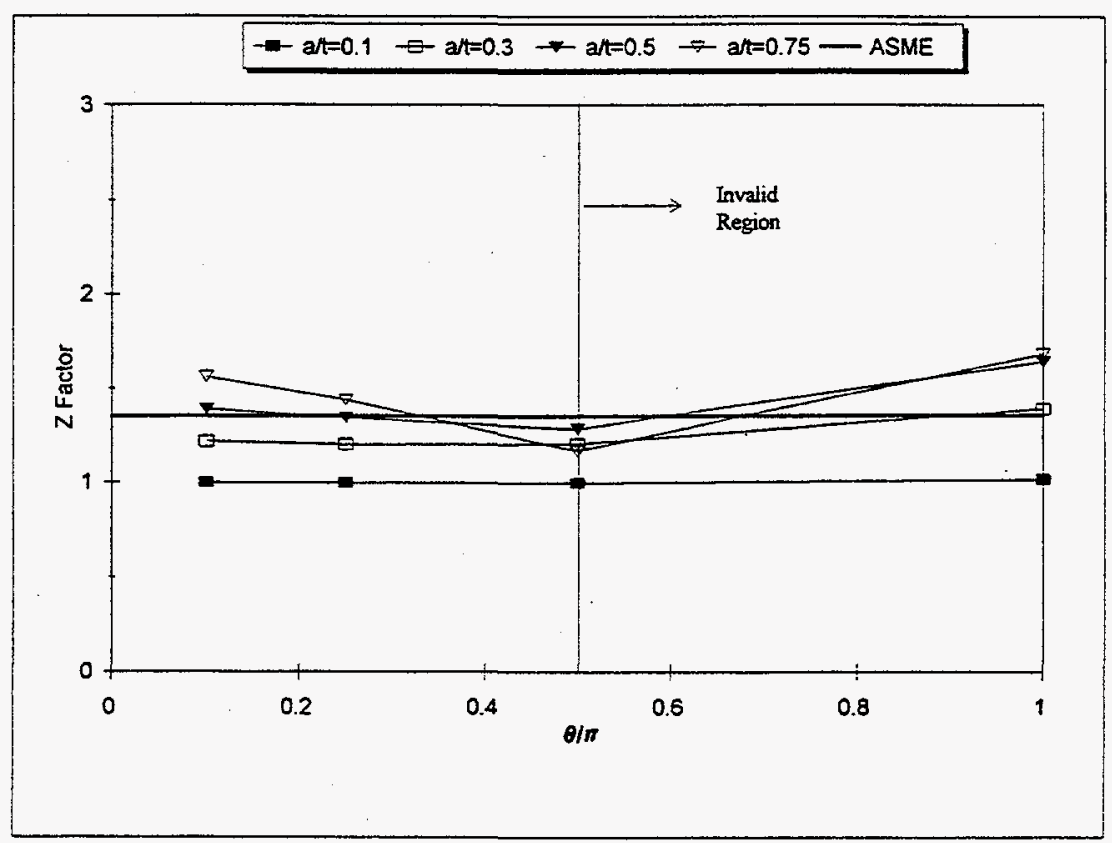

(a) 152-mm (4-inch) diameter pipe

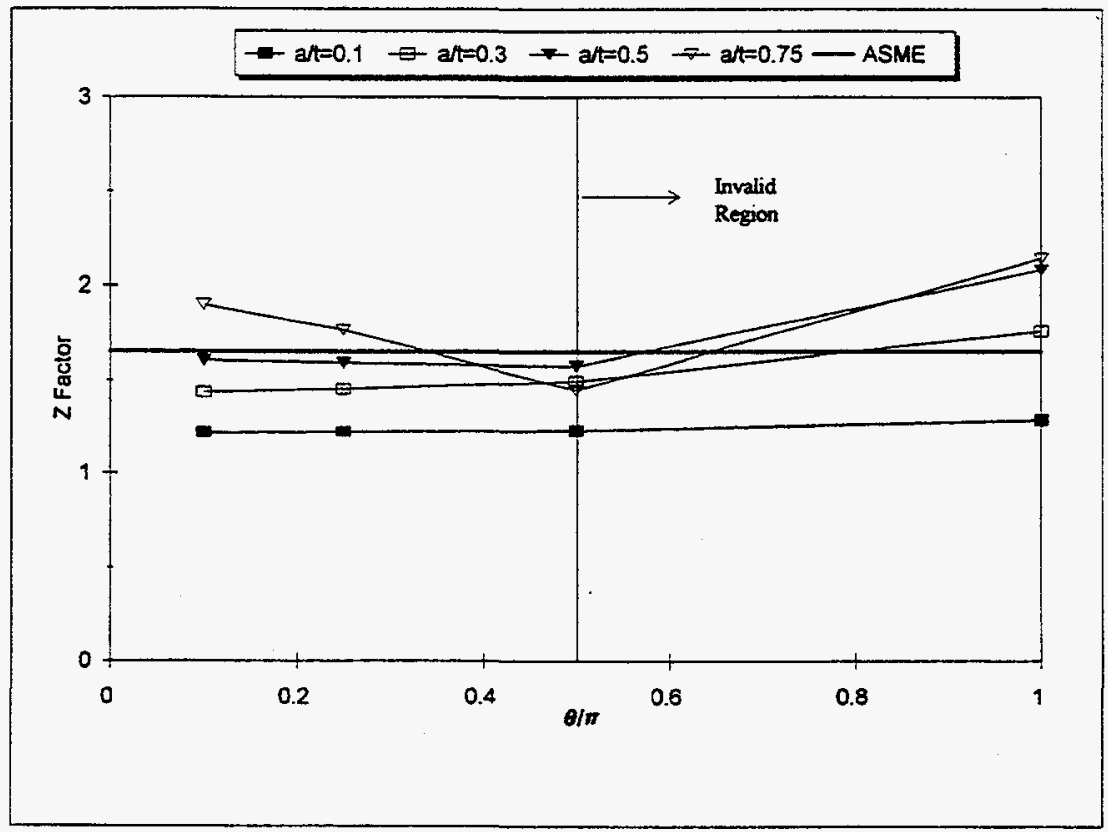

(b) 406-mm (16-inch) diameter pipe

Figure 2.67 Comparison of Z-factors from the Code Case N-494-2 analysis with the ASME Section XI Appendix $\mathrm{H}$ values 


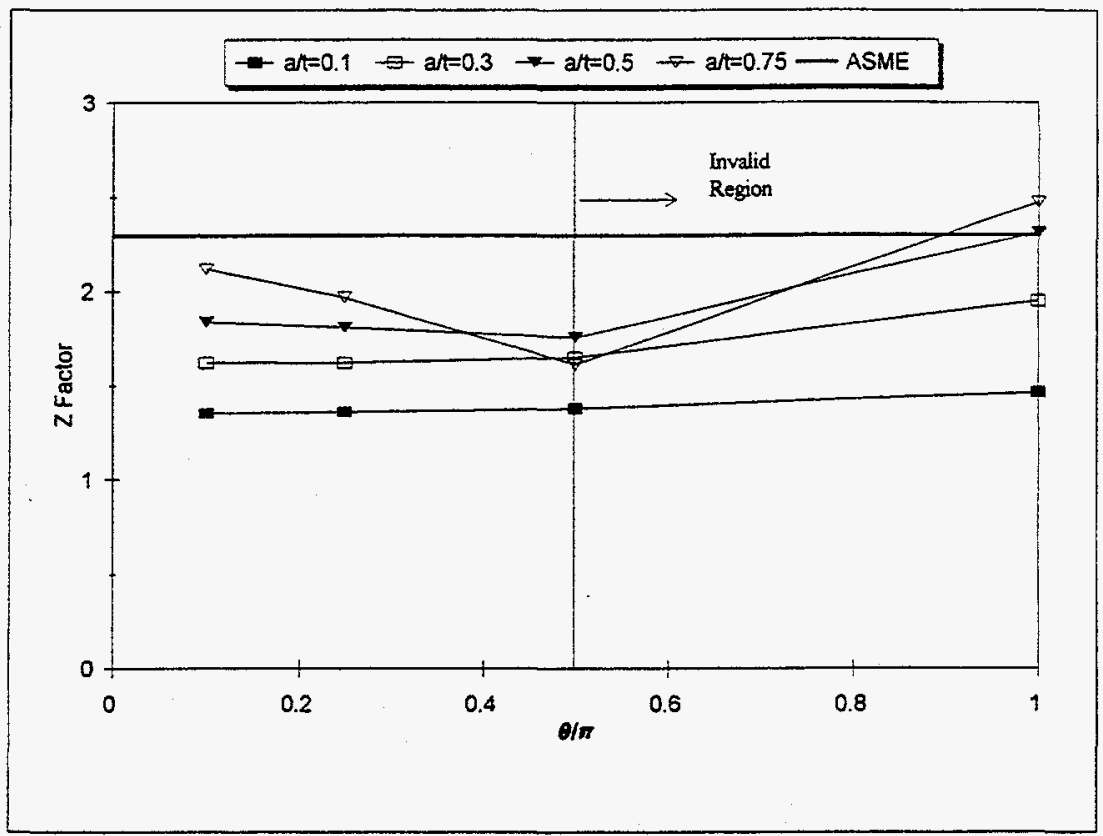

(c) 1,067-mm (42-inch) diameter pipe

Figure 2.67 (continued)

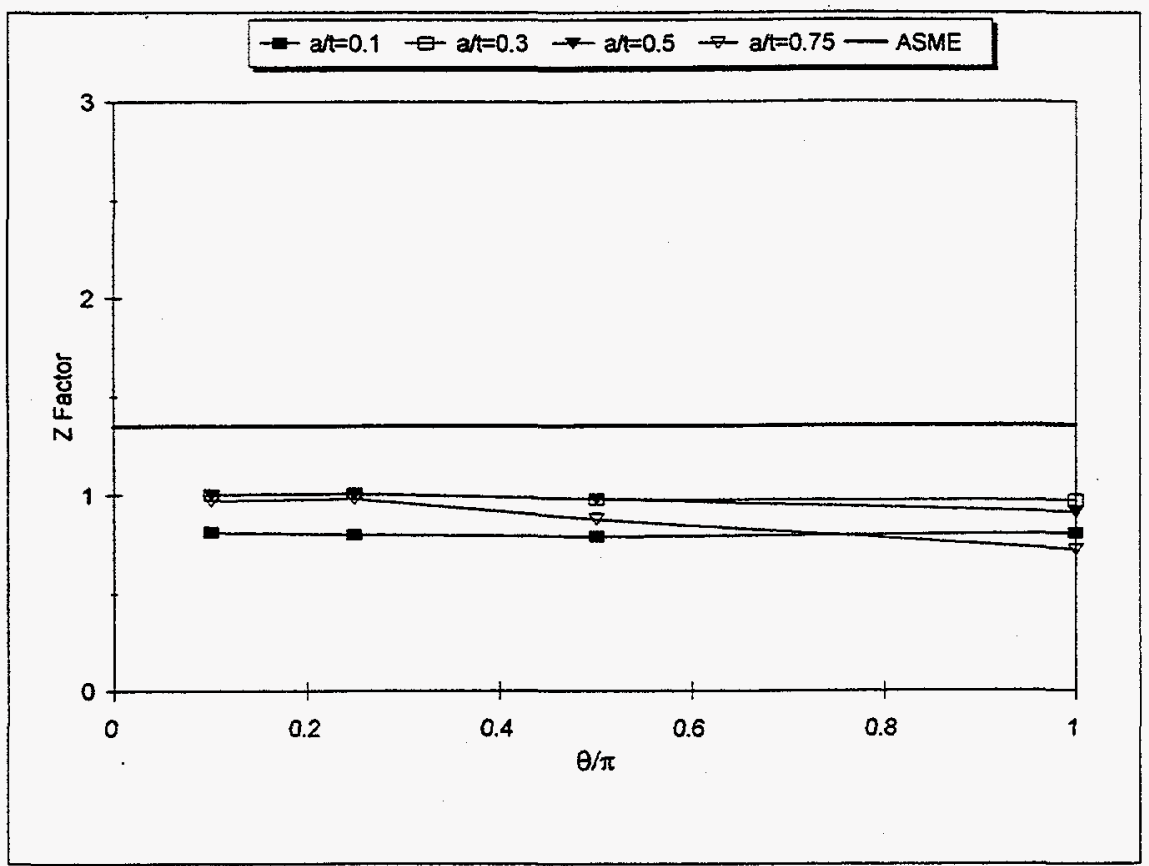

(a) 102-mm (4-inch) diameter pipe

Figure 2.68 Comparison of Z-factors from the SC.TNP1 analysis with the ASME Section XI Appendix $\mathrm{H}$ values 


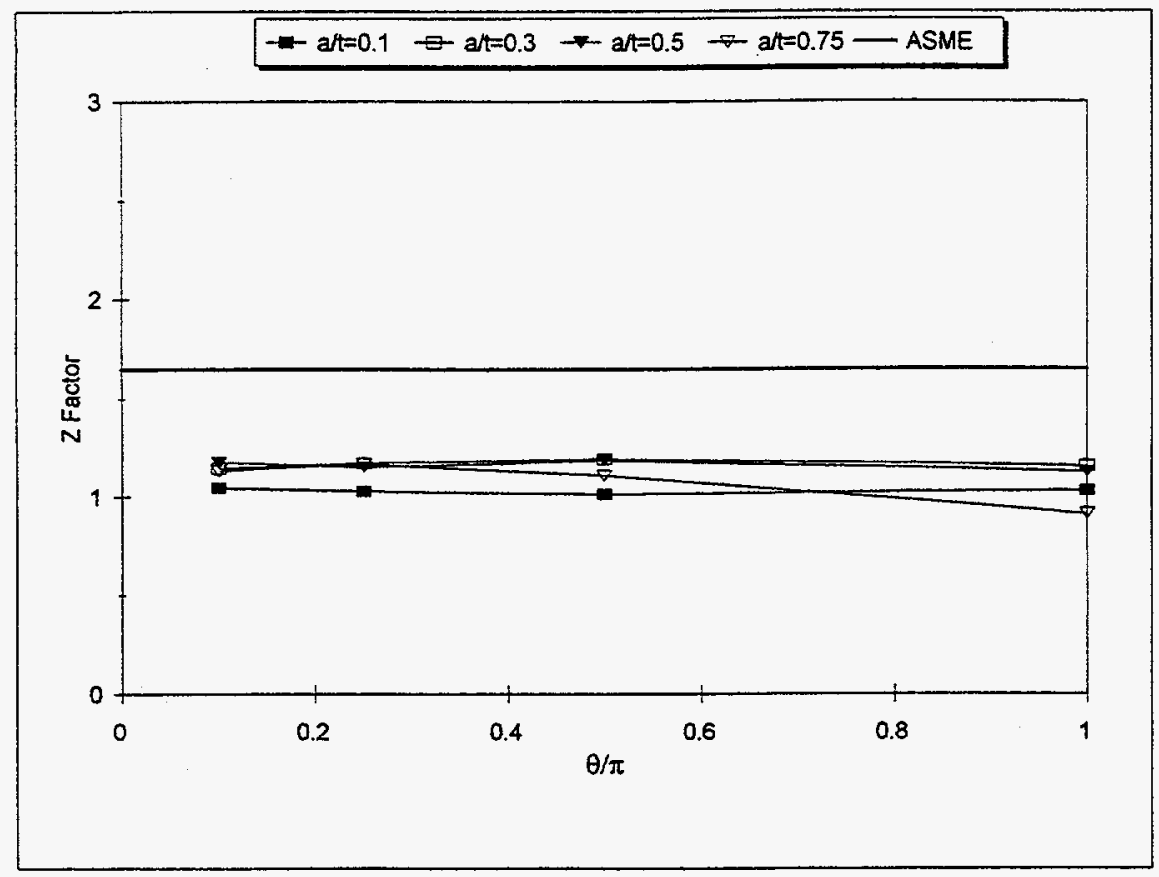

(b) 406-mm (16-inch) diameter pipe

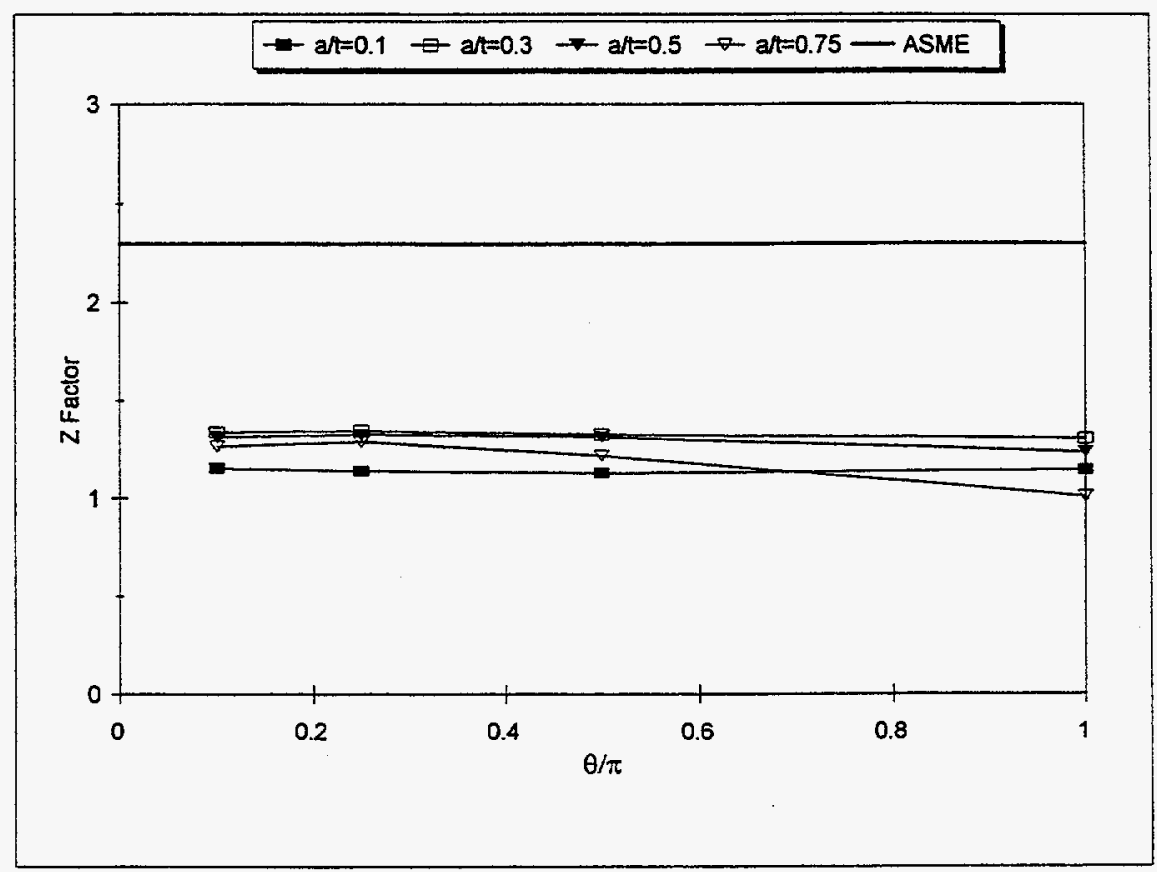

(c) 1,067-mm (42-inch) diameter pipe

Figure 2.68 (continued) 
could be linearly interpolated from the $\theta / \pi=0.1$ value to $Z$ of 1.0 at $\theta / \pi=0.0$. Figure 2.69 shows a comparison of the current ASME ferritic pipe SAW Z-factors and the values calculated from the SC.TNP1 analysis.

Z-factors for pipes with finite-length surface cracks were also developed using the SC.TNP1 procedure for carbon steel base metal, stainless steel weld, and stainless steel base metal cases (Ref. 2.152). The stainless steel base metal case used the J-R curve for a low sulfur stainless steel base metal, see discussion in Section 2.2.5.5 in this report. This result substantiated that the Net-Section-Collapse solution was appropriate to use for stainless steel pipe with diameters up to $1,016 \mathrm{~mm}$ (40 inches). However, if the stainless steel base metal has a lower toughness, as noted in Section 2.2.5.5 for higher sulfur compositions or as noted in Section 2.2.6.2 from cyclic loading, then a Z-factor approach may be needed to account for EPFM fracture.

It was very encouraging to see that the Z-factors from a surface-cracked pipe analysis were not highly variable with flaw size. This trend makes it relatively easy to codify an EPFM approach. This effect also explains why the DPZP approach worked reasonably well even though it did not account for flaw size dependancy in its Z-factor correction, i.e., Equation 2-89.

(4) The Z-factors calculated using two significantly different J-R curves from the same ferritic SAW (i.e., a $J_{M}-R$ curve and $J / T$ extrapolated $J_{D}-R$ curve) show little difference for surfacecracked pipe, see Figure 2.70. This contrasts with the through-wall-cracked pipe Z-factors calculated using the same J-R curves, which showed a significant difference. These two J-R curves did not differ until there was more than $5 \mathrm{~mm}(0.2 \mathrm{inch})$ of crack growth. Since the surface-cracked pipe analyses show little crack growth up to maximum load, this explains why the surface-cracked-pipe J-estimation schemes were insensitive to the different J-R curves.

(5) The SC.TNP1 based Z-factors could be combined with the Charpy energy/DPZP criterion to take advantage of the desirable features of both approaches. However, the effect of $R_{m} / t$ ratios needs to be examined further.

The motivation for all of these potential improvements to the Code is:

- To make the analyses consistent,

- To make the flaw evaluations easy to use,

- To expand the scope of the analyses, and

- To make certain that there is an adequate amount of conservatism in the analyses.

A good number of the items in the list presented above are related to $Z$-factors, the mechanism used to modify the Net-Section-Collapse analysis to account for EPFM behavior. In simple terms,

$$
\sigma_{\mathrm{nsc}}(\mathrm{a} / \mathrm{t}, \theta)=\mathrm{Z} \sigma_{\mathrm{EPFM}}
$$




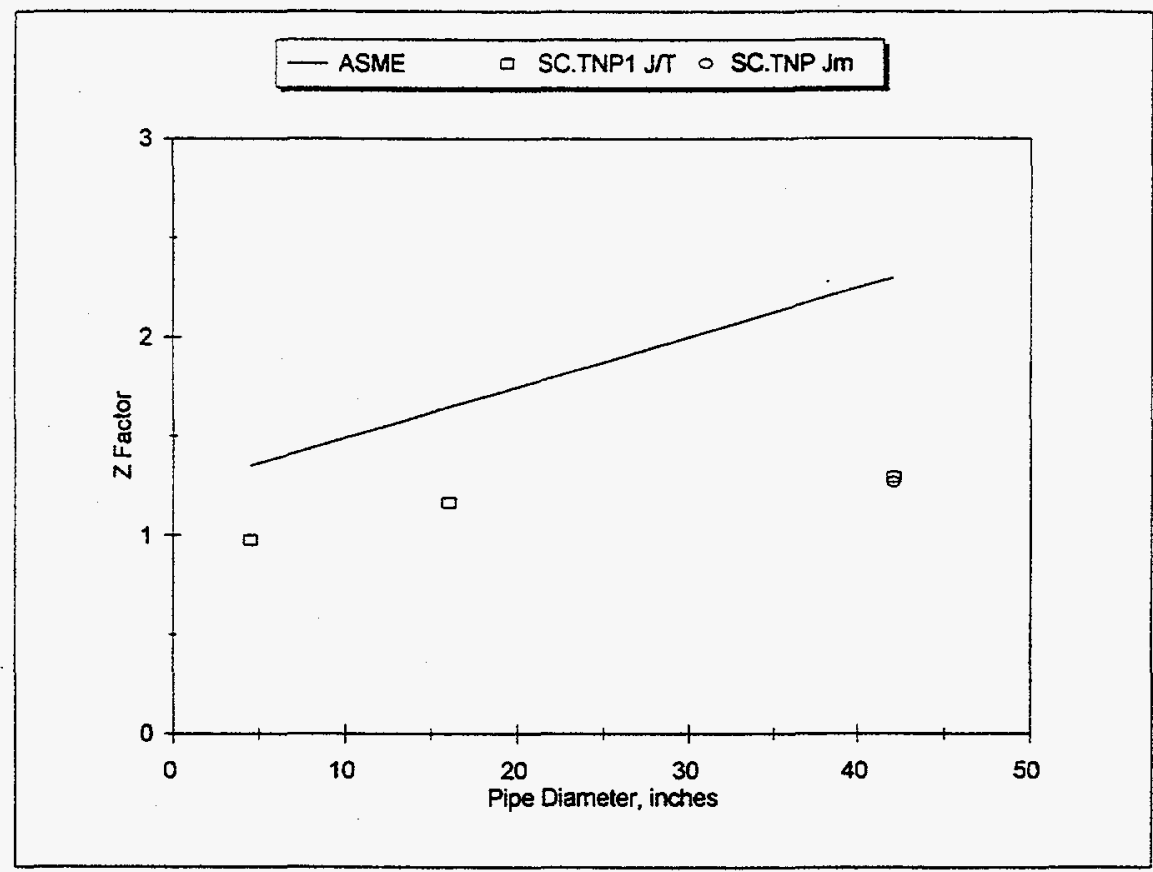

Figure 2.69 Comparison of the SC.TNP1 Z-factors with the ASME Appendix H equation Z-factor values versus pipe diameter using the $J / T$ extrapolated $J_{D}-R$ curve

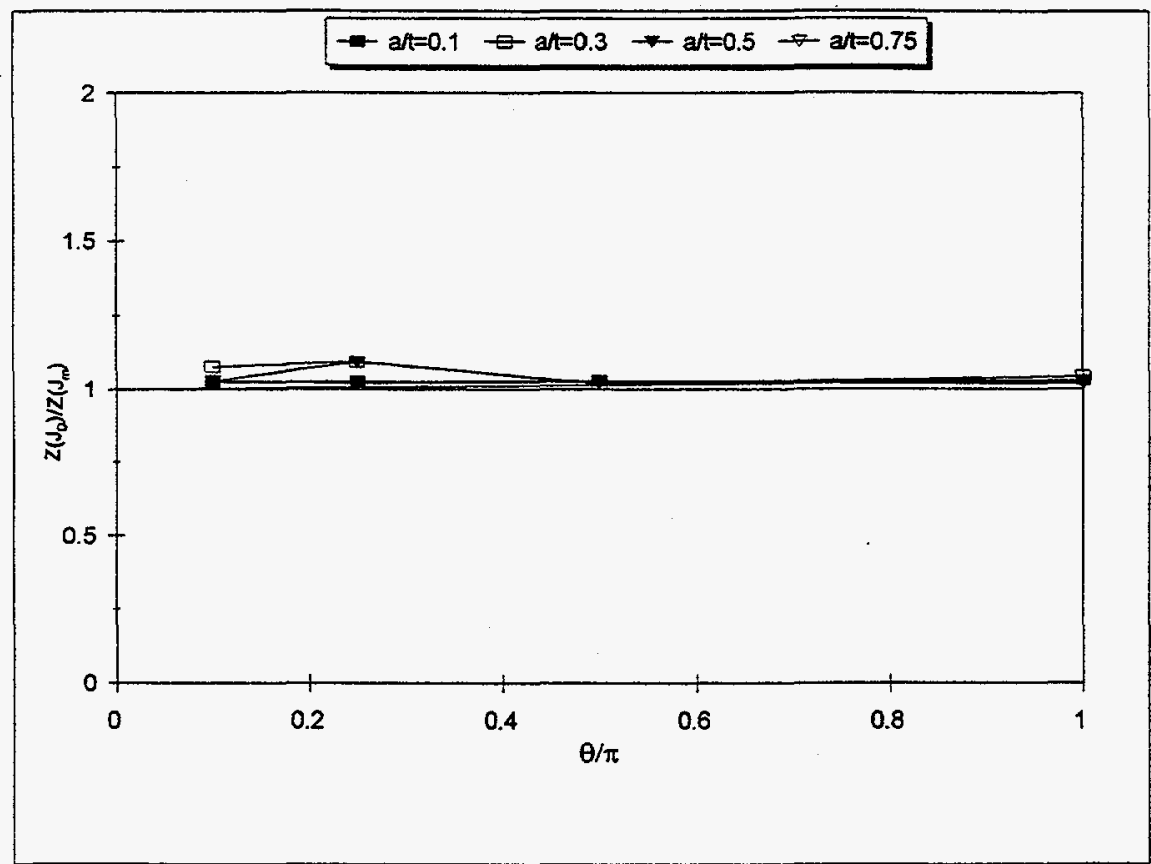

Figure 2.70 Ratio of SC.TNP1 Z-factors using $J / T$ extrapolated $J_{D}-R$ curve to $Z$-factors using $J_{M}-R$ curve versus $\theta / \pi$ 
where
$\sigma_{\text {nsc }} \quad$ Net-Section-Collapse stress
a/t flaw depth to wall thickness ratio
$\theta \quad$ flaw half angle
$\sigma_{\mathrm{EPFM}} \quad$ applied stress for EPFM failure.

From Equation 2-90, it is clear that for a given applied stress, reducing $Z$ increases the allowable flaw size. Thus, the Z-factors currently in the Code, because they are larger than the Z-factors calculated using more contemporary analysis methods, underestimate the allowable flaw size. These factors are being addressed by the ASME Section XI Working Group on Pipe Flaw Evaluation.

The various solutions discussed above have been programmed into the NRCPIPES computer code (Ref. 2.13).

Analysis of Experiments. Each of the surface cracked pipe analysis procedures discussed above has technical strengths and weaknesses, various ranges of applicability, and a different ease of use. In order to select the most appropriate method to use in a given circumstance, the technical limitations, range of applicability, and ease of use must be carefully balanced. In general, the technical limitations and range of applicability issues will dominate the choice of analysis method, and fortunately, these can be objectively assessed by comparing analysis predictions with experiments.

As documented in Reference 2.13, 28 pure bending and 16 combined pressure and bending surfacecracked pipe experiments were selected for analysis to provide insight into the accuracy, conservatism and input data sensitivity of the following surface crack analyses:

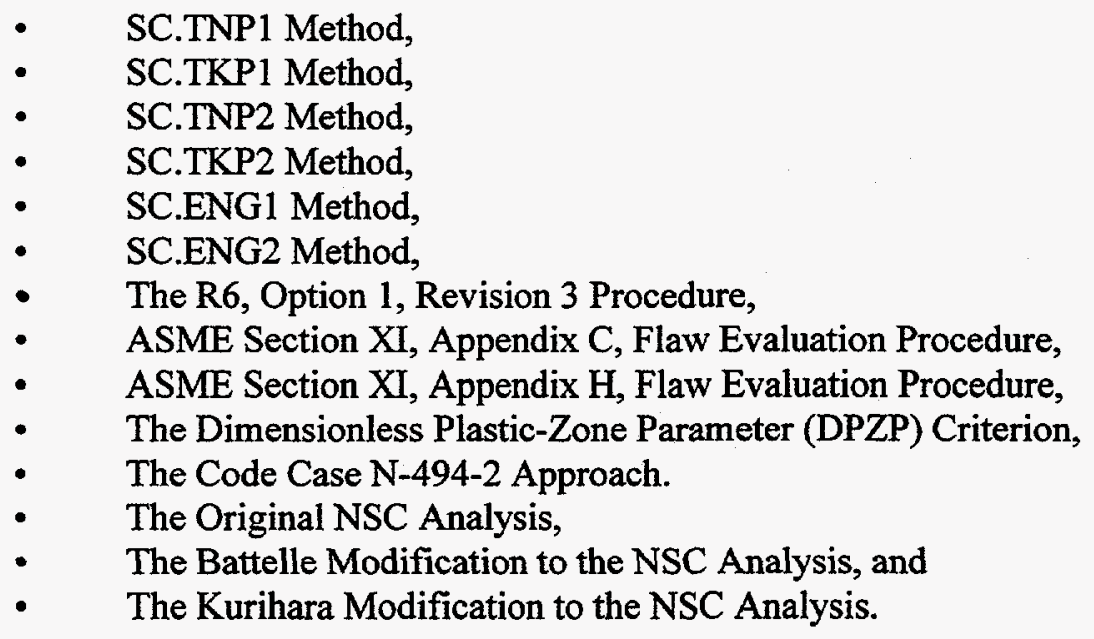

The selected experiments represent a range of pipe sizes, flaw sizes, and flaw materials and should, therefore, provide a reasonable means of assessing the merits of the various analyses.

Using NRCPIPES Version 2.0a to conduct the analyses and grouping the evaluations into different types of initial flaws and loading conditions, the performance of the various surface crack analysis methods were 
statistically evaluated. Tables 2.8 and 2.9 show the initiation and maximum moment statistical results, respectively. Looking at the tables, the following observations can be made:

Limit-Load Approaches. The Original Net-Section-Collapse equation on average underpredicted the maximum experimental moments for the pure bending case. The Battelle modification to the Original NSC criterion agreed better with the experimental data, but on average resulted in a slight overprediction of the maximum experimental moments for the pure bending case. Because the empirical correction factor used in the Battelle modification was obtained by a linear fit of the experimental data to account for pipe $\mathrm{R} / \mathrm{t}$ effects, one would expect that the experimental maximum moment would be predicted better by this method than the original criterion. Using the Kurihara modification (Ref. 2.143) to the NSC criterion, which was developed for short deep surface flaws to analyze all flaw sizes, one significantly underpredicts the experimental data in certain situations. For the combined pressure and bending case, the original NSC criterion had the best agreement of the three methods with the experimental data. However, this method, as seen by the average value, did overpredict the experimental data. On average, the Battelle modification overpredicted the experimental data by 15 percent. This is probably because the effect of internal pressure is to increase the pipe resistance to ovalization, and hence the ovalization correction factor used may not be appropriate for combined loading. The Kurihara modification on average underpredicted the experimental stresses for the combined load case.

Prediction of Moments at Crack Initiation. For the pure bending cases, the SC.TNP1, SC.TNP2, and SC.ENG1 methods are the most accurate when mean values of all the data are compared, although the SC.TNP1 method did overpredict the experimental data slightly on average. For the limited number of short surface-cracked pipe experiments, the SC.TNP2 and SC.ENG1 methods were found to be the most accurate methods considered. For the combined-load cases, all methods underpredicted the experimental values of the initiation stress significantly. This is also true for the case when only the short surface crack experiments are included in the analysis. The SC.TNP1 method resulted in the best predictions of the various methods.

When only pipe experiments involving surface cracks in welds under combined bending and tension loads are considered, all the methods again underpredicted the initiation stresses significantly. These findings indicate that for combined bending and pressure loading of pipes, some improvements are still needed in predicting initiation loads.

One important point to note is that the SC.ENG1, SC.ENG2, SC.TNP2, and SC.TKP2 J-estimation schemes predict the value of the crack-driving force, $\mathrm{J}$, from the finite element analyses given in Reference 2.13 quite well. In predicting initiation loads, however, improvements in predictions over SC.TNP1 and SC.TKP1 are not as significant. This discrepancy may be indicative of anisotropy and constraint differences when using the L-C oriented C(T) specimen data for a circumferential surface crack that is really growing in the $\mathrm{L}-\mathrm{R}$ direction.

Prediction of Maximum Moments. For pure bending the following observations can be made:

- The method that gave the most accurate predictions of the maximum loads was the SC.TNP1 method where the mean experiment-to-predicted maximum load ratio was 1.02 and the standard deviation was also the lowest at 0.14 . 
Table 2.8 Mean and coefficient of variation of initiation stress ratios predicted by various fracture analyses methods

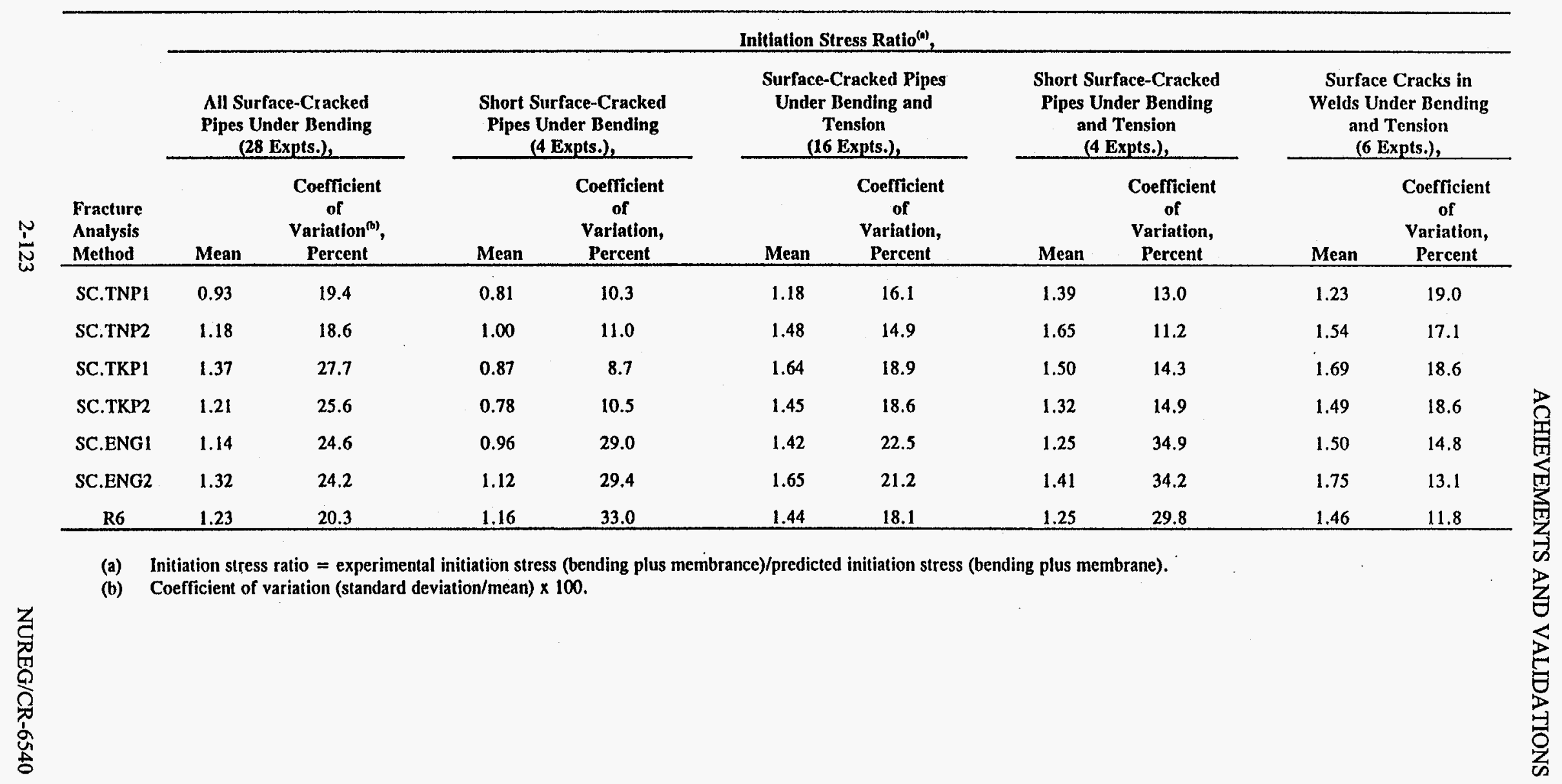


Table 2.9 Mean and coefficient of variation of maximum load ratio predicted by various fracture analyses methods

\begin{tabular}{|c|c|c|c|c|c|c|c|c|c|c|}
\hline \multirow[b]{3}{*}{$\begin{array}{l}\text { Fracture } \\
\text { Analysis } \\
\text { Melhod } \\
\end{array}$} & \multicolumn{10}{|c|}{ Maximum Stress Ratio ${ }^{(0)}$, } \\
\hline & \multicolumn{2}{|c|}{$\begin{array}{c}\text { All Surface-Cracked } \\
\text { Pipes Under Bending } \\
\text { (28 Expts.), } \\
\end{array}$} & \multicolumn{2}{|c|}{$\begin{array}{c}\text { Short Surface-Cracked } \\
\text { Pipes Under Bending } \\
\text { (4 Expts.) }\end{array}$} & \multicolumn{2}{|c|}{$\begin{array}{c}\text { Surface-Cracked } \\
\text { Pipes } \\
\text { Under Bending and } \\
\text { Tension } \\
\text { (16 Expts.), } \\
\end{array}$} & \multicolumn{2}{|c|}{$\begin{array}{c}\text { Short Surface-Cracked } \\
\text { Pipes Under Bending } \\
\text { and Tension } \\
\text { (5 Expts.) }\end{array}$} & \multicolumn{2}{|c|}{$\begin{array}{c}\text { Surface Cracks in } \\
\text { Welds Under } \\
\text { Bending and Tension } \\
\text { (7 Expts.), } \\
\end{array}$} \\
\hline & Mean & $\begin{array}{c}\text { Coefficient } \\
\quad \text { of } \\
\begin{array}{c}\text { Variation } \\
\text { Percent }\end{array} \\
\end{array}$ & Mean & $\begin{array}{l}\text { Coefficient } \\
\text { of } \\
\text { Variation, } \\
\text { Percent } \\
\end{array}$ & Mean & $\begin{array}{c}\text { Coefficient } \\
\text { of } \\
\text { Variation, } \\
\text { Percent } \\
\end{array}$ & Mean & $\begin{array}{l}\text { Coefficient } \\
\text { of } \\
\text { Variation, } \\
\text { Percent }\end{array}$ & Mean & $\begin{array}{c}\text { Coefficient } \\
\text { of } \\
\text { Variation, } \\
\text { Percent }\end{array}$ \\
\hline SC.TNP1 & 1.02 & 13.7 & 0.87 & 4.4 & 1.10 & 13.6 & 0.93 & 7.5 & 1.12 & 14.9 \\
\hline SC.TNP2 & 1.30 & $13.8^{\prime}$ & 1.06 & 5.4 & 1.41 & 14.2 & 1.17 & 7.0 & 1.44 & 15.6 \\
\hline SC.TKPI & 1.49 & 24.2 & 0.93 & 3.0 & 1.38 & 37.7 & 1.02 & 10.8 & 1.66 & 25.5 \\
\hline SC.TKP2 & 1.32 & 22.0 & 0.83 & 4.7 & 1.21 & 37.2 & 0.89 & 8.7 & 1.45 & 26.0 \\
\hline SC.ENG1 & 1.24 & 20.2 & 0.99 & 22.6 & 1.39 & 21.6 & 1.02 & 18.2 & 1.44 & 16.3 \\
\hline SC.ENG2 & 1.43 & 20.8 & 1.17 & 25.1 & 1.65 & 20.6 & 1.21 & 20.8 & 1.75 & 14.6 \\
\hline R6 Opt. 1 & 1.33 & 15.8 & 1.18 & 25.8 & 1.43 & 28.0 & 1.12 & 17.1 & 1.50 & 12.8 \\
\hline Sec XI App C $C^{(c)}$ & 1.19 & 17.6 & 1.14 & 14.3 & 1.16 & 16.4 & 1.04 & 28.0 & 1.37 & 4.2 \\
\hline Sec XI App $H^{(d)}$ & 1.87 & 8.6 & $N \cdot A \cdot{ }^{(e)}$ & N.A. & 2.14 & 13.6 & 1.89 & 3.1 & 2.06 & 14.0 \\
\hline $\mathrm{N}-494-2^{(\mathrm{d})}$ & 1.43 & 14.0 & N.A. & N.A. & 1.42 & 12.6 & 1.43 & 17.9 & 1.43 & 14.6 \\
\hline DPZP & 1.18 & 14.4 & 1.19 & 15.4 & 1.05 & 12.4 & 0.95 & 12.4 & 1.01 & 8.3 \\
\hline NSC-Orig & 1.10 & 13.6 & 1.11 & 12.1 & 0.92 & 13.0 & 0.78 & 4.1 & 0.86 & 8.2 \\
\hline NSC-Battelle & 0.98 & 11.2 & 0.98 & 8.6 & 0.85 & 12.9 & 0.79 & 13.1 & 0.78 & 8.2 \\
\hline NSC-Kurihara & 1.29 & 11.6 & 1.30 & 12.6 & 1.13 & 16.8 & 0.92 & 1.3 & 1.07 & 9.0 \\
\hline
\end{tabular}

(a) Maximum load ratio $=$ experimental maximum load/predicted maximum load.

(b) Coefficient of variation $=$ (standard deviation $/$ mean) $\times 100$.

(c) Austenitic pipe only.

(d) Ferritic pipe only.

(e) N.A. = Not applicable. 
- The next most accurate methods were the Battelle DPZP method and the ASME austenitic pipe Appendix- $\mathrm{C}$ method (with safety factor of 1.0). The mean experiment-to-predicted maximum load ratios were 1.18 and 1.19 , respectively. The standard deviations were 0.17 and 0.21 , respectively.

- The method that underpredicted the maximum loads the most was the ASME Section XI ferritic pipe Appendix- $\mathrm{H} Z$-factor approach with a mean experiment-to-predicted maximum load ratio of 1.87 and standard deviation of 0.16. The ASME Code Case N-494-2 analysis method for ferritic pipe was more accurate than the Appendix- $\mathrm{H} \mathrm{Z}$-factor method with a mean experiment-to-predicted maximum load ratio of 1.43 and standard deviation of 0.20 .

- When only short ( $<25$ percent of the pipe circumference) flaw lengths are included in the statistical analysis, the SC.TNP2, SC.ENG1, and the Battelle-modified NSC methods resulted in the most accurate predictions of the maximum moments.

Considering the cases involving combined pressure and bending:

- The method that gave the most accurate predictions of the maximum loads was the DPZP method where the mean experiment-to-predicted maximum load ratio was 1.05 and the standard deviation was also the lowest at 0.13 . This method was more accurate for combined loading than for pure bending.

- The next most accurate methods were the SC.TNP1 method and the ASME austenitic pipe Appendix $\mathrm{C}$ method (with safety factor of 1.0). The mean experiment-to-predicted maximum load ratios were 1.10 and 1.16 , respectively. The standard deviations were 0.15 and 0.19 , respectively. The SC.TNP1 method was slightly less accurate for combined loading, and the ASME Section XI Appendix C mean value was slightly better for combined loading.

- The method that underpredicted the maximum loads the most was the ASME Section XI ferritic pipe Appendix $\mathrm{H} Z$ Z-factor approach with a mean experiment-to-predicted maximum load ratio of 2.14 and standard deviation of 0.29 , which was higher than for pure bending. The ASME Code Case N-494-2 analysis method for ferritic pipe was more accurate than the ASME Appendix $\mathrm{H}$ Z-factor analysis with a mean experiment-to-predicted maximum load ratio of 1.42 and standard deviation of 0.18 , which was close to the same values as for pure bending.

- When only the five short-surface-cracked-pipe experiments were considered in the analysis, the SC.TKP1, SC.ENG1, and Appendix C methods agreed best with the experimental data.

It is somewhat disappointing to note that the new J-estimation schemes developed to specifically address the problem of surface cracks in welds, SC.ENG1 and SC.ENG2, significantly underpredicted the experimental stresses for the seven weld experiments. The average ratios of the combined maximum experimental stress to the combined predicted stress (including the membrane stress due to internal pipe pressure) for the seven weld crack experiments were 1.44 and 1.75 for SC.ENG1 and SC.ENG2, respectively. This compares with the stress ratio for the original SC.TNP method (SC.TNP1) of 1.12. As previously noted, although the SC.TNP2, SC.TKP2, SC.ENG1, and SC.ENG2 methods agree well with 
the $\mathrm{J}$ values from finite element analyses, anisotropy and constraint effects from using the L-C oriented $C(T)$ specimen J-R curves could have resulted in these analyses underpredicting the maximum loads.

The results presented in Tables 2.8 and 2.9 are a statistically-based measure of the performance of the various analysis methods over the full range of pipe sizes and flaw sizes in each of the different loading/flaw type categories. Within an analysis method, however, there are sensitivities to certain input parameters that can bias the statistics. Parameters such as outside diameter, $R_{m} / t$ ratio, crack length in terms of fraction of the circumference, crack depth to wall thickness ratio, strain hardening exponent, and the effect of internal pressure can have a profound impact on the accuracy of any of the surface crack analysis methods.

Based on parametric sensitivity analyses, it appears that the accuracy of the various methods, as measured in terms of maximum moment or maximum stress ratio, is less dependent on pipe diameter, $R_{m} / t$ ratio, crack length, crack depth, strain-hardening exponent, and pipe pressure, for the pure bending experiments than it is for the combined pressure and bend experiments. For most of the analyses, the maximum moment ratio for the pure bending experiments was independent of the various test parameters. However, the maximum stress ratio for the combined pressure and bend experiments for a number of these same analyses, most notably the SC.TKP and SC.ENG analyses, showed fairly strong dependence on a number of these test parameters. The accuracy of the SC.ENG analyses tended to show a dependence on almost all of the test parameters for the combined pressure and bend experiments, particularly $R_{m} / t$ ratio, see Figure 2.71. This is a consequence of extrapolation errors in a $\overline{\mathrm{G}}_{\mathrm{N}}$ function embedded in the analysis that is only tabulated at $R / t$ values of 5,10 and 20 .

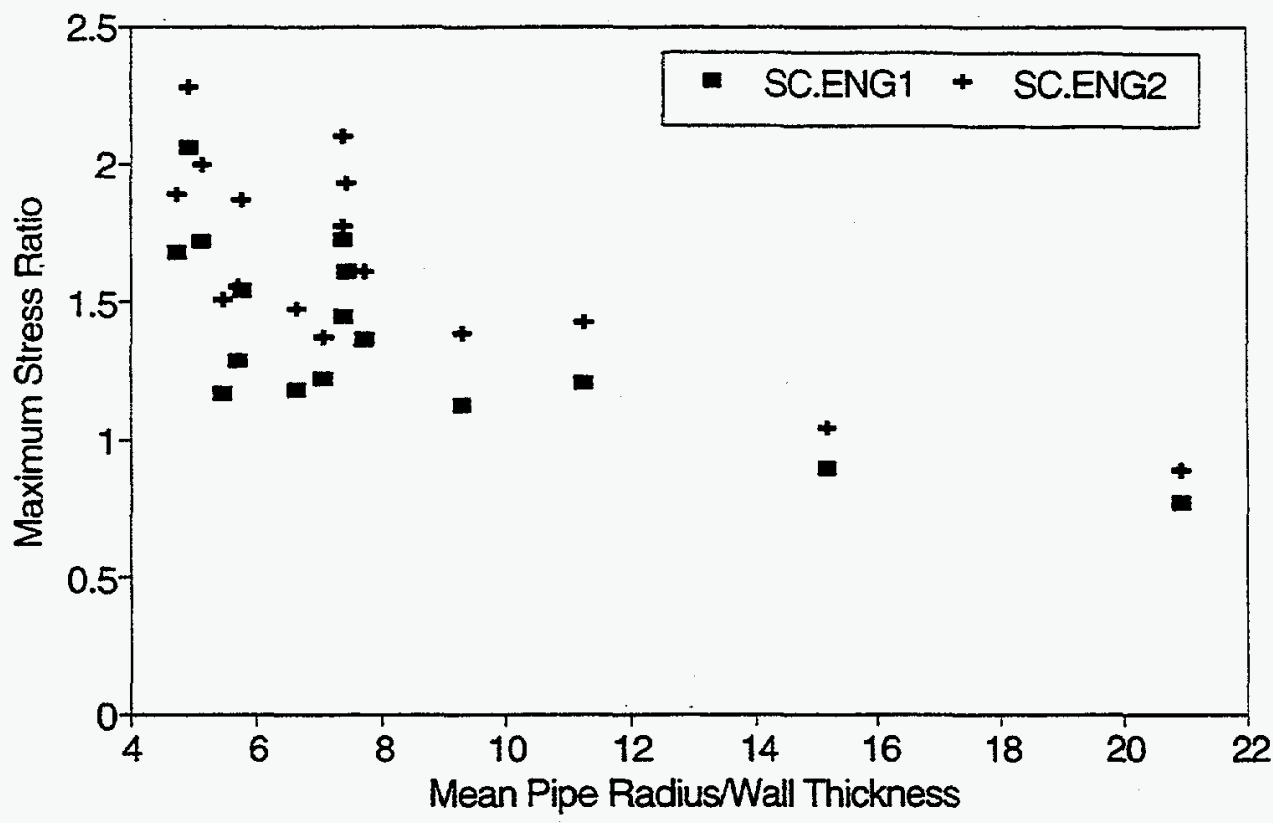

Figure 2.71 Plot of the maximum stress ratio (maximum experimental stress/maximum predicted stress) for the SC.ENG1 and SC.ENG2 analyses as a function of mean pipe radius-to-pipe wall thickness ratio $\left(R_{m} / t\right)$ for the combined pressure and bend experiments 
Of the three families of J-estimation schemes, the accuracy of the SC.TNP analysis was the least dependent on the six test parameters considered. Consequently, the SC.TNP analysis may be the most appropriate of the J-estimation schemes for use in analyses. Of the two SC.TNP analyses, the SC.TNP1 method will, on average, result in a more accurate prediction of load although the likelihood of overpredicting the actual failure stresses is higher using this method than it is in using the SC.TNP2 method.

Considering all the analysis methods, the simple DPZP method seems to be the least dependent on the six parameters evaluated in the sensitivity analyses. It is also one of the more accurate methods, based on its average value of the maximum moment or stress ratio and its standard deviation. The only significant limitation with the DPZP analysis is that it does not provide any crack deflection (rotation) information.

Effect of Anisotropy and Constraint on Toughness. As shown earlier in this report, the SC.TKP2, SC.TNP2, SC.ENG1 and SC.ENG2 analyses were found to agree the best with $J$ values from finite element analyses, but underpredicted the loads more than anticipated. This may be due to using the J-R curve data from L-C oriented C(T) specimens. The L-C orientation corresponds to the crack growing as a circumferential through-wall crack around the pipe circumference, whereas the surface crack growth is in the radial or L-R orientation. Furthermore, there may also be effects of constraint between the $C(T)$ specimen and a surface crack in a pipe that also differ. The effect of these parameters are discussed below in reference to the surface-cracked pipe predictions.

Anisotropy. Typically, toughness anisotropy, if it exists, manifests itself as increased toughness in the surface crack growth direction and is caused by mechanical processing of the steel in the pipe fabrication process. As discussed in Section 2.2.5.4 on material properties, ferritic steels are well known to have toughness that is dependent on the orientation of the specimen. Wrought TP304 stainless steel, on the other hand, does not exhibit such behavior. Very little is known about toughness orientation effects in austenitic and ferritic welds.

The effect of anisotropy, if it exists, is to generally increase the load-carrying capacity for surface crack growth in relation to the load carrying capacity in the through-wall crack growth direction. Since most predictions of surface crack behavior will use L-C orientation (circumferential through-wall crack growth direction) toughness data, the predictions will underestimate the load carrying capacity. For ferritic pipes, the toughness change can range from negligible to an increase of 2.5 to 3 times the toughness in the circumferential through-wall crack growth direction. For wrought TP304 stainless steel, because the toughness is generally high enough that failures are at limit load, increased toughness in the surface crack growth direction, if it exists, should not have a major effect.

Constraint. When a crack is subjected to high tensile stresses, it will strain in the crack opening direction. Due to the presence of the material along the direction of the crack, transverse strain will also develop, i.e., through the thickness on a $C(T)$ specimen. When plastic deformation occurs at the crack tip, the tendency to strain in the transverse direction becomes even larger. Because material immediately behind the crack tip at the crack faces is stress free, it will have no transverse strain. Material just outside of the plastic zone will want to strain in the transverse direction, but to a much lesser degree than the material in the plastic zone. Since the material outside the plastic zone restrains the plastic zone transverse strain, it causes transverse stresses at the crack tip. Thus, a triaxial state of stress can be present at the crack tip which may either promote crack growth or retard it. This effect, the inducement of triaxial stresses at the crack tip, 
arises from the constraining influence of material away from the plastic zone, and is simply referred to as constraint effects.

The topic of constraint effects on fracture is currently in an evolving phase. Much work is being done in the area to quantify effects that have been known to exist for decades. Two prevailing constraint parameters are the T-stress (Ref. 2.82) and J-Q parameter (Ref. 2.153). Reference 2.154 gives a good comparison of $T$-stress parameters from many specimen geometries, including a $C(T)$ specimen and a circumferential surface crack in a pipe. These results show positive $T$ values for $C(T)$ specimens, indicative of high constraint conditions, and negative $T$ values for the circumferential surface crack in a cylinder, indicative of low constraint conditions. The low constraint condition means that the apparent toughness of the material in this geometry will be higher than in the $C(T)$ specimen. The quantitative effects of these differences in the T-stress values on toughness are not known for the materials of concern, and the relative magnitude of the effect of constraint to the anisotropy effects is not known. Nevertheless, the constraint aspects would contribute to the surface-cracked pipe apparent toughness being higher than the $\mathrm{C}(\mathrm{T})$ specimen values.

As a final comment, it appears that anisotropy and constraint effects on toughness appear to be making the SC.TNP2, SC.TKP2, SC.ENG1, and SC.ENG2 methods more conservative than desired in predicting initiation and maximum loads. On the other hand, the SC.TNP1 analysis, which predicted the experimental maximum loads well, appears to overpredict the applied $\mathrm{J}$ but to a degree that compensates for the anisotropy and constraint effects. Until a better understanding of anisotropy and constraint effects is developed, it is suggested that the SC.TNP1 analysis be used as a reasonably good estimator of the maximum loads. For other applications where knowing J more accurately is desired, then the SC.TNP2, SC.TKP2, SC.ENG1 or SC.ENG2 analyses should be used. An application where having a good prediction of $\mathrm{J}$ is important would be in making low-cycle fatigue crack growth analyses for surfacecracked pipe as was done in Reference 2.73 for circumferential through-wall-cracked pipe.

\subsubsection{Complex- or Compound-Cracked Pipe}

A complex or compound crack is one that is a combination of a surface crack and a through-wall crack in the same circumferential plane. One of the first widely publicized occurances of such a crack was at a safe end in the Duane Arnold nuclear plant (Ref. 2.155). Figure 2.72 shows the Duane Arnold crack compared with an idealized complex crack used in research programs at Battelle (Ref. 2.156), and David Taylor Research and Development Center, DTRC, (now Naval Surface Warfare Center at Carderock) (Ref. 2.157).

A complex crack can occur whenever there is a cracking mechanism that can create long surface flaws, i.e., IGSCC as in the Duane Arnold case, corrosion-fatigue (Ref. 2.158), and thermal fatigue. If cracks of these types can occur, then the NRC Standard Review Plan for Leak-Before-Break (SRP 3.6.3) will not allow LBB to be applied on that piping system.

Complex cracks are not only important from the fact that this is a severe flaw that can occur in service, but also because such flaws are important in understanding the stability behavior of long surface cracks. As a surface crack reaches maximum load, the crack grows through the thickness. This results in a complex crack during the remaining fracture event. Some aspects of this will be reviewed later in this section. 
- Measured crock depth

-...-. Estimated crock depth

DIII IGSCC

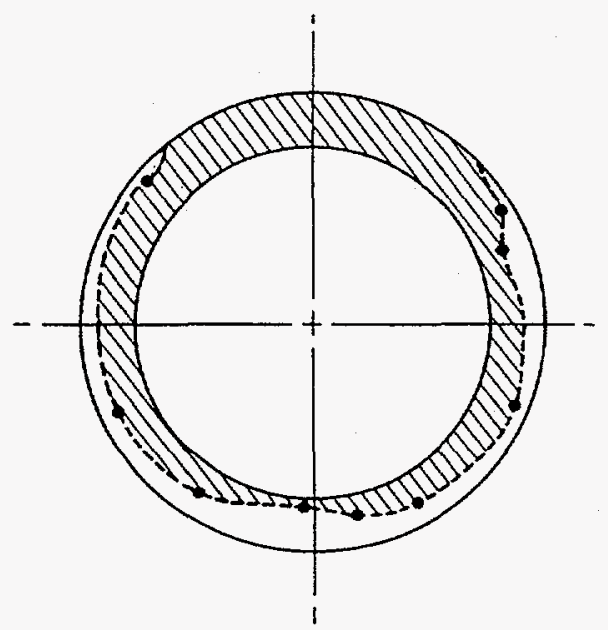

Duane-Arnold Crack Found in Service

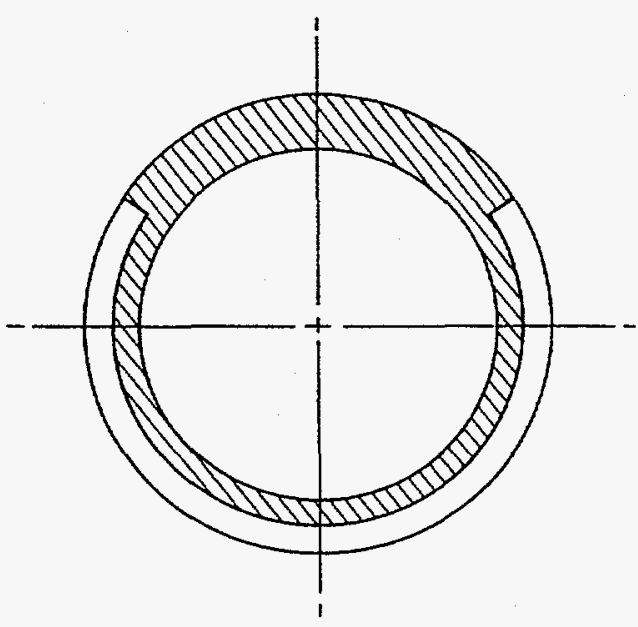

Simulated Complex Crack

Figure 2.72 Comparison of typical crack found in service with laboratory simulated "complex crack"

Complex Cracked-Pipe Fracture Behavior. The first analysis of a complex crack was performed in Reference 2.155 by Paris, Tada, and Gamble. The tearing instability analysis was conducted and also was published in a subsequent technical paper (Ref. 2.159).

The first experiment on this type of crack was performed as part of an EPRI/Battelle program (Ref. 2.141). At that time, it was observed that the crack-opening angle (COA) during crack growth was much lower for the complex-cracked pipe than a pipe with a simple through-wall flaw. Subsequent analysis by Pan and Wilkowski (Ref. 2.160), showed that the complex-cracked pipe J-R curve (calculated from an $\eta$-factor analysis) was much lower than the J-R curve from an idealized circumferential through-wall flaw, see Figure 2.73. The physical observation of a lower crack growth resistance from the COA agreed with the $\mathrm{J}-\mathrm{R}$ curve being much lower for the complex-cracked pipe.

Experimental work on complex cracks was undertaken at DTRC and Battelle. The DTRC work was on cracks in 102-mm (4-inch) diameter stainless steel pipes with simple circumferential through-wall cracks and complex cracks in the center of a TIG weld (Ref. 2.157). The tests were done at $288 \mathrm{C}(550 \mathrm{~F})$ in four-point bending. The complex-cracked pipe J-R curves were substantially below the J-R curves from simple through-wall flawed pipe tests and the J-R curves from $\mathrm{C}(\mathrm{T})$ tests. 


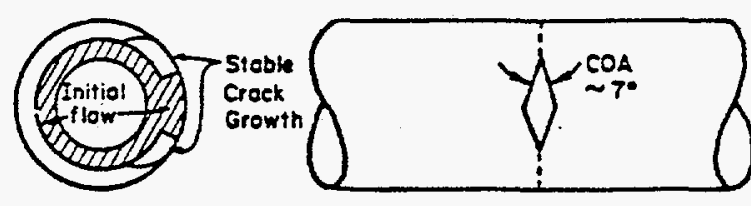

Internal Surface Crack That Penetrates the Wall Thickness (Complex Crack)

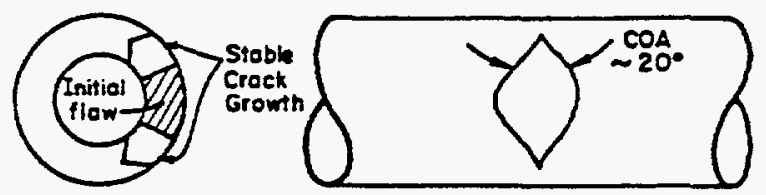

Idealized Through-Wall Crack (TWC)

(a) Circumferential crack morphology during ductile tearing

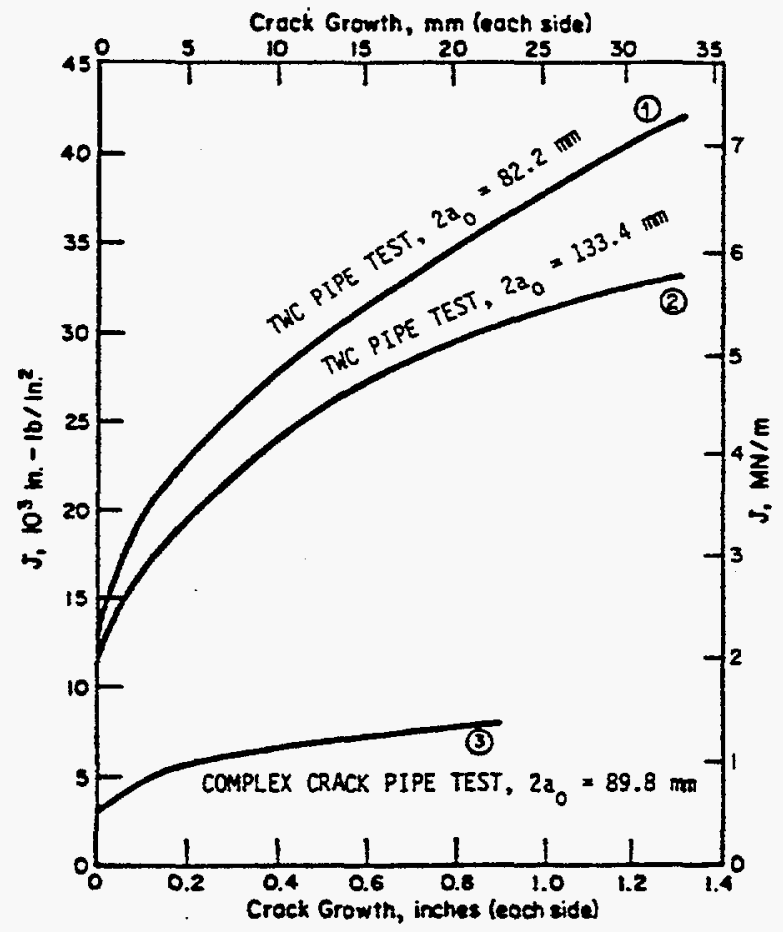

(b) Calculated J-R curves from Type 304 stainless steel pipe tests on the same material

Figure 2.73 Physical observations and calculated J-R curves for Type 304 stainless steel pipe with initial idealized through-wall cracks and complex cracks 
The later Battelle work was done as part of the NRC's Degraded Piping Program (Ref. 2.28). This involved experiments on TP304 stainless steel, Inconel 600, and A106 B pipes with complex cracks in the base metals. All tests were done at $288 \mathrm{C}(550 \mathrm{~F})$ in four-point bending without internal pressure. The pipes were all 152-mm (6-inch) nominal diameter with Schedule 100 thickness [about $13 \mathrm{~mm}$ ( 0.5 -inch) thick]. Experiments were conducted with several different depths of surface cracks, but the through-wall crack length was always constant. Figure 2.74 shows a comparison of the moment versus rotation curves for two complex-cracked pipe experiments (a/t of approximately $1 / 3$ and $2 / 3$ ), relative to a simple throughwall-cracked pipe experiment. From this figure, two important aspects can be seen. First, the area under the curves is much smaller for the complex-cracked pipe. Second, after maximum load is passed, the slope of the curve is much greater for the complex-cracked pipe. This means that a compliant instability is more likely to occur with the complex-cracked pipe than a simple through-wall-cracked pipe.

During these tests, the crack growth was monitored by the dc-electric potential method (Ref. 2.161). There were also occasional unloadings to mark the crack position. The crack growth patterns are shown in Figure 2.75. Note in this figure that the crack growth is much greater on the inside surface along the surface crack. Hence, the surface crack is providing some extra constraint to reduce the toughness, or there is a radial crack driving force component that is not accounted for.

J-R curves were calculated from the various pipe experiments using the typical $\eta$-factor analysis to see the effect of the surface crack depth. Figure 2.76 shows the deformation J-R curves from the two complexcracked pipe experiments. It was found that at any given value of crack growth, the J values from the two curves had about the same ratio. Interestingly, this occurred for all materials. As a result of this, an empirical constraint parameter was developed from all the complex-cracked pipe test data that existed. Figure 2.77 shows the ratio of the complex-cracked pipe J-R curves to a simple through-wall-cracked pipe experiment J-R curves as a function of the surface crack a/t. The DTRC results were slightly lower than the Battelle results, but that might be complicated by the cracks being in weld metal in the DTRC experiments. The ratio $\mathrm{J}_{\mathrm{CC}} / \mathrm{J}_{\mathrm{TWC}}$ in this figure can be used as a constraint parameter on the J-R curve for fracture predictions of complex-cracked pipe.

It is worthwhile noting here that the $\eta$-factor solution used in the EPRI/Battelle, DTRC, and the later NRC/Battelle work, all used the simple or idealized through-wall-cracked pipe solutions. There was a correction for the reduced pipe thickness, but any crack-driving force in the radial direction was not accounted for.

Relevance of Complex-Cracked Pipe Behavior to Surface-Cracked Pipe Instability Behavior. As previously noted, for a pipe with a long surface-crack, the surface-crack will grow radially in an elliptical fashion, and will then penetrate the wall thickness over a relatively short length. The subsequent crack growth will essentially be that of a complex-cracked pipe. There are several examples of long surfacecracked pipe experiments, where a significant instability occurred in displacement-controlled loading. This behavior is consistent with the reduced tearing resistance with a complex-cracked pipe.

Considering TP304 stainless steel pipe used in the Battelle complex-cracked pipe experiments, three 360degree surface-cracked pipe experiments were conducted with different system compliances (Ref. 2.162). Great care was required to design a test system to get totally stable tearing in one of the tests. Figure 2.78 shows a comparison of the stable crack growth pipe test with extremely low compliance, and an instability behavior in a moderate compliance test frame. 


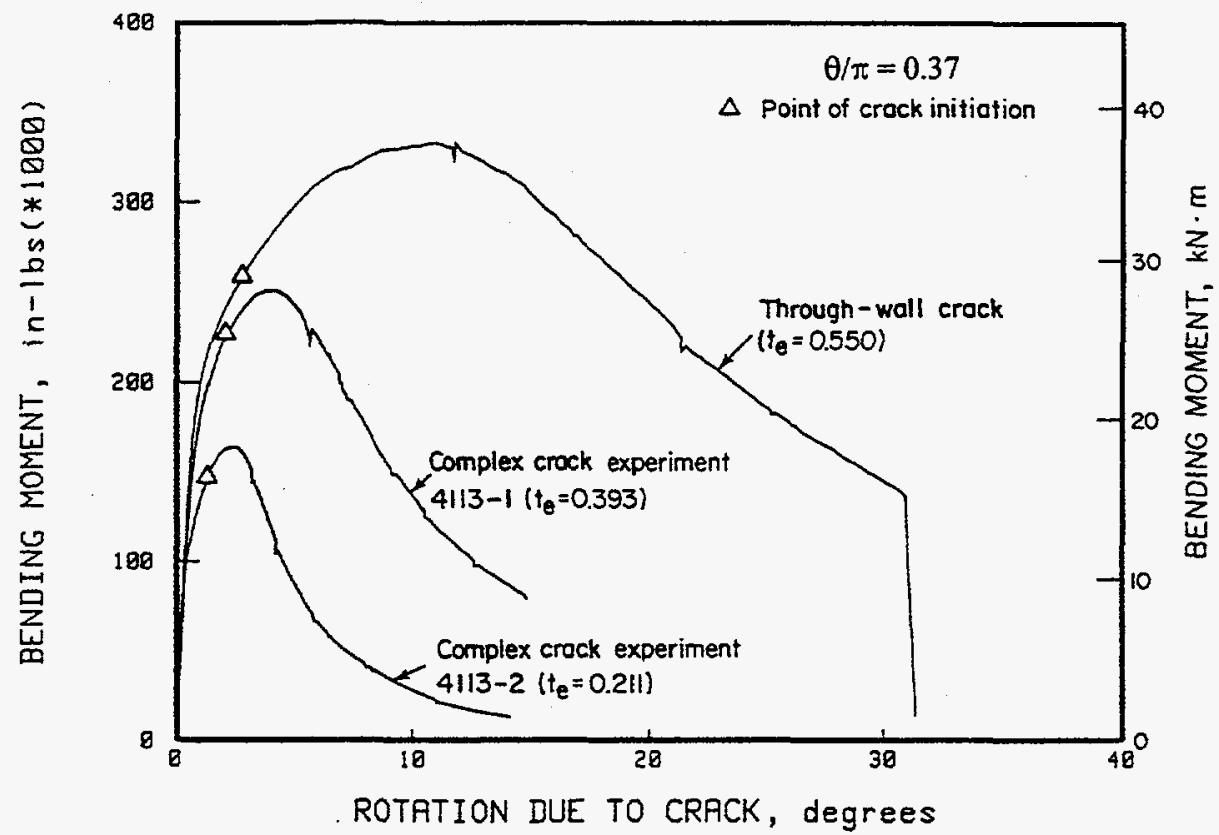

Figure 2.74 Comparison of SA-376 TP304 stainless steel complex-cracked pipe data to simple through-wall-cracked pipe data

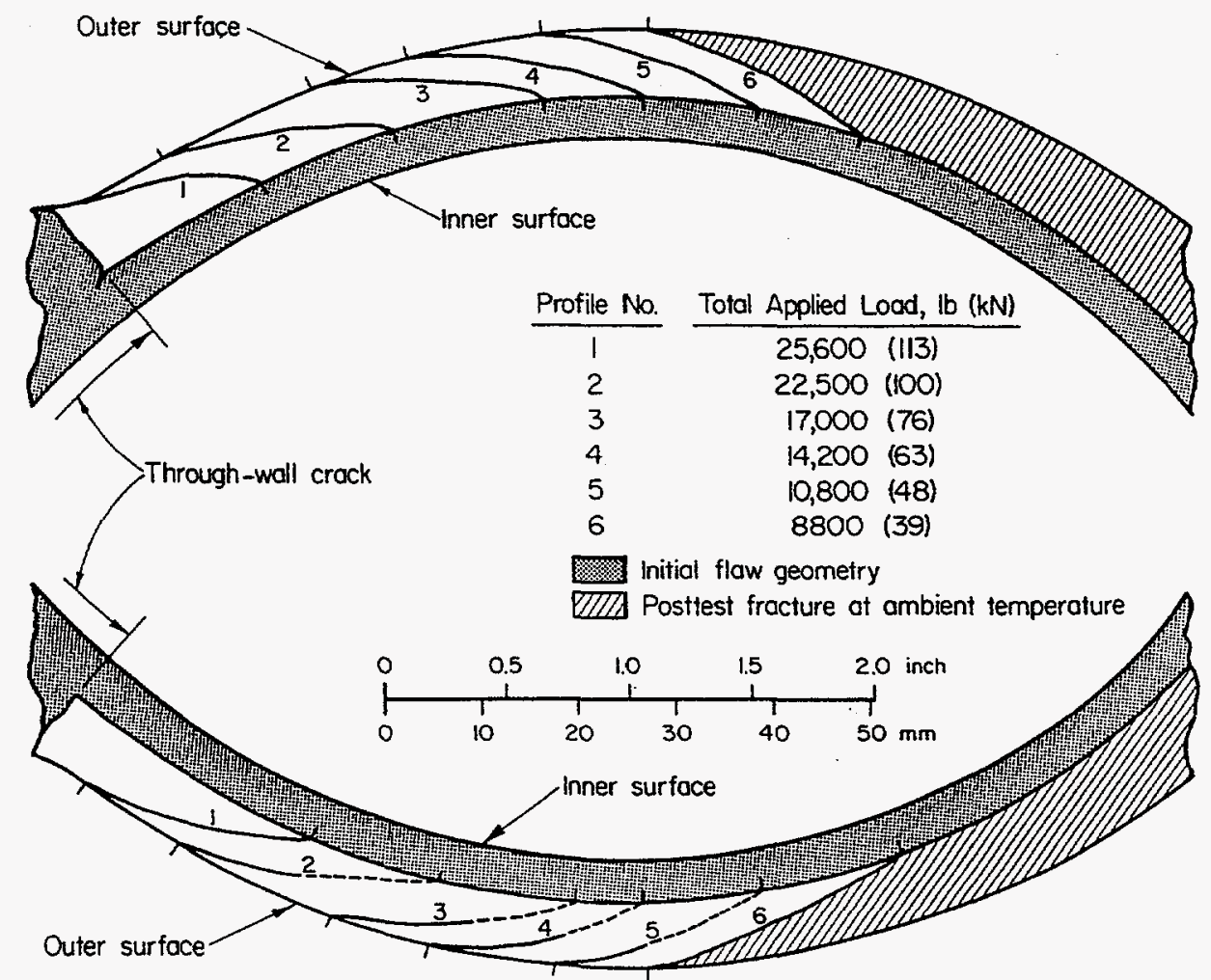

Figure 2.75 Posttest fracture surface from Experiment 4113-1 showing crack-growth profiles caused by unloadings 


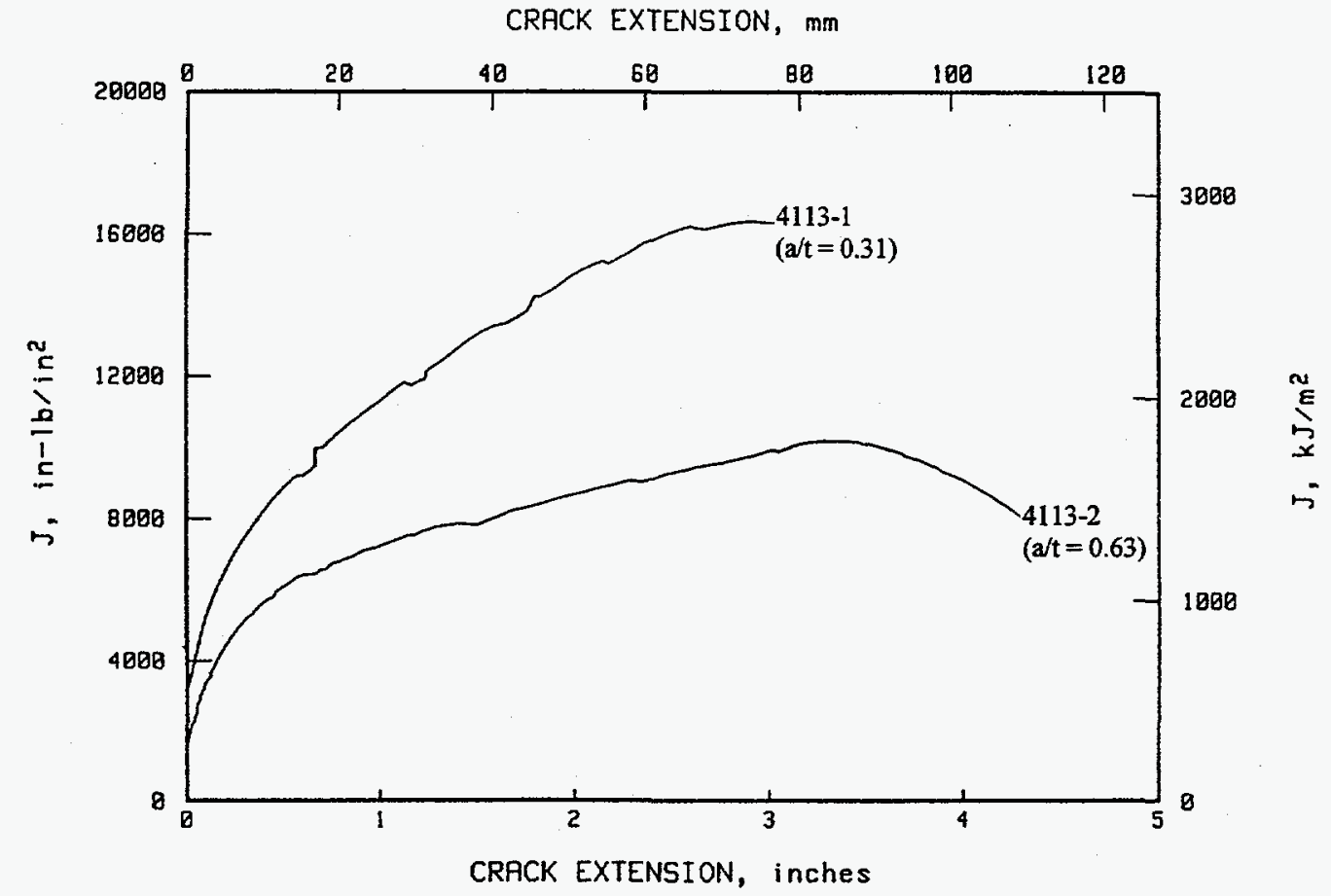

Figure 2.76 Computed J-R curves using $\eta$-factor analysis for Type 304 stainless steel 152-mm (6-inch) diameter complex-cracked pipes tested at $288 \mathrm{C}(550 \mathrm{~F})$

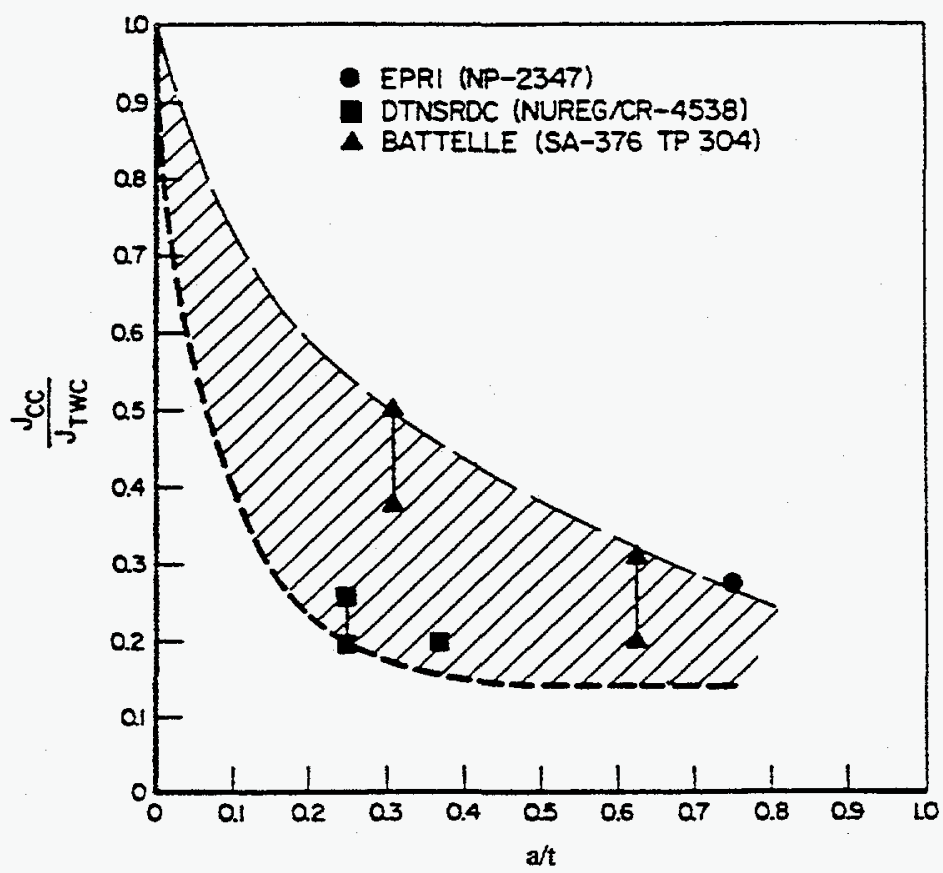

Figure 2.77 Ratio of $\mathrm{J}$ from complex-cracked pipe experiments to $\mathrm{J}$ of the simple through-wallcracked pipe experiments as a function of a/t for various experiments 


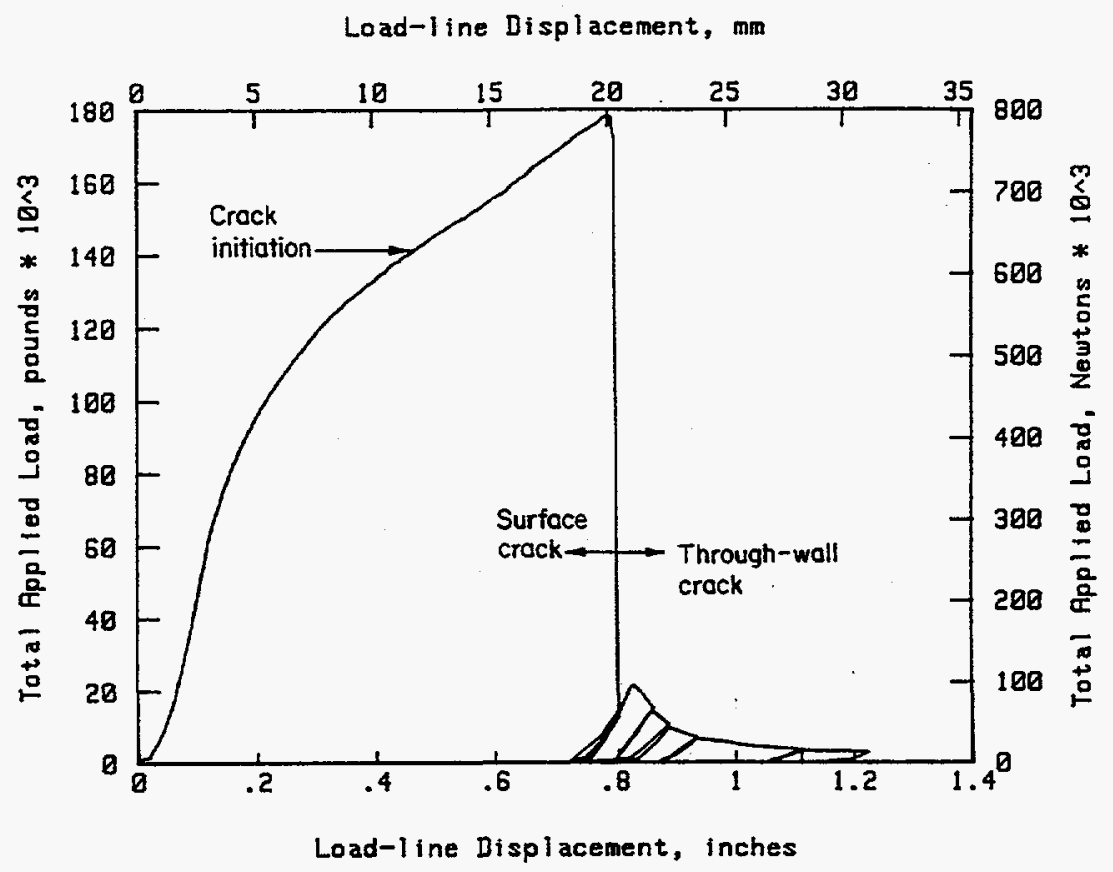

(a) Instability in a moderate compliant test frame

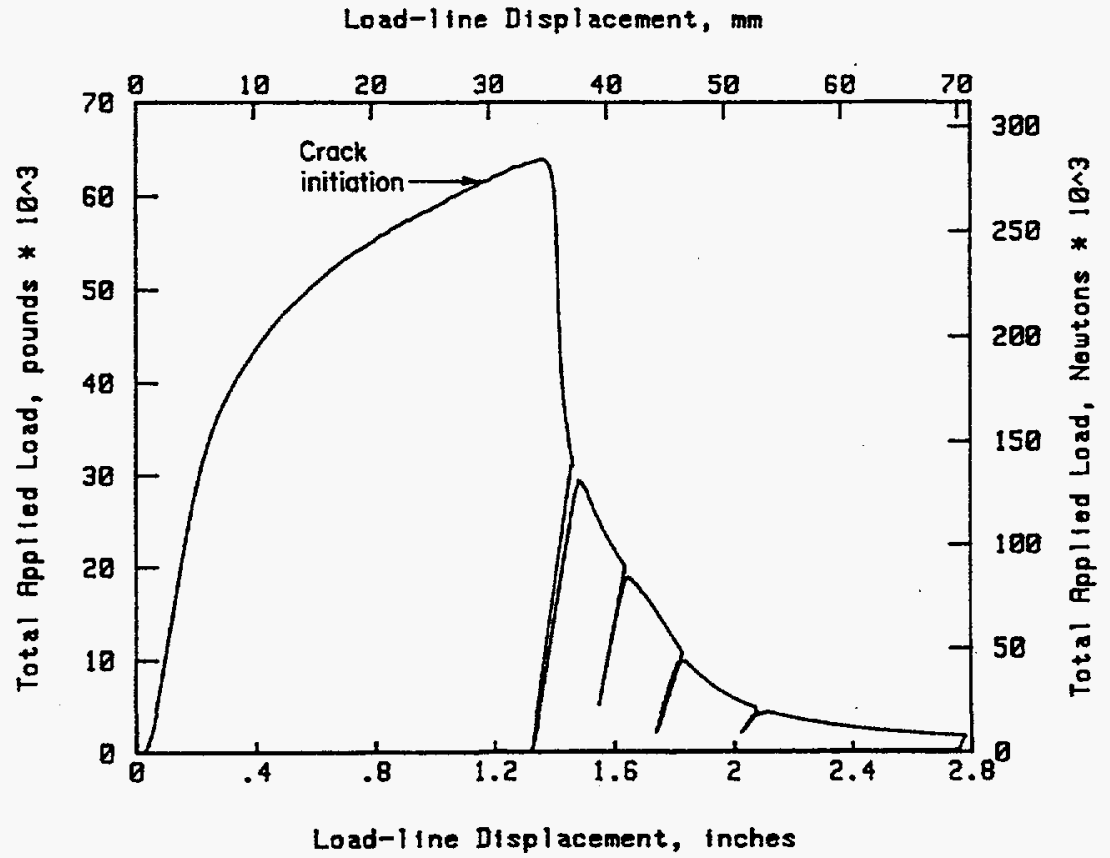

(b) Stable crack growth in low compliance test frame

Figure 2.78 Comparison of stable crack growth pipe test with low compliance with instability behavior in a moderate compliant test frame 
Another case where there was a large instability in a long surface-cracked pipe experiment, involved an experiment on a pipe with a 360-degree microbiologically induced flaw at a girth weld (Ref. 2.163). Figure 2.79 shows the load-displacement record from this experiment. It can be seen that there was a large crack jump and if the pressure in the test had been higher [it was only $0.7 \mathrm{MPa}(100 \mathrm{psi})$ ], then there would have been a complete double-end break.

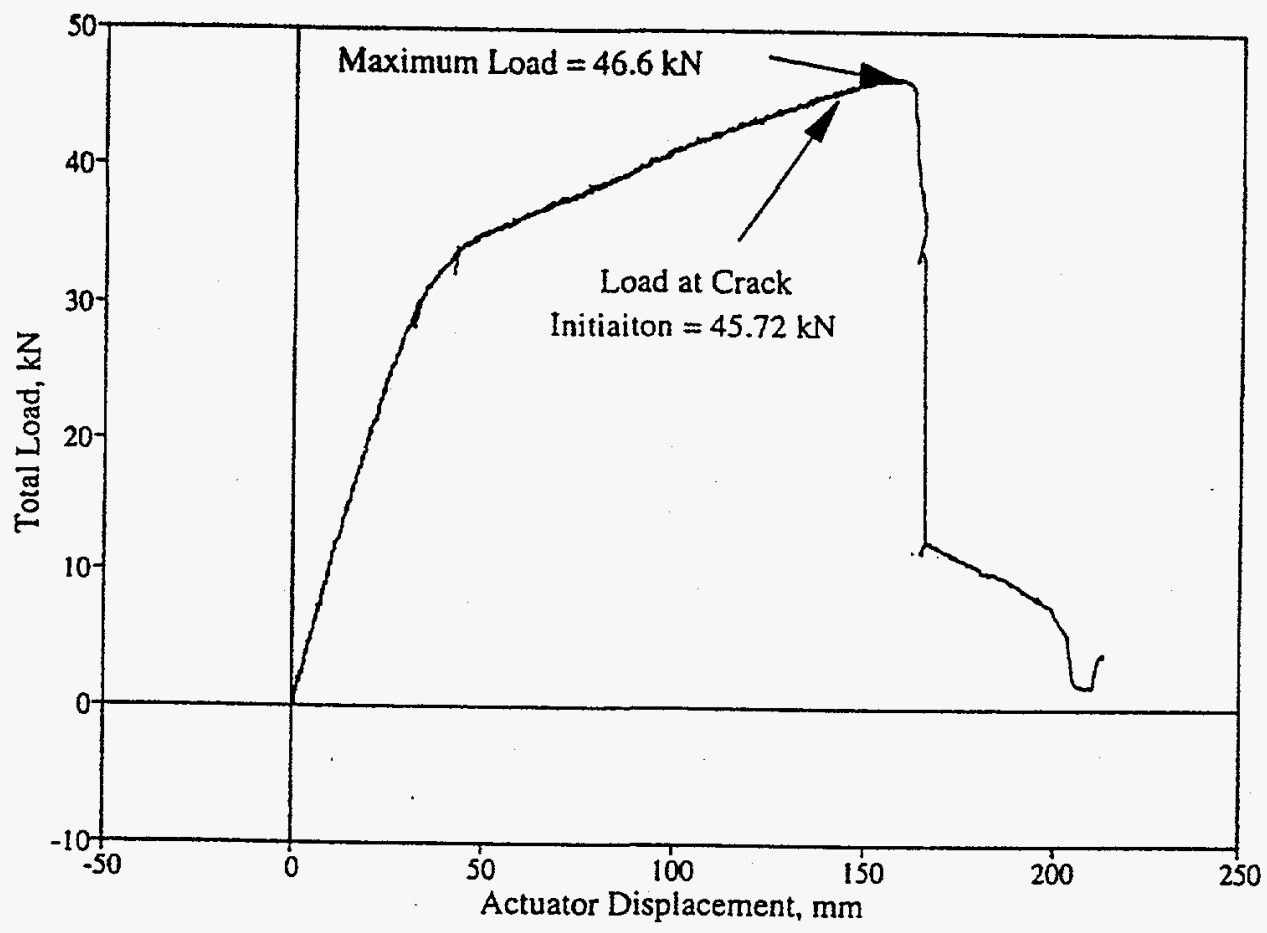

Figure 2.79 Total applied load versus actuator displacement for the Haddam Neck (Connecticut Yankee) Plant MIC experiment

\subsubsection{Moment-Rotation Predictions}

The ability to predict the moment-rotation behavior of a cracked pipe can be important if the actual stresses have some displacement-controlled component, or are inertial stresses. If the loading is strictly loadcontrolled, then the displacements are not very important. Many analysis methods have the capability to make predictions of the pipe's moment versus the rotation due to the crack relationship. Such a prediction capability is important for understanding the stability behavior of either circumferential through-wall or surface-cracked pipe. 
Through-Wall-Cracked Pipe Moment-Rotation Predictions. There are numerous circumferential through-wall-cracked (TWC) pipe analyses that can predict the moment-rotation or load-displacement relationships. Load versus load-line displacement curves are used for analysis of four-point bend pipe experiments, whereas the moment-rotation curves are frequently used in the fracture stability analyses (see Section 2.3.2.5 in this report).

The rotations $(\phi)$ or load-line displacements $(\Delta)$ are typically broken into four components.

or

$$
\phi_{\text {Total }}=\phi_{c}{ }^{c}+\phi_{e}{ }^{n c}+\phi_{p}^{c}+\phi_{p}^{n c}
$$

$$
\Delta_{\text {Total }}=\Delta_{\mathrm{e}}{ }^{\mathrm{c}}+\Delta_{\mathrm{e}}^{\mathrm{nc}}+\Delta_{\mathrm{p}}^{\mathrm{c}}+\Delta_{\mathrm{p}}^{\mathrm{nc}}
$$

where the subscripts " $\mathrm{e}$ " and " $\mathrm{p}$ " refer to elastic and plastic components, and the superscripts " $\mathrm{c}$ " and "nc" refer to the rotation or displacement contributions from the cracked pipe and the non-cracked pipe. The piping fracture analyses typically only deal with the rotation or displacement contributions due to the crack.

Some TWC analyses that predict the displacements or rotations due to the crack are:

- The Original GE/EPRI method (Ref. 2.102), and modifications of it (Ref. 2.119),

- The Tada-Paris NUREG/CR-3464 method (Ref. 2.65),

- The LBB.NRC method (Ref. 2.116),

- The LBB.ENG2 method (Ref. 2.120), and

- The LBB.GE method (Ref. 2.121).

In the GE/EPRI method, the elastic and plastic rotations due to the crack are calculated using the $V_{3}$ and $h_{4}$ functions, respectively.

$$
\phi^{c}=\phi_{c}{ }^{c}+\phi_{p}^{c}=4\left(R_{m} / I\right) V_{3}+\alpha \epsilon_{o} h_{4}\left(M / M_{o}\right)^{n}
$$

where

$\begin{array}{ll}\mathrm{R}_{\mathrm{m}} & =\text { pipe mean radius } \\ \mathrm{I} & =\text { cross-sectional moment of inertia } \\ \alpha, \epsilon_{\mathrm{o}}, \mathrm{n} & =\text { Ramberg-Osgood stress-strain coefficients (see Equation 2-35) } \\ \mathrm{M} & =\text { applied moment } \\ \mathrm{M}_{\mathrm{o}} & =\text { limit-load moment (see Equation 2-34) } \\ \mathrm{V}_{3}, \mathrm{~h}_{4} & =\text { tabulated influence functions (Refs. 2.102 and 2.119) }\end{array}$

The Tada/Paris method calculates the plastic rotations by determining the plastic zone at the crack tip, and then reducing the stiffness in the elastic solution. 
The LBB.NRC method (Ref. 2.116) for through-wall-cracked pipes subjected to bending is similar to the Paris/Tada method except that the plastic component of rotation due to a crack is written as

$$
\phi_{\mathrm{p}}^{\mathrm{c}}=\alpha\left(\frac{\sigma}{\sigma_{\mathrm{f}}}\right)^{\mathrm{n}-1} \phi_{\mathrm{c}}^{\mathrm{c}}
$$

with $\phi_{c}^{c}=\phi_{c}^{c}\left(\theta_{e}\right)$ from the Paris/Tada solution. Hence, the elastic component of rotation is increased by the Irwin plastic-zone correction and the plastic component of rotation is increased or decreased depending on the current applied stress level relative to the flow stress, $\sigma_{f}$. In this method, the effects of strainhardening are incorporated in the evaluation of the rotation.

The LBB.ENG method defines the rotations by using a reduced thickness analogy, see Figure 2.80 . The thickness of the reduced region $\left(t_{e}\right)$ in Figure 2.80 is equivalent to the thickness needed to reach limit load using the Net-Section-Collapse analysis. The plastic rotation due to the crack is determined from

$$
\phi_{p}^{c}=\left(t / t_{e}\right)^{n-1}(\pi / 4 \hat{K})^{n} \alpha\left(\sigma / \sigma_{f}\right)^{n-1} \phi_{e}^{c}
$$

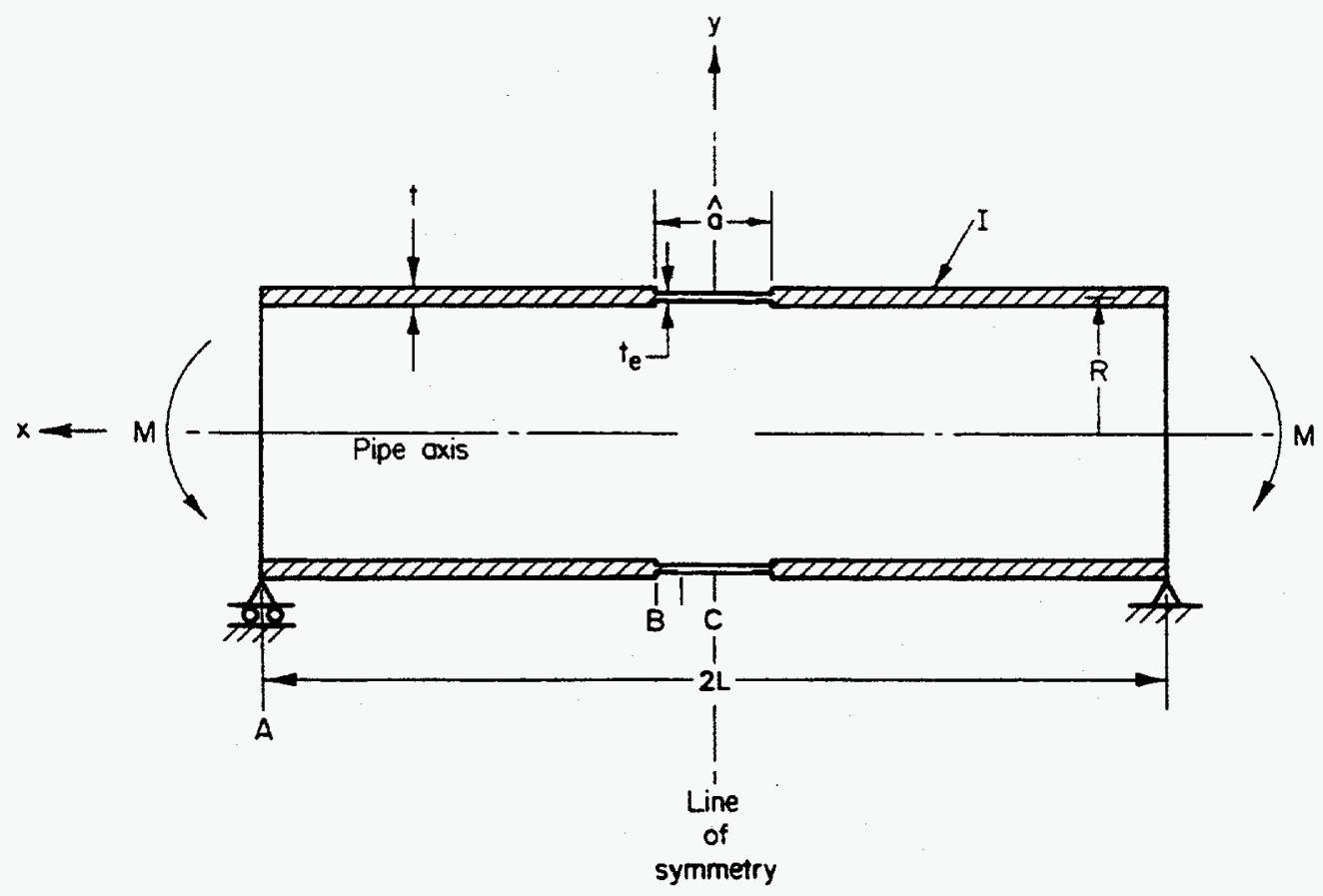

Figure 2.80 Reduced section analogy by the LBB.ENG and SC.ENG methods 
where $\hat{\mathbf{K}}$ is a stiffness parameter that is defined in Reference 2.164 .

The LBB.GE method uses the GE/EPRI V-and h-functions to calculate the moment and rotations. However, unlike the GE/EPRI method, the LBB.GE method integrates the moment-rotation curve in an $\eta$ factor analysis to determine the $J$ values. The moment-rotation curves for the GE/EPRI and LBB.GE methods will be identical up to crack initiation. After crack initiation, however, the differences in the $J$ solutions will cause the crack lengths, and hence, the rotations to be different.

Comparisons with Predicted Circumferentially Through-Wall-Cracked Pipe Experimental Results. Numerous comparisons have been made over the years between experimental and predicted momentrotation curves (Refs. 2.8, 2.14, 2.55, and 2.121. In general, it has been found that to get good agreement, the best predictions occur using the Modified J-R curve (Ref. 2.29) and fitting the engineering stress-strain curves between 0.1 percent strain and the strain at 80 percent of the ultimate strength. Some may argue that the true stress-strain curve should be used, but it should also be recognized that all the J-solutions (including the GE/EPRI solutions) use small strain, small displacement theory. Hence, using the engineering rather than true stress-strain curve compensates for that difference. Use of the standard deformation theory J-R curve will cause the loads (after maximum load is passed in displacementcontrolled loading) to be much lower than the experimental results.

Figures 2.81a and 2.81b show comparisons of load versus load-point displacement predictions for a 406mm (16-inch) diameter, stainless steel, submerged-arc-welded pipe with a crack in the center of the weld using the NRCPIPE computer program (Ref. 2.14) which implements all of the analyses discussed above. (The base metal stress-strain curve was used with weld metal J-R curve.) Note that at the end of the loaddisplacement record, the crack growth was about $190 \mathrm{~mm}$ ( 7.5 inches) at each crack tip. The use of the linear extrapolated $\mathrm{J}_{\mathrm{M}}-\mathrm{R}$ curve from the $1 \mathrm{~T} \mathrm{C}(\mathrm{T})$ specimen with $7.6 \mathrm{~mm}(0.3 \mathrm{inch})$ of stable crack growth worked amazingly well.

Similar results are shown in Figures 2.82a and 2.82b for a circumferential through-wall crack in the fusion line in a bimetallic weld of a 914-mm (36-inch) diameter, by $85.9-\mathrm{mm}$ (3.38-inch) thick cold-leg pipe (Ref. 2.39). (The carbon steel base metal stress-strain curve was used with the weld metal J-R curve.) Again, the predictions using the linearly extrapolated $J_{M}-R$ curve were in excellent agreement with the experimental results. This is especially noteworthy since the maximum useable crack growth data in the 2T $\mathrm{C}(\mathrm{T})$ specimens was about $15.2 \mathrm{~mm}(0.6 \mathrm{inch})$, and the predictions required comparisons with the pipe test data with $405 \mathrm{~mm}$ (15.9 inches) of crack growth from each crack tip.

In both of these two cases, the $C(T)$ specimen J-R curve was successfully extrapolated by a factor of over 25. The accuracy trend using the $\mathrm{J}_{\mathrm{M}}-\mathrm{R}$ curve in the pipe estimation schemes to predict moment-rotation (or load-load-line displacement) behavior was also reported by $\mathrm{Ph}$. Gilles of Framatome during the IPIRG-2 program in their investigation of French pipe experiments.

A final note is that although this procedure worked extremely well, the NRCPIPE code which implements the various predictive J-estimation schemes is based on deformation theory J-R curve methodology. To be strictly correct, the Modified J crack growth terms should be used in these estimation schemes. We suspect that this will not change the predictions significantly, since the crack growth in the pipe experiments is still a small amount of the pipe cross-section. Nevertheless, this should be confirmed in the future. 


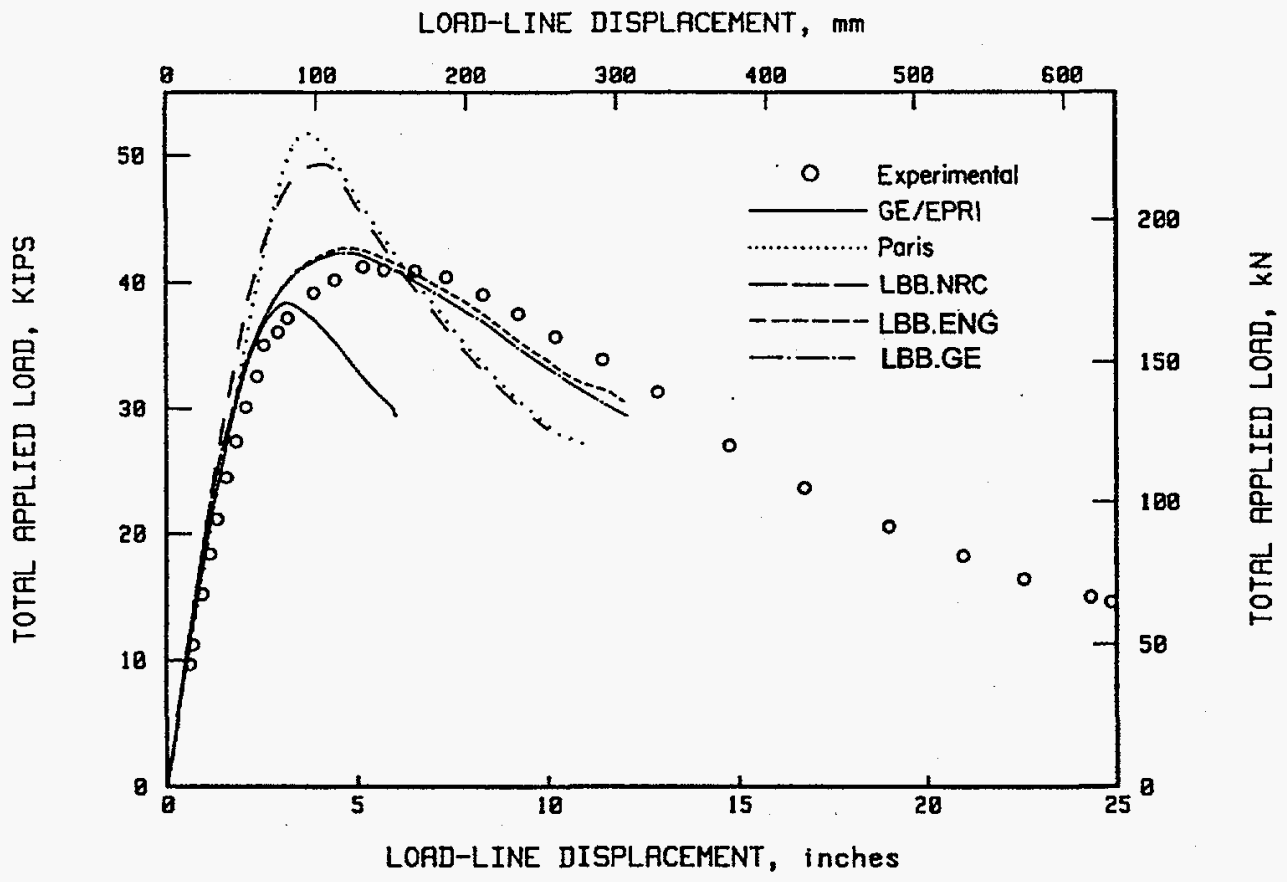

(a) Base metal stress-strain curve and $J_{D}-R$ curve

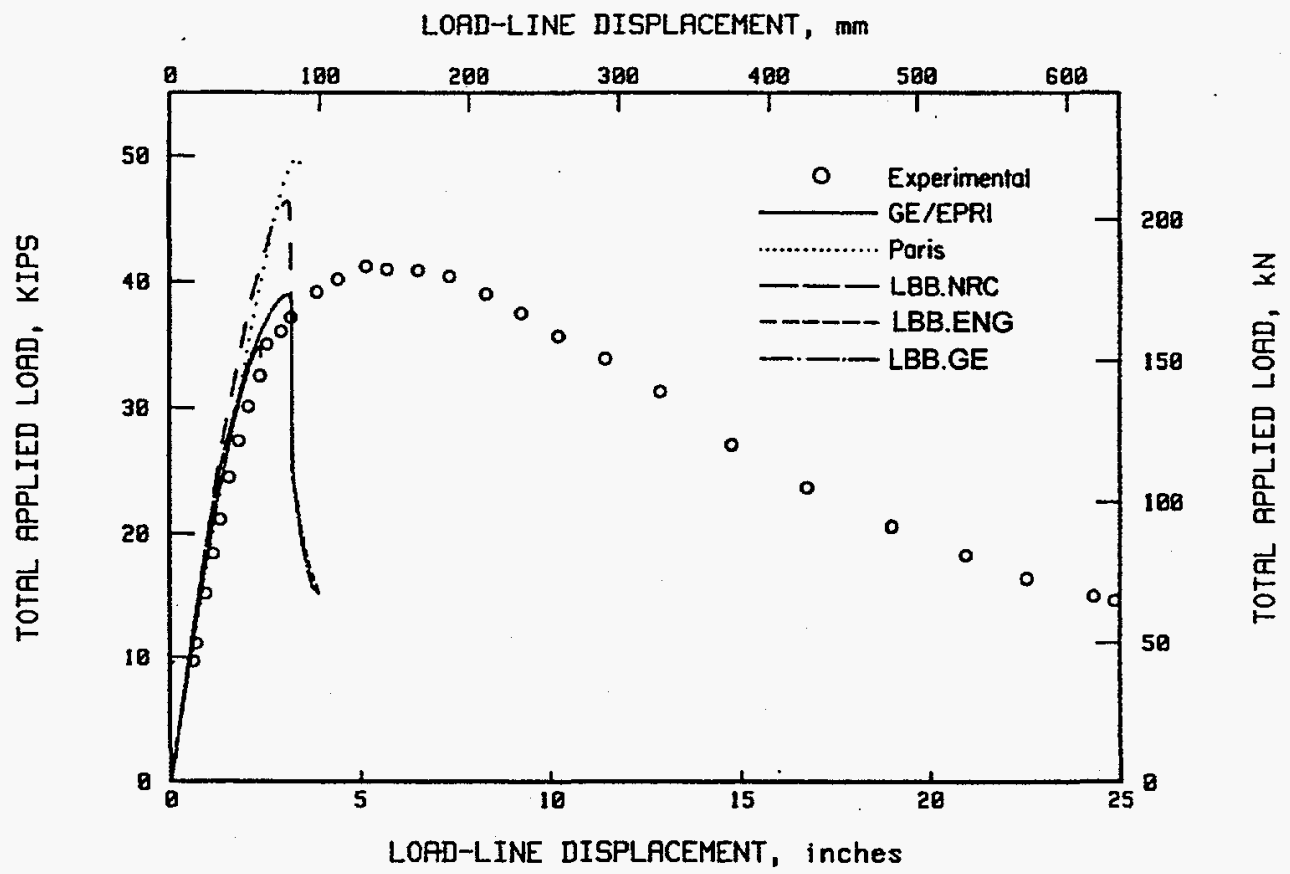

(b) Base metal stress-strain curve and $J_{M}-R$ curve

Figure 2.81 Predicted load versus load-line displacements compared with results from Experiment 4141-3 on 406-mm (16-inch) diameter Type 304 stainless steel as-welded SAW pipe 


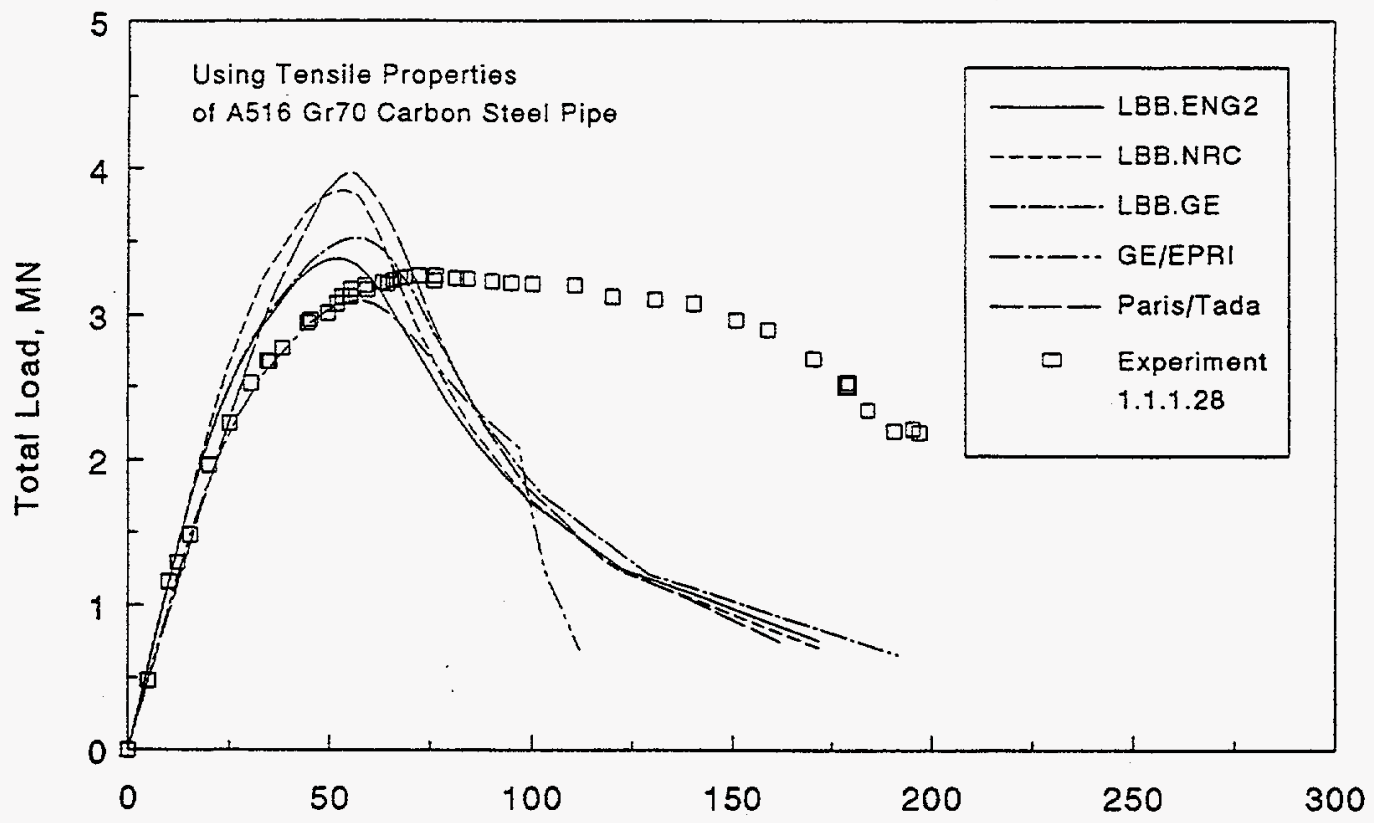

Pipe Displacement at Load Point, $\mathrm{mm}$

(a) Using $J_{D}-R$ curve

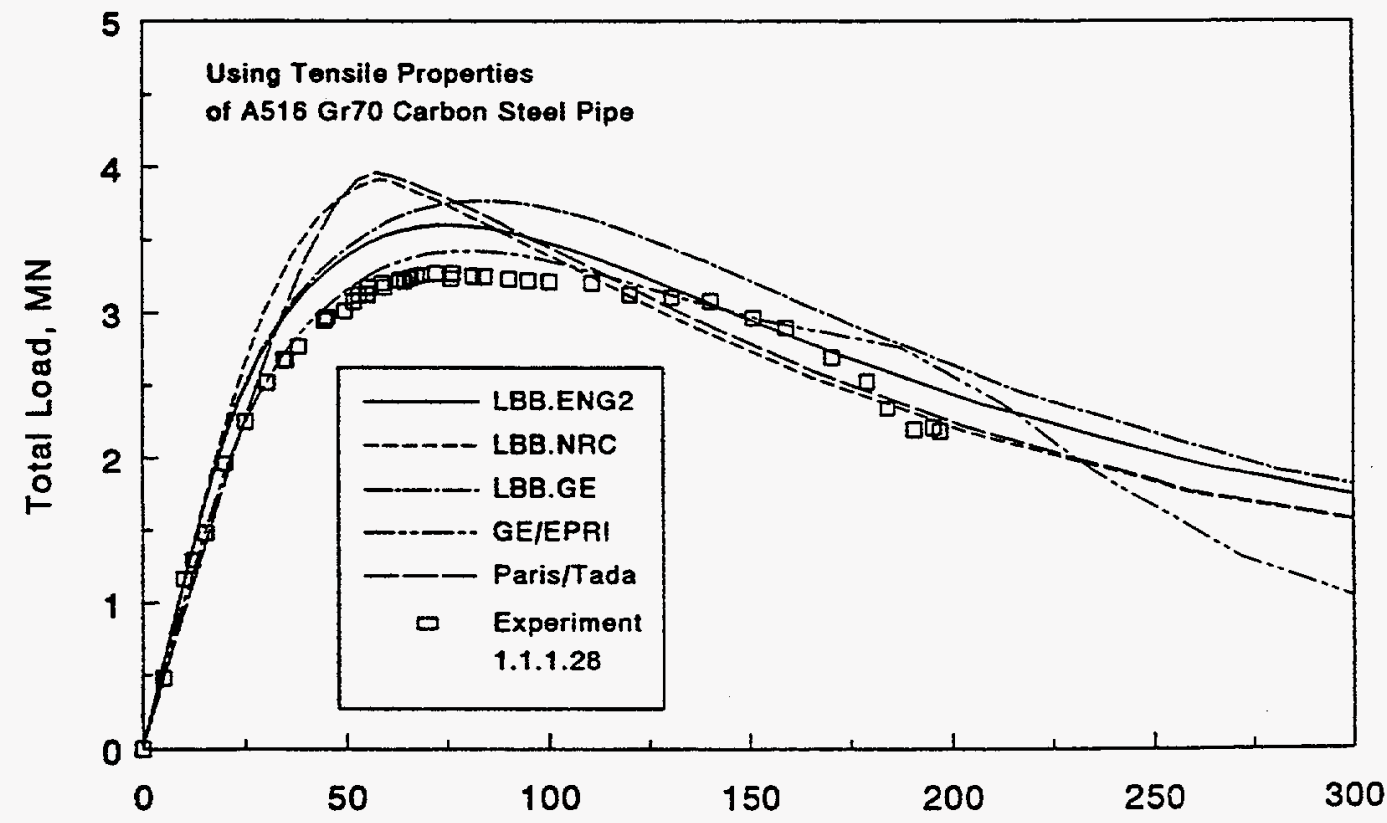

Pipe Displacement at Load Point, mm

(b) Using $\mathbf{J}_{\mathbf{M}}-\mathbf{R}$ curve

Figure 2.82 Comparison of the experimental moment-rotation curve with the predicted momentrotation curves for bimetallic weld cold leg experiment 
Surface-Cracked-Pipe Moment-Rotation Predictions. There are fewer circumferential surface-cracked pipe analysis methods than through-wall-cracked (TWC) pipe analyses methods for predicting momentrotation or load-displacement curves. As noted above for TWC pipe, load versus load-line displacement curves are used for analysis of four-point bend pipe experiments, whereas the moment-rotation curves are more useful in fracture stability analyses.

Some surface-cracked pipe analyses that predict the displacements or rotations due to the crack are:

- $\quad$ SC.TNP thin-shell analysis, where the original analysis (SC.TNP1) from Reference 2.142 was further improved by FEM calibrations in Reference 2.13 (SC.TNP2).

- The SC.TKP thick-shell analysis, where the original analysis (SC.TKP1) from Reference 2.142 was further improved by FEM calibrations in Reference 2.13 (SC.TKP2).

- The SC.ENG1 and SC.ENG2 methods which were developed in Reference 2.13. The SC.ENG1 uses the original Net-Section-Collapse equations within it, whereas the SC.ENG2 solution uses the Kurihara-modified Net-Section-Collapse solution.

The GE/EPRI solutions in Reference 2.136 were only for $\mathrm{J}$ versus moment ( $\mathrm{h}_{1}$ functions), and no displacement or rotation functions were determined. Reference 2.165 discusses the problem in defining the rotation functions for a surface-cracked pipe or elbow.

In the SC.TNP analysis, the rotation of the pipe (note $\phi$ is the total rotation), is defined by

$$
\phi_{p}^{c}=2 \alpha \epsilon_{0} t M^{n} /\left[R_{m}\left(4 t \sigma_{0} H_{n} R_{m}^{2}\right)^{n}\right]
$$

and in the SC.TKP solution,

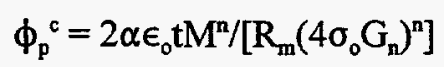

where

$$
\begin{array}{lll}
\mathrm{R}_{\mathrm{m}} & =\text { mean pipe radius } \\
\mathrm{t} & =\text { pipe wall thickness } \\
\alpha, \epsilon_{0}, \sigma_{0}, \mathrm{n} & =\text { Ramberg-Osgood stress-strain parameters (see Equation 2-35) } \\
\mathrm{M} & =\text { applied moment } \\
\mathrm{H}_{\mathrm{n}}, \mathrm{G}_{\mathrm{n}} & =\text { tabulated influence functions. }
\end{array}
$$

The functions $H_{n}$ and $G_{n}$ were derived in Reference 2.142 from an analytical expression incorporating the GE/EPRI solution for a 360-degree surface-cracked pipe under tension loading. 
The SC.ENG methods use a parallel development to the LBB.ENG method that was for through-wall cracks, where

$$
\phi_{p}^{c}=\left(t / t_{e}\right)^{n-1}(\pi / 4 \hat{K})^{n} \alpha\left(M / M_{0}\right)^{n-1} \phi_{e}^{c}
$$

where

$$
t_{e}=\text { equivalent thickness }
$$

and the parameter $\hat{\mathrm{K}}$ is analytically determined and can contain either the original Net-Section-Collapse (NSC) or Kurihara-modified NSC pipe limit-load solutions. Hence, the $\hat{\mathbf{K}}$ functions are different when using the Original Net-Section-Collapse solutions in SC.ENG1, or when using the Kurihara modified NetSection-Collapse solutions in SC.ENG2, see Reference 2.13.

In general, the efforts that have gone into the development and validation of the displacement and rotation functions for circumferentially surface-cracked pipe have been far less extensive than that for circumferentially through-wall-cracked pipe.

Comparisons with Predicted Circumferential Surface-Cracked-Pipe Experimental Results. Numerous comparisons have been made at Battelle using the NRCPIPES code over the years. Four such cases from Reference 2.13 are shown in Figures 2.83 to 2.86. Table 2.10 lists the experimental parameters. As can be seen in these figures, the predictions are less accurate than the through-wall-cracked pipe results shown earlier, but are still useful in an engineering sense.

Table 2.10 Experimental parameters for experiments shown in Figures 2.83 through 2.86

\begin{tabular}{|c|c|c|c|c|c|c|c|}
\hline $\begin{array}{c}\text { Expt. } \\
\text { Number }\end{array}$ & Material & $\begin{array}{c}\text { Outside } \\
\text { Pipe } \\
\text { Diameter, } \\
\mathbf{m m}\end{array}$ & $\begin{array}{c}\text { Pipe Wall } \\
\text { Thickness, } \\
\mathbf{m m}\end{array}$ & $\begin{array}{c}\text { Internal } \\
\text { Pipe } \\
\text { Pressure, } \\
\text { MPa }\end{array}$ & $\begin{array}{c}\text { Test } \\
\text { Temp., } \\
\text { C }\end{array}$ & $\boldsymbol{\theta} / \boldsymbol{\pi}$ & $\mathbf{a} / \mathbf{t}$ \\
\hline 1.2 .1 .20 & TP304 & 406 & 9.50 & 1.55 & 93 & 0.25 & 0.476 \\
\hline 1.2 .3 .15 & A516 Grade 60 & 711 & 22.7 & 9.56 & 288 & 0.25 & 0.50 \\
\hline 1.2 .3 .16 & TP316L SAW & 711 & 30.2 & 10.1 & 288 & 0.25 & 0.50 \\
\hline 1.2 .3 .17 & A106B SAW & 610 & 42.7 & 15.5 & 288 & 0.25 & 0.605 \\
\hline
\end{tabular}

\subsubsection{Circumferential Cracked-Pipe Stability Analyses}

The previously discussed engineering flaw assessment methodologies in Sections 2.3.2.2 and 2.3.2.3 predict the initiation and maximum load-carrying capacity of cracks in pipes. They do not, however, make any assessment of the stability of the flaws when the flaws reach maximum load unless all stresses are load-controlled, which is not typical for real piping systems. Stability in this context means the absence of large amounts of rapid crack growth. If a crack has a large maximum moment capacity, and the piping 


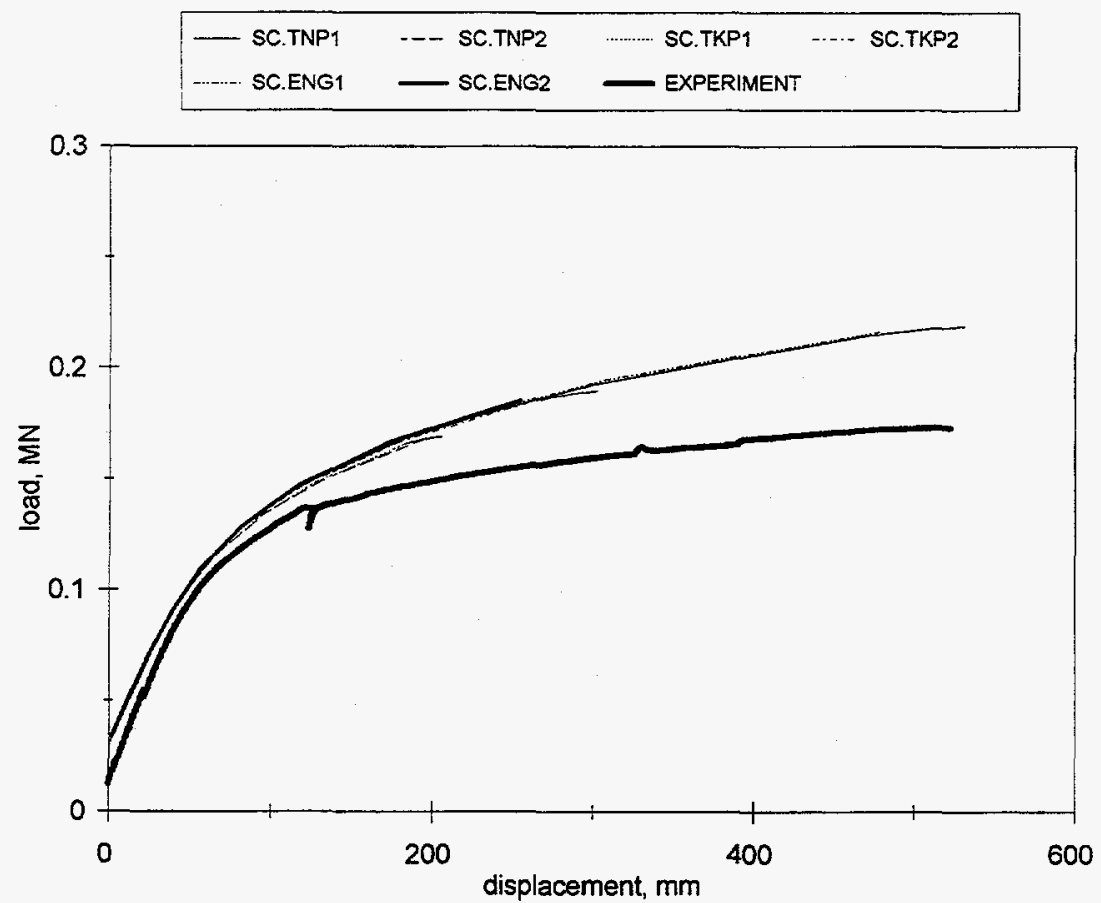

Figure 2.83 Comparison of experimental data with analytical prediction of load versus pipe displacement at the load points for Experiment 1.2.1.20

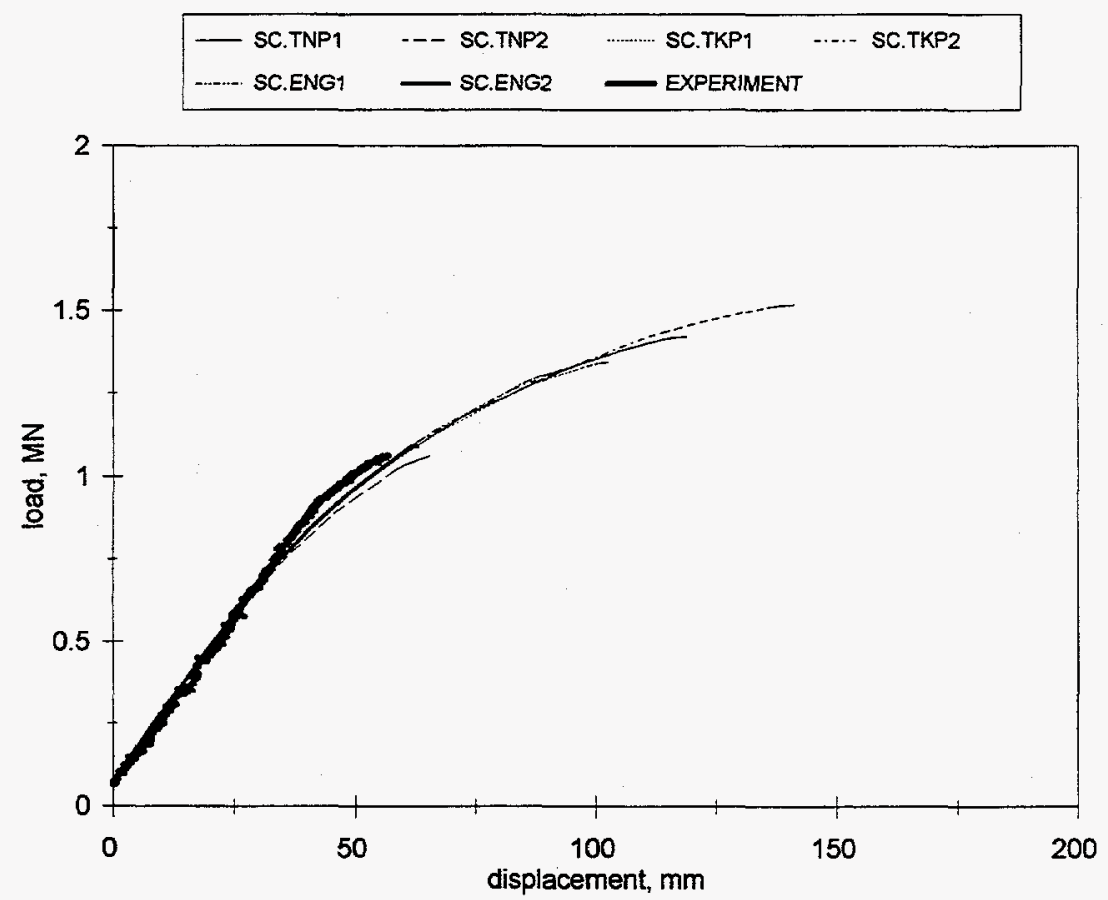

Figure 2.84 Comparison of experimental data with analytical prediction of load versus pipe displacement at the load points for Experiment 1.2.3.15 

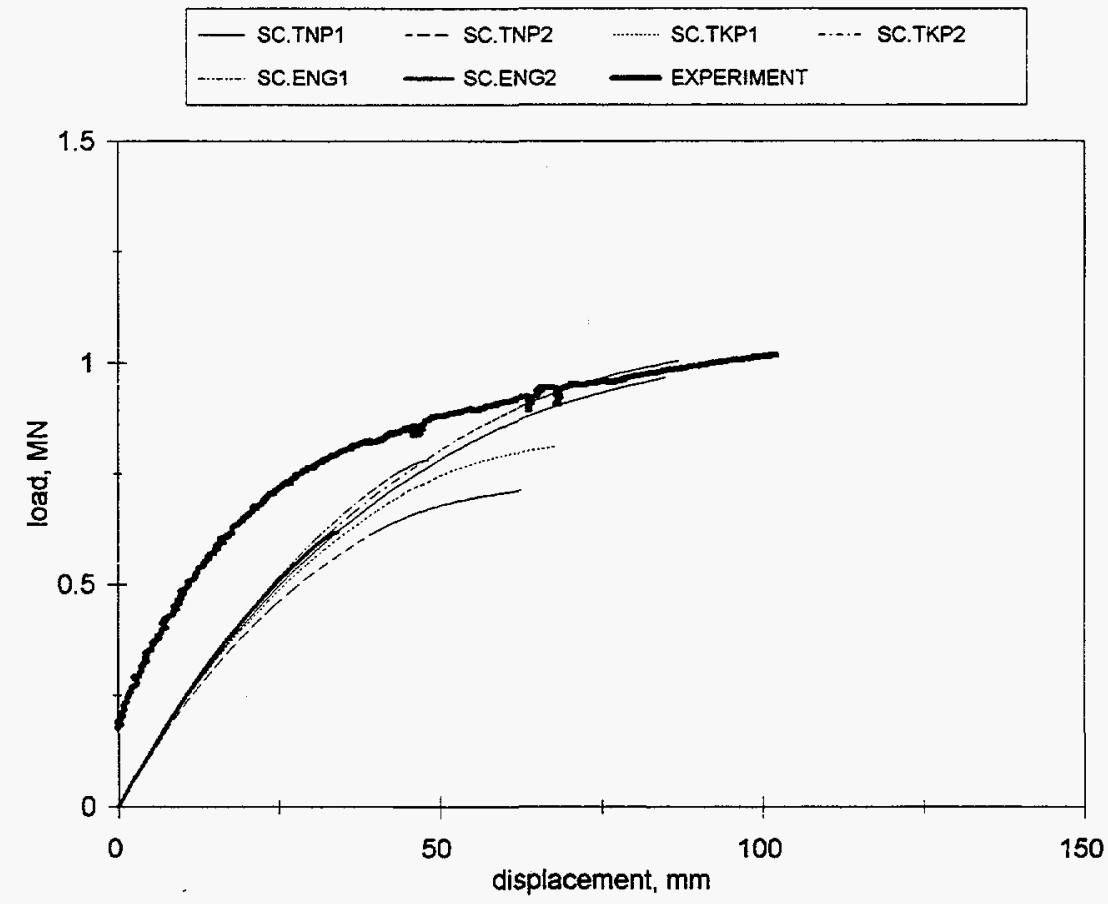

Figure 2.85 Comparison of experimental data with analytical prediction of load versus pipe displacement at the load points for Experiment 1.2.3.16

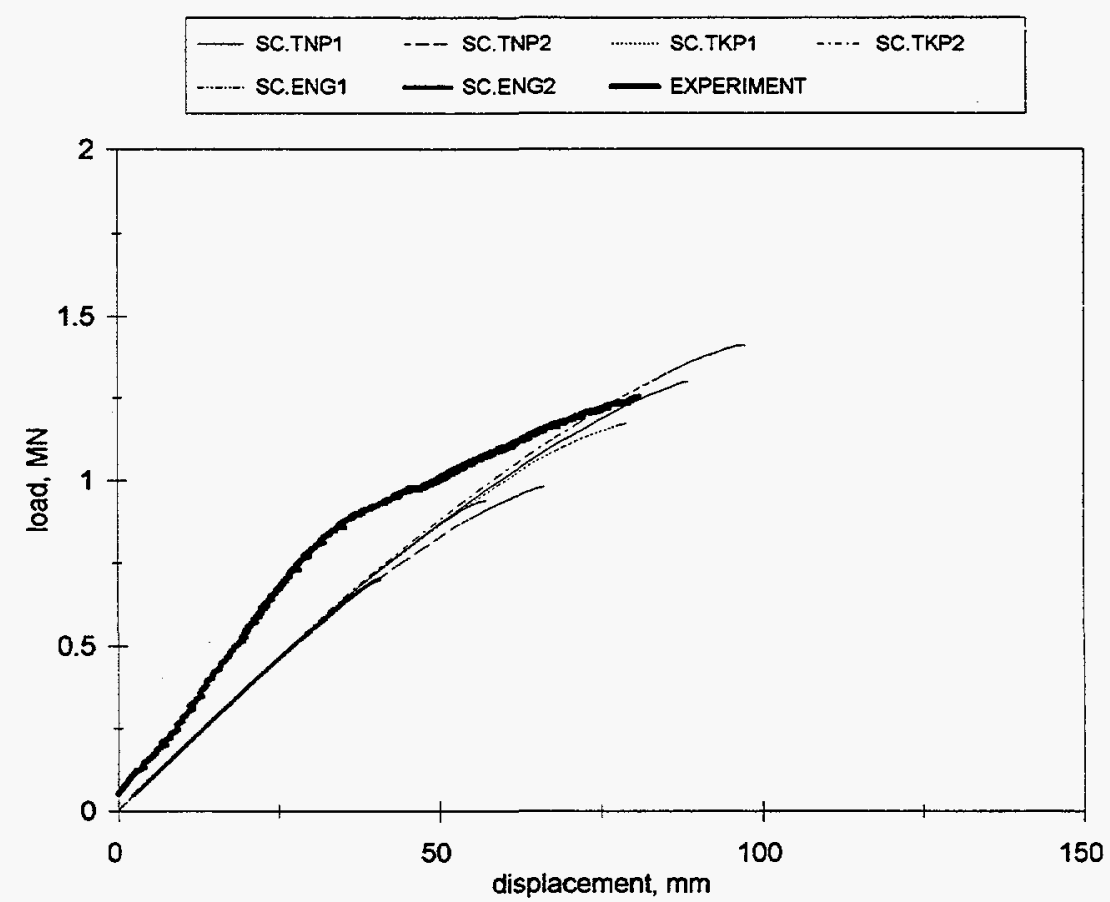

Figure 2.86 Comparison of experimental data with analytical prediction of load versus pipe displacement at the load points for Experiment 1.2.3.17 
system that contains the crack is very compliant, the applied load that would cause the crack to propagate will cause a great deal of elastic deformation in the pipe system. The elastic deformation of the pipe system will result in a large amount of stored energy in the pipe system which may be released in the form of rapid, unstable crack growth after maximum load. Less compliance in the test system or lower momentcarrying capacity of the crack tend to enhance stability.

There currently are three engineering analysis flaw stability assessment strategies, $\mathrm{J} / \mathrm{T}$ stability analysis, the Battelle Energy Balance stability analysis, and nonlinear dynamic finite element analysis. In all cases, the methods are founded on the idea of determining the energy stored in the pipe system that can be made available to drive the crack, and comparing this available energy to the energy that is needed to grow the crack.

Fully Plastic J/T Stability Analysis. The J-integral/tearing modulus, fully plastic J/T, analysis is a method currently used to make an assessment of the stability of cracked structures. Paris and his coworkers popularized the methodology (Ref. 2.166). A rather extensive compilation of $\mathrm{J} / \mathrm{T}$ solutions for various loading modes (displacement-controlled and load-controlled) and assumed material behavior can be found in Reference 2.138 .

Simply stated the $\mathrm{J} / \mathrm{T}$ instability criteria for cracked pipe can be expressed as:

$$
\mathrm{J}_{\text {spplied }}>\mathrm{J}_{\mathrm{Ic}}
$$

and

$$
\mathrm{T}_{\text {applied }}>\mathrm{T}_{\text {material }}
$$

If the applied $\mathrm{J}$ is greater than $\mathrm{J}_{\mathrm{Ic}}$, the crack will grow. Then, if the applied tearing modulus $\left(\mathrm{T}_{\text {applied }}\right)$ becomes greater than the material's tearing resistance $\left(T_{\text {material }}\right)$, crack growth instability will occur.

Graphically, the $\mathrm{J} / \mathrm{T}$ methodology is shown in Figures 2.87 and 2.88. In the left-hand part of Figure 2.87, applied $\mathrm{J}$ is computed as a function of load for the given pipe, crack, and material. Applied $\mathrm{J}$ is also calculated as a function of applied $\mathrm{T}$ and plotted on the right-hand side of the figure. Next, a $\mathrm{J} / \mathrm{T}$ curve representing the material's crack growth resistance, as developed from a compact tension or pipe specimen $\mathrm{J}-\mathrm{R}$ curve, is plotted on the right-hand portion of the figure from data shown in Figure 2.88. $\mathrm{J}_{\text {applied }}$ and $T_{\text {applied }}$ solutions, as a function of load, can be found in Reference 2.138. Instability is predicted to occur when the applied and material $\mathrm{J} / \mathrm{T}$ curves intersect, see right hand part of Figure 2.87 .

$\mathrm{J} / \mathrm{T}$ analyses can be performed for surface cracks or through-wall cracks under assumed load-controlled or displacement-controlled stresses, with various assumed material behaviors (LEFM, small-scale yielding, fully plastic, EPFM, etc.). $\mathrm{J} / \mathrm{T}$ analysis can predict the occurrence of an instability, but it does not predict how severe the instability will be. That is, it is typically assumed that once an instability starts it will continue until there is complete fracture. In addition, $\mathrm{J} / \mathrm{T}$ analysis is limited to the bounding cases of fully displacement-controlled or fully load-controlled stresses. 


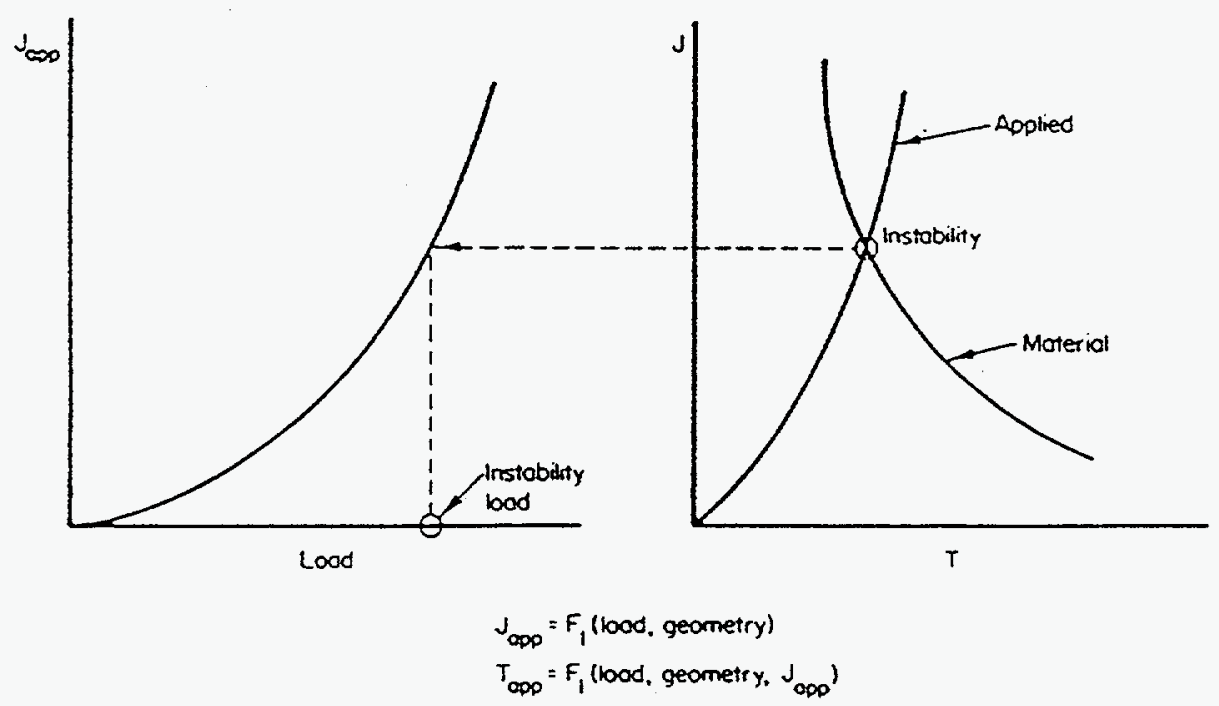

Figure $2.87 \mathrm{~J} / \mathrm{T}$ stability assessment methodology

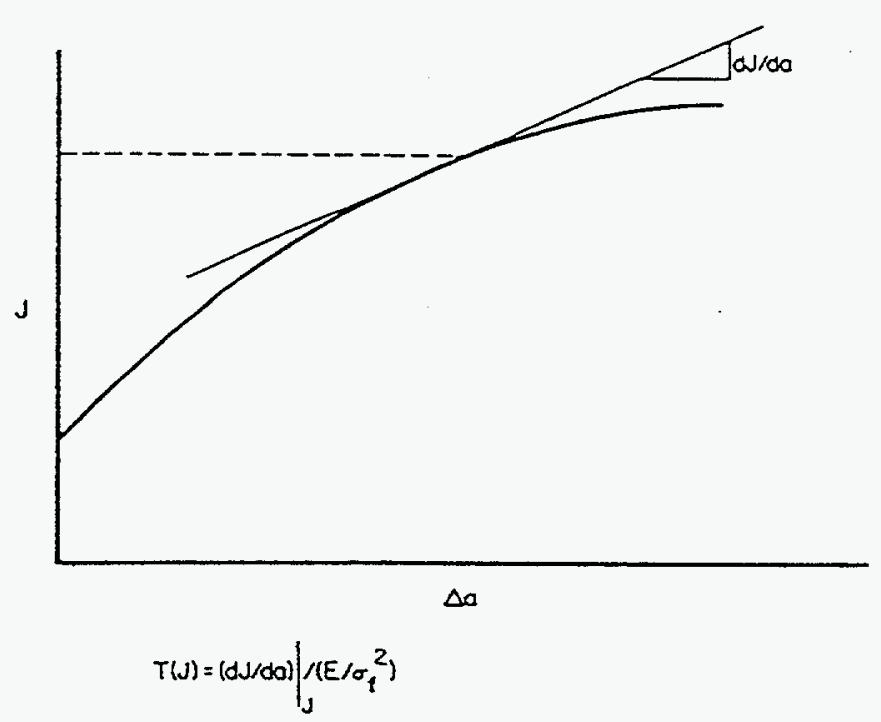

Figure 2.88 Material $\mathrm{J} / \mathrm{T}$ behavior 
Energy Balance Stability Analysis. The Energy Balance Stability Method is a technique that was developed in the Degraded Piping Program (Ref. 2.162) to predict the onset of crack instability and to estimate the crack length at arrest of a limited instability for either a through-wall or surface-cracked pipe. In general, it can use any elastic-plastic J-estimation scheme to calculate the moment-rotation (or forcedisplacement) response of a cracked pipe to determine the energy absorbed in the fracture process, and the elastic energy in the pipe system to determine the energy available to drive the instability. It has been verified for some compliant surface-cracked pipe fracture experiments (Refs. 2.61 and 2.162), throughwall-cracked pipe experiments (Refs. $2.167,2.168$, and 2.169), and complex-cracked pipe experiments (Ref. 2.60).

The basic process used to conduct an energy balance stability assessment is shown in Figures 2.89 to 2.91 Although the process is described in moment-rotation coordinates and refers to a surface crack transitioning to a through-wall crack, the concept is perfectly general and applies equally well to loaddisplacement coordinates and pure through-wall cracks.

In Figure 2.89a, the moment-rotation behavior of a surface crack is shown. The crack is assumed to be a circumferential plane of zero axial length, with all effects of the pipe on either side excluded. At any point on the loading curve, the shaded area describes the elastic energy that is stored in the cracked pipe. In Figure $2.89 \mathrm{~b}$, the elastic energy stored in the attached piping is shown, assuming that all of the piping remote from the crack remains elastic and that the loading and unloading compliances are equal and linear. Figure $2.89 \mathrm{c}$ is the sum of the energies shown in Figures $2.89 \mathrm{a}$ and $2.89 \mathrm{~b}$. This is the total energy available to drive a crack.

The energy absorbed by a through-wall crack growing from length $\theta_{i}$, the original length of the surface crack, to some final length $\theta_{\text {tot }}$ is shown in Figure 2.90. Figure 2.91 shows the energy being absorbed to propagate the through-wall crack being made equal to the available elastic energy from the crack and the attached piping system. Stability is determined by how far out on the through-wall crack curve the energies balance.

In contrast to the $\mathrm{J} / \mathrm{T}$ analysis, the Energy Balance analysis can estimate how far the crack will propagate; given that the energies balance at a given crack rotation that is above zero moment, the companion through-wall crack J-estimation scheme can be used to find the crack length at that rotation. The Energy Balance method can also deal with combined displacement- and load-controlled stresses. If the applied moment on the crack due to pressure and dead weight, for instance, is greater than the moment where the energies balance (see the horizontal load-controlled moment line in Figure 2.91), the crack will not arrest, but would be expected to grow to a DEGB.

Dynamic Non-Linear Stability Analysis. The analyses described in the previous sections make liberal use of engineering assumptions to intentionally induce conservative estimates of flaw behavior. Foremost among the assumptions that contribute to the conservatism are:

(1) The fracture and pipe response are assumed to be decoupled.

(2) An elastic uncracked pipe stress analysis is used to determined the moments or stresses at the crack location. 


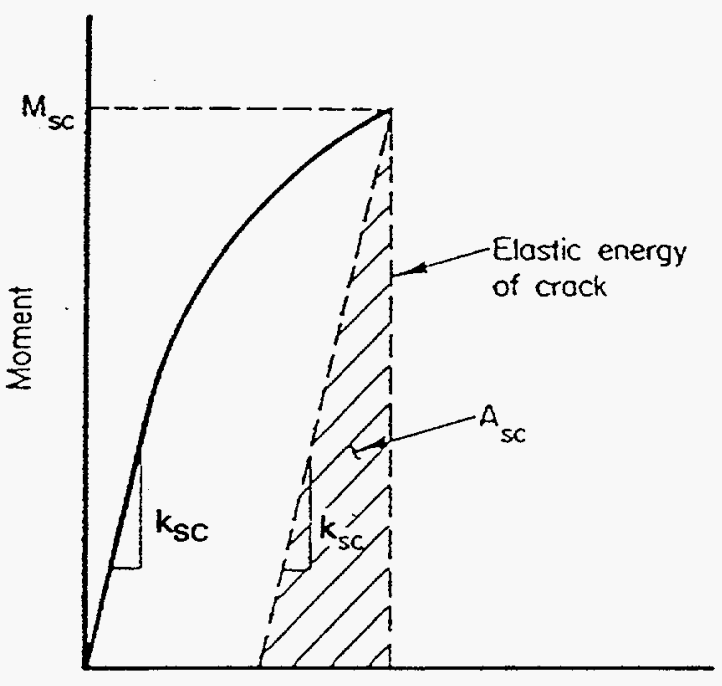

Rotation Due To Crack

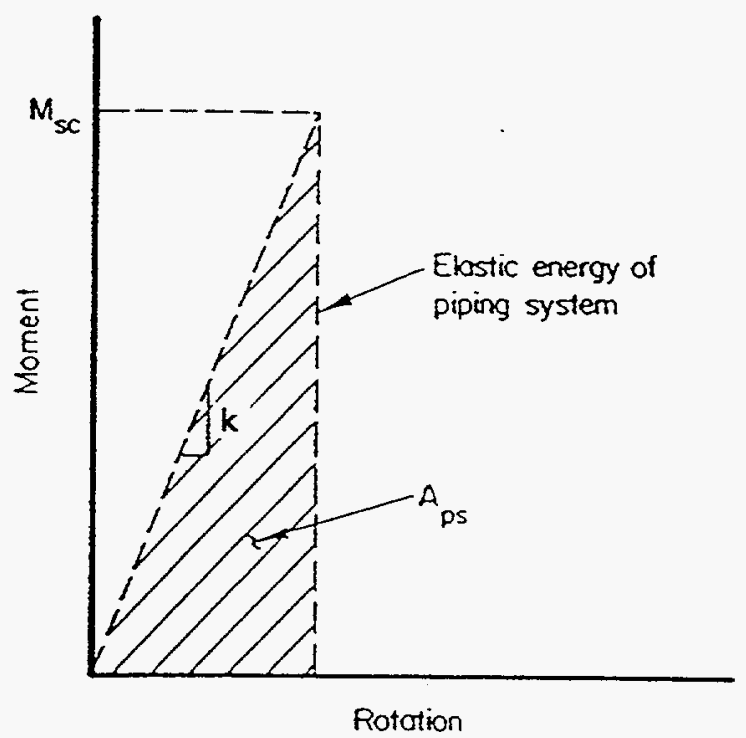

(b) Pipe-system behavior

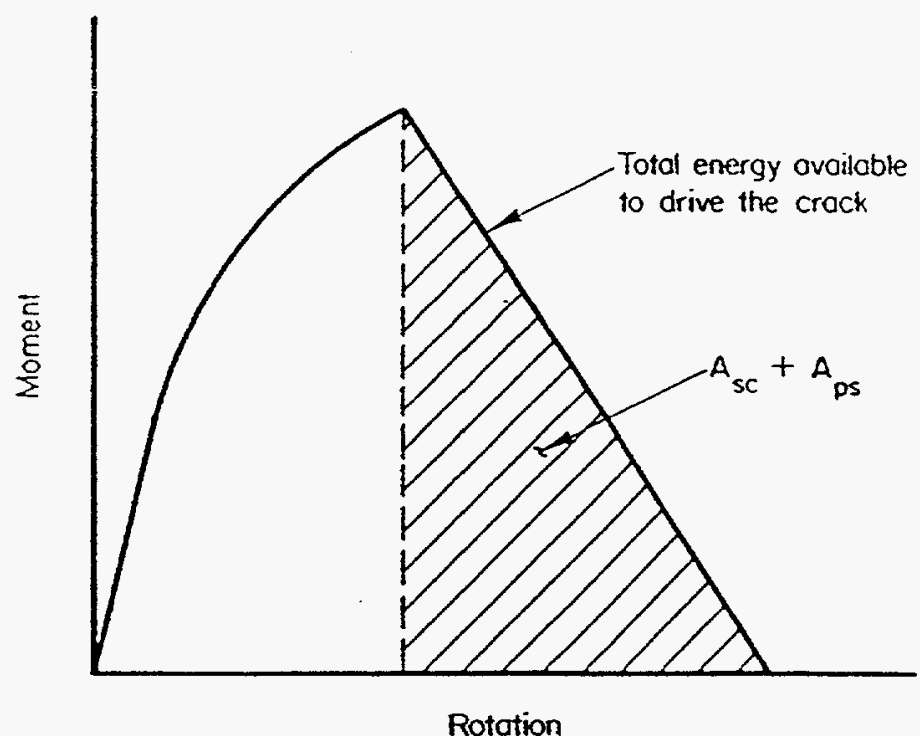

(c) Combined energy

Figure 2.89 Energy available for driving an instability 
Section 2

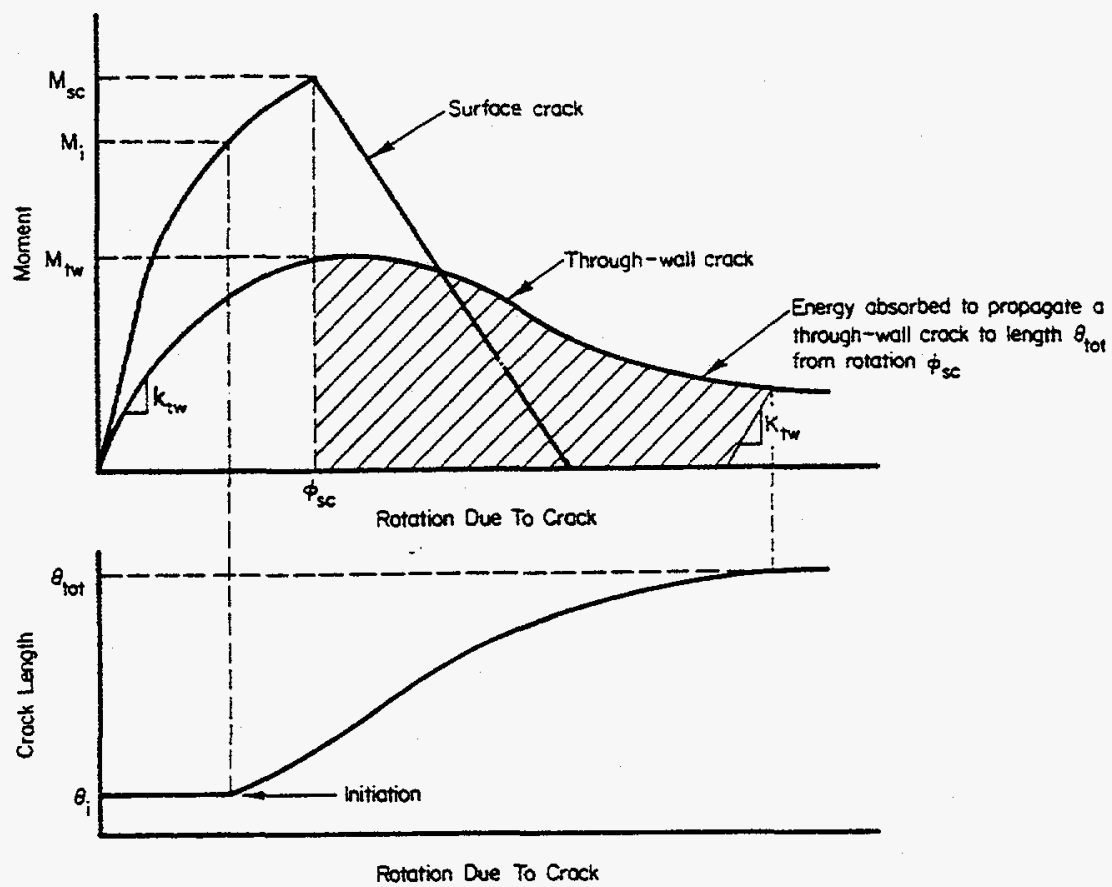

Figure 2.90 Crack propagation behavior

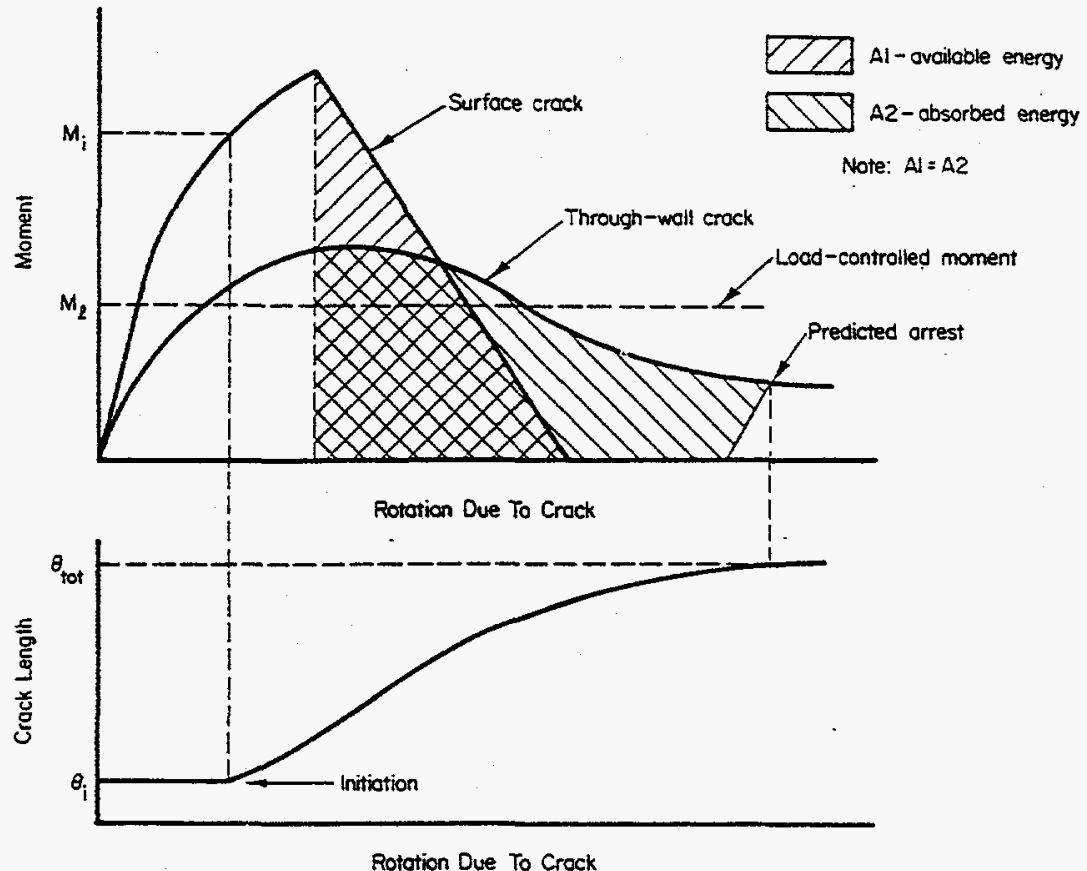

Figure 2.91 Energy Balance diagram showing balanced available and absorbed energies 
(3) The transient nature of dynamic loads is ignored, i.e., stresses are applied statically and in a load-controlled manner.

(4) "Design" values for flaw material properties are generally used.

From a plant design and operation perspective, this conservatism is generally desirable. From the point of view of analysis margin assessment, or the point of view of pipe fracture experiment design, the inherent conservatism of the engineering fracture mechanics analyses is not appropriate. To address this issue, state-of-the-art nonlinear FEA pipe stability fracture analysis methods that directly deal with the four points listed above have been developed.

There are at least three different categories of cracked-pipe dynamic stability analyses. These are:

- Complete three-dimensional finite element modeling,

- Substructuring, using beam elements for the uncracked pipe and three-dimensional elements at the crack location, and

- Using beam elements for the uncracked pipe and a nonlinear spring element to simulate the crack response.

Complete three-dimensional, elastic-plastic, dynamic analysis is extremely costly, time consuming, and is not a practical engineering tool. Substructuring with beam elements and three-dimensional elements at the crack is more practical, but for a surface-crack problem, the finite element mesh is very complicated. Griesbach (Ref. 2.170), conducted a substructured dynamic analysis for a through-wall crack with a relatively coarse shell element mesh, see Figure 2.92, and Brosi did a similar analysis for analysis of an

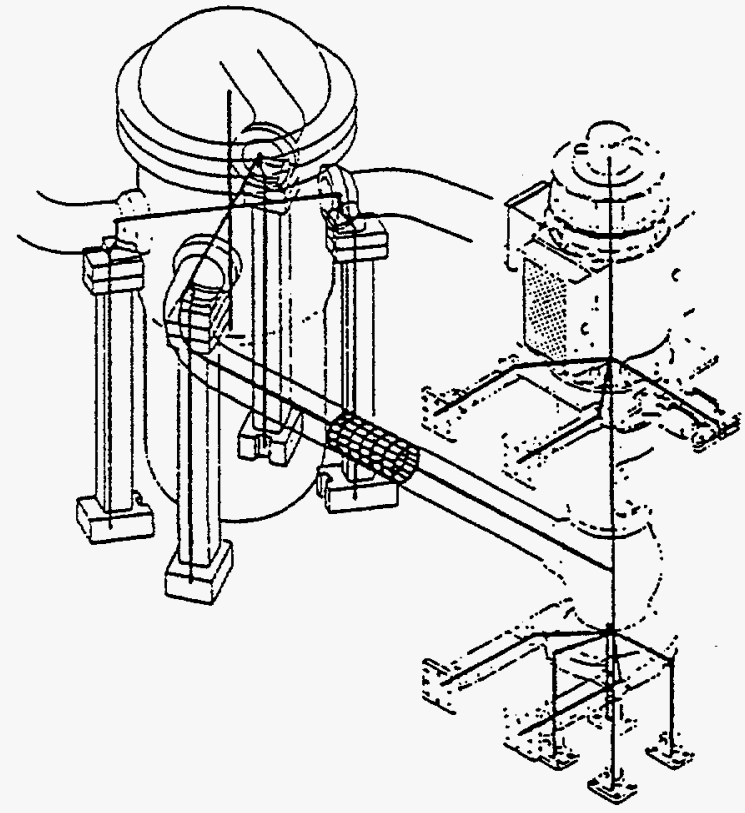

Figure 2.92 Cracked pipe analysis beam and shell piping system model of Griesbach (Ref. 2.170) 
HDR circumferential surface-cracked pipe experiment using 3D elements (Ref. 2.171) while Kussmaul et al. analyzed the same experiment using line-spring elements with pipe shell elements (Ref. 2.172). Mesh development and computer time for a more detailed analysis, particularly for surface cracks, makes such an approach very expensive.

The final approach, the one used by Battelle during the IPIRG programs, has proven to be very economical, and is possibly the most accurate approach. In this approach, the crack response is represented by a nonlinear spring and the dynamic response of the pipe system becomes an inherent part of the fracture analysis. This is somewhat similar to the French CEA approach that embedded the Tada-Paris J-estimation scheme directly in their FEM code to determine the moment-rotation response of the cracked pipe under dynamic loading (Ref. 2.173).

Using the nonlinear spring approach, the crack is treated as a single degree-of-freedom moment-rotation response at a point. With reference to Figure 2.93, the crack is implemented in the ANSYS finite element computer program (Ref. 2.174) using standard elements in series and parallel. The surface crack is modeled with three combination elements (STIF40) in parallel, configured as spring-sliders. This
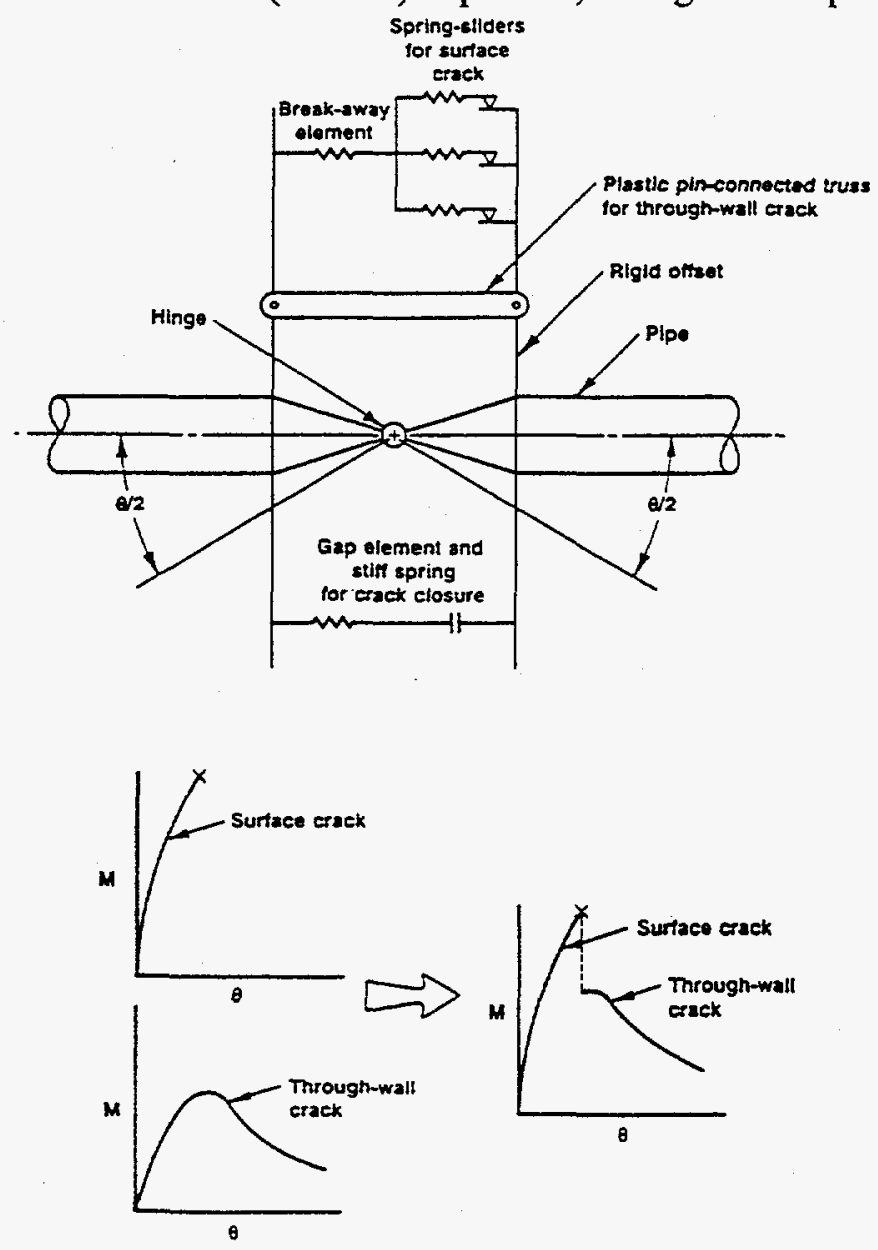

Figure 2.93 Combined surface-crack and through-wall-crack model for analyzing dynamic surface to through-wall-crack transitions 
implements a three-segment nonlinear moment-rotation response. A fourth STIF40 element in series with the surface crack STIF40's is configured as a break-away element, i.e., the element is removed when a maximum force (moment) is attained. Through-wall cracks are modeled using a truss element, STIF8, with rigid offsets and a kinematic hardening plastic stress-strain response. This implements a five-segment nonlinear moment-rotation response that can displace beyond maximum load into a locally negative stiffness regime. An additional STIF40 element, not shown in Figure 2.93, that is in parallel with all of the preceding elements is configured as a very stiff spring with a gap. This STIF40 element provides a crack closure function, i.e., it makes the crack behave like competent pipe when the crack faces close in compression. The pipe system is modeled with standard straight and curved pipe elements, STIF16 and STIF18, respectively.

The key element in implementing the nonlinear FEA fracture stability analysis is to define the nonlinear moment-rotation response for the crack. The method that Battelle uses to do this is the J-estimation schemes previously discussed. The basic assumptions for defining the nonlinear crack response are:

- For low-cycle high amplitude loading, the cyclic load effects on the crack growth are assumed to be small; crack growth is dominated by ductile tearing under increasing load amplitude.

- High strain rate effects on crack growth and on the constitutive relationship are typically ignored, even though they may tend to influence crack growth and the plastic flow for some materials (Ref. 2.175). Rarely will one have access to dynamic material property data (i.e., dynamic tensile or J-R curve data).

- Only a separation mode (Mode I) of crack propagation under bending is assumed. This implies that the crack section is considered to be rigid in all degrees of freedom except the rotation corresponding to the crack opening.

- The rotational deformation due to the crack and relevant plastic deformations are confined to the crack section.

In particular, Battelle has developed and uses the SC.TNP1 J-estimation scheme for finite-length, circumferential, surface-cracked pipe predictions (Refs. 2.13 and 2.142) and the LBB.ENG2 J-estimation scheme for circumferential through-wall cracked pipe (Refs. 2.120 and 2.121).

The basic procedure used to perform a nonlinear FEA fracture mechanics flaw stability evaluation is as follows:

(1) The geometry of the basic pipe system is modeled using finite elements (straight and curved pipe elements).

(2) A J-estimation scheme analysis is performed to define the moment-rotation response of the crack by itself. If a surface crack is being analyzed, moment-rotation response must be defined for the surface crack and the expected through-wall-crack response after surface crack penetration.

(3) The predicted moment-rotation response of the cracked section is implemented in the finite element model using nonlinear springs. If a surface to through-wall crack transition is 
possible, a break-away element is used in series with the surface crack springs. Crack closure springs must also be used to prevent "crack growth" behavior during compressive loading.

(4) For circumferentially surface-cracked pipe, conduct a dynamic time-history analysis and note if and when the maximum surface-cracked pipe moment is achieved. If the maximum surface crack moment is not achieved, then the analysis terminates and the conclusion is that the surface crack does not penetrate the pipe wall. If maximum moment is attained, restart the analysis at the time step of maximum moment of the surface crack with the break-away element invoked. This will "remove" the surface crack from the subsequent load steps.

(5) Conduct dynamic time-history analysis of the piping system as a circumferential through-wall or complex crack ${ }^{*}$ problem. At some point, the moment capacity of the crack may be exhausted, in which case one would predict that a DEGB, i.e., a instability, had occurred. If the crack unloads before reaching zero moment capacity, then continue with Step 6.

(6) At the point of crack unloading, determine the amount of crack growth and save the restart files for the dynamic analysis.

(7) At the given amount of crack growth, conduct a through-wall or complex crack analysis to determine the compressive response of the cracked section. This is a plasticity-type calculation and not a J-estimation scheme crack growth analysis.

(8) At the given amount of crack growth, conduct a J-estimation scheme crack analysis with the new crack length and the initiation toughness of the J-R curve, $J_{i}$, set to the value attained when the crack unloaded. This basically implements the change in compliance caused by the longer crack while retaining the correct moment-rotation response when the crack reinitiates.

(9) Restart the dynamic cracked-pipe analysis with new material properties. The tensile part of the moment-rotation curve comes from Step 8 and the compressive part comes from Step 7.

Recycle to Step 5, as needed.

In implementing the nonlinear springs, careful attention to all of the series/parallel spring combinations must be observed. Energy dissipation, due to cyclic loading of the nonlinear crack prior to initiation, is an inherent part of the analysis described above. Loading past maximum moment, transition of a surface crack to a through-wall crack, reinitiation of a crack that has already extended, and direct assessment of the propensity for a DEGB are also possible.

Validation. The validity of the various stability analyses can be checked by seeing if they can predict the stability for some actual experiments. Ideally, the analyses should also be able to predict how far the crack should grow if there was a limited crack jump, i.e., the pipe did not break in half.

\footnotetext{
* A complex crack is a through-wall crack with a surface crack in the same circumferential plane
} 
To make this assessment, five quasi-static through-wall cracked pipe experiments from David Taylor Research Center (DTRC) on 203-mm (8-inch) diameter A106 Grade B pipe (Ref. 2.168) and two, dynamic, surface-cracked, water-hammer-loading, pipe-system experiments were evaluated (Ref. 2.169).

The objective of the quasi-static David Taylor Research Center (DTRC) experiments was to provide data to evaluate the Tada-Paris $\mathrm{J} / \mathrm{T}$ instability analyses. The five experiments chosen for this analysis had different crack lengths and test system compliances, but the same pipe material and nominal pipe size. The relevant experimental data are summarized in Table 2.11, while the test system configuration is shown in Figure 2.94. With reference to Figure 2.94, if a crack has a large maximum moment and the belleville springs are relatively soft, the applied load from the pistons will be large and hence, the deflections of the springs will be large. At large spring deflections, there will be a large amount of stored energy in the springs available to drive the crack unstable after maximum load. Less compliance in the test system or lower moment-carrying capacity of the crack tends to enhance stability. The cracks in Experiments 7,11 , and 12 were stable while the cracks in Experiments 13 and 14 were unstable.

Table 2.11 Test matrix for instability assessments of A106 steel pipes subjected to four-point bending

\begin{tabular}{|c|c|c|c|c|c|c|}
\hline $\begin{array}{c}\text { DTRC Pipe } \\
\text { Experiment } \\
\text { No. }\end{array}$ & $\begin{array}{c}\text { Pipe } \\
\text { Length, } \\
\mathbf{m m}^{(\mathbf{a})}\end{array}$ & $\begin{array}{c}\text { Mean } \\
\text { Radius, } \\
\mathbf{m m}^{(\mathbf{a})}\end{array}$ & $\begin{array}{c}\text { Mean } \\
\text { Thickness, } \\
\mathbf{m m}^{(\mathbf{a})}\end{array}$ & $\begin{array}{c}\text { Initial Crack } \\
\text { Length (2c), } \\
\mathbf{m m}^{(\mathbf{a})}\end{array}$ & $\begin{array}{c}\text { Moment } \\
\text { Arm } \\
\text { Length } \\
\text { (span), } \\
\mathbf{m m}^{(\mathbf{b})}\end{array}$ & $\begin{array}{c}\text { Total } \\
\text { Machine } \\
\text { Stiffness, } \\
\mathbf{N} / \mathbf{m m}\end{array}$ \\
\hline 7 & 1219 & 102 & 13.7 & 210 & 457 & 87,550 \\
\hline 11 & 1067 & 102 & 15.2 & 160 & 381 & 6,480 \\
\hline 12 & 1067 & 102 & 13.9 & 149 & 381 & 6,480 \\
\hline 13 & 1067 & 103 & 13.4 & 138 & 381 & 6,340 \\
\hline 14 & 1067 & 103 & 14.6 & 124 & 381 & 6,480 \\
\hline
\end{tabular}

(a) $25.4 \mathrm{~mm}=1.0 \mathrm{inch}$

(b) $0.17513 \mathrm{~N} / \mathrm{mm}=1.0 \mathrm{lb} / \mathrm{in}$. 


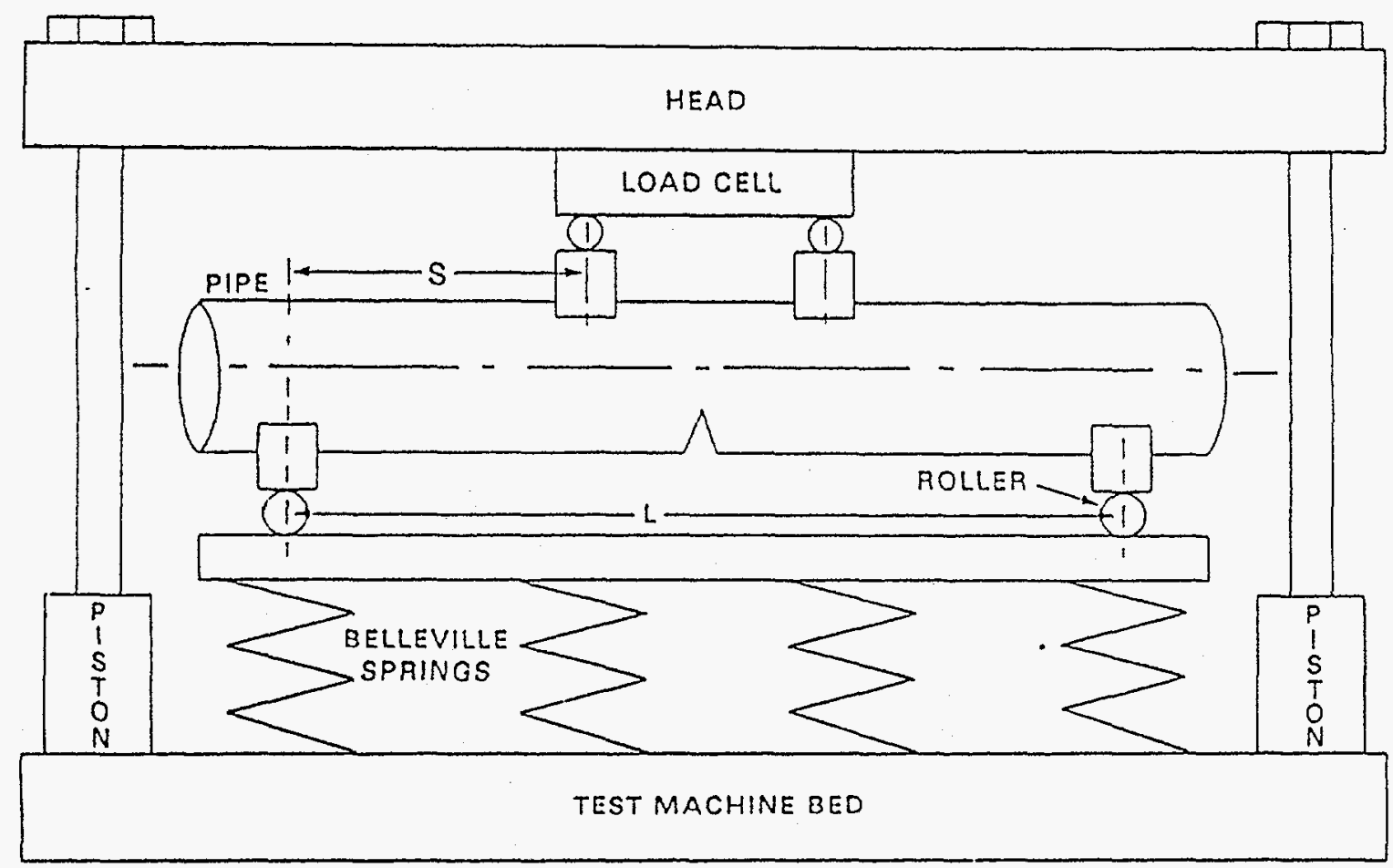

Figure 2.94 Schematic of DTRC compliant instability pipe experiments

The objective of the dynamic water hammer loading experiments was to gather data on the fracture resistance of surface cracks in an actual pipe system under high-rate dynamic loading. Figure 2.95 shows the test system configuration. The experiments were conducted by rupturing the disk on the free end of the pipe system and then rapidly closing the valve at SRV 350 to create a water hammer shock wave that would load the crack. Although the experiments were not specifically designed to study instability behavior, they provide a good opportunity to assess the validity of various stability analysis methods. 


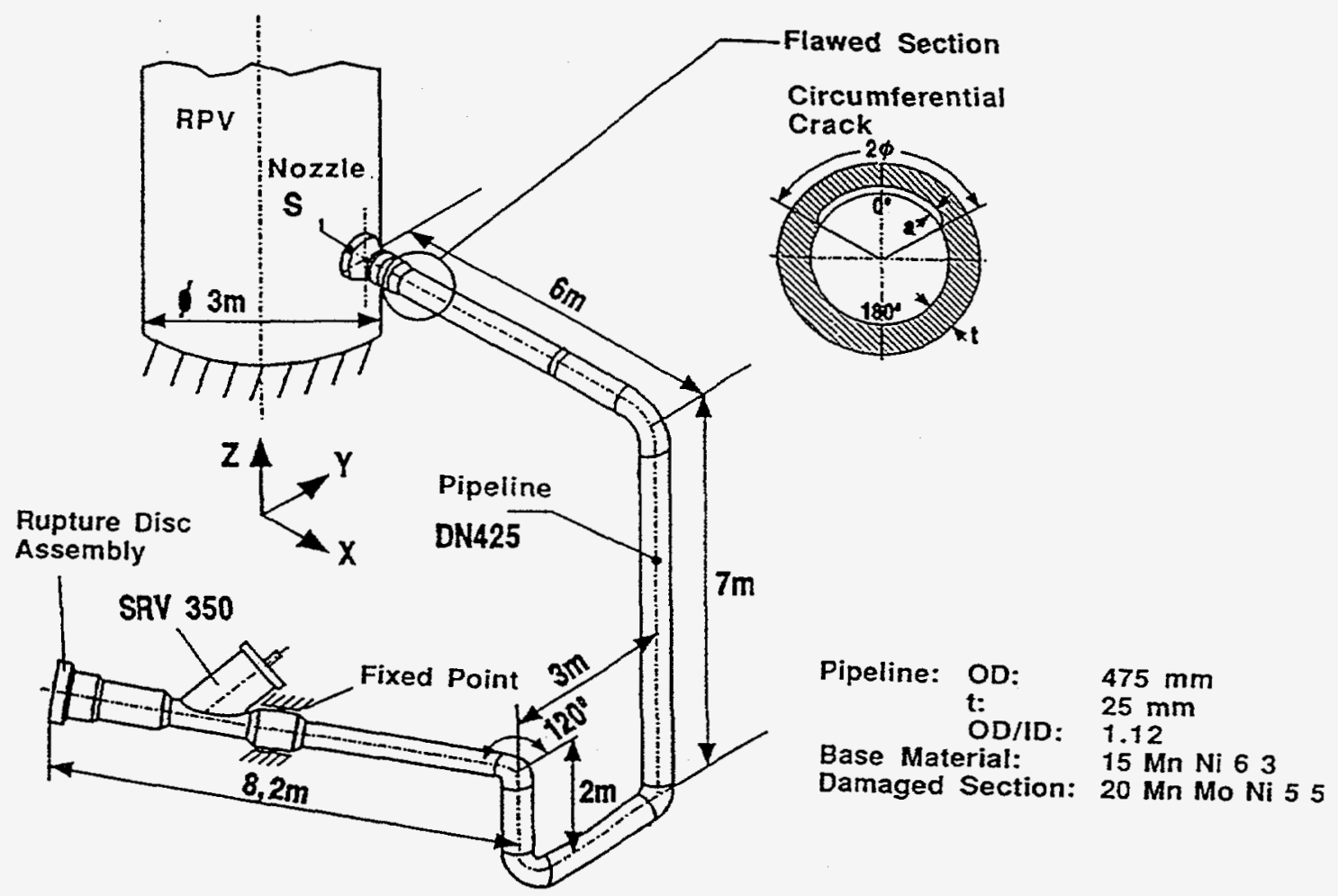

Figure 2.95 HDR-E31 test system with flawed section

Evaluation of the validity of the various stability analysis methods under quasi-static conditions using the DTRC test data is shown in Table 2.12. In this case, an EPFM J/T stability analysis by Zahoor (Ref. 2.138) was used. The prediction of instability for DTRC Experiments 11 and 12 is not consistent with the test observations. The universal disagreement between all of the predictions and the observed stability for Experiments 11 and 12 raises the issue of the sensitivity of the stability predictions to stiffness changes. However, as shown in Figures 2.96 through 2.98 and Table 2.13 the analyses do not support the hypothesis that slight stiffness measurement errors can explain why the stability of Experiments 11 and 12 is incorrectly predicted.

Considering the performance of the various stability analyses under dynamic loading conditions, Figures 2.99 through 2.101 and Table 2.14 suggest that Energy Balance and dynamic nonlinear stability analyses do a better job of predicting stability. These two methods show discrepancies in predicted crack growth, but they do in fact show that the cracks are not unstable. 
Table 2.12 Stability comparison for DTRC compliant instability experiments

\begin{tabular}{|c|c|c|c|c|c|}
\hline $\begin{array}{c}\text { DTRC } \\
\text { Experiment }\end{array}$ & $\begin{array}{c}\text { Spring } \\
\text { Stiffness, } \\
\text { N/mm }\end{array}$ & Experiment & $\begin{array}{c}\text { Dynamic } \\
\text { Nonlinear }\end{array}$ & $\begin{array}{c}\text { Energy } \\
\text { Balance }\end{array}$ & $\begin{array}{c}\text { Zahoor } \\
\text { EPFM J/T }\end{array}$ \\
\hline 7 & 87,563 & Stable & Stable & Stable & Stable \\
\hline 11 & 6,480 & Stable & Unstable $^{(\text {b) }}$ & Unstable $^{(\text {b) }}$ & Unstable \\
\hline 12 & 6,480 & Stable & Unstable $^{(\text {b) }}$ & Unstable $^{(b)}$ & Unstable \\
\hline 13 & 6,340 & Unstable & Unstable $^{(\text {Unstable }}$ & Unstable \\
\hline 14 & 6,480 & Unstable & Unstable $^{(\text {b) }}$ & Unstable $^{(b)}$ & Unstable \\
\hline
\end{tabular}

(a) $0.17513 \mathrm{~N} / \mathrm{mm}=1.0 \mathrm{lb} / \mathrm{in}$.

(b) Although not analyzed, these experiments are almost certainly unstable due to similarity with Experiment 13.

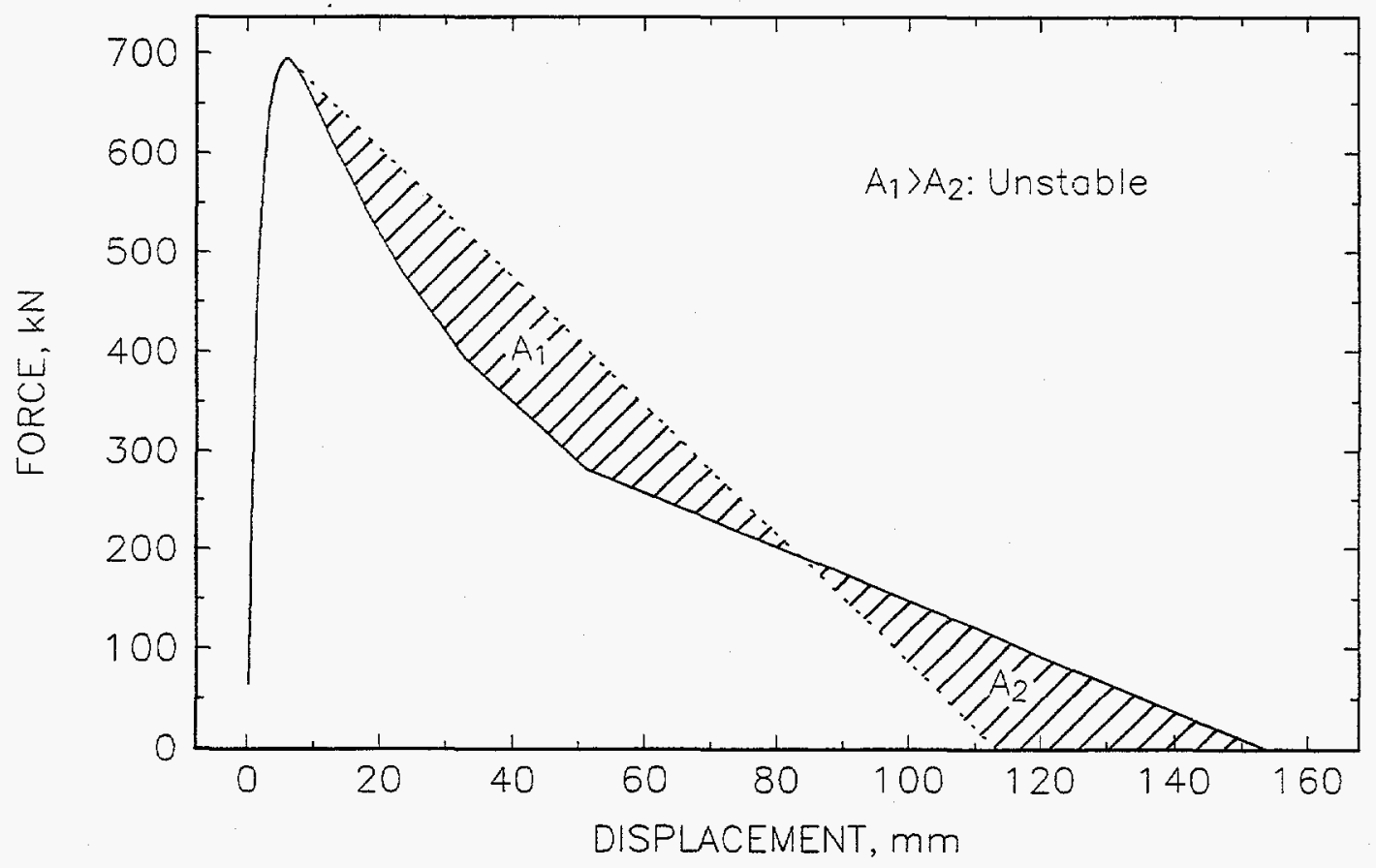

Figure 2.96 Energy balance for DTRC Experiment 13 with $6,480 \mathrm{~N} / \mathrm{mm}(37,000 \mathrm{lb} / \mathrm{in})$ system stiffness 


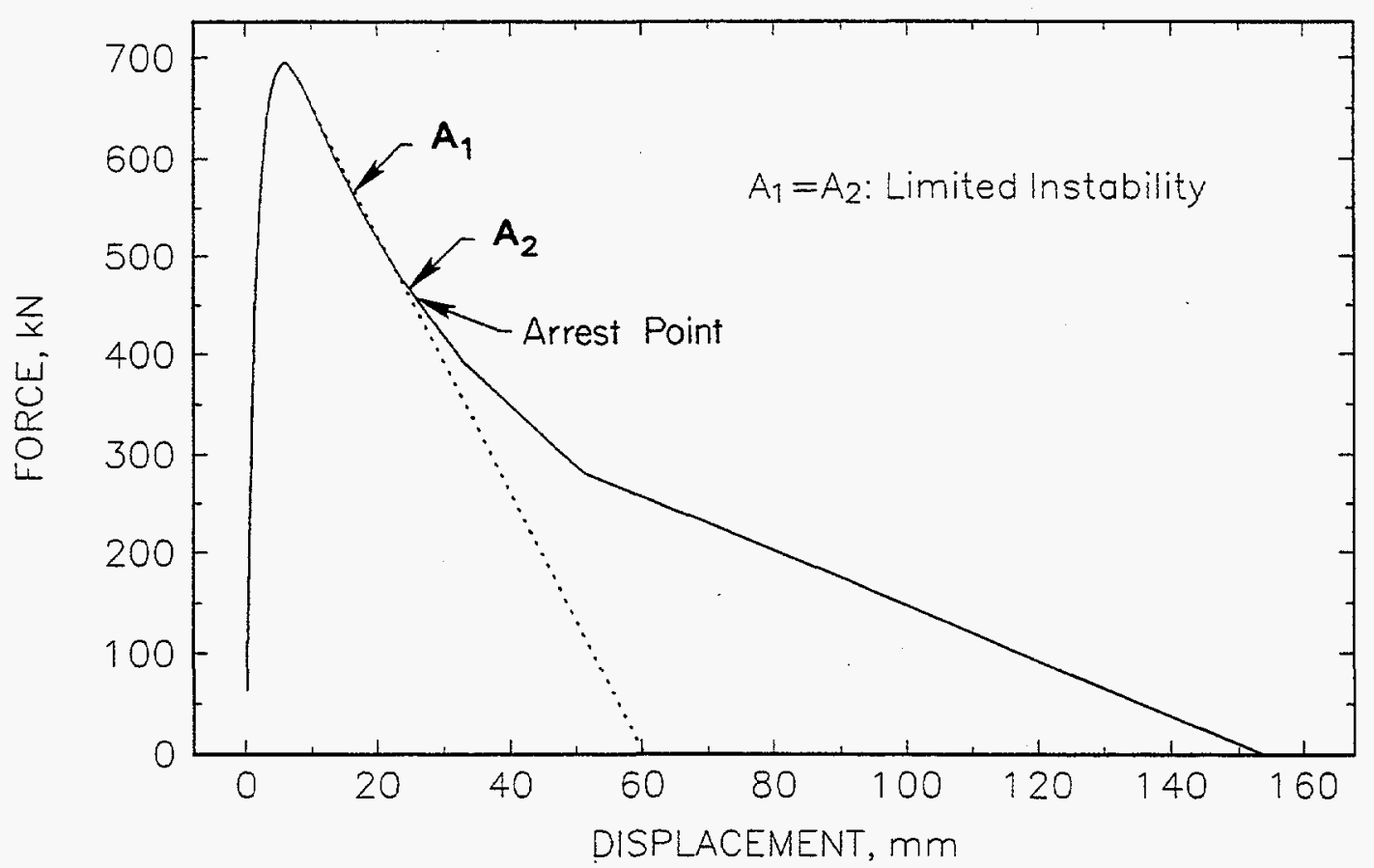

Figure 2.97 Energy balance for DTRC Experiment 13 with 12,959 N/mm (74,000 lb/in) system stiffness

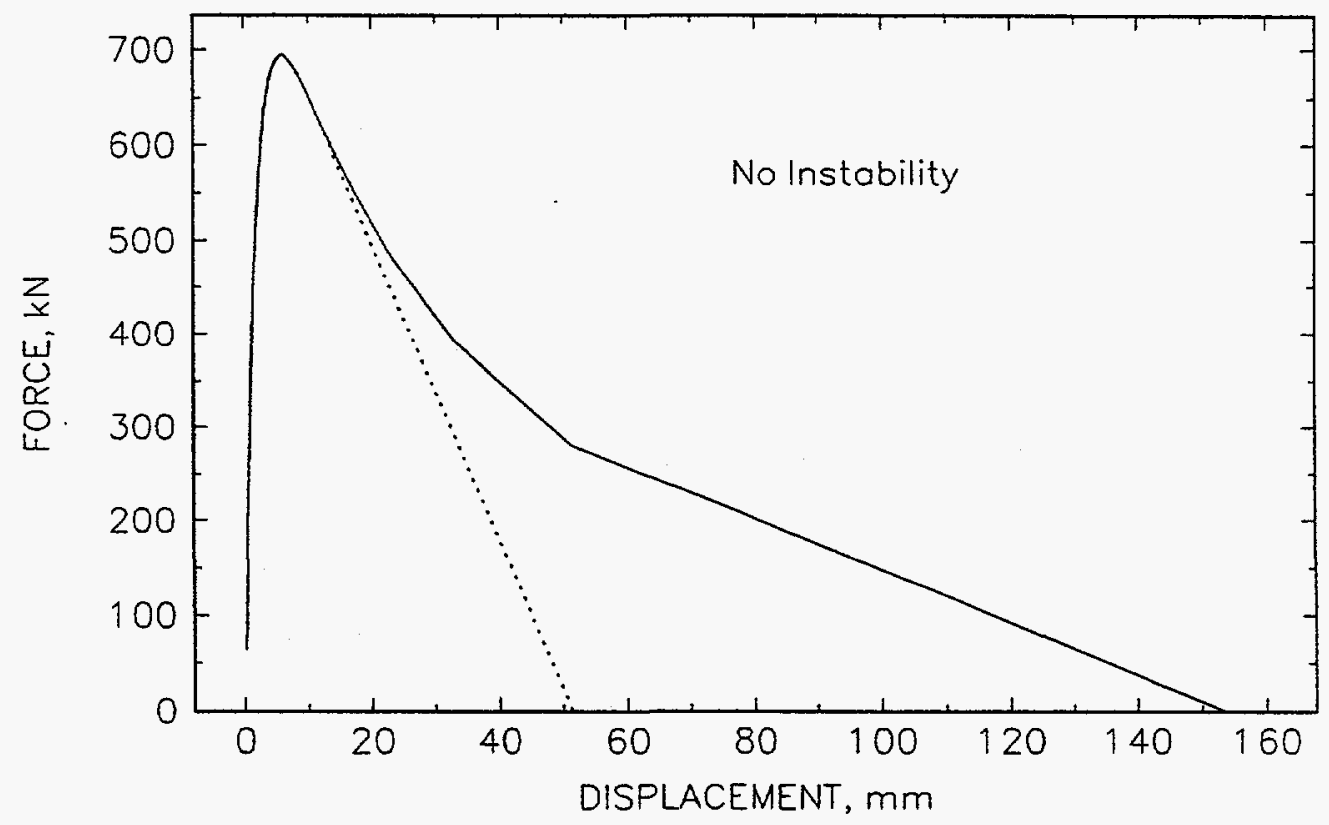

Figure 2.98 Energy balance for DTRC Experiment 13 with 15,761 N/mm (90,000 lb/in) system stiffness 
Table 2.13 Stability comparison for DTRC compliant instability Experiment 13 with various hypothetical stiffnesses

\begin{tabular}{|c|c|c|c|c|}
\hline $\begin{array}{c}\text { Spring Stiffness, } \\
\text { N/mm }\end{array}$ & Experiment & $\begin{array}{c}\text { Dynamic } \\
\text { Nonlinear }\end{array}$ & Energy Balance & $\begin{array}{c}\text { Zahoor } \\
\text { EPFM J/T }\end{array}$ \\
\hline 6,340 & Unstable & Unstable & Unstable & Unstable \\
\hline $10,508^{(\mathrm{b})}$ & - & Unstable $^{(\mathrm{c})}$ & Unstable $^{(\mathrm{c})}$ & Stable \\
\hline $12,959^{(\mathrm{b})}$ & - & Unstable & $\begin{array}{c}\text { Unstable } \\
\text { (limited) }\end{array}$ & Stable \\
\hline $15,761^{(\mathrm{b})}$ & - & $\begin{array}{l}\text { Unstable } \\
(\text { limited })\end{array}$ & Stable & Stable \\
\hline $19,264^{(\mathrm{b})}$ & - & Stable $^{(\mathrm{d})}$ & Stable $^{(\mathrm{d})}$ & Stable \\
\hline
\end{tabular}

(a) $0.17513 \mathrm{~N} / \mathrm{mm}=1.0 \mathrm{lb} / \mathrm{in}$.

(b) Not used in experiment.

(c) Although not analyzed, these experiments almost certainly unstable based on comparison with higher stiffness analyses.

(d) Not analyzed, but almost certain stable based on other Experiment 13 predictions.

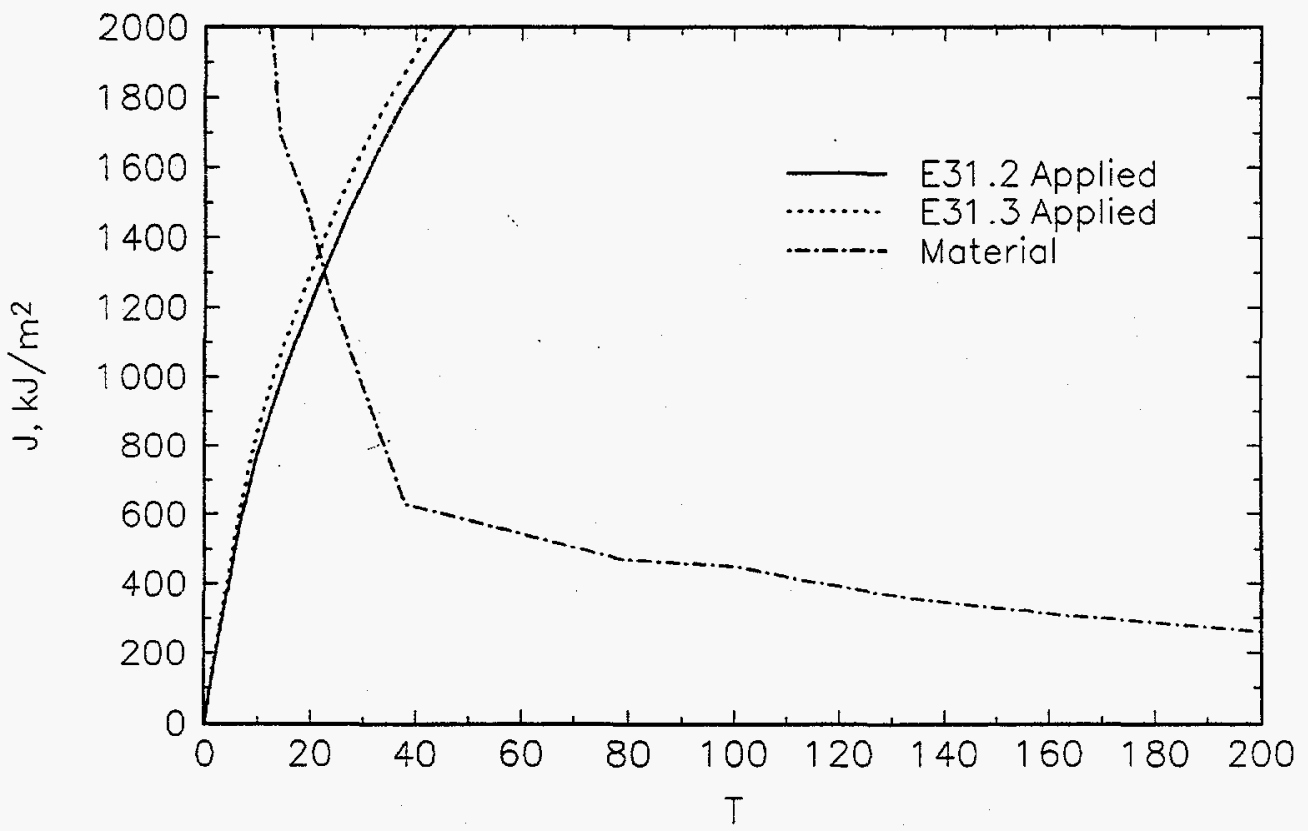

Figure 2.99 Load-controlled J/T stability analysis of HDR-E31 experiments 


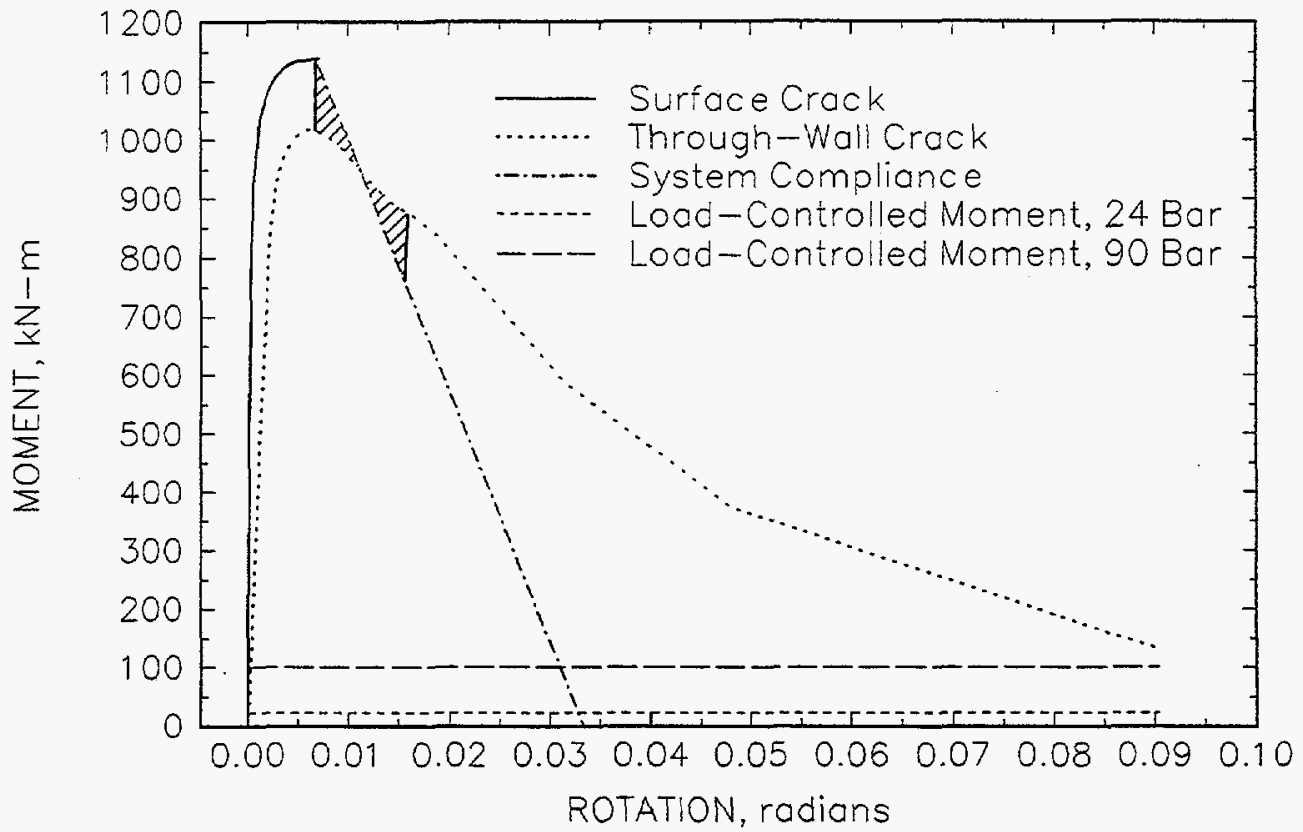

Figure 2.100 Energy Balance stability analysis of HDR-E31.2 (Rotation is total rotation)

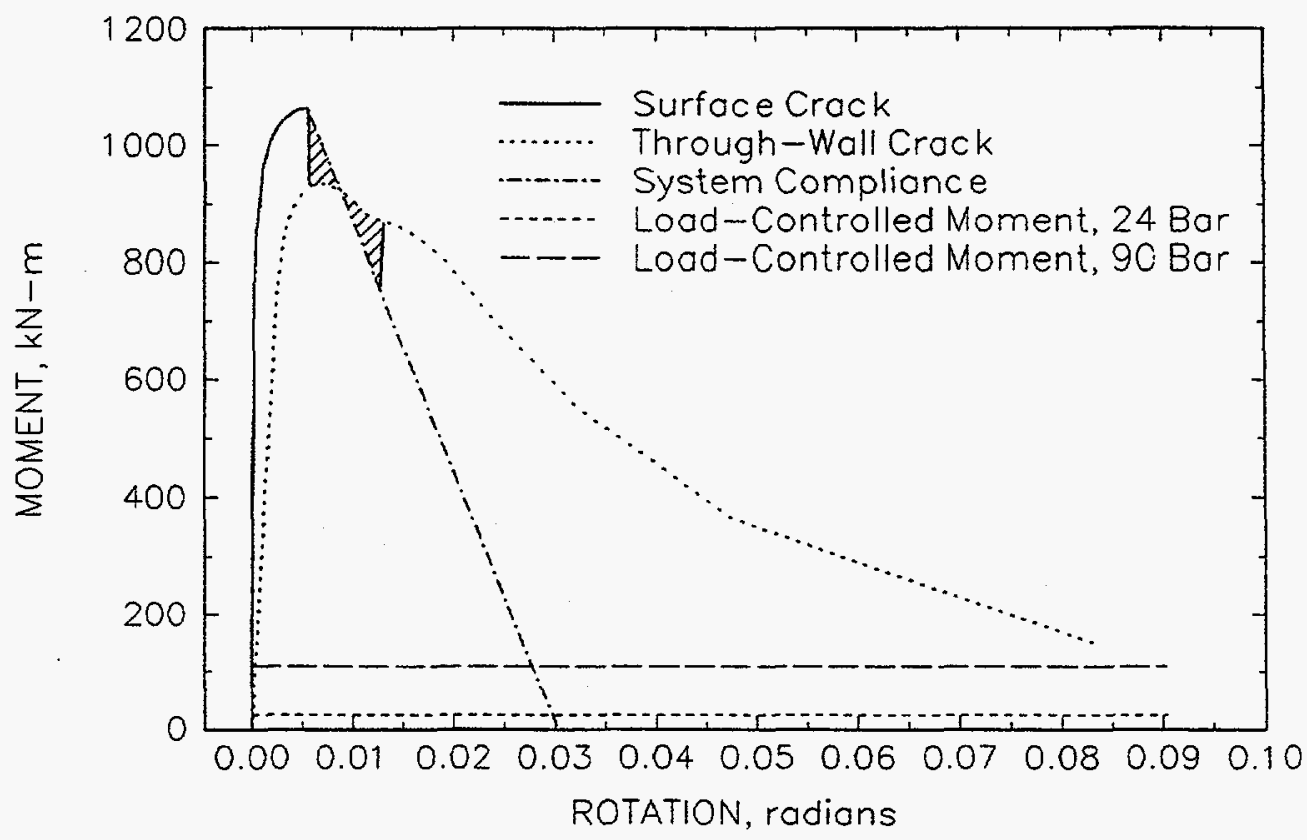

Figure 2.101 Energy Balance stability analysis of HDR-E31.3 (Rotation is total rotation) 
Table 2.14 Flaw stability predictions for the E31 experiments

\begin{tabular}{|l|l|l|}
\hline \multicolumn{1}{|c|}{ Method } & \multicolumn{1}{c|}{ E31.2 } & \multicolumn{1}{c|}{$\mathbf{E 3 1 . 3}$} \\
\hline Experiment & No SC penetration & TWC growth to $2 \theta=43^{\circ}$ on OD \\
\hline $\begin{array}{l}\text { J/T } \\
\text { (load controlled) }\end{array}$ & Unstable TWC & Unstable TWC \\
\hline Energy Balance & TWC growth to $2 \theta=99^{\circ}$ & TWC growth to $2 \theta=94^{\circ}$ \\
\hline Nonlinear FEA & TWC growth to $2 \theta=83^{\circ}$ & TWC growth to $2 \theta=85^{\circ}$ \\
\hline
\end{tabular}

There is no clear explanation for the discrepancies between the experiments and the predictions. It is safe to say, though, that all of the methods tend to overestimate the propensity for an instability. At present there is not a wealth of data to make assessments of the validity of stability prediction methods. However, based on the available data, the dynamic nonlinear stability analysis, by virtue of coupling the pipe system dynamics with the fracture analysis, appears to be the most accurate, while the $\mathrm{J} / \mathrm{T}$ stability analysis is the least accurate. This conclusion is further reinforced by the extremely good prediction of surface crack penetration and subsequent initial cycles of loading on the resulting through-wall crack in the IPIRG-1 aged cast stainless steel dynamic pipe-system experiment, see Figure 2.102 (Ref. 2.169).

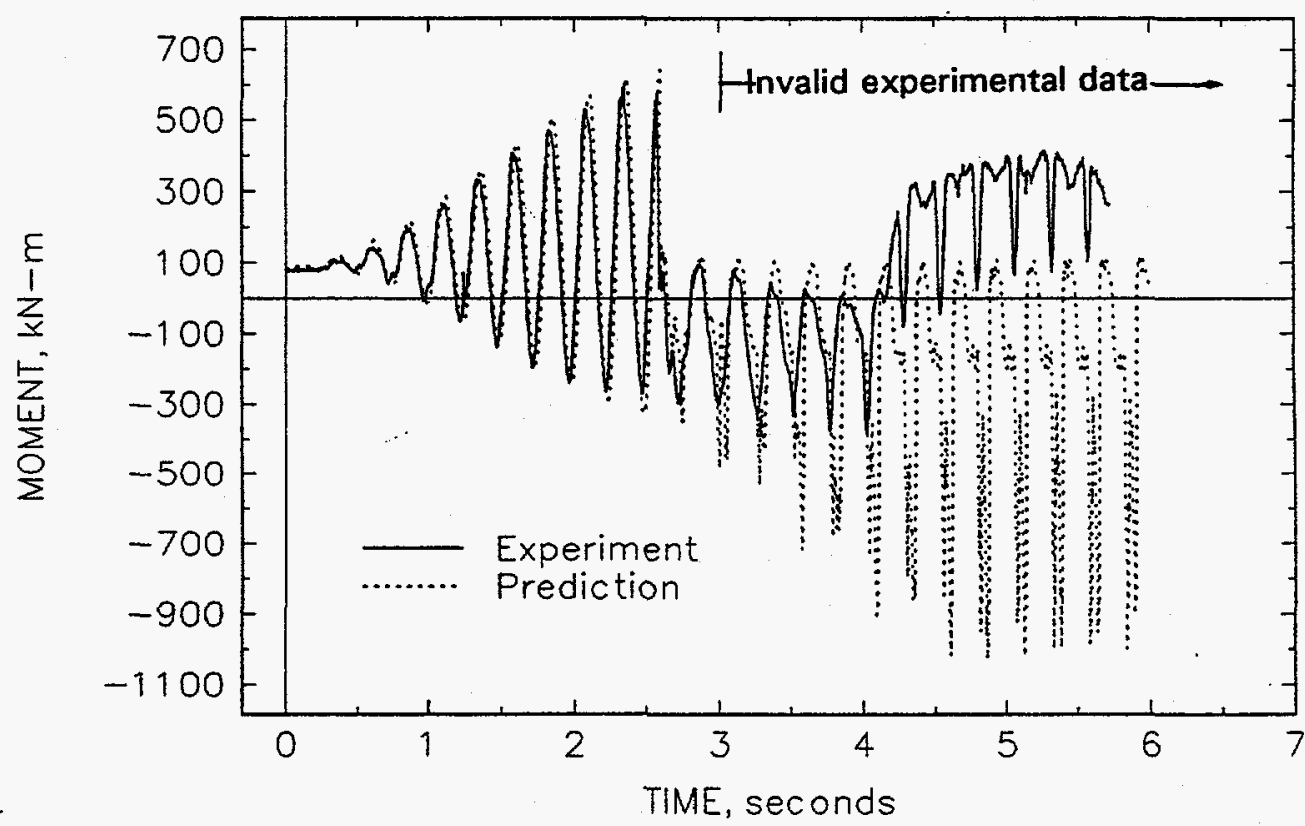

Figure 2.102 Comparison of crack section moment as a function of time for IPIRG-1 Experiment 1.3-7 


\subsection{Circumferential Through-Wall-Cracked Pipe Crack-Opening Displacement Predictions and Leak-Rate Analyses}

Leak-before-break (LBB) analyses for circumferentially cracked pipes are currently being conducted in the nuclear industry to justify elimination of pipe whip restraints and jet impingement shields which are present because of the expected dynamic effects from pipe rupture. The application of the LBB methodology frequently requires calculation of leak rates. These leak rates depend on the crack-opening area of a circumferential through-wall crack in the pipe. For LBB applications, it is desired to have an analysis that will slightly under predict the loads and under predict the displacements in the elastic and small-scale plasticity range, see Figure 2.103. In addition to LBB analyses, which assume a hypothetical flaw size, there is also interest in the integrity of actual leaking cracks corresponding to current leakage detection requirements in NRC Regulatory Guide 1.45, or for assessing temporary repair of Class 2 and 3 pipes that have leaks as is being evaluated in ASME Section XI. The results in this section are applicable to various aspects of these practical concerns.

Traditionally, the development of crack-opening models have been focussed on idealized conditions for analyzing cracked pipes. For example, it is generally assumed that a simple circumferential through-wall crack exists in the pipe with the crack located in the center of the bending plane. The crack-opening area is

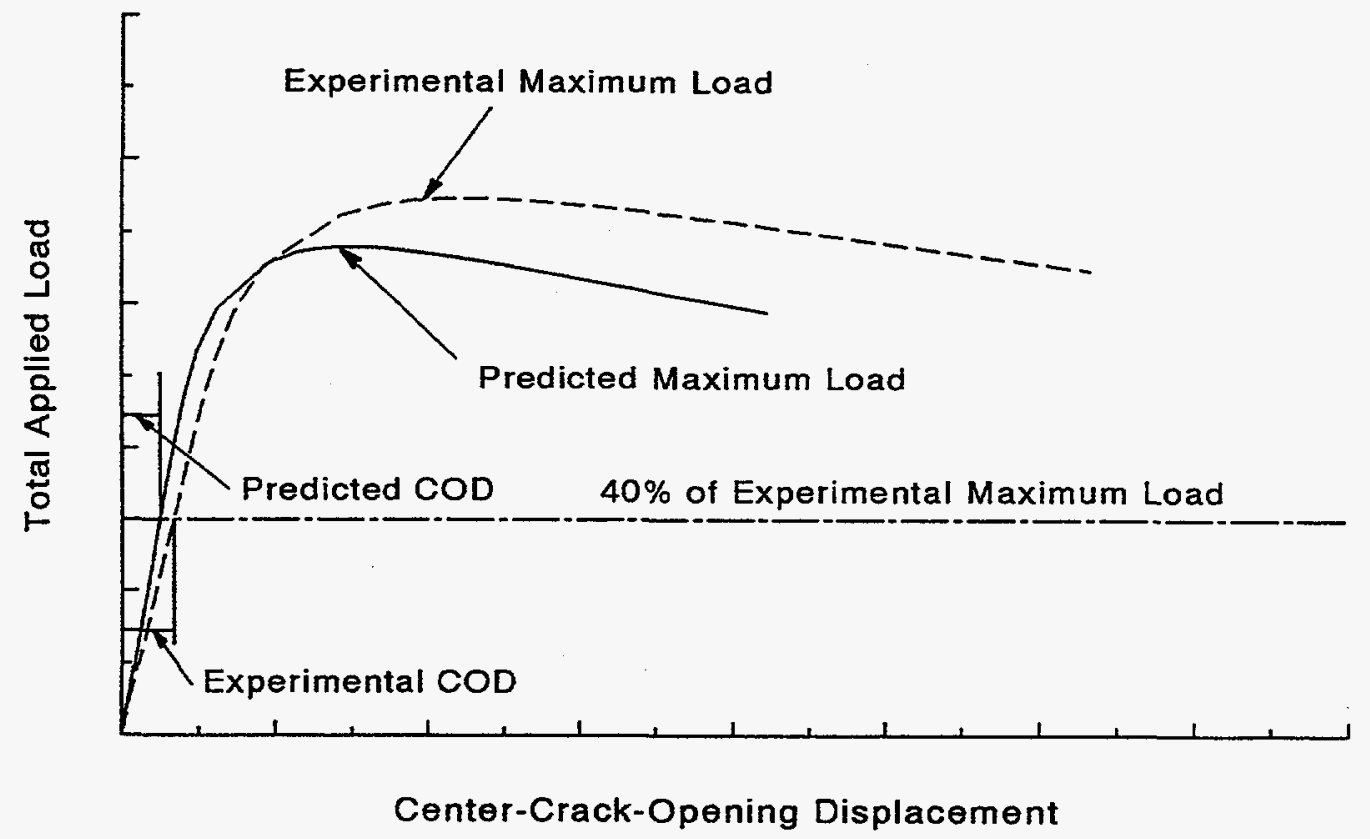

Figure 2.103 Schematic comparison of predicted and experimental load versus center-crackopening displacement in a pipe (ideally COD and load are underpredicted for LBB analyses) 
calculated when this pipe is subjected to remote loads that may include pure bending, pure tension, or combined bending and tension. However, in reality, the loading conditions, the pipe and crack geometries, and the boundary conditions can be much more complicated. For example, a crack in a pipe may become off-centered due to random imperfections around the pipe circumference, or the pipe may be restrained from pressure-induced bending if the crack is close to a nozzle. Additionally, the crack may be located at a thickness transition (e.g., a girth-weld crack by a nozzle), or the pipe may have significant weld residual stresses, which can affect the crack opening, in addition to remote bending loads. Other scenarios can also be envisioned. Currently, there are no engineering methods or guidelines available to analyze pipes for these practical conditions. While some of these aspects are applicable to LBB analyses, other aspects are more applicable to evaluating flaw stability for a real flaw rather than a hypothetical flaw.

The crack-opening displacement (COD) and leak-rate work is reviewed in the following sections. The results summarized in the COD section come mainly from References 2.15 and 2.45 with some input from Reference 2.10, and involve the following topics:

- Current predictive models and their performance

- Crack-opening displacements for combined stresses with torsional loads

- Analysis of off-centered cracks

- Effect of pipe system boundary conditions on fracture and leak rate

- Analysis of a girth weld nozzle crack at a thickness transition

- Evaluation of the effects of weld residual stresses.

The discussion of work on leak rates comes from References 2.10 and 2.176 , and the SQUIRT leak-rate code user's guide and includes:

- Crack morphology considerations for leak-rate prediction

- $\quad$ The SQUIRT leak-rate code.

\subsubsection{Crack-Opening-Displacement Analyses}

LBB procedures involve a two-step analysis. The first is to determine the crack length that would exist at normal operating conditions, and the second step deals with determining the fracture loads. To determine the relative importance of these two steps, probabalistic analyses were developed in Reference 2.176 and later extended in Reference 2.10. An example calculation from Reference 2.10 is shown in Figure 2.104. This figure shows the conditional failure probability versus leak-rate for different normal operating stresses and normal plus safe shutdown earthquake (N+SSE) stresses. As can be seen in this figure, the predominant factor in the failure probabilities is the normal operating loads, which are related to the leakrate analyses. Hence, it is more important to focus on factors that affect leak-rate rather than factors that affect fracture behavior. With this in mind, various methods and factors that affect crack-opening displacement evaluations are reviewed below.

\subsubsection{Summary of Predictive Models}

There are two principal methods that are commonly used for predicting crack-opening for circumferentially cracked pipe. These are finite element analyses and J-estimation schemes. The finite 


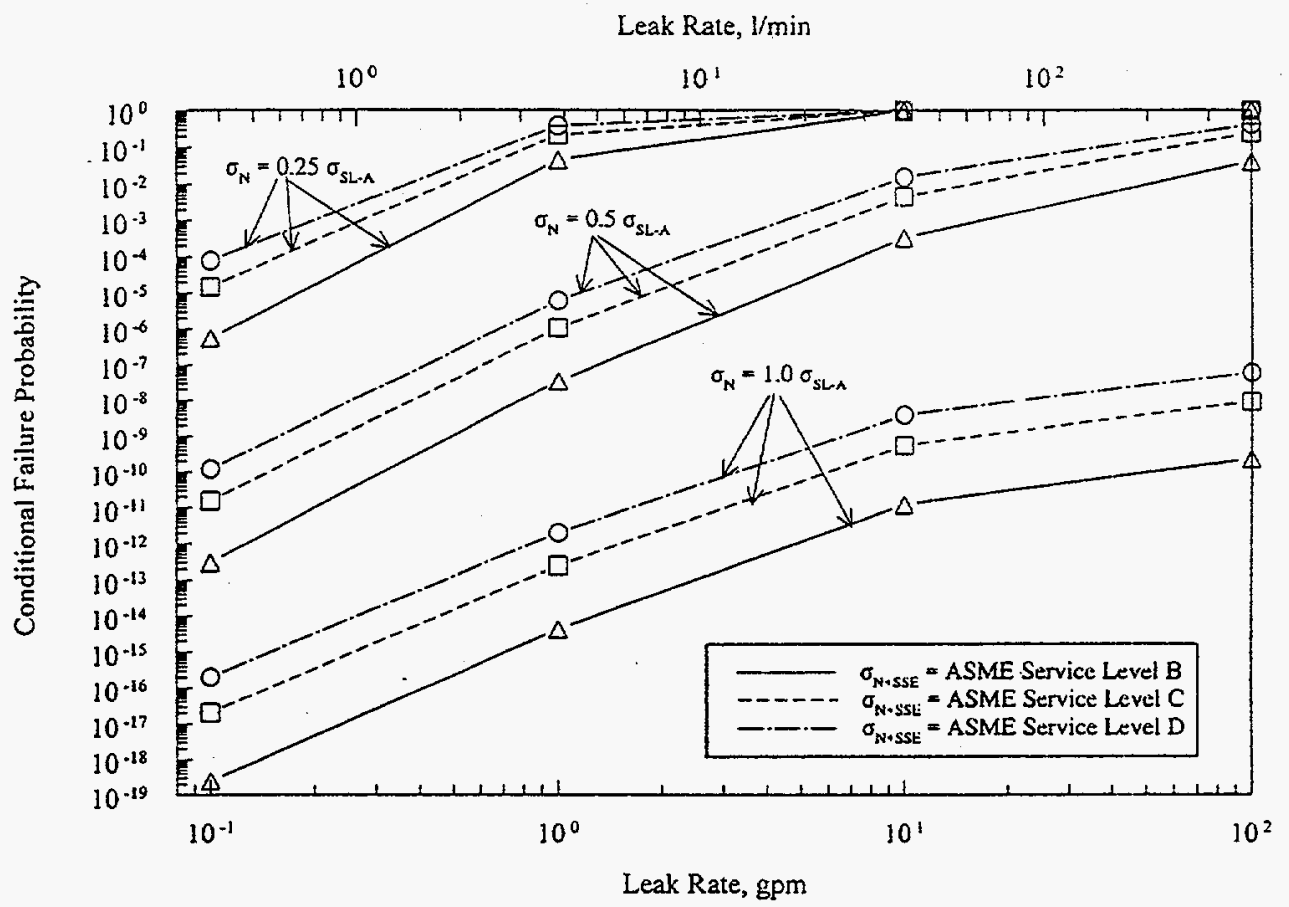

Figure 2.104 Conditional failure probability of a BWR side-riser TP304 pipe system for various combinations of normal operating and N+SSE stresses (base metal), from Reference 2.176

element analyses of crack-opening displacement, although in principle quite simple, involve a great deal of computational effort to model the 3-dimensional geometry of the crack under load. In contrast, the Jestimation schemes make various simplifying assumptions and often rely upon curve fitting of previously developed finite element solutions to generate approximate crack-opening solutions. The level of effort associated with conducting a $\mathrm{J}$-estimation analysis is significantly less than that for conducting the finite element analyses.

In the following paragraphs, a short summary for each of the J-estimation schemes is provided with the estimation formulas for COD. Methods considered are the:

(1) GE/EPRI method (Refs. 2.102, 2.119, and 2.177)

(2) Paris/Tada method (Ref. 2.65)

(3) LBB.NRC method (Ref. 2.116)

(4) LBB.ENG2 method (Refs. 2.55, 2.120, and 2.121, and

(5) LBB.ENG3 method (Refs. 2.126 to 2.128 )

The evaluations of COD are discussed for various loading conditions, e.g., pure bending, pure tension, and combined bending and tension. The $\mathrm{J}$ solutions were previously reviewed in Section 2.3.2.1 of this report. 
The GE/EPRI Method. The GE/EPRI method is based on a compilation of finite element solutions for TWC pipes using the deformation theory of plasticity. These solutions are catalogued in References 2.102 , 2.119 , and 2.177 for various geometric and material parameters.

The elastic and plastic parts of the center-crack-opening displacement for the case of pure bending, as defined by the GE/EPRI method, are

$$
\begin{gathered}
\delta_{e}=4 a \frac{R_{m}}{I} V_{1}^{B}\left(a / b, R_{m} / t\right) \frac{M}{E} \\
\delta_{p}=\alpha \epsilon_{o} a h_{2}^{B}\left(a / b, n, R_{m} / t\right)\left(\frac{M}{M_{0}}\right)^{n}
\end{gathered}
$$

where

$\begin{array}{lll}\mathrm{R}_{\mathrm{m}} & = & \text { pipe mean radius } \\ \mathrm{t} & = & \text { pipe wall thickness } \\ \mathrm{I} & = & \text { pipe cross-sectional moment of inertia } \\ \mathrm{a} & = & \text { crack length } \\ \mathrm{b} & = & \text { remaining ligament } \\ \mathrm{E} & = & \text { modulus of elasticity } \\ \mathrm{M} & = & \text { applied moment } \\ \mathrm{M}_{\mathrm{o}} & = & \text { limit-load moment (see Equation 2-34) } \\ \alpha, \epsilon_{\mathrm{o}}, \mathrm{n} & = & \text { Ramberg-Osgood stress-strain parameters (see Equation 2-35) }\end{array}$

$V_{1}{ }^{B}\left(a / b, R_{m} / t\right)$ and $h_{2}{ }^{B}\left(a / b, n, R_{m} / t\right)$ are the elastic and plastic influence functions, respectively, for COD under pure bending.

The GE/EPRI influence functions for the case of a pure tension load, $P$, were compiled using a tensile load applied at the ends of the pipe caused by an end-capped pipe with internal pressure. This analysis assumes the pipe is free to rotate due to the eccentricity from the crack, i.e., there is a pressure-induced bending stress. The corresponding equations for the elastic and plastic $C O D$ values are

$$
\begin{gathered}
\delta_{e}=\frac{2 a}{\pi R_{m} t} V_{1}^{T}\left(a / b, R_{m} / t\right) \frac{P}{E} \\
\delta_{p}=\alpha \epsilon_{o} a h_{2}^{T}\left(a / b, n, R_{m} / t\right)\left(\frac{P}{P_{o}}\right)^{n}
\end{gathered}
$$


where $V_{1}{ }^{T}\left(a / b, R_{m} / t\right)$ and $h_{2}{ }^{T}\left(a / b, n, R_{m} / t\right)$ are the elastic and plastic influence functions, respectively, for crack-opening displacement under pure tension, $\mathrm{P}$ is the axial tensile force due to an internal pipe pressure, and

$$
P_{o}=2 \sigma_{o} R_{m} t\left[\pi-\theta-2 \sin ^{-1}\left(\frac{1}{2} \sin \theta\right)\right]
$$

is a reference load representing the limit-load of a TWC pipe under pure tension if $\sigma_{0}$ is the collapse stress.

For a pipe subjected to a combined bending and tension loading, the elastic and plastic COD values are

$$
\begin{gathered}
\delta_{e}=4 a \frac{R_{m}}{I} V_{1}^{B}\left(a / b, R_{m} / t\right) \frac{M}{E}+\frac{2 a}{\pi R_{m} t} V_{1}^{T}\left(a / b, R_{m} / t\right) \frac{P}{E} \\
\delta_{p}=\alpha \epsilon_{o} a h_{2}^{B+T}\left(a / b, n, R_{m} / t, \lambda\right)\left(\frac{P}{P_{o}^{\prime}}\right)^{n}
\end{gathered}
$$

where $h_{2}{ }^{B+T}\left(a / b, n, R_{m} / t, \lambda\right)$ is the plastic influence function for crack-opening displacement under combined bending and tension,

$$
\mathbf{P}_{0}^{\prime}=\frac{1}{2}\left[-\frac{\lambda P_{0}^{2} R_{m}}{M_{0}}+\sqrt{\left(\frac{\lambda P_{0}^{2} R_{m}}{M_{0}}\right)^{2}+4 P_{0}^{2}}\right]
$$

is another reference load representing the limit load of a TWC pipe under combined bending and tension if $\sigma_{0}$ is the collapse stress, and $\lambda=M / \mathrm{PR}_{\mathrm{m}}$ is the load factor. Again, the tension component assumes the pipe is free to rotate due to the eccentricity of the crack.

The values of the above influence functions for TWC pipes under pure bending, pure tension, and combined bending and tension were compiled by Kumar et al. (Refs. 2.102 and 2.119) and Kishida and Zahoor (Ref. 2.177) for specific pipe geometries (e.g., $R_{\mathrm{m}} / t=5,10$, and 20 ), crack sizes $(a / b=1 / 16,1 / 8$, $1 / 4$, and $1 / 2)$, and material constants $(n=1,2,3,5,7)$. For a pipe with an arbitrary geometry and material properties, the corresponding influence functions can be evaluated from multiple interpolation of these functions at the pre-determined values of $R_{m} / t$, $a / b$ (i.e., $\theta / \pi$ ), $n$, and $\lambda$. See References $2.102,2.119$, and 2.177 for further details on these functions.

Plastic-Zone Size Correction in the GE/EPRI Method. In Reference 2.178, it has been claimed that the linear-elastic solutions of $\mathrm{J}, \mathrm{COD}$, and other fracture parameters of interest underestimate the actual values when $\mathrm{M} / \mathrm{M}_{\mathrm{o}}$ exceeds 0.5 and the plastic components of the above parameters are small, e.g., for large $\mathrm{n}$ values. This is the apparent reason why Kumar et al. (Ref. 2.119) extended the plastic-zone size formula 
established by Rice (Ref. 2.179) for the antiplane shear problem. According to Reference 2.119, the effective (half) crack length, $a_{e}$, is given by

$$
a_{e}=a+k r_{y}
$$

where

$$
r_{y}=\frac{1}{\beta_{1} \pi} \frac{n-1}{n+1}\left(\frac{K_{I}}{\sigma_{0}}\right)^{2}
$$

$\mathrm{K}_{\mathrm{I}}$ is the mode-I stress intensity factor, and

$$
K= \begin{cases}\frac{1}{1+\left(M / M_{0}\right)^{2}} & \text { (pure bending) } \\ \frac{1}{1+\left(P / P_{0}\right)^{2}} & \text { (pure tension) }\end{cases}
$$

The value of $\beta_{1}$ in Equation 2-110 depends on the state of stress, e.g., $\beta_{1}=2$ for plane stress and $\beta_{1}=6$ for plane strain. For a through-wall-cracked pipe under pure bending or tension, the stress state is dominated by the plane stress condition (i.e., $\beta_{1}=2$ ).

Equation 2-109 was developed in order to increase the value of elastic J or COD when the applied load becomes closer to the reference load, e.g., when $M$ becomes closer to $M_{o}$. There is no sound technical justification for the choice of the $1 /\left[1+\left(\mathrm{M} / \mathrm{M}_{\mathrm{o}}\right)^{2}\right]$ or $1 /\left[1+\left(\mathrm{P} / \mathrm{P}_{\mathrm{o}}\right)^{2}\right]$ function in Equation 2-111 except to ensure continuity of the partial derivatives of $J$ with respect to applied load at $M=M_{o}$ or $P=P_{0}$. Past experience at Battelle suggests that when using the GE/EPRI method for TWC pipes, the plastic-zone correction in the elastic solution may be a contributor to the overprediction of applied crack-driving force. Nevertheless, it has been suggested in References 2.102, 2.119, and 2.177 that the plastic-zone correction be used in the elastic solution, i.e.,

$$
\delta_{e}(a, M)=\delta_{e}\left(a_{e}, M\right)
$$

for a pipe under pure bending. Similar plastic-zone corrections can also be used for a pipe subjected to pure tension or combined bending and tension.

The Paris/Tada Method. In the Paris/Tada method (Ref. 2.65), the elastic crack-opening area, $A_{c e}$, for a TWC pipe under combined bending and tension was derived from the energy method (Castigliano's theorem) which gave 


$$
A_{c e}=\frac{\pi R_{m}^{2}}{E}\left[\sigma_{B} I_{B}(\theta)+\sigma_{T} I_{T}(\theta)\right]
$$

where $I_{B}(\theta)$ and $I_{T}(\theta)$ are the bending and tensile compliance functions defined in Reference 2.65, $\sigma_{B}=M /\left(\pi R_{m}^{2} t\right)$ is the nominal bending stress at the mean pipe diameter, $\sigma_{T}=p / 2 \pi R_{m} t$ is the nominal tensile (axial) stress for an uncracked pipe section, and $\theta$ is the half crack angle. Further simplification of Equation 2-113, details of which are given in Reference 2.65, yields

$$
A_{c e} \simeq \frac{\pi R_{m}^{2}}{E} I_{T}(\theta)\left[\sigma_{B} \frac{3+\cos \theta}{4}+\sigma_{T}\right]
$$

Equations 2-113 and 2-114 are valid only for the linear-elastic condition. Again, the tension contribution to the COD assumes that the pipe is free to rotate from the tension loading and the eccentricity created by the crack. However, for the elastic-plastic condition, Paris and Tada extended these equations by incorporating a plastic-zone correction. Accordingly, for an EPFM analysis, the crack-opening area is given by

$$
A_{c o} \simeq \frac{\pi R_{m}^{2}}{E} I_{T}\left(\theta_{e}\right)\left[\sigma_{B} \frac{3+\cos \theta_{e}}{4}+\sigma_{T}\right]
$$

where $\theta_{\mathrm{e}}$ is half of the effective crack angle already defined in Equation 2-116, i.e.,

$$
\theta_{e}=\theta+\frac{1}{\beta_{1} \pi R_{m}}\left(\frac{K_{I}}{\sigma_{y}}\right)^{2}
$$

where $\sigma_{y}$ is the yield strength of the material, and $\beta_{1}=2$ or 6 depending on whether plane stress or plane strain conditions apply, respectively. Assuming an elliptical crack-opening shape, the total center-crackopening displacement is

$$
\delta \simeq \frac{2 R_{m}^{2}}{a E} I_{T}\left(\theta_{e}\right)\left[\sigma_{B} \frac{3+\cos \theta_{e}}{4}+\sigma_{T}\right]
$$

Setting $\sigma_{\mathrm{T}}=0$ or $\sigma_{\mathrm{B}}=0$ in Equation 2-117, one can compute the COD under pure bending or pure tension, respectively. 
The LBB.NRC Method. The crack-opening area calculations by the LBB.NRC method are almost identical to those by the Paris/Tada method just discussed. According to Reference 2.116, Equations 2-116 and 2-117 are also used to compute COA and COD, respectively. However, in these equations, the effective crack angle $\theta_{e}$ is not the same as in the Paris/Tada method. The $\beta_{1}$ term in the equation for plastic-zone correction (see Equation 2-116) in the Paris/Tada and the LBB.NRC method is calculated by forcing the solution to reach the limit load of a cracked pipe for large values of the stress intensity factor. Further details on the derivation of $\beta_{1}$ are available in References 2.65 and 2.116 .

The LBB.ENG2 Method. The LBB.ENG2 method was originally developed by Brust (Ref. 2.55) to compute the energy release rate and crack-opening for through-wall-cracked pipes. As described earlier in Section 2.3.2.1, this method involves an equivalence criterion incorporating a reduced thickness analogy for simulating system compliance due to the presence of a crack in a pipe.

For the case of a pure bending load, the elastic COD solution is the same as in the GE/EPRI method (i.e., Equation 2-101). Initially, there were attempts to use some of the closed-form solutions, for instance, as developed in References 2.180; however, these analytical solutions were smaller by a factor of three compared with the numerical solutions, as well as with the experimental data. Therefore, the numerical solutions of the GE/EPRI method were selected for the elastic component of COD in this method. The plastic component of COD is obtained from

$$
\delta_{p}=R_{m}\left[1+\sin \frac{\theta}{2}\right] \phi_{p}^{c}
$$

where the plastic rotation in the presence of a crack, $\phi_{p}^{c}$, is given by (Refs. $2.55,2.120$, and 2.121)

$$
\phi_{p}^{c}=L_{B}(n, \theta) \frac{\alpha}{E \sigma_{o}^{n-1}} \frac{I_{B}(\theta)}{\left(\pi R_{m}^{2} t\right)^{n}} M^{n}
$$

The term $R_{m}[1+\sin (\theta / 2)]$ in Equation 2-118 is the distance from the rigid-plastic neutral axis to the center of the crack and $L_{B}(n, \theta)$ is a tabulated influence function.

For the pure tension load case, the estimate of $\delta$ has a functional form similar to that for the bending case. The crack-opening displacement is again separated into elastic and plastic components. The elastic COD is given by the same equation as the GE/EPRI method (i.e., Equation 2-103). The plastic COD is given by

$$
\delta_{\mathrm{p}}=\frac{\alpha \epsilon_{\mathrm{o}}\left(\frac{\sigma_{\mathrm{T}}}{\sigma_{\mathrm{o}}}\right)^{\mathrm{n}-1}}{1-\frac{\theta}{\pi}-\frac{2}{\pi} \sin ^{-1}\left(\frac{1}{2} \sin \theta\right)}+\mathbf{R}_{\mathrm{m}}\left[1+\sin \frac{\theta}{2}\right] \phi_{\mathrm{p}}^{\mathrm{c}}
$$


In Equation 2-120, the first term is due to the tension load and the second term is due to the induced bending caused by the tension load on the cracked pipe (which assumes the pipe is free to rotate). The second term could be eliminated to account for a pipe system restraining the induced bending. Note that $\phi_{\mathrm{p}}^{\mathrm{c}}$ in this equation is the plastic rotation in the presence of the crack that is caused only by the pressure- or tension-induced bending. This bending moment can be inserted in Equation 2-119 to obtain $\phi_{p}^{c}$.

For combined bending and tension, the elastic COD is obtained by superposing the solutions for pure bending and pure tension, which are given by Equations 2-101 and 2-103, respectively. The plastic COD is given by the same form as shown by Equation 2-120, but the $\phi_{p}^{c}$ term in that equation now includes both the applied moment and the induced bending due to tension.

The LBB.ENG3 Method. The LBB.ENG3 method, developed by Rahman and Brust (Refs. 2.126 to 2.128), improves the computation of the J-integral and COD for TWCs in pipe welds by incorporating weld-metal strength properties. The method is similar to the LBB.ENG2 method and is also based on an equivalence criterion incorporating reduced thickness analogy for simulating the system compliance due to the presence of a crack in the pipe.

The equations for the estimates of COD by the LBB.ENG3 method are identical to those of the LBB.ENG2 method, except the plastic rotation due to the presence of a crack is evaluated considering the tensile properties of both the base and weld metals. According to this method, $\phi_{\mathrm{p}}^{c}$ can be obtained from

$$
\phi_{p}^{c}=L_{B}\left(n_{1}, n_{2}, \theta\right) \frac{\alpha_{1}}{E_{2} \sigma_{o 1}^{n_{1}-1}} \frac{I_{B}(\theta)}{\left(\pi R_{m}^{2} t\right)^{n_{1}}} M^{n_{1}}
$$

Further details can be found in References 2.126 to 2.128 .

Note that Equation 2-121 has characteristics similar to those of Equation 2-119 which is used to calculate $\phi_{p}^{c}$ for a base-metal crack (the LBB.ENG2 method). However, as evidenced by the 1 and 2 subscripts in Equation 2-121, the tensile strength properties of both base and weld metals are accounted for in calculating the plastic rotation. When differences in the base metal and weld metal properties vanish, it can be shown that Equation 2-121 degenerates to Equation 2-119 as one would expect. Hence, the LBB.ENG2 method can be treated as a special case of the more general LBB.ENG3 method.

\subsubsection{Comparison of Predictive Models with Experimental Data}

An in-depth review was conducted in Reference 2.15 to evaluate current models for predicting crackopening in circumferentially cracked pipes. The results from twenty-five full-scale pipe fracture experiments, conducted in the NRC's Degraded Piping Program, the International Piping Integrity Research Group (IPIRG) Program, and the NRC's Short Cracks in Piping and Piping Welds Program, were used to verify five different estimation methods as well as finite element analysis predictions. 


\section{Conclusions From Finite Element Analyses}

- The results from several finite element analyses (Refs. 2.15 and 2.16) showed that prior to the start of ductile tearing, the crack-opening shape for a pipe would approximately follow an elliptical profile. Both large-diameter pipes with short cracks and small-diameter pipes with long cracks were analyzed under pure bending and combined bending plus tension to reach this conclusion. Hence, one can calculate the center-crack-opening displacement and use an elliptical shape assumption for leak-rate analyses.

\section{Conclusions From Statistical Evaluation of Current Predictive Models}

Standard statistical analyses were performed to assess the accuracy of the predictive models in estimating the center-crack-opening displacement for a number of different pipe tests. The statistics involved calculation of the mean, standard deviation, and coefficient of variation (COV) of the ratio between the experimental and predicted values of the center-crack-opening displacement when the applied load is 40 percent of the experimental maximum load. (Note, the fracture behavior at this load is essentially elastic and is relevant to LBB analyses.)

The analyses of through-wall-cracked pipe experiments were broken down into pipes with base metal cracks under bending, pressure, and combined pressure and bending. The statistics of these analyses are given in Table 2.15. The statistical results for short circumferential crack lengths and cracks in the center of girth welds are given in Table 2.16. Note, the mean value of the experimental-to-predicted values are desired to be slightly greater than 1.0 .

Conclusions from analyses of simple through-wall-cracked pipes:

- When all TWC pipe experiments were considered, all of the predictive models underpredicted the mean value of the COD (i.e., mean ratio greater than 1). For LBB analyses, it is desired to underpredict the experimental COD values. The GE/EPRI methods (with the original and newly developed influence functions) predicted experimental COD with very good accuracy in terms of the mean value of the crack-opening ratio, but their predicted COVs were much higher. The differences between the statistics for the GE/EPRI method based on the original influence functions and those from the work in Reference 2.15 were not significant. The LBB.ENG2 and LBB.ENG3 methods slightly underpredicted the mean experimental COD with much lower COVs. The LBB.NRC method underpredicted the experimental COD more than the LBB.ENG2 or LBB.ENG3 methods with higher values of COV. Among all methods, the Paris/Tada method underpredicted the experimental COD by the largest margin in terms of both mean and COV of the predicted crack-opening ratio.

- For pipes under pure bending loads, the LBB.ENG2 (mean ratio = 1.07) and LBB.ENG3 (mean ratio $=1.10)$ methods slightly underpredicted the experimental COD when the mean values were compared. The LBB.NRC (mean ratio $=1.16$ ) and Paris/Tada method (mean ratio $=1.60$ ) also underpredicted the COD with the Paris/Tada method underpredicting the most. It is interesting to note that the GE/EPRI methods (mean ratio $=0.84$ and 0.74 for original and newly developed influence functions, respectively) overpredicted the mean COD for this loading condition, which is undesirable from an LBB viewpoint. 
Table 2.15 Mean and coefficient of variation of the ratio between experimental and predicted values of center-crack-opening displacement by various methods for simple throughwall-cracked pipes under various loading conditions

\begin{tabular}{|c|c|c|c|c|c|c|c|c|}
\hline \multirow[b]{3}{*}{$\begin{array}{l}\text { Fracture } \\
\text { Analysis } \\
\text { Methods } \\
\end{array}$} & \multicolumn{8}{|c|}{ Ratio of Center-Crack-Opening Displacement $t^{(a)}$} \\
\hline & \multicolumn{2}{|c|}{$\begin{array}{l}\text { All TWC Pipes } \\
\text { (15 Tests) }\end{array}$} & \multicolumn{2}{|c|}{$\begin{array}{c}\text { TWC Pipes } \\
\text { Under Pure Bending } \\
\text { (11 Tests) } \\
\end{array}$} & \multicolumn{2}{|c|}{$\begin{array}{c}\text { TWC Pipes } \\
\text { Under Pressure } \\
\text { (1 Test) } \\
\end{array}$} & \multicolumn{2}{|c|}{$\begin{array}{c}\text { TWC Pipes Under } \\
\text { Pressure and } \\
\text { Bending } \\
\text { (3 Tests) } \\
\end{array}$} \\
\hline & Mean & $\begin{array}{c}\text { Coefficient } \\
\text { of } \\
\text { Variation }^{(b)}, \\
\text { percent }^{(2)} \\
\end{array}$ & Mean & $\begin{array}{c}\text { Coefficient } \\
\text { of } \\
\text { Variation } \\
\text { percent }\end{array}$ & Mean & $\begin{array}{c}\text { Coefficient } \\
\text { of } \\
\text { Variation } \\
\text { percent }\end{array}$ & Mean & $\begin{array}{c}\text { Coefficient } \\
\text { of } \\
\text { Variation }^{(b)} \text {, } \\
\text { percent } \\
\end{array}$ \\
\hline $\begin{array}{l}\text { GE/EPRI } \\
\text { (Original) }\end{array}$ & 1.01 & 72.8 & 0.84 & 51.7 & 0.75 & $-(c)$ & 1.70 & 69.9 \\
\hline $\begin{array}{c}\text { GE/EPRI } \\
\text { (NRC/Battelle) }\end{array}$ & 1.02 & 86.5 & 0.74 & 59.5 & $-(d)$ & $-(c)$ & 1.78 & 69.8 \\
\hline Paris/Tada & 2.96 & 146 & 1.60 & 39.2 & $-(d)$ & $-(c)$ & 6.59 & 107 \\
\hline LBB.NRC & 1.61 & 90.9 & 1.16 & 47.6 & $-(d)$ & $-(c)$ & 2.82 & 79.4 \\
\hline LBB.ENG2 & 1.16 & 47.0 & 1.07 & 45.5 & 1.0 & $-(c)$ & 1.57 & 41.4 \\
\hline LBB.ENG3 & 1.18 & 45.7 & 1.10 & 44.1 & 1.0 & $-(c)$ & 1.57 & 41.4 \\
\hline
\end{tabular}

(a) Ratio of center-crack-opening displacement = experimental center COD/predicted center COD; the CODs were measured and calculated at 40 percent of experimental maximum load

(b) Coefficient of variation $=($ standard deviation $/$ mean $) \times 100$

(c) Not applicable

(d) Not determined 
Table 2.16 Mean and coefficient of variation of the ratio between experimental and predicted values of center-crack-opening displacement by various methods for simple throughwall-cracked pipes with short cracks and cracks in girth welds

\begin{tabular}{|c|c|c|c|c|}
\hline \multirow[b]{3}{*}{$\begin{array}{l}\text { Fracture } \\
\text { Analysis } \\
\text { Methods }\end{array}$} & \multicolumn{4}{|c|}{ Ratio of Center-Crack-Opening Displacement ${ }^{(a)}$} \\
\hline & \multicolumn{2}{|c|}{$\begin{array}{c}\text { TWC Pipes with } \\
\text { Short Cracks }(\theta / \pi \leq 0.12) \\
(4 \text { Tests })\end{array}$} & \multicolumn{2}{|c|}{$\begin{array}{c}\text { TWC Pipes with } \\
\text { Cracks in Girth Welds } \\
\text { (6 Tests) }\end{array}$} \\
\hline & Mean & $\begin{array}{c}\text { Coefficient } \\
\text { of } \\
\text { Variation }^{(\mathrm{b})}, \\
\text { percent } \\
\end{array}$ & Mean & $\begin{array}{c}\text { Coefficient } \\
\text { of } \\
\text { Variation }^{(b)}, \\
\text { percent }\end{array}$ \\
\hline $\begin{array}{l}\text { GE/EPRI } \\
\text { (Original) }\end{array}$ & 0.74 & 31.0 & 0.67 & 70.4 \\
\hline $\begin{array}{c}\text { GE/EPRI } \\
\text { (NRC/Battelle) }\end{array}$ & 0.76 & 36.0 & 0.62 & 67.0 \\
\hline Paris/Tada & 1.42 & 37.2 & 1.61 & 33.5 \\
\hline LBB.NRC & 1.30 & 21.4 & 1.04 & 45.1 \\
\hline LBB.ENG2 & 1.45 & 26.8 & 1.01 & 58.3 \\
\hline LBB.ENG3 & 1.47 & 27.3 & 1.06 & 55.3 \\
\hline
\end{tabular}

(a) Ratio of center-crack-opening displacement = experimental center COD/predicted center COD; the CODs were measured and calculated at 40 percent of experimental maximum load

(b) Coefficient of variation $=($ standard deviation $/$ mean $) \times 100$

- $\quad$ For a pipe under pure tension from pressure loading, similar trends were exhibited by the GE/EPRI, LBB.ENG2, and LBB.ENG3 methods. The comparisons of the COD predictions by the LBB.ENG2 and LBB.ENG3 methods with the experimental data were excellent.

- $\quad$ For pipes under combined bending and tension, all methods considered in this study underpredicted the experimental COD. The qualitative behavior is similar to that exhibited for the fracture results of all pipe experiments discussed earlier. On a quantitative scale, however, the magnitudes of underprediction were much higher regardless of the methods used. Once again, the Paris/Tada method significantly underpredicted the COD values.

- The mean results for pipes with short cracks indicate that the crack-opening would be underpredicted by the Paris/Tada, LBB.NRC, LBB.ENG2, and LBB.ENG3 methods and overpredicted by the GE/EPRI method. A similar trend was found for pipes under pure 
bending. The results for pipes with cracks in girth welds also reveal a similar qualitative behavior. For the girth weld cracks, the LBB.ENG2 and LBB.ENG3 methods predicted crack-opening displacement with reasonable accuracy with mean ratios close to one.

Conclusions from analyses of complex-cracked pipes:

- Complex-cracked pipe experiments, i.e., a pipe with a 360-degree circumferential surface crack and a finite length through-wall crack in the same plane, were analyzed using the LBB.ENG2 method in Reference 2.176. Regardless of whether a constraint factor was applied to the J-R curves, the LBB.ENG2 method overpredicted (in terms of the mean value) crack-opening displacement for pipes with complex cracks, see Table 2.17 . This is clearly opposite to the behavior exhibited by this method in analyzing simple through-wall-cracked pipes. Further breakdown of the statistics for shallow cracks $(a / t \leq 0.5)$ and deep cracks $(a / t z$ $0.5)$ reveals that this estimation method provides better predictions of the experimental COD if the depth of the 360-degree surface crack is smaller. For example, the mean values of the crack-opening ratio were 0.77 for shallow cracks and 0.33 for deep cracks. Nevertheless, the LBB.ENG2 predictions for complex-cracked pipes were much larger than the experimental COD values. This overprediction of the LBB.ENG2 method is due to the over-simplification in the estimation formulas for TWC pipes used for predicting the COD of complex-cracked pipes. Hence, further developments are necessary to improve crack-opening models for complex-cracked pipes.

Table 2.17 Mean and coefficient of variation of the ratio between experimental and predicted values of center-crack-opening displacement by the LBB.ENG2 method for complexcracked pipes with shallow and deep surface cracks

Ratio of Center-Crack-Opening Displacement ${ }^{(2)}$

\begin{tabular}{|c|c|c|c|c|c|c|}
\hline \multirow[b]{2}{*}{$\begin{array}{l}\text { Fracture } \\
\text { Analysis } \\
\text { Methods } \\
\end{array}$} & \multicolumn{2}{|c|}{$\begin{array}{c}\text { All CC Pipes } \\
\text { (10 Tests) }\end{array}$} & \multicolumn{2}{|c|}{$\begin{array}{c}\text { CC Pipes with } \\
\text { Shallow Cracks } \\
\text { (a/t } \leq 0.5) \\
\text { (7 Tests) } \\
\end{array}$} & \multicolumn{2}{|c|}{$\begin{array}{c}\text { CC Pipes with } \\
\text { Deep Cracks } \\
\text { (a/t } \geq 0.5) \\
(3 \text { Tests }) \\
\end{array}$} \\
\hline & Mean & $\begin{array}{c}\begin{array}{c}\text { Coefficient } \\
\text { of } \\
\text { Variation }^{(b)} \\
\text { percent }^{-}\end{array} \\
\end{array}$ & Mean & $\begin{array}{c}\begin{array}{c}\text { Coefficient } \\
\text { of } \\
\text { Variation }^{(b)}, \\
\text { percent }\end{array} \\
\end{array}$ & Mean & $\begin{array}{c}\begin{array}{c}\text { Coefficient } \\
\text { of } \\
\text { Variation }^{(\mathrm{b})}, \\
\text { percent }\end{array} \\
\end{array}$ \\
\hline $\begin{array}{c}\text { LBB.ENG2 } \\
\left(\text { Using } \mathrm{J}_{M}{ }^{\mathrm{TWC}} \text { ) }\right.\end{array}$ & 0.63 & 41.5 & 0.77 & 24.7 & 0.33 & 36.5 \\
\hline 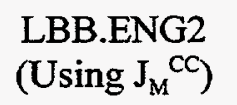 & 0.64 & 41.7 & 0.77 & 25.0 & 0.33 & 36.5 \\
\hline
\end{tabular}

(a) Ratio of center-crack-opening displacement = experimental center COD/predicted center COD; the CODs were measured and calculated at 40 percent of experimental maximum load

(b) Coefficient of variation $=($ standard deviation $/$ mean $) \times 100$ 
- In analyzing pipes with a leaking crack that may potentially be a complex crack, it may not always be possible to accurately estimate the depth of the internal surface crack unless detailed nondestructive examination is performed. For such a crack, if the depth of the surface crack is overestimated, the current analysis methods would overpredict crack-opening. Hence, for a given leak rate, this will cause the crack length to be underestimated resulting in an overprediction of the pipe's maximum load-carrying capacity. On the other hand, if the depth of the surface crack is underestimated or ignored, the predictive methods would underestimate crack-opening, and hence, also underestimate the load-carrying capacity of the pipe.

\subsubsection{Sensitivity Analysis}

There are numerous factors in crack-opening analyses that can affect the predicted results. For some of these factors, the predicted crack-opening displacement is insensitive to large changes in the parameter. For other factors, the predicted crack-opening displacement changes dramatically for small input changes. In order to make the best possible crack-opening displacement estimates, it is important to have a sense of what model input parameters control the analysis results and where attention needs to be focussed in addressing model input data requirements.

In conducting a sensitivity study to evaluate the effects of crack-face pressure, Ramberg-Osgood fit parameters, and errors in the elastic modulus on the crack-opening predictions, the results showed:

- In general, the crack-face pressure would increase the crack-opening displacement. The magnitude of this increase depends on the crack size, pressure on the crack face, and the applied remote moment. For a linear-elastic analysis, when the crack size is small $(\theta / \pi \leq 1 / 16)$, the crack-face pressure can be neglected. For a large crack size $(\theta / \pi \geq 1 / 4)$, if the crack-face pressure is close to the pipe pressure and the applied remote moment is comparable to the moment due to the crack-face pressure, its effects can become important. However, since the pressure through the thickness varies due to various pressure drop contributions (Ref. 2.181), the ratio of the crack-face pressure to the pipe pressure increases with the crack-opening. The possibility of having a large crack-face pressure and small applied moment (which is a tight crack case) is very unlikely. Hence, the effects of crack-face pressure for large cracks should also be negligible.

- The Ramberg-Osgood fit in various strain regions of actual tensile data showed distinct variations in the parameters, $\alpha$ and $n$, particularly when the low-strain and high-strain regions were considered. The effects of these variations on the crack-opening predictions were more significant for stainless steel pipe than for carbon steel pipe. In particular, when $\alpha$ and $n$ were based on fitting the stress-strain curve in the low-strain region, the predicted crack-opening displacements in the stainless steel pipe were much lower than the experimental data. This is desirable for LBB analysis.

- If the crack-opening analysis is linear-elastic, an accurate estimate of the elastic modulus can become important. In one stainless pipe test (Experiment 1.1.1.26) from the Short Cracks Program (Ref. 2.14), the elastic modulus was measured to be $157.5 \mathrm{GPa}\left(22.84 \times 10^{6} \mathrm{psi}\right)$, considerably lower than handbook values which typically vary from $179.27 \mathrm{GPa}\left(26 \times 10^{6} \mathrm{psi}\right)$ to $182.7 \mathrm{GPa}\left(26.5 \times 10^{6} \mathrm{psi}\right)$ for austenitic materials. Hence, the crack-opening displacement 
could be underpredicted by 13.8 percent to 16.0 percent by using these two handbook values for the elastic modulus instead of the measured value. For LBB applications, a conservative misprediction occurs if the elastic modulus is overpredicted, such as in this case.

\subsubsection{Crack-Opening Displacements for Combined Stresses with Torsional Loads}

In Reference 2.45 , the effects of combined tension, bending, and torsional loading on $\mathrm{J}$ and crack-opening displacements (COD), as well as the effect of anisotropy on angled crack growth in ferritic pipe were addressed. The results on combined tension, torsion, and bending loads on COD are of particular interest here. These results represent the first case of assessing the effects of torsional loads on $J$ and COD values.

For flaw evaluation procedures, the torsional stresses may frequently be ignored since the flaw evaluation standards typically call for the primary bending stresses to be used. In LBB applications using NRC SRP 3.6.3, one is required to "specify the type and magnitude of loads applied (forces, bending, and torsional moments), their source(s) and method of combination." Hence, the torsional stresses are required to be included, but the method of combining them to get an effective stress or moment is not specified."

Some ways to define an effective stress or moment are:

(1) The effective moment, $M_{\text {eff }}$, can be determined as the square root of the sum of the squares of the torque, $T$, and the bending moment, $M_{b}$.

(2) The effective moment can be determined as the moment resulting from an effective stress obtained using the Von Mises stress from the bending stress, $\sigma_{b}$, caused by a bending moment and the torsional stress, $\tau_{\mathrm{T}}$, caused by the torque.

(3) The effective moment can be determined as the moment resulting from an effective bending stress, $\sigma_{\text {eff }}$, obtained using square root of the sum of the squares of the bending stress, $\sigma_{b}$, caused by the bending moment, and the torsional stress, $\tau_{\mathrm{T}}$, caused by the torque.

(4) The effective moment can be given by the bending moment only, ignoring the torque.

The four different approaches to handle combined torsion and bending can be cast in the form of a single equation, given below. Referring to the above numbered descriptions, mathematically they may be expressed as:

$$
M_{\text {eff }}=\sqrt{M_{b}^{2}+\left(c_{e} T\right)^{2}}
$$

* The combination rule in SRP 3.6.3 is for the combination of moments from dead-weight, SAM, inertial, and thermal expansion, not for bending and torsion combinations. 
(1) $c_{e}=1 \Rightarrow$ Effective moment from resultant of bending moment plus torque

(2) $c_{e}=\frac{\sqrt{3}}{2} \Rightarrow$ Effective moment calculated from $\sigma_{\text {eff }}=\sqrt{\sigma_{b}{ }^{2}+3 \tau_{T}^{2}}$

(3) $c_{e}=\frac{1}{2} \Rightarrow$ Effective moment calculated from $\sigma_{\text {eff }}=\sqrt{\sigma_{b}^{2}+\tau_{T}^{2}}$

(4) $c_{e}=0 \Rightarrow$ Effective moment calculated ignoring torque

In Equation 2-122, $\mathrm{c}_{\mathrm{e}}$ defines the effective bending moment parameter. The upper and lower bounds for calculating the effective moment are defined by $c_{e}=1$ and $c_{e}=0$. The other two approaches lie between these two extremes as indicated by Equation 2-122.

To make an assessment of which approach is best, a detailed finite element analysis was conducted using $3 \mathrm{D}$ brick elements with a circumferential though-wall crack. The bending moment-to-torque ratios were $3: 1$ and 1:1, as well as a no torque case. These bending-to-torque ratios were determined from a survey of piping stress analysis reports and discussions with piping stress analysts (Ref. 2.45). All of the cases examined had the same amount of axial tension.

The profiles of the crack-opening shape are shown in Figures 2.105 and 2.106. Note that for the nontorsion and the low-torsion cases (i.e., $\mathrm{M}_{\mathrm{b}} / \mathrm{T}=3$ ) that the crack-opening shape is essentially elliptical. For the higher torsion case (i.e., $M_{b} / T=1$ ), the elliptical shape is slightly skewed.

A comparison of the maximum crack-opening displacement versus effective moment curves using the different $c_{e}$ definitions given earlier is shown in Figure 2.107. This figure shows that at low amounts of torsion $\left(M_{b} / T=3\right)$, any definition of $c_{e}$ gives an effective bending stress that agrees with the non-torsion case. However, for the higher torsion case $\left(M_{b} / T=1\right)$, the definition of $c_{c}$ becomes significant. The best definition was $c_{e}=0.866(\sqrt{3} / 2)$ which is the Von Mises effective stress method for calculating the effective moment.

Since in leak-rate analysis the leak-rate is proportional to the area, it is of interest to see how the crackopening area (COA) evolves with effective moment. The COA versus Von Mises effective moment for the different loading cases is shown in Figure 2.108. Because the Von Mises method compares so well with the pure tension and bending case, this further substantiates that for combined loading with torsion, the Von Mises combination of the bending and torsional stresses is the appropriate solution to use. The Von Mises effective moment approach should work equally well with any crack-opening estimation scheme. 


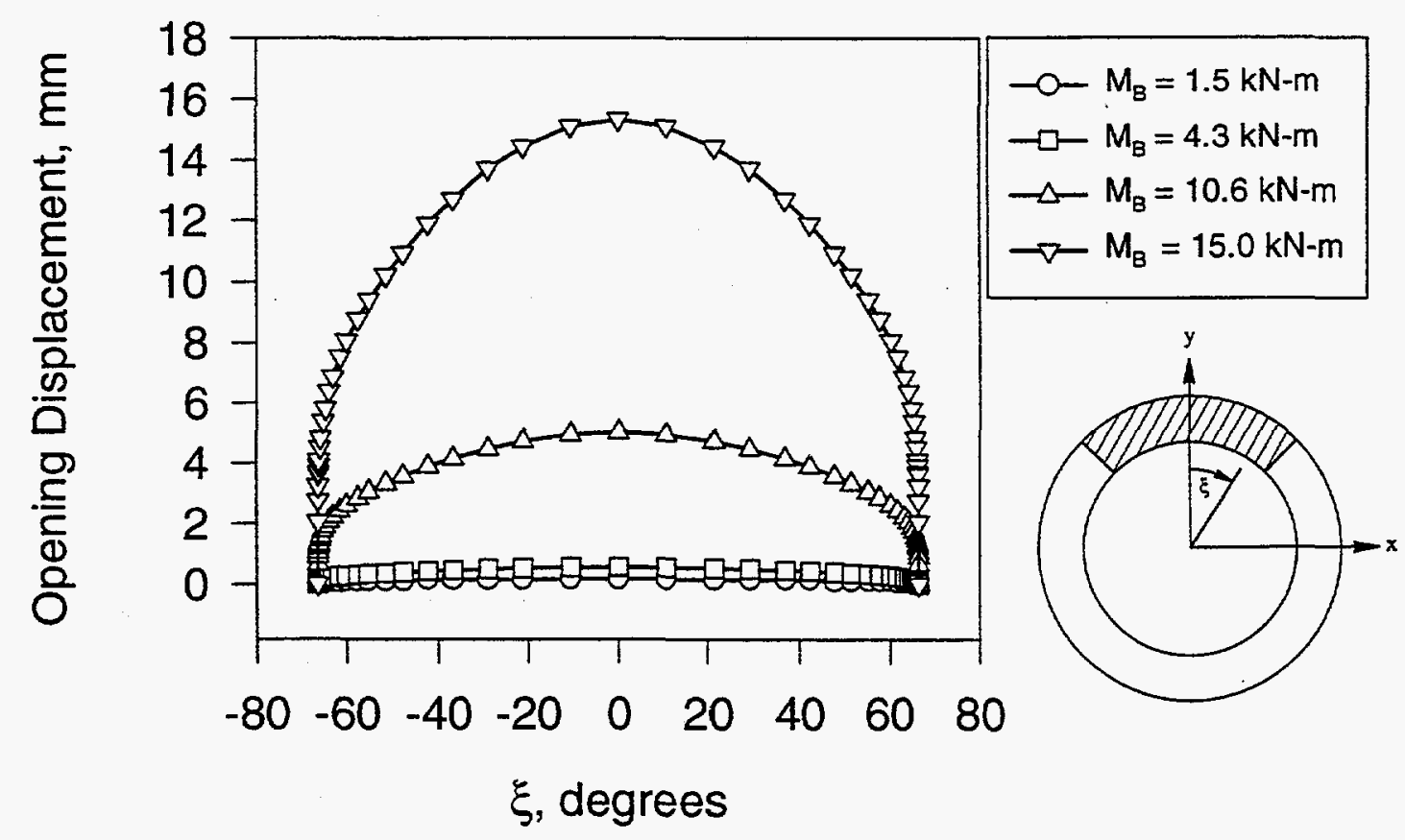

Figure 2.105 Crack-opening profiles at various applied bending moments for tension plus bending 


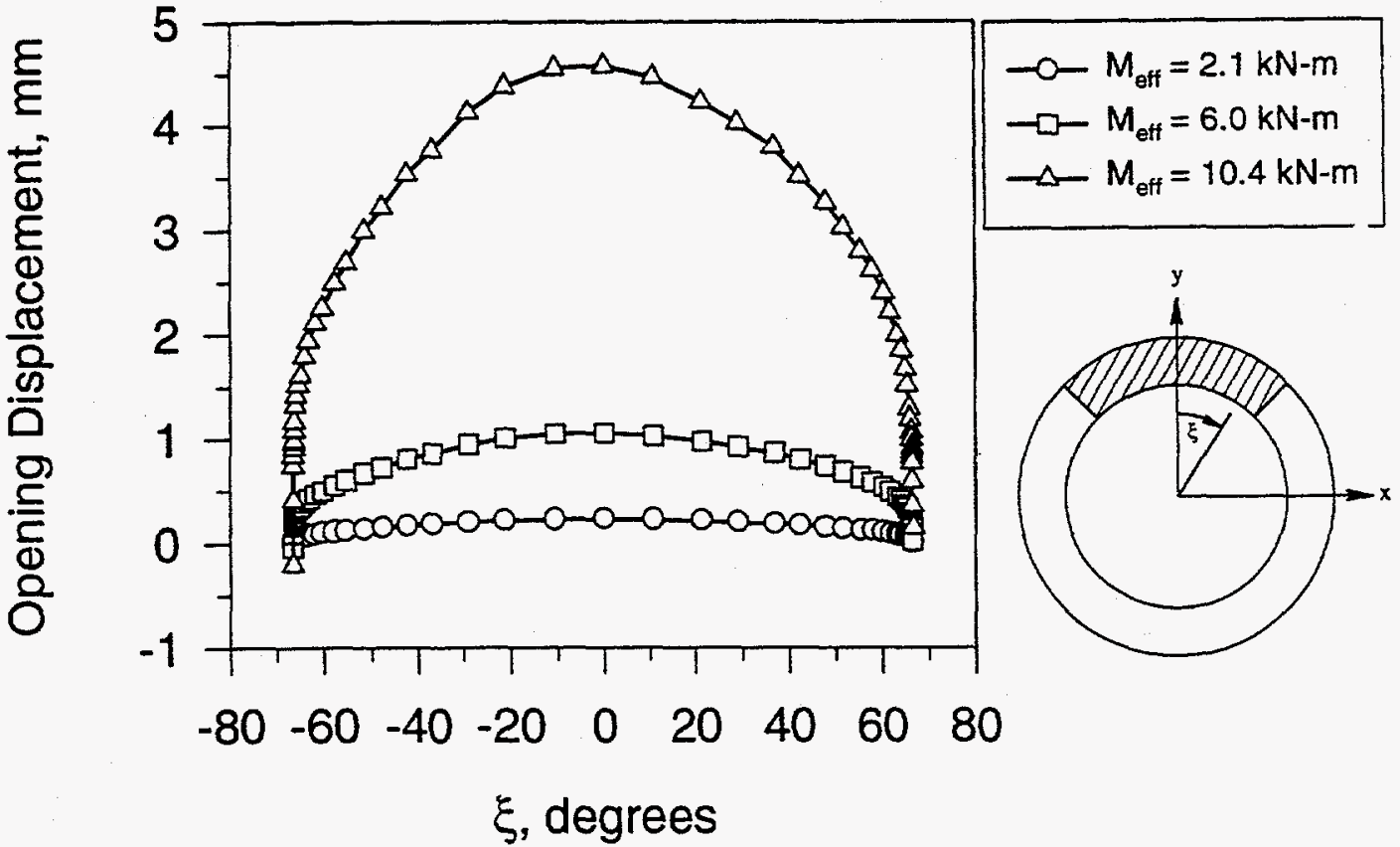

(a) $M_{b} / T=3.0$

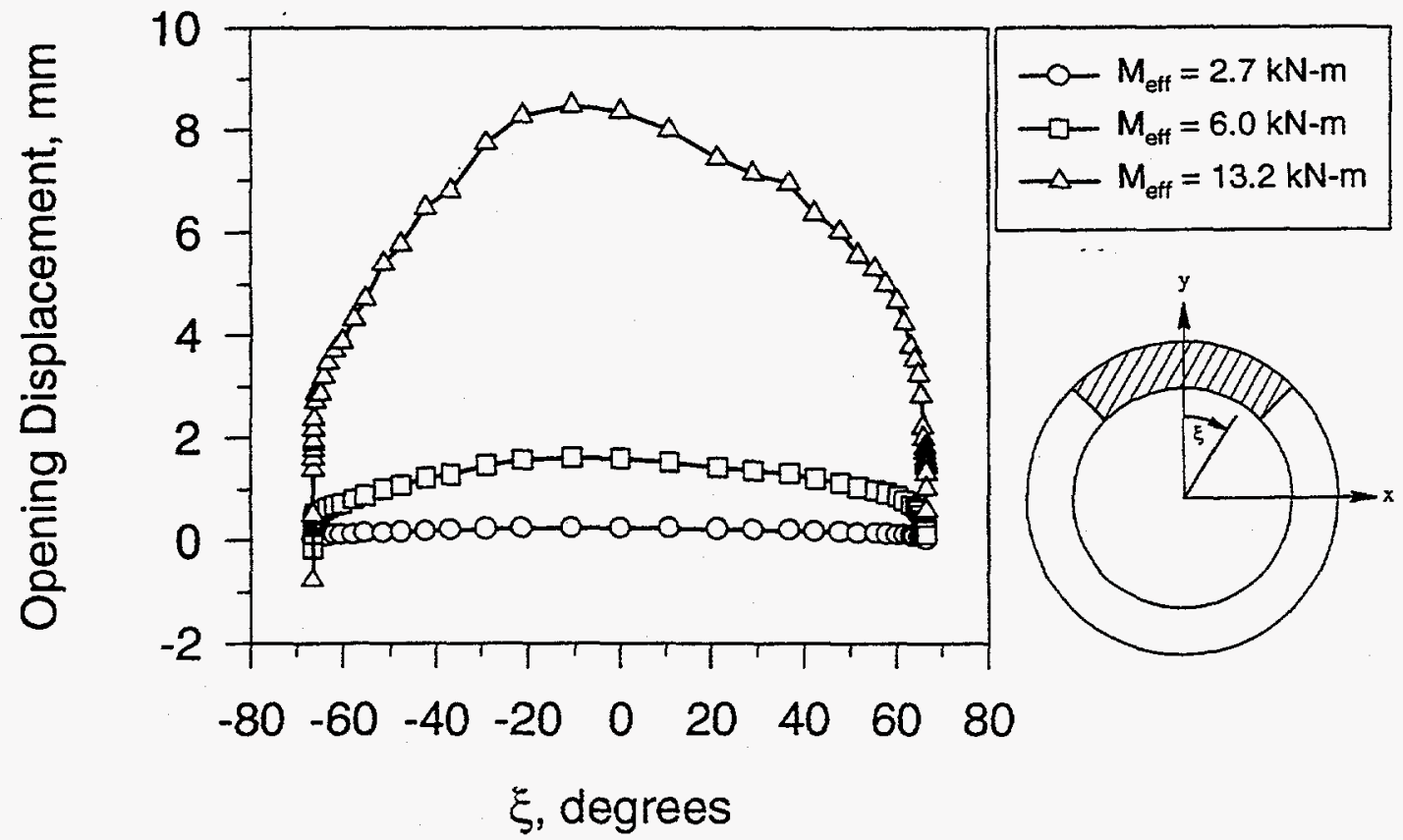

(b) $M_{b} / T=1.0$

Figure 2.106 Crack-opening profiles at various effective moments (calculated using $\mathrm{C}_{e}=\sqrt{3} / 2$ ) for combined tension, bending, and torsion 


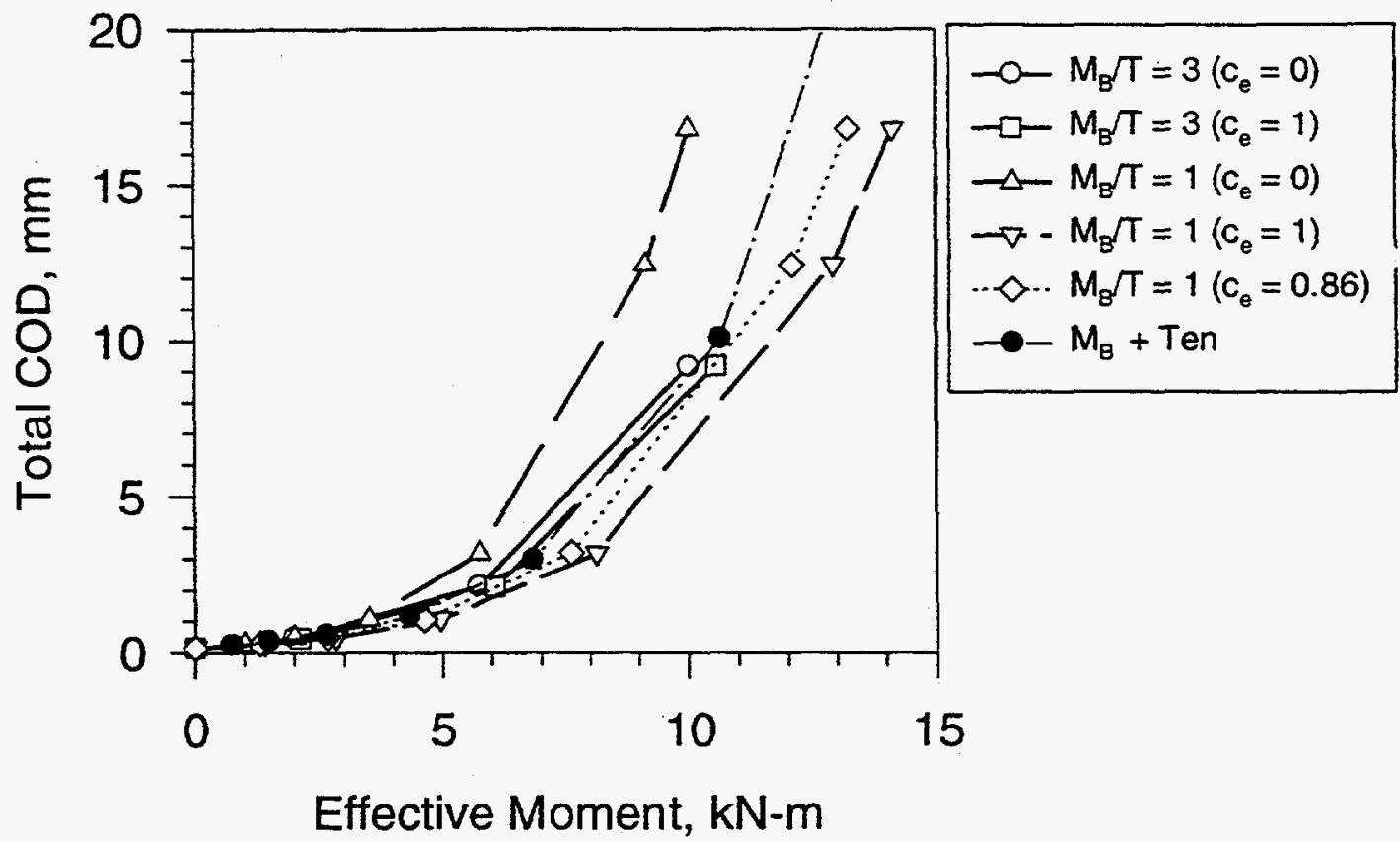

Figure 2.107 Variation of total crack-opening displacement with effective moment for the load cases of tension plus bending and combined tension, bending, and torsion (The effective moment for the latter cases is calculated for several values of $c_{e}$ )

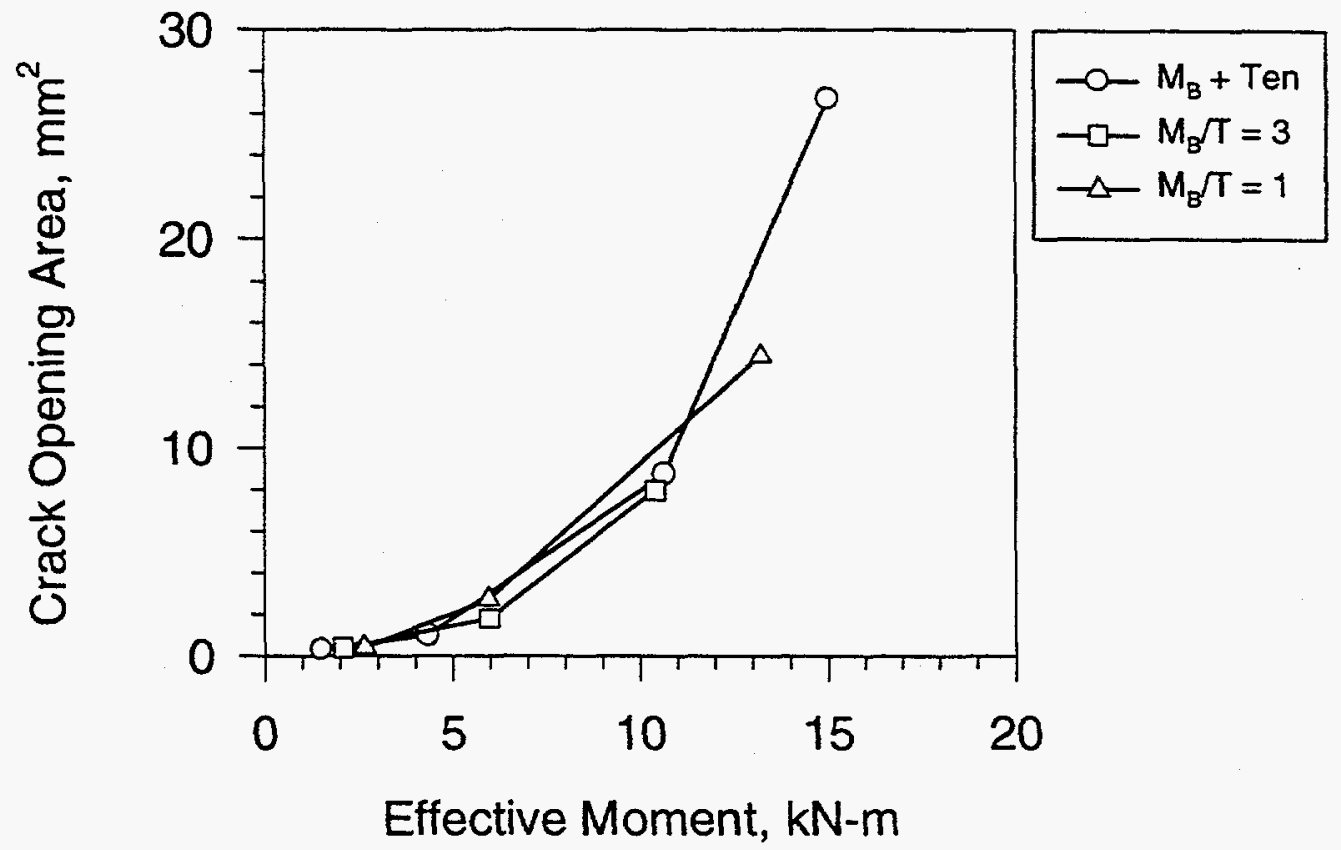

Figure 2.108 Comparison of the variations of total crack-opening area with effective moment for the combined load cases of tension plus bending and tension plus bending plus torsion $\left(c_{\mathrm{e}}=\sqrt{3 / 2}\right)$ 


\subsubsection{Analysis of Off-Centered Cracks}

In a typical plant piping situation, a crack may not necessarily be centered on the primary axis of the bending load, although contemporary analysis methods make this assumption. As documented in Reference 2.15 using both finite element and estimation analyses, off-centered cracks can be handled by resolving the applied moment to the effective moment at the center of the off-centered crack and assuming an elliptical profile for the crack-opening shape with traditional analysis methods. This is an important finding since for leak-rate calculations, accuracy in the prediction of crack-opening area is more significant than that of the crack-opening shape.

This result considers only crack-opening area and not the load-carrying capacity and the fracture stability of the leaking crack. From a qualitative viewpoint, one can argue that when a crack is off-centered, the crack-driving force, be it stress-intensity factor in linear-elastic fracture or J-integral in elastic-plastic fracture, will be lower than that for a centered crack. This assumes that the bending plane is the same for normal moments and seismic moments. However, it is possible that the bending planes will differ between normal operating stresses and under seismic loading. Hence, an off-centered crack, which may increase the length of the leakage flaw due to reduced crack-opening, can have positive effects on the load-carrying capacity of pipes. It would be interesting to see how they would be countered by the positive effects related to the structural integrity of the pipes. At this time, there are no EPFM or limit-load solutions (or experiments) for an off-centered crack in a pipe under bending.

\subsubsection{Effect of Pipe System Boundary Conditions on Fracture and Leak Rate}

In virtually all nuclear pipe fracture analyses, the pipe system stress analysis and the fracture analyses are decoupled. That is, typically the stresses in an uncracked-pipe system are determined, then those stresses are used in an analytical fracture analysis. Earlier in this report (Section 2.1.5) some of these effects were reviewed.

Of the effects observed, one of the most stunning results came from a pipe-system experiment in the IPIRG-1 program (Ref. 2.61). In that experiment, it was experimentally determined that a guillotine break did not occur until the growing through-wall crack was 95 percent around the pipe circumference, see Figure 2.109. From pressure loads alone, it was expected that a break would occur once the crack reached 65 percent of the circumference. The 95 -percent crack length corresponded to the pressure-induced failure if the induced bending from the pressure stress was fully restrained, see Figure 2.110 . The results from this experiment, with the crack located 3.4 pipe diameters from an elbow, provide strong evidence that pipe- system boundary conditions restrain pressure-induced bending and that this increases the loadcarrying capacity of the crack. Virtually all fracture analyses assume that the pipe is free to rotate due to the pressure-induced bending. Consequently, the contemporary fracture methods will tend to inaccurately predict the propensity for crack instability because they ignore the restraint that pipe-system boundary conditions provide. 


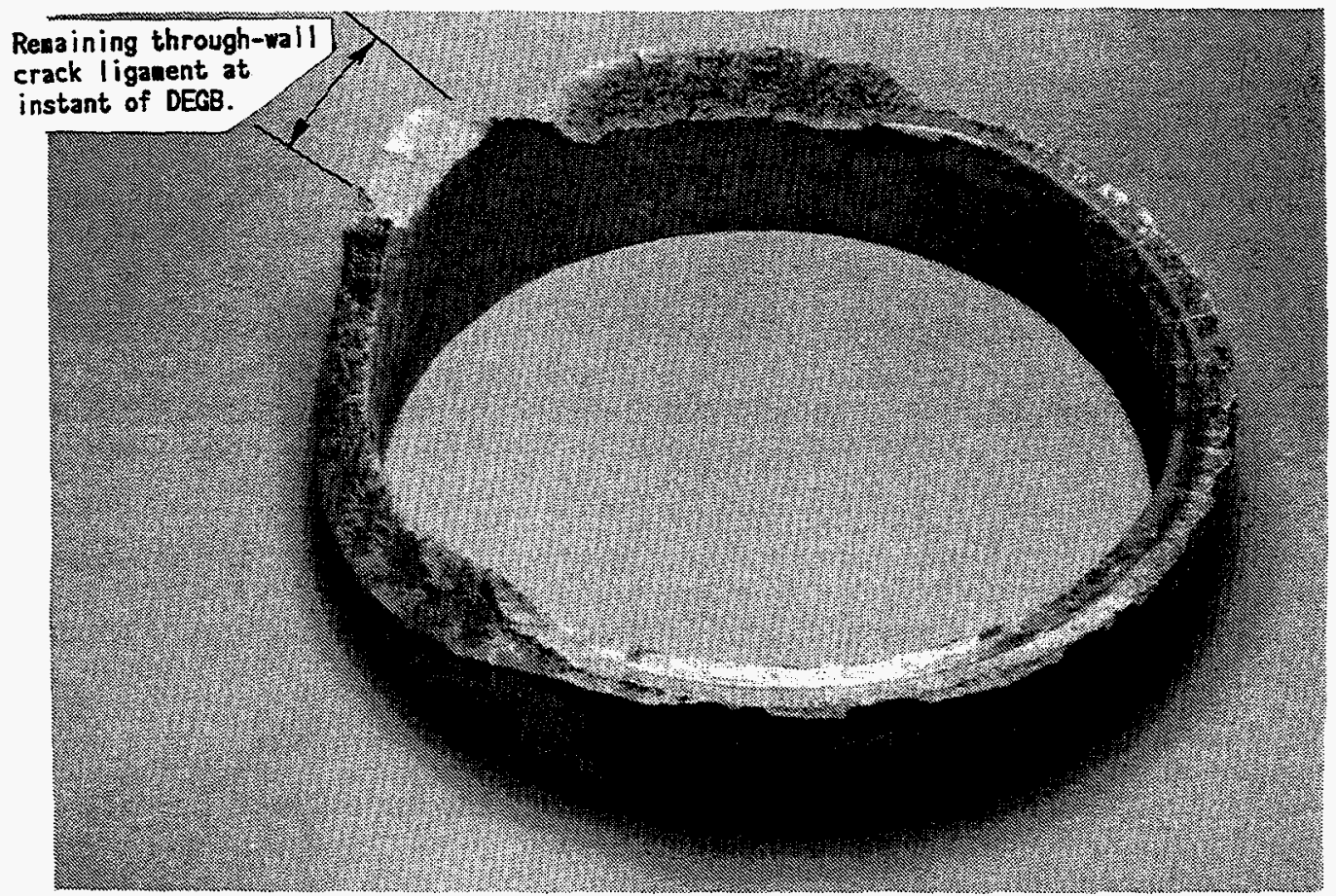

Figure 2.109 Photograph of fracture from aged cast stainless experiment (Experiment 1.3-7)

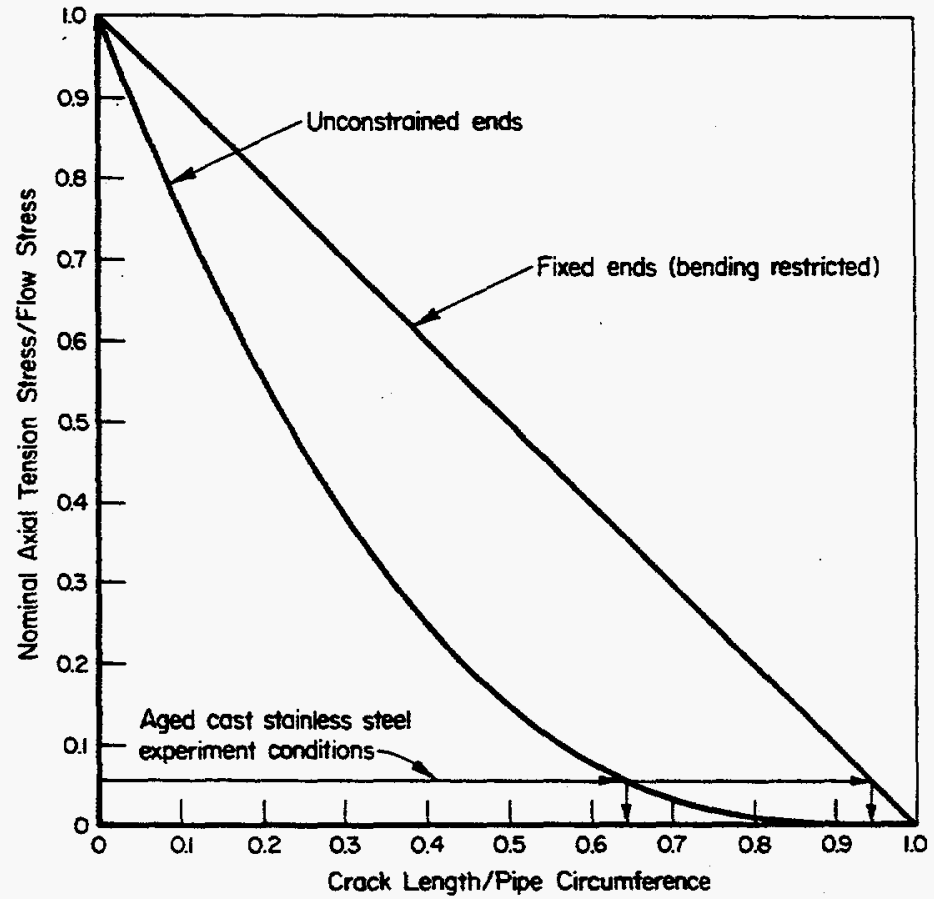

Figure 2.110 Net-Section-Collapse analyses predictions, with and without considering induced bending, as a function of the ratio of the through-wall crack length to the pipe circumference 
After the excitement subsided concerning the apparent beneficial effects of the restraint of pressureinduced bending on fracture loads, it was later noted, that if the failure loads are increased, then the driving force is reduced, so that the crack-opening displacement in the pipe system will be less than what is typically calculated using current crack-opening displacement analyses (Ref. 2.176). Hence, the increased load-carrying capacity that is beneficial to LBB, has a corresponding decrease in crack-opening displacement that is detrimental to LBB. Because the trade-offs between these two effects were not well understood, some selected case studies were undertaken which are summarized below.

Considering the geometry shown in Figure 2.111 , for fully restrained $\left(\mathrm{L}_{\mathrm{r}}=1\right)$ and completely unrestrained conditions applied to $102-\mathrm{mm}$ (4-inch) nominal $\left(\mathrm{R}_{\mathrm{m}} / \mathrm{t}\right.$ of 6$)$ and $711-\mathrm{mm}\left(28\right.$-inch) $\left(\mathrm{R}_{\mathrm{m}} / \mathrm{t}\right.$ of 10$)$ diameter pipes under the following conditions:

- a leak rate of 1.89 liters/min (0.5 gpm)

- IGSCC crack morphology parameters,

- a pressure of $15.5 \mathrm{MPa}(2,250 \mathrm{psi})$, and

- a bending stress chosen to give a total pressure plus bending stress of 50-percent of the Service Level A maximum allowable stress from ASME Section III Article NB-3650 for TP304 pipe,

the leakage-size crack was calculated using the SQUIRT Version 2.4 computer code. These results are shown in Table 2.18. At this leak rate, the large diameter pipe is basically unaffected by the restraint condition while the small diameter pipe is very much affected.

Table 2.18 Differences in leakage flaw sizes due to restraint of pressure induced bending

\begin{tabular}{|c|c|c|c|}
\hline \multicolumn{2}{|c|}{ Outside Pipe Diameter } & \multicolumn{2}{|c|}{$\begin{array}{c}\text { Leakage Crack Length, } \\
\theta / \pi\end{array}$} \\
\hline $\mathbf{m m}$ & inches & Restrained & Unrestrained \\
\hline 114.3 & 4.5 & 0.7250 & 0.2360 \\
\hline 711.2 & 28.0 & 0.0219 & 0.0219 \\
\hline
\end{tabular}

The corresponding LBB fracture loads were evaluated under the following conditions:

- the crack is centered on the bending plane,

- the average stress-strain curve properties for TP304 stainless steel base metal were used from the statistical analysis in Appendix B of Reference 2.176, and

- the crack was assumed to be in the weld, hence the mean minus one standard deviation J-R curve for a stainless steel SAW weld was used, see Reference 2.37. 

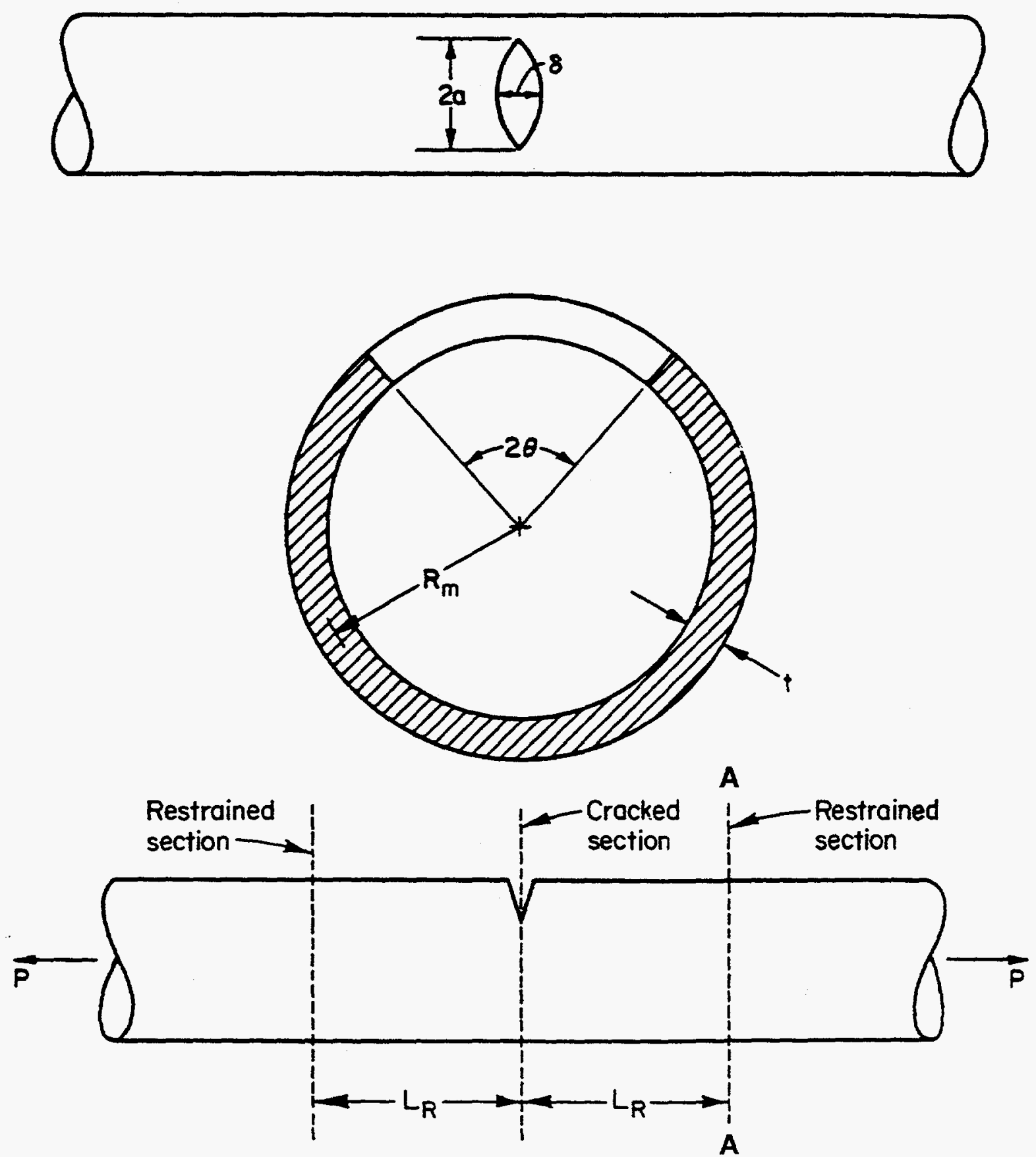

Figure 2.111 Schematic of a through-wall-cracked pipe under pure tension (restrained locations prevent rotation and ovalization) 
Using the LBB.ENG2 analysis modified to eliminate the induced bending from the tension component of the axial stress component, the ratio of the unrestrained to restrained failures loads is shown in Figure 2.112. This result shows that the effects of the restraint of pipe-system boundary conditions were negligible for the 711-mm (28-inch) diameter pipe. This was because for this leak rate, the crack size was a small percent of the circumference, and hence the beneficial effects on fracture and detrimental effects on COD were negligible. However, the effect on the $102-\mathrm{mm}$ (4-inch) diameter pipe was very large. The unrestrained load is a factor of 9 larger than the restrained load. This was a more significant effect than any possible effect from toughness considerations. The reason this occurred was that for this leak rate, under this loading, the crack in the small pipe for the restrained condition had to be very large when compared with the larger diameter pipe. The crack, in fact, became so large from this effect, that any benefits on fracture loads were small, especially considering that the additional loads to fracture were all bending loads, not increases in pressure loads. Also, like any LBB analysis, the calculations were made up to maximum load, and were not an actual determination of a DEGB.

The effect seen in this sample calculation suggests that LBB applications need to be assessed carefully for cases where large crack sizes may occur, i.e., small-diameter pipe, or steam line applications. It also suggests that there may be some concern with LBB applications to intermediate pipe diameters. Fortunately, for large diameter pipe, where LBB is of greatest benefit, there is no detrimental effects from this phenomenon.

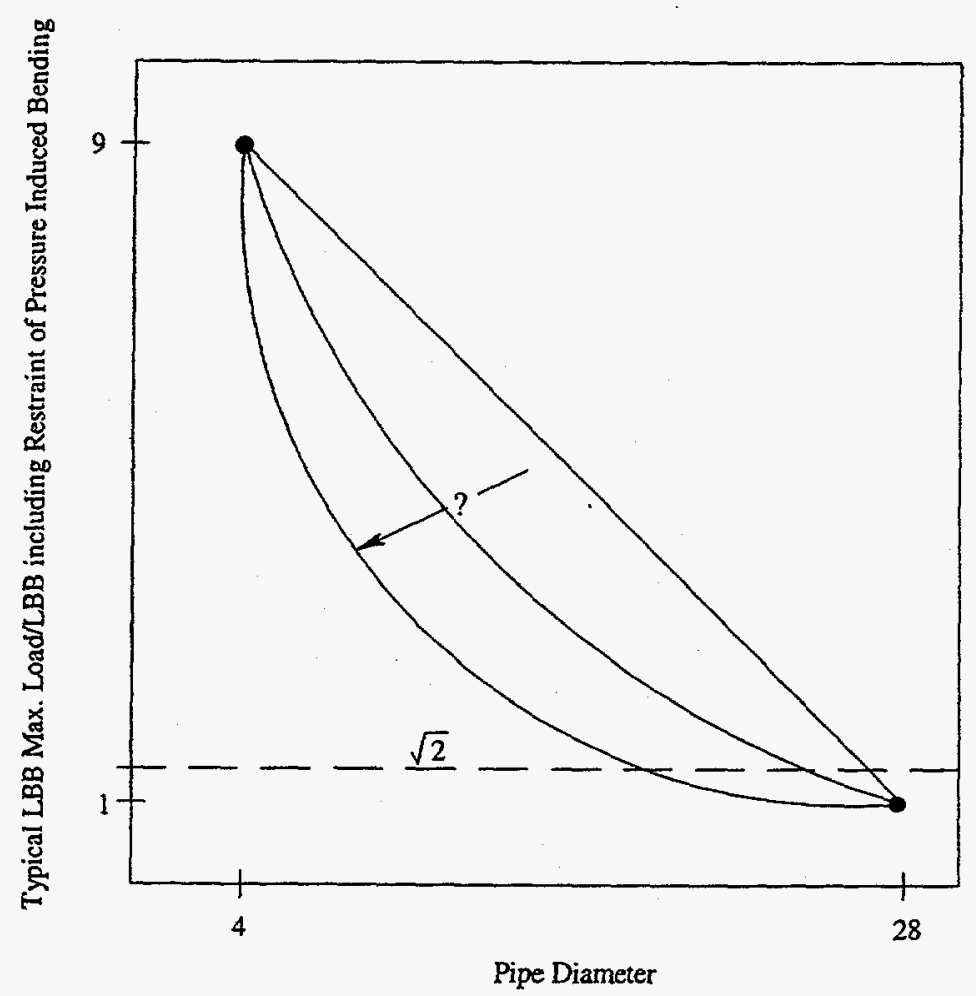

Figure 2.112 Calculated maximum loads for LBB with and without restraint of the pressureinduced bending from the pipe system 


\subsubsection{Analysis of a Girth Weld Nozzle Crack at a Thickness Transition}

A pipe containing a crack in a girth weld at a typical nozzle with a thickness taper on both sides is a common feature in power plant piping. Because it is common and because it may present unique challenges to prediction of crack-opening displacements, some elastic-plastic finite element analyses were conducted and documented in Reference 2.11 were performed. These were conducted to assess the effects of a typical thickness transition and geometric constraint associated with heavy integrally reinforced nozzles on the crack-opening displacement of a carbon steel nozzle containing a circumferential throughwall crack. In this analysis an angled safety injection nozzle on a cold-leg pipe was analyzed, see Figure 2.113. The main result from this study was:

- Due to thickness gradients on both sides of the crack, the fraction of crack-opening displacement on the thinner side of the crack was much larger than that on the thicker side, thereby breaking the symmetry of the crack-opening shape with respect to the crack length. The differences in these components can be significant when the applied moment is large enough to induce plasticity, see Figures 2.114(a) and 2.114(b).

\subsubsection{Evaluation of Weld Residual Stresses}

There is a sense that weld residual stresses can influence crack-opening behavior by causing the crack to want to close, and thus effectively shorten the crack length for leakage purposes (but not fracture analyses). For leak-before-break, this could be important because the leak rate may be reduced without a corresponding change in the fracture loads. Experiments could be done to evaluate these effects, but not without great difficulty and great uncertainty. As an alternative, a great deal of insight can be gained using analytical methods (Ref. 2.182) to simulate weld residual stresses in a finite element analysis.

Using either crack-face pressures to model weld residual stresses, the SAQ solution, or thermal-plastic finite element analysis to simulate the welding process, the Battelle solution, one obtains the crack-opening shape shown in Figure 2.115. The qualitative trend is the same for both analyses, with the Battelle solution giving slightly higher displacements. Other important observations were:

- There was a significant amount of crack-face rotation (or through-thickness bending) from the thinwalled residual stress field.

- For the loads applied, the crack-opening displacements were essentially zero for about 15 percent of the crack length at both ends of the crack, i.e., the effective crack-opening displacement occurred over the center 75-percent of the crack length. Note that if the applied loads were smaller, then the crack could completely close up.

A subsequent analyses by SAQ reported in Reference 2.10 which used the residual stress distributions shown in Figure 2.116 showed that for the thin-walled pipe, the residual stresses would completely pinchoff the flow at a moment corresponding to less than 28.6 percent of the Service Level A maximum stress level (see Figure 2.117). For the thick-walled pipe case, this would occur only at very low applied stresses. 


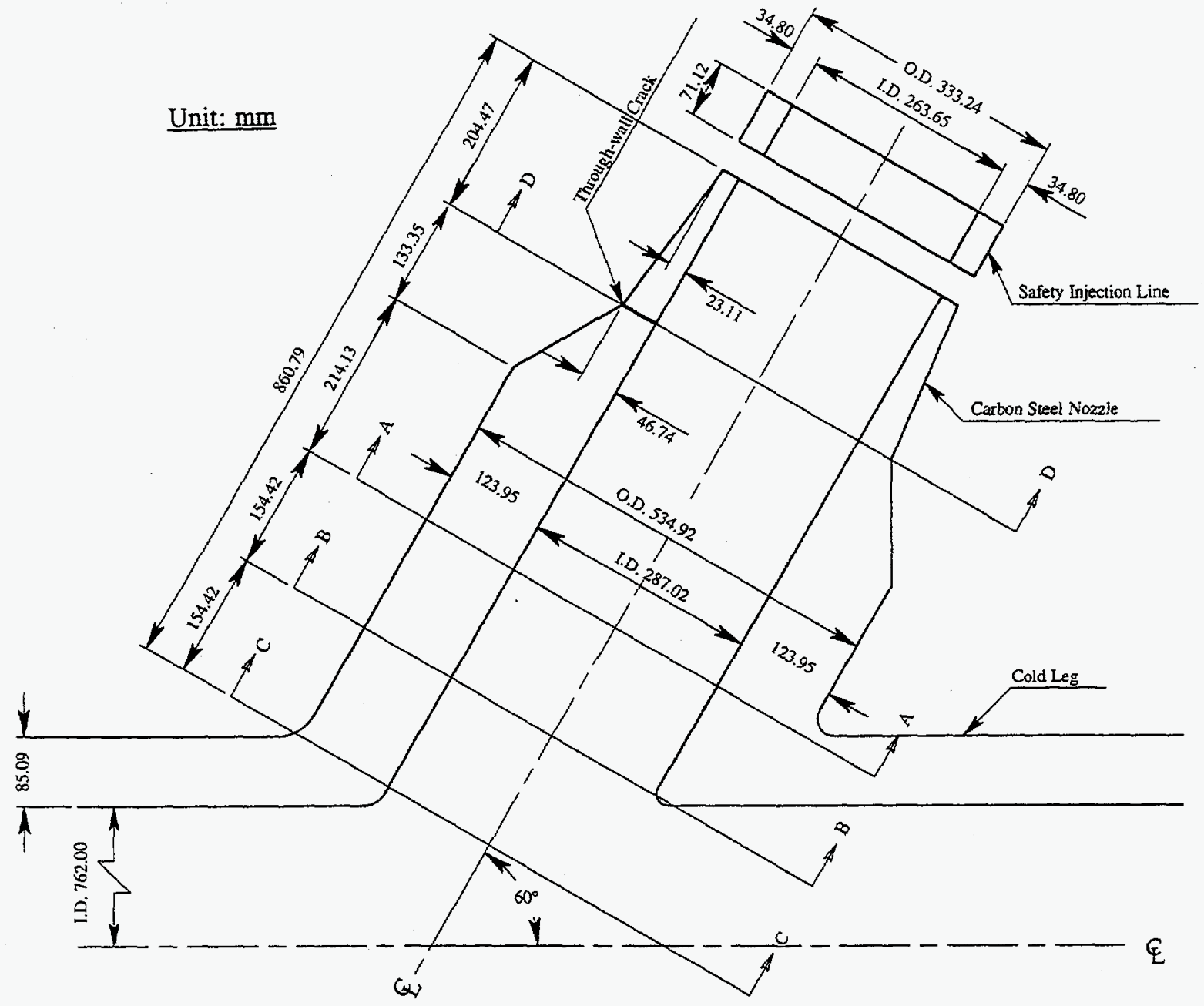

Figure 2.113 Geometric details of a carbon steel nozzle with a through-wall crack at thickness transition, dimensions in $\mathbf{m m}$ 


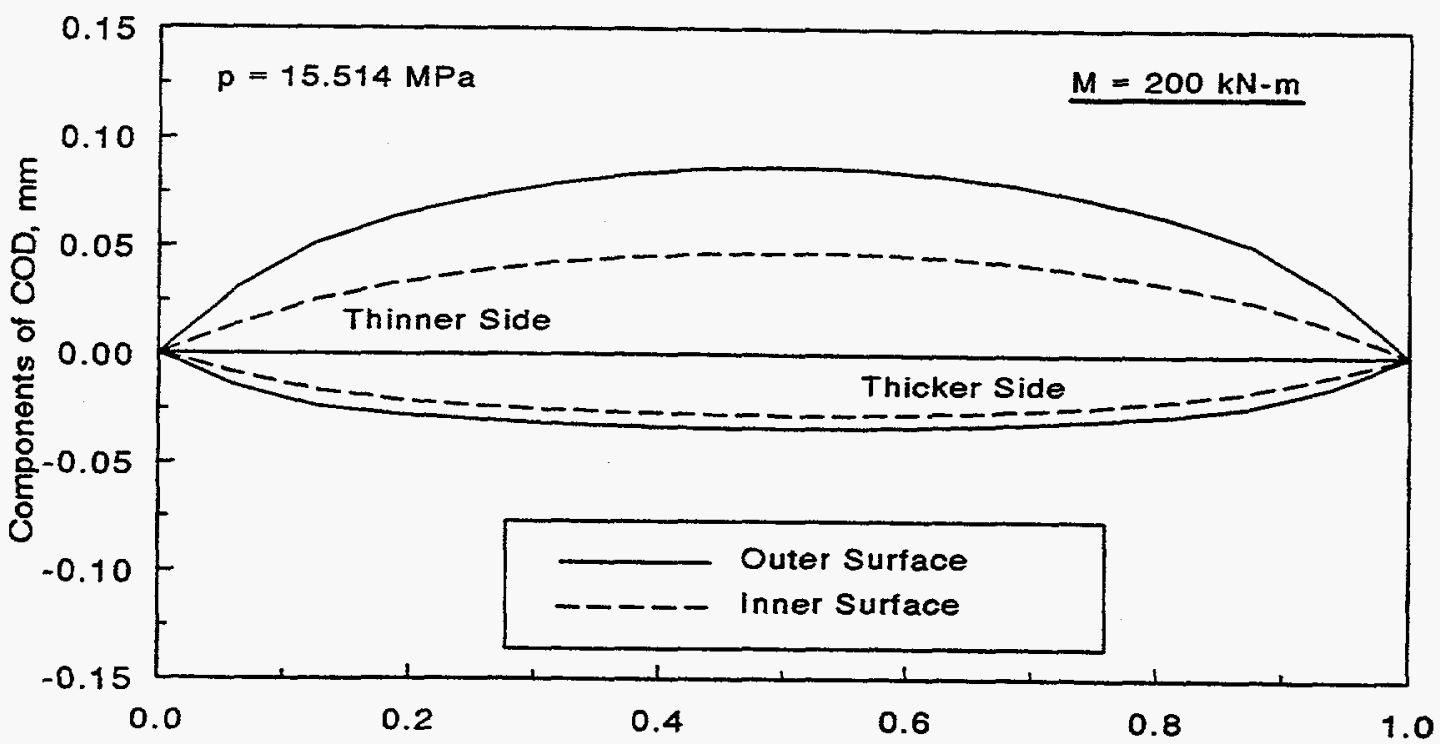

Crack-Tip Distance/Crack Length, mm

(a) $\mathrm{M}=\mathbf{2 0 0} \mathrm{kN}-\mathrm{m}$

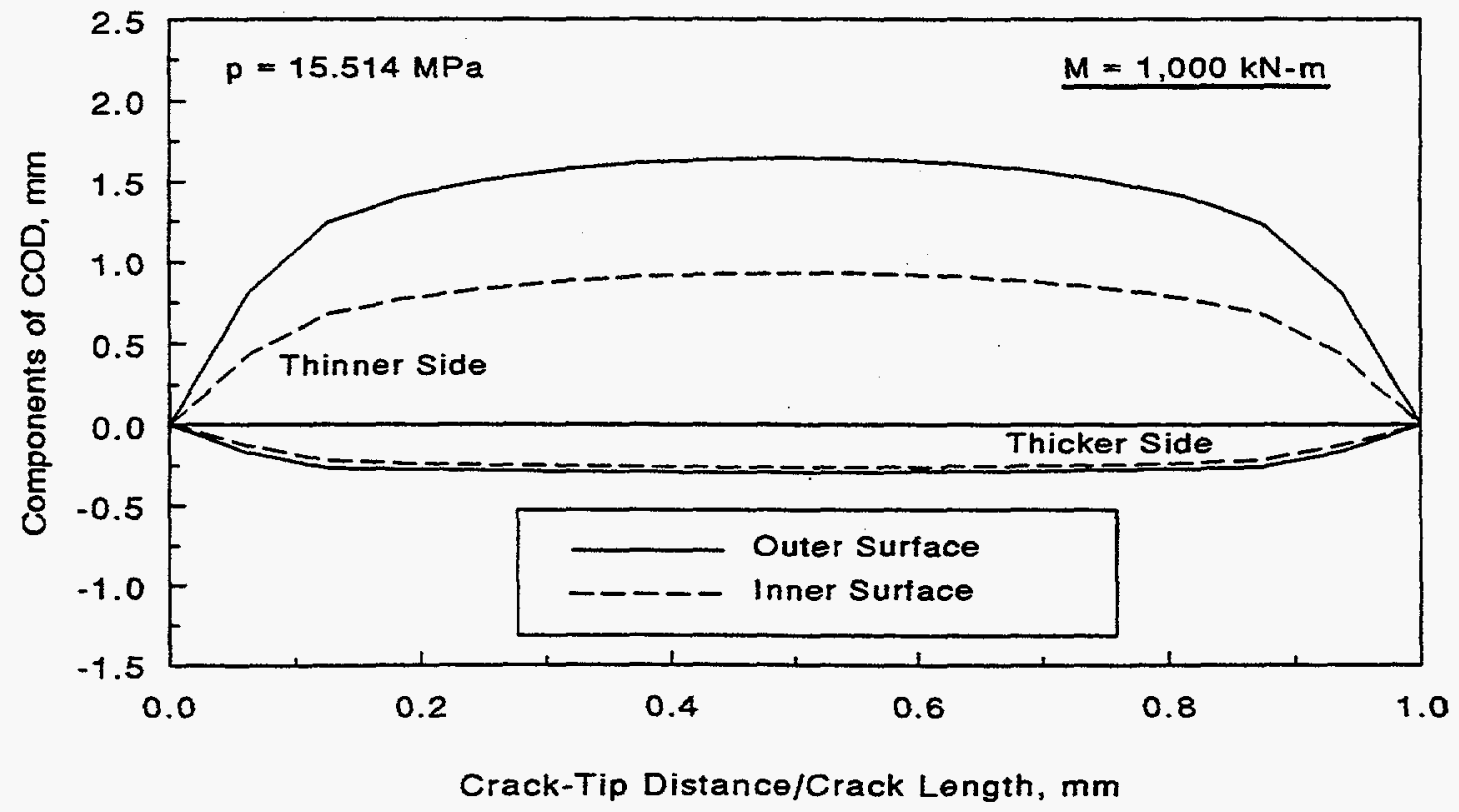

(b) $\mathrm{M}=1.00 \mathrm{MN}-\mathrm{m}$

Figure 2.114 Crack-opening profiles under combined bending and tension 


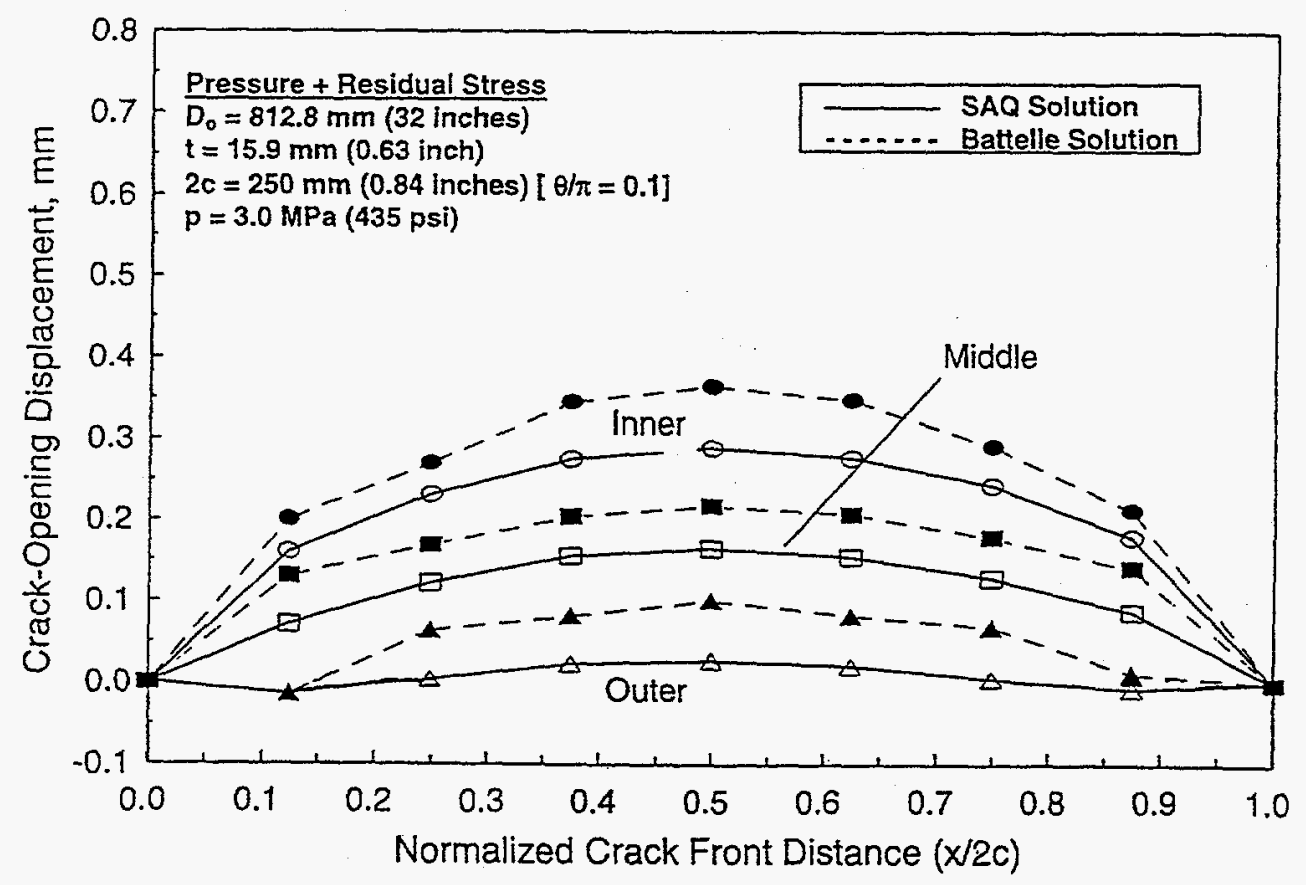

Figure 2.115 Total crack-opening displacement due to residual stresses and pressure 


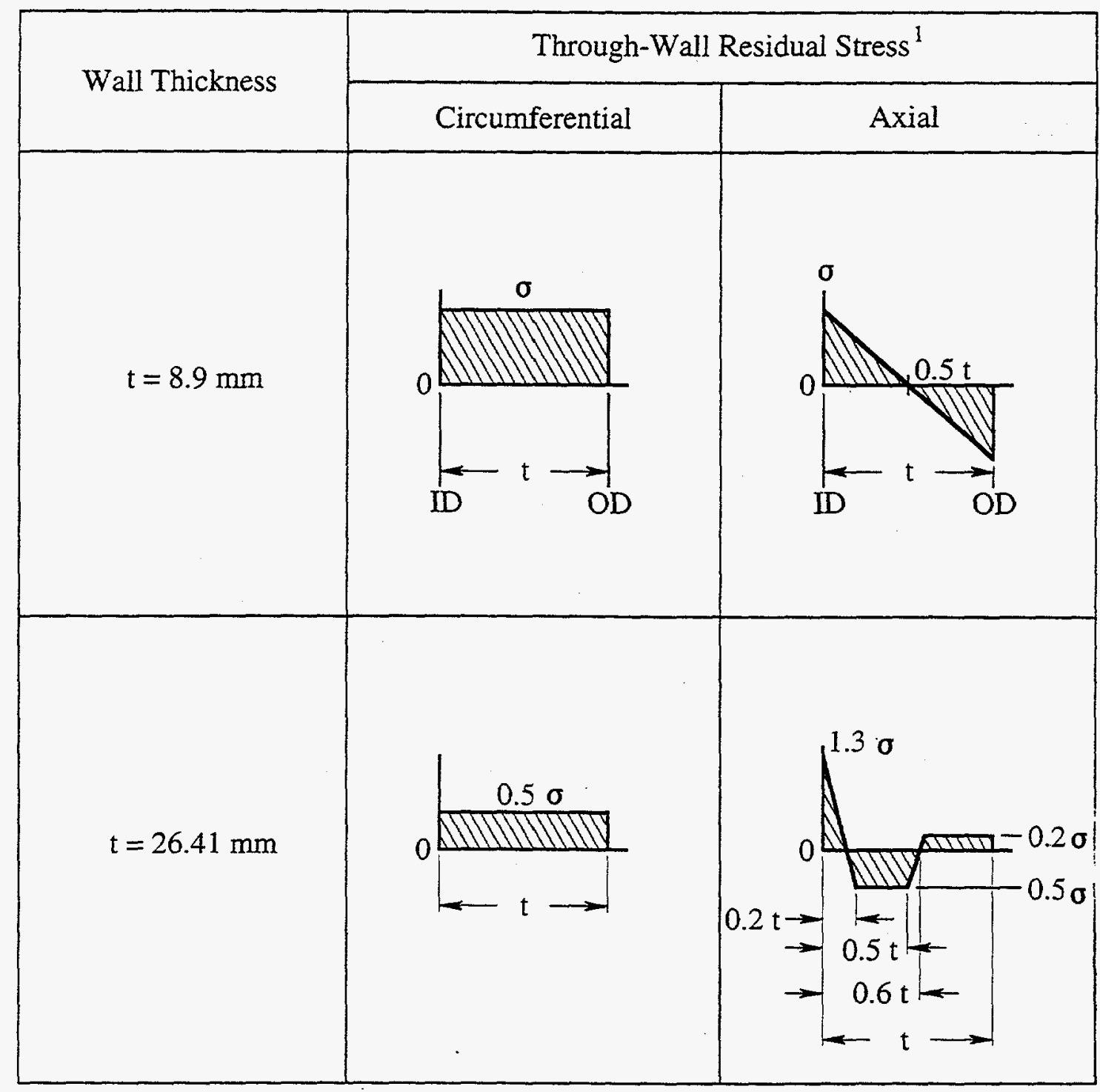

$\sigma=207 \mathrm{MPa}(30 \mathrm{ksi})$

Figure 2.116 Prescribed residual stress field from ASME Section XI IWB-3640 analyses 


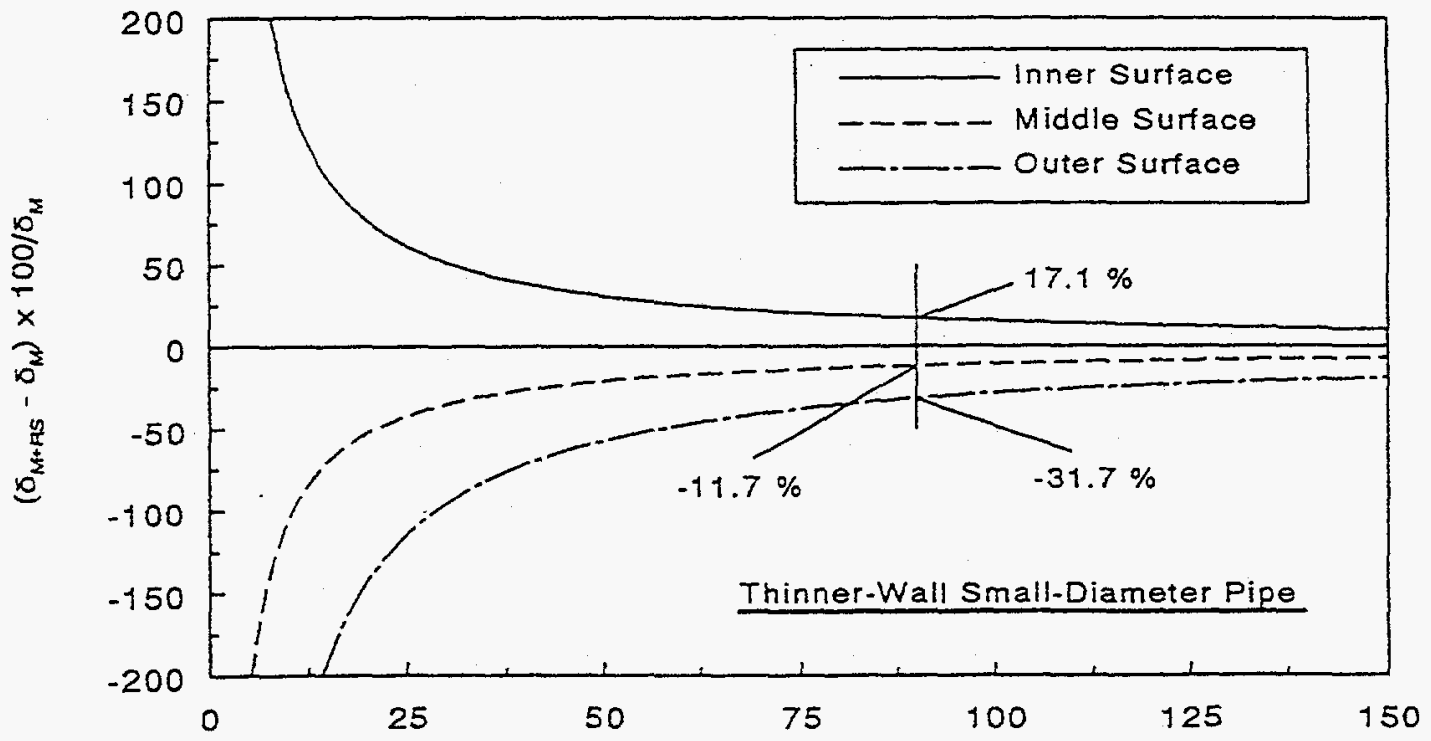

Applied Moment, \% of Service Level A

(a) Small diameter pipe

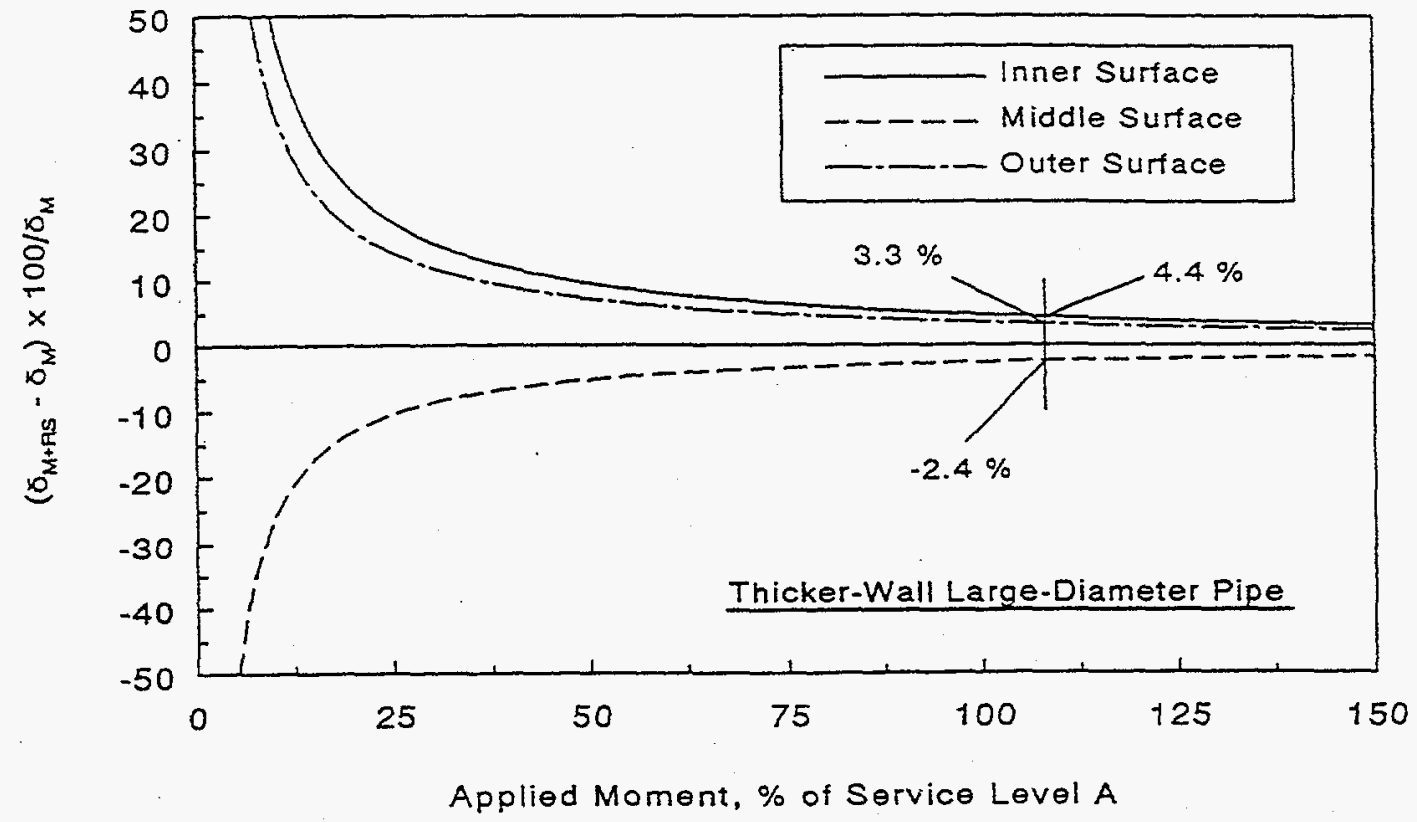

(b) Large-diameter pipe

Figure 2.117 Percentage change in calculated COD due to residual stress as a function of applied moment for small diameter thin-wall and large diameter thick-wall pipe 
As noted in Reference 2.10, the rotations of the crack face by itself has little effect on the leak rate, unless the faces touch. This was supported by unpublished experimental results at $\mathrm{CEGB}^{*}$ and by calculations using the SQUIRT leak-rate code. Consequently, the only important consideration is how far along the crack length the faces will touch. Since leak rates are approximately proportional to the crack-opening area, the ratio of the leak rates with residual stresses versus leak rates without residual stresses is approximately equal to the ratio of the crack lengths where the crack faces do not touch. This leak-rate ratio versus the applied stresses is shown in Figure 2.118. For the thick-walled pipe case, as long as the applied stresses are greater than 10-percent of the allowable stresses, then the residual stresses are unimportant for leak-rate considerations. For the thin-walled pipe, if the applied stresses are less than 40 percent of the Service Level A maximum allowable stresses, then the residual stresses had a significant effect on the leak rate.

\subsubsection{Leak-Rate Evaluations}

One of the first leak-rate models ever developed for nuclear power plant piping was developed by Battelle for the U.S. NRC in Reference 2.183). It employed the basic Henry-Fauske model used in many of the leak-rate codes today. The basic Henry-Fauske approach defines the crack-opening shape as an equivalent circular pipe with an average surface roughness and number of turns along the flow path. At the time of the development of this first method for predicting the leak rate in cracked pipes, the Henry-Fauske approach was easy to handle with the computer capabilities at that time, whereas, current computer

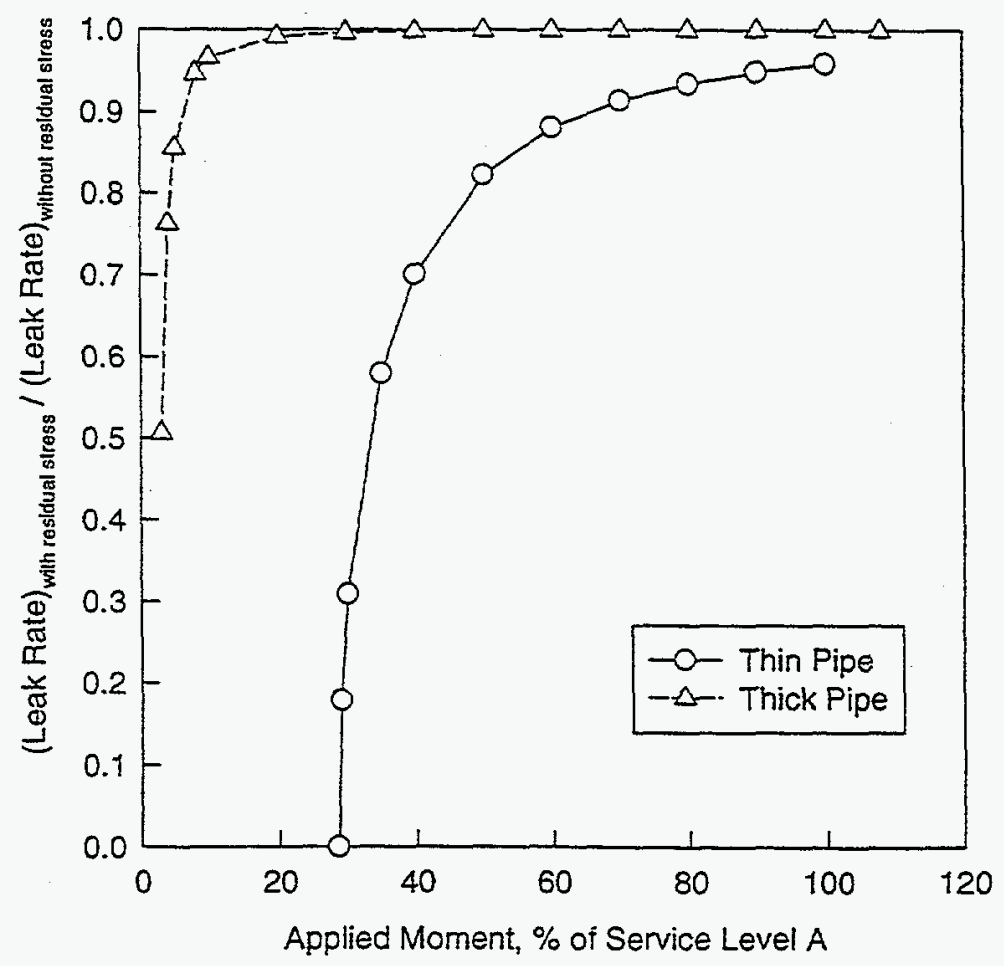

Figure 2.118 Ratio of leak rates, with and without residual stresses, as a function of applied loads

* From discussions with T. Chivers of Nuclear Electric. 
capabilities can handle more sophisticated computational fluid mechanics models that are based on flow through parallel plates. This early thermal hydraulic model for two-phase flow through a crack was subsequently extended and validated by some leak-rate experiments in an EPRI program at Battelle (Ref. 2.181). This work was then taken by EPRI and used as the basis for the PICEP leak-rate code (Ref. 2.184).

At a later time in the IPIRG-1 program, a separate leak-rate code was developed at Battelle for analysis of additional leak-rate tests. This leak-rate code was initially used as a tool for Battelle researchers to make comparisons with the basic Henry-Fauske model in the prior work, but by demand from IPIRG members, the code was made more user friendly and released as SQUIRT Version 2.1 in April 1991. SQUIRT Version 2.3 (November 1994) was released as part of the NRC Short Cracks program and had some technical improvements in the COD calculations, e.g., COD analysis for combined loading was improved, a correction to the friction factor equation was made, and a module for direct LBB calculations was added. As use of the SQUIRT code increased, further changes were subsequently made in Version 2.4 (April 1996) to:

(1) Add warning statements if the user was applying the code beyond its range of applicability, i.e., it is really only for two-phase flow through a crack, and

(2) The default crack morphology parameters were changed to the mean values determined from a statistical analyses conducted in Reference 2.176, see Section 2.4.2.1.

Since the U.S. NRC's initial interest in leak-rate prediction, there have been numerous leak-rate codes developed. Some of these are: FLORA and LEAKV from Siemens/KWU (Refs. 2.185 and 2.186), PIPELEAK by GRS (Ref. 2.186), ASTEQ from France (Ref. 2.187), DAFTCAT by Nuclear Electric, (Ref. 2.188), a Westinghouse code, and several Japanese codes (Refs. 2.189 and 2.190). The aim of all of these codes is the same, namely, prediction of the leak rate from a through-wall crack using the crackopening displacement from a fracture analysis, some description of roughness along the flow path, and the thermo-hydraulic conditions inside the pipe.

\subsubsection{Crack Morphology Considerations for Leak-Rate Prediction}

The key crack-morphology variables considered in most leak-rate analyses are surface roughness, number of turns in the leakage path, and entrance loss coefficients (Refs. 2.16 and 2.184). Examination of service cracks, however, shows that the cracks frequently do not grow radially through the pipe thickness. Hence, a fourth parameter, "actual crack path/thickness," representing deviation from straightness can also play an important role in the calculation of leak rates. Traditionally, this parameter has been ignored.

In addition, current leak-rate calculations do not explicitly account for the effects of crack-opening on the crack-morphology parameters. Examination of service cracks in pipes as well as theoretical considerations suggest that these variables should depend on the magnitude of the crack-opening displacement. But, currently, there are no engineering models that allow for these crack-morphology variables to be functionally dependent on the crack-opening characteristics of a pipe (Ref. 2.191).

* SQUIRT stands for Seepage Quantification of $\underline{\text { Upsets }} \underline{\underline{I}} \underline{\text { Reactor }}$ Tubes. 
To address these issues, an improved crack-morphology model was developed to conduct thermalhydraulic analysis for leak-rate predictions (Ref. 2.10). The model involved improved definitions of surface roughness, number of turns, and path deviation factors as a function of center-crack-opening displacement. Real service cracks were much more tortuous than idealized fatigue cracks typically used in leak-rate tests, see Figure 2.117. This model was an extension of the concepts in Reference 2.189.

The approach to improving the crack-morphology parameters was to write the parameters as a function of $\mathrm{COD}$ and to consider local and global roughness. For a very tight crack, the surface roughness is based on material grain size considerations and turns through the thickness represent the flow path length. As the $\mathrm{COD}$ becomes larger, however, the roughness is dominated by the turns and the flow path length frequently reduces to the pipe wall thickness, see Figure 2.119. Thus, one single model does not correctly capture all of the important physical phenomena that occur during loading of a leaking crack. A local/global model is suggested. A second improvement in crack morphology parameters came about after looking at numerous metallographic sections of service cracks. It was clear that even for a crack formed under similar conditions in the same material, there was a great deal of variability in the morphology. To capture this effect, probabalistic parameters for leak-rate calculations were developed (Ref. 2.10) so that this uncertainty could be considered in leak-rate models.
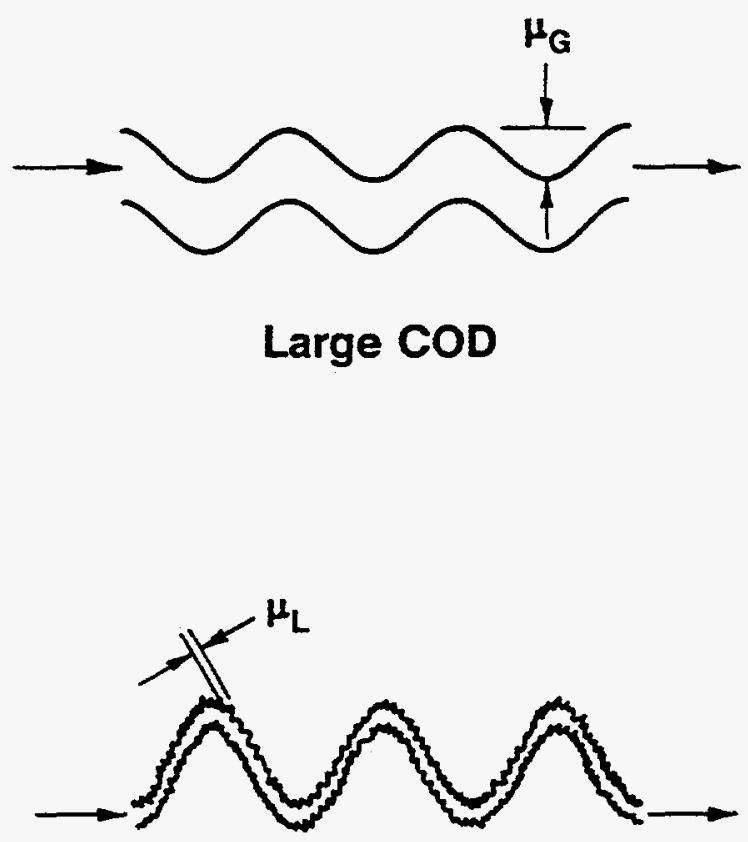

\section{Small COD}

Figure 2.119 Local and global surface roughness and number of turns 
The implication of having the improved crack-morphology variables and statistical crack morphology data is that these data can be used to calculate the probabilistic characteristics of the leak rates and leakage flaw sizes for LBB applications. Following standard statistical analysis procedures, Figures 2.120 and 2.121 show a typical histogram and cumulative probability of leakage flaw sizes in 711-mm (28-inch) diameter Schedule 80 stainless steel pipe assuming an IGSCC mechanism.

Examples of this kind show how the uncertainties in the crack-morphology input can be accounted for in characterizing leakage flaw size for LBB evaluations. Further details on these calculations can be found in References 2.10 and 2.176. The report also contains subsequent probabilistic pipe fracture evaluations for a wide variety of nuclear piping systems in BWR and PWR plants.

\subsubsection{The SQUIRT Leak-Rate Code}

As noted earlier, the SQUIRT leak-rate code was developed at Battelle, and has undergone several improvements. There are four modules in the current version of the SQUIRT Code (Version 2.4).

- SQUIRT1 calculates crack-opening displacements using either the original or new GE/EPRI influence functions developed at Battelle.

- SQUIRT2 performs leak-rate calculations for a given crack-opening shape, thermal hydraulic condition, and crack-morphology parameters.

- $\quad$ SQUIRT3 calculates the leak-rate for a given crack in a pipe under increasing loads. The fracture mechanics analysis uses the GE/EPRI or the more accurate LBB.ENG2 analysis. The thermal hydraulic conditions, crack morphology, and material properties (stress-strain curve and J-R curve) need to be given.

- $\quad$ SQUIRT4 performs the first step in an LBB evaluation, i.e., the crack length is calculated for a given leak-rate, crack morphology parameters (default values included), thermal hydraulic conditions, pipe geometry, and applied stresses on the pipe.

As part of making the final version of SQUIRT, numerous error messages were added so that the user doesn't apply the code outside of the validity region of the equations. Future work may involve improving the analysis in the single-phase all-liquid to two-phase flow regime, and improving the crack morphology model for tight cracks when the surface roughness approaches the crack-opening displacements. In this case, the friction factor equations break down. The problem is overcome by using the local and global surface roughness model described in Section 2.4.2.1.

For the probabalistic analysis in References 2.10 and 2.176, a special version of SQUIRT was developed for NRC and internal Battelle use. This is code is called PSQUIRT and a listing of it is in Appendix E of Reference 2.176. This code determines the frequency distribution of the flaw sizes for a given load level with statistically varied crack-morphology parameters. A separate code called PROLBB performs the conditional probabalistic LBB fracture analysis. This code is FORM/SORM based, and hence, is very computationally efficient compared with Monte Carlo simulations. A listing of PROLBB is given in Reference 2.176.

A comparison of a significant amount of the available leak-rate data with the SQUIRT Version 2.4 code predicted leak rates is shown in Figure 2.122. As can be seen in this figure, a factor of 10 on the predicted leak rate easily bounds all the experimental data. A factor of less than 5 is reasonable for the higher 


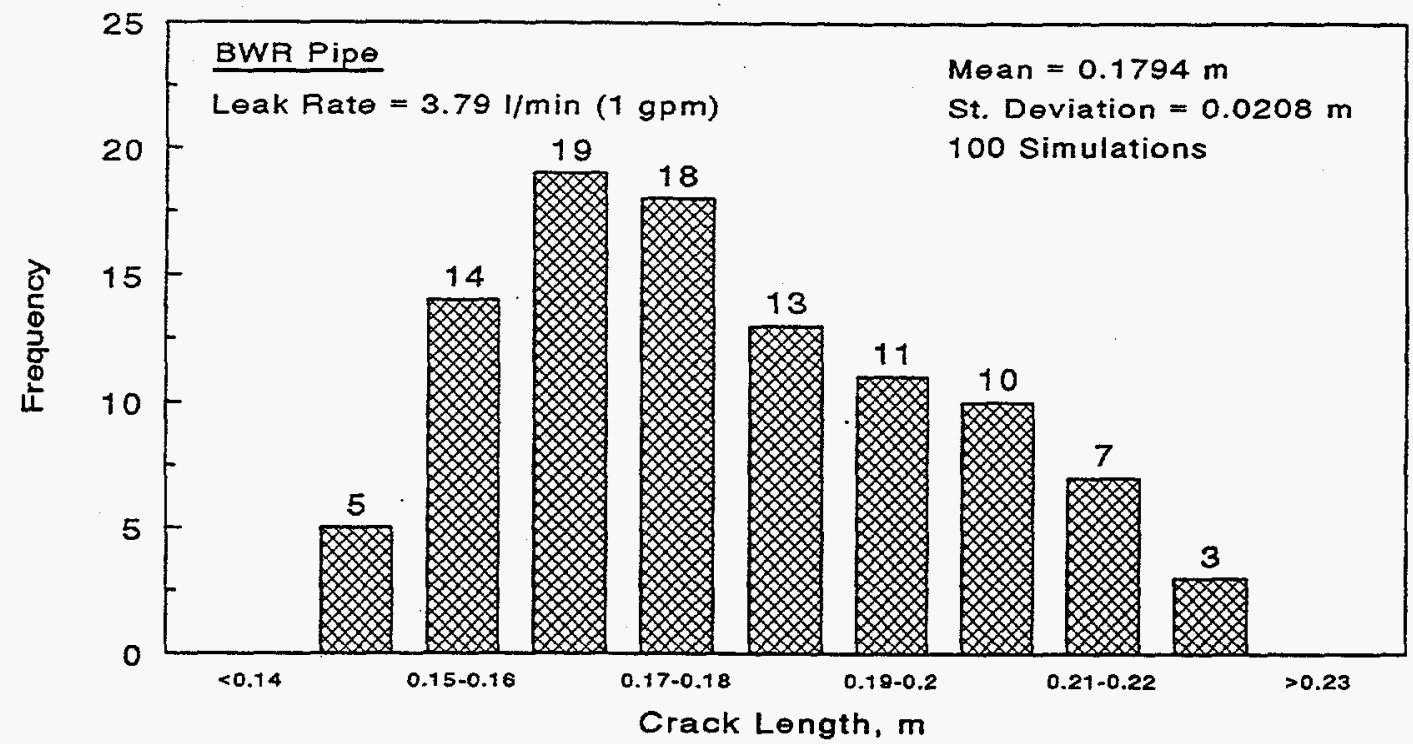

Figure 2.120 Histogram of leakage flaw size in a pipe for 3.785 liter/min (1 gpm) leak rate and 50 percent of ASME Service Level A stress limit

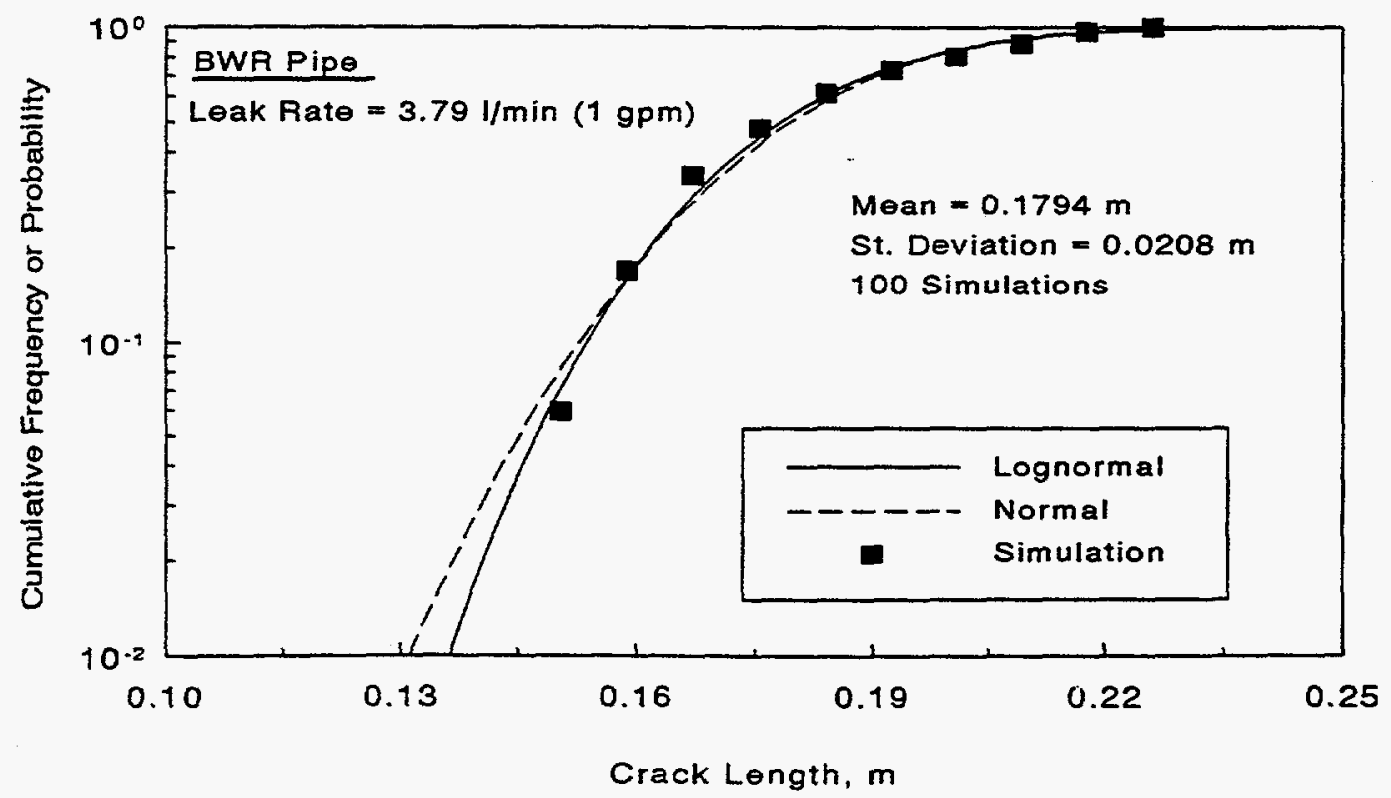

Figure 2.121 Probability distribution of leakage flaw size in a pipe for 3.785 liter $/ \mathrm{min}$ (1 gpm) leak rate and 50 percent of ASME Service Level A stress limit 


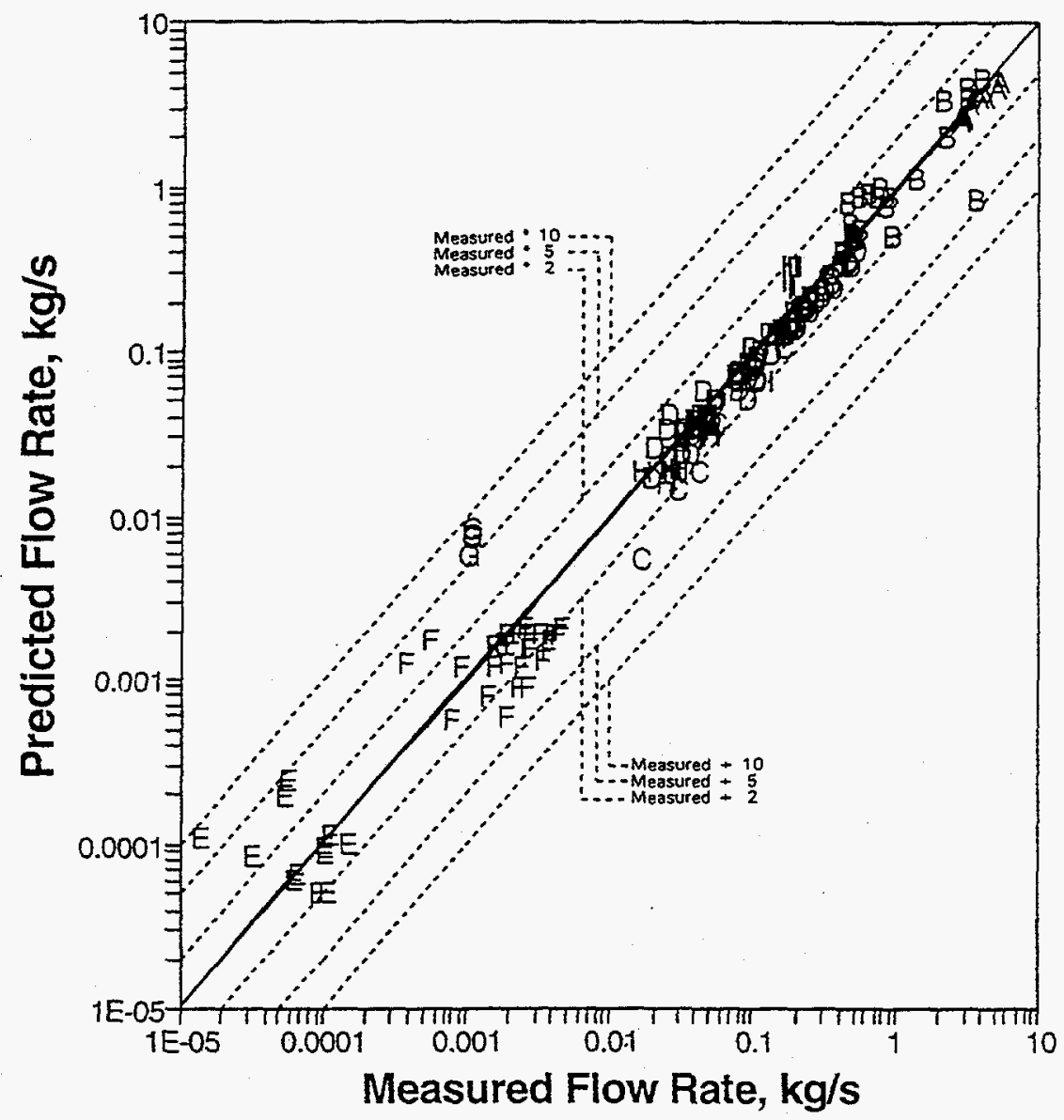

DATA SOURCES

A. Sozzi and Sutherland (1975)

B. Collier (1984) - Tight Slits

C. Yano (1987)

D. Amos and Shrock (1983)

Collier (1984) ISCC

E. $C O D=0.020 \mathrm{~mm}$

F. $\mathrm{COD}=0.050 \mathrm{~mm}$

G. $C O D=0.070 \mathrm{~mm}$

H. $C O D=0.108 \mathrm{~mm}$

l. $\mathrm{COD}=0.220 \mathrm{~mm}$

Figure 2.122 Uncertainty bands for predictions from the SQUIRT thermal-hydraulic model

leak-rate data, but the scatter increases with tighter cracks. (Note, these predictions were made using the experimental crack-morphology parameters, not the default parameters. The default crack morphology parameters are for cracks representative of service cracks, where their roughness is greater than slits or fatigue cracks used in most of the leak-rate experiments.)

\subsection{Fracture Behavior of Elbows}

The bulk of the work done on pipe fracture over the past 25 years has been done on straight pipe. A review of the open literature for elbow and fitting papers to compile a bibliography turned up only 107 papers and an effort to compile a database of fracture experiments turned up only 76 elbow experiments 
and 18 tee experiments (Ref. 2.192). In contrast, thousands of papers on fracture in straight pipe exist and the comparable straight-pipe fracture experiment database contains almost 900 experiments (Ref. 2.133). Nonetheless, cracks still do occur in elbows and tees so methods to analyze cracked elbows and fittings are needed, as well as experiments to validate the predictions.

\subsubsection{Fracture Prediction for Cracked Elbows}

In order to assure the structural integrity of nuclear piping systems, several assessment approaches have been developed, as documented in Section 2.3. All of these approaches are strictly applicable to cracked straight-pipe sections. However, service failures do occur in pipe bend or elbow sections of the piping systems. Simple modifications, or extensions, of approaches applicable to cracked straight-pipe sections may be adequate for pressurized elbows containing cracks. On the other hand, they may not capture all of the important behavior, and so new methods may need to be developed.

It is important to note that in design stress analyses, "limit-load" is defined differently than the "limit-load" in fracture mechanics. The design-stress "limit-load" definition usually refers to when a pipe fitting experiences a limited amount of global plastic bending loads or moments. The design-stress "limit moment" corresponds to a moment where an uncracked pipe/fitting test record or nonlinear analysis moment-displacement curve intercepts an elastic slope with twice the actual elastic compliance, see Figure 2.123. The pipe fracture limit moment occurs when the maximum moment of a cracked structure is reached, and the material is tough enough that there is no significant crack growth prior to reaching maximum load. In this report, limit moment is defined as the maximum moment.

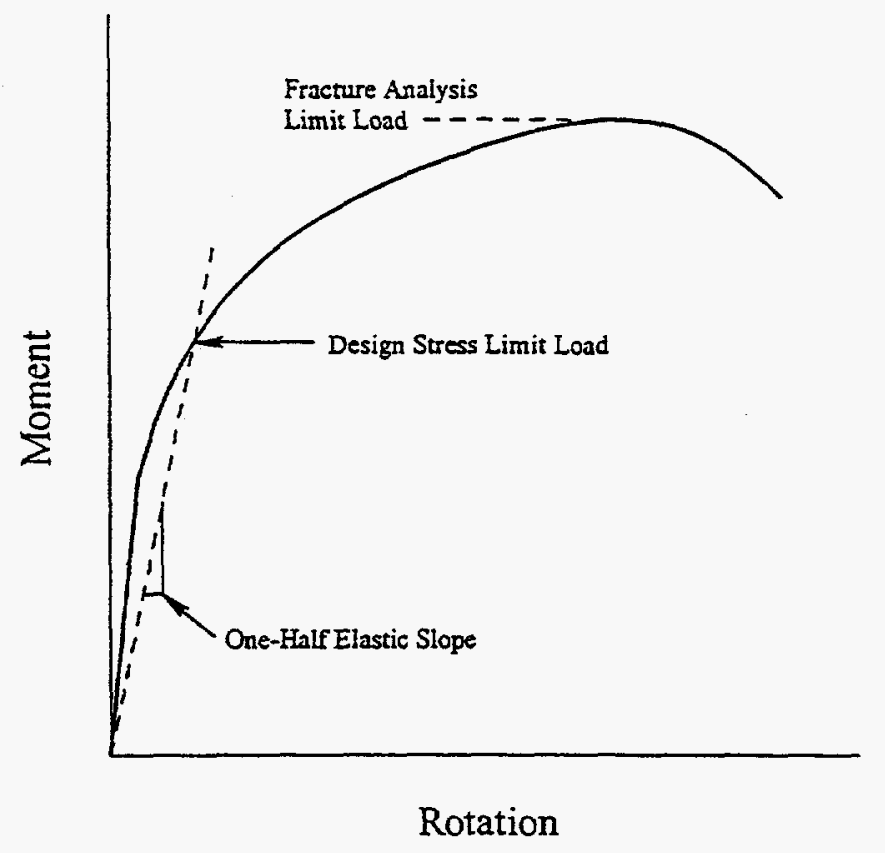

Figure 2.123 Comparison of limit-load definitions by design stress and fracture approaches 


\subsubsection{Straight Pipe Analyses Applied to Elbows}

Straight pipe analysis methods may be perfectly adequate for analyzing cracks in elbows. Accordingly, for circumferential cracks, all of the methods described in Sections 2.3.2.1 and 2.3.2.2 can be directly applied. Likewise, for axial cracks in elbows, methods such as described in References 2.92, 2.96, and 2.122 may be able to be applied. The unknown, of course, in applying these methods to elbows is the margin between the predictions and actual behavior.

\subsubsection{J-estimation Schemes for Cracked Elbows}

In the spirit of the GE/EPRI estimation scheme (Ref. 2.119), a J-estimation scheme can be developed for cracked elbows using detailed finite element analyses. As outlined in Section 2.3.2.2, such an analysis uses a curve fit to finite element results to define influence coefficients that can be used to calculate $J$, pipe rotations, $\mathrm{COD}$, etc,. Owing to the large number of finite element calculations needed to develop an estimation scheme, a three-dimensional finite element analysis involving immense computational effort to assure adequate mesh refinement, enormous computer storage, and significant data reduction, is a formidable task. An attractive alternative, which can be used in this type of work, is the line-spring/shell model, which reduces the three-dimensional surface-crack problem into a more tractable two-dimensional shell problem. This model proposed by Rice and Levy (Ref. 2.193) for linear-elastic, surface-crack problems, has been extended to account for elastic-plastic deformations by Parks and co-workers (Refs. 2.194 to 2.196). The line-spring/shell model has been shown to render reasonably accurate predictions of fracture parameters for surface-cracked pipes and elbows in comparison with the full three-dimensional finite element models (Ref. 2.137).

A summary of the estimation scheme for circumferentially-cracked and axially-cracked pressurized, longradius elbows is given below. Additional details can be found in Reference 2.165 . In the case of a circumferentially-cracked elbow, the constant-depth crack is located on the inside surface of the elbow at the extrados, with the total crack angle of 180 degrees. A closing in-plane bending moment is applied to the pressurized cracked elbow. A separate estimation scheme for a constant-depth, internal, axial crack having a total length of 30 degrees located at the flanks of the pressurized elbow is also presented in Reference 2.165. The loading for this case is an opening, in-plane, bending moment. Solutions are developed for several radius-to-wall-thickness ratios, as well as crack-depth-to-wall-thickness ratios. The allowable pressure, $\mathrm{p}_{\mathrm{a}}$, in the elbow is calculated using an average value of $\mathrm{S}_{\mathrm{m}}$ for various piping materials at an operating temperature of $288 \mathrm{C}(550 \mathrm{~F})$. The allowable pressure for straight pipes according to the ASME Section III, Article NB-3640, is given by

$$
p_{a}=\frac{2 S_{m} t_{p i p e}}{D_{0}-2 y t_{p i p e}}
$$

where $D_{o}$ is the outer diameter of the pipe, $t_{\text {pipe }}$ is the actual thickness of the pipe, and the constant $y$ is taken to be 0.4 .

J-Estimation Scheme for Circumferentially Surface-Cracked Elbows. A sketch of a circumferentially cracked elbow is shown in Figure 2.124. The crack, located at the extrados, will open with an in-plane 


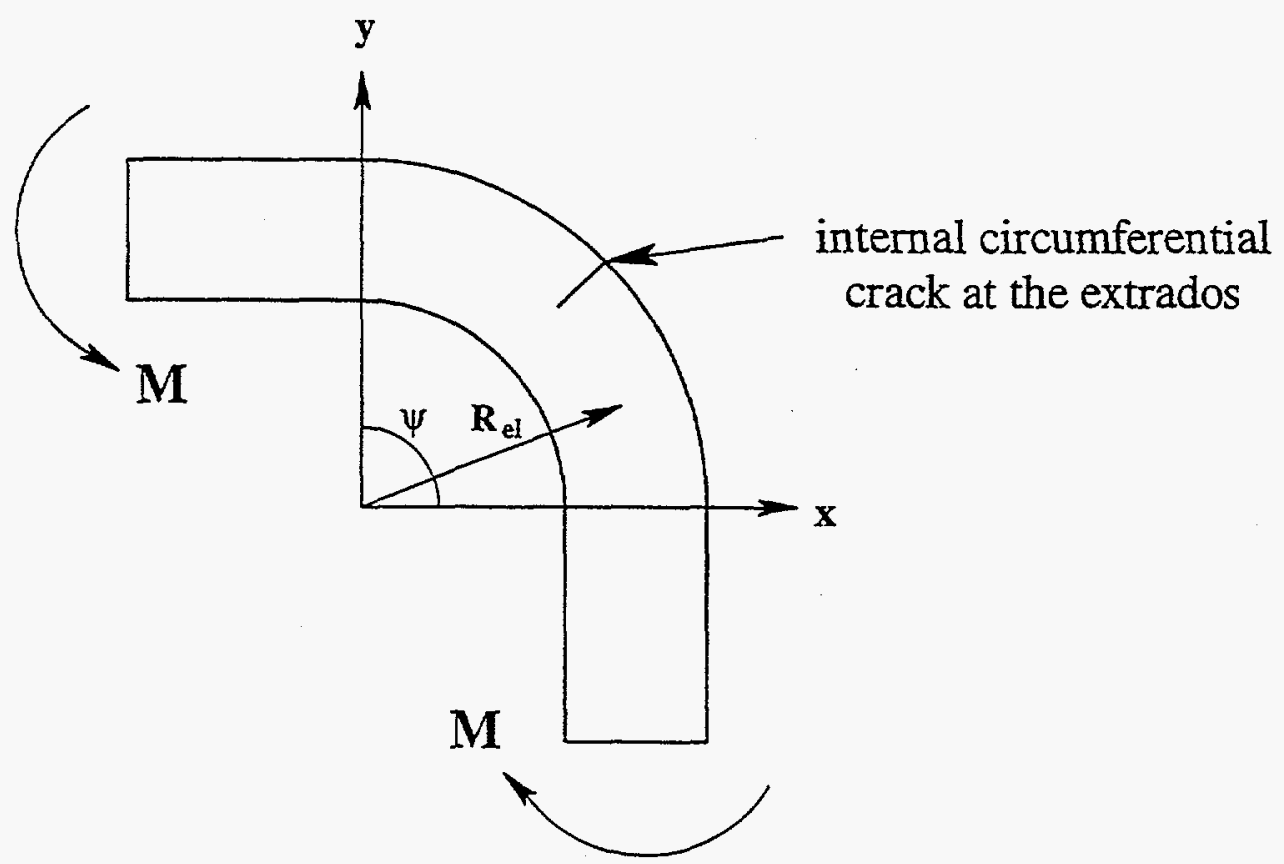

Figure 2.124 Schematic of circumferential crack geometry used for development of an elbow analysis

closing moment. The equations pertaining to the J-estimation scheme for a circumferentially, surfacecracked elbow are given below. The crack-driving force, $\mathrm{J}$, is decomposed into its elastic and plastic parts. The elastic part of the $J$ is obtained through the knowledge of the stress intensity factor associated with internal pressure, $\mathrm{K}_{\mathrm{I}}^{\mathrm{pr}}$, and bending moment, $\mathrm{K}_{\mathrm{I}}{ }^{\mathrm{M}}$. These stress intensity factors are in turn obtained from $F_{1}$ functions as described below.

$$
\begin{gathered}
J=J_{e}+J_{p} \\
J_{c}=\frac{\left(1-v^{2}\right)}{E}\left[K_{I}^{p r}+K_{I}^{M}\right]^{2} \\
K_{I}^{p r}=\frac{p R_{m}}{2 t} \sqrt{\pi a} F_{1}^{p r}\left(y, \lambda, \frac{R_{m}}{t} ; \frac{\theta}{\pi}, \frac{a}{t}\right) \\
K_{I}^{M}=\frac{M R_{m}}{I} \sqrt{\pi a} F_{1}^{M}\left(y, \lambda, \frac{R_{m}}{t} ; \frac{\theta}{\pi}, \frac{a}{t}\right)
\end{gathered}
$$


where,

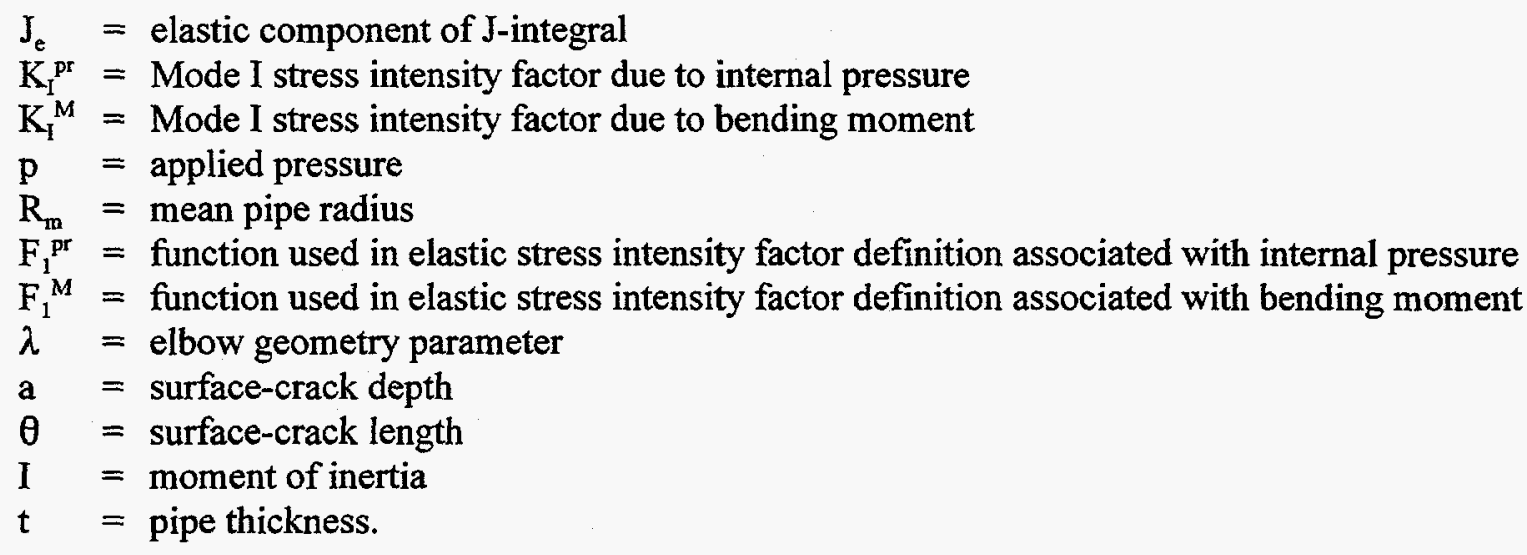

The plastic part of the crack-driving force is given by,

$$
J_{p}=\alpha \epsilon_{0} \sigma_{y} b\left(\frac{R_{m}}{t \lambda}\right) h_{1}^{M}\left[\frac{M}{M_{0}}\right]^{(n+1)} ; b=t-a
$$

where $M_{o}$ is a reference moment for a cracked elbow and the coefficient function, $h_{1}$, is given by

$$
\mathrm{h}_{1}\left(\psi, \lambda, \frac{\mathrm{R}_{\mathrm{m}}}{\mathrm{t}} ; \frac{\mathrm{a}}{\mathrm{t}}, \frac{\theta}{\pi} ; \mathrm{n} ; \mathrm{p}\right)
$$

where $\psi$ is the elbow angle.

Though all relevant dependencies are shown in the $h_{1}$ function, it is emphasized that the dependency on $y$ and $\theta / \pi$ are frozen due to the assumptions given earlier, and the dependency on the internal pressure, $p$, is limited as explained earlier. The choice of the reference moment, $M_{0}$ used in Equation 2-128 is quite arbitrary. However, $h_{1}{ }^{M}$ functions amenable to interpolation are obtained only with a proper choice of $M_{0}$. Owing to the fact that no simple expression for the limit moment for a circumferentially cracked elbow is available in the published literature, two different expressions are provided for $M_{0}$, both of which pertain to a straight pipe with an equivalent crack. The following expressions are used for $M_{0}$ :

(i) GE/EPRI approach (used for surface-cracked straight pipes)

$$
M_{\mathrm{o}(\mathrm{GE})}=M_{0}^{\mathrm{nc}} \frac{\mathrm{A}^{\mathrm{nc}}}{\mathrm{A}}
$$

where,

$$
\text { A }=\text { total area of cross-section }
$$




$$
\begin{aligned}
& A^{n c}=\text { area of uncracked cross-section } \\
& M_{0}^{n c}=2 \sigma_{0} t\left(R_{0}^{2}+R_{i}^{2}\right) \\
& \sigma_{0} \quad=\text { reference stress, typically taken as the yield strength. }
\end{aligned}
$$

(ii) Net-Section Collapse (NSC) approach (used for surface-cracked straight pipes)

For $\beta<\pi-\theta$

$$
\begin{gathered}
M_{o(N S C)}=2 R_{m}^{2} t \sigma_{f}\left[2 \sin \beta-\frac{a}{t} \sin \theta\right] \\
\beta=\frac{\pi-\theta(a / t)}{2}-\frac{\pi R_{i}^{2} p}{4 R_{m} t \sigma_{f}}
\end{gathered}
$$

For $\beta>\pi-\theta$

$$
\begin{aligned}
& M_{o(N S C)}=2 R_{m}^{2} t \sigma_{f}\left[\left(2-\frac{a}{t}\right) \sin \beta\right] \\
& \beta=\frac{\pi}{2-a / t}\left[1-a / t-\frac{R_{i}^{2} p}{2 R_{m} t \sigma_{f}}\right]
\end{aligned}
$$

where $\beta$ is the angle from the bottom of the pipe (opposite of the center of the crack) to the fully plastic neutral axis.

The J-estimation scheme for the case when the GE/EPRI approach is used to define $M_{0}$ is referred to as SC.ELB2. The J-estimation scheme for the case where the NSC approach is used to define $M_{o}$ is referred to as SC.ELB1.

J-estimation Scheme for Axially Surface-Cracked Elbows. A sketch of an axially surface-cracked elbow is shown in Figure 2.125. Two constant-depth cracks were located at the internal surface of the pipe at each of the flank (crown) locations of the elbow. A 30-degree long crack is assumed at each location. Owing to this geometry, the opening of the cracks will occur when an in-plane opening moment is applied. In the finite element analysis, only one quarter (containing one axial crack) of the cracked elbow is modeled due to symmetry. It is assumed that the total driving force, $\mathrm{J}$, for a pressurized, axially-cracked elbow subjected to bending can be written as the sum of the elastic part due to internal pressure and 


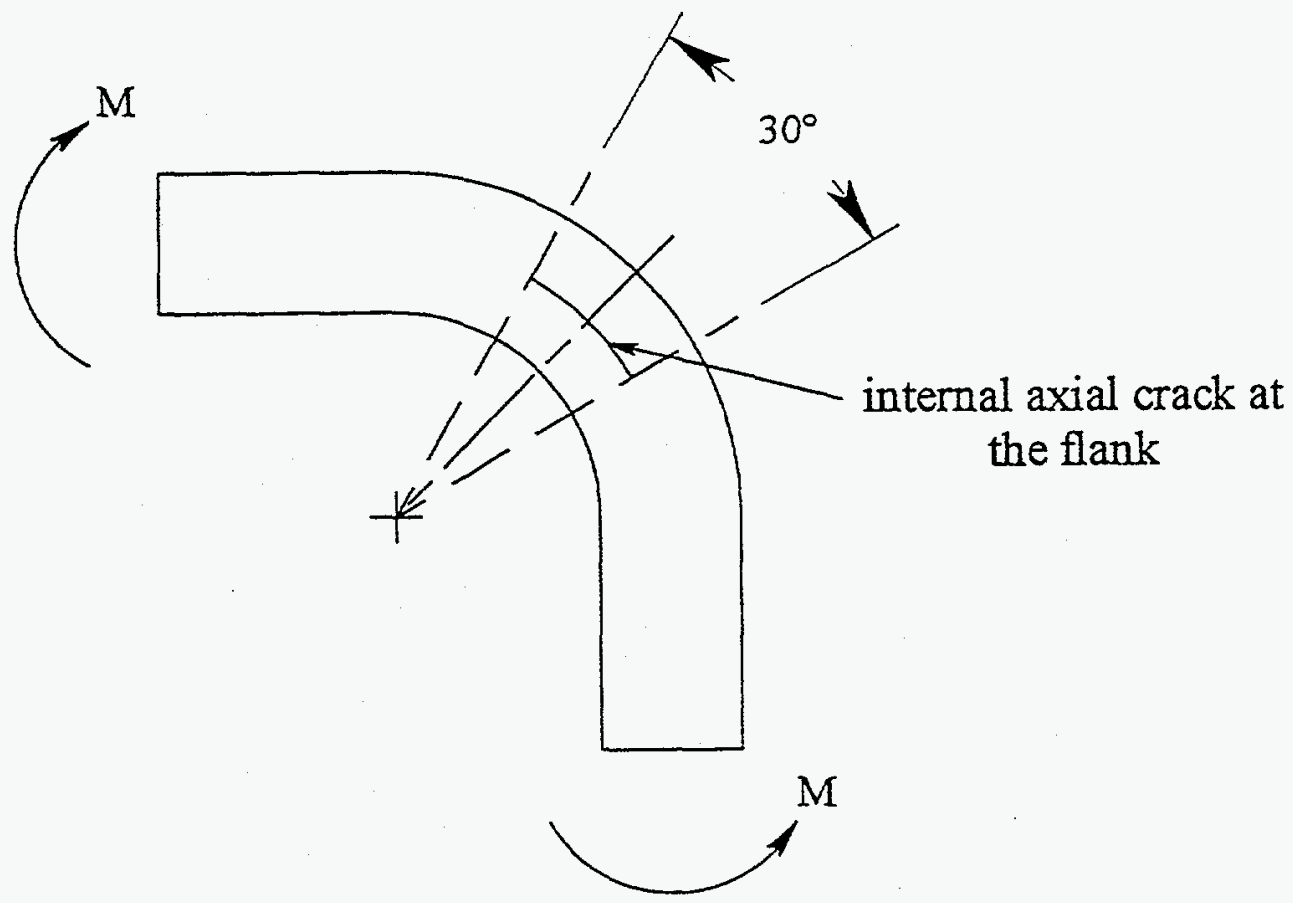

Figure 2.125 Schematic of axial crack geometry used for development of elbow analysis

bending, $\mathrm{J}_{\mathrm{e}}^{\mathrm{p+M}}$, the plastic part due to internal pressure, $\mathrm{J}_{\mathrm{p}}^{\mathrm{p}}$, and the plastic part due to subsequent bending, $\mathrm{J}_{\mathrm{p}}^{\mathrm{M}}$, as given by,

$$
J=J_{e}^{p+M}+J_{p}^{p}+J_{p}^{M}
$$

where

$$
\begin{aligned}
& \mathrm{J}_{\mathrm{e}}^{\mathrm{p}+\mathrm{M}}=\text { elastic part of } \mathrm{J} \text { associated with combined internal pressure and bending } \\
& \mathrm{J}_{\mathrm{p}}^{\mathrm{p}}=\text { plastic part of } \mathrm{J} \text { associated with internal pressure } \\
& \mathrm{J}_{\mathrm{p}}{ }^{\mathrm{M}}=\text { plastic part of } \mathrm{J} \text { associated with bending }
\end{aligned}
$$

with the elastic part given by,

$$
\mathrm{J}_{\mathrm{e}}{ }^{\mathrm{p}+\mathrm{M}}=\frac{\left[1-\mathrm{v}^{2}\right]}{\mathrm{E}}\left[\mathrm{K}_{\mathrm{I}}^{\mathrm{p}}+\mathrm{K}_{\mathrm{I}}^{\mathrm{M}}\right]^{2}
$$

and

$$
\mathrm{K}_{\mathrm{I}}^{\mathrm{p}}=\frac{\mathrm{pR}_{\mathrm{m}}}{\mathrm{t}} \sqrt{\pi \mathrm{a}} \mathrm{F}_{1}^{\mathrm{p}}\left(\psi, \lambda, \frac{\mathrm{R}_{\mathrm{m}}}{\mathrm{t}} ; \ell, \frac{\mathrm{a}}{\mathrm{t}}\right)
$$




$$
\mathrm{K}_{\mathrm{I}}^{\mathrm{M}}=\frac{\mathrm{MR_{ \textrm {m } }}}{\mathrm{I}} \sqrt{\pi \mathrm{a}} \mathrm{F}_{1}^{\mathrm{M}}\left(\Psi, \lambda, \frac{\mathrm{R}_{\mathrm{m}}}{\mathrm{t}} ; \ell, \frac{\mathrm{a}}{\mathrm{t}}\right)
$$

where $\ell=$ total length of axial surface crack.

The plastic part of the crack-driving force due to pressure loading is assumed to be represented by,

$$
\mathrm{J}_{\mathrm{p}}^{\mathrm{p}}=\alpha \sigma_{\mathrm{o}} \epsilon_{\mathrm{o}} \mathrm{b} \lambda \mathrm{h}_{1}^{\mathrm{p}}\left[\frac{\mathrm{p}}{\mathrm{p}_{\mathrm{o}}}\right]^{\mathrm{n}+1} ; \mathrm{b}=\mathrm{t}-\mathrm{a}
$$

where,

$$
\mathrm{h}_{1}^{\mathrm{p}}=\mathrm{h}_{1}^{\mathrm{p}}\left(\psi, \lambda, \frac{\mathrm{R}_{\mathrm{m}}}{\mathrm{t}} ; \ell, \frac{\mathrm{a}}{\mathrm{t}} ; \mathrm{n}\right)
$$

where $p_{o}$ is the limit pressure of a corresponding straight pipe with an equivalent axial crack. The limit pressure, $p_{o}$, is calculated using the following expression initially developed at Battelle in the 1960's and is given in Section XI of the ASME Section XI Boiler and Pressure Vessel Code,

$$
p_{0}=\frac{\sigma_{0} t}{R_{m}} \frac{[t / a-1]}{\left[t / a-\frac{1}{M_{2}}\right]}
$$

with

$$
\mathrm{M}_{2}=\left[1+\left(\frac{1.61}{4 \mathrm{R}_{\mathrm{m}} \mathrm{t}}\right) \ell^{2}\right]^{0.5}
$$

where $\ell$ is the total length of the axial crack. The plastic part of the crack-driving force due to subsequent bending is represented by,

$$
J_{p}^{M}=\alpha \sigma_{o} \epsilon_{o} b\left[\frac{R_{m}}{t \lambda}\right] h_{1}^{M}\left[\frac{M}{M_{o(e)}}\right]^{n+1} ; b=t-a
$$

where 


$$
\mathrm{h}_{1}^{\mathrm{M}}=\mathrm{h}_{1}^{\mathrm{M}}\left(\Psi, \lambda, \frac{\mathrm{R}_{\mathrm{m}}}{\mathrm{t}} ; \frac{\theta}{\pi}, \frac{\mathrm{a}}{\mathrm{t}} ; \mathbf{n} ; \mathbf{p}\right)
$$

and

$$
M_{o(e)}=0.935 \sigma_{o}\left(8 R_{m}^{2} t\right) \lambda^{2 / 3}
$$

In the above expression, $\mathrm{M}_{\mathrm{o}(\mathrm{e})}$ defines the limit moment for an uncracked elbow as proposed by Griffiths (Ref. 2.197). The J-estimation scheme developed as part of this effort for axially cracked elbows is referred to as SC.ELB3.

Using the above expressions for the crack-driving force, the $F_{1}$ and $h_{1}$ functions were determined for axially and circumferentially cracked elbows. Additional details are presented in Reference 2.165.

\subsubsection{Analysis of Surface-Cracked-Elbow Experiments}

The main objective addressed in this section is to evaluate whether existing straight-pipe analysis techniques are suitable for use in predicting the fracture stresses for elbows containing circumferential surface cracks. To accomplish this, four elbow experiments from the IPIRG-2 program were analyzed using the straight-pipe fracture prediction analysis methods, and the elbow fracture analysis prediction methods just discussed. The results are shown as fracture ratios (maximum experimental stress divided by the maximum predicted stress). The analysis predictions considered combined pressure and bending loading. The bending stress was calculated from the experimental and predicted moment values using the flexural stress formulation $\mathrm{Mc} / \mathrm{I}$, where I equals $0.0491\left(\mathrm{D}_{\mathrm{o}}{ }^{4}-\mathrm{D}_{\mathrm{i}}{ }^{4}\right)$. The membrane stress was calculated using the ASME Section III equation $\left(\mathrm{PD}_{\mathrm{o}} / 4 \mathrm{t}\right)$. These formulations assume circular cross-sections and a constant wall thickness, which seldom occur in actual elbows. However, these assumptions are used by the analysis predictions. Because the objective was to assess the applicability of straight-pipe analysis techniques, no adjustments were made to the analysis predictions for variations in wall thickness, out-ofroundness, or crack angle. Local crack depth, a, and local wall thickness, $t$, corresponding to the location of maximum a/t along the crack length were used in the analyses. Quasi-static stress-strain properties were used in the analysis of all experiments. Quasi-static J-R curves were used in the analysis of the quasi-static experiments, while dynamic J-R curves were used to analyze the dynamic elbow pipe-system experiments. This combination of material property data has been demonstrated to give the best fracture predictions for straight-pipe analyses (Ref. 2.80).

The results of these analyses are given in Table 2.19. Comparing these fracture ratios with straight-pipe experiments loaded in combined bending and pressure shows that the elbow data fall within an established scatter band associated with straight-pipe experiments (Ref. 2.13) for the SC.TNP1 and ASME methods. Except for Experiment 2-2, there is also good agreement for the R6 analysis, with the Experiment 2-2 ratio falling slightly above the expected scatter band (mean plus one standard deviation). For the Net-SectionCollapse (NSC) and DPZP analysis, the average fracture ratios for the elbow experiments are 20 and 26 percent higher than the corresponding straight-pipe ratios, respectively. The reason is not clear as to why 
Table 2.19 Fracture ratios for IPIRG-2 Task 2 elbow experiments

\begin{tabular}{|c|c|c|c|c|c|c|c|c|c|c|}
\hline $\begin{array}{l}\text { Expt. } \\
\text { Number }\end{array}$ & Material & $\begin{array}{l}\text { Loading } \\
\text { condition }\end{array}$ & $\begin{array}{c}\text { SC.ELB1 } \\
\text { (elbow) }\end{array}$ & $\begin{array}{c}\text { SC.ELB2 } \\
\text { (elbow) }\end{array}$ & $\begin{array}{c}\text { NSC } \\
\text { (straight) } \\
\end{array}$ & $\begin{array}{l}\text { SC.TNP1 } \\
\text { (straight) }\end{array}$ & $\begin{array}{c}\text { DPZP } \\
\text { (straight) }\end{array}$ & $\begin{array}{c}\text { R6 } \\
\text { (straight) }\end{array}$ & $\begin{array}{c}\text { ASME } \\
\text { App. C } \\
\text { (straight) }\end{array}$ & $\begin{array}{c}\text { ASME } \\
\text { App. H } \\
\text { (straight) }\end{array}$ \\
\hline $2-1$ & $\begin{array}{c}\text { A106-B } \\
\text { Carbon Steel }\end{array}$ & $\begin{array}{c}\text { Pipe } \\
\text { System }\end{array}$ & 0.94 & 1.18 & 1.37 & 1.23 & 1.38 & 1.79 & $n / a$ & 2.36 \\
\hline $2-2$ & $\begin{array}{c}\text { A106-B } \\
\text { Carbon Steel }\end{array}$ & Quasi-static & 0.94 & 1.14 & 1.33 & 1.15 & 1.33 & 1.92 & $\mathbf{n} / \mathbf{a}$ & 2.26 \\
\hline $2-3$ & $\begin{array}{c}\text { WP304L } \\
\text { Stainless Steel }\end{array}$ & $\begin{array}{c}\text { Pipe } \\
\text { System }\end{array}$ & 1.31 & 1.19 & 1.37 & 1.27 & 1.37 & 1.57 & 1.45 & $\mathbf{n} / \mathbf{a}$ \\
\hline $2-4$ & $\begin{array}{c}\text { WP304L } \\
\text { Stainless Steel }\end{array}$ & Quasi-static & 1.15 & 0.99 & 1.20 & 1.12 & 1.21 & 1.39 & 1.28 & $\mathbf{n} / \mathbf{a}$ \\
\hline
\end{tabular}

今̊

\begin{tabular}{|c|c|c|c|c|c|c|c|}
\hline \multirow{3}{*}{$\begin{array}{l}\text { Comparison of experimental maximum } \\
\text { moment with analytical predictions for } \\
\text { combined bending and pressure load cases for } \\
\text { straight pipe. }\end{array}$} & & $\begin{array}{l}\text { NSC } \\
\text { (straight) }\end{array}$ & $\begin{array}{l}\text { SC.TNP1 } \\
\text { (straight) }\end{array}$ & $\begin{array}{c}\text { DPZP } \\
\text { (straight) }\end{array}$ & $\begin{array}{c}\text { R6 } \\
\text { (straight) }\end{array}$ & $\begin{array}{c}\text { ASME } \\
\text { App. C } \\
\text { (straight) }\end{array}$ & $\begin{array}{c}\text { ASME } \\
\text { App. H } \\
\text { (straight) }\end{array}$ \\
\hline & Average & 0.92 & 1.10 & 1.05 & 1.43 & 1.16 & 2.14 \\
\hline & Std. Dev. & 0.12 & 0.15 & 0.13 & 0.40 & 0.19 & 0.29 \\
\hline
\end{tabular}


the NSC analysis consistently predicts higher stress ratios for the elbow experiments. The reason that the DPZP analysis predicts higher stress ratios than previously observed for the straight-pipe experiments is probably a carry over of the inaccuracy associated with the NSC analysis since the DPZP predictions are based on the NSC predictions.

The two elbow estimation procedures show fracture ratios that are, in general, closer to 1.0 than the straight-pipe predictions. The most accurate correlation (closest to 1.0) was found with the SC.ELB1 procedure when applied to the carbon steel elbow data. (The SC.ELB1 method is that method which uses the GE/EPRI method to define the reference moment, $M_{0}$.) However, this analysis results in a slight overprediction of the experimental moments. The fracture ratios for the stainless steel elbow data are similar to values using the SC.TNP1 method for straight pipe.

This finding suggests that straight-pipe analyses can be used to predict the behavior of circumferential cracks located in the extrados of a long-radius elbow, at least for the $R_{m} / t$ ratios, crack sizes, etc., considered in these experiments. This could be a significant result, since it would imply that certain straight-pipe estimation schemes can be used and maintain the same degree of accuracy as expected with predictions on straight pipe. However, caution should be taken to consider the limited scale for which these comparisons have been made. Variables such as elbow diameter, crack geometry, $R / t$ ratio, and material should be considered before making a broad statement about the suitability of these procedures for the analysis of elbow fracture on a general scale.

\subsubsection{Analysis of Through-Wall-Cracked-Elbow Experiments}

Experiments on through-wall-cracked elbows subjected to in-plane bending have been performed by CEACEN Saclay (Ref. 2.198). These data are included in the ELBOWCK elbow database. These experiments were conducted on 102-mm (4-inch) nominal diameter elbows, having a circumferential crack located at the elbow extrados. Maximum moment data were collected for an in-plane bending applied in both the opening and closing modes for crack lengths $(\theta / \pi)$ up to 0.42 .

Limit-load solutions for straight pipe (Ref. 2.118) and elbows (Ref. 2.197) are compared against the experimental moments to demonstrate the accuracy of these solutions for predicting the failure stress of through-wall-cracked elbows.

Figure 2.126 shows the data for the through-wall-crack analyses, with the experimental maximum moments. The straight-pipe and elbow predictions give similar predictions for $\theta / \pi$ between 0.3 and 0.5 . For shorter crack lengths, the solutions begin to diverge. Table 2.20 gives the results in terms of fracture ratios.

Table 2.20 Fracture ratios for through-wall-cracked elbows

\begin{tabular}{lccccccc}
\hline $\begin{array}{l}\theta / \pi \\
\text { (moment direction) }\end{array}$ & $\begin{array}{c}\mathbf{0 . 1 7} \\
\text { (close) }\end{array}$ & $\begin{array}{c}\mathbf{0 . 2 5} \\
\text { (close) }\end{array}$ & $\begin{array}{c}\mathbf{0 . 2 5} \\
\text { (open) }\end{array}$ & $\begin{array}{c}\mathbf{0 . 3 3} \\
\text { (close) }\end{array}$ & $\begin{array}{c}\mathbf{0 . 3 3} \\
\text { (open) }\end{array}$ & $\begin{array}{c}\mathbf{0 . 4 2} \\
\text { (close) }\end{array}$ & $\begin{array}{c}\mathbf{0 . 4 2} \\
\text { (open) }\end{array}$ \\
\hline $\begin{array}{l}\text { Limit Moment } \\
\text { (straight pipe) }\end{array}$ & 0.87 & 0.99 & 1.13 & 1.12 & 1.18 & 1.13 & 1.26 \\
& 1.21 & 1.23 & 1.41 & 1.19 & 1.25 & 1.27 & 1.42 \\
$\begin{array}{l}\text { Limit moment } \\
\text { (elbow) }\end{array}$ & 1.27 & & & & & & \\
\hline
\end{tabular}




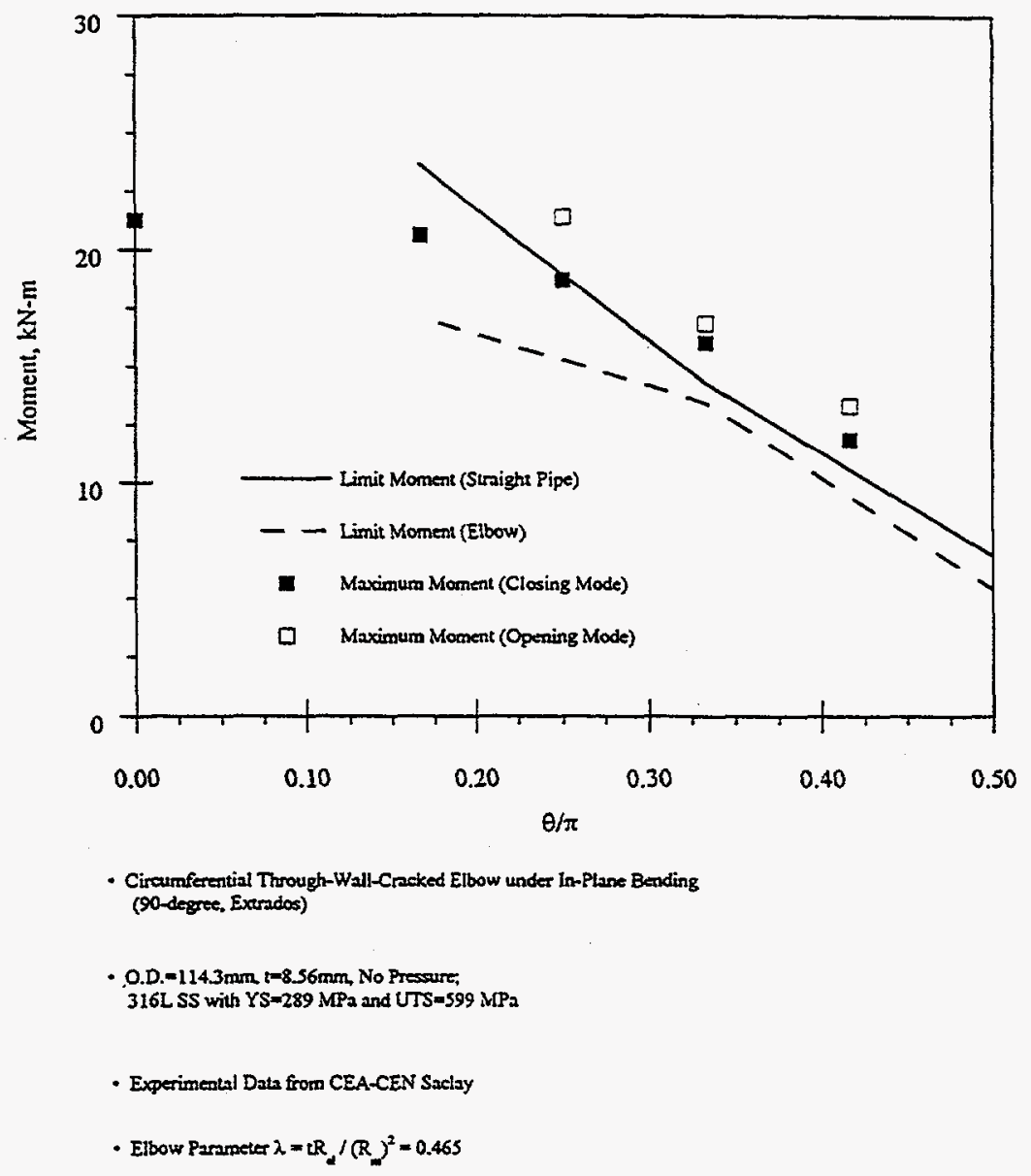

Figure 2.126 Maximum moment data for circumferential through-wall-cracked elbow experiments

\subsubsection{A Simplified Method for Analysis of Cracked Elbows}

Developing an extensive set of J-estimation schemes for elbows is a formidable task. The effort documented in Section 2.5.1.2 was a major effort involving a large matrix of finite element analyses. Even though a number of variables were considered (such as crack depth, $R_{\mathrm{m}} / \mathrm{t}$ ratios, and strain-hardening exponents), these analyses were limited to one crack length, in-plane bending and long radius 90-degree elbows. There are a significant number of other variables, and these make the development of such solutions a formidable task for all pipe fittings and loading combinations. The lack of such detailed solutions for a wider variety of problems, in combination with the desire to have a codifiable approach, leads to consideration of using a simplified solution that could be used as a failure avoidance criterion. Note that the term "failure avoidance criterion" is used since it is recognized that one is seeking a conservative solution, not necessarily the most accurate solution.

The basic premise for developing a fitting failure avoidance analysis procedure involves finding some simple relationship between a straight-pipe failure avoidance criterion and a pipe fitting failure. For 
instance, a simple multiplier on the straight-pipe solution might be able to be used for a crack in a fitting of the same physical dimensions. In this context, either the ASME $B_{2}$ or $C_{2}$ elbow stress indices could be used as a stress multiplier on the straight-pipe flaw evaluation solutions. The $B_{2}$ index is a stress multiplier for bending stresses relative to the bending stress in a straight pipe for limit-load analyses from a design stress viewpoint.

A means to determine whether or not a simple failure avoidance analysis that could be readily codified can be developed could follow three general steps:

(1) J versus moment curves can be analytically generated for the same size crack in both a straight pipe and a comparable fitting for a stationary crack, i.e., no crack growth, under combined pressure and bending, with the pressure levels being the same.

(2) From these calculations, the ratio of the moment for the straight pipe to that for the elbow case at the same value of applied $\mathrm{J}$ can be determined. A critical aspect is whether or not this moment ratio varies much with the applied $\mathrm{J}$ level. As will be shown later, this moment ratio was virtually independent of the applied $\mathrm{J}$ level for $\mathrm{J}_{\mathrm{IC}_{\mathrm{C}}}$ values of typical nuclear piping steels.

(3) The moment ratio at constant applied J values can then be compared with the ASME stress indices for pipe and elbows with different $R_{m} / t$ ratios. A consistent relationship in this comparison determines the applicability of this approach.

The approach outlined above was applied to both axial and circumferential surface cracks in elbows and is shown in Figures 2.127 and 2.128 (Ref. 2.192). These data suggest that there is more than a casual

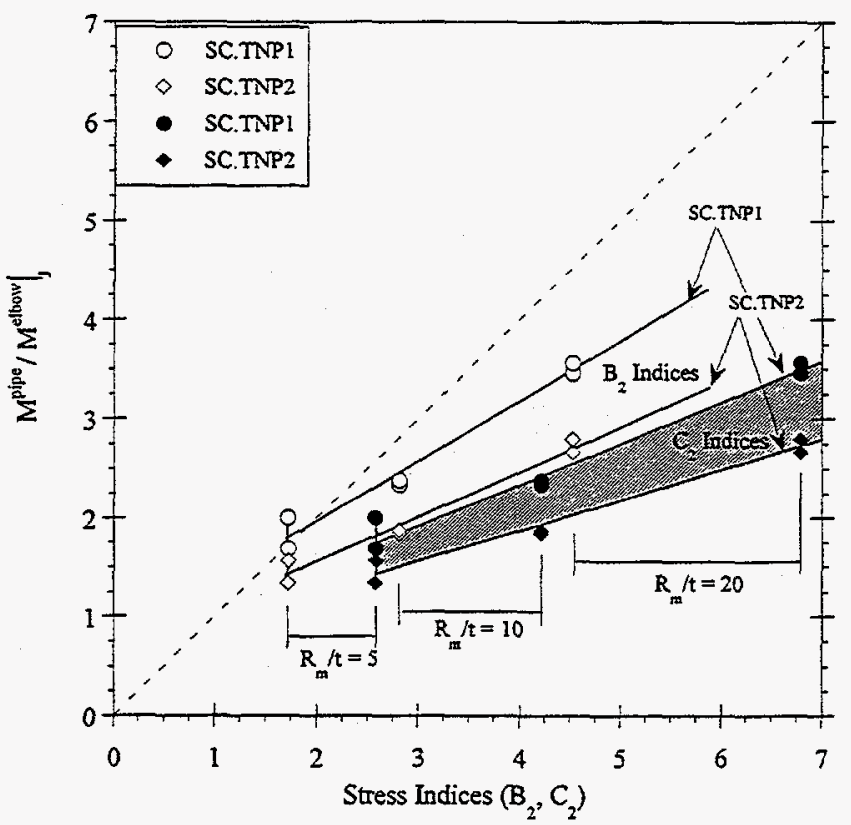

Figure 2.127 Comparison of ASME elbow stress indices to ratio of moment for circumferential, surface-cracked, straight pipe to moment for axial, flank, surface-cracked elbow at the same $J$ values $\left(M^{\text {pipe }} / M^{\text {ebowi }} / \mathbf{J}\right)$ 


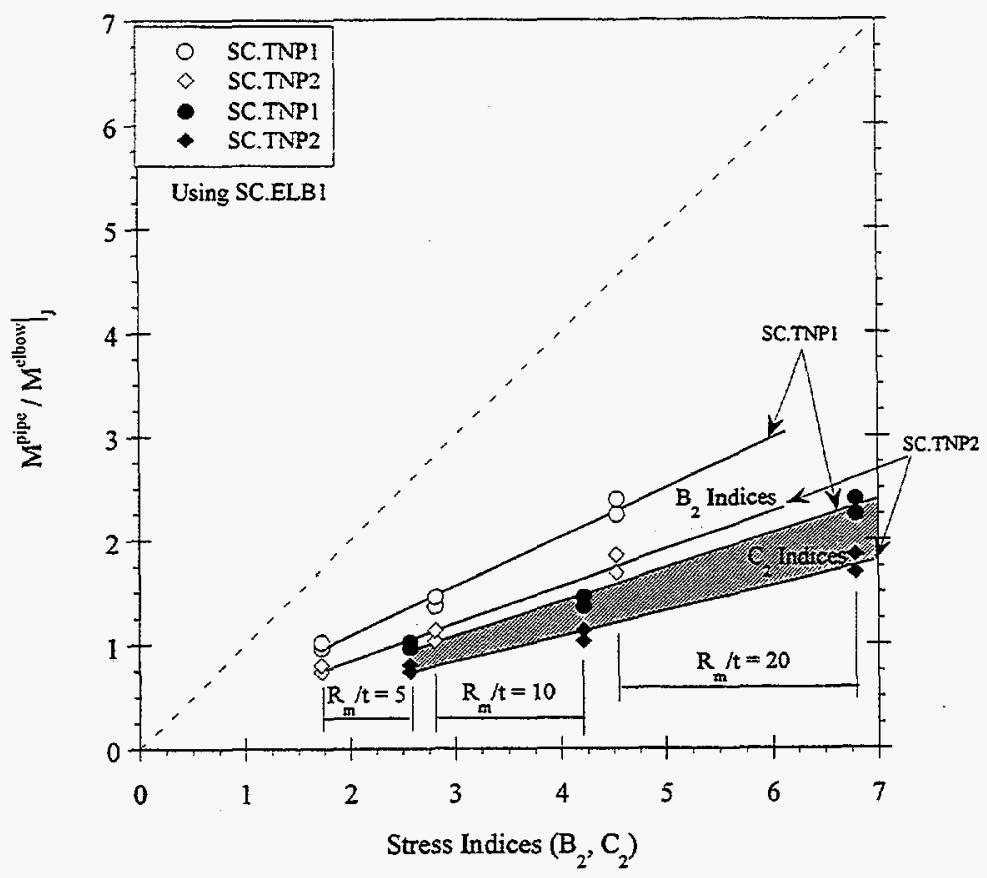

(a) Using SC.ELB1 analysis

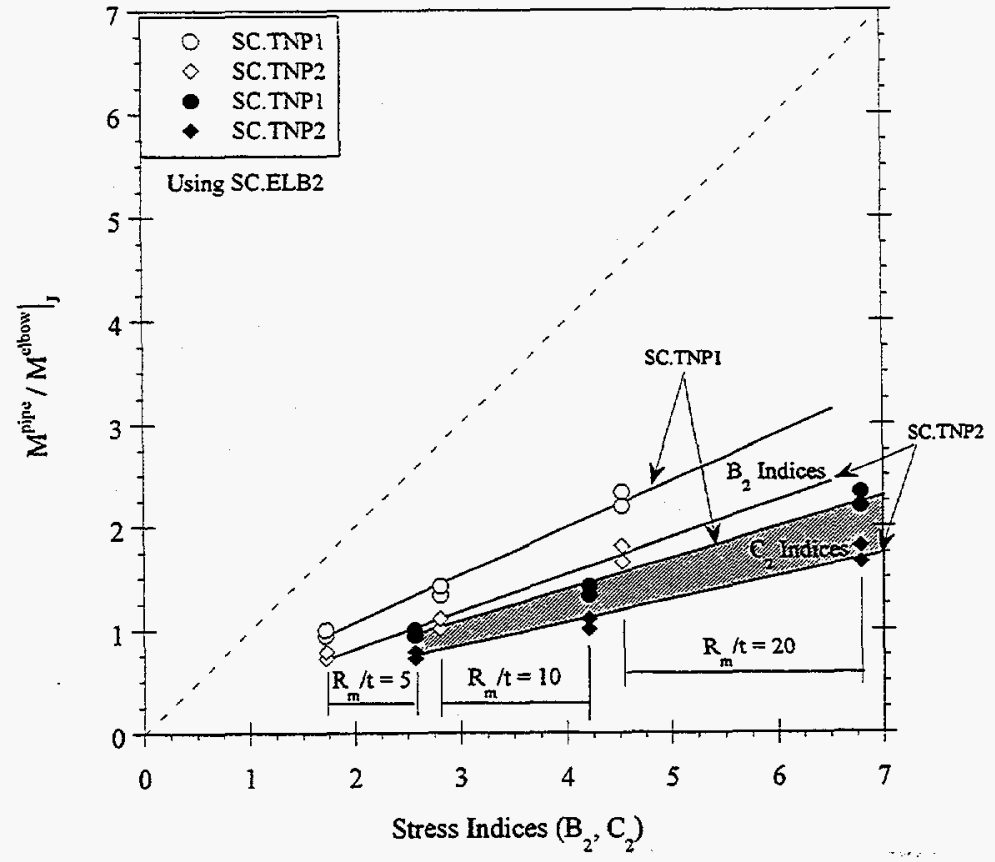

(b) Using SC.ELB2 analysis

Figure 2.128 Comparison of ASME elbow stress indices to ratio of moment for circumferential, surface-cracked, straight pipe to moment for circumferential, extrados, surfacecracked elbow at the same $J$ values $\left(\mathbf{M}^{\text {pipe }} / \mathbf{M}^{\text {elbow }} l_{J}\right)$ 
correlation between the stress indices and the moment ratio of the straight pipe and elbow over a reasonable range of applied J values. Applying this methodology to some actual experiments, Figure 2.129 , the real data support the hypothesis.

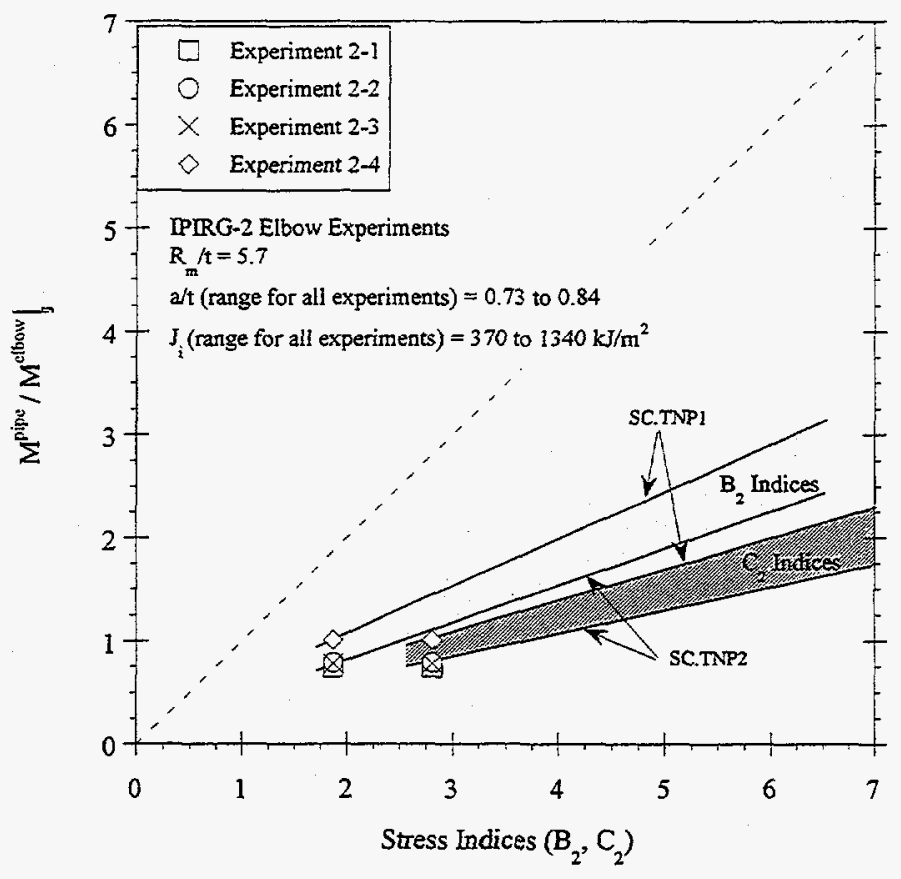

Figure 2.129 Comparison of IPIRG-2, circumferential, extrados, surface-cracked, experiments on A106-90 and WP304L elbows to criteria developed in Figure 2.128 (SC.ELB1 and SC.ELB2 analyses virtually identical)

To use the information in Figures 2.127 and 2.128 in an actual fracture evaluation, two approaches could be followed (Ref. 2.200). The first is the simplest, but perhaps the most conservative. This approach is to simply take the ASME Section III stress indices and use them directly as simple multipliers, i.e.,

$$
\mathrm{M}^{\mathrm{elbow}}=\mathrm{M}^{\mathrm{pipe}} / \mathrm{B}_{2}
$$

Because the $B_{2}$ indices are closer to the $1: 1$ moment ratio line than the $C_{2}$ indices, more accurate predictions would be made using the $B_{2}$ indices. 
Alternatively, one could define a new parameter, called $\Upsilon_{x}^{f}$ (where $f$ is the type of fitting, and $x$ is for the crack orientation) that curve fits the data in Figures 2.127 and 2.128. Using this parameter, the elbow moments are

$$
\mathrm{M}^{\mathrm{elbow}}=\mathrm{M}^{\mathrm{pipe}} \mathbf{\Upsilon}_{\mathrm{x}}^{\mathrm{f}}
$$

For the axial, flank, surface-crack case:

$$
\begin{aligned}
& \Upsilon_{\mathrm{a}}^{\mathrm{e}}=0.601 \mathrm{~B}_{2}+0.755 \text {, using the SC.TNP1 straight-pipe analysis } \\
& \Upsilon_{\mathrm{a}}^{\mathrm{e}}=0.462 \mathrm{~B}_{2}+0.618 \text {, using the SC.TNP2 straight-pipe analysis }
\end{aligned}
$$

For the circumferential, extrados, surface-crack case:

$$
\begin{aligned}
& \Upsilon_{c}^{e}=0.465 B_{2}+0.136, \text { using the SC.TNP1 straight-pipe analysis } \\
& \Upsilon_{c}^{e}=0.351 B_{2}+0.121 \text { using the SC.TNP2 straight-pipe analysis. }
\end{aligned}
$$

The $\Upsilon_{a, c}^{e}$ values are shown in Figure 2.130. Generally, the experimental results agreed better with the SC.TNP2 $\Upsilon_{a, c}^{e}$ values, except for the one IPIRG-2 stainless steel circumferential surface-crack elbow experiment, Experiment 2-4, which agreed better with the SC.TNP1 $\Upsilon^{\circ}$ value. Using the SC.TNP1 based $\Upsilon_{a, c}^{e}$ values would be slightly more conservative than the SC.TNP2 $\Upsilon_{a, c}^{e}$ values, yet still reasonably accurate.

\subsubsection{Lessons Learned From the Elbow Studies}

As a result of the efforts related to elbows, some key observations have been made. These observations are:

(1) The existing database of fitting fracture experiments is somewhat limited. A majority of the data are focussed on uncracked burst strength of elbows and tees. Limited data are available for both axial and circumferential through-wall cracks. Data are available for axial surface-cracked elbows in the extrados, intrados, and flank orientations. For the circumferential surface-cracked elbows, data are available for cracks located on the intrados and flank. The IPIRG-2 elbow fracture experiments are the only extrados, surface-cracked data that seem to be available. The IPIRG-2 elbow data were also the only data pertaining to circumferential, extrados, surface-cracked elbows under combined pressure and bending loading conditions at dynamic loading rates. 


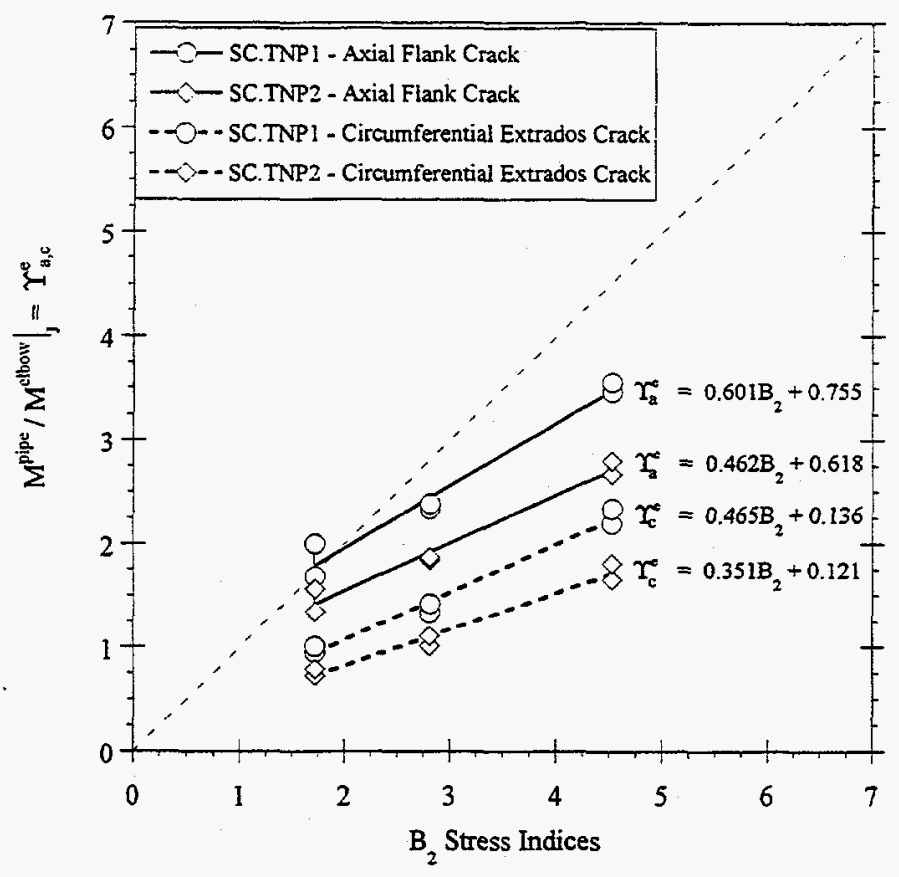

Figure 2.130 Comparison of axial-flank and circumferential-extrados surface-cracked elbow failure avoidance criteria

(2) All of the straight-pipe analysis techniques underpredicted the experimental moments for the $R_{m} / t=6$ elbows tested.

(3) The fracture ratios (experimental/predicted maximum stresses) for all four elbow experiments considered, based on the straight-pipe SC.TNP1 method, were slightly above the previously established scatter band of fracture ratios for the SC.TNP1 analysis method when used on straight pipe. This tends to indicate that the straight pipe SC.TNP1 method is adequate for predicting the load-carrying capacity of circumferential cracks along the extrados of an elbow, at least for the $R_{m} / t=6$ ratios, pipe diameters, and crack geometries considered in the IPIRG- 2 effort. For higher $R_{m} / t$ ratio elbows, the elbow failure loads are expected to be below the straight-pipe results.

(4) The SC.ELB2 method results in a reasonable underprediction of the experimental moments for these circumferential extrados-type cracks. For both materials and for all of the crack sizes considered, the difference in predictions between the SC.ELB2 elbow solution and the SC.TNP1 straight pipe solution is less than 10 percent for the $R_{m} / t=6$ elbow examined. This is well within the typical experimental scatter band observed in straight-pipe experiments.

(5) An assessment of the new elbow J-estimation schemes for the case of the axially oriented, elbow flank cracks was not done directly. This was because no data exist in the ELBOWCK database which had exactly the same flaw length as used in the new elbow J-estimation scheme. Relative 
comparisons between the axial and circumferential cracked elbow analyses, using similar size cracks, showed the crack-driving force $(J)$ was much higher for the axial crack case.

(6) An effort was undertaken to see if the elbow analyses developed could be simplified to a readily codifiable procedure, and if that same process could also be extended to other crack lengths. The approach undertaken was to see if there was a multiplier that could be used on the circumferential surface-cracked straight-pipe solutions. The simplest and most conservative approach was to estimate the elbow failure loads by using the straight-pipe loads divided by the ASME $\mathrm{B}_{2}$ stress indices for elbows. This was always conservative, but perhaps too conservative for circumferential flaws in elbows, or at higher $R_{m} / t$ ratios. The second approach was to investigate whether a more accurate solution could be used rather than just the $B_{2}$ stress indices. A stress multiplier, called the $\Upsilon$-function, was developed from the ratio of the moments in the straight pipe to that in the elbow at constant values of J (for the same crack sizes in the pipe and elbow). Comparisons to the IPIRG-2 circumferential extrados experiments and an EDF axial, flank crack experiment on an aged cast stainless steel elbow were in good agreement with the $\Upsilon$ analysis. This method looks extremely promising, but some further validation is needed before it is ready for code implementation. The $\Upsilon$-function was theoretically found to be valid through the elastic-plastic region especially at high J values, and is therefore also valid for limit-load solutions. Finally, from this exercise, it is now seen how $\Upsilon$-functions could be more easily developed for through-wall cracks in elbows, cracks in tees, or cracks in any other pipe fitting. This could be done without the extensive J-estimation scheme development effort that was done in Reference 2.192.

\subsection{References}

2.1 Schrammel, D., "Comparison of Measurements and Calculations for High-Level Seismic Tests of Piping at the HDR (Test Group SHAM)," SMiRT 11 Transactions, Vol. K, Paper K32/3, Tokyo Japan, pp 445-450, August 18-21, 1991.

2.2 Park, Y. J., Curreri, J. R., and Hofmayer, C. H., "The High Level Vibration Test Program Final Report,"NUREG/CR-5585, 1991.

2.3 Kussmaul, K., Kerkhof, K., Diem, H., Schrammel, D., and Katzenmeier, "Simulation of Earthquake Induced Vibrations Subjected to a Piping System," SMiRT 12 Transactions, Vol. K, Paper K18/1, Stuttgart Germany, pp 133-138, August 15-20, 1993.

2.4 "Piping and Fitting Dynamic Reliability Program - Program Summary," EPRI TR-102792, Vols. 1-5, 1995.

2.5 Olson, R., and others, "Margins from Dynamic FEM Analysis of Cracked Pipe Under Seismic Loading for the DOE New Production Reactor," PVP Vol. 280, pp 119-134, June 1994.

2.6 "Report of the U.S. Nuclear Regulatory Commission Piping Review Committee - Investigation and Evaluation of Stress Corrosion Cracking in Piping of Boiling Water Reactor Plants," NUREG1061, Vol. 1, August 1984. 
2.7 "Proceedings: Second Seminar on Countermeasures for Pipe Cracking in BWRs," Vol. 1: Problem Resolution, EPRI NP-3684-SR, September 1984.

2.8 Wilkowski, G. M., and others, "Analysis of Experiments on Stainless Steel Flux Welds," NUREG/CR-4878, April 1987.

2.9 Dong, P., and others, "Effects of Weld Residual Stresses on Crack-Opening Area Analysis of Pipes for LBB Applications," Proceedings of the Seminar on Leak Before Break in Reactor Piping and Vessels, NUREG/CP-0155, pp 283-298, April 1997.

2.10 Ghadiali, N., and others, "Deterministic and Probabilistic Evaluations for Uncertainty in Pipe Fracture Parameters in Leak-Before-Break and In-Service Flaw Evaluations," NUREG/CR-6443, June 1996.

2.11 Rahman, S., and others, "Summary of Results from the IPIRG-2 Round Robin Analyses," NUREG/CR-6337, February 1996.

2.12 Olson, R., and others, "Design of the IPIRG-2 Simulated Seismic Forcing Function," NUREG/CR6439, February 1996.

2.13 Krishnaswamy, P., "Fracture Behavior of Short Circumferentially Surface-Cracked Pipe," NUREG/CR-6298, November 1995.

2.14 Brust, F. W., and others, "Assessment of Short Through-Wall Circumferential Cracks in Pipes," NUREG/CR-6235, April 1995.

2.15 Rahman, S., and others, "Refinement and Evaluation of Crack-Opening-Area Analyses for Circumferential Through-Wall Cracks in Pipes," NUREG/CR-6300, March 1995.

2.16 Paul, D. D., "Evaluation and Refinement of Leak-Rate Estimation Models,"NUREG/CR-5128, Rev. 1., June 1994.

2.17 Wilkowski, G., and others, "Degraded Piping Program - Phase II," Semi-Annual Report, October 1985- March 1986, NUREG/CR-4082, Vol. 4, September 1986.

2.18 Marschall, C. W., and others, "Effect of Dynamic Strain Aging on the Strength and Toughness of Nuclear Ferritic Piping At LWR Temperatures," NUREG/CR-6226, October 1994.

2.19 Bloom, J., and Malik, S., "Procedures for the Assessment of the Integrity of Nuclear Pressure Vessels and Piping Containing Defects," EPRI NP-2431, 1982.

2.20 Wilkowski, G. M., and Scott, P. M., "A Statistically Based Circumferentially Cracked Pipe Fracture Mechanics Analysis for Design or Code Implementation," Nuclear Engineering and Design, Vol. 111, pp 173-187, 1989. 
2.21 Rolfe, S. T., and Novak, S. R., "Slow-Bend $\mathrm{K}_{\mathrm{Ic}}$ Testing of Medium-Strength High-Toughness Steels," Review of Developments in Plane Strain Fracture Toughness Testing, ASTM STP 463, American Society for Testing and Materials, pp 124-159, 1970.

2.22 Hiser, A. L., "Correlation of Irradiation-Induced Transition Temperature Increases from $\mathrm{C}_{\mathrm{v}}$ to $\mathrm{K}_{\mathrm{Jc}} / \mathrm{K}_{\mathrm{Ic}}$ Data," NUREG/CR-5494, March 1990.

2.23 Ritchie, R. O., and others, "Critical Fracture Stress and Fracture Strain Models for the Prediction of Lower and Upper Shelf Toughness in Nuclear Pressure Vessel Steels," Metallurgical Transactions $A$, Volume 10A, pp 1557-1570, October 1979.

2.24 Kussmaul, K., and Roos, E., "Statistical Evaluation of Post-Yield Fracture Mechanics Properties on the Base of the Notched Bar Impact Test," Nuclear Engineering and Design, Vol. 87, pp 123-137, 1985.

2.25 Eason, E. D., and others, "Multivariable Modeling of Pressure Vessel and Piping J-R Data," NUREG/CR-5729, May 1991.

2.26 Hutchinson, J. W., and Paris, P. C., "Stability Analysis of J-Controlled Crack Growth," ElasticPlastic Fracture, ASTM STP 668, American Society for Testing and Materials, pp 37-64, 1979.

2.27 "Report on the U.S. Nuclear Regulatory Commission Piping Review Committee - Evaluation of Potential for Pipe Breaks," Prepared by the Pipe Break Task Group, NUREG/CR-1061, Vol. 3, November 1984.

2.28 Wilkowski, G. M., and others, "Degraded Piping Program - Phase II," Summary of Technical Results and Their Significance to Leak-Before-Break and In-Service Flaw Acceptance Criteria, March 1984 - January 1989, NUREG/CR-4082, Vol. 8, March 1989.

2.29 Ernst, H. A., "Materials Resistance and Instability Beyond J-Controlled Crack Growth," Elastic Plastic Fracture, ASTM STP 803, Vol. 1, American Society for Testing and Materials, pp 191$213,1983$.

2.30 Papaspyropoulos, V., and others, "Predictions of J-R Curves With Large Crack Growth From Small Specimen Data," NUREG/CR-4575, September 1986.

2.31 Rousselier, G., "Ductile Fracture Models and Their Potential in Local Approach of Fracture," Nuclear Engineering and Design, Vol. 105, pp 97-111, 1987.

2.32 Roussilier, G., and others, "A Methodology for Ductile Fracture Analysis Based on Damage Mechanics: An Illustration of a Local Approach of Fracture," Nonlinear Fracture Mechanics: Volume II - Elastic-Plastic Fracture, ASTM STP 995, American Society for Testing and Materials, pp 332-354, 1989.

2.33 Shih, C. F., and others, "Validity Limits in J-Resistance Curve Determination - An Assessment of the $\mathrm{J}_{\mathrm{M}}$ Parameter," NUREG/CR-6264, Vol. 1, February 1995. 
2.34 Shih, C. F., and others, "Validity Limits in J-Resistance Curve Determination - A Computational Approach to Ductile Crack Growth Under Large-Scale Yielding Conditions," NUREG/CR-6264, Vol. 2, February 1995.

2.35 Hiser, A. L., and others, "A User's Guide to the NRC's Piping Fracture Mechanics Database (PIFRAC),"NUREG/CR-4894, May 1987.

2.36 Wilkowski, G. M., and others, "Short Cracks in Piping and Piping Welds," Seventh Program Report, March 1993 - December 1994, NUREG/CR-4599, Vol. 4, No. 1, April 1995.

2.37 Ghadiali, N., and Wilkowski, G. M., "Fracture Mechanics Database for Nuclear Piping Materials (PIFRAC)," in Fatigue and Fracture - 1996 - Volume 2, PVP-Vol. 324, pp 77-84, July 1996.

2.38 Rosenfield, A. R., and others, "Stainless Steel Submerged Arc Weld Fusion Line Toughness," NUREG/CR-6251, April 1995.

2.39 Scott, P. M., and others, "Fracture Evaluations of Fusion Line Cracks in Nuclear Pipe Bimetallic Welds," NUREG/CR-6297, April 1995.

2.40 Förster, K, and others, "Crack Resistance of Austenitic Pipes with Circumferential Through-Wall Cracks," Proceedings of the Joint LAEA/CSNI Specialists' Meeting on Fracture Mechanics Verification by Large-Scale Testing, NUREG/CP-0131, pp 823-839, October 1993.

2.41 Wilkowski, G. M., and others, "Degraded Piping Program - Phase II," Semiannual Report, October 1984 - March 1985, NUREG/CR-4082, Vol. 2, July 1985.

2.42 Miglin, M. T., and others, "Effects of Strain Aging in the Unloading Compliance J Test," in Elastic-Plastic Fracture Test Methods: The User's Experience, ASTM STP 856, E. T. Wessel and F. J. Loss, Eds., American Society for Testing and Materials, Philadelphia, pp 150-165, 1985.

2.43 Maricchiolo C. and Milella, P. P., "Fracture Behavior of Carbon Steel Pipes Containing Circumferential Cracks at Room Temperature and 300 C," Nuclear Engineering and Design, 111, pp 35-46, 1989.

2.44 McCabe, D. E., and others, "Ductile Fracture Toughness of Modified A 302 Grade B Plate Materials," NUREG/CR-6426, Vol. 2, November 1996.

2.45 Mohan, R., and others, "Effects of Toughness Anisotropy and Combined Tension, Torsion, and Bending Loads on Fracture Behavior of Ferritic Nuclear Pipe," NUREG/CR-6299, April 1995.

2.46 Wilkowski, G. M., “Anisotropic Fracture Toughness Effects on Failure Modes of Piping," ASME Journal of Pressure Vessel Technology, Vol. 113, pp 154-158, May 1991.

2.47 Wilkowski, G. M., and others, "Degraded Piping Program - Phase II," Semiannual Report, April 1986 - September 1986, NUREG/CR-4082, Vol. 5, April 1987. 
2.48 Embury, J. D., Petch, N. J., Wraith, A. E., and Wright, E. S., "The Fracture of Mild Steel Laminates," Transactions of the Metallurgical Society of AIME, Vol. 239, pp 114-118, January 1967.

2.49 Dabkowski, D. S., Kondel, P. J., and Baldy, M. F., "Factors that Effect Splitting in Plate Steels," Welding Journal, 1975.

2.50 Wilkowski, G. M., and Eiber, R. J., "Ductile Fracture Propagation Resistance for Rising Shelf Controlled-Rolled Steels," What Does Charpy Energy Really Tell Us?, published by ASM, ISBN 0-87170-027-1, pp 108-132, February 26-March 2, 1978.

2.51 Miyoshi, E., and others, "The Effect of Separation on the Propagating Shear Fracture," Paper 4, Crack Propagation in Pipelines, March 1974.

2.52 Hiser, A. L., and Terrell, J. B., "Size Effects on J-R Curves for A 302-B Plate," NUREG/CR-5265, January 1989.

2.53 Nakagaki, M., and others, "Analysis of Cracks in Stainless Steel TIG Welds," NUREG/CR-4806, December 1986.

2.54 Vassilaros, M., Hays, R., and Gudas, J., "Investigation of the Ductile Fracture Properties of TP304 Stainless Steel Plate, Welds, and 4-inch Pipe", in 12th WRSIM, NUREG/CP-0057, January 1985.

2.55 Scott, P., and others, "An Experimental and Analytical Assessment of Circumferential ThroughWall Cracked Pipes Under Pure Bending," NUREG/CR- 4574, September 1986.

2.56 Rudland, D. L., and others, "Fracture Toughness Evaluations of TP304 Stainless Steel Pipes," NUREG/CR-6446, February 1997.

2.57 Chopra, O. K., Sather, A., Bush, L. Y., "Long-Term Embrittlement of Cast Duplex Stainless Steels in LWR Systems,"NUREG/CR-4744 Vol. 4, No., 2, June 1991.

2.58 Bonnet, S., and others, "Relationship Between Evolution of Mechanical Properties of Various Cast Duplex Stainless Steels and Metallurgical and Aging Parameters: An Overview of Current EDF Programmes," Material Science Technology, Vol. 6, pp 221-229, 1990.

2.59 Chopra, O., "Estimates of Fracture Toughness of Cast Stainless Steels in LWR Systems," in Transactions of the Eighteenth Water Reactor Safety Information Meeting, NUREG/CP-0113, October 1990.

2.60 Wilkowski, G. M., and others, "Degraded Piping Program - Phase II," Seventh Program Report: October 1987 - January 1989, NUREG/CR-4082, Vol. 7, March 1989.

2.61 Scott, P., and others, "Crack Stability in a Representative Piping System Under Combined Inertial and Seismic/Dynamic Displacement-Controlled Stresses - Subtask 1.3 Final Report," NUREG/CR6233, Vol. 3, June 1997. 
2.62 Bamford, W. H., and others, "Thermal Analysis of Cast Stainless Steel, and Its Impact on Piping Integrity," PVP Vol. 95, pp 137-172, June 1983.

2.63 LeDelliou, P., and others, "Fracture Mechanics Analysis of Cast Duplex Stainless Steel Elbows Containing a Surface Crack," PVP Vol. 323, pp 117-123, July 1996.

2.64 Krishnaswamy, P., and others, "Effect of Aging on the Predicted Maximum Moment-Carrying Capacity of Circumferentially Cracked Cast Stainless Steel Pipe," presented at the NRC Aging Research Information Conference, March 1992.

2.65 Paris, P. C., and Tada, H., "Application of Fracture Proof Methods Using Tearing Instability Theory to Nuclear Piping Postulating Circumferential Through Wall Cracks," NUREG/CR-3464, September 1983.

2.66 Milne, I., and others, "Assessment of the Integrity of Structures Containing Defects," CEGB Report R/H/R6 - Revision 3, 1986.

2.67 Wilkowski, G. M., and others, "International Piping Integrity Research Group (IPIRG) Program," Program Final Report, NUREG/CR-6233, Vol. 4, June 1997.

2.68 Hopper, A., and others, "The Second International Piping Integrity Research Group (IPIRG-2) Program," Final Report, October 1991 - April 1996, NUREG/CR-6452, March 1997.

2.69 Landes, J. D., and McCabe, D. E., "Load History Effects on the $\mathrm{J}_{\mathrm{R}}$-Curve," Elastic-Plastic Fracture: Second Symposium, Volume II - Fracture Resistance Curves and Engineering Applications, ASTM STP 803, C. F. Shih and J. P. Gudas, Eds., American Society for Testing and Materials, pp II723 - II738, 1983.

2.70 Advances in Fracture and Fatigue for the 1990's - Volume 1 - Load History Effects of Fracture Resistance, PVP Vol. 166, G. M. Wilkowski and H. Kobayashi, Eds., 1989.

2.71 Dowling, N. E., and Begley, J. A., "Fatigue Crack Growth During Gross Plasticity and the J-Integral," Mechanics of Crack Growth, ASTM STP 590, pp 82-103, 1976.

2.72 Joyce, J. A., and Hackett, E. M., "Elastic-Plastic Characterization of a Cast Stainless Steel Pipe Elbow Material," NUREG/CR-5774, January 1992.

2.73 Wilkowski, G. M., and others, "Low-Cycle Fatigue Crack Growth Considerations in Pipe Fracture Analyses," PVP Vol. 280, pp 281-297, June 1994.

2.74 Brust, F. W., and others, "A Combined Numerical/Experimental Study of Ductile Crack Growth After a Large Unloading Using T", J, and CTOA Criteria," Engineering Fracture Mechanics, Vol. 22, No. 6, pp 1079-1103, 1985.

2.75 Brickstad, B., "Numerical Analysis of IPIRG Cracked Pipe Experiments Subjected to Dynamic and Cyclic Loading," SA/FoU-Report 92/05, 1992. 
2.76 Rudland, D. L., and others, "The Effects of Cyclic and Dynamic Loading on the Fracture Resistance of Nuclear Piping Steels," NUREG/CR-6440, December 1996.

2.77 Kramer, G., and others, "Stability of Cracked Pipe Under Seismic/Dynamic DisplacementControlled Stresses - Subtask 1.2 Final Report,"NUREG/CR-6233, Vol. 2, June 1997.

2.78 Scott, P., and others, "The Effect of Dynamic and Cyclic Loading During Ductile Tearing on Circumferentially Cracked Pipe: Experimental Results," PVP Vol. 280, pp 207-220, June 1994.

2.79 Wilkowski, G., and others, "The Effect of Dynamic and Cyclic Loading During Ductile Tearing on Circumferentially Cracked Pipe: Analytical Results," PVP Vol. 280, pp 221-239, June 1994.

2.80 Scott, P., and others, "IPIRG-2 Task 1 - Pipe System Experiments with Circumferential Cracks in Straight-Pipe Locations," NUREG/CR-6389, February 1997.

2.81 Olson, R., Scott, P., and Wilkowski, G. M., "Lessons Learned About the Seismic Time-Histories on Pipe Fracture," SMiRT 14, Vol. K, pp 125-136, August 1997.

2.82 Hancock, J. W., and others, "Constraint and Toughness Parameterized by T," Constraint Effects in Fracture, ASTM STP 1171, American Society for Testing and Materials, pp 21-40, 1993.

2.83 Shih, C. F., and others, "A Framework for Quantifying Crack Tip Constraint," Constraint Effects in Fracture, ASTM STP 1171, American Society for Testing and Materials, pp 2-20, 1993.

2.84 Podlasek, R. J., and others, "Predicting the Fracture Initiation Transition Temperature in High Toughness, Low Transition Temperature Line Pipe With the COD Test," ASME Journal of Engineering Materials and Technology, pp 330-334, October 1974.

2.85 Sugie, E., and others, "Influence of Thermal Stress Relieving on Fracture Toughness of UOE Pipe," UTR-79019, Kawasaki Steel Corporation, Chiba, Japan, January 1979.

2.86 Kiefner, J. F., "Fracture Initiation," in 4th Symposium on Line Pipe Research, published by American Gas Association, A.G.A. Catalogue No. L30075, November 1969.

2.87 Wilkowski, G. M., and others, "Development of Analyses to Predict the Interaction of Fracture Toughness and Constraint Effects for Surface Cracked Pipe," Project PR-3-407 for the A.G.A. Welding Supervisory Committee, April 1985.

2.88 Kramer, G. S., and others, "Flaw Tolerance of Spiral-Welded Line Pipe," A.G.A. NG-18 Report No. 154, January 1987.

2.89 Eiber, R., J., and others, "Investigation of the Initiation and Extent of Ductile Pipe Rupture," Battelle Memorial Institute Report to the Atomic Energy Commission, BMI-1908, 1971.

2.90 Kussmaul, K., and others, "Phänomenologische Behälterberstversuche - Phase I," BMFT Report BMFT-TB-1500 279, by MPA-Stuttgart, July 1985. 
2.91 Sturm D., and others, "Phänomenologische Behälterberstversuche - Phase II," BMFT Report BMFT-TB-1500 279, by MPA-Stuttgart, December 1987.

2.92 Maxey, W. A., and others, "Ductile Fracture Initiation, Propagation, and Arrest in Cylindrical Vessels," Fracture Toughness, Proceedings of the 1971 National Symposium on Fracture Mechanics, Part II, ASTM STP 514, American Society for Testing and Materials, pp 70-81, 1972.

2.93 Folias, E. S., "The Stresses in a Cylindrical Shell Containing an Axial Crack," ARL 64-174, Aerospace Research Laboratories, October 1964.

2.94 Krenk, S., "Influence of Transverse Shear on an Axial Crack in a Cylindrical Shell," International Journal of Fracture, Vol. 14, No. 2, April 1978.

2.95 Kanninen, M. F., and others, "The Development of a Plan for the Assessment of Degraded Nuclear Piping by Experimentation and Tearing Instability Fracture Mechanics Analysis - Appendices," NUREG/CR-3142, Vol. 2, June 1983.

2.96 Kiefner, J. F., and others, "Failure Stress Levels of Flaws in Pressurized Cylinders," Progress in Flaw Growth and Fracture Toughness Testing, ASTM STP 536, American Society for Testing and Materials, pp 461-481, 1973.

2.97 Kiefner, J. F., and Duffy, A. R., "Criteria for Determining the Strength of Corroded Areas of Gas Transmission Lines," in American Gas Association - Operating Section - 1973 Transmission Conference, April 1973.

2.98 Kiefner, J. F., and others, "A Modified Criterion for Evaluation the Remaining Strength of Corroded Pipe," (with RSTRENG), American Gas Association, Catalog No. L51609, PR3-805, December 1989.

2.99 Stephens, D. R., and others, "Technologies for the Evaluation of Erosion/Corrosion, Pitting, Blisters, Shell Out-of-Roundness, Weld Misalignments, Bulges and Dents in Pressurized Components," Battelle Report the Pressure Vessel Research Council, August 1997.

2.100 Chell, G. G., "Application of the CEGB Failure Assessment Procedure, R6, to Surface Flaws," ASTM STP 1074, pp 525-544, 1990.

2.101 Chell. G. G., "Elastic-Plastic Fracture Mechanics," CEGB Report RD/L/R 2007, CEGB, U.K., January 1980.

2.102 Kumar, V., and others, "An Engineering Approach for Elastic-Plastic Fracture Analysis," EPRI Report NP-1931, July 1981.

2.103 Diercks, D. R., and others, "Steam Generator Tube Integrity Program," NUREG/CR-6511, Vol. 1, April 1997. 
2.104 Erdogan, F., and Ratwani, M., "Fracture of Cylindrical and Spherical Shells Containing a Crack," Nuclear Engineering and Design, Vol. 20, pp 265-286, 1972.

2.105 Stoppler, W., Sturm, D., Scott, P., and Wilkowski, G., "Analysis of the Failure Behavior of Longitudinal Flawed Pipes and Vessels," Proceedings of 18th MPA Seminar, Stuttgart, Germany, October 1992.

2.106 Eiber, R. J., "Fracture Propagation," 4th Symposium on Line Pipe Research, Pipeline Research Committee of American Gas Association.

2.107 Maxey, W. A., and others, "Brittle Fracture Arrest in Gas Pipelines," A.G.A. Report L51433, April 1983.

2.108 Smith, R. B., and Eiber, R. J., "Field Failure Survey and Investigations," 4th Symposium on Line Pipe Research, Pipeline Research Committee of American Gas Association, November 1969.

2.109 Eiber, R. J., "Field Failure Investigations," Paper G, 5th Symposium on Line Pipe Research, Pipeline Research Committee of American Gas Association, November 1974.

2.110 Maxey, W., Keifner, J. F., and Eiber, R. J., "Ductile Fracture Arrest in Gas Pipelines," A.G.A. Catalogue number L32176, May 1976.

2.111 Popelar, C., and others, "Steady State Crack Propagation in Pressurized Pipelines," A.G.A. Report No. L00033, 1978.

2.112 Sanders, J. L., Jr., "Circumferential Through-Cracks in Cylindrical Shells Under Tension," Journal of Applied Mechanics, Vol. 49, pp 103-107, March 1982.

2.113 Sanders, J. L., Jr., "Circumferential Through-Cracks in a Cylindrical Shell Under Combined Bending and Tension," Journal of Applied Mechanics Vol. 50, pp 221, March 1983.

2.114 Folias, F. S., "An Axial Crack in a Pressurized Cylindrical Shell," International Journal of Fracture Mechanics, Vol. 1, pp 104-113, 1965.

2.115 Erdogan, F., and Ratwani, M., "Fatigue and Fracture of Cylindrical Shells Containing Circumferential Cracks," International Journal of Fracture Mechanics, Vol. 6, pp 379-392, 1970.

2.116 Klecker, R., and others, "NRC Leak-Before-Break (LBB.NRC) Analysis Method for Circumferentially Through-Wall Cracked Pipes Under Axial Plus Bending Loads," NUREG/CR4572, May 1986.

2.117 Roos, E., and others, "Assessment of Large-Scale Pipe Tests by Fracture Mechanics Approximation Procedures with Regard to Leak-Before-Break," Nuclear Engineering and Design, Vol. 112, pp 183-195, 1989.

2.118 Kanninen, M. F., and others, "Mechanical Fracture Predictions for Sensitized Stainless Steel Piping with Circumferential Cracks," EPRI Report NP-192, September 1976. 
2.119 Kumar, V., and others, "Advances in Elastic-Plastic Analysis," EPRI Report NP-3607, August 1984.

2.120 Brust, F. W., and Gilles, P., "Approximate Methods for Fracture Analysis of Tubular Members Subjected to Combined Tensile and Bending Loads," ASME Journal of Offshore Mechanics and Arctic Engineering, Vol. 116, pp 221-227, November 1994.

2.121 Brust, F. W., "Approximate Methods for Fracture Analyses of Through-Wall Cracked Pipes," NRC Topical Report by Battelle Columbus Division, NUREG/CR-4853, February 1987.

2.122 ASME Boiler and Pressure Vessel Code, Code Case N-494, 1995 Edition, July 1995.

2.123 ASME Boiler and Pressure Vessel Code, Section XI, Rules for Inservice Inspection of Nuclear Power Plant Components, 1995 Edition, July 1995.

2.124 Zahoor, A. and Kanninen, M. F., "A Plastic Fracture Mechanics Prediction for Fracture Instability in a Circumferentially Cracked Pipe in Bending - Part I. J-Integral Analysis," Journal of Pressure Vessel Technology, Vol. 103, pp 352-358, 1981.

2.125 Wilkowski, G. M., Zahoor, A., and Kanninen, M. F., "A Plastic Fracture Mechanics Prediction of Fracture Instability in a Circumferentially Cracked Pipe in Bending - Part II: Experimental Verification on a Type 304 Stainless Steel Pipe," Journal of Pressure Vessel Technology, Vol. 103, pp 359-365, 1981.

2.126 Rahman, S., and others, "An Approximate Method for Estimating Energy Release Rates of Through-Wall Cracked Pipe Weldments," Proceedings of the 1991 ASME Pressure Vessels and Piping Conference, Vol. 215, 1991.

2.127 Rahman, S., and Brust, F., "An Estimation Method for Evaluating Energy Release Rates of Circumferential Through-Wall Cracked Pipe Welds," Engineering Fracture Mechanics, Vol. 43, No. 3, pp 417-430, 1992.

2.128 Rahman, S., and Brust, F., "Elastic-Plastic Fracture of Circumferential Through-Wall Cracked Pipe Welds Subject to Bending," Journal of Pressure Vessel Technology, Vol. 114, No. 4, pp 410-416, November 1992.

2.129 Gilles, P., and Brust, F., “Approximate Fracture Methods for Pipes - Part I: Theory," Nuclear Engineering and Design, Vol. 127, pp 1-17, 1991.

2.130 Gilles, P., and others, "Approximate Fracture Methods for Pipes - Part II: Applications," Nuclear Engineering and Design, Vol. 127, pp 19-31, 1991.

2.131 "Evaluation of Flaws in Austenitic Steel Piping," (Technical basis document for ASME IWB-3640 analysis procedure), prepared by Section XI Task Group for Piping Flaw Evaluation, EPRI Report NP-4690-SR, April 1986. 
2.132 "Evaluation of Flaws in Ferritic Piping," EPRI Report NP-6045, prepared by Novetech Corporation, October 1988.

2.133 Scott, P. M., and Wilkowski, G. M., "Development and Application of a Database of Pipe Fracture Experiments," PVP Vol. 323, Fatigue and Fracture, Vol. 1, July 1996.

2.134 Brust, F. W., Ahmad, J., Brickstad, B., Faidy, C., and Gilles, P., "Comparisons Between Finite Element Analysis Predictions and Pipe Fracture Experiments," Nuclear Engineering and Design, Vol. 143, pp 201-215, 1993.

2.135 Solicitation for Public Comment on Standard Review Plan 3.6.3 "Leak-Before-Break Evaluation Procedures," Federal Register, Vol. 52, No. 167, pp 32633, Friday, August 28, 1987.

2.136 Kumar, V. and German, M., "Elastic-Plastic Fracture Analysis of Through-Wall and Surface Flaws in Cylinders," EPRI Report NP-5596, January 1986.

2.137 Mohan, R., "Application of the Line-Spring/Shell Model of Surface-Cracked Pipes and Elbows," in Fatigue and Fracture - Volume II, ASME PVP Vol. 324, pp 47-64, 1996.

2.138 Zahoor, A., "Ductile Fracture Handbook," Vols. 1-3, EPRI NP-6301-D, June 1989.

2.139 Mohan, R., Wilkowski, G. M., Bass, B., and Bloom, J., "Finite Element Analyses to Determine the R/t Limits for ASME Code Case N-494 FAD Curve Procedure," Vol. PVP- 350, pp 77-88, July 1997.

2.140 Wilkowski, G. M., and Eiber, R. J., "Evaluation for Tensile Failure of Girth Weld Repair Grooves in Pipe Subjected to Offshore Laying Stresses," Journal of Energy Resources Technology, Trans. ASME 103, pp 48-55, March 1981.

2.141 Kanninen, M. F., and others, "Instability Predictions for Circumferentially Cracked Type 304 Stainless Steel Pipes Under Dynamic Loadings," EPRI Report NP-2347, Vol. 2, Appendices, April 1982.

2.142 Scott, P. M., and Ahmad, J., "Experimental and Analytical Assessment of Circumferentially Surface-Cracked Pipes Under Bending,"NUREG/CR-4872, April 1987.

2.143 Kurihara, R., and others, "Estimation of the Ductile Unstable Fracture of Pipe with a Circumferential Surface Crack Subjected to Bending," Nuclear Engineering and Design, Vol. 106, pp 265-273, 1988.

2.144 Rahman, S., and Wilkowski, G. M., "Net-Section-Collapse Analysis of Circumferentially Cracked Pipes: Part I - Arbitrary-Shaped Cracks and Generalized Equations," ASME PVP Conference, PVP Vol. 350, pp 45-62, July 1997.

2.145 Pan, J., "Some Considerations on Estimation of Energy Release Rates for Circumferentially Cracked Pipe," Journal of Pressure Vessel Technology, Vol. 106, pp 391-398, November 1984. 
2.146 Bloom, J. M., "Validation of a Deformation Plasticity Failure Assessment Diagram Approach to Flaw Evaluation," Elastic Plastic Fracture: Second Symposium, Volume II - Fracture Resistance Curves and Engineering Applications, ASTM STP 803, 1983.

2.147 Bloom, J. M., "Deformation Plasticity Failure Assessment Diagram (DPFAD) for Materials with Non-Ramberg-Osgood Stress-Strain Curves," Journal of Pressure Vessel Technology, Vol. 117, pp 346-356, 1995.

2.148 Scott, P. M., and others, "The IPIRG-1 Pipe System Fracture Tests - Analytical Results," ASME PVP Vol. 280, pp 153-165, June 1994.

2.149 Wilkowski, G. M., Stephens, D., Krishnaswamy, P., Leis, B., and Rudland, D., "Progress in Development of Acceptance Criteria for Local Thinned Areas in Pipe and Piping Components," Post-SMiRT Seminar \#2, Current Issues in the Evolution of Risk-Informed Integrity Engineering, Paper 2.3, August 1997.

2.150 "PVRC Recommendations on Toughness Requirements for Ferritic Materials," WRC Bulletin 175, August 1972.

2.151 Landes, J. D., and McCabe, D. E., "Elastic-Plastic Methodology to Establish R-Curves and Instability Criteria," Topical Report on Toughness Characterization of Austenitic Stainless Steel Pipe Weldments, AWI CP-86-003, February 1986.

2.152 Choi, Y. H., Lee, J. B., and Wilkowski, G. M., "Development of New Z-factors for the Evaluation of a Surface Crack in Nuclear Piping," SMiRT 14, Volume G, pp 603-610, August 1997.

2.153 O'Dowd, N. P., and Shih, C. F., "Family of Crack-Tip Fields Characterized by a Triaxiality Parameter - I. Structure of Fields," Journal of Mechanics and Physics of Solids, Vol. 39, No. 8, pp 989-1015, 1991.

2.154 Sherry, A. H., and others, "Compendium of T-stress Solutions for Two and Three Dimensional Cracked Geometries," Fatigue and Fracture of Engineering Materials \& Structures, Vol. 18, No. 1, pp 141-155, 1995.

2.155 "Investigation and Evaluation of Stress-Corrosion Cracking in Piping of Light Water Reactor Plants,"NUREG-0531, February 1979.

2.156 Kramer, G., and others, "An Assessment of Circumferentially Complex-Cracked Pipe Subjected to Bending,"NUREG/CR-4687, October 1986.

2.157 Hays, R. A., and others, "Fracture Analysis of Welded Type 304 Stainless Steel Pipe," NUREG/CR-4538, Vol. 1, May 1986.

2.158 Goldberg, A., and others, "Evaluation of Cracking in Feedwater Piping Adjacent to the Steam Generators in Nine Pressurized Water Reactor Plants," NUREG/CR-1603, October 1980. 
2.159 Tada, H., Paris, P., and Gamble, R., "Stability Analysis of Circumferential Cracks in Reactor Piping Systems," Fracture Mechanics, 12th National Symposium on Fracture Mechanics, ASTM STP 700, 1980.

2.160 Pan, J. and Wilkowski, G., "Application of Tearing Instability Analyses for Complex Crack Geometries in Nuclear Piping," in CSNI Specialist Meeting on Leak-Before-Break in Nuclear Reactor Piping, NUREG/CP-0051, September, 1983.

2.161 Wilkowski, G. M. and Maxey, W. A., "Applications of the Electric Potential Method for Measuring Crack Growth in Specimens, Flawed Pipes, and Pressure Vessels," presented at the ASTM 14th National Symposium on Fracture Mechanics, Los Angeles, California, ASTM STP 791, June 30, 1981.

2.162 Wilkowski, G. M. and Kramer, G., "An Energy Balance Approach to Estimate the Initiation and Arrest of Ductile Fracture Instability in Circumferentially Cracked Pipe," ASME Special Technical Publication, Vol. 167, pp 103-114, July 1989.

2.163 Rudland, D. L., Scott, P. M., Wilkowski, G. M., and Rahman, S., "Fracture Evaluation of an InService Piping Flaw Caused by Microbiologically Induced Corrosion," in Fatigue and Fracture 1996 - Volume 1, PVP-Vol. 323, pp 71-82, July 1996.

2.164 Scott, P. M., and Brust, F. W., "An Experimental and Analytical Assessment of Circumferential Through-Wall Cracked Pipe Under Pure Bending," NUREG/CR-4574, June 1986.

2.165 Mohan, R., and others, "Development of a J-Estimation Scheme for Internal Circumferential and Axial Surface Cracks in Elbows," NUREG/CR-6445, June 1996.

2.166 Tada, H., and Paris, P., "Tearing Instability Handbook," NUREG/CR-1221, January 1980.

2.167 G. M. Wilkowski, A. Zahoor, and M. F. Kanninen, "A Plastic Fracture Mechanics Prediction of Fracture Instability in a Circumferentially Cracked Pipe in Bending - Part II, Experimental Verification on a Type 304 Stainless Steel Pipe," in Journal of Pressure Vessel Technology, Vol. 103, No. 4, pp 359-365, Nov. 1981.

2.168 Vassilaros, M., and others, "J-Integral Tearing Instability Analyses for 8-Inch Diameter ASTM A106 Steel Pipe," NUREG/CR-3740, April 1984.

2.169 Olson, R., and others, "Validation of Analysis Methods for Assessing Flawed Piping Subjected to Dynamic Loading," NUREG/CR-6234, August 1994.

2.170 Griesbach, T. J., "Dynamic Elastic-Plastic Behavior of Circumferential Cracks in a Pipe Subject to Seismic Loading," ASME, Paper 80-C2/PVP 151, April 1980.

2.171 Brosi, S., and others, "Precracked Pipe Under Waterhammer Action," Transactions of 12th SMiRT Conference, Volume G, pp 405-410, August 1993. 
2.172 Kussmual, K., and others, "Leak-Before-Break Behavior of a Piping System DN 425 Subjected to Transient Loading by Water Hammer," Transactions of 12 th SMiRT Conference, Volume G, pp 399-404, August 1993.

2.173 Bouchard, J., and others, "A Special Cracked Pipe Element for Leak Before Break Applications," Transactions of 10th SMiRT Conference, Volume G, pp 357-362, August 1989.

2.174 Swanson Analysis Systems, Inc., ANSYS Finite Element Computer Program, Houston, Pennsylvania.

2.175 Marschall, C. W., and others, "Loading Rate Effects on Strength and Fracture Toughness of Pipe Steels Used in Task 1 of the IPIRG Program," NUREG/CR-6098, October 1993.

2.176 Rahman, S., and others, "Probabilistic Pipe Fracture Evaluations for Leak-Rate-Detection Applications," NUREG/CR-6004, April 1995.

2.177 Kishida, K., and Zahoor, A., "Crack-Opening Area Calculations for Circumferential Through-Wall Pipe Cracks," EPRI Report NP-5959-SR, August 1988.

2.178 Shih, C. F., "J-Integral Estimates for Strain Hardening Materials in Antiplane Shear Using Fully Plastic Solutions," ASTM STP 590, pp 3-22, 1976.

2.179 Rice, J. R., "A Path-Independent Integral and Approximate Analysis of Strain Concentration by Notches and Cracks," Journal of Applied Mechanics, 35, pp 376-386, 1968.

2.180 Yoo, S. H., and Pan, J., "Closed Form Displacement Solutions for Circumferentially Cracked Pipes in Bending and Tension," University of Michigan Report No. UM-MEAM-88-06, October 1986.

2.181 Collier, R.P., and others, "Two-Phase Flow Through Intergranular Stress Corrosion Cracks and Resulting Acoustic Emission," EPRI Report NP-3540-LD, April 1984.

2.182 Dong, P., and others, "Effect of Weld Residual Stresses on the Crack-Opening-Area Analysis of Pipes for LBB Applications," NUREG/CP-0155, pp 283-298, April 1997.

2.183 Mayfield, M. E., and others, "Cold Leg Integrity Evaluation," NUREG/CR-1319, February 1980.

2.184 Norris, D., and others, "PICEP: Pipe Crack Evaluation Program," EPRI Report NP-3596-SR, 1984.

2.185 Keim, E., "Determination of Leakage Areas in Nuclear Piping," NUREG/CP-0155, pp 277-282, April 1997.

2.186 Grebner, H., and others, "Experiences with Leak Rate Calculation Methods for LBB Applications," NUREG/CP-0155, pp 335-348, April 1997. 
2.187 Sharples, J. K., and others, "Leak-Before-Break Assessments of Pressurized Components," SMiRT 14, Paper G08/3, pp 309-316, August 1997.

2.188 Chivers, T., "Assessments of Fluid Friction Factors for Use in Leak Rate Calculations," NUREG/CP-0155, pp 349-358, April 1997.

2.189 Matsumoto, K., and others, "Study on Coolant Leak Rates Through Pipe Cracks: Part 2 - Pipe Test," ASME PVP Vol.165, pp 113-120, July 1989.

2.190 Yano, T., and others, "Leak Flow Rate From Through-Wall Crack in Pipe," Proceedings of 1987 ASME/JSME Thermal Engineering Joint Conference, pp 301-308, 1987.

2.191 Wilkowski, G., and others, "Pipe Fracture Evaluations for Leak Rate Detection: Deterministic Models," PVP Vol. 266, pp 243-254, July 1993.

2.192 Kilinski, T., and others, "Fracture Behavior of Circumferentially Surface-Cracked Elbows," NUREG/CR-6444, December 1996.

2.193 Rice, J. R., and Levy, N., "The Part-Through Surface Crack in an Elastic Plate," Journal of Applied Mechanics, Vol. 39, pp 185-194, 1972.

2.194 Parks, D. M., "The Inelastic Line-Spring: Estimates of Elastic-Plastic Fracture Mechanics Parameters for Surface Cracked Plates and Shells," Journal of Pressure Vessel Technology, Vol. 103, pp 246-254, 1981.

2.195 Parks, D. M., and White, C. S., "Elastic-Plastic Line-Spring Finite Elements for Surface Cracked Plates and Shells," Journal of Pressure Vessel Technology, Vol. 104, pp 287-292, 1982.

2.196 Lee, H., and Parks, D. M., "Enhanced Elastic-Plastic Line-Spring Finite Element," International Journal of Solids and Structures, Vol. 33, pp 2293-2418, 1995.

2.197 Griffiths, J. E., "The Effect of Cracks on the Limit Load of Pipe Bends Under In-Plane Bending," International Journal of Mechanical Science, Vol. 21, pp 119-130, 1979.

2.198 Moulin, D., and others, "Experimental Evaluation of J in Cracked Straight and Curved Pipes Under Bending," 10th SMiRT, Vol. G, pp 323-326, 1989.

2.199 Wilkowski, G., and others, "Short Cracks in Piping and Piping Welds - Semiannual Report, AprilSeptember, 1991," NUREG/CR-4599, Vol. 2, No. 1, September 1992.

2.200 Wilkowski, G., M., Mohan, R., and Kilinski, T., "Simplified Analysis Procedure for Axial and Circumferential Surface Cracks in Elbows under Pressure and Bending," ASME PVP Conference, PVP Vol. 350, pp 129-140, July 1997. 


\subsection{TECHNICALLY EVOLVING ISSUES AND ASPECTS NOT WELL UNDERSTOOD}

While the research conducted at Battelle and other institutions over the last 15 years has significantly advanced the state-of-the-art understanding of the fracture behavior of piping and piping systems in commercial nuclear power plants, there remain a number of technical issues that are still not fully understood and for which the technology may be still evolving. One of the last activities associated with the Second IPIRG program (IPIRG-2) was a task to identify any remaining gaps in the technology so that decisions could be made with regard to the need and priority for future research efforts (Ref. 3.1). These needs, i.e., unresolved issues, were then prioritized as part of an NRC-sponsored piping review meeting held at Battelle in June of 1996. The highest priority issues then formed the basis for the Battelle Integrity of Nuclear Piping (BINP) program.

As part of the prioritization process, issues were identified either as being of importance for regulatory organizations or as being of importance to the industry. In the sections that follow, those issues will be identified and briefly discussed. Those issues of importance for regulatory concerns will be discussed first, followed by the discussion of the issues of concern to industry. Additionally, there were numerous events that occurred during the course of the years, primarily in experimental efforts, that were unusual occurrences. These aspects are documented in Section 3.3.

\subsection{Issues of Importance for Regulatory Organizations}

Those issues of importance for regulatory concerns included:

- Pipe-System Boundary Condition Effects on Crack-Opening Displacement (COD) Predictions for Leak-Before-Break (LBB) Evaluations - In the IPIRG-1 program (Ref. 3.2), scoping analyses showed that the piping system can restrain the pressure-induced bending which may occur for a through-wall-cracked pipe. While this restraint of bending can be beneficial to the load-carrying capacity of a pressurized through-wall-cracked pipe, it also has a down side. In Reference 3.1 it was shown that for small diameter pipe [e.g., 102-mm (4-inch)] diameter, that the LBB predicted failure load was reduced by a factor of 9 . This was due to the smaller crack-opening displacements, and associated longer crack lengths for a specified leak rate, due to the restraint of pressure-induced bending at a location near a physical restraint, such as near a nozzle, see Figure 3.1. For large diameter pipe [e.g., 711-mm (28-inch) diameter] at the same leak rate, i.e., a short crack length, it was shown that the effect was negligible. However, no analyses were done for cases with intermediate crack lengths [e.g., 203 to 508 -mm ( 8 to 20 -inch) diameter pipe or a main steam line]. In addition, the experimental validation of this analysis is still lacking.

- Effect of Weld Residual Stresses on Leakage Area Calculations for LBB Analyses - Results from the IPIRG-2 program (Ref. 3.1) showed that for "thin-wall" piping systems, the residual stresses tend to rotate the crack faces and may close the crack, especially for the case where the operating stresses are below 40 percent of the Service Level A maximum value, see Figure 3.2. As a result of this crack 


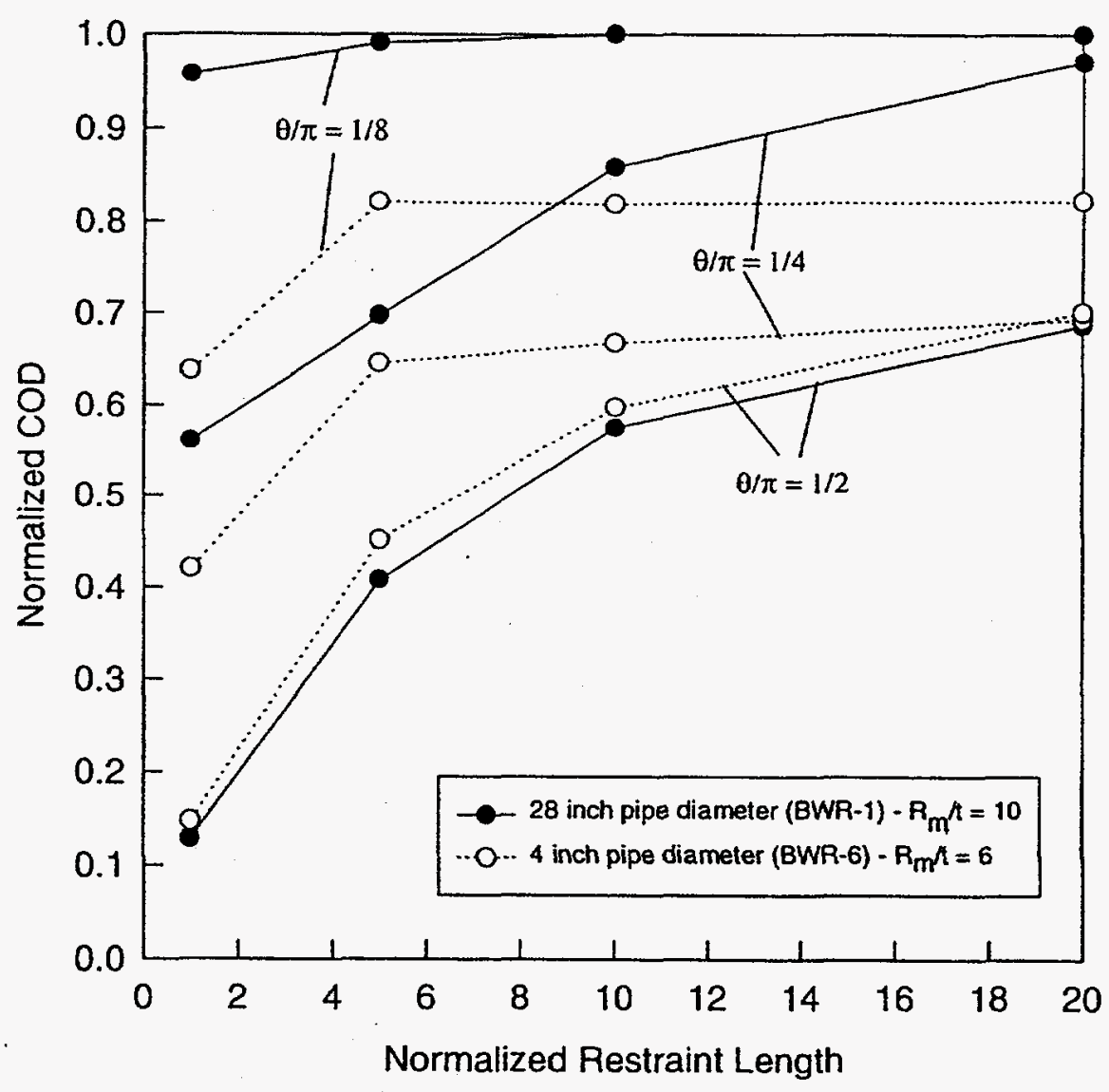

Figure 3.1 Effects of fully restrained bending conditions from crack location on COD normalized by the unrestrained COD 


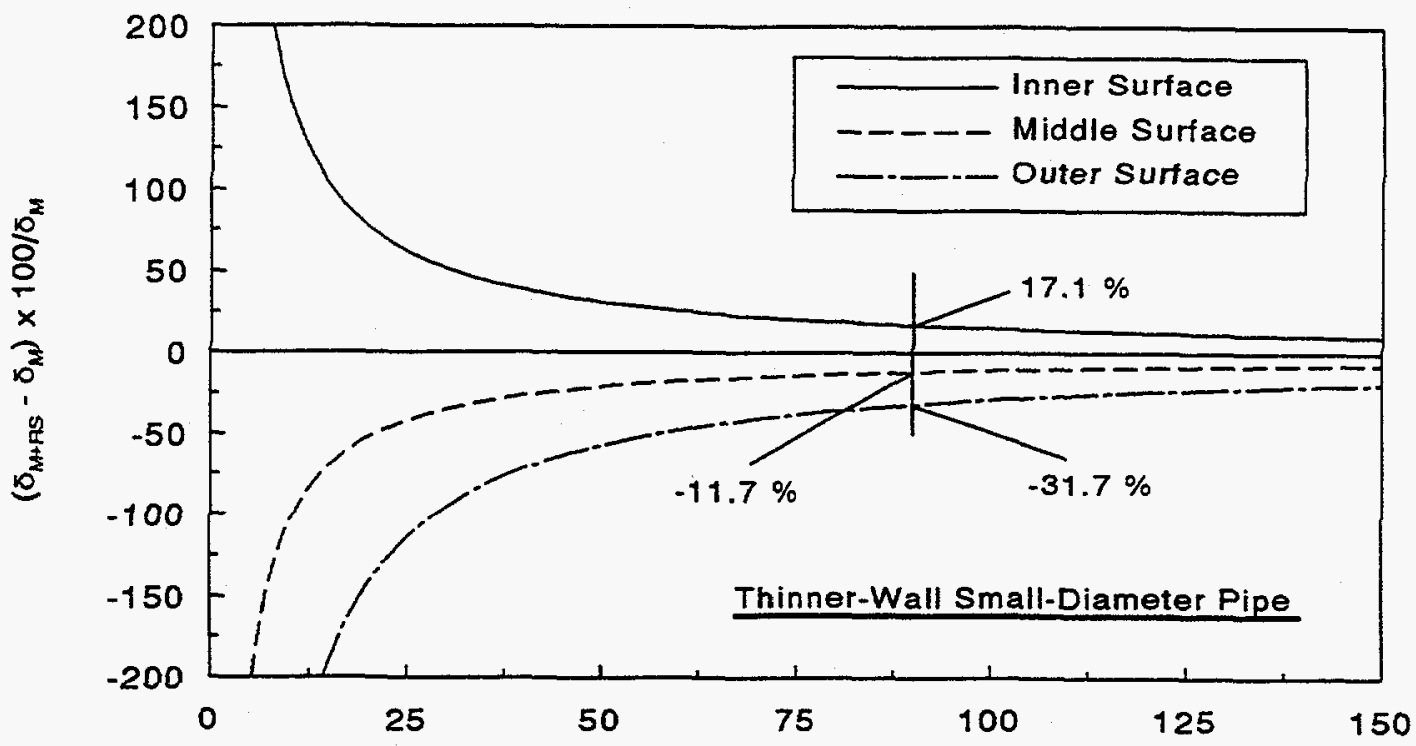

Applied Moment, \% of Service Level A

(a) Thin-walled small-diameter pipe

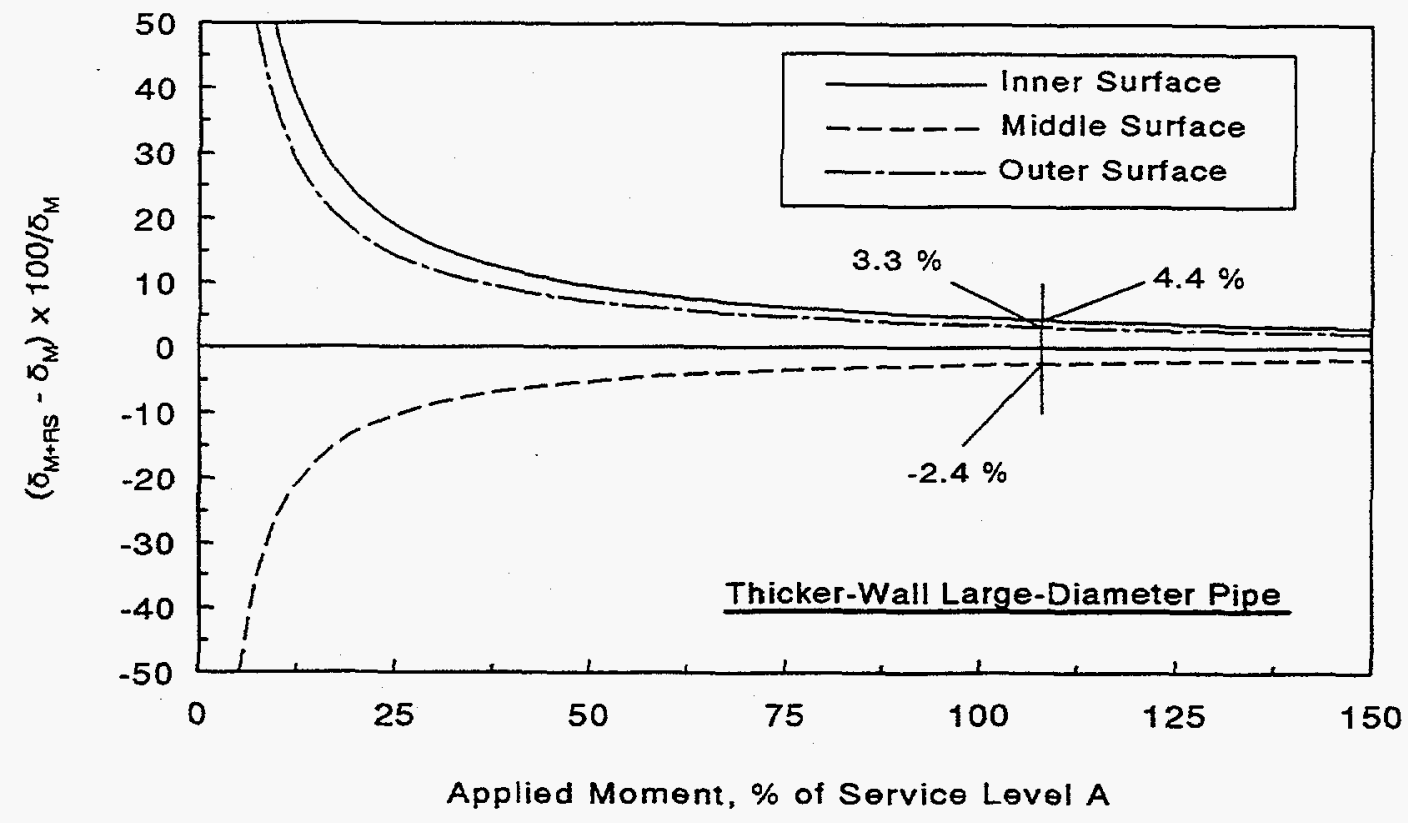

(b) Thick-walled large-diameter pipe

Figure 3.2 Percentage change in calculated COD due to residual stress as a function of applied moment 
closure effect, the actual through-wall crack for an LBB analyses may be longer than anticipated for a given leak rate based on current analysis schemes. As a result of this longer crack length, the actual failure loads may be lower than anticipated.

- Significance of Large Secondary Stresses on Pipe Fracture - Currently the ASME Code does not explicitly include seismic anchor motion (SAM) stresses in its flaw evaluation procedures.

Furthermore, thermal expansion $\left(\mathrm{P}_{\mathrm{e}}\right)$ stresses are included, but only with a safety factor of 1.0. In addition, for cracks in austenitic base metals, thermal expansion stresses are excluded from the analysis altogether. On the other hand, the R6 methodology (Ref. 3.3) suggests that in the elastic region, these secondary-type stresses make a full contribution to a fracture assessment through their inclusion in the calculation of the total stress intensity factor. In post-yield fracture, the R6 methodology treatment of secondary stresses is less certain. Data from the IPIRG-1 program showed that SAM and thermal expansion stresses contribute as much to fracture as do the primary stresses for the case where the surface crack is large and the failure stresses are below the yield strength of the pipe system. This behavior is consistent with the Local Overstrain warning in ASME Section III NC-3672.6(b) and ANSI B31.1 Paragraph 119.3. These warnings essentially say that if there is a large cross-section change where yield occurs over a limited area, then displacement-controlled stresses will act as a primary stress. If the failure stresses are above yield, then some of the secondary stresses will be relieved by yielding of the uncracked pipe, but this depends on the pipe-system geometry and material strain-hardening. Hence, the technical basis for handling secondary-type stresses in the post-yield regime has not been developed to date.

- ASME Section III Fatigue Criteria Considering Workmanship Type Flaws - Fatigue analyses are an important consideration for plant life extension. Supposedly the Fatigue Design Curves included in ASME Section III, which are based on smooth specimen data, include a factor of safety of 2 on stress or 20 on life. However, results published in Reference 3.4 showed that flaws which could pass the workmanship standards of Article IWB-3510 of ASME Section XI, or locations with high weld residual stresses, could cause fatigue failures to occur sooner than predicted based on the ASME Fatigue Design Curves, see Figure 3.3. This issue appears to be especially important for the lower stress cases where the lives are greater than 100,000 cycles and more of the overall fatigue life is associated with crack initiation instead of crack propagation.

- Fracture Criteria for Aged Cast Stainless Steel Pipe/Fittings - Cast stainless steels, especially those with a high ferrite content, are susceptible to thermal aging. Argonne National Laboratories has done a significant amount of work on this subject over the past 10 to 15 years (Ref. 3.5). As a result of this aging process, the fracture toughness goes down, but the strength goes up. The effect of this phenomenon on the fracture behavior of cracked pipe is unclear. Past Battelle calculations for an NRC Aging Conference (Ref. 3.6) showed that the effect of this aging process on the predicted load-carrying capacity of a cracked pipe in such a material was a function of the analysis method used. The R6 Option 1 analysis method (Ref. 3.3) predicted that the load-carrying capacity would decrease with time. The Tada/Paris method (Ref. 3.7) predicted that the load-carrying capacity increased with time. The Dimensionless-Plastic-Zone-Parameter (DPZP) method (Ref. 3.8) showed that the effect on the load-carrying capacity was a function of the pipe diameter and crack geometry (i.e., surface crack versus through-wall crack). Additional evaluations are needed to determine which analyses methods should be used for analysis of aged cast stainless steel products. 


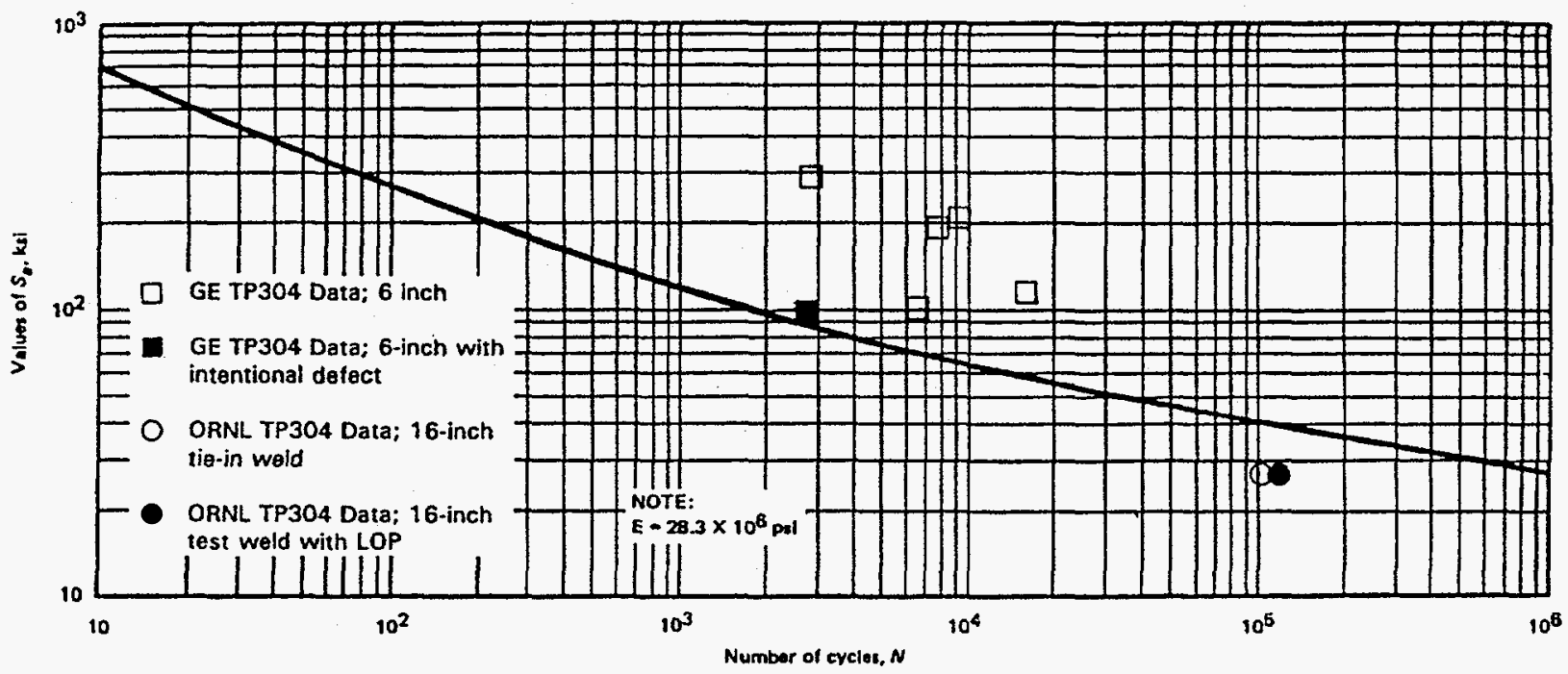

(a) Stainless steel data

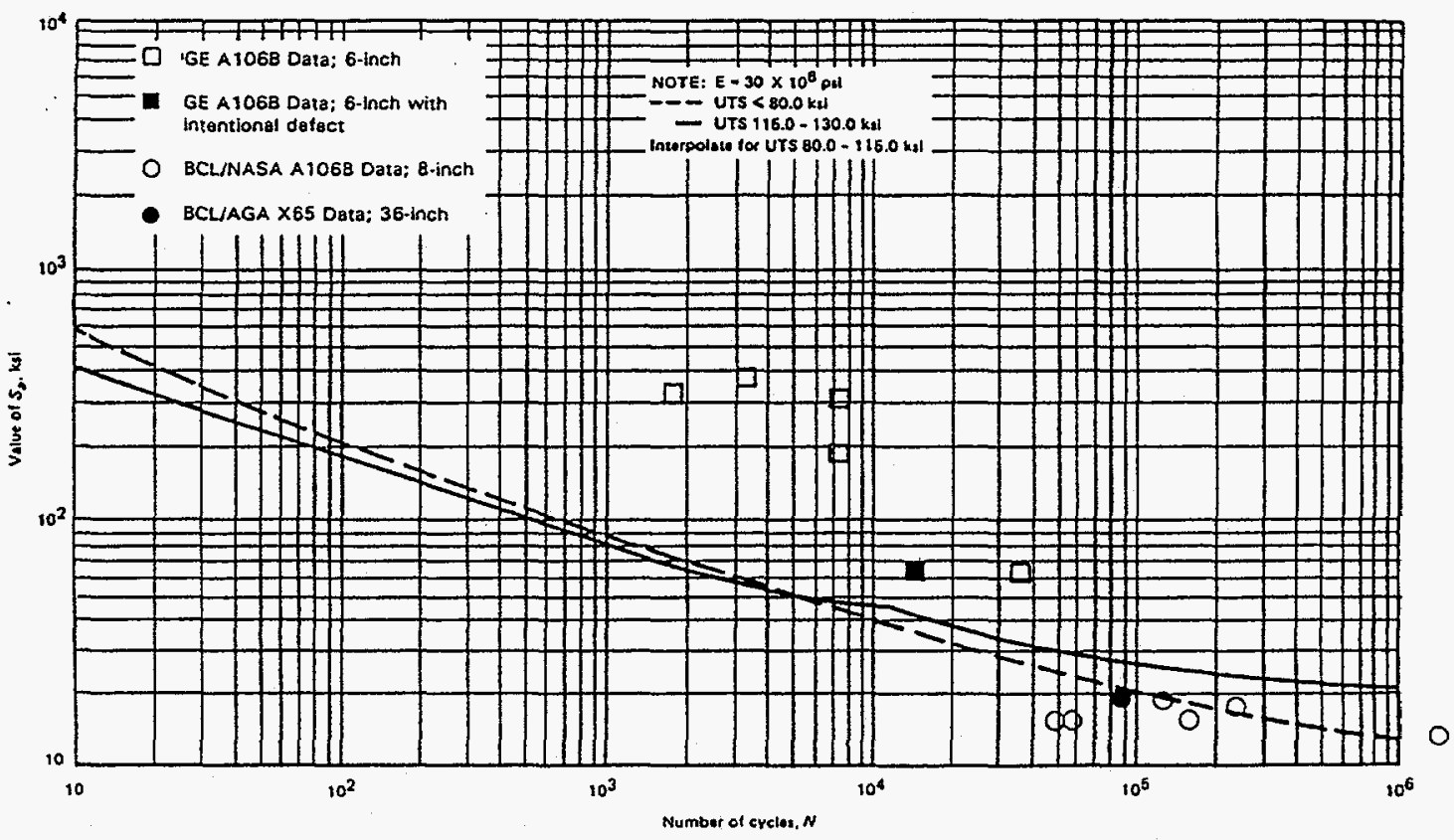

(b) Carbon steel data

Figure 3.3 Comparison of full-scale component fatigue data with ASME Section III fatigue design curves 
- Bimetallic Welds Fabricated with Stainless Steel Weld Metal - Efforts in the NRC Short Cracks Program (Ref. 3.9) showed that bimetallic welds fabricated using an Inconel weld procedure had sufficiently high fusion-line toughness that the maximum load-carrying capacity could be adequately predicted using the carbon-steel base-metal properties. However, the adequacy of bimetal welds fabricated using a stainless steel weld metal is less certain. For such welds, there is a tendency to form a carbon depleted zone in the heat-affect-zone which lowers the toughness. Data provided to Battelle by researchers in the Czech Republic (Ref. 3.9) illustrates that the fracture toughness for such stainless steel welds may be a factor of 2 to 3 lower than bimetal welds made using an Inconel procedure, see Figure 3.4. In addition, the effects of dynamic and cyclic loading on the fracture toughness of the fusion line of bimetal welds is unknown.

- Stainless Steel Fusion Line Toughness - Stress corrosion cracks are more likely to form along the fusion line of a weld than they are in the weld metal itself. In a number of the full-scale stainless steel weld pipe tests conducted by Battelle, the crack grew out of the center of the weld and followed the fusion line. In an investigation of this effect as part of the Short Cracks Program (Ref. 3.10), it was found that the J-R curve for the fusion line was flat after $2 \mathrm{~mm}(0.08 \mathrm{inch})$ of crack growth, see Figure 3.5, thus explaining this behavior. In addition, SEN(T) data from the Degraded Piping Program (Ref. 3.11 ) showed that the crack-tip-opening angle (CTOA) of the fusion line was a factor of 3 less than the CTOA for a crack in the center of a SMAW. Currently, however, flaw evaluation criteria such as ASME Section XI for ferritic and austenitic welds do not consider this effect. These criteria are based on data developed for the case where the crack is centered in the weld. Furthermore, the effects of dynamic and cyclic loading on the fusion line toughness is unknown at this time.

- Cyclic Loading Effects on Fracture - As part of the IPIRG-2 program, significant progress was made towards understanding the effects of cyclic loading on the fracture behavior of nuclear grade pipe steels (Ref. 3.12). It was concluded that the bounding seismic load history, as far as damage is concerned, is probably somewhere between the dynamic/monotonic type history which may be representative of the Kobe and Northridge earthquakes, and an earthquake which exhibits a fully reversed history with a gradual increasing amplitude for the first five seconds.

- Effect of Thickness Transitions at Nozzles for COD Predictions - Results from one of the IPIRG-2 round-robin problems (Ref. 3.13) showed that the crack-opening displacement (COD) on the thicker side of a thickness transition at a nozzle is less than what would be normally expected based on a crack-opening area analysis using a uniform wall thickness section. Such a reduction in COD will result in a longer crack length for a specified leak rate. Currently, no specific guidance exist as to how to handle this potential nonconservatism in an LBB-type analysis.

- Dynamic Strain Aging Effects on Toughness - In the IPIRG programs, dynamic loading was found to reduce the toughness of ferritic steels to as little as 55 percent of the quasi-static toughness value (Ref. 3.14). This effect has been attributed to dynamic strain aging (Ref. 3.15). All U.S. grades of ferritic steels tested had some pipe lengths that were susceptible to these toughness losses, but some lengths of pipe were not affected. This variability is probably due to cooling rates in fabrication that are not specified. Appropriate specifications could possibly produce pipe that is not sensitive to the detrimental effects of dynamic strain aging. In the interim, a lower-bound toughness for pipe in service for LBB and flaw evaluation criteria needs to be established. 
Section 3

TECHNICALLY EVOLVING ISSUES AND ASPECTS NOT WELL UNDERSTOOD

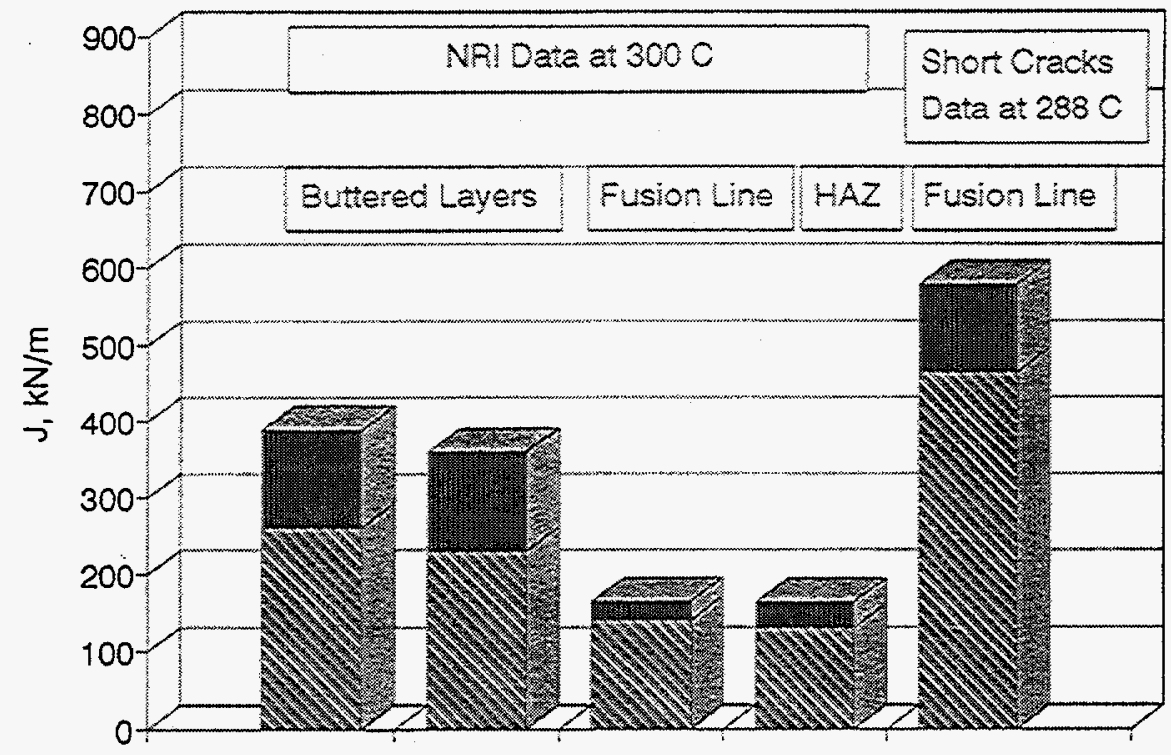

$1 \mathrm{~mm}$ Crack Growth $2 \mathrm{~mm}$ Crack Growth

Figure $3.4 \mathrm{~J}$-values at $1 \mathrm{~mm}(0.04$-inch) and $2 \mathrm{~mm}(0.08$ inch) of crack extension for bimetallic welds evaluated by NRC-Rez and Battelle

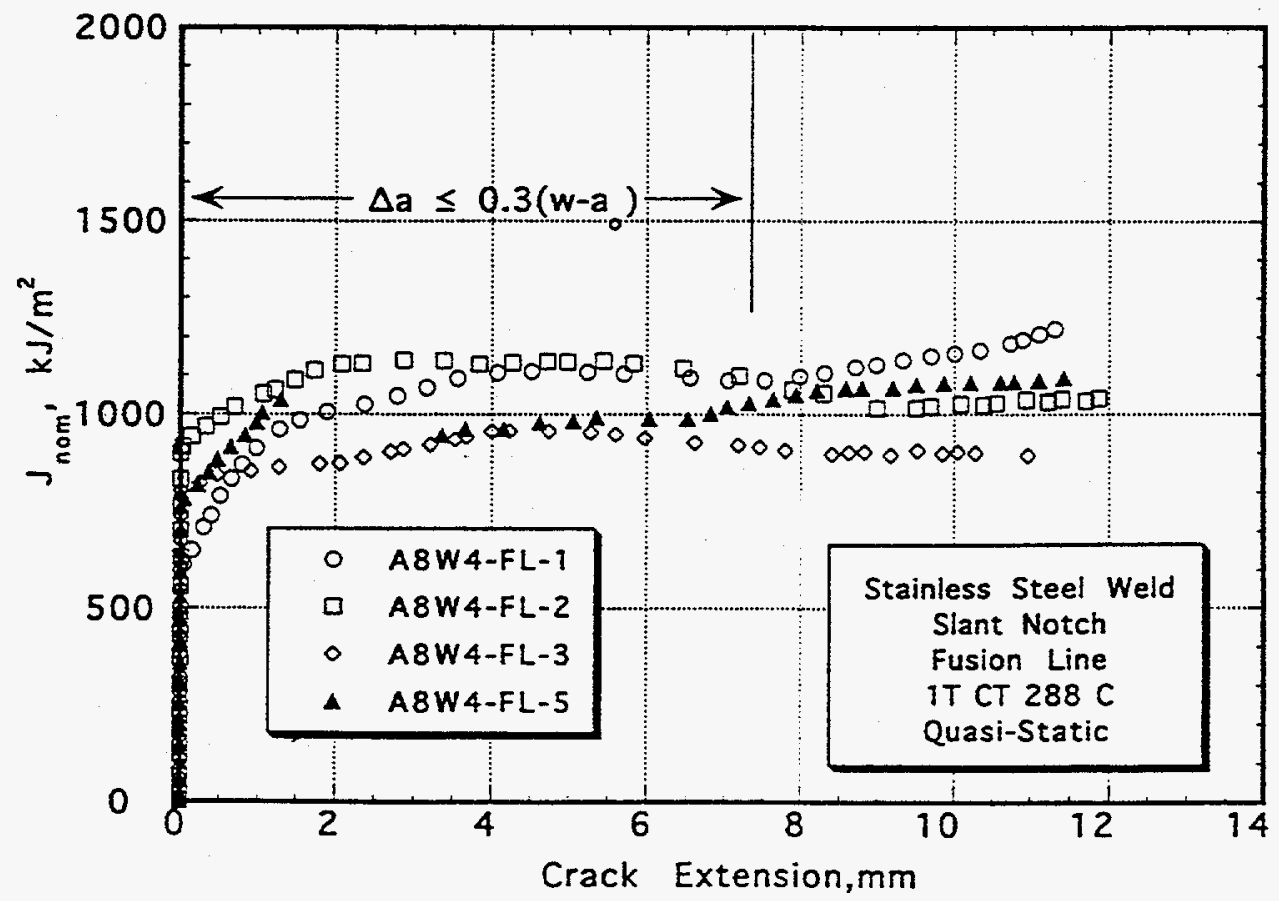

Figure 3.5 J-resistance curves of slant-notch, fusion-line specimens [limit on J-R curve data is $\Delta a$ $\left.\leq 0.3\left(W-a_{0}\right)\right]$ (Note: The sudden load drop for Specimen A8W4-FL-5 corresponded to a significant crack jump as shown in the load-displacement data) 
- Leak-Rate Code Improvement/Validation - Virtually all leak-rate codes use the same friction factor equation. This equation will mathematically have problems as the crack-opening displacement approaches the surface roughness. Using a COD-dependant roughness and number of turns with a local and global values, as discussed in Section 2.4, will give a better physical model to the problem and will also help to eliminate mathematical problems.

Additionally, the current leak-rate codes are rather simplified in that they consider the crack to be a circular pipe with an equivalent hydraulic diameter. To have accuracies of only plus or minus a factor of five is understandable with such crude modeling. This approach was used since parallel plate flow models were too complicated for the PC computers of early 1980 's. At this point in time, the computer hardware has advanced so that parallel plate models could be implemented into a leak-rate code. Furthermore, ten years ago, there were only one or two general three-dimensional computational fluid mechanics (CFM) codes, whereas today there are about a dozen. Hence, the software has also improved. These CFM models could be used to tune the leak-rate analyses in areas such as the transition region where the $C O D$ and roughness approach the same values.

Adding to the statistical database of crack morphology parameters for in-service cracks would also be beneficial if probabalistic LBB analyses are to be conducted.

- Fracture of Pipes with an Off-Center Circumferential Through-Wall Crack - In LBB analyses, it is assumed that there is a leaking circumferential through-wall crack that is centered on the bending plane for normal operating stresses. That same crack is then assumed to experience SSE loading with the crack still centered on the bending plane. This is highly unlikely, hence, current LBB analyses involve fictitious conditions.

In the NRC piping programs, elastic analyses were conducted for the crack-opening-area of an offcentered crack. (A crack may occur off of the principal bending plane due to a manufacturing defect or non-axisymmetric weld residual stresses.) The analytical solutions were validated by FEM analyses. However, no solutions or experiments exist for a crack that is off-centered and loaded to maximum load. These solutions might be of value if one is to consider that a leaking crack may really occur in service, where it is most likely that the crack is not centered on the normal operating stress bending plane or the SSE bending plane (or it might be off-centered for both loading conditions).

- Reexamination of COD Model Comparison with Experimental Data - Earlier in this report it was noted that the COD predictions on the average were good or conservative from an LBB viewpoint. However, the standard deviation of the predictions was extremely high, so that there may be many nonconservative cases. The comparisons done in NUREG/CR-6300 involve older pipe test data that should be reviewed better to ensure its fidelity.

\subsection{Issues Beneficial to Industry}

Those issues of particular benefit to the industry included:

- Margins from Nonlinear Cracked Pipe Dynamic Analyses - Elastic uncracked pipe stress analyses can be very conservative when used in a pipe fracture analysis. Past Battelle nonlinear cracked-pipe 
element seismic analysis has shown that the margin on failure loads of using such a coupled approach over using uncracked elastic stress analysis peak loads in a pipe EPFM analysis was a factor of 5 . Accounting for this margin by using a coupled nonlinear stress/fracture analysis may make it possible to qualify lines for LBB which are currently marginally unacceptable using the existing methodologies. This methodology could be used to assess more realistic margins, and could be a basis for either reducing applied safety factors or simplifying flaw evaluation or LBB procedures.

- Flaw Evaluation Criteria for Class 2, 3, and Balance of Plant (BOP) Piping - The current flaw evaluation criteria in ASME Section XI are only for flaws found in Class 1 piping systems. Recently, however, the inspection requirements required in Section XI for Class 2, 3, and BOP piping have been increased. As a result of the increased inspection requirements, more flaws are being found in such piping systems. In addition, these other than Class 1 piping systems may become more of a contributor to the overall risk associated with the plant. Furthermore, due to the generally thinner wall thickness of these piping systems, any workmanship-sized flaws will be more significant on a relative basis. Also, the thinner walled (larger $\mathrm{R} / \mathrm{t}$ ratio) Class 2,3 , and BOP piping will have lower failure stresses than typical Class 1 piping in the limit-load, EPFM, and LEFM regimes, see Figure 3.6. On the other hand, the lower constraint conditions associated with thin-walled surface-cracked pipe will lower the brittle-to-ductile transition temperature of the cracked pipe, providing an unknown level of additional margin, see Figure 3.7. Prior to the establishment of a credible and defensible flaw evaluation criteria for Class 2, 3, and BOP piping, all of these issues should be addressed.

- Flaw Evaluation Criteria for Fittings - As plants continue to age, more instances of flaws found in fittings are being reported. A number of such instances have been reported on in ASME Section XI Code Committee meetings. The main effort to address this issue is the work conducted on elbows as part of the IPIRG-2 program (Refs. 3.16 and 3.17), and work in France (Refs. 3.18 and 3.19). As part of the Battelle effort, a flaw evaluation criteria, based on the $\mathrm{B}_{2}$ stress indices, for possible inclusion into the ASME Code was proposed for elbows, see Figure 3.8. However, only minimal efforts have been made to validate these criteria. In addition, little or no work has been done to address the issue of flaws found in service in other piping components, such as tees.

- Erosion/Corrosion Flaw Acceptance Criteria - Erosion/Corrosion flaws occur frequently in service. There have been a number of in-service failures which have had very serious consequences for the industry (Refs. 3.20 and 3.21), although no radiation has been released. However, currently validated flaw acceptance criteria do not exist for such flaws, especially for flaws found in pipe fittings, such as tees and elbows. A new ASME Code Case is being developed for E/C Flaw Acceptance criteria, but it is based more on pipe stress design rules rather than margins from failure.

- Evaluation of and Improvements to the ASME Section III Seismic Design Rules - The 1995 edition of the ASME Code provided new, more liberal seismic design rules in Section III. To date, the U.S. NRC has not approved these new rules for U.S. plants. The IPIRG results showed that even cracked pipe can tolerate larger loads, i.e., the three cracked pipe-system experiments which were subjected to a simulated-seismic time history resulted in no damage to the crack section for an SSEtype loading. Although there is a general feeling that the 1989 ASME Section III pipe design stress rules could be relaxed, there does not appear to be a good technical basis to explain the extent of the relaxation allowed by the new rules. As the rules are currently written, any piping system which was 


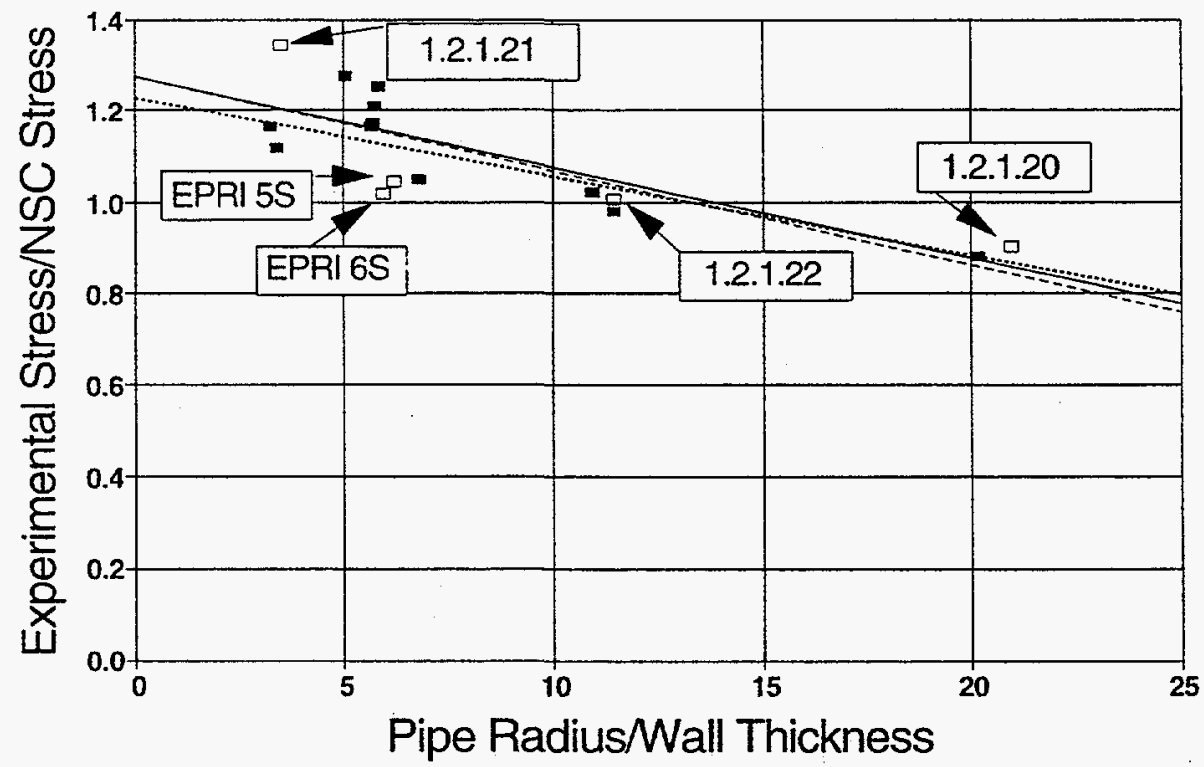

- Long Crack Data $\square$ Short Crack Data — Fit for All Data

.... Fit for Long Crack ....... Fit for Short Crack

Figure 3.6 Plot of the ratio of experimental stress to Net-Section-Collapse predicted stress as a function of pipe radius-to-thickness ratio $\left(R_{m} / t\right)$

$$
\begin{aligned}
& x=\text { Surface-cracked pipe data } \\
& 0=t x t \text { COD bend specimens }
\end{aligned}
$$

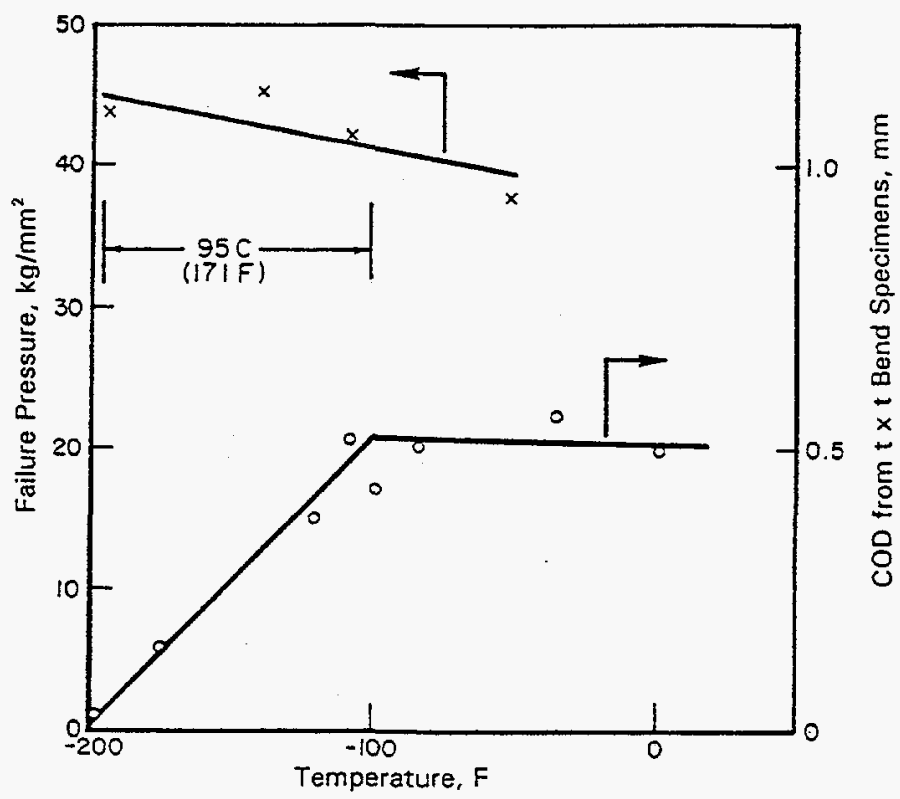

Figure 3.7 Example of transition temperature differences between bend specimens and surfacecracked pipe 


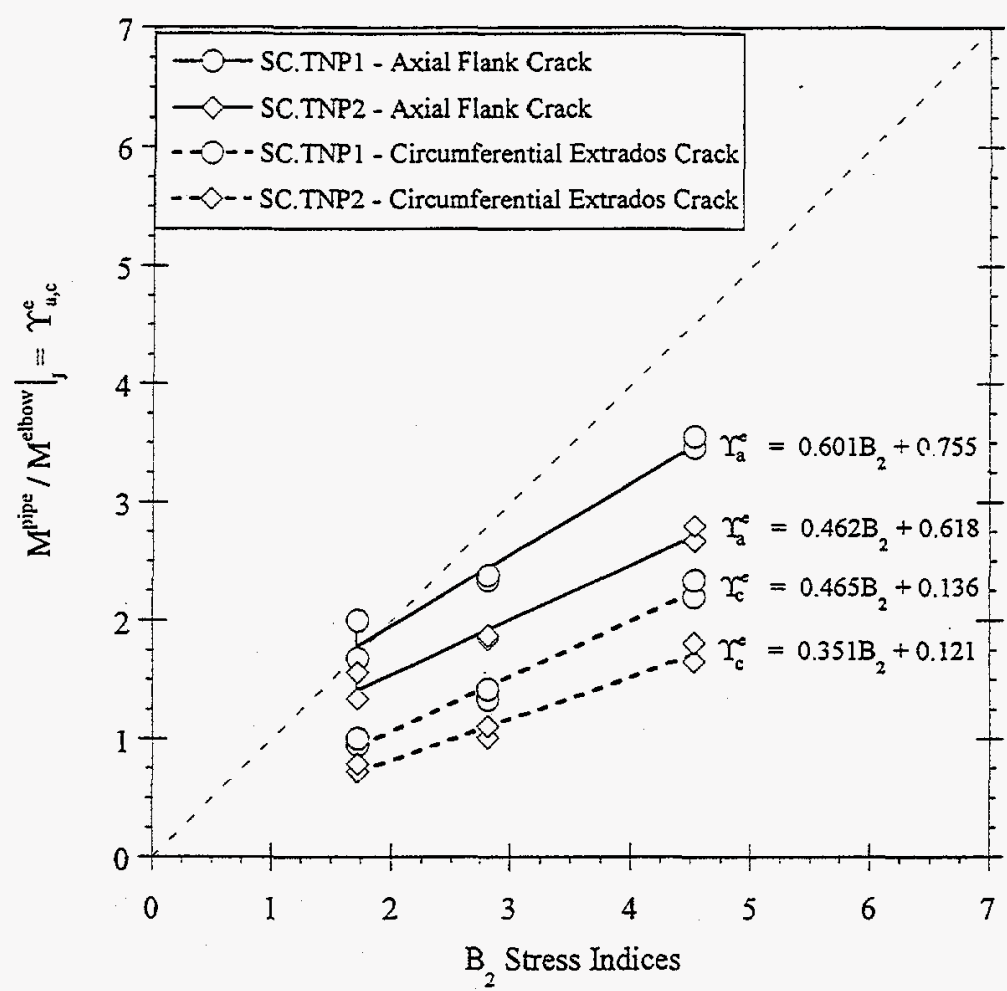

Figure 3.8 Comparison of axial-flank and circumferential-extrados surface-cracked elbow failure avoidance criteria

designed to these rules would have to be repaired or replaced if a flaw larger than a workmanship size flaw was found in service because the existing flaw evaluation criteria in Section XI are not compatible with the new rules in Section III.

- Replacement Criteria for "Instantaneous" DEGB - An initial design consideration for reactor core make-up water, and subsequent design criterion for core supports and piping supports etc., assumed that there could be a brittle fracture that would cause the pipe to separate almost instantaneously. This criterion from the early days of nuclear power, can now be addressed using the cracked-pipe element methodology that was developed during the IPIRG programs. From the IPIRG pipe-system experiments and analyses, it is now understood that in order to get a DEGB to occur in one large amplitude cycle of reasonable magnitude, that an extremely long circumferential surface crack is needed. Using the cracked-pipe analysis methodology, the bounding cases for crack opening rate, occurrence of a DEGB and subsequent rate of separation of the pipe ends can be calculated from the pipe system conditions (like masses, pipe stiffness either side of the crack, and thermal hydraulic conditions). Such an analysis would also have an impact on the insulation damage for the BWR suction strainer blockage issue.

- Improvements for cracked-pipe load predictions under combined bending and tension loading As was noted earlier in this report, the piping system tends to restrain the free rotation that might occur with cracked pipe under pressure loading. This restraint will increase the load-carrying capacity and reduce the crack-opening displacement. The increased load-carrying capacity could be accounted for in the J-estimation scheme analyses, such as those in the NRCPIPE code. 
- Variable Depth Surface-Cracked-Pipe Flaw Evaluation Criteria - Many flaw evaluation criteria assume that one should assume the maximum flaw depth for the entire length of the flaw, or assume it is elliptical with the maximum flaw depth and length. Frequently, in service circumferential flaws depths are highly variable. Accounting for the variable depth flaw shape, as is done in the Modified ANSI B31G criterion for corrosion flaws in gas and oil pipelines, would be of benefit. Much of the methodology to do this already exists and was cited earlier in this report.

- Update of the GE/EPRI Handbook Solutions - Since the original GE/EPRI handbook was published in 1981, numerous crack behavior solutions for various geometries, material response and loading conditions have been developed, but have not been collected in one spot. There were subsequent solutions in the GE work, many different pipe and elbow solutions in the Battelle/NRC work, and solutions to many other geometries in the literature. These should be assembled into one handbook and updated periodically.

- Automated FEM Pipe Fracture Code to Replace J-estimation Scheme Codes - J-estimation schemes are closed-form solutions that approximate (i.e., estimate) more accurate finite-element analysis results. Many circumferential through-wall-cracked and surface-cracked pipe J-estimation schemes are given in the NRCPIPE and NRCPIPES codes. These estimation schemes were originally developed because full finite element analyses were very costly, time consuming, and computer hardware was inadequate. Current computer hardware, however, is constantly improving, and is now capable of conducting special purpose 3D finite element analyses on personal computers. It is possible to link a special purpose mesh generator, public domain FEM analysis code, and post-processors to calculate $\mathrm{J}$ for cracked pipe, and essentially make it look like a black box (like the NRCPIPE code) as far as the user is concerned. This would eliminate concern over the accuracy or approximations in some of the methods proposed.

- Assessment of UT Flaw Sizing Effects on Surface-Cracked Pipe Moment-Carrying Capacity An initial scoping exercise on the uncertainty of flaw depth sizing on the moment-carrying capacity of TP304 stainless steel base metal with circumferential flaws was conducted in NUREG/CR-6443. That effort employed 1989 EPRI stainless steel pipe UT round-robin results. The statistical analysis showed that if the circumferential crack length was short (i.e., $\theta / \pi<0.25$ ) then the uncertainty in flaw depth sizing was not very important. This was because the failure loads all approached those of an uncracked pipe. Similarly if the flaw depth was shallow (i.e., $a / t<0.25$ ), then the statistical errors in sizing the flaw were not very significant since again the failure loads are close to that of an uncracked pipe. The largest concern was with deep long flaws.

Similar analyses could be conducted for cracks in stainless steel welds. Data were not readily available for ferritic pipe UT inspection uncertainty. If available, then a similar exercise could be conducted. The results of these studies may be of value in showing that for certain flaw size ranges, those flaws could perhaps be considered acceptable without any analysis.

- Updating Databases and Computer Code Maintenance - As more data become available, it is desirable to have that data archived for future statistical analysis or for validation of any potential new fracture analysis or parameter that may appear in the future. Some of the databases maintained at Battelle are given below. 
The EDEAC database contains specimen test data involving environmentally assisted cracking in aqueous environments, i.e., fatigue crack propagation, slow strain rate, and stress-corrosion cracking data. The materials are nuclear pipe and vessel ferritic, low alloy, and austenitic base metals and welds. It is currently on a CD-ROM complete with a database search engine.

The PIFRAC database is a good start for material property archiving in that it already has over 800 stress-strain curves and $800 \mathrm{~J}-\mathrm{R}$ curves (complete with load-displacement-crack growth data and specimen dimensions).

Pipe and fitting fracture tests data are included in AXIALCK (straight pipe with axial cracks - 250 experiments), CIRCUMCK (straight pipe with circumferential cracks - 800 experiments), ELBOWCK (elbows with axial or circumferential cracks - 78 experiments), and TEECK (tees with various crack orientations - 12 experiments). The AXIALCK database is a compilation of Battelle and MPA experiments, and there are probably another 500 experiments in the literature that could be added. The rest of the databases require occasional updating. These databases are of value for statistical analysis for codes and standards work.

Although other databases on crack morphology (for leak-rate work) and fatigue crack growth pipe experiments were established in the course of conducting engineering efforts over the years, they do not exist in a format that is releasable at this time.

\subsection{Observations of Aspects Not Well Understood}

Over the course of 15 to 20 years of experimental and analytical work on nuclear pipe fracture behavior, numerous observations from experimental efforts and some analytical efforts were made that were found to be unusual or unexpected. Some of these are better understood now, while others are documented here for archival purposes.

\subsubsection{Irregular Fatigue Crack Growth}

During the course of conducting pipe fracture experiments, surface-cracked pipe specimens were frequently fatigue precracked. In some cases, the fatigue crack growth is not uniform or does not have the anticipated shape. Figure 3.9 shows the fatigue crack shape from a surface-cracked TP304 pipe. Note the excursions of the crack growth at several locations along the crack front. Most of these were away from the center of the flaw, which was also the center of the bending plane. Fortunately, the deeper crack fronts away from the center of the crack did not affect the anticipated fracture load based on the depth of the flaw at the center of the crack. If the deepest part of the crack was used in the assessment for the entire length of the surface flaw, then the predictions would have been significantly less than the experimental loads.

\subsubsection{Fatigue Crack Growth in Cyclic Compressive Loading with Mean Stresses from a Weld}

On occasions, specimens and pipes are fatigue precracked for test specimens where the cracks were close to welds. In one program, a double-submerged arc axial seam weld was loaded in through-thickness cyclic 
Figure 3.9 Photograph shows the internal scallops which comprised the initial flaw. The fatigue precrack can be clearly seen in this specimen (1.1-6) and it shows the two crack excursions which nearly made the flaw a TWC rather than SC. The deep fatigue cracks are very near the end of the flaw and did not appear to affect the maximum moment achieved during the test 
bending. Under the through-thickness bending, it was anticipated that the crack would grow on the OD surface where the cyclic loads were in tension. Although the crack did grow there, it also grew in the ID surface at the same time. On the ID surface, the applied bending stresses were compressive, however in the presence of tensile weld residual stresses, the cyclic stresses went from tension to compressive loading as the applied loads went from zero to compression. Hence, cyclic compressive loadings in the presence of a weld residual stress field can cause fatigue crack growth.

\subsubsection{Splitting in Stainless Steel C(T) Specimens Causing Reduced Toughness}

In reviewing our database for determining the statistical scatter in J-R curve toughness of TP304 stainless steel, a few specimens were found to have significantly lower J-R curves. The $C(T)$ specimens were in the $\mathrm{L}-\mathrm{C}$ orientation, which corresponds to a through-wall circumferential crack. In all of these specimens, there was a lamination that caused the material to separate at the midthickness. This lamination effect is well known in the oil and gas pipeline industry to cause a lowering of the upper shelf toughness of a material (Refs. 3.22 and 3.23). This happened for specimens from two different pipe sizes and from different manufacturers.

\subsubsection{Through-Thickness Toughness Anisotropy}

It has been documented in many places that the toughness of ferritic steels is typically higher in the through-thickness direction, i.e., L-R or C-R orientations, than the directions representing a through-wall crack, i.e., L-C or C-L directions. The higher toughness in those directions probably explains why many of the J-estimation schemes that are tuned to finite element analyses under predict the fracture loads when the $\mathrm{L}-\mathrm{C}$ orientation toughness is used.

Unfortunately, there typically are no fracture toughness data in the radial directions. On occasions there are Charpy data in the literature for all orientations. In some work done at Battelle for an A516 Grade 70 ferritic plate material, it was shown that the ratio of the toughness in the L-C and L-R directions in Charpy specimens was equal to the ratio of the $J_{\mathrm{Ic}}$ values in those directions. Hence, it is possible that the ratio of the Charpy energies in the two orientations could be used as an anisotropy correction parameter on the L-C or C-L toughness. This would help improve the accuracy of the fracture analyses.

\subsubsection{Through-Thickness Splitting Causing Surface Crack Arrest}

The occurrence of a lamination or through-thickness split frequently is associated with steels that are not thought to be very clean, i.e., due to $\mathrm{MnS}$ inclusions. The result, as noted in Item 3.3.3, is to reduce the effective toughness for a through-wall crack. On the other hand, it has been observed that such a lamination effect can significantly increase the fracture resistance of a surface-cracked pipe. Figure 3.10 shows the results where a surface crack was arrested by a lamination. Under proper conditions, laminations or separations (Ref. 3.24) will act as a beneficial crack arrestor. This composite structure can be quite beneficial for surface flaws. In fact, the A302 steel in Reference 3.25 seemed to have a very low toughness in the $C-L$ orientation, but if tested in the C-R direction, then it may have behaved with higher toughness than could be obtained with a very clean steel. 


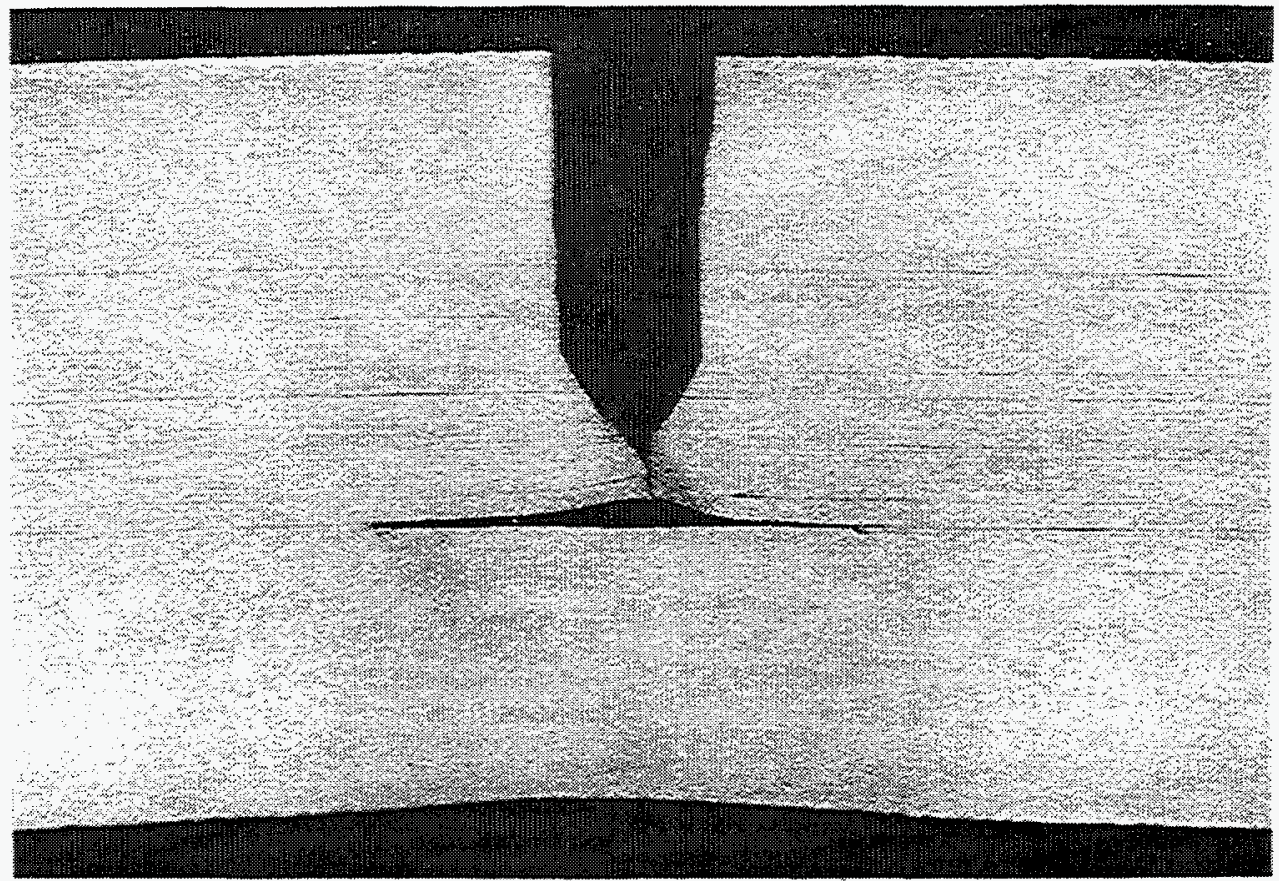

Figure 3.10 Arrest of axial surface crack in Battelle pipe test by through-thickness splitting

\subsubsection{Toughness Anisotropy for Circumferential Through-Wall-Cracked Pipe}

Toughness anisotropy in the C-L versus L-C directions was believed to have caused circumferentially cracked pipe under pure bending to have the crack grow in a helical and sometimes axial direction. These test results, along with the combined pressure and bending experimental results to date, have shown that the helical crack growth actually improved the load-carrying capacity and pipe deformation capability. Since no pipe fracture experiments have been conducted under torsional loading, it can not be said how pipe with material anisotropy will behave under torsion or torsion combined with pressure and bending loads.

\subsubsection{Crack Growth Around Hard Spots}

In a few pipe tests, cracks had propagated by ductile tearing into a region that had a hard spot. One such case in a stainless steel is shown in Figure 3.11. The result was that the crack preferred to grow around the hard spot, which caused a small local instability.

\subsubsection{SEN(T) Fusion Line Toughness of Stainless Steel Weld Fusion Lines}

During the early days of the NRC's Degraded Piping Program, SEN(T) specimens were tested with cracks in the base metal, center of the weld, and in the HAZ. In one specimen, the HAZ crack was very close to the stainless steel SMAW fusion line. The crack in this case grew along the fusion line on one side of the specimen with a significantly smaller crack-tip-opening angle (CTOA). The amount of the crack growth in that region was also much larger than the crack front that stayed in the HAZ sensitized base metal. The CTOA for the crack in the fusion line was about one third of that found for a crack in the SMAW weld metal. 


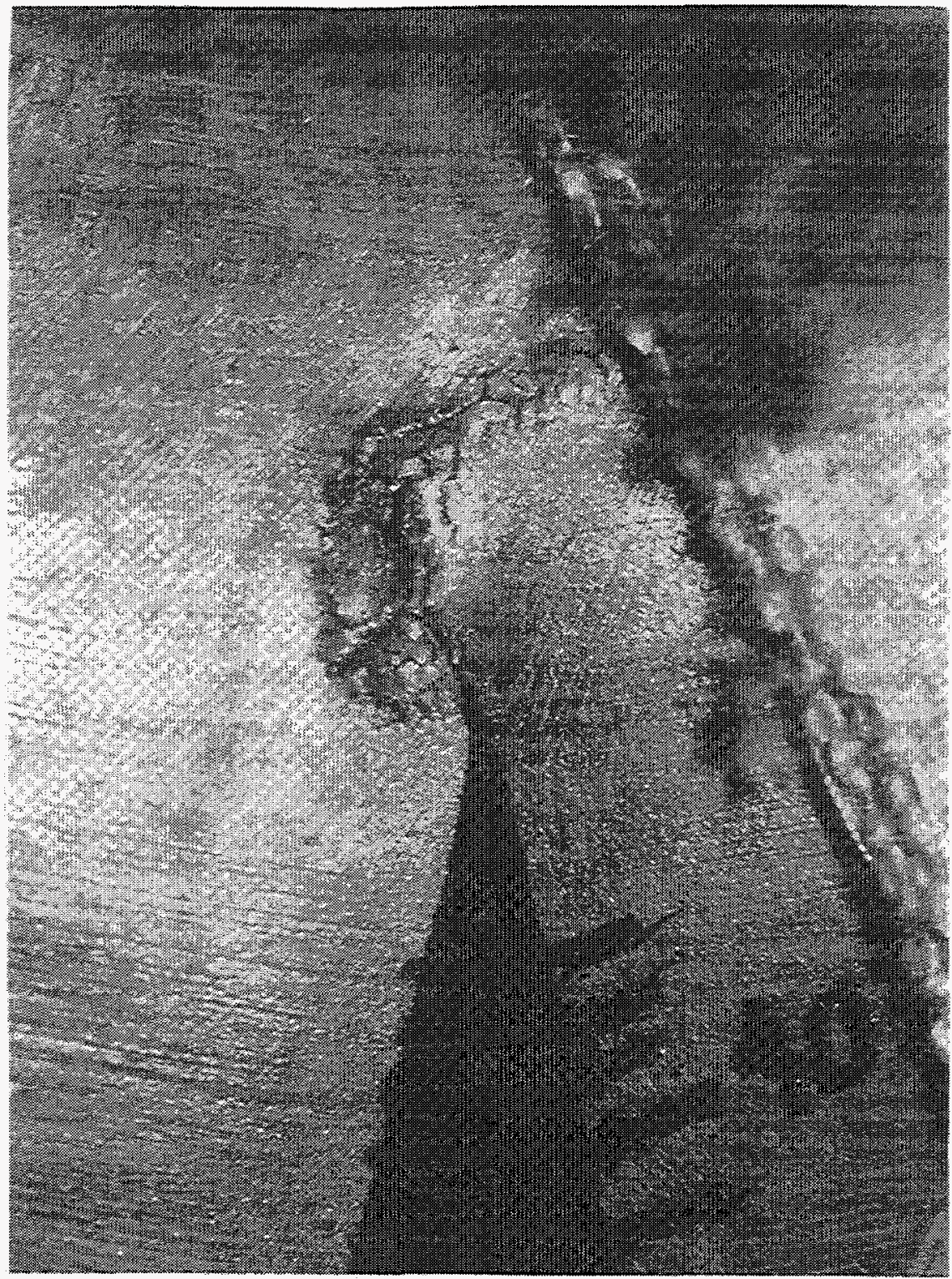

Figure 3.11 Fracture surface as a ductile tear in TP304 stainless steel grew through a "hard spot"

The implication here is that the crack initiation toughness and crack growth resistance in the fusion line was much less than in the SMAW. The lower crack propagation resistance was found to be true in limited $\mathrm{C}(\mathrm{T})$ tests in Reference 3.10, but the initiation toughness aspect has not been examined much to date. Since IGSCCs are more likely to occur in fusion lines than in weld metal, this may be worthy of further investigation. 


\subsubsection{Unstable Crack Jumps in Ferritic Steels at LWR Temperatures}

At the start of the NRC's Degraded Piping Program, it was decided to conduct all the pipe tests at LWR temperatures. Much to our surprise, in most of the ferritic pipe tests there were a series of limited unstable crack jumps. These crack jumps also occurred in specimen tests, and recently were found in vessel welds in Reference 3.26. Studies on the test machine compliance did not explain the start of the instabilities, although the length of the crack jump seemed to be affected by the machine compliance. The fracture surfaces were ductile, and frequently showed a blue surface right after testing. Blue embrittlement is an old term related to dynamic strain aging (DSA). Eventually it was determined that the unstable crack jumps were related to DSA, but there is no metallographic evidence of what triggered the instability. We now believe that there may have been a build-up of dislocations in the crack area that were pinned by the free nitrogen atoms. Once a critical load level was reached, these dislocations slipped and caused the crack to become unstable. Why some steels behave this way and others in the same grade of steel do not is believed to be due to pipe fabrication procedures, but this is not known for sure yet.

One of the largest unstable crack jumps occurred in an 203-mm (8-inch) diameter A106 Grade B pipe test with the crack in the center of a MIG weld. The crack jumped 1/4 of the way around the pipe circumference after reaching maximum load. Interestingly, the instability occurred once the crack grew out of the weld into the base metal.

\subsubsection{Similitude Between Lab Specimens and Cracked Pipe Under Cyclic Ductile Tearing}

During the course of the IPIRG program, the interaction of cyclic loading during ductile tearing was extensively studied. Using a fixed cyclic plastic displacement increment that is some fraction of the displacement to reach crack initiation in a monotonic test, it was found that good similitude between the $J$ at crack initiation was achieved for $\mathrm{C}(\mathrm{T})$ specimens and through-wall cracked pipe. However, the subsequent crack growth per cycle in the pipe specimens was much greater than in the $C(T)$ specimens. This resulted in more cyclic damage occurring in the $C(T)$ specimens than the pipe tests, and the $C(T) J-R$ curves were lower.

Similitude between lab specimens and pipe tests for cyclic loading can be attained by changing the $C(T)$ plastic displacement increment after initiation, and these displacements can now be estimated from the existing pipe J-estimation schemes. If this can be done successfully, then it will be possible to conduct $\mathrm{C}(\mathrm{T})$ tests for any size pipe simulating the cyclic effects of any seismic loading history.

\subsubsection{1 $J_{M}-$ Why Does it Work so Well for Pipe Test Predictions?}

From analysis of many pipe fracture experiments at Battelle and in work in France, it has consistently been found that the Modified $J-R\left(J_{M}-R\right)$ curve is far superior in predicting pipe displacement and loads with large amounts of crack growth than the J-R curves based on deformation theory (i.e., $J_{D}-R$ curves). Possible hypotheses why the $J_{M}-R$ curve works so much better than the $J_{D}-R$ curve is that:

(a) after a small amount of crack growth the $J_{M}-R$ remains linear, i.e., $d J_{M} / d a$ is a constant.

(b) experimental observations show that with large amounts of crack growth, the crack-tip-opening displacement (CTOA) also remains constant, and 
(c) some limited pipe test data showed that $\mathrm{dJ}_{\mathrm{M}} /$ da is linearly related to CTOA, see Figure 3.12 .

The $J_{M}$ fracture parameter, however, was discredited when it was found that for some materials the $J_{M}-R$ curve hooks upwards, i.e., the exponent in a power-law equation was greater than 1.0. Interestingly, when this occurs, the $J_{D}-R$ curve is, typically, linear. $J_{D}-R$ curves usually have a power-law shape curve with an exponent less than 1.0. Hence, for engineering purposes, it might be more accurate to make predictions of load and displacements during large crack growth with a $J_{M}-R$ curve if the $J_{D}-R$ curve is not linear, or use the $J_{D}-R$ curve if the $J_{M}-R$ curve hooks upward.

\subsubsection{Complex-Cracked Pipe Fracture Behavior}

As noted earlier in this report, a complex crack is a long surface crack that penetrates the wall thickness over a short region. The presence of the internal surface crack appears to offer additional constraint that significantly lowers the fracture toughness. The observed lower CTOA values in complex-cracked pipe tests when compared with simple through-wall-cracked pipe tests validates this. On the other hand, there

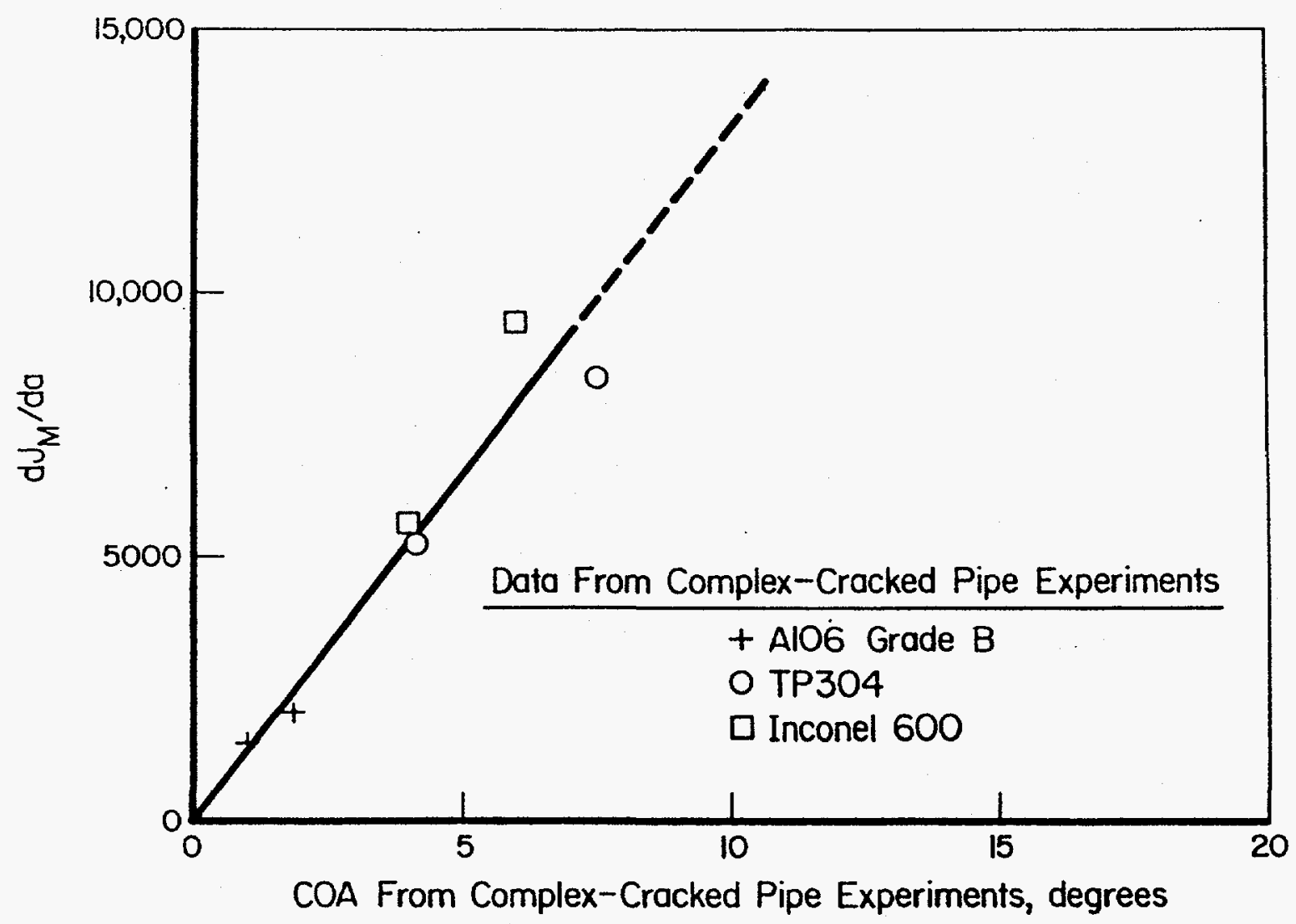

Figure 3.12 Observed relationship between $d J_{M} / d a$ and crack-tip-opening angle (CTOA) from complex-cracked pipe tests 
has never been a detailed finite element simulation of a complex crack. It is suspected that there is a radial component to the crack-driving force that is not accounted for in the current simplistic treatment of the complex crack. Such an investigation may give insight into understanding the load and COD predictions better.

\subsubsection{LBB Behavior of Circumferential Surface-Cracked Pipe Under Load-Controlled Bending}

The Net-Section-Collapse analysis is fundamentally used around the world for circumferentially crackedpipe analyses. For circumferentially surface-cracked pipe, the lower bounding predicted moments coincide with the through-wall-cracked pipe curve. However, for short deep cracks, experimental data show that the maximum loads may be less than those predicted by the through-wall-crack curve. This results in a load-controlled LBB condition that cannot be predicted using the Net-Section-Collapse analysis. Such behavior is well documented for axial surface cracks. Clearly, the limit-load solution for circumferential cracks could use improvement in this area.

\subsubsection{Brittle-to-Ductile Transition Temperature of Surface-Cracked Pipe}

As noted earlier in Section 3.2, the brittle-to-ductile fracture transition temperature for a surface-cracked pipe is much lower than that for a bend bar or $C(T)$ specimen. This may be explainable using fracture mechanics constraint theory. An important but practical point that will need to be addressed in this regard is what happens with a surface crack in a weld residual stress field. The through-thickness weld residual stresses may increase the constraint and possibly cause a loss of the apparent toughness. Interestingly, although the original Hancock K-T constraint work was done for welded offshore structures, the effect of weld residual stresses on the constraint parameter has yet been investigated.

\subsubsection{FEM Analyses of Stainless Steel Cracked Pipe and Specimens}

During the course of the IPIRG program, numerous finite element round-robin analyses were conducted. In modeling pipe fracture experiments, it was found that various analysts could readily reproduce each other's results, but in many wrought stainless steel pipe tests, the finite element analyses significantly underpredicted the load at crack initiation, i.e., by 30 percent in several cases. A significant effort was undertaken to determine whether the experimental results were erroneous. Additional pipe tests, even at different laboratories, showed that there were no significant experimental errors, i.e., test loads were reproduced within 5 percent. The finite element modeling in cases were very elaborate and modeled all the pipe saddles and loading fixtures.

Interestingly, there was one stainless steel pipe test where the material exhibited a significant amount of anisotropy in the tensile test (the fracture area on a round-bar tensile specimen was a 2:1 ellipse), but all the analyses predicted that pipe experiment quite well. (This pipe test was also duplicated.) The analysis, however, did not include this anisotropic behavior. Also of note, this same experiment was predicted quite well by the GE/EPRI estimation scheme (which is based on FEM analyses), but the GE/EPRI estimation scheme typically underpredicts the experimental results. Although there is some evidence that constitutive laws may be at fault for such a high strain-hardening material, there is no good study to make such a conclusion or give guidance to the analysts. 


\subsubsection{Closure}

The various factors described in Section 3.3 illustrate many aspects that one may not have thought of prior to conducting detailed experiments or analyses. Many of these may not be highly important, but may be useful to some investigator in the future should they encounter these phenomenon.

\subsection{References}

3.1 Ghadiali, N., and others, "Deterministic and Probabilistic Evaluations for Uncertainty in Pipe Fracture Parameters in Leak-Before-Break and In-Service Flaw Evaluations," NUREG/CR-6443, June 1996.

3.2 Scott, P., and others, "Crack Stability in a Representative Piping System Under Combined Inertial and Seismic/Dynamic Displacement-Controlled Stresses - Subtask 1.3 Final Report," NUREG/CR6233, Vol. 3, June 1997.

3.3 Milne, I., and others, "Assessment of the Integrity of Structures Containing Defects," CEGB Report R/H/R6 - Revision 3, 1986.

3.4 Scott, P., and Wilkowski, G., "A Comparison of Recent Full-Scale Component Fatigue Data With the ASME Section III Fatigue Design Curves," ASME PVP Vol. 306, July 1995.

3.5 Chopra, O., and others, "Long-Term Embrittlement of Cast Duplex Stainless Steels in LWR Systems," NUREG/CR-4744, Vol. 4, No. 2, June 1991.

3.6 Krishnaswamy, P., and others, "Effect of Aging on the Predicted Maximum Moment-Carrying Capacity of Circumferentially Cracked Cast Stainless Steel Pipe," NRC Aging Research Information Conference, NUREG/CP-0122, pp 341-368, March 1992.

3.7 Paris, P., and Tada, H., "Application of Fracture Proof Methods Using Tearing Instability Theory to Nuclear Piping Postulating Circumferential Through Wall Cracks," NUREG/CR-3464, September 1983.

3.8 Wilkowski, G., and Scott, P., "A Statistically Based Circumferentially Cracked Pipe Fracture Mechanics Analysis for Design or Code Implementation," Nuclear Engineering and Design, Vol. $111, \mathrm{pp} 173-187,1989$.

3.9 Scott, P. M., and others, "Fracture Evaluations of Fusion Line Cracks in Nuclear Pipe Bimetallic Welds," NUREG/CR-6297, April 1995.

3.10 Rosenfield, A. R., and others, "Stainless Steel Submerged Arc Weld Fusion Line Toughness," NUREG/CR-6251, April 1995.

3.11 Wilkowski, G. M., and others, "Degraded Piping Program - Phase II," Semiannual Report: October 1984-March 1985, NUREG/CR-4082, Vol. 2, July 1985. 
3.12 Rudland, D. L., and others, "The Effects of Cyclic and Dynamic Loading on the Fracture Resistance of Nuclear Piping Steels," NUREG/CR-6440, December 1996.

3.13 Rahman, S., and others, "Summary of Results from the IPIRG-2 Round Robin Analyses," NUREG/CR-6337, February 1996.

3.14 Marschall, C. W., and others, "Loading Rate Effects on Strength and Fracture Toughness of Pipe Steels Used in Task 1 of the IPIRG Program," NUREG/CR-6098, October 1993.

3.15 Marschall, C. W., and others, "Effect of Dynamic Strain Aging on the Strength and Toughness of Nuclear Ferritic Piping At LWR Temperatures," NUREG/CR-6226, October 1994.

3.16 Mohan, R., and others, "Development of a J-Estimation Scheme for Internal Circumferential and Axial Surface Cracks in Elbows," NUREG/CR-6445, August 1996.

3.17 Kilinski, T., and others, "Fracture Behavior of Circumferentially Surface-Cracked Elbows," NUREG/CR-6444, December 1996.

3.18 LeDelliou, P., and others, "Fracture Mechanics Analysis of Cast Duplex Stainless Steel Elbows Containing a Surface Crack," ASME PVP Vol. 323, June 1996.

3.19 Moulin, D., and others, "Experimental Evaluation of $\mathrm{J}$ in Cracked Straight and Curve Pipes Under Bending," 10 SMiRT, Vol. G, pp 323-326, 1989.

3.20 Cragnolino, G., and others, "Review of Erosion-Corrosion in Single-Phase Flow," NUREG/ CR-5156, April 1988.

3.21 Hietanen, O., "Some Aspects of Erosion-Corrosion in Louiisa NPP," in Kärntoknik-93 (Nuclear Technology), October 26-27, 1993.

3.22 Dabkowski, D. S., Kondel, P. J., and Baldy, M. F., "Factors that Effect Splitting in Plate Steels," Welding Journal, 1975.

3.23 Wilkowski, G. M., and Eiber, R. J., "Ductile Fracture Propagation Resistance for Rising Shelf Controlled-Rolled Steels," What Does Charpy Energy Really Tell Us?, published by ASM, ISBN 0-87170-027-1, pp 108-132, February 26-March 2, 1978.

3.24 Embury, J. D., Petch, N. J., Wraith, A. E., and Wright, E. S., "The Fracture of Mild Steel Laminates," Transactions of the Metallurgical Society of AIME, Vol. 239, pp 114-118, January 1967.

3.25 Hiser, A. L., and Terrell, J. B., "Size Effects on J-R Curves for A 302-B Plate," NUREG/CR-5265, January 1989.

3.26 McCabe, D. E., and others, "Ductile Fracture Toughness of Modified A 302 Grade B Plate Materials," NUREG/CR-6426, Vol. 2, November 1996. 


\subsection{CONCLUSIONS}

Since the inception of the need to deal with pipe fracture possibilities in the early days of nuclear plant design, a tremendous wealth of data and analytical tools have become available. At the same time, as we have gained knowledge on the topic, other unknown factors have now been encountered. The following sections summarize some of the conclusions from the current state-of-the-art in piping fracture mechanics.

\subsection{Stress Analysis Aspects}

- During the IPIRG program, numerous round-robin exercises were undertaken. Several of these involved comparisons of piping stress analyses. Although not a throughly exhaustive effort, it was concluded that the stress analysis portion of a fracture evaluation must be done with extreme care. In the numerous round-robin exercises related to predicting stresses in the IPIRG pipe test system, disagreement among the solutions offered by the various analysts was always a great source of consternation. In some cases, the differences were small. In other cases, the differences were very large. In either event, a great deal of effort was spent trying to determine the cause of the differences for an elastic analysis of a pipe system that has very well-defined boundary conditions. For a real piping system where friction at hangers likely will come into play, agreement among solutions will be even harder to attain.

After working through numerous simple problems, it was found that the discrepancies turned out to be interpretation errors - either different assumptions made about inputs or misinterpretation of how a program was going to handle a certain feature that was invoked. In a few cases, finite element computer program documentation was found to be inadequate. After resolving all of these issues, all solutions fell into reasonable agreement.

On a rather basic level, the problems encountered in the IPIRG round-robin analyses could affect all pipe fracture evaluations. The same issues; (1) incomplete problem statements, (2) incorrect program inputs, (3) poorly documented program features, and (4) program errors, can affect the results of any stress analysis that is used as an input to a fracture evaluation. There is no simple fix that will eliminate these potential problems in the stress analyses. One can only be vigilant and review the stress analysis carefully to ensure that one or more of the factors listed above has not tainted the results.

One of the key conclusions from the IPIRG program and other dynamic pipe-system analysis efforts is that there can be significant inherent margins in a typical uncracked pipe elastic stress analysis relative to real pipe fracture behavior. This comes from the fact that elastic stress analysis may overpredict the actual forces and moments, especially in a dynamic/cyclic loading case such as in seismic events, where any plasticity will increase the effective damping. The plasticity at the crack will further increase the effective damping so that the real dynamic loads would not be as high as in the elastic stress analysis. In one case, a factor of 5 on seismic bending moments was reported. A better quantification of this could help in either reducing applied safety factors, simplifying procedures, and subsequently making LBB applications acceptable for more piping systems (e.g., steam lines). 
The role of secondary stresses in pipe fracture is not entirely agreed upon, but is becoming more clear. Secondary stresses such as thermal expansion and seismic anchor motion, may in cases act as a primary stress or may be less detrimental. If there is a large crack in the pipe system, so that the crack location would fail below yield of the uncracked pipe in the pipe loop, then the secondary stresses will behave as a primary stress. This is consistent with the warning about "local overstrain" in the piping design codes, i.e., Section III Article NB-3672.6(b) and ANSI B31.1 Paragraph 119.3. This is also consistent from a fracture mechanics viewpoint, since fracture instability of a circumferential surface crack requires very little pipe-system compliance to start the instability.

From this viewpoint, then, as the flaw size decreases so that the failure stresses are above yield, then the rest of the pipe loop may experience plasticity and mitigate the importance of the secondary stresses. The secondary stresses will not lose their importance in a step function manner at the yield loads, but depending on the pipe geometry and strain-hardening characteristics, they will become less important than the primary stresses in some nonlinear function. This nonlinear decay in the secondary stress importance has not been defined yet.

- Residual stresses are well known to be very important for subcritical crack growth such as IGSCC, fatigue, and even creep. In pipe fracture experiments at LWR temperatures, the majority of the experimental data had fracture occurring on the upper shelf, and showed that weld residual stresses can be ignored. However, in an LBB analysis, the leakage rate typically depends on crack-opening displacements under elastic loading conditions. In this case, there are analytical results that show that the weld residual stresses may affect the leakage rates, especially with "thin-walled" pipe residual stress fields where the stresses through the thickness go from tension to compression.

There are an infinite number of time histories that can be generated for the same response-spectrum curve. In elastic stress analysis, the stresses from different frequencies are superimposed, so that the order of their occurrence is not important. In the IPIRG programs, it was discovered that the timehistory of a seismic event can be important to the material response. The build-up of the cyclic amplitudes will affect how damage is accumulated at the crack tip. Experimental results showed that in compressive loading, voids ahead of the crack tip can flatten. Upon subsequent tensile loading, these flattened voids connect together easier, hence lowering the ductile fracture resistance.

It was concluded in the IPIRG program that seismic events are always dynamic in nature, hence dynamic material properties would apply. However, the cyclic nature and the corresponding degradation effects from the cyclic loading during ductile tearing are probabalistic in nature. A worst case seismic time-history was proposed (for cyclic damage), but the statistical distribution of time-histories and their degradation effects from cyclic damage has not been addressed to date.

- Pipe-system fracture interactions, or the coupling of the stress analysis and the fracture mechanics analysis, have traditionally not been done. During several programs at Battelle, such evaluations have been done and yielded startling results. One result mentioned earlier was that the nonlinear fracture behavior adds damping to the seismic loading, hence seismic moments are not as high as would be determined in a typical elastic analysis.

Another example of the significance of coupling the stress analysis and pipe fracture analysis is relevant to LBB analysis. In this case, the leakage is typically determined using the normal operating elastic stresses in a crack-opening fracture mechanics equation. All of the known crack- 
opening fracture analyses assume that the pipe is an end-capped vessel, where the presence of the crack can cause free rotations of the vessel. In an actual pipe system, these rotations are restrained. The restrained rotations will increase the fracture loads, but decrease the crack-opening displacements. The first aspect is beneficial to LBB, whereas the second aspect is detrimental. An IPIRG pipe-system test demonstrated the benefits to fracture. Initial scoping studies were conducted to see what the combined effect might be. The results showed that for large diameter pipe, where the LBB crack size is small, there is negligible effect. However, if the LBB crack size becomes larger, i.e., small diameter pipe or a main steam line leak at the same leak rate as in the large diameter pipe case, then the restraint of the pressure-induced bending can have a tremendously negative effect on the LBB crack size and the maximum fracture loads. In one case, the maximum fracture loads were reduced by a factor of 9 . Clearly, the factor of 9 is much greater than the $\sqrt{2}$ applied safety factor. Such an effect may be important for intermediate pipe sizes as well, and hence, warrants further study.

\subsection{Material Property Aspects}

- Well documented fracture toughness testing standards exist now, and from experience in roundrobins activities, J-R curves are calculated accurately and reproducibly.

- Predicting fracture toughness and tensile stress-strain curves at operating temperatures from mill data is difficult. It may be better to use statistically bounding values from a database such as PIFRAC. In some round-robin analyses, the variability in predicting fracture loads for cracked pipe using mill property data seemed to be more sensitive to the accuracy of the tensile stress-strain curve, than the J-R curve.

- Ferritic steels at LWR temperatures are sensitive to dynamic strain aging (DSA). This causes an increase in the ultimate strength, reduction in the elongation to fracture, and reduction in the toughness at LWR temperatures compared to lower temperatures. Unstable ductile crack jumps that have been observed in many pipe and laboratory specimen experiments at $288 \mathrm{C}(550 \mathrm{~F})$, have been attributed to DSA.

Virtually all the U.S. grades of ferritic steel tested at Battelle had some pipe lengths sensitive to DSA. A screening criterion using the ratio of the Brinell hardness at room temperature to the high temperature hardness was found to be a simple way to determine whether or not the material was sensitive to DSA. Although one cannot predict when an unstable crack jump will occur, one can predict which ferritic steels are sensitive to such behavior.

These results imply that there is probably some way to vary the pipe fabrication procedures to produce ferritic pipe of a particular grade that is not sensitive to DSA. Hence, it might be possible to specify such a procedure for the purchase of ferritic pipe for new plants or replacement piping for an existing plant.

- Austenitic materials are frequently used in nuclear piping. Some important conclusions relative to austenitic pipe materials are given below. 
- Wrought stainless steels and Inconels are generally believed to be so tough that pipes made from these materials should fail by limit-load rather than by elastic-plastic fracture mechanics (EPFM). This is generally true. However, recently it has been found that some TP304 pipes that had higher sulfur content had a correspondingly lower toughness. Typically, the sulfur content of stainless steels may be around 0.002 percent, whereas the pipe recently assessed had a sulfur content of 0.017 percent and failed by EPFM in a 406-mm (16-inch) diameter pipe test. Since the sulfur content allowed by ASME and ASTM specifications can be up to 0.030 percent, it is possible for stainless steels to fail in an EPFM manner. This work suggests that a sulfur limit could be developed to ensure limit-load failure in stainless steels, and this limit should be easily achieved by most manufacturers.

- Cast stainless steels in their initial fabricated state are very tough at LWR operating temperatures. They are, however, susceptible to thermal aging. Much work has been done in predicting the aging effects by Argonne, Framatome, and Westinghouse. The thermal aging hardens the material and causes a reduction in toughness. The hardening of the material increases the load-carrying capacity, whereas the toughness loss reduces the fracture loadcarrying capacity. There is an interaction of the two effects on the fracture load-carrying capacity, but one must be very careful in the analysis procedures used. Past investigations showed that one analysis procedure (Tada-Paris) predicted the fracture load-carrying capacity would increase with time, while another analysis procedure (R6) showed that the fracture loadcarrying capacity would decrease with time. A third analysis procedure (the Battelle Dimensionless Plastic-Zone Parameter analysis) showed that both trends could occur depending on the pipe size, type of flaw, and the flaw size. The appropriate analysis procedure for this problem still needs to be determined.

- Base metals are subject to anisotropic effects on material properties. This is a well known fact, but frequently ignored in nuclear piping applications. For instance, ferritic steels are particularly sensitive to anisotropy effects. The toughness corresponding to the axial through-wall crack direction is the lowest toughness, with the toughness corresponding to the circumferential throughwall crack being significantly greater. This effect frequently causes circumferential cracks in ferritic base metal pipe bending tests to grow in a helical direction. The results to date for pure bending and pressure plus bending experiments suggest that the helical crack growth, although not predictable by typical analysis methods, is a beneficial effect in that it increases the energy absorbed. In one case, however, a circumferential crack in the base metal of a seam-welded pipebending test without pressure grew in the axial direction. The effects under torsion loading with such anisotropic behavior are unknown at this time.

Anisotropy can also play a strong role in the toughness of a surface crack. The current analysis procedures in the ASME Code use data for the crack growth in the through-wall crack direction, i.e., in the $\mathrm{L}-\mathrm{C}$ direction for a circumferential through-wall crack. In the radial direction (L-R direction), which corresponds to surface-crack growth, the toughness is typically much higher, especially for ferritic base metals. Unfortunately, there is virtually no data for crack growth resistance in this direction. This probably explains why some of the surface-cracked-pipe J-estimation schemes that agree well with finite element analyses, underpredicted experimental loads when using the L-C oriented J-R curve. There is evidence that correlations could probably be established using Charpy data in the different orientations to J-R curves in the L-R direction. 
- The occurrence of circumferential flaws is generally related to the presence of girth welds. Some important conclusions relative to the toughness of weldments are given below.

- In determining the fracture toughness of welds, it is important to keep the specimens as close to the actual thickness as possible. This is because even a submerged arc weld may have several passes of TIG weld, followed by several passes of SMAW, and possibly finished with SAW. Hence, weldments frequently are a composite structure.

- It was statistically determined that there was no difference between stainless steel SMAW and SAW J-R curves. Hence, future ASME pipe flaw evaluation standards need only consider one case.

- Stainless steel fusion lines have been found to have essentially a flat J-R curve after $2 \mathrm{~mm}(0.08$ inch) of crack growth. This probably explains why in many pipe tests where the cracks were put in the center of a SAW, the crack turned and followed the fusion line. For stainless steel welds, the weld metal J-R curve should probably be used for the first $2 \mathrm{~mm}(0.08 \mathrm{inch})$ of crack extension, then the fusion line J-R curve should be used.

- Bimetallic weld fusion lines, when using Inconel 182 weld metal, had comparable toughness to the carbon steel base metal. Stainless steel bimetallic welds, however, may have lower fusion line toughness due to carbon depletion in the HAZ.

- The appropriate loading rate for a fracture toughness test to represent seismic loading can be approximated by one-quarter of the period of the first natural frequency of a pipe system. This comes from the fact that high amplitude loadings are typically around the piping-system first natural frequency, and that the cracked pipe could experience all the plasticity in one cycle. For a pipe system with a $4 \mathrm{~Hz}$ natural frequency, the corresponding time to crack initiation in a test specimen would be 0.062 seconds. If it takes multiple plastic cycles to get to crack initiation, the effective time could be up to 0.2 seconds. There is probably little difference in the toughness values at these two loading rates, even for a DSA-sensitive ferritic steel. Some loading rate effects observed for various steels are summarized below.

- Since dynamic strain aging involves diffusion of free nitrogen and carbon atoms that pin dislocations, it is sensitive to temperature and strain rate. At strain rates comparable to seismic loading, some ferritic steel base metals will have a lower toughness than at quasi-static rates. The ratio of the high temperature to room temperature hardness DSA screening criteria was useful in determining which base metals were adversely affected by DSA at seismic loading rates.

- For ferritic welds under dynamic loading, the loading rate effects were either negligible or beneficial. This is because the little dynamic ferritic weld data available were for welds that had a drastically different DSA sensitivity than the ferritic base metals.

- Dynamic loading rates on austenitic steels caused the toughness to either not change or increase. Typically, for higher yield-to-ultimate strengths, the dynamic toughness increased more. Weld metals with higher yield-to-ultimate strengths saw the most benefit from dynamic loading. 
- Seismic loading involves not only dynamic loading, but also cyclic loading. A significant amount of work was undertaken during the course of the IPIRG programs at Battelle to understand these effects.

Cyclic loading prior to and during ductile tearing can have a detrimental effect on a material's fracture toughness. Typically, in flaw evaluation and LBB analyses, the cyclic loading aspects are ignored, i.e., a quasi-static monotonic J-R curve is used with the peak dynamic applied stress. There are several different analysis methodologies that can be used to account for the cyclic effects. One is the Dowling $\Delta \mathrm{J}$ approach, which would involve considerable analysis efforts to employ, and the other is to apply a bounding effect on the monotonic J-R curve to account for cyclic effects. The later is a simple approach to employ in current flaw assessment methodologies. The magnitude of this cyclic effect on the J-R curve depends on the ratio of the minimum to maximum loads (R-ratio), the build-up of the amplitudes (similar to ratcheting effects), the yield-to-ultimate strength of the material, and the initial toughness of the material. Fully-reversed loading with a cyclic build-up of the amplitudes can cause a reduction in the apparent J-R curve up to 30 percent of the monotonic $\mathrm{J}-\mathrm{R}$ curve for low yield-to-ultimate strength materials. As noted earlier, it was concluded that dynamic loading effects on material properties would occur for all seismic events, but that cyclic effects may be important in some subset of seismic events. The statistical distribution of cyclic damaging seismic time-histories is unknown at this time, although bounding cases have been established.

- An evaluation of the interaction of dynamic and cyclic loading effects on the toughness of piping materials showed that the effects can be combined by simply multiplying the individual effects from the dynamic or cyclic loading. Hence, there was no observed synergistic effect that made the combined load histories better or worse than the individual effects.

- Constraint effects in fracture is a relatively new concern relative to the similitude between laboratory specimens and full-scale fracture behavior. From numerous comparisons between pipe and $C(T)$ specimen results, it has been found that the material fracture resistance in a through-wallcracked pipe is equal to or slightly greater than that from the $C(T)$ specimen. (Assuming the same crack orientation and load history.)

There may, however, be constraint effects for a surface-cracked pipe compared with standard laboratory test specimens, e.g., bend bar or $\mathrm{C}(\mathrm{T})$ specimens. There are some data that show that surface-cracked pipe has a significantly lower transition temperature than three-point bend specimens, and that the upper-shelf toughness may be higher in surface-cracked geometry than the bend-bar or $\mathrm{C}(\mathrm{T})$ orientations. The recently developed constraint parameters and damage mechanics models support the past experimental observations. The benefits may be significant in application to pipe fracture criteria for Class 2, Class 3, and balance of plant (BOP) piping where the operating temperatures are much lower than Class 1 piping. Existing criteria assume that LEFM fracture toughness is applicable in these temperature ranges, but in reality, the surface-cracked pipe may behave ductily. These effects, especially in the presence of weld residual stresses, are worth further consideration. 


\subsection{Piping Fracture Mechanics Analyses}

Conclusions from the piping fracture mechanics analysis developments are summarized below. This is given in the categories of straight pipe and elbows.

\subsubsection{Straight Pipe}

For flaws in straight pipe, the most likely cracking scenario is a circumferential crack, typically at a girth weld. Axial flaws, although a problem more in the oil and gas industries, are less of a problem in the nuclear industry, other than for the case of erosion-corrosion flaws.

\subsubsection{Axial Cracks}

Most of the developmental work on axial flaw analyses came from earlier work done for the oil and gas industry at Battelle. Some confirmatory experiments were conducted at LWR temperatures at Battelle, and subsequently at MPA in Germany and other places. From this work, criteria for predicting failure pressures and unstable crack propagation/arrest behavior relative to nuclear pipe were developed.

Crack Initiation. For axial cracks, one usually is trying to determine the failure pressure for an initial flaw. Adequate methods exist to make these predictions, and are incorporated in the ASME and other codes. Leak-Before-Break behavior usually occurs under pressure loading for surface flaws that are short and deep. Such flaws will penetrate the thickness, but the resulting through-wall flaw will be stable.

Crack Propagation/Arrest. Once an axial crack starts to propagate, continued propagation depends on the decompression characteristics of the pressuring fluid. For water at ambient temperature, only a very brittle fracture could propagate very far since the water decompresses fast. However, at LWR temperatures, the water will decompress to the saturation pressure and the saturation pressure will be maintained for a long time and thus will be available to drive a crack. Piping systems that have little subcooling, i.e., BWR and Candu plants, are more likely to have unstable crack propagation than systems that have a significant amount of subcooling, i.e., PWRs.

\subsubsection{Circumferential Cracks}

Circumferential cracks are the main concern in the nuclear industry. Circumferential through-wall cracks are important from an LBB viewpoint. Circumferential surface cracks are important from an in-service flaw evaluation procedures perspective.

Through-Wall Cracks. There are numerous analysis procedures for circumferential through-wall flaws. The Sanders elastic solutions are adequate, the Net-Section-Collapse (limit-load) solution is reasonably adequate (although perhaps in need of modifications for an $\mathrm{R} / \mathrm{t}$ or ovalization correction), and the EPFM solutions have been validated against full-scale pipe tests to determine their statistical accuracy. Of the different EPFM analyses, some are intended to be accurate prediction tools, while others are failure avoidance criteria for Code procedures. The GE/EPRI, R6 Option 1, and ASME Code criteria underpredict the experimental moments the most. The GE/EPRI method was intended to be an accurate prediction tool, whereas the R6 and ASME Code criteria are intended to be failure avoidance criteria, and hence, were not intended to have a high degree of accuracy. It should also be noted that in several round- 
robin efforts it was found that many people claim that they were doing an R6 analysis, but they were just using the framework of that methodology with different combinations of elastic solutions, limit-load solutions, and cut-off stress definitions. Hence, there can be an appearance that there is a lot of scatter in R6 results.

The most accurate circumferential through-wall-cracked pipe analysis methods were the LBB.NRC, LBB.ENG2 J-estimation schemes and the Battelle semi-empirical Dimensionless Plastic-Zone Parameter (DPZP) criterion. The coefficient of variance of these methods is around 10 to 13 percent.

Some of the more sophisticated analysis procedure can predict not only the J versus applied load values, but also crack-opening displacements and rotations or displacements of the pipes due to the crack. The moment versus rotation prediction capability is advantageous for stability analyses.

Surface Cracks. How to handle circumferential surface cracks is a practical in-service problem. Flaw evaluation criteria exist in the ASME Code, and are evolving elsewhere.

The LEFM solutions for constant-depth circumferential surface cracks need to be improved to include the effects of $R / t$ ratios. The Net-Section-Collapse analysis is the most frequently used limit-load solution. This solution could be improved to account for $\mathrm{R} / \mathrm{t}$ effects, and the fact that short deep cracks will tear through the thickness at loads below the through-wall crack curve of the same crack length.

There are fewer EPFM or J-estimation schemes for finite-length circumferential surface cracks than for through-wall cracks. There are a few GE/EPRI function values, but not enough to use them as a practical analysis tool. The other J-estimation schemes that have been developed are those from Battelle. Of them, four have been calibrated against a number of finite element analyses. Although they agreed well with the finite element moment versus applied $\mathrm{J}$ values, when used to predict pipe fracture tests using L-C oriented J-R curves, they tend to significantly underpredict the experimental loads. This may come from anisotropy and constraint effects, as noted earlier. The most accurate methods for combined pressure and bending maximum load predictions were the Battelle DPZP and SC.TNP1 criterion.

For the ASME criteria, the austenitic pipe Appendix $\mathrm{C}$ criterion was much more accurate than the ferritic pipe Appendix $\mathrm{H}$ criterion. The mean experimental-to-predicted values were 1.16 and 2.14 , respectively, and the coefficient of variance for these methods was 19 and 29 percent, respectively. Clearly, improvements could be made, especially for the ferritic pipe Appendix $\mathrm{H}$ criterion. The Code Case N-494-2 for ferritic pipe did better than Appendix $\mathrm{H}$, with a mean experimental-to-predicted value of 1.42, and coefficient of variance of 18 percent. The R6 Option 1 method (as programed in the NRCPIPES Code - Version 2.0) had the same accuracy as the Code Case N-494-2, but the coefficient of variance was twice as large.

The ASME Appendices $\mathrm{C}$ and $\mathrm{H}$ are really based on circumferential through-wall cracked pipe analyses. Using the more accurate surface-cracked pipe analyses to date, it was found that the EPFM correction factor on the limit-load solution, called a Z-factor, was essentially independent of the surface-crack geometry. New Z-factors can be made based on these more accurate solutions, and could use Charpy energy rather than J-R curves. 
Complex Cracks. A complex (or compound) circumferential crack is one that is a long surface crack that penetrates the thickness over a short length. Such flaws have occurred in service with cracking mechanisms such as IGSCC and thermal fatigue.

It has been found that the internal surface crack provides constraint to the through-wall crack so that the apparent toughness is reduced below that of the plain through-wall crack, and fracture instability is more likely to occur. The magnitude of constraint depends on the depth of the surface crack. Such behavior is a good reason why leak-before-break should not be allowed for a mechanism where a long surface crack can exist.

Instability Analyses. Instability analyses have progressed considerably. The initial formulations considered that instability occurred at maximum load, or were load-controlled analyses. The developments in the $\mathrm{J}$-integral/Tearing modulus $(\mathrm{J} / \mathrm{T})$ arena considered instability for either load-controlled or displacement-controlled loading. The next development was the Battelle Energy Balance Method, which could accommodate combinations of load- and displacement-controlled stresses, transitions from a surface to a through-wall crack, and could predict not only the start of an instability, but also estimate how far the crack might jump and possibly arrest. This was a big improvement over the simple $\mathrm{J} / \mathrm{T}$ analyses, but considered that all loads and displacements were applied for an infinite time, which is not realistic for seismic loading.

The next generation of instability analyses involved coupling the fracture analyses with the dynamic stress analysis. Full 3D analyses are too time consuming, even with today's computers. The next level involved development of a cracked-pipe element that could be implemented into a computer code, such as ANSYS with pipe/beam elements. This approach was undertaken in the IPIRG program at Battelle initially for the design of pipe-system experiments. It was sufficiently successful, that numerous improvement were made, and it has been applied in several practical applications. The coupling of the dynamic stress analysis and the fracture mechanics analysis made improvements to the stability analysis, since it could now account for unloading and reloading effects, as well as proper consideration of the effect of the inertial and seismic anchor motion loads. Realistic fracture margins can now be determined with this methodology.

Crack-Opening Area/Leak Rates. There are several circumferential through-wall-cracked pipe analyses to predict the crack-opening area (COA) or displacements (COD). From these analyses, and with a thermal hydraulic code, the leak rates can be calculated for LBB analyses. The leak rates are calculated at the normal operating loads. Probabalistic LBB analyses have shown that the conditional failure probabilities are more sensitive to the normal operating loads (the COA leak-rate part of the analysis) than the SSE loads (the fracture part of the analysis). Hence, it may be more worthwhile to pay more attention to the accuracy of the COA/leak-rate analyses.

There are essentially two COA/COD type of analyses. The Tada/Paris method calculates the crackopening area directly. The GE/EPRI method calculates the COD at the center of the crack, and then, assuming that the crack-opening shape is elliptical, the COA is calculated. For LBB analysis, it is desirable to slightly underpredict the actual $C O D$. That way, for a given leak rate, a conservative crack size is determined. From comparison with experimental results, the GE/EPRI COD predictions on average are much more closer to the experimental results than the Tada/Paris method. (Experimental-to-predicted values of 1.01 versus 2.96.) The coefficients of variance for these analysis methods, however are quite 
high, i.e., 80 to 150 percent. Compared with the coefficient of variance of 10 to 15 percent for maximumload predictions, this is very high. These results are perhaps worthwhile reviewing further.

In more recent years, various studies have identified several factors that can affect the COD/COA values. Some of these are: thickness transitions such as at a nozzle, effects of weld residual stresses, off-centered cracks, combined loading with torsion, and the effect of pipe-system boundary conditions on crackopening behavior. The last of these effects was found to have a tremendous effect on LBB acceptability, especially for cases where there would be a long crack, i.e., small and intermediate diameter pipe, and main steam lines.

\subsubsection{Elbows and Pipe Fittings}

In elbow and pipe fitting structural integrity work, there are different definitions of limit-load that should be recognized. In pipe stress analysis work, the limit load is defined as the stress when the load causes a displacement equal to twice the elastic displacement. In fracture work, the limit-load is equal to the maximum load. There can be a significant difference in the limit-load between the two definitions, depending on the strain-hardening characteristics of the material involved. The work in this report used limit-load as the maximum fracture load.

For elbows and other pipe fittings, there is considerably less experimental and analytical results than for straight pipes. For a given applied moment, the stresses in the elbow are higher than straight pipe, hence there has been some concern over fracture and LBB applications for elbows. This is particularly true for erosion-corrosion type flaws. A good bibliography of elbow and fitting fracture papers and service experience is given in Appendix A of NUREG/CR-6444. From this, a database of elbow and tee fracture experiments was established, see Appendices B and C in the same NUREG report.

In the IPIRG-2 program, a sizable effort was undertaken to develop and validate a J-estimation scheme for axial and circumferential internal surface cracks in elbows under pressure and bending. The axial cracks were on the side (flank or crown) of the elbow, and the circumferential cracks were centered on the extrados of the elbow. A J-estimation scheme using the GE/EPRI methodology was developed from a matrix of over 100 finite element analyses. Nevertheless, this was not a sufficient matrix to handle all the variables to make it generally applicable. Several quasi-static elbow tests and pipe-system experiments were conduced on flawed elbows. These results showed that the J-estimation scheme was reasonably accurate.

In order to extend the Battelle/IPIRG-2 elbow J-estimation schemes to more cases of elbows, and establish a relatively simple analysis for elbow flaws for codes and standards purposes, a simplified elbow analysis was developed. This model showed that the crack-driving force in the elbow could be related to that in a straight pipe by a simple elbow geometrical relationship that incorporated the ASME $B_{2}$ stress indices for elbows. This geometric relationship was independent of the load level, and actually worked better in the EPFM and limit-load region. Comparisons to a few additional elbow tests showed that this approach was not only simple, but quite accurate. Additional validation, especially for higher $\mathrm{R} / \mathrm{t}$ elbows, short radius elbows, and elbows with other than 90 -degree bends, is still needed to have a technical basis that is defensible for codification purposes. 
The same methodology that was used to establish the simplified elbow approach, could also be applied to cases of flaws in tees or branch connections.

\subsection{Aspects Not Well Understood and Evolving Technologies}

Throughout this report, there was reference to various aspects of pipe fracture that are not completely understood, and evolving technologies that could be useful in understanding these aspects. As part of an NRC Piping Integrity Review committee effort, Battelle summarized the work done over the last 15 years, and identified these aspects. These aspects were classified as those that might be of concern to regulators, those that might be beneficial to industry, and some aspects that could be beneficial to both parties, depending on the viewpoint taken. Some of the more important ones are given below. A detailed discussion of these aspects is given in Section 3 of this report.

\subsubsection{Aspects Potentially of Regulatory Concern}

- Pipe-System Boundary Condition Effects on Crack-Opening Displacement (COD) Predictions for Leak-Before-Break (LBB) Evaluations - In the IPIRG-1 program, it was found that the piping system can restrain the extent of the pressure-induced bending which may occur for a through-wallcracked pipe. While this restraint of bending can be beneficial to the load-carrying capacity of a pressurized through-wall-cracked pipe, it also has a down side in that crack size for a given leak rate can be substantially larger than expected. The magnitude of this effect depends on the through-wallcrack length. For large diameter pipe [e.g., 711-mm (28-inch) diameter], it was shown that the effect was minimal. For small diameter pipe with the same required leak rate, however, there was a factor of 9 difference in the LBB fracture loads when considering this effect. This effect may also be important for intermediate diameter pipe and LBB applications for steam lines where the crack lengths for a given leak rate may be greater than for a subcooled water line.

- Effect of Weld Residual Stresses on Leakage Area Calculations for LBB Analyses - Residual stresses tend to rotate the crack faces, which may close the crack. As a result of this crack closure effect, the actual through-wall crack for an LBB analyses may be longer than anticipated based on current analysis schemes.

- Significance of Large Secondary Stresses on Pipe Fracture - Data from the IPIRG-1 program showed that seismic anchor motion (SAM) and thermal expansion stresses contribute as much to fracture as do the primary stresses for the case where the surface crack is large. In this case, the failure stresses are below the yield strength of the pipe system. This is consistent with the "Local Overstrain" warnings in the ASME piping design stress rules. Hence, a screening criterion can be created to show when the secondary stresses should be treated as a primary stress. In the post-yield regime, the criterion should be sensitive to the pipe-system geometry, and strain-hardening of the uncracked pipe material. No simple codifiable criteria exists yet for determining how much the effect of the secondary stresses may be diminished if the failure stresses in the pipe system would be above yield.

- ASME Section III Fatigue Criteria Considering Workmanship Type Flaws - Results to date showed that flaws which could pass the workmanship standards of Article IWB-3510 of ASME 
Section XI, or cases where there are high weld residual stresses, could cause fatigue failures to occur sooner than predicted based on the ASME Fatigue Design Curves. This issue is especially important for the lower-stress cases where the lives are greater than 100,000 cycles. A workmanship flaw stress index should be developed for inclusion in the ASME Code rules.

- Fracture Criteria for Aged Cast Stainless Steel Pipe/Fittings - For cast stainless steels, as aging takes place at operating temperatures, the fracture toughness goes down, but the strength goes up. With the same material property input, different analyses can produce opposite trends in the predicted load-carrying capacity as a function of time. Validation of acceptable analysis procedures is needed.

- Bimetallic Welds Fabricated with Stainless Steel Weld Metal - For Inconel bimetallic welds, the carbon steel fusion line has comparable toughness to the base metal. Stainless steel welds may have a much lower toughness due to carbon depletion in the HAZ. The effect of dynamic or cyclic loading on such fusion lines is unknown at this time, and would be hard to estimate from the current trends with base metals.

- Stainless Steel Fusion Line Toughness - Stress corrosion cracks are more likely to form along the fusion line of a weld than they are in the weld metal itself. In a number of the full-scale stainless steel weld pipe tests conducted by Battelle, the crack grew out of the center of an SAW and followed the fusion line. The J-R curve for the fusion line was found to be flat after $2-\mathrm{mm}(0.08$ inch) of crack growth, thus explaining this behavior. Currently, flaw evaluation criteria such as ASME Section XI for ferritic and austenitic welds do not consider this effect in that these criteria are based on data developed for the case where the crack is centered in the weld. As with the bimetallic weld fusionline case, the effect of dynamic and cyclic loading on the fusion-line toughness is unknown at this time.

- Cyclic Loading Effects on Fracture - The bounding seismic load history, as far as damage to material properties, is probably somewhere between the dynamic/monotonic type history which may be representative of the Kobe and Northridge earthquakes, and an earthquake which exhibits a fullyreversed history with a gradually increasing amplitude for the first five seconds. Quantifying the statistical distribution of the magnitude of this damage has not been attempted to date. The work on the IPIRG programs establish a methodology where this can now be done.

- Dynamic Strain Aging Effects on Toughness - All U.S. grades of ferritic steels tested had some pipe lengths that were susceptible to the detrimental effects of dynamic strain aging on the toughness. This effect is particularly noticeable at LWR operating temperatures and at loading rates corresponding to seismic loading. The variability in the material sensitivity is probably due to cooling rates in fabrication that are not specified. Appropriate specifications could possibly produce pipe that is not sensitive to the detrimental affects of dynamic strain aging. In the interim, a lower-bound for LBB and flaw evaluation criteria needs to be established.

\subsubsection{Issues of Importance to the Industry}

Those issues of particular importance to the industry included: 
- Margins from Nonlinear Cracked-Pipe Dynamic Analyses - Elastic uncracked pipe stress analyses can be very conservative when used in a pipe fracture analysis. Past Battelle analysis has shown that when coupling the fracture mechanics and stress analyses for seismic loading, a factor of 5 on margins was gained in one case. Using this methodology, it would be possible to determine what more realistic margins might be so that, perhaps, either applied safety factors could be reduced, procedures could be simplified, or additional applications of LBB might be possible.

- Flaw Evaluation Criteria for Class 2, 3, and Balance of Plant (BOP) Piping - The current flaw evaluation criteria embodied in ASME Section XI are only for flaws found in Class 1 piping systems. Recently, however, the inspection requirements embodied in Section XI for Class 2, 3, and BOP piping have been increased, and hence more flaws have been found in such piping systems. Such piping systems may be a higher contributor to the overall risk associated with the plant than Class 1 piping. Two technical problems need to be addressed for extending the flaw evaluation criteria for Class 2,3 , and BOP piping. One is that such piping typically has a higher $\mathrm{R} / \mathrm{t}$ ratio than Class 1 piping, and the analyses need to be extended and validated in that range. Secondly, these piping systems operate at lower temperatures and there is a concern about a transition from brittle to ductile fracture. Past experimental data and recent developments in constraint fracture mechanics theory suggest that the brittle-to-ductile transition temperature is much lower for a surface-cracked pipe than expected from laboratory specimens, e.g., bend bar and $C(T)$ specimens.

- Flaw Evaluation Criteria for Fittings - As plants continue to age, more instances of flaws found in fittings are being reported. There is a much smaller amount of elbow and other fitting fracture data and associated analyses. In the IPIRG-2 program, a simplified flaw evaluation criteria for possible inclusion into the ASME Code was proposed for elbows. This work showed that a simple geometric relationship between a crack in an elbow and the same size crack in a straight pipe existed. Hence, existing straight-pipe solutions could be used with this geometric multiplier for elbow cracks. In order to establish a technical basis for a Code procedure, further validation of this criterion is needed, especially for higher $\mathrm{R} / \mathrm{t}$ ratio elbows, short radius elbows, and elbows with other than 90-degree bends. A similar procedure to that used in development of the elbow criterion could also be implemented for flaws in tees and branch connections.

- Erosion/Corrosion Flaw Acceptance Criteria - Erosion/Corrosion flaws occur frequently in service and can have serious consequences for the industry. However, current and proposed flaw acceptance criteria are based on design stress equations with unknown safety factors. Failure of such flawed components should correspond to predictions from limit-load solutions. Developing flaw acceptance criteria based on margins from failure should reduce over-conservatisms in the design stress approach.

- Evaluation of and Improvements to the ASME Section III Seismic Design Rules - The 1995 edition of the ASME Code provided new, more liberal seismic design rules in Section III. To date, the U.S. NRC has not approved these new rules for U.S. plants. Although there is a feeling that the 1989 design stress rules could be relaxed, the technical basis to explain the extent of the relaxation allowed by the new rules does not seem to be adequate for numerous reasons. Additionally, the 1995 rules are such that if there was a flaw greater than the workmanship flaw standards in Section XI Article IWB-3514, then the pipe would have to be repaired or replaced, i.e., the Section III design 
stresses are too high for the flaw evaluation standards. This step change in acceptance of flaws, suggests that the technical basis for the design rules should consider that workmanship flaws exist.

- Replacement Criteria for an Instantaneous DEGB - The assumption of an instantaneous DEGB is a very conservative assumption for thermal hydraulic loads on the reactor pressure vessel, vessel internal core structure, pipe supports, estimating the amount of damage to insulation for BWR strainer suction blockage concerns, etc.,. This criterion was assumed when fracture mechanics was in its infancy, and it was assumed that the pipe would break in a brittle manner. With the current state-ofthe-art cracked-pipe dynamic finite element methodology established during the course of the IPIRG programs at Battelle, it is now possible to make reasonable predictions about the rate of crack opening and pipe separation speed. Video tape and some experimental data from the IPIRG pipe-system experiments demonstrated that the break opening time is much slower. Opening times of even 50 milliseconds, in cases, could be a tremendous improvement to the instantaneous assumption that is now employed.

- Weld Metal Versus Base Metal Response to Dynamic/Cyclic Loading - As noted during the course of this report, seismic loading involves dynamic and cyclic loading during ductile tearing. From the work in the IPIRG program, it appears that weld metals respond much better to dynamic/cyclic loading than base metals do. In fact, from the IPIRG simulated-seismic pipe-system experiments, cracks in carbon steel SAW and stainless steel SAW performed better than stainless steel base metals. 


\section{APPENDIX A - STRESS ANALYSIS METHODS}

\section{A.1 Introduction}

One of the fundamental elements of piping fracture analyses is a prediction of the stresses at known or assumed flaws. The stresses may arise as the result of relatively static loads, i.e., dead weight and thermal expansion or contraction, or the stresses may be the consequence of dynamic action, i.e., earthquakeinduced anchor motion or inertial loads. Regardless of the cause, the stresses are the driving force for propagation of defects in the pipe.

\section{A.2 Current Stress Classifications}

\section{A.2.1 ASME Code Stress Limits}

The ASME Boiler and Pressure Vessel Code (Ref. A.1), provides stress limit design criteria for piping in Section III that protects the structural integrity of the pressure boundary for the reactor system. The Code sets limits for Design Loadings, Service Loadings (Levels A, B, C, and D), and Test Loadings, although the required loadings or load combinations to be used are not specified.

\section{A.2.1.1 ASME Stress Categories}

Three categories of stress are considered in Section III; primary, secondary, and peak stresses. Primary stresses are developed by imposed loads and are required to satisfy global system equilibrium. Primary stresses are not self-limiting and are load controlled. Secondary stresses are self-limiting, are developed by constraint of adjacent material, and are displacement controlled. Peak stresses are the result of local discontinuities and include the effects of stress concentrations.

Primary stresses are directly limited by the Code. Hoop stress due to pressure, or the moment caused by dead weight are examples of primary stresses. Secondary stresses, such as the restraint of free thermal expansion, are limited in the Code by restricting the range of stresses permitted in going from one condition to another. Peak stresses are limited in the Code by restricting the range of peak stress to a magnitude that gives an acceptable fatigue life.

\section{A.2.1.2 ASME Service Level Limits}

The ASME Code does not prescribe the loading or combination of loadings that are to be considered at each of the different Level conditions. Rather, the loading or load combinations are set by the plant owner. Level B conditions are expected to occur during the life of the plant, and the piping must be able to withstand this loading without damage requiring repair. Level $\mathrm{C}$ limits permit large deformations in areas of structural discontinuities that may require components to be removed for inspection or repair. At Service Level D, gross deformations are permitted that may require the component to be removed from service. 
Consistent with the increase in acceptable damage in going from Service Level A to Service Level D, the design stress limits go up (see Tables A.1 and A.2). For Class 1, 2 or 3 piping, the primary stress limit at Service Level D is 200 -percent of the value at the Design Loading condition. The rationale for increasing design stress limits is lower probability of occurrence.

For seismic loads, two levels of loading are generally considered, the operating basis earthquake (OBE) which is the magnitude earthquake that could be expected to occur during the life of the plant, and the safe shutdown earthquake (SSE) which is the maximum credible earthquake that the plant must be able to survive without causing a nuclear incident. The U.S. NRC considers the OBE as Service Level B, and the SSE as Service Level D. In checking compliance with the Section III requirements, the OBE is combined with sustained loads and operating transients. The SSE is combined with sustained loads plus either: 1) loss-of-coolant accidents, or 2) design-basis pipe or main steam and feedwater pipe breaks.

\section{A.2.1.3 ASME Section XI Stresses}

The flaw evaluation procedures of ASME Section XI (Ref. A.2), for circumferential flaws are based on knowing three stresses; the uniform longitudinal stress acting on the cross-section of the pipe (membrane stress), $P_{m}$, the component of primary stress that is proportional to the distance from the centroid of the section (bending stress), $P_{b}$, and thermal expansion stress (bending, membrane or both), $P_{c}$. The value of $\mathrm{P}_{\mathrm{m}}+\mathrm{P}_{\mathrm{b}}$ corresponds to the left-hand side of Equation 9 of ASME Section III Article NB-3652.

Section XI refers to stresses at three different conditions, normal operating, which corresponds to Level B of Section III, emergency conditions, which corresponds to Level C, and faulted conditions, Level D. All of the stresses required for a Section XI flaw evaluation are readily obtained from the outputs of typical finite element piping stress analysis programs, either directly or via simple calculations knowing the internal forces and cross-sectional properties.

Thermal expansion stresses are not considered to have the same flaw propagation potential in Section XI of the ASME Code as the primary membrane and bending stresses, $P_{m}$ and $P_{b}$. Thermal stresses are reduced by dividing the thermal stress by a factor greater than one to reflect the fact that they tend to be self-

limiting secondary stresses. One factor, 2.77 , is used for normal operating conditions, and another, 1.39 , is used for emergency and faulted conditions.

\section{A.2.2 R6 Stresses}

The R6 fracture assessment procedure (Ref. A.3), provides methods to evaluate: (1) the limiting load to avoid failure of a structure containing a known or postulated defect, (2) the maximum tolerable flaw size for a structure subjected to a specified loading, (3) the margin between a given flaw and the limiting flaw size, and (4) the sensitivity of the margins to the various factors that contribute to the capacity of a given flaw. In performing R6 fracture evaluations, a critical element is to know the stresses at the actual or assumed defect.

\section{A.2.2.1 R6 Load Categories}

The R6 flaw evaluation procedure divides stresses into two categories, primary, $\sigma_{p}$, and secondary, $\sigma_{\mathrm{s}}$. According to the R6 documentation, $\sigma_{\mathrm{p}}$ stresses are stresses that contribute to the plastic collapse of the 
Table A.1 ASME Section III Class 1 piping design limits

\begin{tabular}{|c|c|c|c|c|}
\hline \multirow[b]{2}{*}{$\begin{array}{c}\text { Service } \\
\text { Load }\end{array}$} & \multicolumn{2}{|c|}{ Primary Stress } & \multirow{2}{*}{$\begin{array}{c}\text { Secondary Stress } \\
\\
\text { Primary Plus Secondary } \\
\text { Stress Range } \\
\text { (NB-3653.1, Equation 10) }\end{array}$} & \multirow{2}{*}{$\begin{array}{c}\text { Peak Stress } \\
\text { Peak Stress Range for } \\
\text { Fatigue Life Calculation } \\
\text { (NB-3653.2, Equation } 11 \\
\text { or } \\
\text { NB-3653.6, Equation 14) }\end{array}$} \\
\hline & $\begin{array}{l}\text { Allowable } \\
\text { Pressure } P_{\mathrm{a}} \\
\text { (NB-3641.1, } \\
\text { Equation 3) }\end{array}$ & $\begin{array}{c}\text { Membrane Plus } \\
\text { Bending } \\
\text { (NB-3652, Equation 9) }\end{array}$ & & \\
\hline Design & $P \leq P_{a}$ & Equation $9 \leq \mathrm{S}_{\mathrm{m}}$ & not considered & not considered \\
\hline Level A & not considered & not considered & Equation $10 \leq 3 \mathrm{~S}_{\mathrm{m}}$ & $\Sigma \mathrm{n} / \mathrm{N} \leq 1.0$ \\
\hline Level B & $\mathrm{P} \leq 1.1 \mathrm{P}_{\mathrm{a}}$ & $\begin{array}{l}\text { Equation } 9 \leq 1.8 \mathrm{~S}_{\mathrm{m}} \\
\quad \text { and } \\
\text { Equation } 9 \leq 1.5 \mathrm{~S}_{\mathrm{v}}\end{array}$ & Equation $10 \leq 3 \mathrm{~S}_{\mathrm{m}}$ & $\Sigma \mathrm{n} / \mathrm{N} \leq 1.0$ \\
\hline Level C & $\mathrm{P} \leq 1.5 \mathrm{P}_{\mathrm{a}}$ & $\begin{array}{c}\text { Equation } 9 \leq 2.25 \mathrm{~S}_{\mathrm{m}} \\
\text { and } \\
\text { Equation } 9 \leq 1.8 \mathrm{~S}_{\mathrm{v}}\end{array}$ & not considered & not considered \\
\hline Level D & $\mathrm{P} \leq 2.0 \mathrm{P}_{\mathrm{a}}$ & $\begin{array}{l}\text { Equation } 9 \leq 3.0 \mathrm{~S}_{\mathrm{m}} \\
\quad \text { and } \\
\text { Equation } 9 \leq 2.0 \mathrm{~S}_{\mathrm{v}}\end{array}$ & not considered & not considered \\
\hline
\end{tabular}

Table A.2 ASME Section III Class 2 and 3 piping design limits

\begin{tabular}{|c|c|c|c|c|}
\hline & $\begin{array}{l}\text { Allowable } \\
\text { Pressure P, }\end{array}$ & $\begin{array}{c}\text { Sustained } \\
\text { Mechanical Loads } \\
\end{array}$ & $\begin{array}{c}\text { Occasional } \\
\text { Mechanical Loads } \\
\end{array}$ & Thermal Expansion \\
\hline $\begin{array}{l}\text { Service } \\
\text { Load }\end{array}$ & $\begin{array}{c}\text { (NC/ND-3641.1, } \\
\text { Equation 5) }\end{array}$ & $\begin{array}{c}\text { (NC/ND-3652, } \\
\text { Equation 8) }\end{array}$ & $\begin{array}{c}\text { (NC/ND-3653.1, } \\
\text { Equation 9) }\end{array}$ & $\begin{array}{c}\text { (NC/ND-3653.2, } \\
\text { Equation 10, } \\
\text { Equation 10a and } \\
\text { Equation 11) } \\
\end{array}$ \\
\hline Design & $\mathrm{P} \leq \mathrm{P}_{2}$ & Equation $8 \leq 1.5 \mathrm{~S}_{\mathrm{h}}$ & not considered & not considered \\
\hline Level A & not considered & not considered & not considered & $\begin{array}{l}\text { Equation } 10 \leq \mathrm{S}_{\mathrm{a}} \\
\text { Equation } 10 \mathrm{a} \leq 3.0 \mathrm{~S}_{\mathrm{c}} \\
\text { Equation } 11 \leq\left(\mathrm{S}_{\mathrm{h}}+\mathrm{S}_{\mathrm{a}}\right)\end{array}$ \\
\hline Level B & $\mathrm{P} \leq 1.1 \mathrm{P}_{\mathrm{a}}$ & not considered & $\begin{array}{l}\text { Equation } 9 \leq 1.8 \mathrm{~S}_{h} \\
\quad \text { and } \\
\text { Equation } 9 \leq 2.25 \mathrm{~S}_{\mathrm{y}}\end{array}$ & $\begin{array}{c}\text { Equation } 10 \leq S_{2} \\
\text { Equation } 10 \mathrm{a} \leq 3.0 \mathrm{~S}_{c} \\
\text { Equation } 11 \leq\left(\mathrm{S}_{\mathrm{b}}+\mathrm{S}_{3}\right)\end{array}$ \\
\hline Level C & $\mathrm{P} \leq 1.5 \mathrm{P}_{\mathrm{a}}$ & not considered & $\begin{array}{c}\text { Equation } 9 \leq 2.25 \mathrm{~S}_{\mathrm{h}} \\
\text { and } \\
\text { Equation } 9 \leq 1.8 \mathrm{~S}_{\mathrm{v}}\end{array}$ & not considered \\
\hline Level D & $\mathrm{P} \leq 2.0 \mathrm{P}_{\mathrm{a}}$ & not considered & $\begin{array}{l}\text { Equation } 9 \leq 3.0 \mathrm{~S}_{\mathrm{h}} \\
\text { and } \\
\text { Equation } 9 \leq 2.0 \mathrm{~S}_{\mathrm{y}}\end{array}$ & not considered \\
\hline
\end{tabular}


Appendix A

structure, while $\sigma_{s}$ stresses do not. The decision on how stresses are classified is left to the analyst, with the guidance that if there is doubt, the stresses should be assumed to be primary stresses.

Primary stresses are produced by applied external loads such as pressure, dead weight, or structural interaction and are assumed to be load controlled. Secondary stresses are generally self-equilibrating, i.e. the net force and bending moment is zero at the pipe cross section, and are produced by thermal gradients and welding processes, for example.

R6 prescribes that the stress analysis be linear and for the uncracked condition. Any justifiable method can be used so long as it predicts the stresses resulting from pressure, dead weight, forces, moments, temperature differences, and residual stresses. For consistency, the stress analysis should predict upper bound stresses.

\section{A.3 Stress Analysis Methods}

Prediction of the stresses in piping is done on a routine basis using finite element computer programs. Equilibrium equations written for individual pipe elements are assembled into a global set of equations which describe the equilibrium of the overall structure. Boundary conditions and loads are then applied, and the displacements of the piping system are found. Given the displacements, internal forces and stresses for individual elements can be determined. The equilibrium equations can be written for static conditions or they can be written for loads that vary with time. Using the full power of the finite element method, analyses can involve material or geometric nonlinearities (small deflection assumption not made) or strictly linear behavior can be invoked.

The basic output of a typical finite element piping stress analysis is internal forces (moments and forces). Using the individual element equilibrium assumptions, the internal forces can be converted into shear, normal, and bending stresses. When linear analyses are used, stresses arising from various different sources can be independently calculated and then summed using superposition principles. In nonlinear analyses, all the loads must be applied simultaneously and in a sequence consistent with the actual circumstances to properly include possible path-dependent behavior.

Regardless of the details of a particular piping stress analysis, the driving force for propagation of an existing or an assumed defect will be stresses (axial, shear, bending, and torsion) or the compatible equilibrium forces at the flaw location. The stresses or equilibrium forces may be available for various loading cases (thermal expansion, pressure, seismic anchor motion, inertial loading, etc.) as separate items, or they may be presented as a total stress.

\section{A.3.1 Current Methods}

Most contemporary pipe fracture evaluations use linear, uncracked pipe stress analyses. Generally speaking, the bulk of piping stress analysis is performed using beam-based pipe elements. Straight pipe is modeled using a circular cross-section beam, while elbows are modeled as curved, circular cross-section beams. The beam elements only consider axial deformation and bending and so the basic beam behavior must be supplemented with additional known conditions, i.e., Barlow's formula for hoop stress, flexibility factors for elbows, etc., to approximate the true shell response of pipe. In more demanding applications, 
shell or three-dimensional brick elements may be used to more accurately capture a peculiar piping deformation or stress phenomenon.

\section{A.3.2 Advanced Dynamic Methods}

The analyses described in the preceding section make liberal use of engineering assumptions to intentionally induce conservative estimates in a pipe fracture evaluation. Foremost among the assumptions that contribute to the conservatism are:

(1) The fracture and pipe response are assumed to be decoupled

(2) The stress analysis is elastic

(3) The transient nature of dynamic loads is ignored, i.e., stresses are applied statically and in a load-controlled manner

From a plant design and operation perspective, this conservatism is generally desirable. From the point of view of analysis margin assessment, or the point of view of pipe fracture experiment design, the inherent conservatism of the engineering fracture mechanics analyses is not appropriate. To address this issue, a state-of-the-art nonlinear FEA pipe fracture analysis method that directly deals with the three points listed above was developed in the IPIRG-1 program (Refs. A.4 and A.5). The nonlinear FEA pipe fracture analysis was subsequently modified to incorporate additional known dynamic pipe fracture phenomena in a research program that analyzed waterhammer events at the HDR test facility in Germany (Ref. A.6).

\section{A.3.2.1 Nonlinear Spring Model}

The method that Battelle pursued and refined in the IPIRG-1 and HDR programs for the dynamic analysis of flawed piping described the behavior of the flaw as a stiffness in moment-rotation coordinates, see Figure A.1, with the basic moment-rotation input coming from quasi-static pipe test data or from some suitable fracture mechanics analysis. The nonlinear cracked section is implemented in the finite element analysis using spring-slider elements (STIF40, Combination Element) and a two-force truss (STIF8, ThreeDimensional Spar Element) in the ANSYS Version 4.4a computer program.

The multi-linear spring-slider and truss model is attached to a pair of coincident nodes at the crack location in the pipe model, coupling the two nodes together in the relative rotation bending degree-of-freedom of the attached pipe elements. The remaining five degrees of freedom; the two shears, the torsion, the tension, and the remaining bending degree-of-freedom, are rigidly coupled with constraint equations. To accommodate crack closure in the nonlinear spring model, a very stiff spring is inserted that is "activated" when the rotations try to become negative.

In use, a time-history dynamic analysis must be done when a nonlinear FEA pipe fracture analysis is performed. The method permits an analyst to calculate the maximum moment and the time required to attain this moment for both surface and through-wall cracks. Energy dissipation, due to cyclic loading of the nonlinear crack prior to initiation, is an inherent part of the time-history analysis. Loading past maximum moment, Figure A.2, transition of a surface crack to a through-wall crack, Figure A.3, and reinitiation of a crack that has already extended, Figure A.4, are other features that can be incorporated in a nonlinear dynamic cracked pipe analysis. 
Appendix A

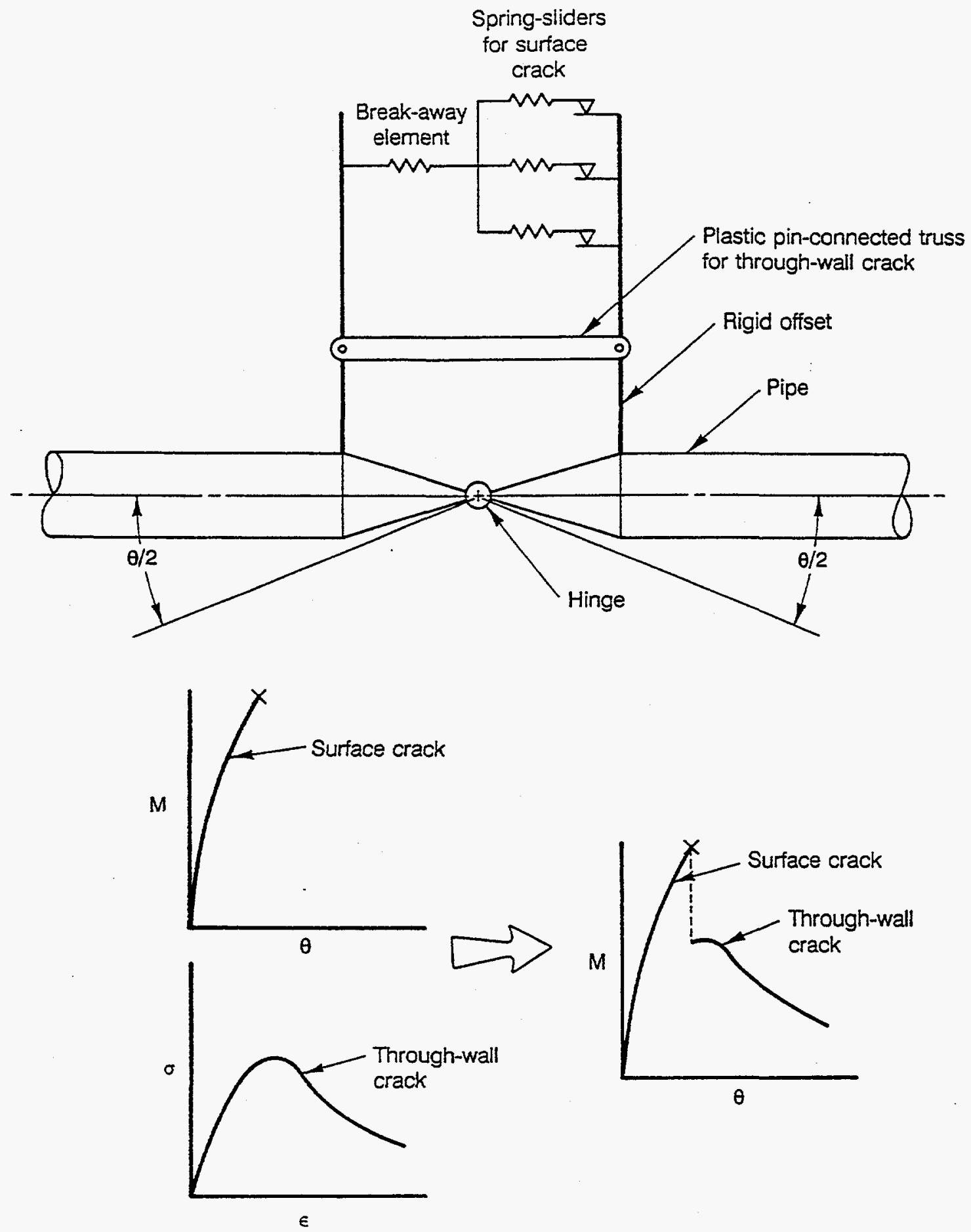

Figure A.1 Nonlinear spring model for dynamic cracked pipe analysis 
Appendix A

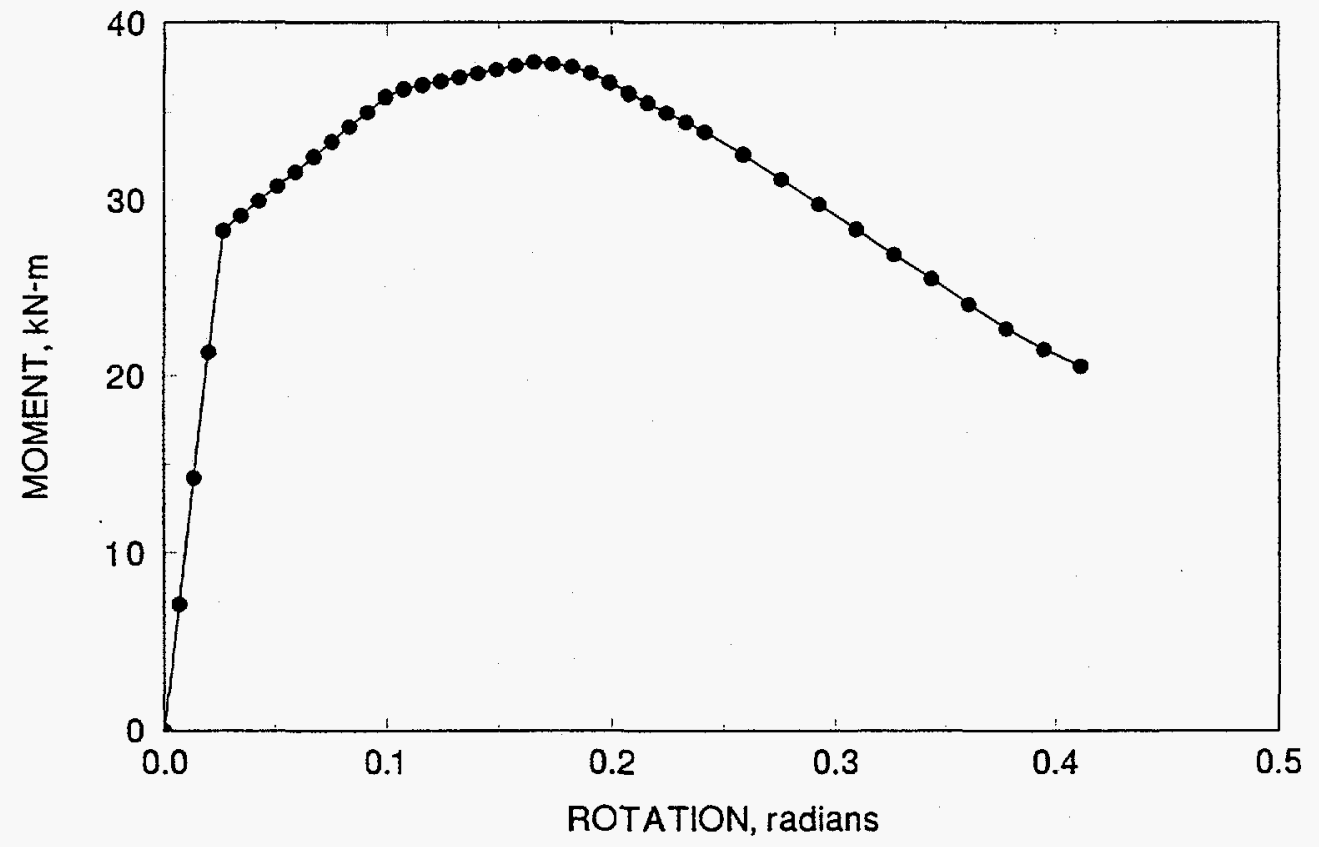

Figure A.2 Nonlinear FEA pipe fracture crack model analysis of a through-wall crack demonstrating correct modeling of negative stiffness behavior past maximum load

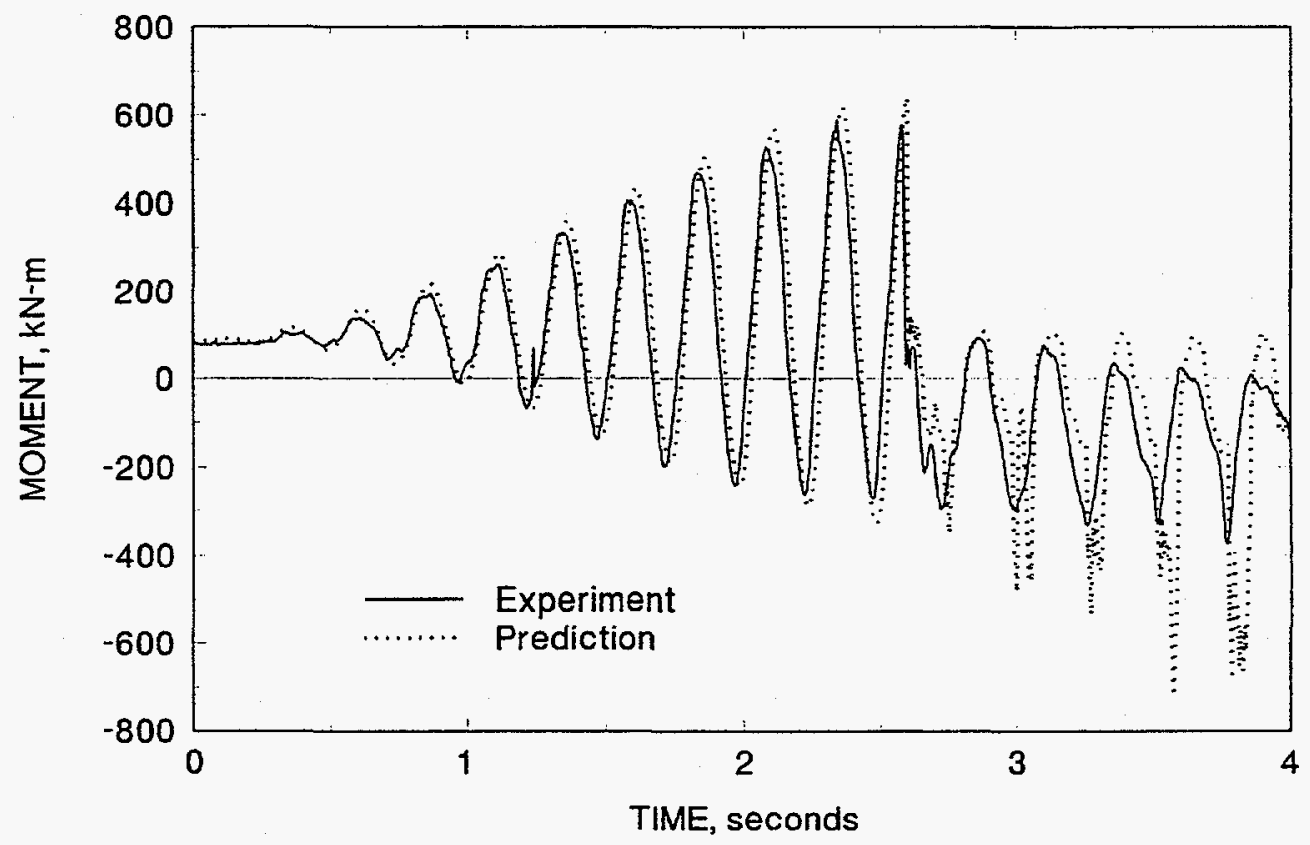

Figure A.3 Comparison showing surface to through-wall crack transition behavior of nonlinear FEA pipe fracture model for IPIRG-1 Experiment 1.3-7 (aged CF8M cast stainless steel, single frequency pipe-system test) 


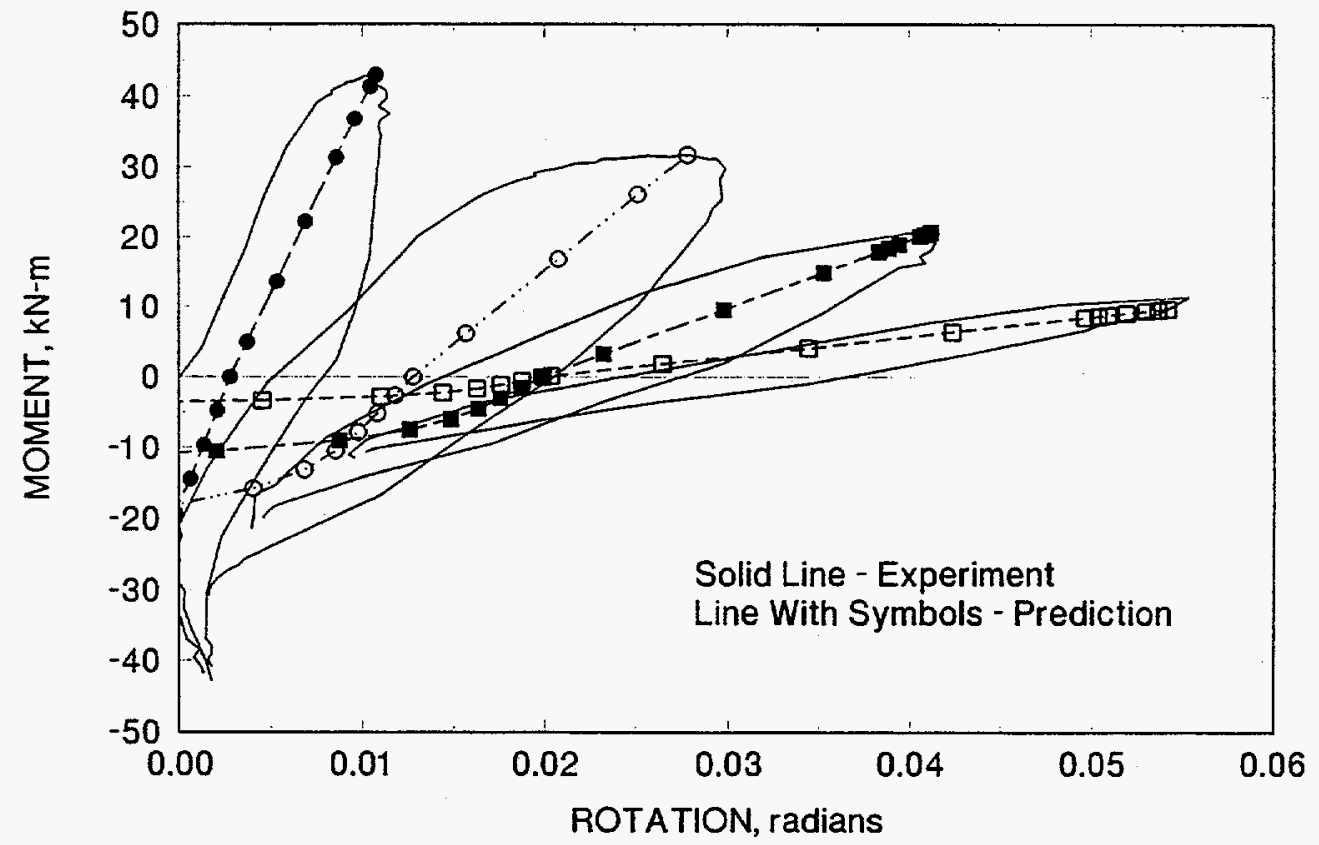

Figure A.4 Nonlinear FEA pipe fracture model unloading behavior for selected cycles of IPIRG-1 Experiment 1.2-4 (A106 Grade B through-wall crack, $R=-1$ cyclic loading)

The nonlinear FEA pipe fracture analysis method has been used extensively for design and analysis of the IPIRG pipe-system experiments (Refs. A.7 and A.8), design and analysis of the IPIRG-1 Task 1.1 inertial loading experiments (Ref. A.9), analysis of the HDR waterhammer experiments (Ref. A.6), analysis of the U.S. Department of Energy's New Production Reactor (Ref. A.10), and numerous other small piping system analyses.

The principal attraction for use of a nonlinear FEA pipe fracture analysis is that, depending on the quality of the fracture mechanics analysis used to generate the input moment-rotation curve, substantial margins can be realized, which the more conventional analyses ignore.

\section{A.3.3 Seismic Loading}

Time varying loads can be handled in two different ways. The most direct approach is to write and solve the equilibrium equations as a step-by-step time history. Loads are applied in an incremental fashion and the history of moment and axial force at the crack location can be determined.

For the case of linear analysis with ground motion excitation, i.e., seismic loading, response spectrum analysis methods can be used to effectively reduce the computational effort to finding natural frequencies and mode shapes of the structure and performing some simple multiplications. The output of a response spectrum analysis is peak moment, force, or stress. The shortcoming of response spectrum methods is that time phasing of the piping response is lost. 
Appendix A

\section{A.4 Comments on Stress Analyses for Fracture Evaluations}

\section{A.4.1 Solution Accuracy}

The results of a pipe fracture evaluation are contingent on an accurate stress analysis. This means that the stress analyst must correctly interpret the problem to be solved, he must make correct assumptions if explicit information is not stated, he must use his analysis program correctly, and the program must not have errors.

Unfortunately, all of the prescriptions noted above are not always met. In performing analyses of the IPIRG-1 Subtask 1.3 pipe-system experiments, various organizations solving the same problem got substantially different answers. Through diligent investigation and consideration of an increasingly more complex set of problems with closed-form solutions, it was discovered that:

- Experienced analysts get different solutions to the same problem for at least four reasons:

(1) Incomplete problem statements

(2) Incorrect program inputs

(3) Poorly documented program features

(4) Program errors

- When the analysts solve the same problem correctly, all analysts, using different programs, get nearly the same solution.

The stress analyses done for operational nuclear plant flaw evaluations are very likely affected by the same problems that were discovered during the IPIRG Round-Robin analyses. All four of the reasons for different solutions could, and most likely do, affect plant design and operation analyses.

Two remedies for assuring that the stress analyses for fracture evaluations are correct were suggested by the IPIRG-1 Round-Robin experience:

- Program errors and poorly documented features can be discovered by computer code benchmarking and accreditation.

- Incomplete problem specification and program input errors can be uncovered by thoroughly reviewed, independent, redundant calculations performed by teams of highly qualified analysts using separate analysis programs.

Submission of solutions to carefully selected, simple test cases with readily obtained closed-form solutions for the types of analyses to be performed could be a licensing prerequisite for acceptance of design analyses. Independent redundant calculations are probably expensive to implement, but would probably uncover user or problem statement deficiencies, and will also uncover computer code problems. 


\section{A.4.2 Elastic Analysis for an Inherently In-Elastic Behavior}

A linear analysis is used, in nearly all cases, when stress analyses are done for fracture evaluations. There is a sense that the linear analysis overpredicts the stresses and hence, the crack-driving force. Local plasticity at the crack section tends to cause dissipation of energy and tends to limit the moment that can be achieved.

Table A.3 summarizes the results of comparing linear stress analyses with an IPIRG-1 pipe-system experiment. Except for the ratio calculated using a static stress analysis, the linear time-history results consistently overpredict the stresses (moments). If these results can be generalized, this suggests that the predicted maximum flaw size would be smaller than what could actually be tolerated, simply because the linear stress analysis overestimates the crack driving force. In many cases, it is not worth the trouble to try to demonstrate that the margin introduced by using the linear analysis is actually there. In those critical cases where it is essential to reduce conservatism in the calculations, more sophisticated analyses, such as the nonlinear spring FEA fracture analysis must be invoked.

\section{A.4.3 Seismic Time-History Effects}

There are two methods for considering seismic loading - time history and response spectrum analyses. In the case of response spectrum analyses, the analysis is quite simple and inexpensive. In return for the ease of application, response spectrum analysis provides only peak stress information without regard to timephasing of the piping system response. In contrast, time history analysis preserves the time-phasing of each stress cycle applied at the crack location.

Table A.3 Summary of elastic stress analysis predictions of the maximum load for a stainless steel base metal surface-cracked pipe-system experiment

\begin{tabular}{|c|l|}
\hline \hline Elastic Analysis/ Experiment & \multicolumn{1}{c|}{ Basis } \\
\hline 0.92 & Moment not including thermal expansion or SAM \\
\hline 1.50 & Inertial plus SAM moments \\
\hline 0.56 & Total moment from a static analysis \\
\hline 1.42 & Total moment \\
\hline 1.42 & Total stress \\
\hline 1.14 & Total stress less SAM stress \\
\hline 2.00 & Inertial stress only \\
\hline
\end{tabular}

In many cases, the stress analysis, whether it is to be a time history or a response spectrum analysis will have a floor response acceleration spectrum as the input. The equivalence, in terms of the fatigue and fracture behavior of a crack, of various time histories derived from the same acceleration spectrum is a concern. 
In a series of IPIRG-2 Round-Robin analyses (Ref. A.11), four different but "equal" displacement time histories were created from a peak-broadened acceleration response spectrum. In spite of being "equal", the moments that the different time histories induced in a linear finite element model of the IPIRG piping system were substantially different. The obvious conclusion is that the time histories were not really "equal" in terms of crack-driving potential.

Figures A.5 through A.8 show that four time histories, calculated by different analysts, are consistent with the input spectrum. All time histories looked qualitatively similar. Moment-time responses for the four displacement time histories, Figures A.9 through A.12 were quite different, however, with two solutions generating a maximum of $313.0 \mathrm{kN}-\mathrm{m}$ crack-opening moment and another solution generating a maximum of only $259.3 \mathrm{kN}$-m crack-opening moment at 2-percent damping. Table A.4 summarizes the moment responses.

On the basis of these results, it is not clear that merely being consistent with a given input spectrum is any guarantee that one will have upper bound, lower bound, or average crack driving potential. This comment certainly applies to the IPIRG simulated-seismic forcing function, and probably applies to other analyses that use spectrum-compatible time history excitations as well. Other prescriptions on spectrum matching are probably required to give bounding behavior. Further work in this area may be required.

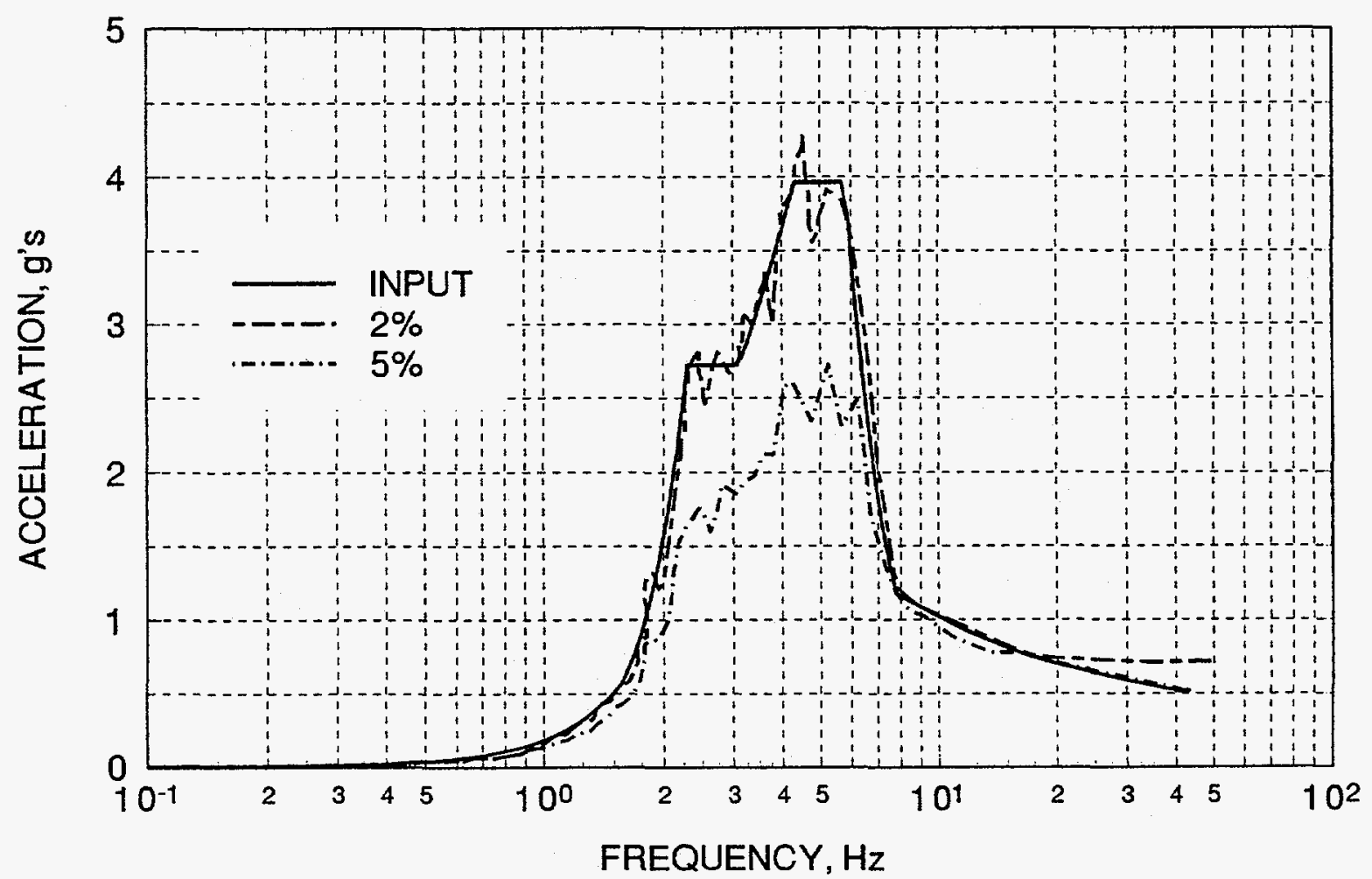

Figure A.5 Spectra for compatible time history 1 
Appendix A

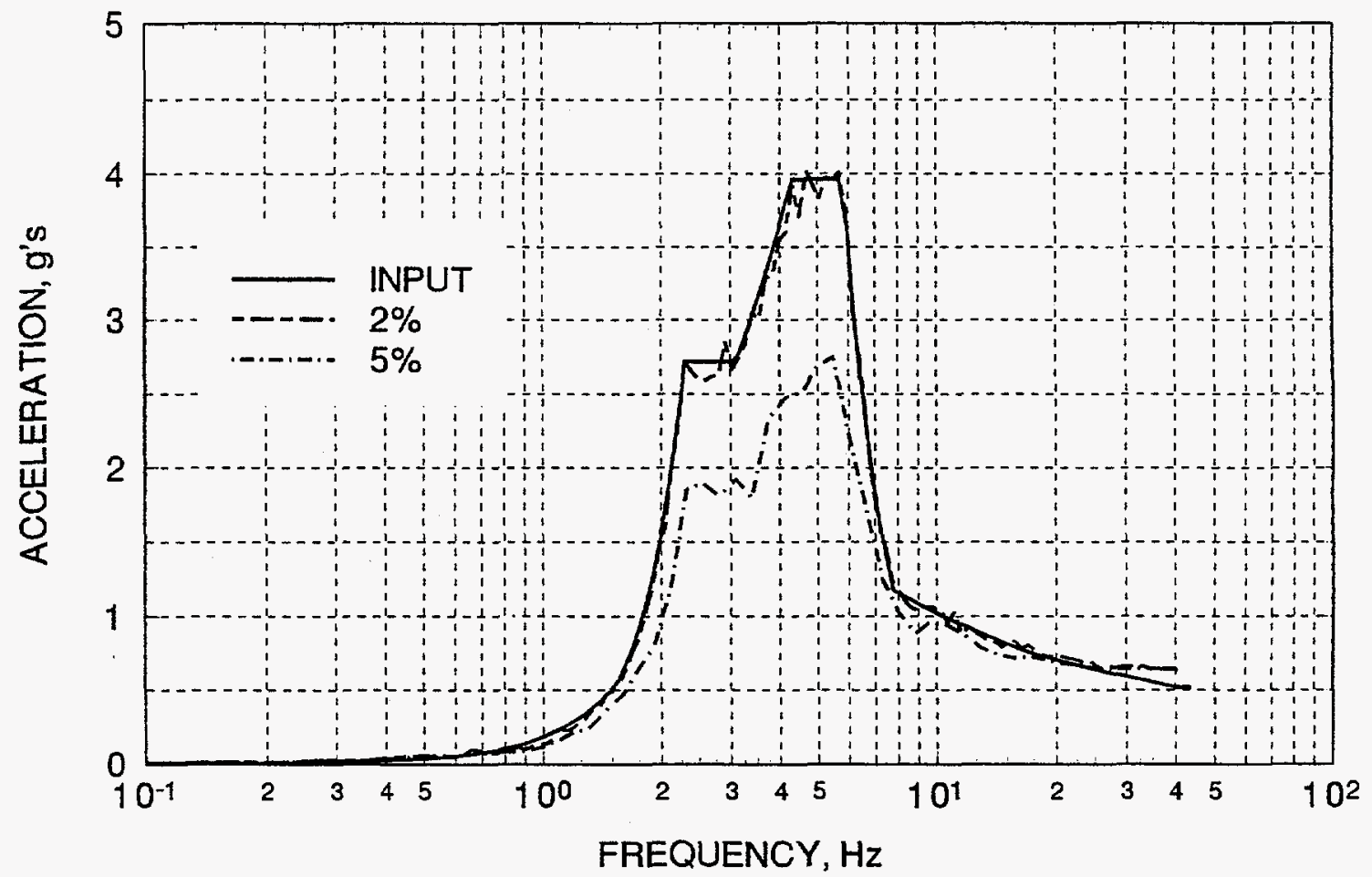

Figure A.6 Spectra for compatible time history 2

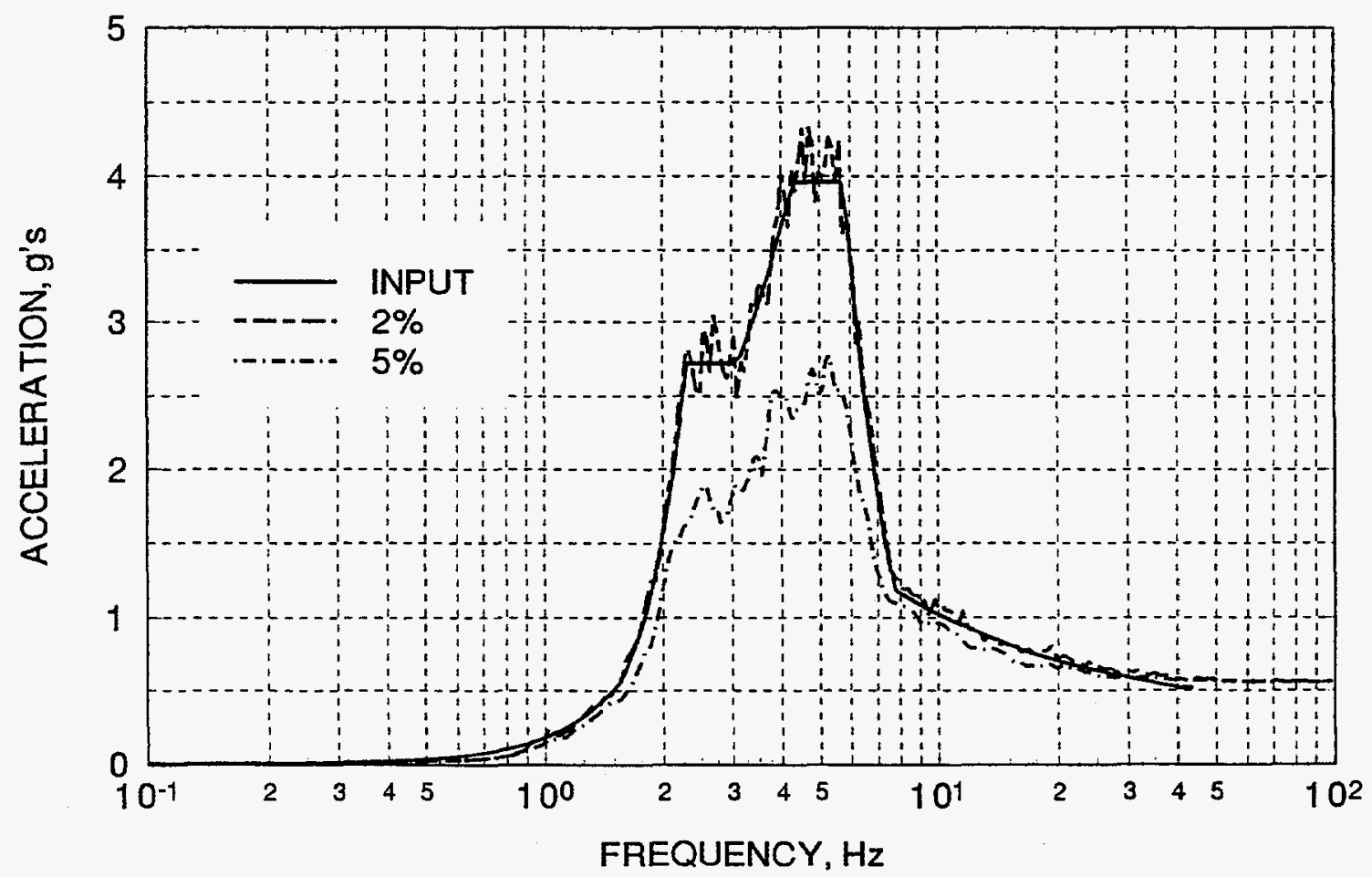

Figure A.7 Spectra for compatible time history 3 
Appendix A

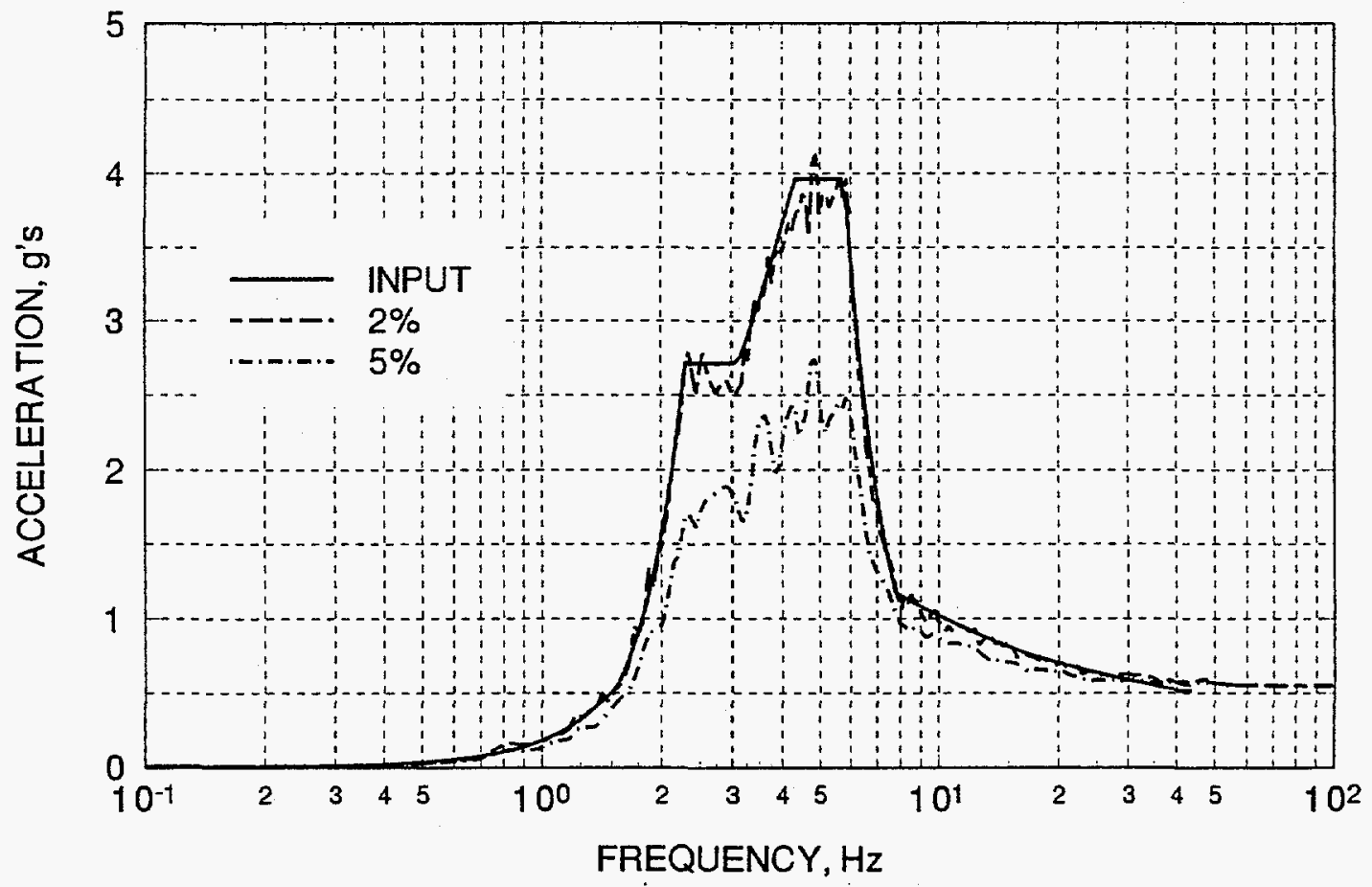

Figure A.8 Spectra for compatible time history 4

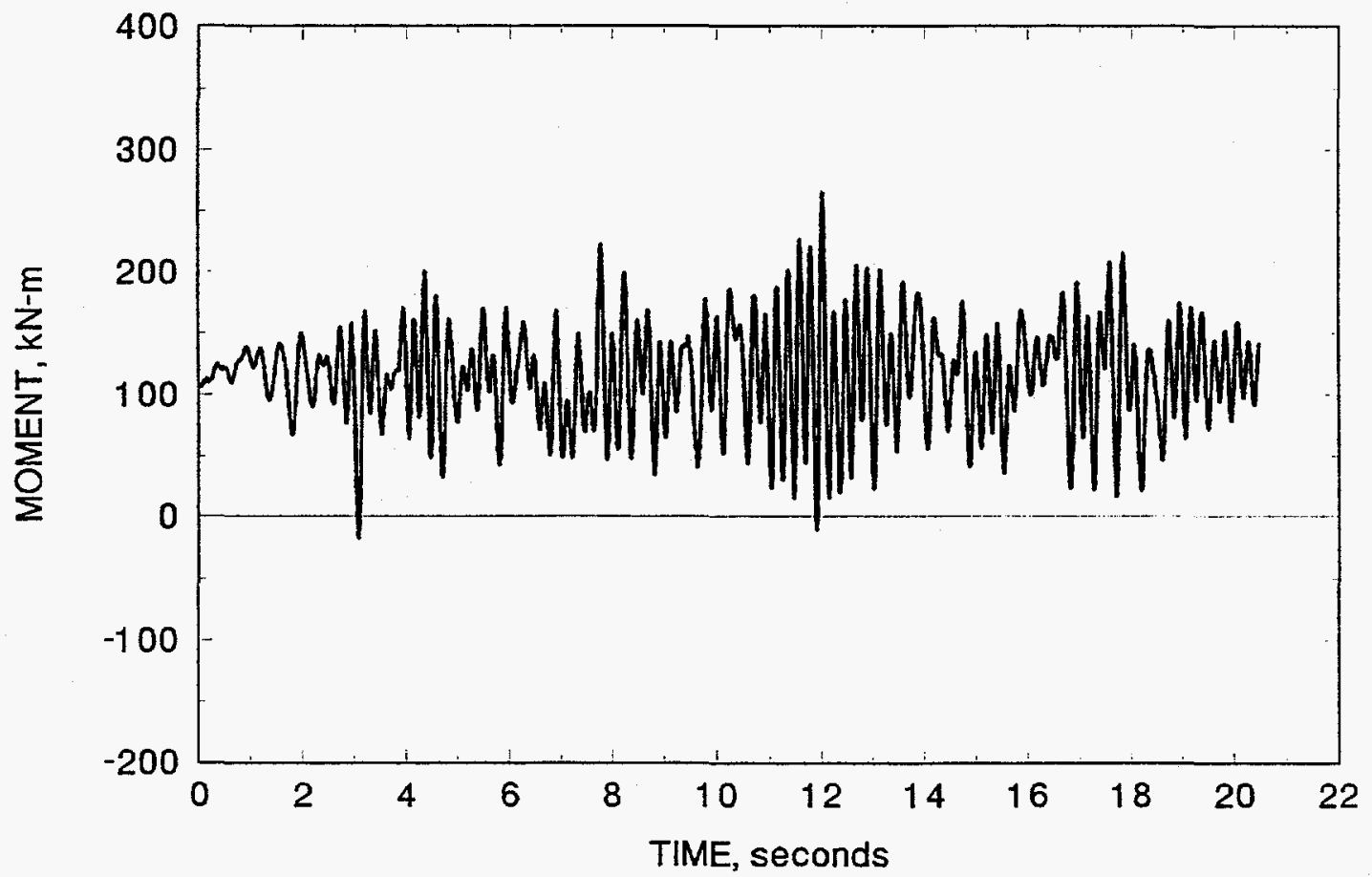

Figure A.9 Moment-time for spectrum-compatible time history 1 
Appendix A

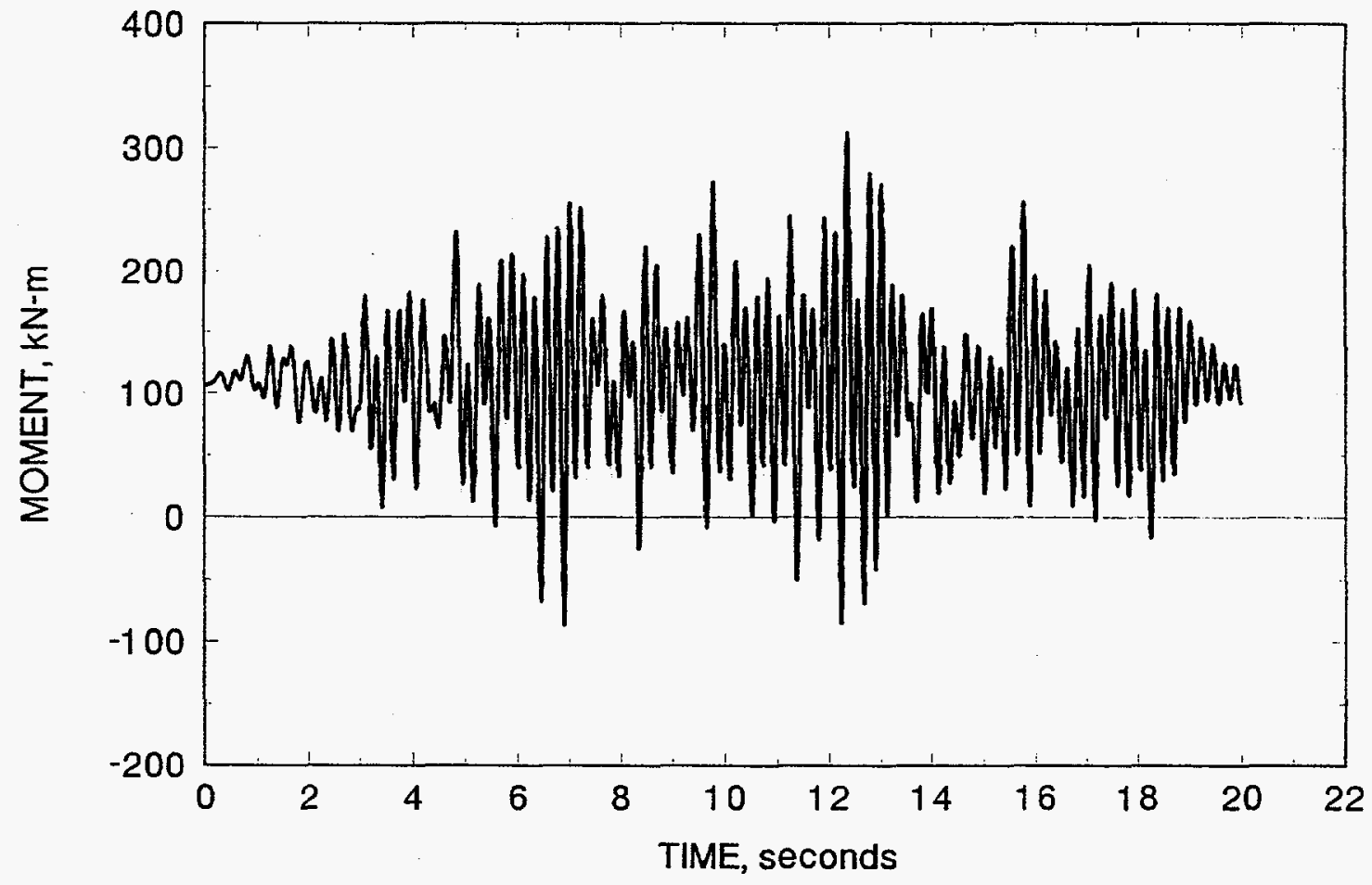

Figure A.10 Moment-time for spectrum-compatible time history 2

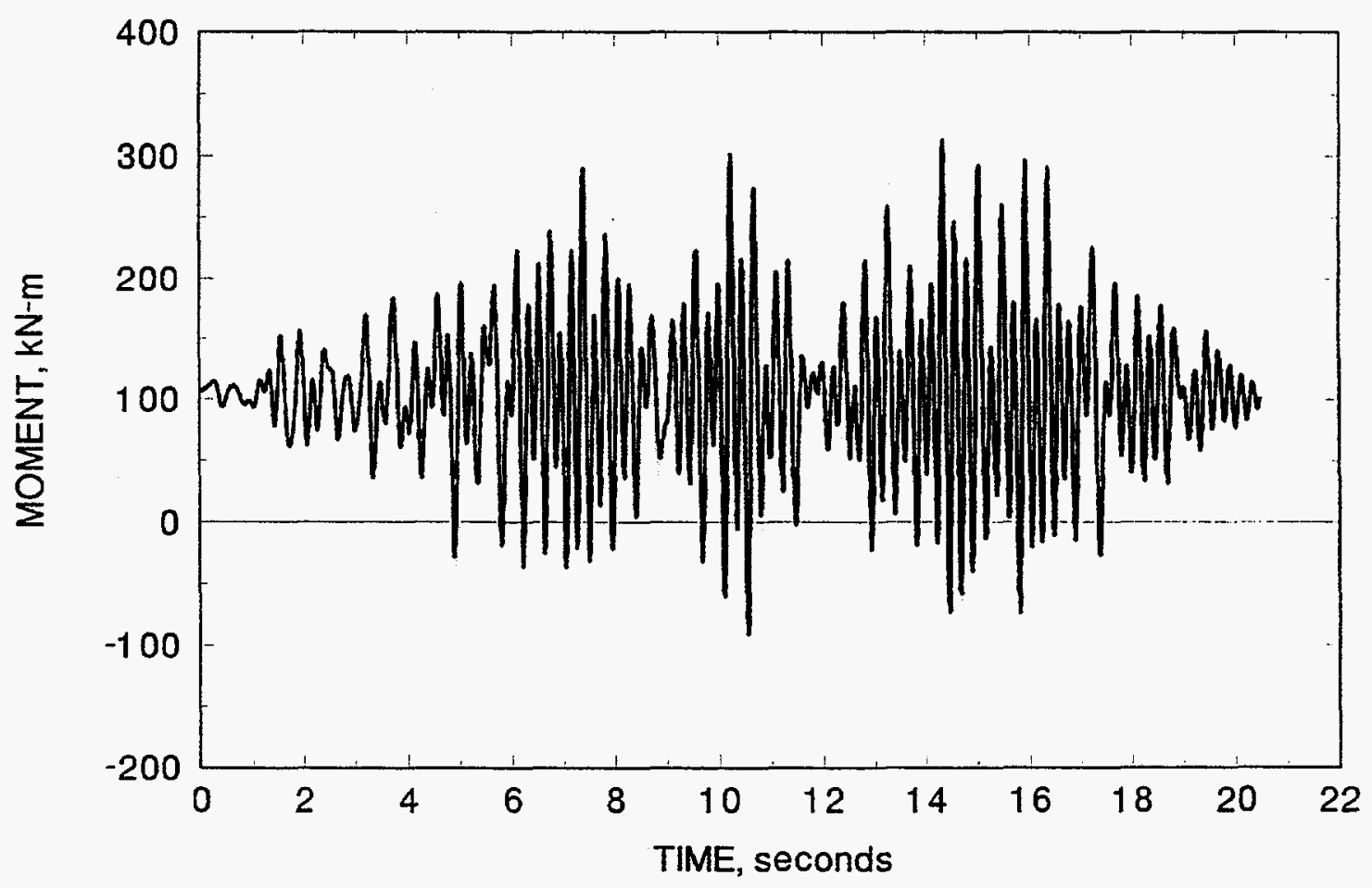

Figure A.11 Moment-time for spectrum-compatible time history 3 
Appendix A

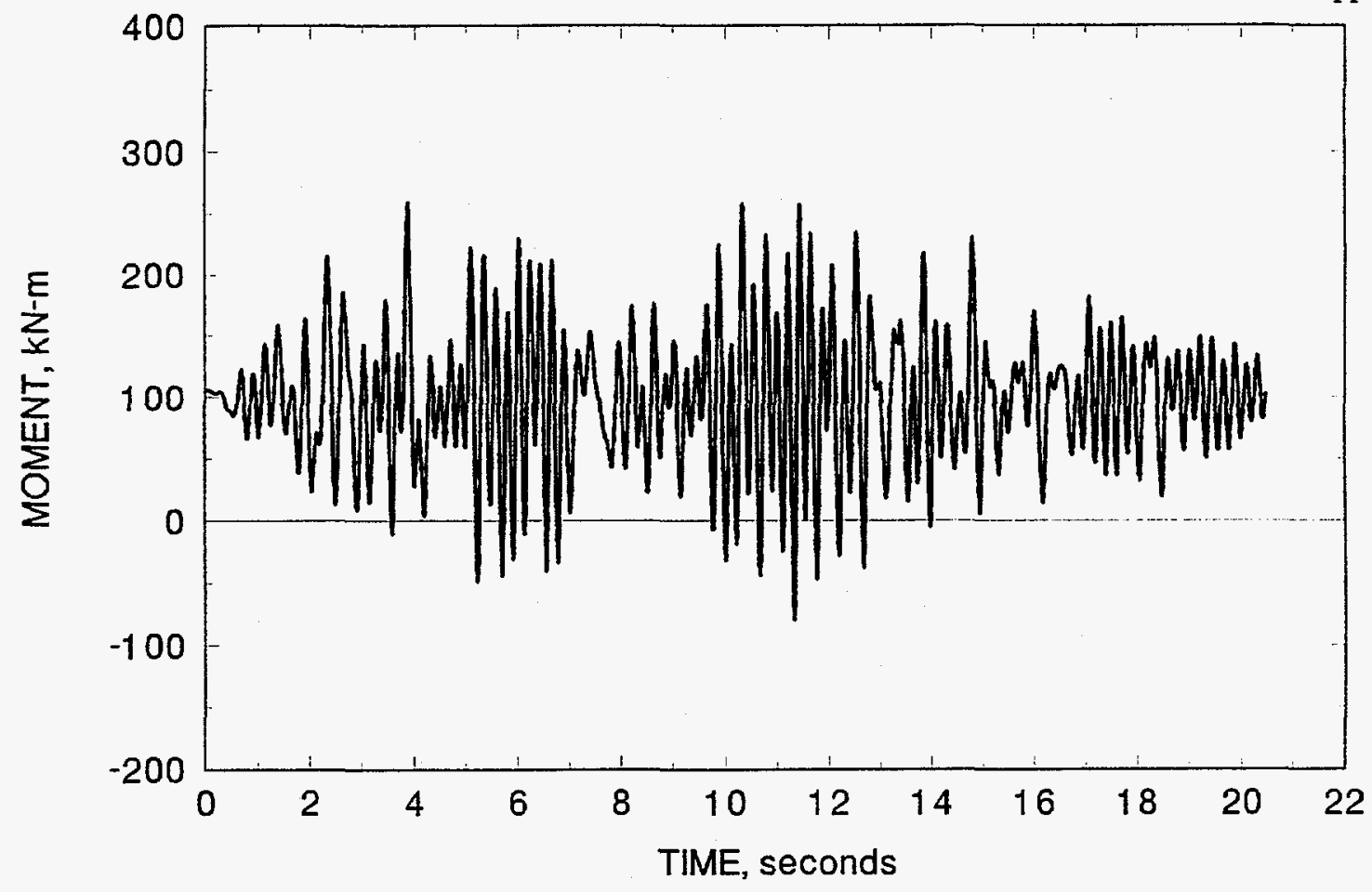

Figure A.12 Moment-time for spectrum-compatible time history 4

Table A.4 IPIRG pipe-system moment response summary using spectrum-compatible displacement time histories and linear stress analysis

\begin{tabular}{|c|c|c|}
\hline Solution & $\begin{array}{c}\text { Maximum Moment, } \\
\text { kN-m }\end{array}$ & $\begin{array}{c}\text { Minimum Moment, } \\
\mathbf{k N}-\mathbf{m}\end{array}$ \\
\hline \hline 1 & 259.7 & -17.9 \\
\hline 2 & 313.0 & -86.8 \\
\hline 3 & 313.0 & -90.6 \\
\hline 4 & 259.3 & -79.4 \\
\hline
\end{tabular}

\section{A.4.4 Combined Bending and Torsion}

The issue of how to combine the three bending moments that act at a flaw location is a concern. Section III of the ASME Code suggests that the resultant moment, $M_{e q}{ }^{2}=\left(M_{x x}{ }^{2}+M_{y y}{ }^{2}+M_{z z}{ }^{2}\right)$, should be used. R6 gives no direct guidance, other than to suggest that the stresses in the flaw evaluation should be upper bound values.

Including the torsional moment in the resultant moment does tend to produce an upper bound estimate of the crack opening moment for Mode I crack behavior. It is, however, inconsistent to convert the resultant 
Appendix A

moment to bending stress with the simple $\sigma_{\mathrm{b}}=\mathrm{Mc} / \mathrm{I}$ equation if torsion is embedded in the moment. The effect of off-axis moments on Mode I crack behavior has not been studied in sufficient detail. Hence, the present fracture evaluation methodologies are not advanced enough to be able to properly consider this.

For the present, it would appear that the only rationale for using the resultant moment is that the stresses should be an upper bound. Until such time as the fracture behavior of flaws under multi-axis loading is known, or when it becomes important to reduce inherent conservatism to the minimum, use of the resultant moment probably is the only option.

\section{A.5 General Guidance}

The basic methods for determining the stresses in nuclear plant piping are well known. There are, however, application issues such as incorrect program inputs, program bugs, etc. that will almost always be present. The fracture analyst must be constantly aware that the stresses he is given may be suspect. There are two levels of stress analysis that can be performed, the linear response spectrum analysis and the nonlinear FEA fracture analysis. Presently, the bulk of the stress analyses done for fracture evaluations uses the former, but in exceptional cases where designs are on the fringes, the nonlinear analyses can be used to show that margins do indeed exist.

In perspective, the stress analysis cannot be any better than known input data and it is constrained by the time and money that can be spent. Although one can use up a great deal of resources trying to more accurately predict the applied stresses, incremental improvements in prediction of the stresses may, quite likely, be overshadowed by uncertainties in the fracture analysis (flaw geometry, material properties, etc.)

\section{A.6 References}

A.1 American Society of Mechanical Engineers, ASME Boiler and Pressure Vessel Code, Section III Rules for Construction of Nuclear Power Plant Components, July 1995 Edition.

A.2 American Society of Mechanical Engineers, ASME Boiler and Pressure Vessel Code, Section XI Rules for Inservice Inspection of Nuclear Power Plant Components, July 1995 Edition.

A.3 Milne, I., and others, "Assessment of the Integrity of Structures Containing Defects," CEGB Report R/H/R6 - Rev. 3, 1986.

A.4 Wilkowski, G., and others, "International Piping Integrity Research Group (IPIRG) Program," NUREG/CR-6233 Vol. 4, June 1997.

A.5 Olson, R., Scott, P., and Wilkowski, G., "Application of a Nonlinear Spring Element to Analysis of Circumferentially Cracked Pipe Under Dynamic Loading," in Pressure Vessel Fracture, Fatigue, and Life Management, ASME PVP Vol. 233, pp 279-292, June 1992.

A.6 Olson, R., and others, "Validation of Analysis Methods for Assessing Flawed Piping Subjected to Dynamic Loading," NUREG/CR-6234, August 1994. 
A.7 Olson, R., and others, "The IPIRG Dynamic Pipe Loop Test Facility," Nuclear Engineering and Design, Vol. 144, pp 77-90, 1993.

A.8 Scott, P., Olson, R., and Wilkowski, G., "The IPIRG-1 Pipe System Fracture Tests - Experimental Results," in Fatigue, Flaw Evaluation, and Leak-Before-Break Assessments, ASME PVP Vol. 280, pp 135-151, June 1994.

A.9 Scott, P., and others, G., "Stability of Cracked Pipe Under Inertial Stresses," NUREG/CR-6233 Vol. 1, August 1994.

A.10 Olson, R. J., Wolterman, R. L., and Wilkowski, G. M., "Margins from Dynamic FEM Analysis of Cracked Pipe Under Seismic Loading for the DOE New Production Reactor," in Fatigue, Flaw Evaluation, and Leak-Before-Break Assessments, ASME PVP Vol. 280, pp 119-134, June 1994.

A.11 Rahman, S., and others, "Summary of Results from the IPIRG-2 Round-Robin Analyses," NUREG/CR-6337, February 1996. 